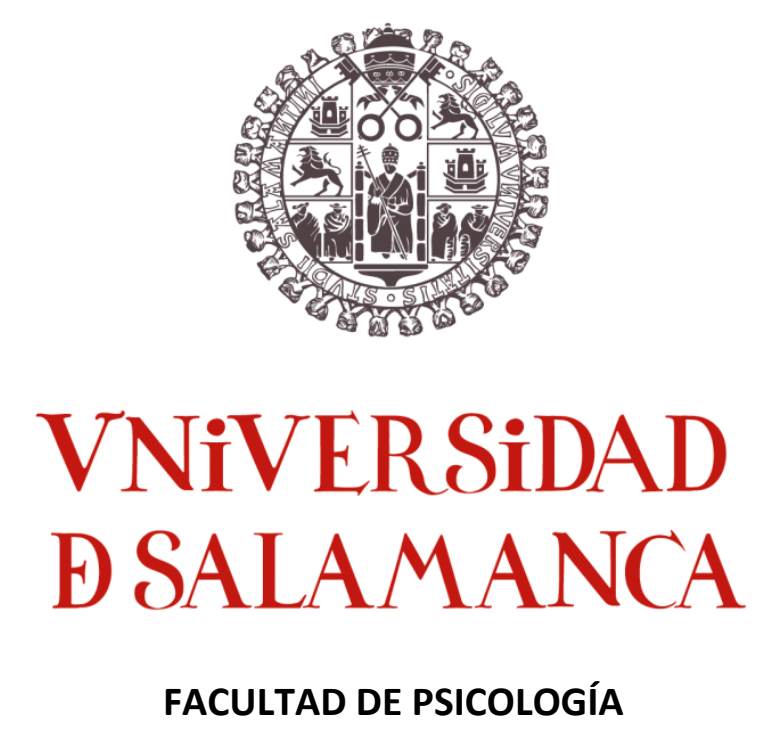

DEPARTAMENTO DE PSICOLOGÍA SOCIAL Y ANTROPOLOGÍA

TESIS DOCTORAL

\title{
ETNOGRAFÍA DE LOS OROMO-GUJII: HISTORIA, EDUCACIÓN Y CALIDAD DE VIDA
}

\section{Autor: ÁLVARO HIERRO SAN MARTÍN}

Dirigida por:

FRANCISCO GINER ABATI

Catedrático del Departamento de Psicología Social y Antropología CRISTINA JENARO RÍO

Profesora Titular del Departamento de Personalidad, Evaluación y Tratamiento Psicológicos 


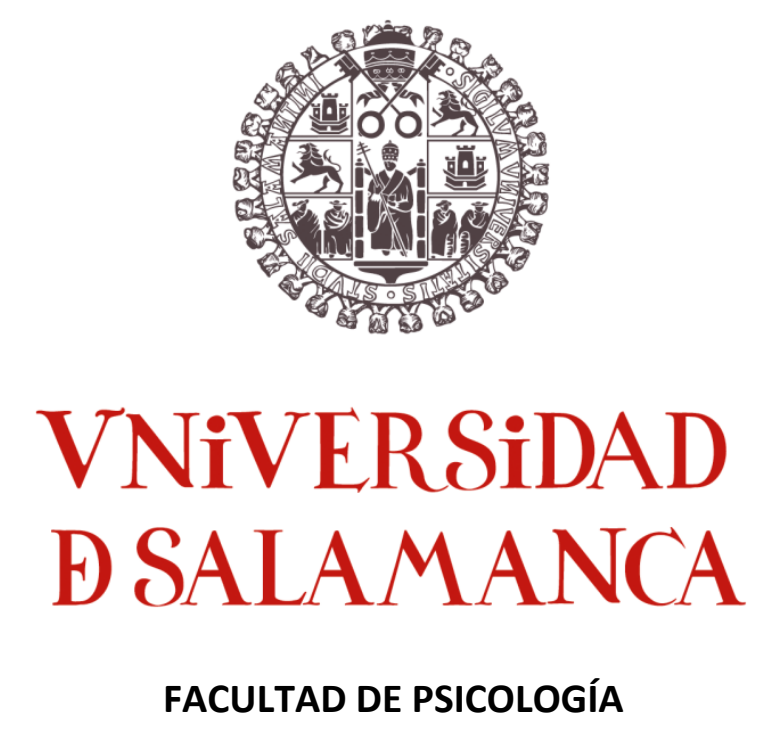

DEPARTAMENTO DE PSICOLOGÍA SOCIAL Y ANTROPOLOGÍA

TESIS DOCTORAL

\section{ETNOGRAFÍA DE LOS OROMO-GUJII: HISTORIA, EDUCACIÓN Y CALIDAD DE VIDA}

Autor: ÁLVARO HIERRO SAN MARTÍN

Dirigida por:

FRANCISCO GINER ABATI

Catedrático del Departamento de Psicología Social y Antropología

CRISTINA JENARO RÍO

Profesora Titular del Departamento de Personalidad, Evaluación y Tratamiento Psicológicos

SALAMANCA, 2014 
“Olkaa'an fuudhan malee olka'an hinfuudhan"

Una persona recoge mañana lo que planta hoy

Proverbio Gujii 
VNiVERSiDAD

DSALAMANCA
FACULTAD DE PSI COLOGí A

Avda. de la Merced, 109-131, 37005 Salamanca,
Teléfono 923294500 Ext. 3301, Fax 923294607

Dr. D. FRANCISCO GINER ABATI, Catedrático del Departamento de Psicología Social y Antropología y Dra. Da CRISTINA JENARO RIO, Profesora Titular del Departamento de Personalidad, Evaluación y Tratamiento Psicológicos

\section{CERTIFICAMOS:}

Que el presente trabajo de investigación titulado "ETNOGRAFÍA DE LOS OROMO-GUJII: HISTORIA, EDUCACIÓN Y CALIDAD DE VIDA", constituye el trabajo de investigación que presenta D. ÁLVARO HIERRO SAN MARTín para optar al grado de Doctor.

El trabajo, realizado bajo nuestra dirección, reúne los requisitos de calidad, originalidad y presentación exigibles a una investigación científica y está en condiciones de ser sometida a la valoración del Tribunal encargado de juzgarla.

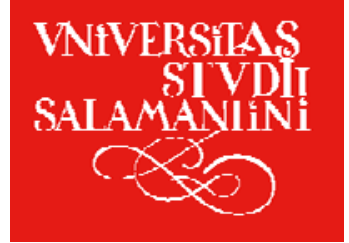

Para que conste firmamos la presente en Salamanca, a 11 de noviembre de 2014,

Fdo. Francisco Giner Abati

Fdo. Cristina Jenaro Río 


\section{AGRADECIMIENTOS}

Mis primeras palabras de agradecimiento han de ser para mi familia, que siempre me ha apoyado a lo largo de mi vida y a la que debo agradecer innumerables cosas. En esta ocasión querría agradecerles especialmente cómo soportaron y comprendieron la distancia que nos separaba, tanto en los momentos buenos como en los no tan buenos, y cómo sus llamadas, cartas y paquetes me alegraron la vida en los momentos de mayor soledad.

Especialmente querría agradecérselo a mis padres, hermana, cuñado y sobre todo a mi pequeño sobrino Alejandro cuyo nacimiento me produjo una enorme alegría y que espero que cuando dentro de muchos años lea esta Tesis esté orgulloso del trabajo de quien ya será entonces su viejo "Titi".

En segundo lugar quiero mostrar mi más sincero agradecimiento a los Misioneros Combonianos de Etiopía y en especial a los miembros de la Misión de Qillenso, quienes más allá de darme la oportunidad de realizar esta investigación me trataron como a uno más. Por otra parte al permitirme compartir su día a día y experiencias no solo lograron que vislumbrara otra forma de ver la vida, sino que consiguieron que creciera como persona. Por ello creo que jamás podré llegar a demostrarles todo el cariño y agradecimiento que siento por el apoyo y confianza que depositaron en mí.

No puedo dejar de agradecer a mis tutores el trabajo, dedicación y esfuerzo que han realizado conmigo y sin el cual no podría haber llevado a cabo la presente investigación. En especial querría agradecer al Dr. Francisco Giner Abati la oportunidad que me brindó de conocer Etiopía y África, la cual fue un punto de inflexión en mi vida e hizo que este continente y particularmente Etiopía se hayan convertido en parte de mi.

A la Dra. Cristina Jenaro Río querría agradecerle su trabajo y cariño constante a la hora de realizar esta Tesis Doctoral, sin olvidarme de la paciencia y comprensión que ha mostrado en los momentos más complicados de este proceso. 
Además agradezco su inestimable ayuda a la hora de lograr que me adentrara en el, para mí hasta entonces, misterioso mundo de la estadística.

A Raquel quiero agradecerle todo su apoyo, cariño y comprensión a lo largo de este proceso, especialmente pues su paciencia y amor me ayudó a superar los momentos de mayor nerviosismo y frustración.

Querría agradecerles a mis amigos el interés que han mostrado a la hora de escuchar una y otra vez "mis batallitas". Sus muestras de amistad en forma de mensajes y correos, además sus recibimientos en mis visitas a España, me ayudaron a recargar pilas para volver a Etiopía. No quiero olvidarme tampoco de mi amigo David quien soportó con estoicismo mis llamadas llenas de quejas interminables y me acompañó en las periódicas y muy necesarias escapadas a Addis Abeba.

Quiero hacer una mención especial a Chuchi y a Marga de la biblioteca de Psicología, pues su ayuda y profesionalidad han sido fundamentales para el buen desenlace de esta investigación.

Por último y no por ello menos importante querría mostrar mi más sincero agradecimiento a todos los Gujii que participaron de una u otra manera en la elaboración de esta Tesis y sin cuyos conocimientos, ayuda y amistad, la realización de este trabajo de investigación no habría sido posible. 


\section{ÍNDICE DE CONTENIDOS}

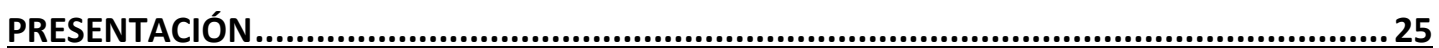

CAPÍTULO 1. ETIOPÍA: PASADO, PRESENTE Y FUTURO .............................................. 33

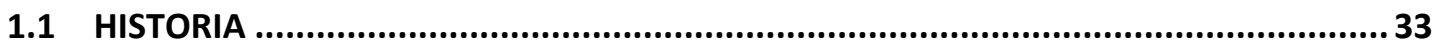

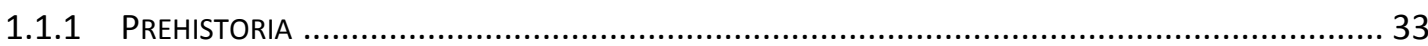

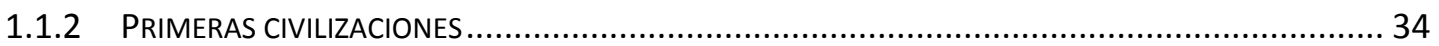

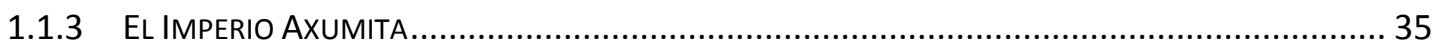

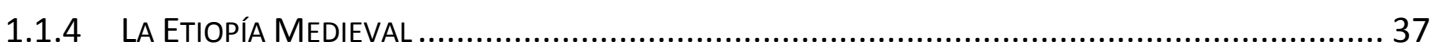

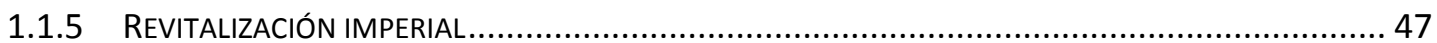

1.1.6 El GOBIERNO DE HAILA SELASI ................................................................ 52

1.1 .7 EL COMITÉ DERG .................................................................................. 56

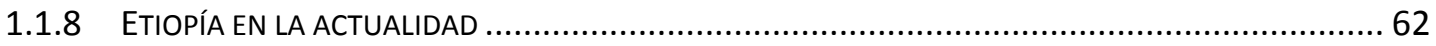

1.2 GEOGRAFÍA........................................................................................ 74

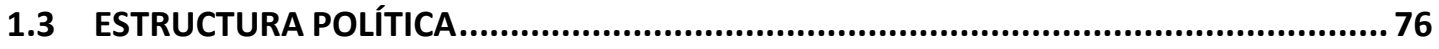

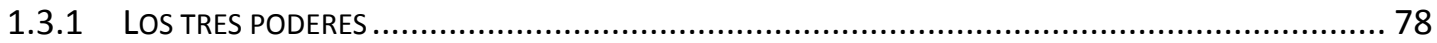

1.3.2 PODER LEGISLATIVO .................................................................................. 78

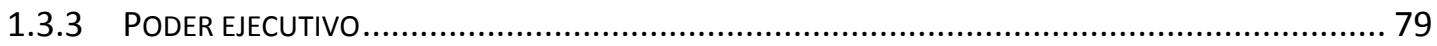

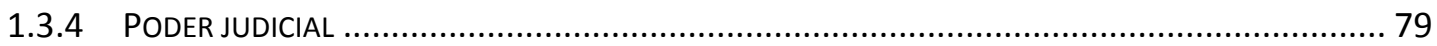

1.4 ECONOMÍA .............................................................................................. 80

1.5 SITUACIÓN SOCIAL Y DEMOGRÁFICA ............................................................... 93

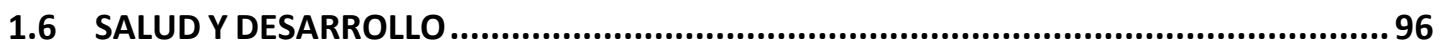

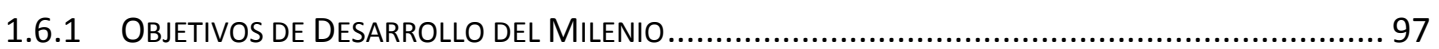

CAPÍTULO 2. LOS OROMO: HISTORIA, CULTURA Y ECONOMÍA ..................................... 115

2.1 INTRODUCCIÓN........................................................................................... 115

2.2 HISTORIA DE LOS OROMO ..................................................................... 116

2.2.1 ORIGEN Y PERIODO ARCAICO ......................................................................... 116

2.2.2 EXPANSIÓN Y ASENTAMIENTO EN NUEVOS TERRITORIOS ............................................. 118

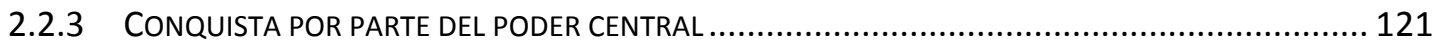

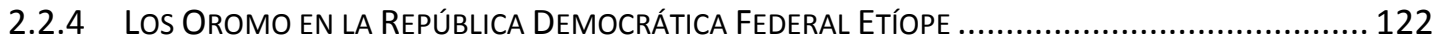

2.3 CULTURA OROMO Y GUJII................................................................... 123

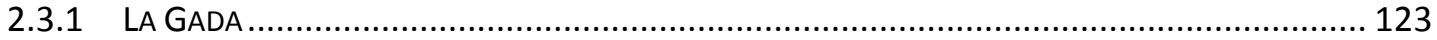

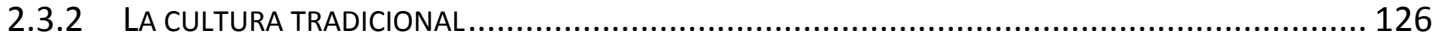

2.3.3 CASAS Y PATRÓN DE POBLAMIENTO ........................................................ 128 


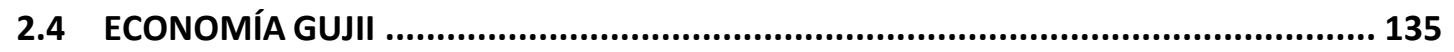

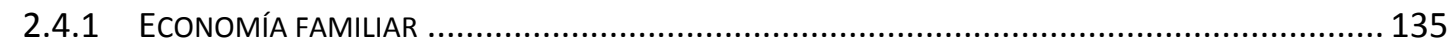

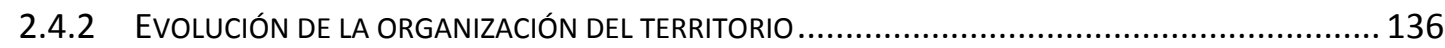

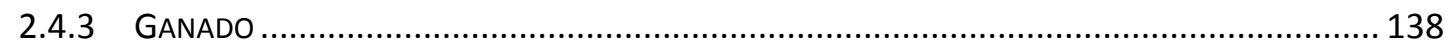

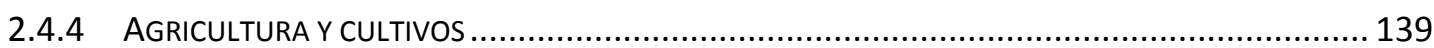

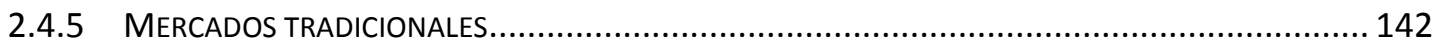

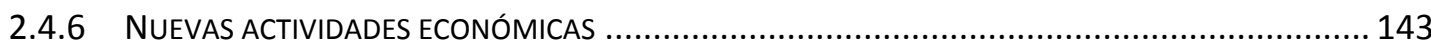

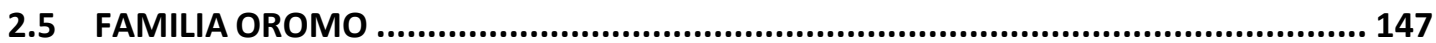

2.5.1 PARENTESCO

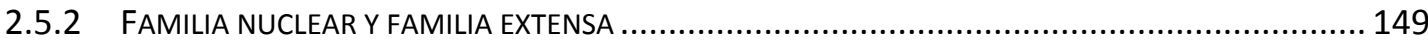

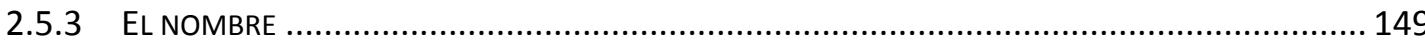

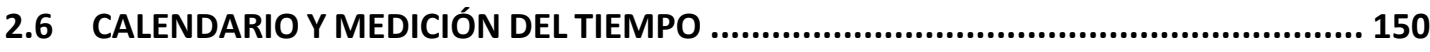

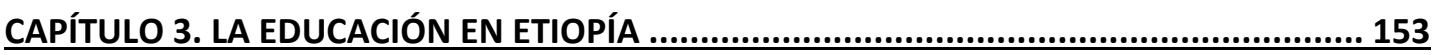

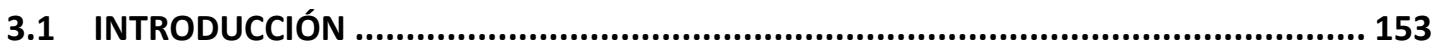

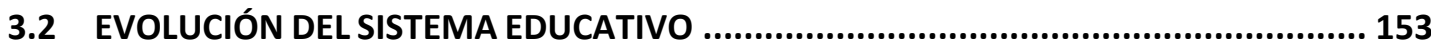

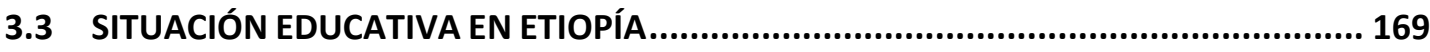

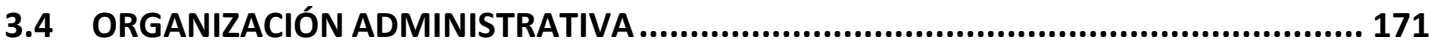

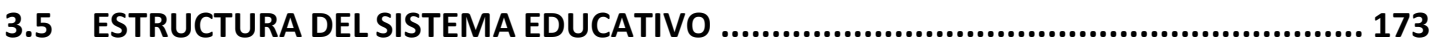

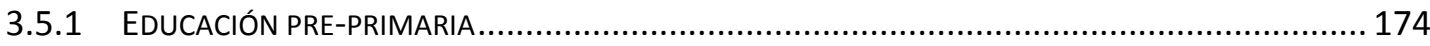

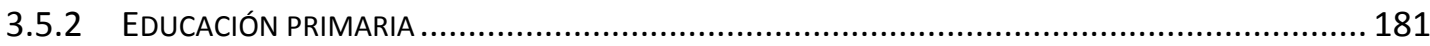

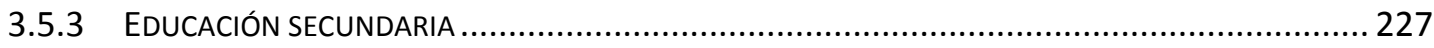

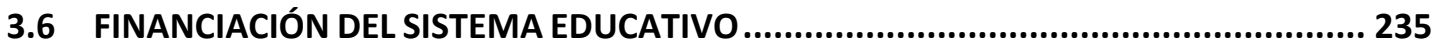

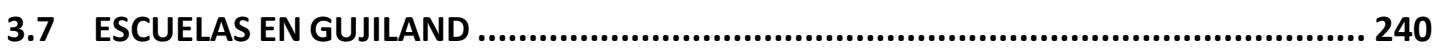

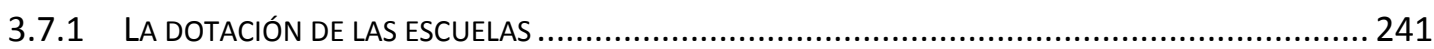

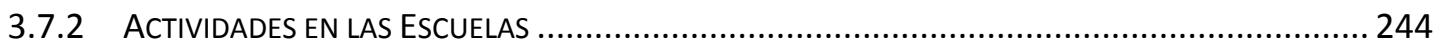

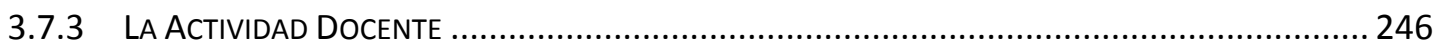

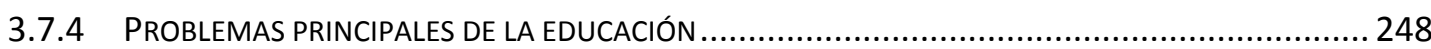

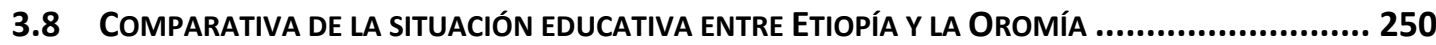

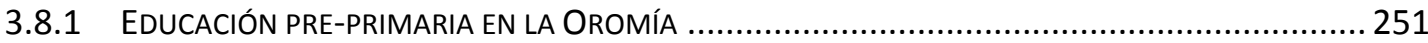

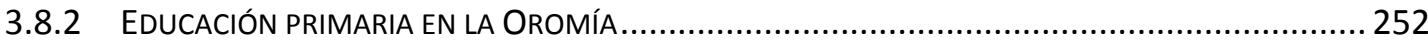

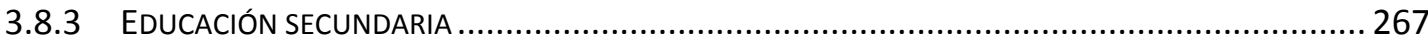

3.9 PRINCIPALES PROBLEMAS DE LA EDUCACIÓN EN ETIOPÍA .................................... 276

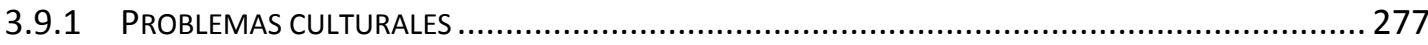




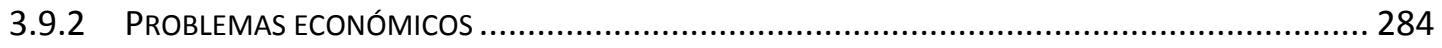

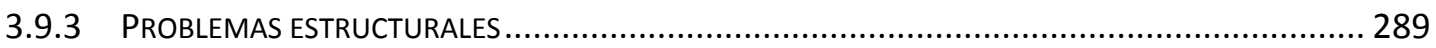

CAPÍTULO 4. ANÁLISIS DE LA SITUACIÓN EDUCATIVA EN LA ESCUELA PRIMARIA DE

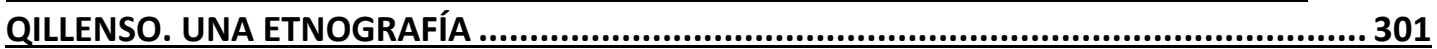

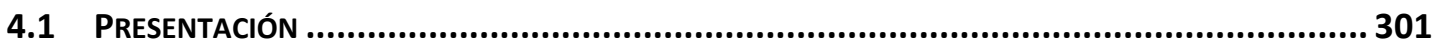

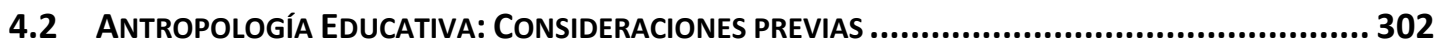

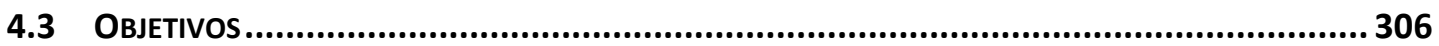

4.4 MÉTODO

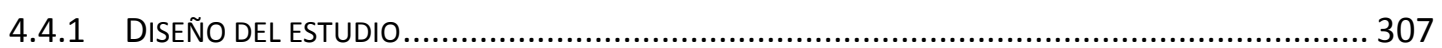

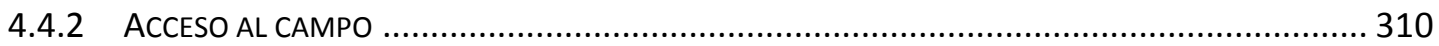

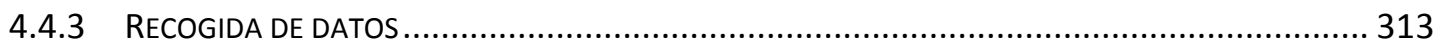

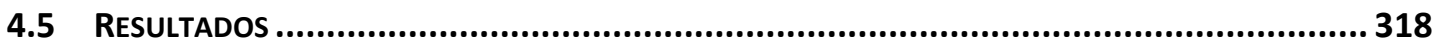

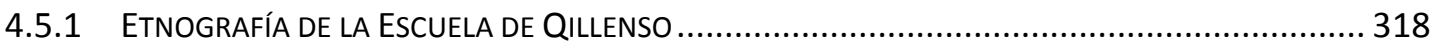

4.5.2 RETOS PRESENTES Y FUTUROS EN LA ESCUELA DE QILLENSO ............................................... 342

CAPÍTULO 5. LA SITUACIÓN DE ALUMNOS DE PRIMARIA OROMO GUJII EN LA ESCUELA DE QILLENSO DESDE SU PROPIA PERSPECTIVA .................................................................363

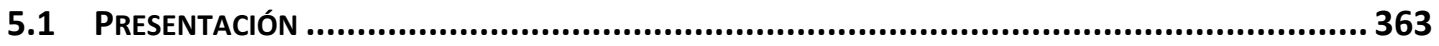

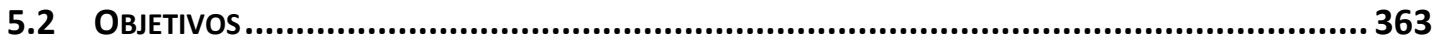

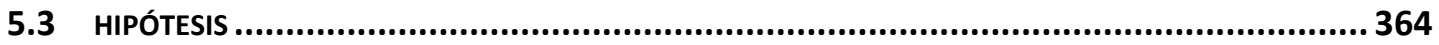

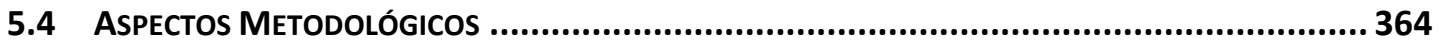

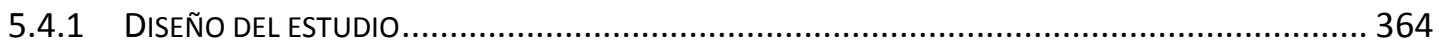

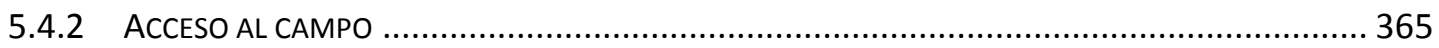

5.4.3 RECOGIDA DE DATOS MEDIANTE CUESTIONARIOS: ASPECTOS PREVIOS ................................... 366

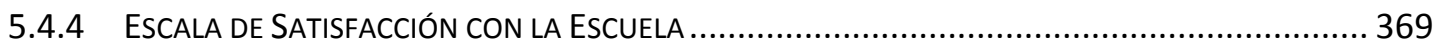

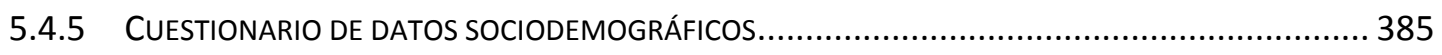

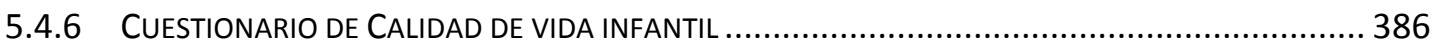

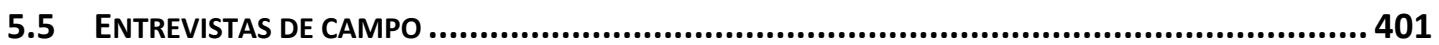

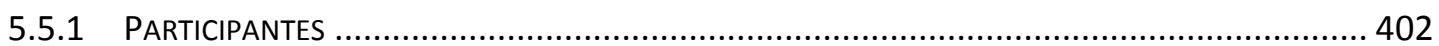

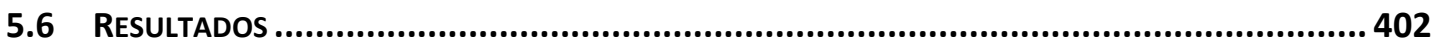

5.6.1 PERFIL SOCIODEMOGRÁFICO Y CIRCUNSTANCIAS QUE RODEAN A LOS ESTUDIANTES DE LA ESCUELA DE

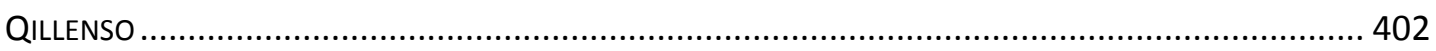

5.6.2 RESULTADOS DE SATISFACCIÓN CON LA ESCUELA Y DE CALIDAD DE VIDA ................................. 406

5.6.3 RELACIÓN ENTRE SATISFACCIÓN ESCOLAR Y CALIDAD DE VIDA ........................................... 410 
5.6.4 IMPACTO DE VARIABLES SOCIOCULTURALES EN LA SATISFACCIÓN ESCOLAR Y EN LA CALIDAD DE VIDA 411

5.7 CONCLUSIONES

416

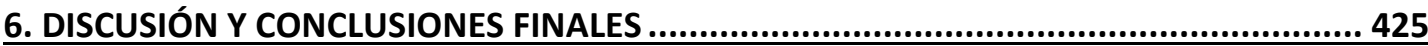

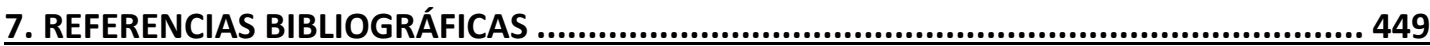

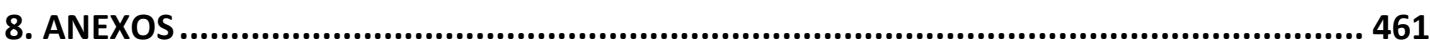

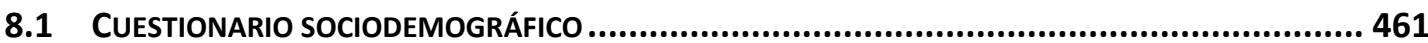

8.2 Cuestionario de Satisfacción con la escuela (Castellano-Oromo) ......................... 465

8.3 ESCALA DE CALIDAD DE VIDA INFANTIL CASTELLANo OROMO ...........................................467 


\section{ÍNDICE DE TABLAS}

Tabla 1. Principales exportaciones e importaciones de Etiopía en 2010 en porcentaje ........ 88

Tabla 2. Escala de la Gada 125

Tabla 3. Tasa de matriculación bruta de educación pre primaria en el curso 2012/13 ...... 175

Tabla 4. Tasa de matriculación neta en educación pre primaria en el curso 2012/13 ......... 176

Tabla 5. Evolución del número de alumnos matriculados en educación primaria (incluyendo ABE y evening class) entre 2008/9 y 2012/13 ............................................................... 182

Tabla 6. Escuelas de primaria existentes en el periodo 2008-2013 ..................................... 183

Tabla 7. Instalaciones disponibles en las escuelas de primaria durante el curso 2012/2013 185

Tabla 8. Número de clases disponibles por curso en 2013 ............................................. 187

Tabla 9. Tasa de ingresos netos en los cursos 2008/8 hasta 2012/13 ................................ 188

Tabla 10. Tasa de ingreso con independencia de la edad para los cursos 2008/9 hasta

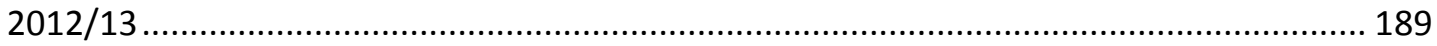

Tabla 11. Comparativa NER entre el primer y Segundo ciclo de primaria en 2012/13 ....... 193

Tabla 12. Evolución de la tasa de alumnos por sección en primaria entre los cursos 2008/9 y

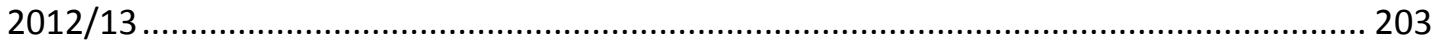

Tabla 13. Evolución del número de profesores en los dos ciclos de primaria entre 2006/7 y

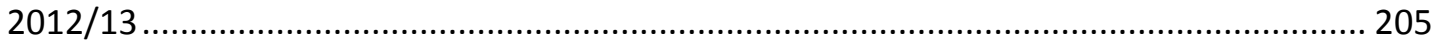

Tabla 14. Distribución por discapacidad y género de los alumnos discapacitados en educación primaria durante el curso 2012/13

Tabla 15. Distribución por grado de los alumnos con discapacidad durante el curso 2012/13

Tabla 16. Evolución porcentaje alumnas matriculadas en educación primaria (incluyendo $A B E$ ) y su comparación respecto al porcentaje de población femenina en edad escolar ... 215

Tabla 17. Comparativa de la tendencia durante el periodo 2008/9-2012/13 del descenso de alumnos matriculados en segundo ciclo de primaria respecto al primer ciclo según el género 219

Tabla 18. Instalaciones disponibles en las escuelas de secundaria durante el curso 2012/13 230

Tabla 19. Distribución de las clases disponibles en las escuelas de secundaria durante el

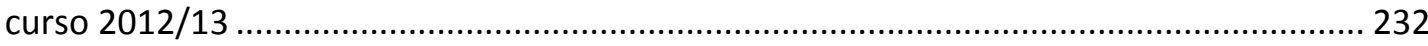

Tabla 20. GER de 1 y 2o ciclo de educación secundaria durante el curso 2012/13 ............ 232

Tabla 21. NER de 1ㅇ y 2o ciclo de secundaria durante el curso 2012/13 ............................. 233

Tabla 22. Evolución de la tasa de alumnos por sección en secundaria entre los cursos

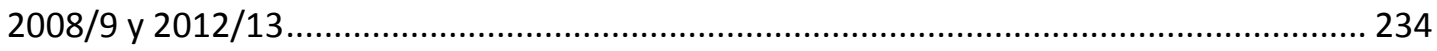

Tabla 23. Evolución P.A.P entre en curso 2008/9 y 2012/13 ............................................. 234 
Tabla 24. Comparativa de la evolución del porcentaje de alumnado femenino en primaria entre el curso 2008/9 y 2012/13 en Etiopía y en la Oromía ................................................ 254

Tabla 25. Evolución del número disponible de escuelas de primaria en la Oromía y Etiopía

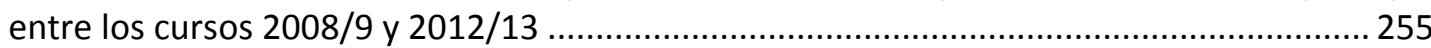

Tabla 26. Comparativa del AIR entre la Oromía y Etiopía durante el curso 2012/13 .......... 256

Tabla 27. Comparativa de la NIT entre la Oromía y Etiopía durante el curso 2012/13 ....... 256

Tabla 28. Comparativa de la Tasa de Matriculación bruta entre la Oromía y Etiopía en el curso 2012/13 257

Tabla 29. Comparativa de la Tasa de Matriculación bruta entre la Oromía y Etiopía en el primer ciclo de educación primaria durante el curso 2012/13 257

Tabla 30. Comparativa de la Tasa de Matriculación bruta entre la Oromía y Etiopía en el segundo ciclo de educación primaria durante el curso 2012/13 ....................................... 258

Tabla 31. Comparativa de la Tasa de Matriculación neta entre la Oromía y Etiopía en el curso 2012/13 259

Tabla 32. Comparativa de la Tasa de Matriculación neta entre la Oromía y Etiopía en el primer ciclo de educación primaria durante el curso 2012/13 260

Tabla 33. Comparativa de la Tasa de Matriculación neta entre la Oromía y Etiopía en el segundo ciclo de educación primaria durante el curso 2012/13 ....................................... 260

Tabla 34. Comparativa de la tasa de repetición en primaria (1-8) en la Oromía y Etiopia .. 261

Tabla 35. Comparativa de la tasa de abandono escolar en primaria (1-8) en la Oromía y Etiopia 262

Tabla 36. Comparativa de la tasa de finalización de primaria en 5o curso del año 2012/13 en la Oromía y Etiopía 262

Tabla 37. Comparativa de la tasa de finalización de primaria en 8o curso del año 2012/13 en la Oromía y Etiopía 263

Tabla 38. Comparativa de la ratio de alumnos por sección entre la Oromía y Etiopía entre los cursos 2008/9 y 2012/13 264

Tabla 39. Comparativa de la ratio de alumnos- profesor entre la Oromía y Etiopía entre los cursos $2008 / 9$ y $2012 / 13$ 264

Tabla 40. Comparativa de la evolución del porcentaje de alumnado femenino en educación secundaria entre el curso 2008/9 y 2012/13 en Etiopía y en la Oromía 269

Tabla 41. Evolución del número disponible de escuelas de secundaria en la Oromía y Etiopía entre los cursos 2008/9 y 2012/13 270

Tabla 42. Comparativa entre la Oromía y Etiopía del GER 1 ㅇ y 20 ciclo de educación secundaria durante el curso 2012/13 272

Tabla 43. Comparativa entre la Oromía y Etiopía del NER 1 ㅇ y 2 o ciclo de educación secundaria durante el curso 2012/13 273

Tabla 44. Comparativa de la ratio de alumnos por sección en educación secundaria entre la Oromía y Etiopía entre los cursos 2008/9 y 2012/13 274 
Tabla 45. Comparativa de la ratio de alumnos-profesor en educación secundaria entre la Oromía y Etiopía entre los cursos 2008/9 y 2012/13

Tabla 46. Propiedades psicométricas de la muestra de ítems de satisfacción con la escuela $(\mathrm{N}=20)$. 369

Tabla 47. Propiedades psicométricas de la muestra de participantes en la escala de satisfacción con la escuela $(\mathrm{N}=68)$ 370

Tabla 48. Propiedades psicométricas de los ítems de la escala de satisfacción con la escuela según el modelo de Rash 375

Tabla 49. Polaridad de los ítems de la escala de satisfacción con la escuela ..... 376

Tabla 50. Ejemplo de preguntas y valoración de su pertinencia 385

Tabla 51. Ítems de calidad de vida infantil eliminados para el presente estudio. 386

Tabla 52. Consistencia interna de la escala y los factores de Calidad de Vida Infantil 387

Tabla 53. Correlaciones de Pearson entre las dimensiones y total de la escala de Calidad de Vida infantil 387

Tabla 54. Propiedades psicométricas de la muestra de ítems de calidad de vida ( $N=43) \ldots 388$

Tabla 55. Propiedades psicométricas de la muestra de participantes en la escala de calidad de vida ( $\mathrm{N}=67)$ 388

Tabla 56. Propiedades psicométricas de los ítems de la escala de calidad de vida según el modelo de Rash. 391

Tabla 57. Polaridad de los ítems de la escala de calidad de vida........................................... 392

Tabla 58. Distribución de los participantes por edades .......................................................... 402

Tabla 59. Distribución de participantes en niveles educativos ................................................ 403

Tabla 60. Distribución de los participantes según el tiempo que tardan en desplazarse de casa al colegio 404

Tabla 61. Estadísticos descriptivos de las puntuaciones en satisfacción con la escuela ..... 406

Tabla 62. Distribución, en porcentajes, de las puntuaciones en satisfacción con la escuela 407

Tabla 63. Estadísticos descriptivos de las puntuaciones en calidad de vida infantil 408

Tabla 64. Distribución de frecuencias de respuestas en la escala de Calidad de Vida 409

Tabla 65. Correlaciones de Pearson entre las dimensiones de calidad de vida y satisfacción escolar

Tabla 66. Estadísticos descriptivos y significación de las diferencias (Anova) en función del curso.

Tabla 67. Estadísticos descriptivos y significación de las diferencias (Anova) en función del género 414 


\section{ÍNDICE DE FIGURAS}

Figura 1. Recreación de Australopitecos Afarensis infantil y adulta...................................... 34

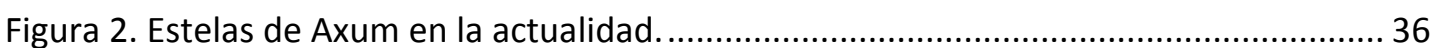

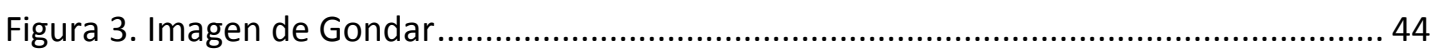

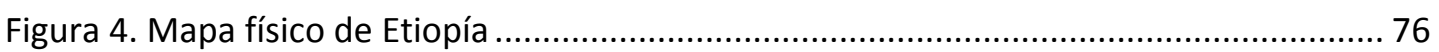

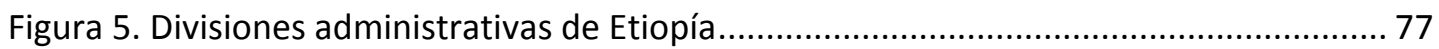

Figura 6. Niveles de organización administrativa de Etiopía. ................................................. 77

Figura 7. Evolución del PIB de Etiopía comparado con el de África Subsahariana y los Países

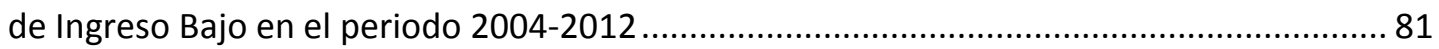

Figura 8. Mapa con los distintos grados de inseguridad alimentaria para Octubre-Diciembre 2013 84

Figura 9. Obras de ampliación en una carretera al norte del país .85

Figura 10. Evolución de la deuda externa pública y públicamente garantizada de Etiopía en Dolares norteamericanos. 90

Figura 11. Evolución del índice de precios al consumo en productos alimenticios y no alimenticios durante el periodo 2000-2011 en Etiopía ......................................................... 91

Figura 12. Pirámide poblacional de Etiopía en 2013 ............................................................... 94

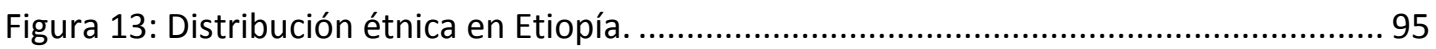

Figura 14. Evolución del IDH de Etiopía comparada con el África Subsahariana, los países

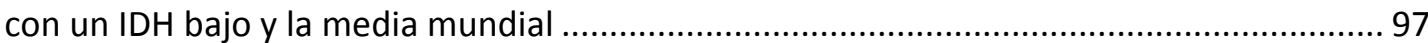

Figura 15: Grafica de las causas de la mortalidad de menores de cinco años en África ..... 104

Figura 16. Casa típica Guji siguiendo el patrón de doblamiento disperso........................... 132

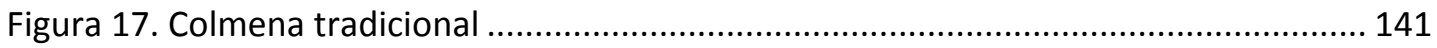

Figura 18. Autobús accidentado en una nueva carretera de Gujiland ............................... 145

Figura 19. Inscripciones en lengua preaxumita en la ciudad de Yeha ................................ 154

Figura 20. Tablilla coránica y manuscrito ortodoxo utilizados para la educación. Museo de la

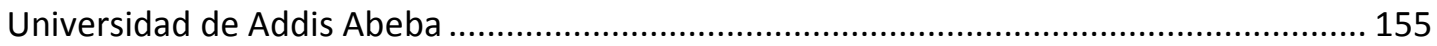

Figura 21. Evolución de la población escolar durante los últimos 5 años .......................... 170

Figura 22. Evolución de los alumnos matriculados en las diversas etapas educativas......... 171

Figura 23. Estructura sistema educativo formal e informal de Etiopía................................. 174

Figura 24. Alumnos del Kindergarden del colegio Mary Help School of Ziway de la misión de

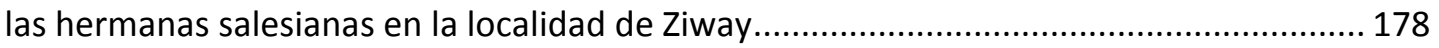

Figura 25. Mapa de Etiopía con la proporción mayores de cinco años de edad capaces de

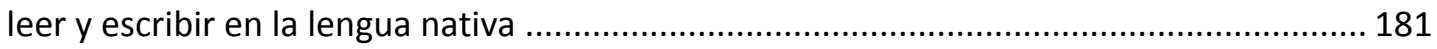

Figura 26. Letrina de una escuela de primaria .................................................................. 186 
Figura 27. Evolución del GER en Primaria (1-8)

190

Figura 28. Evolución de la tasa de matriculación bruta en el Primer Ciclo de la Educación Primaria (1-4) 191

Figura 29. Evolución de la tasa de matriculación bruta en el Segundo Ciclo de la Educación Primaria (1-4) 192

Figura 30. Evolución NET en Primaria (1-8) 193

Figura 31. Porcentaje de alumnos repetidores en cada curso de primaria curso 2011/2012 195

Figura 32. Porcentaje de alumnos que abandonan el sistema educativo en cada curso de primaria durante el curso 2011/2012 197

Figura 33. Comparativa del porcentaje de alumnos que abandonan el sistema educativo en cada curso de primaria durante el curso $208 / 2009$ y $2011 / 12$. 198

Figura 34. Porcentaje de supervivencia hasta 5o entre los cursos académicos 2007/08 y 2011/12 201

Figura 35. Evolución de la tasa de finalización en 5 y 8 o Grado durante los cursos 2008/92012/13 202

Figura 36. Evolución del Ratio de alumnos por profesor en los últimos 5 cursos académicos 204

Figura 37. Profesorado de una escuela de primaria relajándose durante un periodo de descanso 206

Figura 38. Evolución de la proporción de profesorado femenino en primaria entre los cursos $2008 / 9$ y $2012 / 13$ 207

Figura 39. Evolución del porcentaje de profesores suficientemente cualificados en primer y segundo ciclo de primaria entre el 2008 y 2013 208

Figura 40. Comparación de la evolución de la tasa de ingreso neto entre niños y niñas entre $2008 / 9$ y $2012 / 13$ 215

Figura 41. Evolución de la tasa de ingreso con independencia de la edad diferenciada por género 216

Figura 42. Comparativa de las tendencias entre 2008/9 y 2012/13 de la tasa de escolarización bruta en primaria (10-8을 dependiendo del género 217

Figura 43. Comparativa de la tendencia tasa de matriculación bruta en el primer ciclo de primara (1ㅇ-4으) dependiendo del género 218

Figura 44. Comparativa de la tendencia tasa de matriculación bruta en el segundo ciclo de primara (5-8ㅇ) dependiendo del género 218

Figura 45. Grafica comparativa de las diferencias por género en la tasa de matriculación bruta en el segundo ciclo de primaria y la tasa de abandono al finalizar el primer ciclo de primaria 220

Figura 46. Evolución de la diferencia de la NET en primaria dependiendo del género ........221

Figura 47. Tendencias en grado de repetición según el género durante la primaria entre $2007 / 8$ y $2011 / 12$ 222 
Figura 48. Comparativa según el género de la tasa de repetición en cada curso de primaria durante el año académico 2011/12

Figura 49. Tendencia según el género de la tasa de abandono escolar entre el curso 2007/8 y 2011/12 en primaria

Figura 50. Tasa de abandono escolar según el género durante los distintos cursos de la educación primaria durante el curso 2011/12

Figura 51. Evolución de la Tasa de supervivencia entre 2007/8 y 2001/12 según el género 224

Figura 52. Tendencia entre 2008/9 y 2012/13 según el género en la tasa de finalización de primaria en 50 225

Figura 53. Tendencia entre 2008/9 y 2012/13 según el género en la tasa de finalización de primaria en 80 226

Figura 54. Esquema de la educación secundaria en Etiopía y sus distintos itinerarios. Fuente: MoE.

Figura 55. Presupuesto de educación y Presupuesto general del gobierno de Etiopía entre los años 2008-2013. 236

Figura 56. Presupuesto de educación y Presupuesto general de España entre los años 20082013 236

Figura 57. Distribución de los fondos de educación según el nivel educativo en Etiopía ... 238

Figura 58. Birrs estimados destinados por alumno y año en Etiopía 239

Figura 59. Comparativa de las tendencias acumuladas de Etiopía y la Oromía en el aumento anual de alumnos matriculados en educación primaria.. 253

Figura 60. Comparativa de la formación del profesorado durante el curso 2012/13 entre la Oromía y Etiopía. 266

Figura 61. Comparativa de las tendencias acumuladas de Etiopía y la Oromía en el aumento anual de alumnos matriculados en educación secundaria..... 268

Figura 62. Niñas con recipiente para transportar agua fuera de la escuela durante el horario escolar 283

Figura 63. Esquema diseño etnografía escuela de Qillenso 308

Figura 64. Vista De Qillenso por Satélite en la que se resaltan la misión y algunas casas... 311

Figura 65. Imagen de una página del cuaderno de notas 316

Figura 66. Posters con información sobre la organización de la escuela 317

Figura 67. Representación de los alumnos y alumnas de la escuela de Qillenso 318

Figura 68. Esquema de la misión de Qillenso. 319

Figura 69. Interior aula escuela de Qillenso 321

Figura 70. Interior de la oficina del subdirector en la escuela de Qillenso 323

Figura 71. Quema de basura por parte de profesores y alumnos 325

Figura 72. Imagen del campo de futbol, iglesia (primer plano) y escuela de Qillenso (segundo plano) 326 
Figura 73. Reunión de padres, alumnos y profesores al finalizar el curso

327

Figura 74. Proporción anual del alumnado dependiendo del género en la escuela de Qillenso......

329

Figura 75. Evolución del número de alumnos dependiendo de su sexo en la escuela de Qillenso. 331

Figura 76. Distribución de los alumnos matriculados por curso entre 1977 y 2012 en la escuela de Qillenso.

Figura 77. Distribución por curso dependiendo del género del porcentaje de alumnos en la escuela de Qillenso entre 1977 y 2012 335

Figura 78. Evolución anual del porcentaje de alumnos según el curso 336

Figura 79. Evolución anual de la matriculación según el curso de los alumnos de la escuela de Qillenso. 338

Figura 80. Evolución anual de la matriculación según el curso de las alumnas de la escuela de Qillenso. 338

Figura 81. Escolarización según la edad y el género en la escuela de Qillenso 340

Figura 82. Escolarización según la edad y el género en la escuela de Qillenso. 341

Figura 83. Escolarización según la edad de la escolarización obligatoria, y años, en la escuela de Qillenso. 342

Figura 84. Mapa de Wright. Localización de los participantes y los ítems en la variable latente medida 371

Figura 85. Mapa de Wright. Identificación de los participantes y los ítems en la variable latente medida 372

Figura 86. Distribución de personas e ítems en la Escala de Satisfacción Escolar 374

Figura 87. Representación gráfica del comportamiento de los ítems (escala de satisfacción) 378

Figura 88. Gráfico de burbujas de los ítems (Escala de satisfacción escolar) 379

Figura 89. Calibración de los ítems (escala de satisfacción escolar) .....................................380

Figura 90. Curvas características de los ítems (Escala de Satisfacción Escolar) 381

Figura 91. Ejemplo de curva característica del ítem 1 según el modelo Rash, en la escala de Satisfacción con la escuela 382

Figura 92. Funcionamiento diferencial del test para hombres y mujeres (Escala de Satisfacción con la escuela).... 383

Figura 93. Tamaño de las diferencias del FDI en función del género (Escala de satisfacción con la escuela) 384

Figura 94. Mapa de Wright. Identificación de los participantes y los ítems en la variable latente medida (Calidad de vida) 389

Figura 95. Distribución de personas e ítems en la Escala de Calidad de vida 390

Figura 96. Representación gráfica del comportamiento de los ítems (escala de calidad de vida) 395 
Figura 97. Gráfico de burbujas de los ítems (Escala de Calidad de Vida) .............................396

Figura 98. Calibración de los ítems (escala de calidad de vida) .......................................... 397

Figura 99. Curvas características de los ítems (Escala de Calidad de Vida) .......................... 398

Figura 100. Ejemplo de curva característica del ítem 1 según el modelo Rash, en la escala de

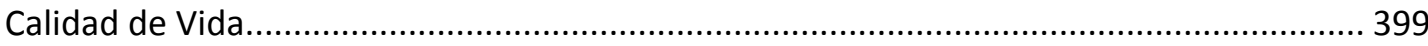

Figura 101. Funcionamiento diferencial del test para hombres y mujeres (Escala de Calidad

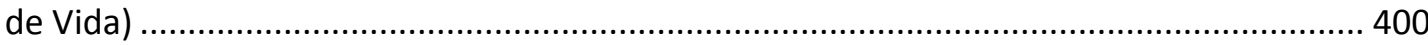

Figura 102. Tamaño de las diferencias del FDI en función del género (Escala de satisfacción

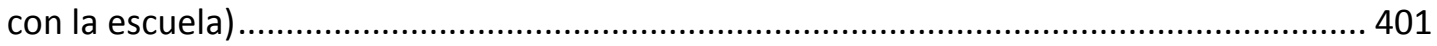

Figura 103. Distribución de los participantes por género................................................. 403

Figura 104. Porcentaje de participantes que han tenido una escolarización continuada o no 405 


\section{PRESENTACIÓN}

La expansión de los sistemas educativos y el acceso de la población a la educación primaria ha estado en el punto de mira de organizaciones internacionales, gobiernos e instituciones de todo tipo desde la Declaración del Milenio firmada en Nueva York en el año 2000 en la que la universalización de la educación primaria fue declarada uno de los Objetivos del Milenio que debían alcanzarse en 2015(www.onu.es).

Estamos convencidos de que la educación es una herramienta fundamental para mejorar la situación de subdesarrollo en la que a día de hoy sigue inmersa una gran cantidad de países. Creemos que la educación no solo puede ayudar a aliviar la situación actual favoreciendo el desarrollo, sino que además es la llave para que las nuevas generaciones que están creciendo en esos países puedan cambiar o al menos alterar parte de las dinámicas internas y realidades que perpetúan esa situación de subdesarrollo. Así pues, creemos que la expansión de la educación no solo ayudaría a que los futuros ciudadanos de estos países tuvieran en su vida una mejor situación económica, social o sanitaria, sino que además les otorgaría una serie de herramientas que les permitirían alcanzar un mayor grado de empoderamiento. Todo ello les permitiría luchar más efectivamente por la defensa de sus derechos y por la abolición de situaciones de indefensión frente a la corrupción o a la marginalización de sectores de la sociedad.

Además estamos firmemente convencidos de que la educación es fundamental para conseguir la igualdad de la mujer, no solo a través de la lucha contra creencias tradicionales y esquemas culturales que relegan a la mujer a una posición de inferioridad frente al hombre, sino también otorgando a las futuras generaciones de mujeres una serie de conocimientos que garanticen que puedan ser económicamente independientes para, de esta manera, asegurar que puedan hacer valer sus derechos.

Lamentablemente, a pocos meses de alcanzarse la fecha limite señalada en la Declaración del Milenio para la consecución de los diversos objetivos queda claro 
que pese a los progresos realizados va a ser imposible alcanzar el objetivo de la universalización de la educación primaria, siendo Etiopía un país que ejemplifica este problema ya que, pese al aumento de inversión en educación por parte del gobierno Etíope, a la presencia de organizaciones no gubernamentales y escuelas religiosas y pese a los sustanciales avances experimentados, no se ha logrado aún una escolarización primaria universal en el país y es difícil que se logre antes de que finalice el plazo.

Debido a lo anteriormente expuesto y a nuestro conocimiento previo de Etiopía y de su realidad educativa pensamos que la realización de un estudio sobre la educación primaria de los miembros de una pequeña etnia de Etiopía en una de las zonas más atrasadas del país constituía un escenario de acción ideal para realizar un estudio de antropología aplicada para el desarrollo. Y ello porque nos podría ayudar a conocer la realidad educativa que se esconde a pie de campo tras las grandes estadísticas de los organismos internacionales. También nos ayudaría a entender las causas de que pese a todos los esfuerzos y recursos invertidos en educación no se haya logrado todavía una plena escolarización y menos aún que los alumnos completen al menos todo un ciclo de educación primaria.

Siguiendo la vocación holística de la antropología, en este trabajo hemos pretendido no solo conocer la realidad del sistema educativo de primaria en los Guji, sino también conocer el contexto cultural, social e histórico que rodea y moldea esta realidad. Por lo tanto, en esta investigación hemos prestado además atención a todos los aspectos relacionados con la estructura y superestructura social. Así pues, el presente trabajo está estructurado en seis capítulos, siguiendo un esquema descendente de lo más general a lo más particular para finalmente llegar a una síntesis

El primer capítulo titulado Etiopía: Pasado, presente y futuro, está dedicado a conocer y comprender Etiopía como realidad compleja, en la que intervienen aspectos históricos, geográficos, étnicos, políticos, sociales y en la se inscribe nuestra investigación sobre la educación primaria de los alumnos Guji en Qillenso. 
Dicho capítulo está dividido en varios apartados interconectado; El primero se centra en el estudio y comprensión de la historia de Etiopía, prestando especial atención a los hechos históricos que tienen como protagonistas a los miembros de la Etnia Oromo y a sus relaciones con las etnias que tradicionalmente han dominado políticamente el país, como son las etnias Amhara y Tigriña. Esta introducción a la historia de Etiopía es necesaria ya que en nuestra experiencia de campo hemos visto la importancia fundamental que los etíopes otorgan a su historia y la etnicidad en sus relaciones del día a día. Esta importancia de la historia y de las relaciones étnicas no solo atañe a las relaciones interpersonales sino que impregna también todo el sistema administrativo y político etíope. Así, la etnicidad se constituye como la base de la organización territorial etíope y es la piedra de toque desde la que se organizan las relaciones entre el poder central fuertemente dominado por amharas y tigriños con las distintas administraciones regionales y con los ciudadanos. Además, la forma en que cada una de las etnias ha construido su propia historia y el encaje de dicha historia en el relato nacional etíope ha tenido su reflejo en la situación educativa que vive cada zona del país ya que, como veremos a continuación, el poder central ha premiado, y sigue haciéndolo, con mayores y mejores inversiones a las zonas dominadas por las etnias de los miembros del gobierno, mientras que los miembros las etnias ajenas al poder central han mostrado en ocasiones recelo o rechazo a la implantación del sistema educativo por parte del gobierno al que veían como algo ajeno que pretendía acabar con su cultura debido a la utilización del mismo método de aculturación por parte del poder.

En las siguientes páginas, una vez expuesta la historia del país, hemos descrito las características básicas de la geografía del país. Hemos decidido incluir este apartado lugar ya que junto con la historia y la cuestión étnica nos permite completar el contexto para comprender los apartados posteriores centrados en la organización administrativa, la economía y la situación política y social del país.

El tercer apartado del primer capítulo se centra en la organización administrativa y territorial de Etiopía. Aquí es perfectamente visible cómo la 
estructura estatal actual está organizada supuestamente para dar respuesta a las tensiones étnicas internas del país, otorgando derechos de autogobierno a cada una de estas etnias. Sin embargo, al mismo tiempo se reserva una cuota muy importante de poder para el gobierno central. Dicho poder central, como exponemos en el primer apartado, acumula en realidad una cuota tan elevada de poder, especialmente en lo relacionado con los aspectos económicos y con las fuerzas de seguridad del Estado, que ha vaciado de capacidad de autogobierno real a las regiones. A ello se añade el hecho de que la dominación e infiltración por parte del partido gubernamental a todos los niveles de la administración hace cuestionable la democracia instaurada en el país en 1994.

En los apartados restantes del primer capítulo ofrecemos además una breve introducción de la situación económica, demográfica y social del país para acabar de completar el cuadro de contextualización de la investigación dentro de la realidad de Etiopía. Finalizamos el primer capítulo con una radiografía de cómo se encuentra Etiopía respecto a los Objetivos del Desarrollo del Milenio actualmente, ya que aunque nuestra investigación se centra tan solo en uno de ellos, es igualmente cierto que los sistemas educativos y los procesos de enseñanza-aprendizaje se encuentran integrados y condicionados por la sociedad en el que se desarrollan. Dicho de otro modo, no podríamos entender los obstáculos a los que se enfrenta la consecución del Objetivo de la Educación Primaria Universal en Etiopía sin conocer el estado del resto de los Objetivos del Milenio con los cuales está interconectado.

El segundo capítulo de la presente Tesis Doctoral, titulado Los Oromo: historia, cultura y economía, está centrado en varios aspectos de la historia y cultura particular de los Oromo, etnia a la que pertenecen los Guji con quienes hemos trabajado. Hay que señalar que, debido a la gran complejidad interna y extensión geográfica de la Etnia Oromo, mientras que el primer apartado de este capítulo hace referencia a los Oromo en general, en los apartados referentes a cultura y economía nos hemos centrado exclusivamente en el caso de los Oromo Guji. Así pues, en el apartado centrado en la historia de los Oromo hemos analizado cómo durante el devenir histórico de este pueblo han venido sucediendo una serie 
de estímulos internos y externos que han ayudado a modelar la identidad y cultura Oromo. También exponemos cómo las fases históricas por las que este grupo ha pasado han determinado su situación y cosmovisión actual.

A continuación, en dicho capítulo, hemos realizado un estudio etnográfico sobre los Oromo Guji de la zona de Qillenso y sus alrededores. Para ello, si bien nos hemos apoyado en algunos estudios previos, hemos utilizado sobre todo nuestra experiencia de campo en la zona, complementada con los datos que hemos obtenido de informantes clave. En este apartado exponemos cómo, por un lado, la forma de vida y los valores culturales tradicionales siguen muy presentes en el día a día de los Guji pero, por otro, queda claro también cómo esta sociedad se encuentra en pleno proceso de transformación debido a las influencias externas que están llegando a la zona y que están introduciendo una nueva serie de valores y formas de vida hasta no hace mucho desconocidas.

Para finalizar el segundo capítulo, hemos analizado el modo de producción de la zona utilizando el mismo sistema de investigación que en el apartado precedente. De esta manera creemos que conocer la cultura y la realidad económica de la zona nos permitirá acceder al marco más inmediato en el que inscribir nuestra investigación en la escuela primaria de Qillenso. Y ello porque es evidente que los aspectos culturales y económicos son determinantes a la hora de comprender la escolarización de los niños y niñas y puede ayudar a entender los grandes obstáculos a los que se enfrenta el logro de dicha escolarización.

Tras estos dos primeros capítulos incluimos otros dos, tercero y cuarto, centrados exclusivamente en el análisis e interpretación de los datos estadísticos que el gobierno de Etiopía, la Región de la Oromía y agencias y organismos internacionales han publicado sobre la situación educativa tanto en Etiopía como en la Oromía. En el primer capítulo analizamos la situación en Etiopía a escala nacional y en el segundo, a escala regional. De esta manera continuamos con el esquema de ir de lo más general a lo más específico para así, cuando analicemos los datos obtenidos en nuestro trabajo de campo en la escuela de Qillenso cerraremos la escala descendente: Etiopía -> Oromía -> Qillenso 
Los dos capítulos sobre la situación educativa en Etiopía y en la Oromía adoptan un mismo esquema, de cara a facilitar la posterior comparativa de las estadísticas. En el análisis de los datos prestamos una especial atención a la evolución habida en los últimos años, exponiendo las tendencias que de ellos se desprenden y que nos permitan vaticinar, en algunos casos, la futura evolución de los datos. Centramos también nuestro análisis en la situación de la escolarización de las mujeres, ya que tradicionalmente ha sido más escasa y, pese a los esfuerzos de los últimos años, su situación sigue siendo de desventaja. Además, como diversos estudios y organizaciones afirman, la escolarización femenina es clave para la mejora de la calidad de vida en un país, como reconocen numerosas organizaciones internacionales, por lo que conocer las causas que lastran los niveles de escolarización femenina es fundamental si se pretende mejorar dicha calidad de vida. Finalmente en ambos capítulos señalaremos los problemas fundamentales detectados tras el análisis de los datos y nuestra experiencia en el país.

En el cuarto capítulo de esta Tesis Doctoral, una vez conocidos tanto los contextos, históricos, culturales y educativos a niveles nacionales y regionales, nos centramos en la escuela de Qillenso y en sus actores principales como objeto de estudio. Para ello hemos realizado un estudio etnográfico de la escuela y su entorno y hemos analizado los datos sobre su alumnado a lo largo de su historia. Ello nos ha permitido obtener una visión completa de la escuela y su entorno, logrando ver cómo es el día a día y la realidad de la educación en una pequeña escuela de educación primaria en una zona rural de Etiopía.

El quinto capítulo se dedica a dar voz a los alumnos de la escuela de Qillenso. De esta manera hemos podido completar la información sobre la escuela y su funcionamiento. Además una vez disponíamos de los puntos de vista de los gobiernos nacional y regional, así como de organizaciones internacionales y de nuestra propia visión, considerábamos fundamental acceder a la visión de los más interesados en la educación en Etiopía y en Qillenso, como son los propios alumnos de la escuela. $Y$ ello porque creemos que si se pretenden generar conocimientos que sirvan para implementar posibles acciones y políticas destinadas a mejorar la 
educación, es clave tener en cuenta la voz de los usuarios de la misma y más aún cuando muchas veces es ignorada por tratarse de la voz de niños y familias pobres alejadas de los círculos de poder.

De esta manera, con el mencionado capítulo, creemos haber obtenido una visión holística sobre el tema, pues hemos analizado desde el nivel más general de la educación en Etiopía hasta su nivel más concreto posible representado por una simple escuela, pasando por el nivel intermedio de la región de Oromía, lo que nos ha permitido observar las similitudes y las diferencias que hay entre lo que dicen los informes internacionales o nacionales y lo que viven día a día miles de niños en las escuelas del país. Además en este estudio hemos analizado los condicionantes históricos, políticos, económicos y culturales que afectan al sistema educativo en el país, y cuyo conocimiento y comprensión es fundamental si se pretende entender el porqué de la realidad educativa tanto en Qillenso como en Etiopía.

Finalizamos la presente Tesis Doctoral con un sexto capítulo en el que recogemos las conclusiones que se derivan de todo el proceso de investigación, tanto del trabajo de campo como del análisis y síntesis de datos y exponemos a su vez las posibles líneas de actuación que quedan abiertas junto a las limitaciones que deberán ser superadas en posteriores estudios. Esperamos que los Anexos incluidos en un último apartado, faciliten la replicación del presente trabajo. 


\section{CAPÍTULO 1. ETIOPÍA: PASADO, PRESENTE Y FUTURO}

Etiopía, cuyo nombre oficial es República Democrática Federal de Etiopía, se encuentra situada en el Este de África, en la zona conocida como Cuerno de África. Su territorio hace frontera con Djibouti $(349 \mathrm{~km})$ Eritrea $(912 \mathrm{~km})$ Kenya $(861 \mathrm{~km})$ Somalia $(1,600 \mathrm{~km})$, South Sudan $(837 \mathrm{~km})$, Sudan (769) (Central Intelligence Agency, 2013). Para comprender la realidad actual de Etiopía es importante conocer su singular desarrollo histórico y cultural que ha diferenciado al país del resto de los de su entorno y de toda África, dando un carácter y un sentido del orgullo y de la identidad a sus habitantes que los diferencia del resto de los africanos y que marca el día a día de sus habitantes especialmente cuando se relacionan con extranjeros. A todo ello aludiremos en las páginas siguientes.

\subsection{HISTORIA}

La historia de Etiopía se caracteriza por su complejidad, ya que en el país coexiste una gran diversidad de grupos étnicos que han experimentado diferentes desarrollos históricos y que incluso han sido antagonistas durante siglos y que en la actualidad conviven en un estado que no está exento del peso de esa historia en sus relaciones internas.

\subsubsection{Prehistoria}

Etiopía es considerada por los estudiosos de la evolución humana como una de las cunas de la humanidad. En su territorio existen yacimientos arqueológicos en los que se han hallado restos de una gran cantidad de diferentes australopitecos y homínidos siendo el más famoso de todos "Lucy" la australopitecos afarensis de 3.2 millones de años de antigüedad (véase Figura 1). De una antigüedad estimada de 3,3 millones de años se encontró en la localidad de Dikika un esqueleto de una niña de la misma especie nombrada "Selam". Este espécimen fue descubierto por el 
antropólogo etíope Zeresenay Alemseged en el año 2000 a pocos kilómetros de donde fue descubierta Lucy en 1974.

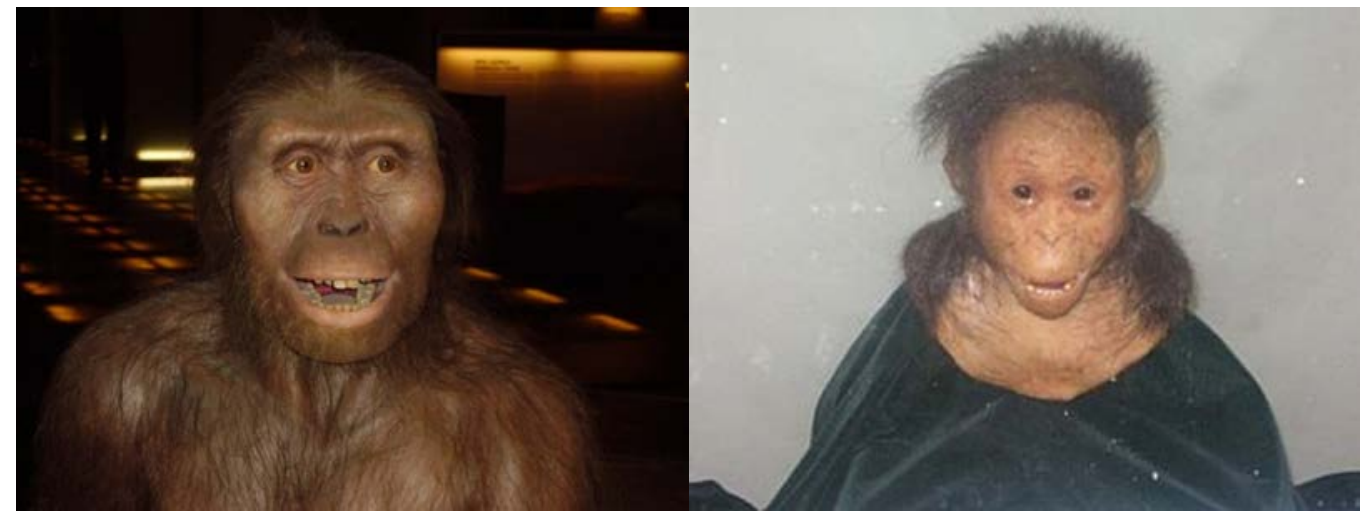

Figura 1. Recreación de Australopitecos Afarensis infantil y adulta

(Fuente: The National Museum of Addis Ababa, Ethiopia)

Muchos expertos defienden que Etiopía es el lugar donde aparecieron por primera vez los seres humanos modernos. Recientemente se han encontrado unos restos atribuidos a una nueva subespecie humana, el Homo sapiens idaltu u hombre de Herto, denominado así por haberse encontrado cerca de la localidad etíope de Herto Bouri en el año 1997 por el equipo de paleoantropólogos dirigido por Tim White. Este descubrimiento, que no se hizo público hasta el año 2003, muestra los restos que datan de unos 160.000 años de antigüedad aproximadamente y que podría ser un antecesor directo del Homo sapiens sapiens.

\subsubsection{Primeras civilizaciones}

Sobre el siglo VIII A.C. se estableció en la zona norte de Etiopía y en la actual Eritrea una civilización conocida como D’mt cuyo centro más importante se encontraba en la ciudad de Yeha. Diversos historiadores como Cain Felder, y Ephraim Isaac consideran que esta civilización tiene un carácter indígena, mientras que otros de sus colegas, como Joseph Michels o Henri de Contenson, apoyan la teoría de que el reino de D'mt surgió de una mezcla de poblaciones locales con los inmigrantes Sabanos, que llegaron de la península arábiga (Henze, 2000). 
Recientemente las últimas investigaciones lingüísticas aseguran que el idioma Ge'ez tiene un origen anterior a la presencia de las poblaciones sabanas en Etiopía y Eritrea. Estos descubrimientos, junto a las evidencias de que la presencia de inmigrantes Sabanos solo duró unas décadas, refuerza la teoría del desarrollo indígena de la civilización de D’mt. Este estado de D’mt entró en decadencia y se dividió en pequeños reinos tras el siglo $V$ A.C., quedando la zona dividida en pequeños reinos Proto-axumitas hasta que uno de ellos logró imponerse sobre el resto de ellos, reunificando la zona y convirtiéndose en el imperio Axumita en el siglo I A.C.

Durante este periodo de tiempo ha sido fechado un par de yacimientos arqueológico en el norte de Kenia (300 A.C. aproximadamente) formado por unos pilares que fueron utilizados como la base del calendario oromo, lo que probaría la presencia de este pueblo cusítico en la zona desde un periodo muy anterior a su supuesta llegada a la zona en el Siglo XVI:

"Namoratunga, a megalithic site in northwester Kenya, has an aligment of 19 basalt pillars that are nonrandomly oriented toward certain stars and costellations. The same stars and costellations are used by modern Cushitic peoples to calculate an accurate calendar" (Lynch y Robbins, 1978, pag.766)

\subsubsection{El Imperio Axumita}

Anteriormente se consideraba que el Imperio Axumita debía su existencia a la presencia de inmigrantes Sabanos de la península arábiga, pero las últimas investigaciones y los nuevos conocimientos sobre D'mt hacen pensar en la actualidad que su origen es puramente indígena (Munro-Hay, 1991).

El Imperio Axumita toma su nombre de la ciudad etíope de Axum, famosa por sus estelas (Figura 2) y que actualmente es una pequeña ciudad del norte del país. 


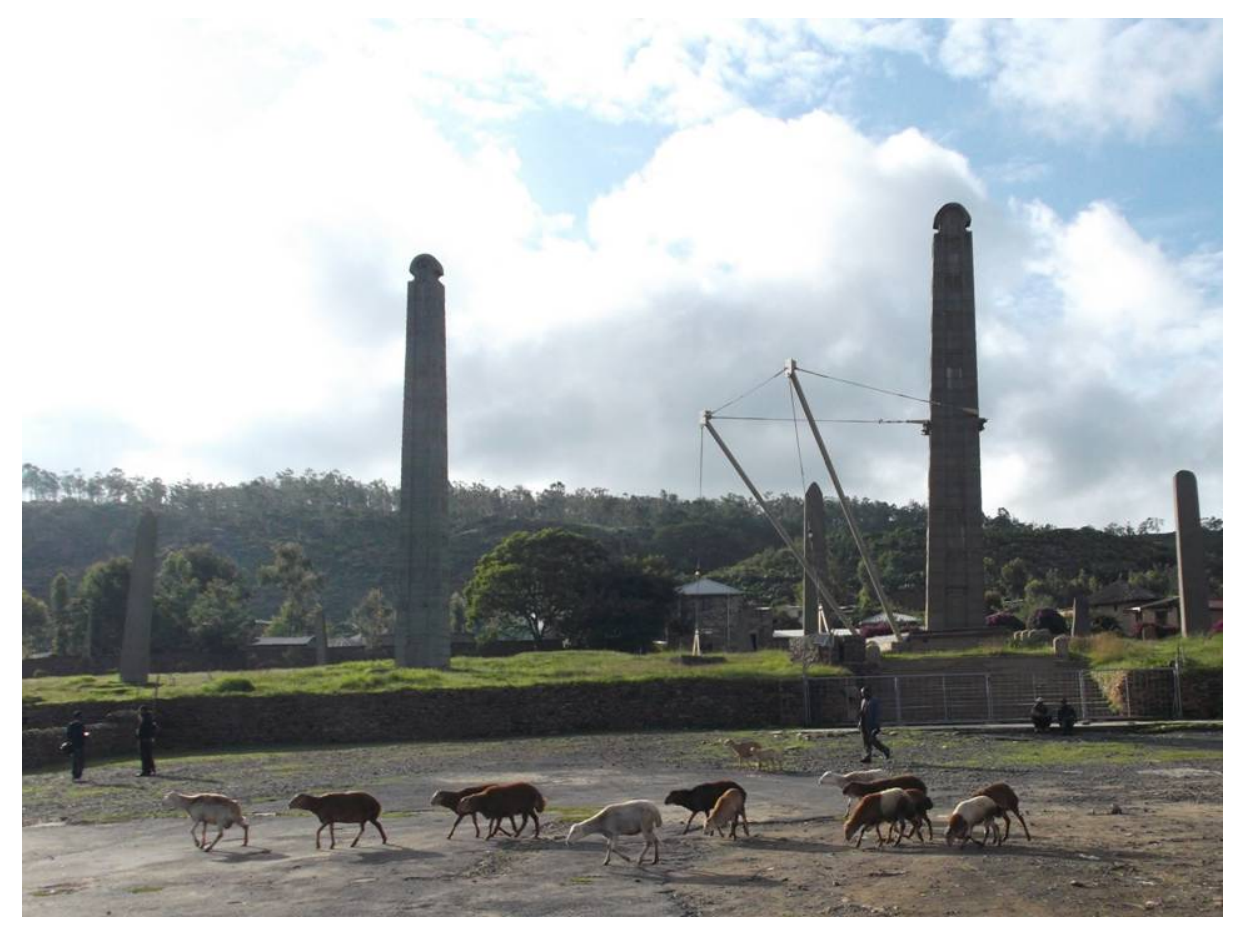

Figura 2. Estelas de Axum en la actualidad.

(Fuente: Autor)

Este imperio se extendió en el tiempo desde el siglo I A.C. hasta la muerte del último de sus reyes en el 960 D.C. En su momento de mayor apogeo y esplendor controlaba territorios que actualmente abarcan Eritrea, la parte norte de Etiopía, zonas del actual Sudan, y partes de Yemen y Arabia Saudí. Este imperio Axumita fue reconocido junto a Roma, Persia y China como uno de los grandes imperios de la antigüedad por el sabio persa Mani en el siglo III D.C. y en el Siglo IV D.C. bajo el Rey Ezana, el Estado convirtió el cristianismo como religión oficial siendo el segundo Estado en el mundo en hacerlo -después de Armenia- pero siendo el primero de los grandes imperios en hacerlo.

Los Axumitas mantuvieron relaciones comerciales tanto con el Imperio Romano Occidental como con Bizancio y estas relaciones se mantuvieron boyantes hasta que la extensión del Islam cortó las vías de comunicación del imperio con Europa. Debido a este boyante comercio exterior, existió una gran acuñación de 
monedas que ha permitido a los historiadores conocer el nombre de muchos de los distintos monarcas que se fueron sucediendo.

En este periodo Axumita es cuando por primera vez los seguidores de una nueva religión, el Islam entraron en contacto con Etiopía, cuyo rey les dio cobijo cuando huían de su persecución en la Meca. El propio profeta indicó a sus seguidores que Etiopía debía ser respetada por la Jihad y que se debía dejar en paz y convivir con los cristianos etíopes. Esta tolerancia se mantendrá durante siglos más o menos estable hasta la invasión musulmana de los reinos cristianos protagonizada por Grang y sus seguidores (Henze, 2000).

Durante estos casi diez siglos de existencia el Imperio Axumita conoció varias fases de apogeo y de decadencia hasta que entró en un declive final de unos tres siglos de duración provocado por factores como el surgimiento del Islam, el agotamiento financiero y humano por las guerras en Arabia o la supuesta llegada de la plaga de Justiniano. Finalmente, la muerte del último emperador en el 960 D.C. a manos de la misteriosa reina Yudit, que arrasó las iglesias y quemó los manuscritos cristianos, marcó el final definitivo de este imperio, tanto que de su nombre en amhárico proviene la palabra "fuego".

\subsubsection{La Etiopía Medieval}

El gran estudioso de la historia etíope, el italiano Conti Rossini, considera que las alusiones a la reina Yudit y a sus hijos junto a las crónicas que hablan de una invasión de Abisinia desde el Sur pueden hacer referencia a la llegada de el pueblo Sidamo a la zona, lo que implicaría un proceso similar a la llegada de la población Oromo siglos más tarde (Henze, 2000). Tras la caída de Axum hubo un vacío de poder ocupado por la dinastía Zagwe que se mantuvo en el poder un limitado espacio de tiempo hasta que llegó la llamada "Restauración Salomónica".

Los monarcas de esta dinastía sostenían que descendían de los monarcas Axumitas, hijos de la supuesta relación entre la reina de Saba y el rey Salomón. Este supuesto origen salomónico de los nuevos monarcas se puede considerar un 
intento de justificar su derecho al trono y de otorgar una sensación de continuidad (Henze, 2000). En palabras de Paul B. Henze:

"It demonstrates the enormous importance of historical continuity in Ethiopia and the deep sense of history that always permeated Ethiopian life" (Henze, 2000, pág. 57)

En nuestra opinión esta continuidad es un rasgo muy importante del "carácter" etíope; mantener las tradiciones y sentir que las "cosas" continúan es muy importante para los etíopes, sobre todos los pertenecientes a las etnias del norte. Bajo esta dinastía salomónica se emprendió la expansión de los reinos cristianos del norte hacia el sur, que se mantuvo en las tierras altas mientras que los nuevos sultanatos islámicos se expandían por el valle del Rift y la costa del cuerno de África pero sin lograr penetrar en las tierras altas (Henze, 2000).

En el dominio de las costas por parte de los musulmanes algunos historiadores (Henze, 2000) ven la razón por la cual los reinos cristianos del interior fueron perdiendo cada vez más el contacto y las relaciones con el mundo exterior. Al mismo tiempo el centro económico y de poder del imperio se fue desplazando hacia el sur con la adquisición de nuevos territorios y el asentamiento de poblaciones cristianas en los mismos, pasando la preeminencia de la etnia tigriña a la amhara, con lo que el idioma de éstos, el amhárico sustituyó al Ge'ez como idioma de la corte y para el uso diario.

Durante el siglo XVI Etiopía se vio sacudida por las guerras entre el reino cristiano de las tierras altas y los sultanatos musulmanes. En estas guerras tuvo especial preponderancia la figura del caudillo musulmán Gragn (Ilamado mano zurda) quien, mediante la invocación de una Jihad, arrasó las tierras altas cristianas quemando monasterios, libros, arrasando ciudades y masacrando a las poblaciones que se negaban a convertirse al Islam logrando incluso asaltar y destruir la antigua capital imperial de Axum. Tal era el trauma que crearon los ataques del Gragn que provocaron el llamado síndrome del Gragn como relataba en 1843 el diplomático ingles William Cornwallis Harris: 
To the present day the most preposterous legends are belived with reference to the personal powersof this fierce invader, his gigantic stature, and the colossal size of his steed.[...] The supernatural achievements of Graan are handed down to posterity in an exant Amháric volume; and inroads gave birth in the mind of the people of Shoa to a superstitious dread of the Adaïel, such as was long entertained of the Turks in Northern Europe, and wich it has been seen extends even to the warlike monarch" (Harris, $1843,6653)$

En estas guerras de carácter religioso intervinieron potencias extranjeras: los portugueses por parte de los cristianos y los turcos al lado de los musulmanes. Tras años de luchas y destrucción, el reino cristiano de las tierras altas logró imponerse al final y destruir la amenaza musulmana. Esta guerra supuso un alto coste tanto en recursos económicos como en demográficos para ambos bandos, y aunque finalmente el reino cristiano salió vencedor de la lucha su territorio estaba asolado, su población diezmada y su economía se encontraban muy debilitadas, por lo que ante la llegada de un nuevo enemigo su posición era muy débil.

"The country has lost hundreds of thousands of lives, a measure of confidence in itself and its religion, and much of its capital" (Marcus, 2002, pág. 34).

Este nuevo enemigo eran los Oromo, etnia que en la actualidad es mayoritaria en Etiopía y cuyo estado étnico federal ocupa un 32\% del territorio actual del país. Este pueblo era muy diferente al enemigo musulmán al que el reino amhara se había enfrentado antes, siendo a su vez culturalmente completamente contrario a los amharas:

"The Oromo are in many ways the antithesis of the Amhara. Not only did the two people confront one another centuries as great historical antagonist, but the tradition they brought to the encounter contrast radically. Where the Amhara system is hieratical, the Oromo is egalitarian. Where the Amhara is individualistic, the Oromo is solidaristic. Where the 
religious and political functions are segregated in Amhara institutions, for the Oromo they are fused. Where the Amhara historical project is to build an empire that of the Oromo is to maintain a parochial tradition." (Levine, 2000, pág. 128)

Estas grandes diferencias entre los Amhara y los Oromo marcarán a partir de este momento la historia de Etiopía, creándose un antagonismo que dura hasta el día de hoy, ya que gran parte de la historia y de la narrativa nacional amhara y por tanto la promovida desde el poder central del estado etíope como la historia oficial del país se ha basado en la lucha contra el "otro" representado por el pueblo Oromo.

Además las guerras entre el reino Amhara y el sultanado musulmán habían tenido un carácter completamente distinto a las guerras contra los Oromo que junto al carácter completamente diferente de estos dos pueblos pueden ser el origen del desprecio que parte de la población amhara siente hacia los Oromo:

"The warfare between the Amhara Kingdom and the Afar and Somalie tribesmen under Grañ was in some respects a clash between similar antagonists. Both were groups of Semitized Ethiopians, adherents of a Semitic religion and followers of political leaders who sought legitimacy trough identification with Semitic ancestors. By contrast, the expansion of the Oromo represents a novel element in politics of the empire-the assertion of a pagan, purely African force”. (Levine, 2000. pág. pág. 78)

La "invasión" Oromo de las tierras altas cristianas y los sultanatos musulmanes se produjeron en el marco de una gran migración o movimiento expansivo atribuido generalmente a una explosión demográfica de la población Oromo. (Etefa, 2008) Este pueblo de lengua cusítica tenía su origen en la zona que actualmente es el Sureste de Etiopía más allá de las montañas Bale y comprendiendo parte del norte de la actual Kenia (Marcus, 2002). Una explicación para este aumento de la población de los Oromo que les permitió presionar sobre 
las débilmente defendidas fronteras imperiales es la facilidad que tiene este grupo para asimilar a los pueblos conquistados:

"Hence, one notable difference between Oromo an Amhara assimilation is that Oromo gradually Grant full citizenship to the peoples they assimilate, a fact that steadily swells their numbers from generation to generation" (Leggesse, 2006 pág. 8).

Otra explicación que se da a esta expansión militar oromo es cultural, ya que debido a su sistema de organización social tradicional (Gada), que en ese momento está en plena vigencia, la guerra expansiva o en busca de botín era necesaria:

"The Galla did not seek to gain recognition for a central authority, to collect tribute, or to impose national religious culture. Their expansion was triggered by two motives: a need to carry out ritually prescribed military expeditions against enemies and search new land to accommodate a rapidly growing population. Its timing was dictated not by the strategic considerations of imperial power, but by a cultural calendar which stipulated that raids against some new enemy should be carried out every eight years" (Levine, 2000 pág. 79).

Este pueblo de pastores nómadas utilizó la superioridad militar que le otorgaba su número y su domino de la caballería para rápidamente adentrarse en el territorio controlado por el monarca amhara y ocupar grandes extensiones de territorio. En la zona Este de la actual Etiopía también lograron imponerse a los habitantes musulmanes de la zona y ocuparon gran cantidad del territorio obligando a los habitantes de Harara (antigua capital de Grang) a llegar a acuerdos con ellos y a construir los célebres muros de la ciudad. En la actualidad gran parte de la población de la región siguen siendo Oromos (Henze, 2000).

Esta superioridad de la caballería permitirá a los Oromo mantener su independencia hasta que la importación masiva de armas de fuego permitirá al ejército imperial subyugarlos. Tras estas primeras victorias Oromo en el Siglo XVI los miembros de esta etnia seguirán expandiéndose por el territorio de la actual Etiopía 
durante aproximadamente un siglo y medio hasta cesar sus avances (Henze, 2000). Esta supuesta aparición de los Oromo en escena en tal "tardía fecha" de la historia etíope es el argumento esgrimido por muchos amharas y tigriños a la hora de considerar a toda esta población como "etíopes de segunda".

Como se ha expuesto anteriormente en la presente Tesis, esta teoría de la llegada a Etiopía de los Oromo durante el Siglo XVI ha sido rebatida por las últimas investigaciones que han demostrado que la presencia de población de etnia oromo en el cuerno de África es muy anterior, por lo que tan solo su expansión hacia el norte sería "tardía". Este racismo contra los Oromo se puede observar en muchas de las obras sobre Etiopía tanto de extranjeros como de etíopes y en nuestra experiencia hemos podido constatarlo, sobre todo al tratar con etíopes de etnia amhara o tigriña. En las fuentes amharas se dio el nombre de Gallas a los Oromo, nombre que estos nunca utilizaron para referirse a ellos mismos y que tiene un claro carácter despectivo:

"The Abyssinians attach a derogatory connotation to the Galla, namely "pagan, savage, uncivilized, uncultured, enemy, slave or inherently inferior" (Melbaa, 1999 pág. 14)

Es en este momento cuando al enfrentarse los reinos amhara a la derrota frente a los Oromo se empieza a crear una corriente ideológica que será reforzada posteriormente con la revitalización imperial en la que se asimila a los Amhara y Tigriños del norte con los verdaderos etíopes mientras que los demás pueblos que habitan Etiopía son considerados una especie de etíopes de segunda que han causado problemas y son el origen de alguno de las situaciones negativas a las que se ha encentrado Etiopía a lo largo de la historia:

"Many other Ethiopianists adopt the same perspective of seeing Ethiopia as consisting of "true Ethiopians" contrasted with whole residual peoples who are on the periphery of the Ethiopian core and whose main contribution to Ethiopia is thought to have been a destructive one. In particular, the Oromo migrations are often seen a kind of "natural disaster" 
that fell upon Abyssinia, not a human activity guide by intelligent thought" (Leggese, 2006 pág. 5).

Un ejemplo de ello podemos encontrarlo en la obra de Ullendorff (1965):

"The Gallas had nothing to contribute to the civilization of Ethiopia: they possessed no material or intellectual culture, and their organization was at a far lower stage of development than that of the population among whom they settled. They were not only the cause of the depressed state into which the country now sank, but they helped to perpetuate a situation from which even a physically and spiritually exhausted Ethiopia might otherwise have been able to recover far more quickly" (Ullendorff, 1965, pág. 76)

En este mismo periodo, tras la derrota del Grang y con la presión de los Oromo hacia el norte, en la corte imperial la presencia de súbditos portugueses pasó de ser un "éxito" a un fracaso total. Los portugueses utilizaron la influencia que habían ganado al ayudarles a derrotar al Grang para intentara introducir el catolicismo en Etiopía e incluso convertirlo en la religión oficial. Convirtieron al catolicismo a personajes clave del momento e incluso lograron que el emperador Susenyos se convirtiera al catolicismo e intentara forzar la conversión de sus súbditos a dicha religión. Esta conversión al catolicismo alentada por los Jesuitas acabó finalmente en una serie de revueltas alentadas por la Iglesia Ortodoxa y por nobles descontentos, como el propio hermano del emperador, quienes le forzaron a reconsiderar su posición y abdicar en su hijo Fasilas (Henze, 2000).

Finalmente los Jesuitas fueron expulsados y se decretó pena de muerte para cualquiera de ellos que intentara permanecer en el país, siendo ejecutados cinco de ellos por orden directa del nuevo emperador. Como expone Henze (2000), durante la década de los 80 muchos etíopes observaron similitudes entre el intento de Susenyos de imponer el catolicismo y el de Mengistu Haile Mariam de imponer el comunismo en Etiopía. De nuevo se puede observar la importancia que tiene para los etíopes el sentido de la continuidad histórica. Con el emperador Fasilas empieza la llamada Época de Gondar en la que por primera vez se establece una capital fija 
para el imperio en dicha ciudad; anteriormente los emperadores desde la época de Axum no habían establecido una capital y dirigían el país desde sus campamentos militares itinerantes. Fasilas construyó en Gondar un castillo de estilo europeo en un complejo amurallado en el cual sus sucesores por 150 años fueron añadiendo más castillos y edificaciones, convirtiendo a Gondar en lo que se ha llamado la "Camelot africana" (véase Figura 3).

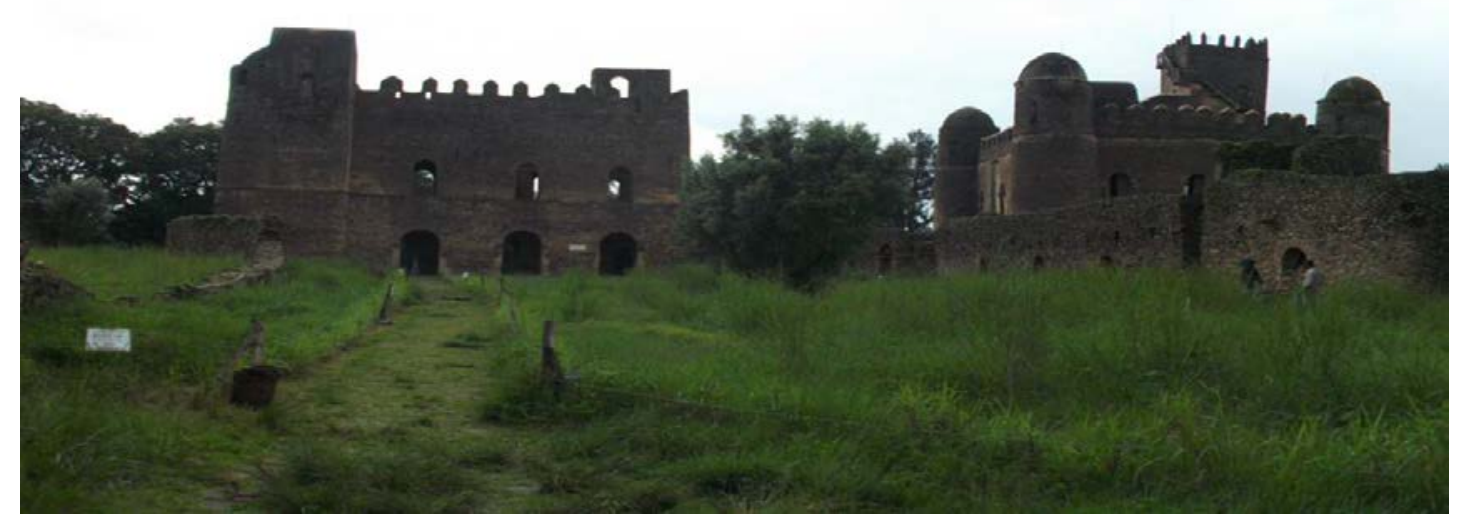

Figura 3. Imagen de Gondar

(Fuente: Autor)

Este momento de la historia de Etiopía es fundamental ya que en él radican las bases de varias características culturales que marcan el carácter del país hasta la actualidad, como son el enfrentamiento entre semíticos y cusíticos (Amhara frente a Oromo) o el miedo a una islamización del país (Síndrome del Grang) que persiste hasta nuestros días y se utiliza para desprestigiar a la oposición acusándola de ser musulmanes integristas y que por ejemplo le costó a principios del Siglo XX el trono imperial a lyasuu. Por último en este momento de la historia etíope surgió una desconfianza frente a los europeos que ayudaría a mantener el país independiente durante el colonialismo.

Tras la muerte de Iyasu II en 1755 y hasta la coloración de Tewodros II en 1855, Etiopía se ve sumergida en la "Era de los jueces", rememorando el antiguo 
testamento cuando Israel no tenía rey, en la que el poder imperial se hunde y los nobles y señores regionales dirigen el destino de sus territorios y la unidad imperial es únicamente nominal (Henze, 2000).

Durante este periodo la dinastía Yejju logra mantener el control de Gondar y retener el título imperial, pero será la región de Shoa la que logre generar una dinámica de estabilidad y crecimiento, entre otros motivos por la incorporación de elementos no amhara, principalmente oromo, tanto a su población como a su clase dirigente. Esta incorporación de nuevos elementos ayudó a la expansión del poder de esta región y sus clases dominantes, provocando que gradualmente durante las siguientes décadas los dirigentes de esta región fueran tomando el control del país y lograran mantener su dominio hasta prácticamente finales del siglo XX. En esta época es fundamental tanto la llegada como la evolución que sufren las distintas poblaciones Oromo, ya que esta evolución marcará de forma determinante el destino del imperio y su unificación:

"Both indirectly and directly, the Galla intrusion constituted a major factor in the nineteenth century unification. It did so indirectly like a stimulus, in that the growth of Galla power in the north, trough enclaves and intrigues, spurred the rulers of Shoa and emperors Tewodros and Yohannes to respond in heroic measure to the challenge of unifying the country. It did so directly both by proving a far-fluing cultural corridor through which the multifarious peoples of Great Ethiopia could more readily be connected and by GallaAmhara-Tigrean military alliances which enabled the Ethiopian state to dominate all the peoples in Great Ethiopia and prevail over external enemies from Sudan and from Italy" (Levine, 2000, pág. 85).

En estas fechas los Oromo que se habían expandido en el Siglo XVI y que se habían asentado en territorios al norte de su centro originario empezaron a separarse en distintas tribus y confederaciones. Este proceso se asentó en varios pilares como eran la evolución natural de su sistema cultural y las dificultades que suponía para el mismo la gran expansión territorial y poblacional, la influencia de las culturas de los pueblos conquistados y la simple distancia física. La influencia 
cultural de los pueblos con los que tenían contacto también hizo que en algunas zonas y tribus su forma de gobierno tradicional dejara paso a formas de gobierno monárquicas, sustituyendo su organización democrática tradicional, pero manteniendo un sistema bastante más igualitario que el de sus contemporáneos amharas y sobre todo manteniendo la independencia respecto a estos últimos.

"Several Oromo kingdoms in western and southwestern Ethiopia gained dominance over the Sidama and Omotic peoples indigenous in the area and remained essentially independent of imperial authority, especially in the Gibe region and in Wollega, till the late $19^{\text {th }}$ century. Strong hereditary leaders emerged who did not recognize subservience to Ethiopian central authority until the time of Menelik II" (Henze, 2000 pág. 92).

Al mismo tiempo, el modo de vida nómada tradicional fue dejando paso a un modo de vida sedentario, sobre todo en los territorios más al norte, en el que los oromo se fueron convirtiendo en agricultores. En algunos de estos territorios las nuevas poblaciones oromo fueron asimiladas tanto físicamente como culturalmente por los antiguos habitantes semíticos o amharas (Henze, 2000). Este proceso se dio también en el sur en el que algunas de las tribus y subtribus Oromo adoptaron tanto la cultura de los pueblos conquistados que en la actualidad han adoptado casi completamente su cultura o u idioma aunque siguen manteniendo su identidad oromo:

"The Otu branch of the Guji Galla has assimilated Sidamo culture so thoroughly that many now speak only the Sidamo language. The southern Guji disparage their northern kinsmen by calling them "half-Sidamo" or "half-Derasa". Galla who settled in proximity to the Gurage adopted the ensete plant culture or their neighbors and have come to resemble them so much that they referred to as "half-Gurage" by other Galla" (Levine, 2000, pág. 81).

En la zona Somalí de Etiopía este proceso de asimilación cultural ha sido tan fuerte que los Oromo son contados por los propios somalíes como unos de ellos 
(Levine, 2000). Este proceso de asimilación fue especialmente relevante en el caso de las élites Oromo, ya que se integraron con las élites de los pueblos conquistados y empezaron a actuar como miembros de estas últimas, abandonando la antigua solidaridad Oromo y reforzando la posición de los amhara en la zona, ayudando con ello a la expansión del poder de los reyes amhara de la región de Shoa como hemos visto anteriormente y que irónicamente acabarán con la independencia de los distintos pueblos Oromo:

"Oromo leaders became a major element in regional politics, but it was rare for the Oromo who are intermixed among the Amhara to act together politically as Oromo above the family and clan level" (Henze, 2000, pág. 91).

Otro ejemplo de ello es lo sucedido con los Oromo que intentaron tomar la región de Gojjam y al ser derrotados se unieron a los amhara, integrándose completamente por lo que su presencia solo se recuerda por los nombres Oromo presentes en los registros de algunas parroquias o los Oromo que se integraron en la élite del gobierno de Gondar (Levine, 2000).

En definitiva tras su expansión las distintas poblaciones Oromo tomaron de las poblaciones que conquistaron los elementos culturales que les permitieron sobrevivir en los nuevos ambientes en los que se encontraban, en algunos casos su adaptación cultural fue tan intensa que se asimilaron completamente con los antiguos habitantes de las zonas y perdieron su identidad mientras que en otros casos mantuvieron su identidad diferenciada y su autonomía política (Levine, 2000).

\subsubsection{Revitalización imperial}

Como señalábamos anteriormente la región de Shoa será la protagonista y gran beneficiada del proceso de unificación imperial. Esta región se hará con el protagonismo y con la posición central del poder debido a la habilidad de sus gobernantes, entre los que se incluía un nutrido grupo de jefes Oromo. Estos gobernantes lograron empezar un periodo de expansión territorial sobre otras regiones cercanas, incluidos otros grupos Oromo que desembocará finalmente en la 
creación del estado etíope moderno. El máximo exponente de este proceso fue Menelik II quien, coronado rey de Shoa, logró hacerse con el poder imperial tras la desaparición de Yohannes IV que reinaba en el norte.

Un hecho destacable es que en la historiografía todo el protagonismo de este proceso fue atribuido exclusivamente a los elementos amhara y en muchas de las obras, tanto de autores etíopes como extranjeros del siglo XIX y XX se recoge este proceso de expansión territorial como un proceso de reunificación imperial que otorga la legitimidad del poder a los elementos amhara y los sitúa como "los auténticos etíopes" despreciando la importancia que tuvo para la misma la presencia de los Oromo (Levine,2000).

Para este proceso de revitalización del poder central es elegida la coronación de Tewodros II en 1855 como fecha del momento en el que Etiopía entra en una nueva fase de su historia (Zewde 2001). Tewodros II es visto por los etíopes como un héroe nacional que intentó modernizar Etiopía, lucho por su unificación y se enfrentó a los extranjeros, teniendo un sangriento final contra las fuerzas expedicionarias británicas. Nosotros mismos hemos visto un gran número de etíopes que llevaban camisetas con la efigie de este emperador como símbolo del orgullo nacional. En realidad Tewodros II tiene una serie de rasgos que le hacen ser una figura complicada y con una serie de claros y sombras. Así, aunque se le ha visto como un reformador y un firme defensor de la modernización de Etiopía, el país no tenía la base ni la preparación para conseguir que sus medidas fueran efectivas. Además, no está tan claro que el tuviera unas firmes ideas de modernización (Zewede, 2001). Además tenía un fuerte sentido militarista, planteaba una lucha contra los enemigos de la fe y poseía un orgullo que le llevó a enfrentarse a los británicos lo que le llevó a su propia destrucción (Bates, 1979). Todos estos aspectos le sitúan más en la idea de un cruzado que en la de un monarca moderno. Por otra parte es cierto que sentó las bases para la recuperación imperial y que su figura posibilitó que el poder imperial se levantara de la posición postrada en la que se hallaba. 
Tras la desaparición de Tewodros II una serie de rivales se enzarzaron en una lucha para ocupar el vacío de poder que su muerte había provocado. Al final dos contendientes se alzaron sobre el resto: Menelik II en la zona de Shoa y Yohanes IV en el norte del país. Estas dos figuras compartieron el poder en Etiopía durante el siglo XIX y de sus relaciones y sentido de Estado se benefició enormemente el país (Zewde, 2001). Mientras Yohanes IV se dedicó a consolidar el poder imperial en el norte del país y a hacer frente al primer intento colonialista italiano, Menelik II se dedicó a extender su poder dirigiendo campañas militares en dirección sur y creando realmente el "Imperio Etíope". En una serie de campañas Menelik II fue capaz de derrotar y anexionar a los distintos reinos Oromo de la zona (Henze, 2000). Estas campañas de Menelik II se basaron en la superioridad armamentística de sus soldados que contaban con armas de fuego mientras que sus rivales Oromo seguían usando armas tradicionales como lanzas y arcos. A continuación con otra serie de campañas logró anexionarse Harar y las regiones colindantes.

Es importante señalar que la posición Oromo estaba debilitada precisamente debido al éxito que habían tenido anteriormente, ya que al expandirse de una manera tan extensa y al haber adoptado parte de la cultura de los pueblos a los que habían conquistado habían pedido la cohesión interna, se habían dividido en diferentes tribus a lo que había que sumar que las enormes distancias hacían imposible que se apoyaran efectivamente entre ellos frente a la expansión Amhara:

"Although most Galla continued to speak Gallinya, they were spread so far over Greater Ethiopia as to prohibit any effective communication. More important they had adopted radically different cultures: some were now Christians, some Muslims, and other remained pagan; some were now plow cultivators, some hoe cultivators, and other remained nomadic pastoralist. They had divided into numerous tribes which were as likely to fight one another as to fight other ethnic group. This precluded concerted defense on a pan-Galla basis" (Levine, 2000, pág. 84)

Las victorias de Menelik II y en especial la de la batalla de Embabo le convirtieron en el único serio candidato al trono imperial ya que, mientras que 
Yohanes IV estaba logrando principalmente mantener su poder territorial, Menelik estaba logrando consolidarlo y extender sus dominios de una manera espectacular (Zewde, 2001)

"During the Europeans'scramble for Africa in the 1880s, the Abyssinian Empire was busy in an Empire-building project launched by its architect, King Menelik of Shawa-later Emperor Menelik II of Ethiopia (Tibebu 1995). Many scholars consider Menelik II as "the only black African leader who actively participated in the sramble for Africa" (Regassa,2012, pág. 521) Las campañas de expansión territorial del reino amhara sobre los territorios Oromo tuvieron diferentes caracteres según la resistencia que las distintas tribus y reinos opusieron al avance de las tropas imperiales, denunciándose por los testigos de la época la perpetración de masacres sobre la población civil y la venta como esclavos de los supervivientes y incluso la utilización de guerra biológica en algunos casos (Melbaa, 1999). Este ascenso al poder imperial por parte de Menlik culminó tras la muerte de Yohanes IV en la batalla de Motamba en 1889 contra los mahadistas de Sudan. Para dar más solidez a su ascenso Menelik firmó un tratado con Italia cuya versión en italiano se diferenciaba de la versión en amhárico y convertía de facto Etiopía en un protectorado italiano lo que provocaría una guerra entre Etiopía e Italia (Henze, 2000).

Nada más conseguido, el poder imperial tuvo que enfrentarse a los intentos italianos de convertir Etiopía en una de sus colonias, el enfrentamiento final se produjo en la batalla de Adwa. Esta batalla y su resultado fueron favorables a los etíopes, tuvo un gran impacto mundial y lo sigue teniendo. En primer lugar, con esta batalla la independencia de Etiopía quedó garantizada durante décadas y se convirtió en un símbolo de esperanza para la población negra mundial ya que había significado la victoria de un país Africano sobre una potencia colonial europea (Zewde, 2001). En la actualidad la batalla de Adwa sigue siendo uno de las piedras de toque del orgullo nacional etíope y es muy común que cualquier etíope te señale en una conversación que ellos, a diferencia del resto de los africanos, nunca fueron colonizados. 
Tras la victoria sobre los italianos, Menelik II se dedicó al gobierno y a las reformas internas en su nuevo Imperio; con habilidad navegó entre los encontrados intereses de las potencias europeas y logró sacar ventajas para su país. Las nuevas provincias incorporadas al imperio fueron administradas de una manera feudal, con tributos en trabajo y en materias primas para los gobernadores y para el estado central, o la atribución de puestos de gobernador de manera hereditaria (Zewde, 2001). De este modo, Etiopía se convirtió en una potencia colonial en África ya que sometió a sus nuevos territorios a una explotación muy similar a la que las potencias europeas ejercían sobre sus territorios de ultramar como las razzias en busca de mano de obra esclava, reasentamientos de poblaciones enteras o confiscación de grandes de cantidades de tierras (Hassen, 2007).

Otra de las estrategias usadas por Menelik II y Yohannes IV fue la implantación del cristianismo ortodoxo en los territorios Oromo y la discriminación del resto de las religiones, tanto otras ramas del cristianismo como el Islam o las religiones tradicionales, llegándose a imponer la conversión obligatoria (Bulcha, 1988).

"They discouraged and suppressed the indigenous religions. However, their efforts to convert their subjects were not concerted. Sporadic forced mass baptisms were carried out, but there was no organized endeavour to bring their religion to the indigenous inhabitants of the annexed territories." (Bulcha, 1988, pag 50)

Con estos movimientos de población y estas capturas de miles de esclavos, se cambió la demografía de regiones enteras de Etiopía y "las nuevas tierras" fueron repartidas entre los nobles amhara fieles al emperador.

"The end of the conquest was followed by the institutionalization of the northern feudal system of exploitation, massive population settlement from the north in the lands of the subjugated peoples, and the imposition of the Amhara language, religion and other forms of culture at expense of the indigenous practices (Tibebu, 1995:44-45, McClellan 1988, en Regassa, 2007, pág. 28) 
La esclavitud etíope hizo que tanto internamente como sobre todo externamente creciera un rechazo a la mano de obra esclava, pero hasta la década de 1920 no se hicieron esfuerzos reales para acabar con ella, teniéndose noticias de que algunos nobles llegaron a pagar servicios médicos por medio de la entrega de esclavos.

"Members of the upper nobility came to have thousands and sometimos tens of thousands of slaves at their disposal. Some of them, like Abba Jifar II, are reputed even to have paid their medical fees in slaves" (Zewde, 2001, pág. 93)

La aplicación del sistema feudal norteño en el sur, el reasentamiento de población y la reducción de miles de personas a la esclavitud provocó grandes cambios demográficos y culturales en el sureste de la actual Etiopía, grandes regiones sufrieron procesos de despoblación mientras que culturalmente se creaba una mayor distancia entre las nacionalidades centrales y periféricas del país (Zewde, 2001).

\subsubsection{El gobierno de Haila Selasi}

Tras la muerte de Menelik II quedó en el poder uno de sus nietos Iyasuu, pero su supuesta profesión del Islam como religión y su política de favorecer al Islam dentro de Etiopía hizo que el rechazo contra su persona fuera aumentando y desembocó en un golpe de Estado de varios nobles, alentado y legitimado por la Iglesia Ortodoxa hizo que fuera apartado del trono y se pusiera en su lugar a la emperatriz Zewditu aunque en realidad quien ostentaba el poder efectivo era el futuro emperador Haila Selasi. Algunos autores como Melbaa (1999) también añaden a este rechazo a lyasuu por parte de la Iglesia y los nobles un componente étnico, ya que Iyasuu descendía directamente de una familia noble Oromo por parte de padre.

El gobierno de Haila Selasi se caracterizó por una dicotomía entre los intentos de mantener el poder absoluto imperial y las reformas para modernizar el país. En sus primeros años de reinado, antes de la invasión italiana de 1936, Haila 
Selasi se dedicó a intentar dotar a Etiopía de un sistema administrativo moderno, promulgó una constitución de estilo japonés en 1931 en la que el emperador se reservaba casi todos los poderes e instauraba dos cámaras de representantes (Marcus,2002).También intentó aumentar el poder del Estado central frente a los gobernadores y nobles de las distintas regiones, favoreció la economía, las relaciones internacionales y la educación e intentó reforzar el ejército para defenderse de las apetencias imperiales italianas. Todas estas reformas para modernizar el país se combinaban con el férreo control que Haila Selasi mantenía sobre el país. Éste controlaba y censuraba los medios de comunicación; hombres fieles a él ocupaban los puestos claves de la administración estatal. En 1936 Italia fuerza la situación hasta invadir Etiopía y obligar a Haila Selasi a huir al exilio. Se sucederán entonces unos años de ocupación por parte de Italia en los que la población etíope sufrirá enormemente (Henze, 2000; Marcus, 2002; Zewde, 2001).

Durante la ocupación las autoridades coloniales italianas intentaron dividir la lealtad de los etíopes atrayendo a muchos oromo que colaboraron con las autoridades italianas soñando con la posterior creación de una república Oromo. Tras la Segunda Guerra Mundial, con la derrota del Eje a manos de los Aliados, Etiopía fue liberada, el emperador volvió de su exilio para recuperar el poder y utilizó una mezcla de personas que le siguieron al exilio para administrar el país, patriotas que habían luchado contra los italianos y colaboradores de los mismos, además invitó a mano de obra extranjera especializada para ayudar a continuar con la modernización del país (Henze, 2000).

Los italianos habían mejorado la administración estatal y habían creado un impacto cultural notable en sus años de ocupación por lo que el país estaba listo para aumentar la profundidad de las reformas y avances económicos. Además, había crecido la demanda de materias primas, manufacturas y profesionales con conocimientos técnicos, por lo que en estos años se vivió un proceso de desarrollo económico y social. La cara negativa de este proceso fue que los beneficiarios del mismo eran una pequeña oligarquía mientras que la población en general se vio obligada a pagar una serie de impuestos nuevos para ellos mientras eran dejados 
fuera de los beneficios del desarrollo (Marcus, 2002). Esto fue especialmente cierto en las zonas rurales donde los campesinos se vieron en ocasiones expulsados de sus tierras para dejar espacio a grandes plantaciones y se tuvieron que convertir en proletarios rurales (Marcus, 2002). Todas estas medidas de modernización se dejaban ver principalmente en la capital y en algunos centros administrativos más importantes de las provincias; además los servicios que ofrecía el Estado no estaban distribuidos equitativamente por el territorio sino que se concentraban en la zona amhara y tigriña, siguiendo la preferencia de favorecer a sus propios territorios y cultura de los miembros de la burocracia del Estado (Marcus, 2002).

"Most institutions of higher education were located in the capital, as were nine of the empire's twenty secondary schools. Of the country's 620 government elementary schools, 38 were in Addis Abeba, 125 were in Eritrea, and most of the remaining were in the north. Such imbalance was further complicated by government's prejudice for its own official culture that stressed Amharic. The Oromo keenly felt this discrimination, since many believed that their taxes probably paid for the north's disproportionate number of clinics, orphanages and other social services" (Marcus, 2002, pág.165).

Además las instituciones educativas ofrecían solo la educación en amhárico y eran utilizadas con fines políticos en gran medida:

"The education system was discriminatory and geared to the needs of the rulers. The schools were intended for glorification and propagation of Abyssinian culture, history and values. They were engaged in creating a national identity, an Amhara one. Oromo were given educational opportunities as part of the assimilation programme" (Melbaa, 1999, pág. 73)

En 1955 fue promulgada otra constitución que pretendía avanzar en la democratización del país, pero que en realidad seguía dejando todo el poder en manos del emperador, el cual se dedicó a gobernar el país de una forma muy 
personalista a la vez que favorecía para los puestos políticos de importancia a sus seguidores más fieles. Con motivo del 25 aniversario de su coronación, Haila Selasi realizó un discurso a la nación donde claramente se veía que había perdido contacto con la realidad de Etiopía. Se centraba únicamente en los éxitos de su reinado dando importancia superlativa a éxitos en el proceso de modernización pero no reconociendo la situación de atraso y subdesarrollo generalizada en el país que se situaba por detrás de muchos otros países africanos. El malestar en Etiopía fue aumentando por los problemas del país y por la falta de una democracia real. Además los problemas étnicos iban aumentando por la situación de desventaja que se encontraban los ciudadanos de etnias distintas a la amhara con la imposición del amhárico como único idioma oficial. Para entender la mentalidad del emperador respecto a la cuestión étnica en el país, es muy significativo que en su propia biografía Haila Selasi ocultara su propia ascendencia Oromo.

Además la línea política seguida bajo el gobierno de Haila Selasi tenía su origen en la época de Menelik II, desde la cual la educación, la religión y el sistema administrativo habían sido usados como un medio para la amharización de los "nuevos territorios" bajo control imperial aunque debido a la limitada capacidad del estado este proceso no había tenido un impacto muy significativo (Bulcha, 1988; Melbaa, 1999).

Especialmente relevante fue el caso de los Oromo y los somalíes de la provincia de Bale que plantearon con el apoyo de Somalia una guerra de guerrillas muy exitosa contra el Estado central en la que se mezclaban motivos religiosos, étnicos y económicos que surgieron a principios de la década de los 1960 y no terminaron hasta 1971 con concesiones por parte del gobierno central y la colocación de líderes locales en los puestos administrativos de la región (Bulcha, 1988; Henze, 2000). En 1960 un intento de golpe de Estado fallido demostró que el descontento estaba presente en la sociedad etíope. Entre los descontentos estaban los estudiantes y los jóvenes que habían recibido una educación superior pero luego no tenían oportunidades de trabajo, aquéllos que no podían seguir formándose 
debido a la falta de oportunidades o aquellos que soportaban las consecuencias de la discriminación que sufrían los no amhara:

"With the objective of redressing ethnic-based domination and oppression, ethnic nationalism entered the political philosophy among the Ethiopian Student Movement (ESM) in the 1960s, and opened new chapter for ethnic politics in the country by the time ethnic questions were condemned by Amhara leaders as a threat to national unity" (Regassa, 2012, pág. 521)

Pese a ello, Haile Selassi siguió apostando por la educación. En este impulso educativo fueron muy importantes los profesores estadounidenses que llegaron a Etiopía como uno de los mayores contingentes de cuerpos de paz de la historia de Estados Unidos destacados en un solo país. Su cifra fue de 900 y con ellos trajeron nuevas ideas de libertad y democracia que ayudaron a desgastar las bases del apoyo popular al emperador aunque no fuera esta su intención (Henze,2000).

\subsubsection{El comité Derg}

En 1973 la popularidad del emperador había seguido sufriendo un proceso de desgaste y en Etiopía el descontento crecía por la lentitud de las reformas democráticas y la necesidad de un desarrollo económico más acelerado. Además el estallido de una hambruna en Wollo y su negligente gestión por parte del gobierno inflamaron aún más los ánimos de los descontentos. En 1974 un grupo de oficiales del ejército de un rango medio-bajo se organizaron en un comité prontamente denominado "Derg" y protagonizaron un golpe de Estado no violento que apartó a Haila Selasi del poder:

"With Addis Abeba cut off from the world and under curfew, a small group of officers went to the palace and, at 6:00 A.M. summoned Haile Sellasie. He appeared in full uniform and, with great dignity, stood proud and erect while a nervous officer read out a proclamation of deposition. The old man declared his acceptance, if it were for the good of the people... Within the our, Radio Addis Abeba reported that Ethiopia had been freed from Haile 
Sellassie's oppression by a Provisional Military Administration Council (PMAC)" (Marcus, 2002, pág. 188).

Como reflexión final podríamos definir el gobierno del emperador Haila Selasi como un intento de llevar a cabo un "Despotismo llustrado" en el que la educación fue objeto de gran interés como instrumento para conseguir una "clase" educada que fuera la base del desarrollo económico del país, pero siempre desde un punto de vista que asimilaba amhara y cristianismo ortodoxo a desarrollo y que además consagraba los privilegios de las élites tradicionales del país. Este grupo de oficiales estaba liderado por el moderado y muy querido general Aman Mikail Andom:

"The new administration, still popularly called the derg, was lead by Gen. Aman Mikail Andom (1924-1974) much revered because he had won the war against Somalia in 1964, had pushed for democratic reforms, for which he had been shunted aside into the Senate, and had cooperated with the military from the beginning" (Marcus, 2002,pág. 189)

Frente a esta figura moderada rápidamente surgió un grupo que representaba la línea dura de la ideología comunista, dentro de este grupo ascendió la figura de un mayor del ejército proveniente de Harar, Mengistu Haile Mariam (Zewde, 2001) que logró finalmente apartar del poder al general y acabar con su vida tras ordenar su detención la noche del 23 de Noviembre de 1974:

"The PMAC thereupon voted Aman out of office, and that night, when he resisted to arrest, he was killed in the ensuing melee" (Marcus, 2002, pág. 190).

Aunque el Derg había utilizado como carta de presentación el nacionalismo, la necesidad de reformas democráticas y la lucha contra la corrupción del régimen anterior bajo la dirección de Mengistu Haile Mariam rápidamente pasó a primar la ideología comunista y a utilizar métodos violentos como medio de asegurarse el poder y acabar con la posible oposición. La noche del 23 de Noviembre de 1974 no solo murió Aman sino que tropas dirigidas por Mengistu acabaron con la vida de sus 
opositores incluidos los 59 miembros del gobierno del emperador que se habían entregado pacíficamente el verano anterior:

"The executed detainees consisted mainly of members of the aristocracy, palace officials, ministres, military commanders, and provincial governors. It took a while to emerge that the Derg had craftily added to the list of victims dissident members from its own rank as well as leaders of the military units who had opposed its assumption of political power" (Zewde, 2001, pág. 239).

A partir de esa fecha Etiopía fue proclamada un país socialista y bajo la dirección del Derg se emprendieron unas campañas de nacionalización de la economía del país, campañas de "villagización" y colectivización de la producción. Estas campañas altamente impopulares tuvieron unas consecuencias nefastas para la economía del país, observándose en las gráficas un descenso del PIB durante los años del Derg. La instauración de estas medidas económicas y sociales y los ataques a las bases tradicionales de la organización social como la religión hicieron que el apoyo popular inicial que veía en el Derg la solución para acabar con los males del gobierno imperial se fuera tornando en descontento y hostilidad hacia el gobierno de Addis Ababa. En el caso de la población Guji en la que se centra esta Tesis se puede observar que en los registros de la escuela de Qillenso unos años después de la llegada al poder de Menguistu hay una proliferación de niños con el nombre de Menguistu pero tras otros pocos años desaparece el nombre totalmente, lo que refleja la pérdida de apoyo popular que sufrió en Dergy la figura de Mengistu Haile Mariam a lo largo de los años.

Las campañas de "villagización" al concentrar la población pretendían favorecer la creación de nuevas escuelas y la asistencia a la misma de los niños, junto a otros programas de desarrollo social como clínicas o campañas de alfabetización para adultos, como nos explicó un anciano de Qillenso. Pero todos estos avances en educación no perseguían la mejora de la calidad de vida y la difusión de la educación básica o el acceso a la sanidad sino tenían el objetivo de la homogenización de la población etíope siguiendo un patrón amhárico, por lo que la 
educación rechazaba completamente los aspectos propios de cada cultura e imponía el amhárico y los aspectos culturales del norte como medio para acabar con el surgimiento de movimientos nacionalistas (James, Donham, Kurimoto,Triulzi y Currey, 2002). La aplicación de la concentración de la población y la creación de explotaciones agrarias comunales fue especialmente nefasta para los Guji como detallaremos posteriormente a lo largo de estas páginas.

Cuando el apoyo popular al gobierno se tornó claramente en descontento y hostilidad surgieron grupos guerrilleros por todas partes del país, especialmente fuertes en el territorio de la actual Eritrea y el Tigray (Henze, 2000; Marcus, 2002). El líder más carismático de este movimiento de oposición en el norte del país fue Meles Zenawi que posteriormente se convirtió en Primer Ministro y dirigió el destino del país durante los siguientes 21 años hasta su muerte en 2012.

Entre los Oromo de la región de Bale y los somalíes, los movimientos independentistas volvieron a surgir con fuerza. Los años de gobierno del Derge se caracterizaron por la aplicación de programas de tipo marxista-estalinista y la utilización de la violencia donde el gobierno se encontraba algún tipo de oposición, llegando a planear una "solución final" para Eritrea (Henze, 2000). En 1977 Mengistu lanzó el llamado "Terror Rojo" en el que la violencia y los asesinatos masivos de sus opositores políticos sumieron al país en un caos. En 1977 Somalia invadió Etiopía; sus tropas avanzaron por el sureste del país hasta asediar Harar y llegar a las montañas Bale habitadas por los Oromo. En estos momentos el Derg jugando la carta del nacionalismo que le brindó el apoyo popular de la población y con el soporte de Moscú y Cuba, logró dar la vuelta a una situación militar desastrosa e imponerse finalmente en la guerra.

En 1982 y 1983 en el norte del país empezaban a notarse síntomas de que se acercaba una hambruna por culpa de la subproducción y la falta de lluvias pero el Derg no hizo nada ya que era una región que en la que la gran mayoría era abiertamente hostil hacia el gobierno. En 1984 la situación era desastrosa y el filtrado de imagines de campesinos al borde de la muerte por inanición hizo que el gobierno tuviera que tomar medidas y permitiera la llegada de ayuda internacional. 
El famoso Live Aid y las imágenes de los telediarios marcaron en las mentes de millones de personas a lo largo del mundo la asociación de Etiopía con el hambre, una imagen que todavía sigue presente.

Son estremecedores los relatos sobre la situación de hambruna a la que se llegó, ocurriendo casos de personas que cocinaron tierra como si fuera Injera y se la comieron debido al hambre extremo (González, 1989). Al mismo tiempo que esto sucedía las guerrillas en el norte, en Eritrea y Tigray iban ganando terreno y poniendo en cada vez en mayores apuros hasta la consecución de la gran victoria de Afabet en 1988 que acabó con la captura de miles de soldados etíopes y de una gran cantidad de equipamiento militar:

"In a four-day battle, the guerrillas of the Eritrean People's Liberation Front (EPLF) destroyed three Ethiopian divisions around this garrison town in northern Eritrea, killing or capturing 18,000 soldiers, four Soviet officers, 50 tanks, 80 heavy guns, 200 trucks and immense quantities of ammunition and supplies. It was the most decisive victory for the rebels since they were forced to retreat from the towns of central Eritrea in 1978, following massive Soviet military intervention on the side of the Marxist Ethiopian government of Mengistu Haile Mariam" (Killion, 1988, Recuperado el 27 de Septiembre de 2013 de http://articles.latimes.com/1988-0501/opinion/op-3277_1_ethiopian-government).

Esta guerra era ampliamente impopular en el resto de Etiopía ya que consumía las vida de miles de hombres y duraba más de una década. A partir de ese momento la situación militar era insostenible para el Derg y junto a la caída de la Unión Soviética y el cese de su ayuda, la realidad es que el gobierno sin el apoyo popular de la población y sostenido únicamente por un ejército que se batía en retirada hizo que Mengistu huyera y el Derg cayera:

"The besieged Derg North Army -close to 200,000 men - surrendered in Asmara two days later. The same day citizens of Addis Ababa gathered to topple the statue of Lenin in park on lower Menelik Avenue across from Africa Hall. Derg forces in the east and south of the country rapidly collapsed." (Henze, 2000, pag. 329). 
Aunque la derrota militar fue un factor decisivo para la caída de la dictadura del Derg no fue el único, de igual manera contribuyó la desastrosa situación económica de Etiopía. El retroceso económico se debió a la presión del estado de guerra continuo sobre la economía y al efecto que sobre esta tuvieron las campañas de nacionalización y de control centralizado de la misma. El Derg adoptó una estrategia de desarrollo económico basada en planes inspirados en los Planes Quinquenales de la Unión Soviética con una economía dirigida que no permitía la existencia de un sector privado y que aumentó en gran medida el aparato estatal y la carga que este suponía para la ya débil economía (Zewde, 2001).

Desde el comienzo de su régimen el Derg había instaurado la confiscación de tierras y su total nacionalización como uno de sus ejes más importantes. En un principio en el sur del país estas medidas habían aumentado la producción ya que los campesinos pensaron que las tierras eran de su propia propiedad una vez las recibieron. Es más, los campesinos Oromo entendieron y celebraron la nacionalización de las tierras por parte del Derg como si les estuviera devolviendo sus tierras arrebatadas por los colonos amharas:

"At the time when he was singing this suunsuma (war song), the king had been deponed and the Derg regime had nationalized the rural land. Nageesso is addressing those who took the Arsi land during the time of the king and oppressed the Arsi. He tells them that he not does not want to name a name. They know themselves who they are and what they did in the past" (Nuresu, 2011, pag. 3).

No obstante, tras el paso de los años, la creación de granjas estatales y de normas de trabajo comunitario hicieron que la producción se hundiera en todo el país (Henze, 2000). De hecho, estos planes no lograron alcanzar el objetivo de aumentar el PIB en un 6,5\% y la renta per cápita en un 3,6\% sino que hicieron que esta última retrocediera un $0,8 \%$ (Zewde, 2001).

Finalmente en 1991 el Derg cayó y dejo un vacío de poder que ocupó rápidamente la oposición, obteniendo el mayor protagonismo y cuota de poder los grupos rebeldes de la regiones norte del país, y dentro de ellos especialmente los pertenecientes a la región del Tigray. De hecho se puede observar que esta región 
es en la actualidad la que mejores infraestructuras tiene. El nuevo gobierno inició una serie de reformas para desmantelar el estado comunista e instaurar la "democracia". Eritrea tras un referendum en 1993 consiguió la independencia y mantuvo inicialmente unas relaciones amistosas con Etiopía, pero tras una serie de reclamaciones fronterizas en 1998 los dos estados entraron en guerra hasta que se firmaron los acuerdos de paz del año 2000 y se envió una misión de paz de la ONU a la zona. Desde entonces las relaciones han oscilado desde gélidas a abiertamente hostiles incluyéndose en el proceso deportaciones masivas, escaramuzas fronterizas y amagos de estallido de las hostilidades.

En estos momentos los dos Estados apoyan movimientos rebeldes en el interior de su oponente y luchan una guerra soterrada en Somalia, donde las tropas etíopes forman parte de la fuerza de la Unión Africana mientras que Eritrea arma a los grupos islamistas que controlan gran parte del país:

"Eritrea is undermining stability in conflict-ravaged Somalia by paying political agents and a warlord linked to Islamist militants to influence the Mogadishu government, U.N. sanctions experts said in a confidential report." (Charbonneau, 2013, Recuperado el 5 de Noviembre de 2013 de: http://www.reuters.com/article/2013/07/17/us-somalia-eritrea-unidUSBRE96G06U20130717).

\subsubsection{Etiopía en la actualidad}

En la actualidad Etiopía se rige bajo una constitución aprobada en 1994. Esta constitución de corte democrático tiene algunas características muy destacables como la base étnica de su sistema federal y el derecho a secesión que los estados federales tienen como ya expusimos anteriormente. Por otra parte tras conocer la realidad política del país actualmente este derecho a la secesión es más nominal que real, ya que dada la falta de libertad política y el giro autoritario que esta teniendo el gobierno no es realista que se produzca a secesión de una parte del país, además la única región que se secesionó fue Eritrea y ello desembocó en una serie de guerras. Esta reforma del estado en base a la etnicidad fue promovida por 
el nuevo partido que tomó el poder tras el derrocamiento del Derg en 1991 y reflejada en la constitución de 1994:

"After assuming state power in 1991, the EPRDF institutionalized ethnicity under formal constitutional recognition in 1994, which was implemented 1995. This formed ethnic federalism with its policy frameworks on decentralization, empowerment, and self-government of ethnically established administrative units" (Regassa, 2012, pág. 522).

En teoría con esta medida se daba solución a uno de los problemas fundamentales del país y se reconocían los derechos de todos los pueblos que configuraban el estado etíope pero a nivel estatal los puestos más importantes siguen estando controlados por los amhara y los tigriños mientras que en las distintas regiones los partidos que gobiernan son los afines al gobierno y las tensiones étnicas siguen presentes, manteniéndose las rivalidades tradicionales entre los distintos pueblos. Es más, algunos autores como Regassa afirman que los conflictos inter étnicos han cobrado más intensidad tras las reformas empezadas en 1991:

"Despite such rhetoric from the government policy in formalising ethnicity as a basic framework and political agenda of the country's political and economic system, and as a mechanism of building a 'new Ethiopia', inter-ethnic conflicts have become more frequent since 1991 than before" (Regassa, 2007, pág. 2).

Así mismo esta nueva organización del Estado se está utilizando para alcanzar otros objetivos políticos y sociales ajenos a los derechos que pretende proteger:

"A common interpretation of why the EPRDF introduced ethnic federalism is that it was a way of institutionalising the principle of "divide and rule" and ensuring the ruling party's position" (Aalen, 2002, pag.9).

La democratización del país deja, bajo estándares occidentales, mucho que desear, pudiéndose definir el país como una "democracia imperfecta" o como una "dictadura encubierta". La corrupción es generalizada, hay control y censura de los 
medios de comunicación, Internet esta censurado y el gobierno utiliza programas para controlar la actividad de los internautas:

"El Gobierno etíope es, probablemente, el primero en dar un paso hacia delante para la instalación de un sofisticado sistema de filtrado que eventualmente le permitirá interceptar correos electrónicos, mensajes publicados en redes sociales y conversaciones de voz por Internet utilizando Voz sobre Protocolo de Internet (VoIP) software como Skype. Por otro lado, el uso de hardware y software de VolP es considerado un crimen por la nueva legislación deservicios de telecomunicacionesEtiopía, que fue ratificada el pasado 24 de mayo. Cualquier persona que viole esta disposición podría ser condenado hasta 15 años de prisión." (Europa Press, 2012. Recuperado el 5 de Noviembre de 2013 de: http://www.elmundo.es/elmundo/2012/06/25/internacional/1340618761.html).

Algunas de las medidas en torno a la censura de Internet como la prohibición de la utilización del programa Skype tuvieron que ser suspendidas por las protestas ante las mismas, durante mi experiencia de campo en Etiopía se podía utilizar el programa Skype sin ningún problema y en los locutorios era fácil de encontrar aunque es verdad que durante unos meses desapareció de los locutorios y cibercafés.

El gobierno etíope es calificado como uno de los gobiernos más activos a la hora de monitorizar y controlar tanto Internet como las líneas telefónicas móviles, encontrandose entre los cinco paises con menos libertad en Internet según la organización de Freedom House en su informe de 2013. Junto a esto se ha producido el encarcelamiento de miembros destacados de la oposición como el famoso blogger Eskinder Nega:

"In February 2011, inspired by the Egyptian military's tolerance of prodemocracy protesters in Tahrir Square, Eskinder wrote an article urging Ethiopian soldiers to heed their example, should demonstrations break out in Addis Ababa. The column appeared on a US-based Ethiopian news website blocked inside his country. In response, the state security detained Eskinder, accusing him of inciting the public against the government. A senior police official threatened to kill him if he did not stop writing about the Arab Spring" (Zakes, 2013, Recuperado el 19 de 
http://www.theguardian.com/world/2013/nov/05/ethiopia-free-eskinder-nega).

Todas estas medidas de represión se intensificaron tras las elecciones de 2005 se saldaron con más de 200 muertos en Addis Ababa y decenas de miles de detenidos a lo largo del país tras las manifestaciones denunciando el fraude electoral. Las elecciones de 2010 también fueron denunciadas como fraudulentas por la oposición, que solo obtuvo dos escaños:

"At the local level, thousands of opposition activists complained of EPRDFsponsored mistreatment, ranging from harassment in submitting candidacy forms to beatings by local militia members, and complained further that there was no forum free of EPRDF control to which to present those complaints." (Fuente: www.state.gov Recuperado el 16 de Diciembre de 2013 de: http://www.state.gov/outofdate/bgn/ethiopia/200314.htm).

De hecho, en el país circula un chiste que compara a la oposición con un deportivo porque solo tiene dos asientos. Los observadores internacionales también secundaron esta opinión de que las elecciones de 2010 no alcanzaron unos estándares de democracia mínimos:

"Observers declared the 2010 elections not up to international standards because an environment conducive to free and fair elections was not in place. According to observers, the EPRDF used the advantage of incumbency to restrict political space for opposition candidates and activists." (Fuente: www.state.gov Recuperado el 16 de Diciembre de 2013 de: http://www.state.gov/outofdate/bgn/ethiopia/200314.htm).

Desde las elecciones de 2005 y utilizando la cobertura de la lucha contra el terrorismo decenas de periodistas han huido del país o han sido encarcelados junto a una gran cantidad de miembros de la oposición:

"En julio de 2009, el Parlamento -en el que 545 de los 547 escaños están controlados por el partido gubernamental-aprobó una ley antiterrorista que desde entonces ha permitido al Ejecutivo del primer ministro Meles Zenawi acusar de traición o terrorismo a cualquier periodista o miembro de la oposición que 
simplemente mencione o haya tenido cualquier tipo de contacto con algún grupo considerado terrorista por el propio Gobierno" (Calatayud, 2013, Recuperado el 5 de Noviembre de 2013

de: http://sociedad.elpais.com/sociedad/2012/02/07/actualidad/1328619408 838695. $\underline{h t m l})$.

Durante el tiempo que estuve en Etiopía varías páginas web de agencias de noticias estuvieron censuradas total o parcialmente como por ejemplo la página web de Aljazeera o el blog de temática etíope nazret.com. Intentar entrar en cualquier página relacionada con los grupos opositores en el extranjero es completamente imposible. Además las ONG y organismos internacionales han denunciado la falta de respeto por los derechos humanos en Etiopía, para acallar estas críticas el gobierno aprobó una ley que controla la actividad de estas organizaciones y ha expulsado a miembros de las mismas del país:

"The virtual ban on foreign funding for nongovernmental organizations (NGOs) imposed by the 2009 Charities and Societies Proclamation (CSP), coupled with governmental intrusion into the operations of human rights groups, has resulted in minimal independent monitoring and reporting on the country's dismal human rights situation." (Yoseph Badwaza, www. http://www.freedomhouse.org/ Recuperado el 19 de Noviembre de 2013 de: http://www.freedomhouse.org/blog/one-year-after-meles-death-citizens-rightshave-yet-be-revived-ethiopia)

Todas estas situaciones han ocasionado que "la política" sea un tema tabú en las conversaciones y que en muy pocas ocasiones se hable y se muestre abiertamente el descontento contra el gobierno. En mi experiencia personal, tan solo en contadas ocasiones y en lugares en los que estaban seguros de la intimidad y de la privacidad de la conversación, algún etíope se ha atrevido a criticar al gobierno y sus medidas.

En la actualidad, las reformas han generado junto a las inversiones extranjeras que la economía etíope sea una de las que experimente unas tasas de crecimiento anual más grandes del mundo, pero las diferencias sociales están 
creciendo enormemente $\mathrm{y}$, mientras está surgiendo una clase alta y una pequeña clase media, el resto de la población sigue sumida en la pobreza. Esta entrada de empresas y capitales extranjeros está creando en ocasiones situaciones de indefensión para los pequeños agricultores, que son presionados o engañados para que abandonen sus tierras. Esto se da sobre todo en las zonas más fértiles del país y con los agricultores de etnias pequeñas y zonas atrasadas, un ejemplo de ello es las campañas de villagización que están siendo llevadas a cabo en la zona del Nilo Azul habitada por los Gumuz o las producidas en el valle del Omo para dejar paso a las grandes explotaciones azucareras:

"En 2011 el Gobierno comenzó a arrendar enormes extensiones de tierra fértil en la región del bajo Omo a empresas malasias, italianas, indias y coreanas para la plantación de biocombustibles y otros cultivos de alto valor económico como palma de aceite, jatropa, algodón y maíz. Ha comenzado a expulsar a indígenas bodis, kwegus y mursis de sus tierras para reasentarlos en otras zonas y dejar así paso al proyecto gubernamental Kuraz Sugar, que podría llegar a cubrir 245.000 hectáreas. Los suris que viven al oeste del Omo también están siendo forzosamente reasentados para dejar paso a la plantación "Koka" de palma de aceite" (www.survidal.es Recuperado el 19 de Noviembre de 2013 de http://www.survival.es/indigenas/valledelomo)

También se han producido denuncias de que en el valle del Omo ha sido utilizada la violencia, los asesinatos y las violaciones contra los miembros de las tribus que no han querido abandonar el lugar:

"Information around forced evictions, beatings, killings, rapes, imprisonment, intimidation and political coercion has been shared and these tactics have been documented as tools used in the resettlement process," (BBC News, 2013. Recuperado de www.bbc.co.uk/news/world-africa-23344154).

El gobierno tiene trabajadores a nivel de Woreda y Kebele cuya función es convencer a los pequeños agricultores que vienen en zonas remotas a que abandonen esos lugares y se trasladen a las nuevas aldeas que están siendo creadas por el gobierno a cambio de un terreno para construir su nueva vivienda y un 
terreno para su explotación agraria cerca de la nueva aldea con la promesa de que en la nueva aldea tendrán acceso a servicios como escuelas, centros de salud, electricidad y la presencia de la carretera.

Las antiguas tierras son entonces arrendadas a grandes empresas de capital extranjero o a colonos de etnia amhara. En conversaciones con residentes europeos en el país, fuimos informados de que una empresa India ha comprador una cantidad ingente de tierras. Según éstos, en la zona Gumuz esta nueva presencia de los colonos está provocando la aparición de incidentes de violencia étnica ya que los Amhara son odiados por los Gumuz debido a que durante siglos capturaron y esclavizaron a los miembros de esta pequeña etnia. Estas confrontaciones han llegado incluso a desembocar en asesinatos (Comunicación personal con el Padre Juan Gonzalez ,2012).

Un ejemplo de la entrada de nuevas empresas multinacionales es la compañía holandesa Sher en la localidad de Ziway, a $163 \mathrm{Km}$ al Sureste de Addis Abeba. Esta empresa dedicada al cultivo de rosas tiene una gran explotación formada por invernaderos en esta ciudad, en su página Web la empresa presenta el proyecto como responsable, basado en el comercio justo y enumera los servicios sociales que otorga a la población de Ziway. Aunque no se puede negar el impacto económico positivo que ha tenido la instalación de esta explotación para Ziway los costes sociales y ambientales también han sido elevados. Las condiciones de trabajo son muy duras y alejadas de lo que la empresa declara, un ejemplo de ello es que los trabajadores no tienen equipo de protección adecuando frente a los productos químicos, los cuales a su vez son vertidos al lago de la localidad sin ningún tipo de control. Por otra parte el hospital construido por la compañía es infrautilizado y en él se producen graves negligencias médicas, según se nos informó, y ante cualquier intento de investigar o denunciar las malas prácticas, el gobierno actúa para silenciarlo.

Para conseguir este proceso de crecimiento el gobierno etíope está desarrollando programas de cinco años que persiguen la industrialización y el desarrollo económico del país: 
"The government's long-term economic development strategy Agricultural-Development-Led-Industrialization (ADLI) - is geared to the transformation of the economic structure. The strategy involves an export-led external sector, and internal emphasis on agriculture to supply commodities for exports, domestic food supply and industrial output, and expand markets for domestic manufacturing." (http://www.mfa.gov.et/ Recuperado el 18 de Noviembre de 2013 de http://www.mfa.gov.et/aboutethiopia.php?pg=3 )

En este proceso de diferenciación social están siendo favorecidos los individuos afines al gobierno ya que logran obtener puestos en la administración pública o son favorecidos a la hora de obtener contratos y concesiones. Además la corrupción está provocando aún más diferenciación social ya que supone una importante fuente de ingreso para los trabajadores del gobierno ante la cual los ciudadanos comunes no pueden luchar. Según fui informado, el proceso habitual cuando alguien es corrupto y miembro del partido, pues casi todos los trabajadores públicos pertenecen al partido, sobre todo si quieren tener posibilidades de ascender, es trasladarlo de lugar para tapar el escándalo. En contadas ocasiones son despedidos o se enfrentan a penas de cárcel. Fuimos testigos de estas situaciones de indefensión ante los corruptos en el caso de un policía que había robado tanto dinero y aceptado tantos sobornos que se había construido una nueva casa por ello y como castigo simplemente había sido trasladado de una capital de woreda a la capital de la woreda vecina en la zona Guji. La policía es un estamento especialmente corrupto, lo que empeora la indefensión frente a la corrupción ya que los mismos que han de perseguirla se benefician enormemente de ella.

Es importante señalar que pese a todas estas reformas se sigue observando fácilmente en el día a día de la vida diaria y en la administración que la mentalidad comunista sigue estando muy presente. Tras la muerte de Meles Zenawi se organizaron manifestaciones y muestras de dolor público similares a las que se pudieron observar tras la muerte del dictador de Corea del Norte. Un año después en el aniversario de su muerte fuimos testigos de nuevo de manifestaciones de" apoyo popular" a su figura, y en todas las escuelas fue obligatorio comprar 
ejemplares de su biografía editada por el gobierno, además el libro era caro para los estándares etíopes, costando 100 Birrs cuando los precios de los libros de texto suelen ser de alrededor de unos 40 o 50 Birrs. Curiosamente el libro solo estaba disponible en amhárico cuando en las escuelas inferiores a grado quinto el amhárico no es impartido en la Oromía.

La administración organiza muchas reuniones y comités para cualquier asunto y a la vez tiene rasgos autoritarios frente a los ciudadanos. Al relacionarse con la administración además se nota la pesadez de la misma y la enorme cantidad de burocracia existente. Pese a todos estos problemas el discurso oficial del gobierno recalca la democracia y observando los programas televisivos y los informativos es muy común que se pronuncie la palabra "democracia."

En suma y como se puede observar a través de estas páginas, el mito de la Etiopía ancestral y monolítica patrimonial de las etnias semíticas amhara y tigriña del norte se ha formado y ha estado presente a lo largo del desarrollo de su historia. Este mito que funda las raíces de Etiopía en el Imperio de Askum y que otorga una continuidad a la idea de Etiopía como una isla de civilización cristina rodeada de musulmanes o paganos a lo largo de las distintas fases de la historia y de los distintos estados que dominaron la zona no solo está fuertemente establecida en Etiopía, sino que gran parte de los estudioso extranjeros han asumido este mito como una verdad.

Como consecuencia de la presencia de este mito, mucha de la historia de Etiopía está contada desde el punto de vista de los etíopes amharas y tigriños principalmente, y desde la Etiopía cristiana ortodoxa, por lo que durante mucho tiempo gran parte de la población etíope no ha se ha visto reflejada en esta historia oficialista más allá de los descendientes de los enemigos derrotados por el Imperio Etíope y han sido tratados por las clases dirigentes como eso mismo.

Este mito no solo no hace justicia a la realidad de los hechos históricos, sino que ha determinado profundamente el devenir de las relaciones interétnicas de los distintos pueblos, al crear un sentido de 'verdaderos' y 'falsos' etíopes que, como 
veremos más adelante en el segundo capítulo, en el caso de los Oromo ha sido el origen $\mathrm{o}$ ha contribuido a formar movimientos nacionalistas que pretenden la separación de algunas etnias del estado etíope al que no reconocen como propio.

Es muy importante entender que en la cosmovisión e imaginario colectivo etíope actual esta idea está muy presente todavía y a su vez está profundamente arraigada, por lo que condiciona la forma en la que los etíopes actuales de distintas etnias ven la historia de su país y afrontan las relaciones con miembros de otras etnias del país. Esto es especialmente significativo en los Oromo, grupo étnico al que pertenecen los participantes de la presente Tesis Doctoral, siendo además la etnia mayoritaria del país, al mismo tiempo que han sido tradicionalmente subyugados y apartados del poder y de las tomas de decisión desde su incorporación plena al Estado etíope. Ello ha generado tensiones étnicas internas dentro del país, suspicacias desde el poder central a cualquier manifestación reivindicativa de una cultura étnica diferente $y$ el surgimiento de grupos independentistas que en ocasiones no han dudado a la hora de tomar las armas.

Por otra parte en mi experiencia personal en el país y en comparación con la búsqueda de documentación para la realización de este trabajo he percibido que las ideas que promueven la independencia de regiones de Etiopía están mucho más presentes entre las poblaciones de las distintas etnias etíopes que viven fuera del país, principalmente en Occidente, que en los propios miembros de esas etnias que viven dentro de Etiopía. Creo sinceramente que en la actualidad estos nacionalismos son un movimiento ideológico fomentado desde las élites en el exilio más que una búsqueda real de las distintas poblaciones etíopes, para mí la lucha política en Etiopía se centra mucho más en conseguir una verdadera democracia, una igualdad real étnica y un verdadero autogobierno que en independencias.

Según algunos autores, la creación del estado federal de base étnica, más que calmar las tensiones entre las distintas etnias que componen el país, las ha fomentado (Hagaman y Mulugeta, 2008). Sin embargo, en mi experiencia personal creo que estas tensiones no tienen la fuerza suficiente como para poder poner en 
peligro la integridad territorial de Etiopía y son el resultado de una lucha por el control del poder político y los recursos financieros.

Puede que el fracaso de esta organización federal a la hora de calmar las tensiones interétnicas se deba a que algunas etnias han logrado patrimonializar gran partes de las estructuras del estado al controlar a su vez la mayoría de los puestos del partido que lleva en el gobierno desde que se instauró el nuevo régimen político en 1991 (Aalen, 2002). Por otra parte, este partido en el poder somete todas las estructuras estatales y federales a sus propias necesidades, habiendo diseñado una constitución afín a sus propios intereses y dejando en papel mojado algunas de las características más importantes de la misma como el derecho a la autodeterminación:

"The architect of the ethnic federal model, the TPLF, had a commitment to the principle of national self-determination during the struggle against the previous regime, and a desire to reconstruct the Ethiopian state in order to neutralise the old repressive elites. But the concern for its own survival as the ruling power led it to impose the federal system from above, practically excluding the other political forces in the country. This essentially undemocratic process made the political opposition view the new federal model as a purely TPLF-dominated project and not as an undertaking favouring the whole Ethiopian population." (Aalen, 2002, pág. 100)

Un ejemplo de ello nos lo da la independencia de Eritrea, la cual en vez de ser aceptada pacíficamente desembocó en una sucesión de guerras y expuso claramente bajo mi punto de vista que cualquier etnia o región que se intentara independizar se enfrentaría primero a la oposición firme del gobierno central. Este argumento queda reforzado con la política de declarar ilegal y terrorista a cualquier grupo independentista que surja en alguna de las regiones, ejemplos de ello son los grupos oromo o somalís como el OLF o el FLNO.

Al mismo tiempo el estado central etíope se reserva la gran mayoría de los recursos financieros por lo que las distintas regiones dependen de su apoyo a la 
hora de poder llevar a cabo proyectos o simplemente financiarse, con lo que el control central queda así reforzado:

"The study of fiscal relations between the regional states and the central government uncovered that the central government has been granted the most lucrative revenue sources in the country. Consequently, the regional states' financial bases are so weak that they remain dependent on federal grants and subsidies to carry out their constitutionally defined responsibilities. Especially the lowland regions, which have the lowest level of socio-economic development, are totally dependent on federal transfers, while the four highland regions at least manage to fund about a fourth of their own expenditures" (Aalen 2002, pág. 101)

El control estatal sobre las regiones tiene un componente étnico a la vez que político, ya que son los miembros del partido de las regiones del norte los que son enviados a controlar de manera oficiosa las regiones del sur del país:

"All in all, it appears that the four lowland regions are the units in the Ethiopian federation which experience the most severe central interference in regional affairs. They are governed by formally independent parties, but are nevertheless practically run by officials from the Regional Affairs Department and centrally assigned party cadres without formal positions." (Aalen, 2002, pág. 88)

Es tal la interferencia central sobre los asuntos de las distintas regiones que los delegados del partido central llegan a controlar e interferir en los asuntos de nivel local:

The activities of the centrally assigned party advisors is not restricted to the regional level, but is extended to both the zone and woreda, and even to kebele level. At the time of my data collection, people mentioned several TPLF-cadres active on the on sub-regional level. 36 A number of "ordinary" people told stories where these cadres had intervened directly in meetings and public gatherings at local level and demanded that the speakers should hold their talks in Amharic, so that they could take record of the discussions (Aalen, 2002, pág. 96).

Es evidente que este tipo de actuaciones no solo pretenden controlar efectivamente todos los grados de la administración, sino además demostrar 
públicamente el poder del partido y asegurar la lealtad de los ciudadanos, o al menos recordarles que el partido está en todas partes y que es mejor no provocar problemas al partido o de oponerse a sus designios. Esta situación crea un miedo a expresar determinadas ideas que es palpable en el día a día.

En conclusión, tras una historia de dominación de unas élites sociales y étnicas sobre el resto de la población del país, ni la imposición de un régimen comunista ni la posterior revolución cambiaron esta situación, ya que simplemente desplazaron a las élites sociales anteriores pero la dominación étnica continuó. En el caso del Derg la dominación étnica fue protagonizada casi exclusivamente por los amhara ya que la población tigriña se opuso fuertemente al gobierno de Mengistu Haile Mariam y fue protagonista en su caída. Con la llegada de la Revolución de 1991 y con el establecimiento de la República Federal los tigriños recuperaron su tradicional relevancia y junto a los amhara siguen dominando el país, en el que se siguen reproduciendo en gran medida las antiguas dinámicas de dominación étnica y económica bajo una apariencia de sistema democrático federal y en el que los pueblos periféricos siguen sometidos a unas campañas de aculturación por parte de las etnias dominantes.

\subsection{GEOGRAFÍA}

La superficie total de terreno contenida en sus 5,328 kilómetros de fronteras es de $1.104 .300 \mathrm{~km}^{2}$ convirtiendo a Etiopía en el vigésimo séptimo país por

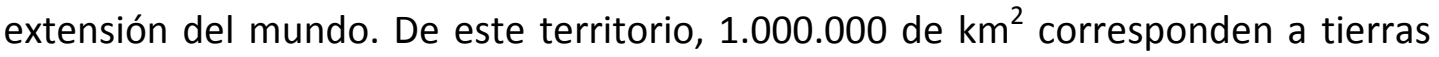
mientras que $104.300 \mathrm{~km}^{2}$ son ocupados por los lagos y ríos del país. Geográficamente destaca por ser un país muy montañoso, pues en Etiopía se concentra el $1 \%$ de las zonas montañosas de África, tanto es así que en Etiopía se encuentran 10 de los 40 picos más elevados del continente africano. Destaca también la presencia del Valle del Rift que atraviesa el país de Norte a Sur. Es importante además destacar que el paisaje "típico" del país está conformado por zonas de llanura a gran altura separadas entre sí por cadenas montañosas. El punto más elevado del país es el pico de Ras Dejen en las montañas Semien en la zona 
Noroeste del país a 4.533 metros sobre el nivel del mar. Por el contrario, el punto de menor altitud se corresponde con la Depresión del Danakil, situada a 125 metros bajo el nivel del mar en el Noreste del país, en el territorio Afar. Tras la independencia de Eritrea en 1993 Etiopía perdió su salida al mar, encontrándose actualmente aislado del Mar Rojo. Etiopía cuenta con una serie de recursos naturales como pequeñas reservas de oro, platino, cobre, potasio, y gas natural. A estos recursos minerales se ha de añadir el gran potencial hídrico del país, que va a ser explotado para la producción eléctrica con la construcción de una serie de presas que, una vez terminadas, cambiarán el patrón energético de la zona:

"In late June, Ethiopia announced that it would build four additional dams on the Blue Nile that will work in conjunction with the Grand Millennium Dam to generate more than 15,000 megawatts of electricity." (Than, 2011, http://www.nationalgeographic.com/ Recuperado el 14 de Noviembre de 2013 de: http://news.nationalgeographic.com/news/2011/07/110713-/ethiopia-southsudan-nile-dam-river-water/)

En la actualidad también se ha abierto el primer parque con aerogeneradores y hay planes para construir parques de placas solares:

"Minister Alemayehu Tegenu said the project represented a significant advance in the country's energy initiatives and its comprehensive Energy Plan, adding the large hydro-electric generation capacity and the wind and geothermal power generation projects coming on-line. He noted it would provide significant power generation capacity much faster than the other renewable technologies" (http://www.ethpress.gov.et/herald/ Recuperado el 18 de Noviembre de 2013 de http://www.ethpress.gov.et/herald/index.php/herald/news/4745-gov-t-approves300mw-solar-energy-project)

De la superficie total de territorio, tan solo un $13 \%$ era superficie roturada en 2003 lo que suponía que $2.896 \mathrm{~km}^{2}$ se utilizaran para cultivos irrigados. Hoy en día la superficie utilizada para la producción de cultivos y alimentos está experimentando un crecimiento debido a la entrada de grandes empresas 
extranjeras que están adquiriendo terreno e instalando grandes explotaciones agrícolas con objetivos comerciales y métodos de producción industrial.

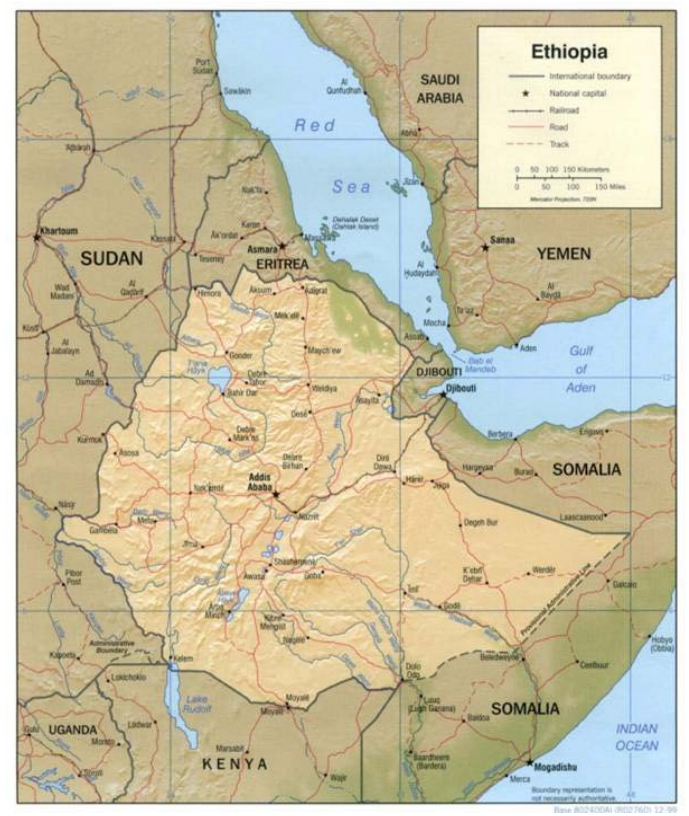

Figura 4. Mapa físico de Etiopía

(Fuente: University of Texas Libraries, Perry-Castañeda Library Map Collection: Ethiopia Maps)

\subsection{ESTRUCTURA POLÍTICA}

La República Democrática Federal de Etiopía es un estado federal compuesto por nueve estados federales (Figura 5) de base étnica y dos ciudades con un estatus especial (Addis Abeba y Dire Dawa) cuya ordenación administrativa y jurídica se basa en la constitución vigente del país aprobada en 1994 que reconoce hasta el derecho a la secesión de estos estados federados:

"La etnicidad es un aspecto clave de la Constitución del 94, estableciéndose incluso en la Carta Magna el derecho a la secesión. De hecho la Constitución etíope comienza "Nosotros, las naciones, nacionalidades y pueblos de Etiopía..." lo cual marca que el federalismo etíope es étnico y no territorial. De ahí que la RFDE esté constituida por nueve estados federados en función de los grupos étnicos: Afaria, Amhara, Benishangul-Gumuz, Gambella, Harar, Oromia, Pueblos y Naciones del Sur, 
Región Somalí y Tigray. Además Addis Abeba y la ciudad de Dire Dawa tienen un estatus especial". (www.exteriores.gob.es, Recuperado el 20 de Octubre de 2013 de: http://www.exteriores.gob.es/Documents/FichasPais/ETIOPIA FICHA\%2OPAIS.pdf)

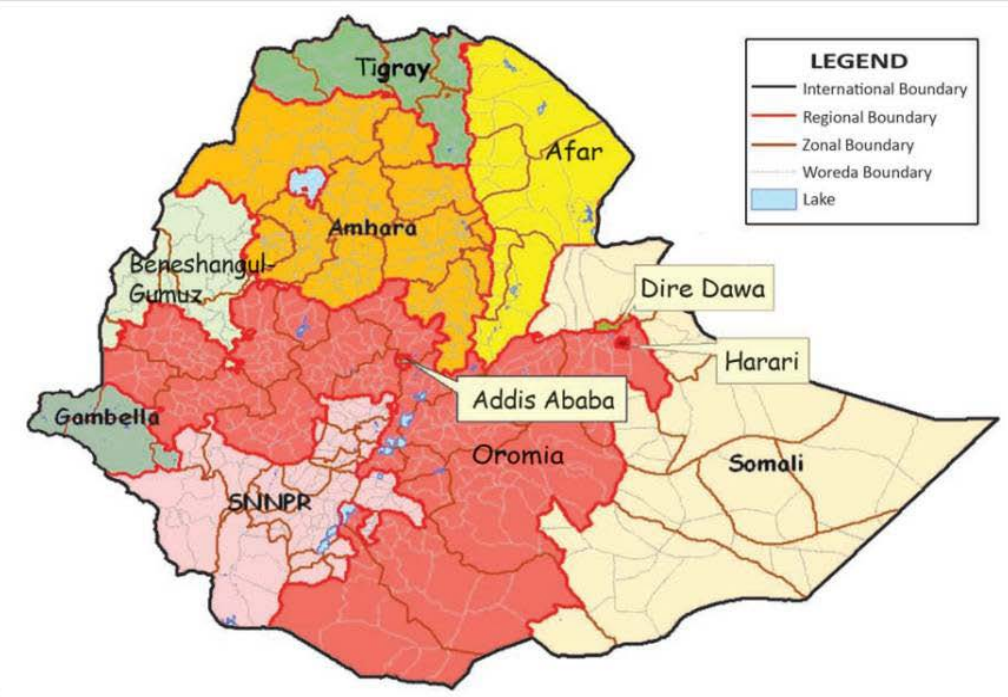

Figura 5. Divisiones administrativas de Etiopía

(Fuente: UNICEF)

Estos estados federales a su vez contienen otra serie de subdivisiones, dejando la administración etíope organizada en 5 niveles (véase Figura 6).

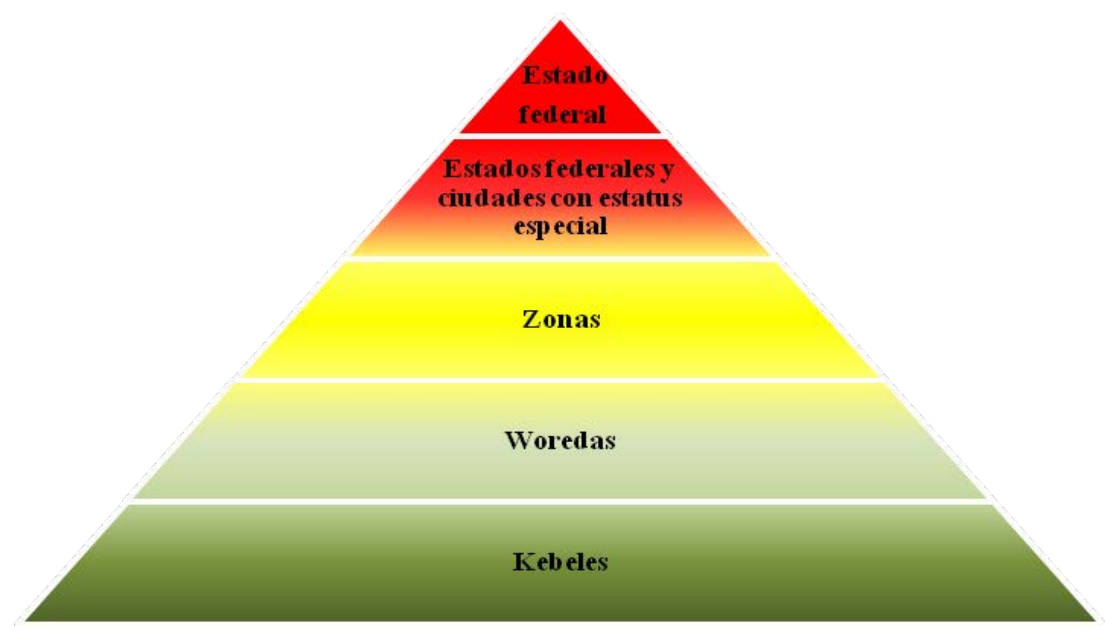

Figura 6. Niveles de organización administrativa de Etiopía.

(Fuente elaboración propia, a partir de Datos UNPAN, 2004) 
Los estados federales y las dos ciudades con estatus especial - equivalente a nuestras comunidades autónomas y a Ceuta y Melilla-, disfrutan de un amplio autogobierno y gestionan una gran cantidad de recursos público de manera directa o en acuerdo con el estado federal central.

A continuación, descendiendo un nivel nos encontramos con las zonas, estas unidades administartivas serían el equivalente a nuestras provincias. El siguiente nivel administraivo es el formado por las Woredas, que serían un equivalente a nuestras comarcas, con su capaital comarcal en la que se se concentra la administración pública. Los Distritos o Kebele son el equivalente a una municipalidad y son la unidad más pequeña de la administración Etíope. En nuestra expereriencia de campo pudimos obseravar como en su gobierno y administración tienen una gran presencia los propios vecinos. Los kebele resuleven los problemas de la comunidad del día a día.

\subsubsection{Los tres poderes}

Según el informe de la United Nations Public Administration Network (UNPAN, 2004), La constitución de 1994 garantiza la separación de poderes entre el legislativo, ejecutivo y judicial y promueve la igualdad de todas las lenguas de las distintas etnias, aunque a nivel federal el amhárico sigue siendo la lengua utilizada por el gobierno.

\subsubsection{Poder legislativo}

La constitución de 1994 estableció un sistema bicameral, con una cámara superior que recibe el nombre de House of Federation y una cámara baja llamada House of People's Representatives pero no tienen las funciones de un sistema bicameral tradicional, sino que cada una de ellas esta especializada en diversos aspectos:

"However, the Ethiopian Parliament is not bicameral in the traditional sense. The House of Peoples' Representatives has legislative and oversight functions while the House of Federation has a constitutional role to safeguard the interests of the nations and nationalities of Ethiopia" (UNPAN, 2004, pag.5). 


\subsubsection{Poder ejecutivo}

La cabeza del Estado es el Presidente de la República; este cargo es electo por seis años no pudiendo ser elegida la misma persona para ocupar el cargo más allá de un segundo mandato. Las funciones del presidente de la República son representativas y protocolarias, no tiene un poder político real en sus manos y no puede pertenecer a ningún partido político (UNPAN, 2004). El poder real está en manos del Primer Ministro, sus mandatos tienen una duración de cinco años y en sus manos concentra los más altos poderes ejecutivos, políticos y el poder militar:

"The Prime Minister is the chief executive, the chairman of the Council of Ministers and the Commander-in-Chief of the National Armed Forces" (UNPAN, 2004, pag, 6).

\subsubsection{Poder judicial}

La independencia del poder Judicial respecto al Ejecutivo está garantizada en la constitución etíope (UNPAN, 2004), pero debido al sistema de elección de los jueces para las cortes más elevadas y a la composición de las cámaras legislativas, donde todos los diputados menos dos pertenecen a los partidos gubernamentales, esta independencia es más bien nominal:

"Federal Supreme Court (the president and vice president of the Federal Supreme Court are recommended by the prime minister and appointed by the House of People's Representatives; for other federal judges, the prime minister submits to the House of People's Representatives for appointment candidates selected by the Federal Judicial Administrative Council)" (UNPAN, 2004, pág. 6).

El sistema judicial etíope esta dividido en dos ramas: el sistema judicial a nivel federal y a nivel regional que tienen competencias sobre distintos asuntos:

"Ethiopia has a dual system of courts - a Federal Judiciary with the Supreme Court at the top along with a separate and parallel judicial system in each Regional State. The Federal Supreme Court, the Federal High Court and the Federal First Instance Court constitute a single Federal Judiciary, having jurisdiction over all cases 
pertaining to federal matters. Likewise, there is a similar court structure in each Regional State that has jurisdiction over all regional matters"(UNPAN, 2004, pág. 6)

Aparte de estas dos ramas judiciales en Etiopía todavía es muy importante la utilidad de los sistemas judiciales tradicionales, como la mediación de ancianos a la hora de resolver conflictos, esto lo pudimos constatar en nuestra experiencia de campo cuando ante el surgimiento de problemas o disputas los ancianos de las familias llegaban a acuerdos para solucionar los diversos incidentes de manera satisfactoria. Entre los Guji, aunque intervenga la justicia ordinaria en casos de asesinatos o similares es necesario llegar a un acuerdo de manera tradicional entre las familias también para evitar que se produzcan venganzas.

Al mismo tiempo observamos que siempre se intentaba evitar el sistema judicial ordinario para soslayar los problemas de la corrupción y la lentitud. En casos como un accidente leve, una pelea o similares que revestían escasa gravedad era especialmente llamativo cómo se intentaba evitar que la policía interviniera en el caso, ya que los policías llegaban a alargar el proceso de resolución del conflicto de manera artificial hasta que recibían una cantidad de dinero. También fuimos testigos de que, hasta no hace mucho tiempo, crímenes de extrema gravedad como el asesinato se resolvían de manera tradicional.

\subsection{ECONOMÍA}

La economía Etiope es una de las economías con un mayor grado de crecimiento del mundo en la última década como muestran los datos del Banco Mundial aunque se aprecia una desaceleración del crecimiento, que ha pasado de más de un 10\% anual a un 7,5\% anual en 2011 (véase Figura 7). 


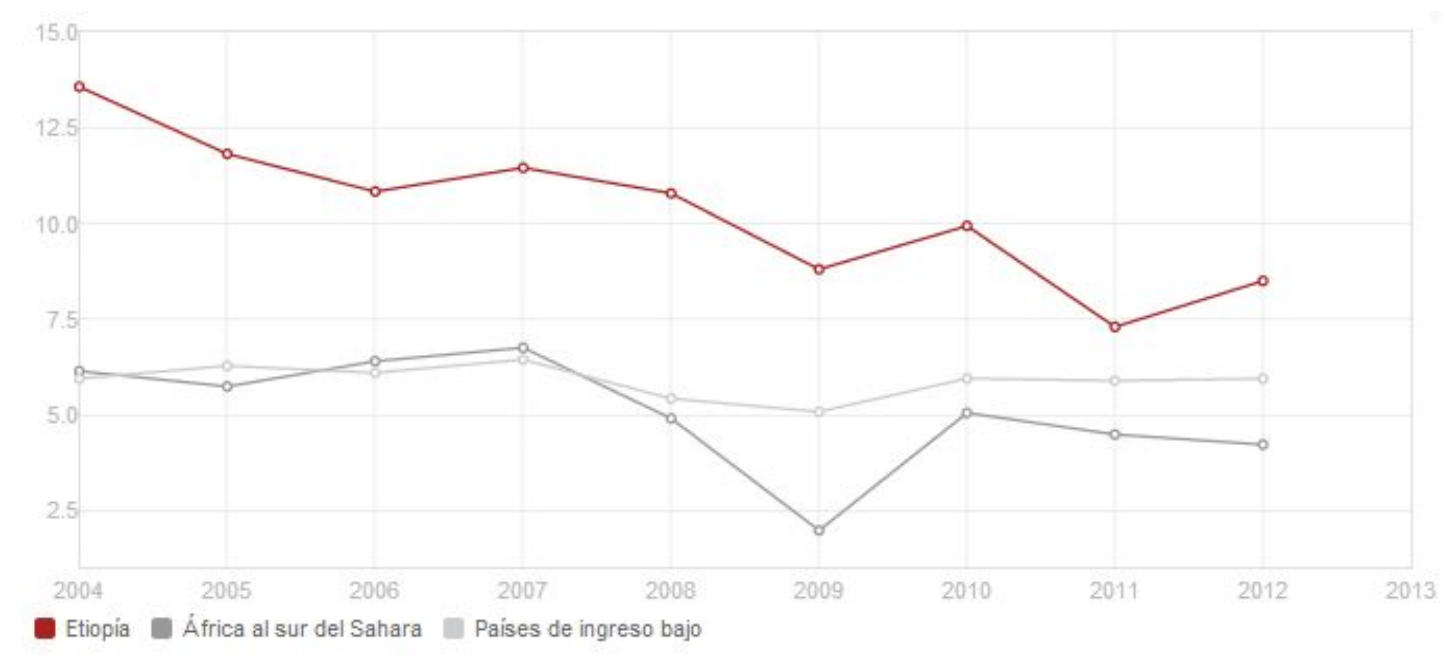

Figura 7. Evolución del PIB de Etiopía comparado con el de África Subsahariana y los Países de Ingreso Bajo en el periodo 2004-2012

(Fuente: Banco Mundial)

La economía etíope sigue siendo principalmente agraria, pero en los últimos años el sector terciario ha ganado importancia, junto a un crecimiento del sector industrial, en la actualidad el PIB etíope se reparte de esta manera: (1) Sector primario: 46,4 \% PIB; (2) Sector secundario: 10,5 5 PIB; y (3) Sector terciario: 43,1 5 PIB. Como hemos podido observar el pilar fundamental en el que se basa la economía etíope es el sector agrario, un sector que supone más del $45 \%$ del PIB etíope y que da trabajo a un $85 \%$ de la población (ICEX 2012). Reconociendo la realidad de que Etiopia es un país de fuerte carácter agrícola y la dependencia que la economía del país tiene de este sector, el gobierno ha implantado el plan estratégico llamado ADLI (Agricultural Development Led-Industrialization):

"Since the new Ethiopian Government made agriculture its primary priority in 1991, Ethiopia has developed and implemented its Agricultural Development Led-Industrialization (ADLI) strategy. The key concept underlying $A D L I$ is an export-led development strategy aimed at promoting economic growth in Ethiopia while coordinating agricultural and industrial development" (Fuente: http://www.ethiopianembassy.org/Recuperado el 29 de Noviembre de 2013 de: http://www.ethiopianembassy.org/PDF/InvestingAgriculture.pdf) 
La filosofía de esta estrategia consiste en crear una base económica agrícola en la que se apoye posteriormente un desarrollo industrial con la creación de industrias subsidiarias o dependientes de los productos agrícolas:

"Tiene el aumento de la productividad de la agricultura como motor de crecimiento, y la industrialización basada sobre todo en la agricultura, de forma que se genere valor añadido y trabajo en el sector que más población activa emplea, evitando que se produzca un éxodo del campo a las ciudades" (Informe ICEX, 2012, pág 7).

La base de este sector está formada por pequeñas explotaciones que son las que aportan la prácticamente totalidad de la producción del país:

"Of the total production in 2011/12, 97 percent (225 million quintal) was produced by smallholder farmers and the rest 3 percent (7 million quintal) was produced by commercial farms. This clearly shows the significance of smallholder farmers in crop production" (Ministry of Finance and Economic Development, 2013 pág. 26 ).

Estas pequeñas explotaciones de carácter familiar mantienen un tipo de agricultura tradicional con muy pocos medios técnicos y utilizando métodos de cultivo y producción tradicionales. En nuestra experiencia de campo pudimos constatar que la explotación del terreno es un asunto familiar y todos los miembros de las familias participan en mayor o menor medida en la producción, que en muchas ocasiones combinan con otro tipo de ocupaciones:

"Forty five per cent of the agricultural labour force is self-employed. Land holdings are increasingly fragmented; it is more and more difficult to secure a livelihood through farming alone in areas where cultivable land is scarce. A significant proportion of self-employed farmers have moved into non-farm employment including daily wage labour, food-for-work programmes, quarrying, mineral extraction and construction" (UNICEF, 2012 pág. 7).

Las pocas piezas de maquinaria industrial que pudimos ver en el país pertenecían a las nuevas explotaciones agrícolas de carácter industrial que están introduciendo algunas empresas multinacionales: 
"The government has allocated about 2.9 million hectares for commercial agricultural ventures. This is about three per cent of Ethiopia's total land area, four per cent of total arable land, and close to 17 per cent of the total land under cultivation" (UNICEF, 2012 pág. 7).

Estas últimas se concentran en cultivos destinados para la exportación, un ejemplo de ello es la producción de flores con destino al mercado europeo:

"Otro ejemplo puesto por el Banco Mundial es el de una empresa etíope que ha abierto su mercado a la Unión Europea. Especializada en producir flores, su éxito ha dado trabajo a 50.000 personas" (Fuente: www.elmundo.es Recuperado el 20 de Noviembre de 2013 de: http://www.elmundo.es/elmundo/2012/05/04/economia/1336156168.htm/).

Como consecuencia de ello la agricultura en Etiopía es poco productiva, y la producción es inestable y está sujeta a factores ambientales que pueden provocar el hundimiento de la producción y como consecuencias episodios de hambruna:

"Vulnerability to environmental and climatic shocks, especially given that food production is rain-fed, remains one of the critical challenges for Ethiopia's agriculture. Despite improvements in yields, productivity is still very low, partly owing to limited use of chemical fertilisers and improved farming practices." (Zerihun, Kibret y Wakiaga, 2014, pág 4). 


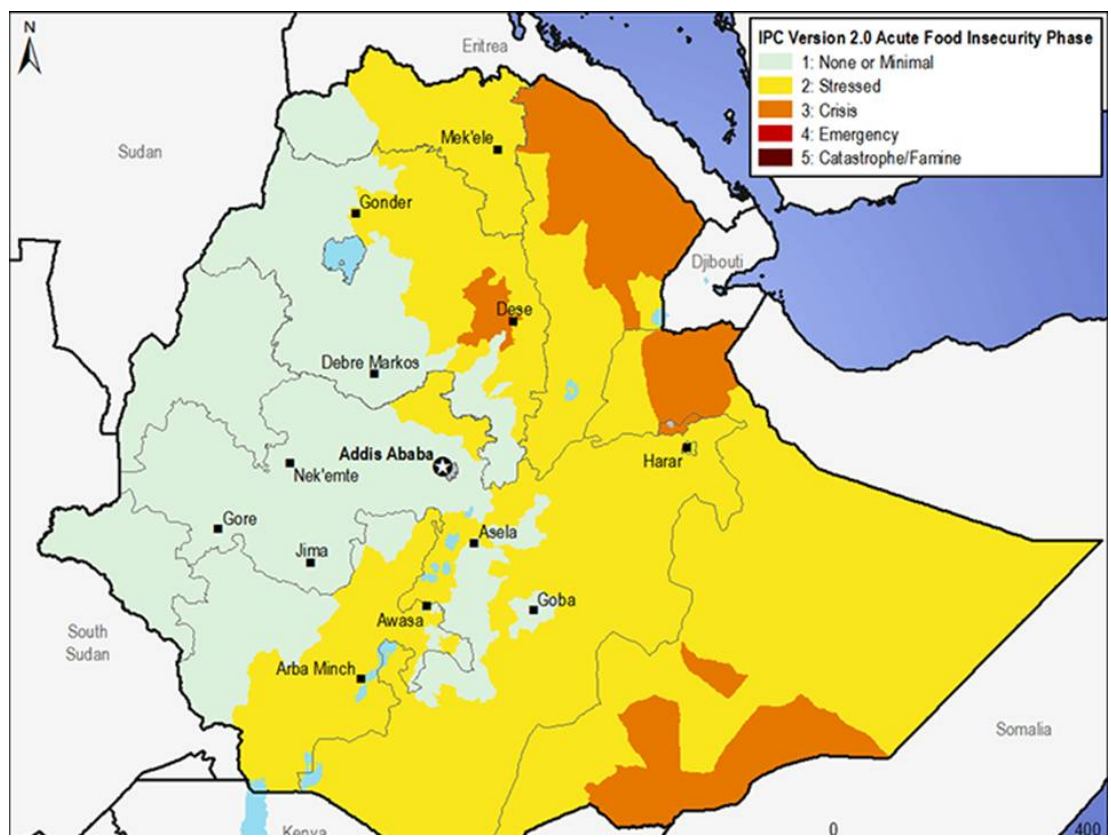

Figura 8. Mapa con los distintos grados de inseguridad alimentaria para Octubre-Diciembre 2013

(Fuente: Fews.net)

Pese a todas las limitaciones señaladas, el sector agrícola tiene un enorme potencial de futuro, ya que el país tiene enormes reservas de tierra susceptible para su utilización agraria sin explotar y la introducción de tecnología y técnicas modernas de producción podría disparar la productividad:

"In spite of these challenges, the potential for growth in agriculture is enormous. Agricultural productivity is one of the lowest in sub-Saharan Africa. This indicates that there are untapped opportunities to increase production and productivity by promoting modern farming practices. Scaling up the practices of model farmers to the others by promoting the use of modern technologies, supporting the commercialisation of agriculture and the production of high value crops, encouraging micro-irrigation schemes, and improving marketing institutions and infrastructures are some of the key policy tools that the government is pursuing to enhance agricultural production and productivity" (Zerihun, Kibret y Wakiaga, 2014, pág 4).

Según datos del Banco Mundial (http://www.worldbank.org/en/country/ethiopia), el sector industrial en la actualidad representa un 10,5\% del PIB del país y es un sector que está experimentando un gran crecimiento debido a diferentes factores: 
"The continued construction boom, together with expansion in mining and manufacturing, helped the industrial sector to grow by $18.5 \%$ during $2012 / 13$. There are positive prospects for 2013/14 and 2014/15 for enhanced growth in the industrial sector, given government attention to the sector, particularly to small and medium manufacturing, to increase value added and job creation."(Zerihun, Kibret y Wakiaga, 2014, pág 3).

Personalmente he observado la gran expansión del sector de la construcción, tanto de carreteras como de edificios, Addis Abeba está cambiando de una manera espectacular con la construcción de grandes edificios o rascacielos y con la mejora de las infraestructuras de la ciudad, como la construcción de un sistema de ferrocarril urbano o la remodelación de partes de la ciudad con la construcción de bloques de apartamentos y la ampliación de algunas de las avenidas más importantes de la ciudad. Este boom de la construcción también se puede encontrar por todo el país. En mi estancia en el país, al visitar una ciudad encontraba obras tanto en el terreno de las infraestructuras como en la construcción de nuevos edificios públicos o privados (Figura 9).

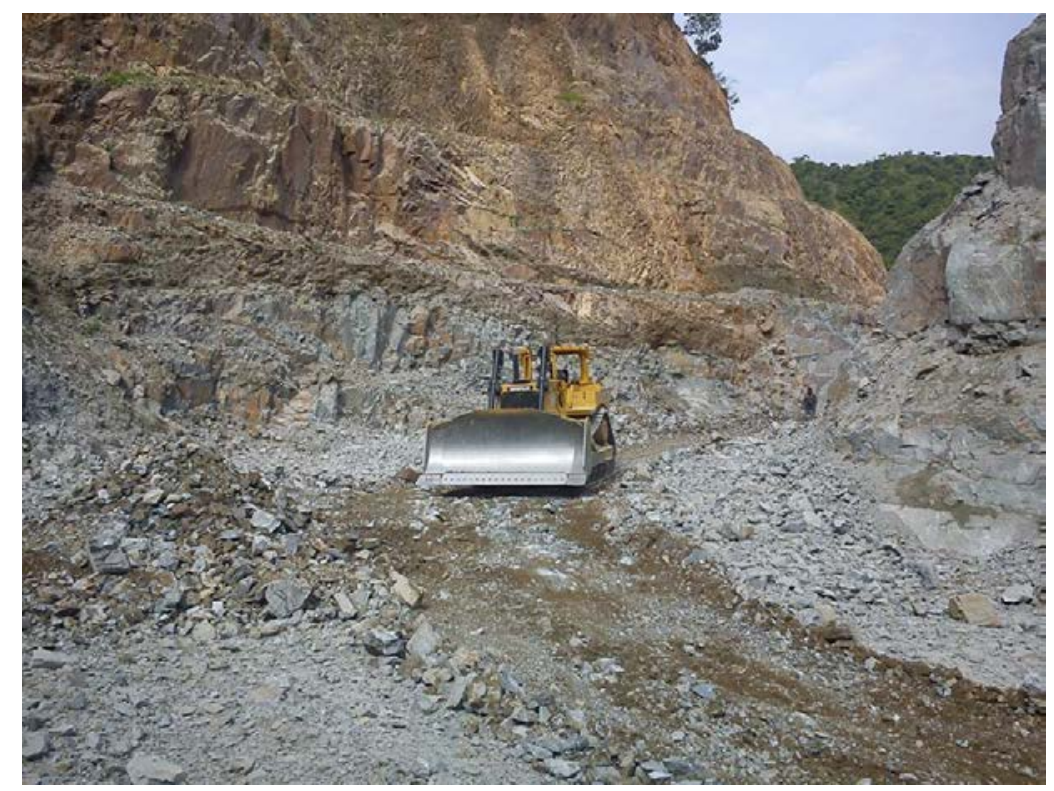

Figura 9. Obras de ampliación en una carretera al norte del país.

(Fuente: Autor) 
La gran mayoría del sector industrial etíope esta formado por pequeñas y medianas empresas, las cuales son favorecidas por el gobierno. En nuestra experiencia de campo pude asistir a varios locales comerciales propiedad del gobierno en los que se vendían la producción de estas empresas y en los planes de desarrollo del gobierno están incluidas medidas para favorecer su creación y expansión:

"To ensure accelerated and sustained industrial development the main focus will be on industries that are labour intensive, have broad linkages with the rest of the economy, use agricultural products as inputs, are export-oriented and import substituting, and contribute to rapid technological transfer. In other words the key strategic direction of industrial development will be micro and small scale industrial development. In addition, medium and large scale industries will also be given special emphasis" (Ministry of Finance and Economic Development, 2013 pág. 31).

Este sector industrial se está viendo muy favorecido por la inversión pública en grandes infraestructuras como presas y vías de comunicación, para muestra de ello los datos ofrecidos por el Ministerio de Economía y Desarrollo Económico sobre la construcción de carreteras:

"During the five year period, it was planned to execute $728 \mathrm{~km}$ rehabilitation of trunk roads, $5023 \mathrm{~km}$ of upgrading of trunk and link roads, 4331 $\mathrm{Km}$ of new trunk/link roads construction, $4700 \mathrm{~km}$ of periodic maintenance 84,649 $\mathrm{Km}$ of routine and term maintenance and other pre-construction studies and capacity building activities within five years time (2010/11-2014/15). As to regional roads, $11212 \mathrm{~km}$ of roads is planned to be constructed and several road maintenance activities are planned to be carried out by regional road authorities, while woreda roads desks plan to construct $71,522 \mathrm{~km}$ of low level all weather roads during the same period" (Ministry of Finance and Economic Development, 2013 pág. 42).

Como ya hemos comentado anteriormente, este sector industrial va a ser alimentado con la energía procedente de las nuevas presas, parques eólicos, y 
parques solares. Junto a estas fuentes de energía, el gobierno esta promoviendo la producción de biocombustibles en el país para alimentar la creciente demanda de energía, a la vez que intentar paliar la dependencia de la importación de petróleo. El sector servicios está siendo uno de los motores principales del desarrollo económico actual y de las altas tasas de crecimiento que Etiopía esta alcanzando en los últimos años:

"Ethiopia's strong economic performance continued for the tenth consecutive year, with real GDP growth estimated at 9.7\% in 2012/13. As in the preceding years, this growth continued to be broad-based, with all sectors contributing; the service sector accounted for $46.1 \%$ of the growth, followed by agriculture (32.1\%) and industry (21.8\%)"( Zerihun, Kibret y Wakiaga, 2014, pág 3).

Este sector servicios se está beneficiando enormemente del turismo, del aumento de la importancia del sector financiero o de la gran creación de pequeños comercios que se está experimentando:

"The service sector was estimated to have grown by 9.9\% during 2012/13, mainly driven by expansion in wholesale and retail trade (34.4\%), transport and communications (17.1\%), hotels and tourism (15.4\%), and other community services.." (Zerihun, Kibret y Wakiaga, 2014, pág 3).

Personalmente he podido observar el gran crecimiento de este sector terciario, tanto en Addis Abeba como en ciudades de tamaño medio o pequeño donde se aprecia una gran expansión de hoteles, restaurantes y comercios minoristas. Otro ejemplo significativo de ello es la expansión de los cajeros automáticos, en el año 2010 solo se podían encontrar en algunos bancos de Addis Abeba y durante 2013 logré encontrarlos por toda Etiopía, hasta en ciudades pequeñas.

El comercio internacional de Etiopía se caracteriza por la exportación de materias primas y productos primarios y la importación de productos elaborados y tecnología (véase Tabla 1). 
Tabla 1. Principales exportaciones e importaciones de Etiopía en 2010 en porcentaje

\begin{tabular}{lr}
\hline Principales exportaciones & Porcentaje del total \\
\hline Café & 31,2 \\
Máquinas y aparatos mecánicos & 23 \\
Legumbres, hortalizas, s/ conservar & 17,6 \\
Semillas oleaginosas, plantas industriales & 14,8 \\
Vehículos automóviles; tractores & 12,3 \\
Productos farmacéuticos & 9,6 \\
Cereales & 8,6 \\
Piedras, metales preciosos; joyería & 7,9 \\
Plantas vivas; pro. Floricultura & 7,1 \\
Aeronaves & 5,9 \\
Animales vivos & 5,7 \\
Abonos & 5,4 \\
Aparatos y material eléctrico & 5,1 \\
Aparatos ópticos, medida, médicos & 4,7 \\
Pieles (excl. Peleter.); cueros & 2,9 \\
Máquinas y aparatos mecánicos & 2,3 \\
Carne y despojos comestibles & 2,1 \\
Aceites esenciales; perfumes. & 2,1 \\
Otros productos químicos & 2 \\
Algodón & 1 \\
\hline
\end{tabular}

(Fuente: Elaboración propia. Datos: Ministerio de Asuntos Exteriores)

El gobierno dirige esta política de desarrollo económico mediante una serie de planes estratégicos de cinco años llamados Growth and Transformation Plan o GTP, en la actualidad está vigente el plan aprobado para el periodo 2010/112014/15:

"The Growth and Transformation Plan(GTP) is directed towards achieving Ethiopia's long term vision and sustaining the rapid and broad based economic growth anchored on the experiences that has been drawn from implementing development policies and strategies and undertaking policy measures for the challenges that has been surfaced in the course of implementation. The overriding development agenda of GTP is to sustain rapid and broad-based growth path witnessed during the past several years and eventually end poverty" (Ministry of Finance and Economic Development, 2010 pág. 7). 
Aunque la economía etíope se basa en el libre mercado, grandes parcelas de la economía están en manos del gobierno o de individuos afines a los partidos gubernamentales:

"State-owned enterprises and ruling party-owned entities dominate major sectors of the economy. There is state monopoly or state dominance in sectors such as telecommunications, power, banking, insurance, air transport, shipping, and sugar. Ruling party-affiliated "endowment" companies have a strong presence in the ground transport, fertilizer, and textile sectors. Both state-owned enterprises and "endowment" companies dominate the cement sector" (Fuente: http://www.state.gov/, Recuperado el 30 de Noviembre de 2013 de: http://www.state.gov/e/eb/rls/othr/ics/2013/204639.htm).

Un ejemplo de ello es Mohammed Al Amoudi al que la revista Forbes sitúa en el puesto número 65 de los hombres más ricos del planeta (www.forbes.com)

"Sheikh Al Amoudi is the largest foreign investor in Ethiopia. MIDROC Ethiopia has interests in property, steel, construction, air transport and manufacturing and also owns the Sheraton Addis. Gold mining is of great importance to the Ethiopian economy. Although only one of 80 or so companies in the Ethiopian mining sector, MIDROC Gold is by far the most significant" (Fuente: http://www.sheikhmohammedalamoudi.info/ Recuperado el 30 de Noviembre de 2013 de: http://www.sheikhmohammedalamoudi.info/connectingeconomies/midroc).

El propio gobierno reconoce la importancia del partido gubernamental en la estrategia económica y afirma inspirarse en el modelo asiático:

"Ethiopia, following the example of Asian industrialization, is convinced of the role that the developmental state and a ruling party can provide to direct development, to stimulate and sustain growth"(Fuente: http://ethemb.se/beta/a/ Recuperado el 29 de Noviembre de 2013 de: http://ethemb.se/beta/a/aboutethiopia/economy/).

Otro de los pilares de este crecimiento es la obtención de fondos en organismos internacionales y la emisión de deuda externa. El resultado es que la 
deuda externa pública etiope o garantizada por fondos públicos ha crecido de manera muy significativa desde el año 2006:

"Since the debt relief granted under the Multilateral Debt Relief Initiative (MDRI) and Heavily Indebted Poor Countries (HIPC) Initiative in 2006, Ethiopia's external debt stock has quadrupled. This is a result of a surge in public enterprises' external borrowings from non-Paris Club sources and commercial banks" " (Zerihun, Kibret y Wakiaga, 2014, pág 7).

Según algunos estudios, esta situación puede suponer una amenaza para el desarrollo económico del país y más con la ralentización que esta sufriendo el crecimiento de la economía etíope (véase Figura 10). Ello puede suponer un problema al tener que destinar un porcentaje más elevado de los recursos disponibles a pagar los intereses de la deuda y crear una mayor dificultad para captar nuevos fondos (Getnet y Getachew, 2007).

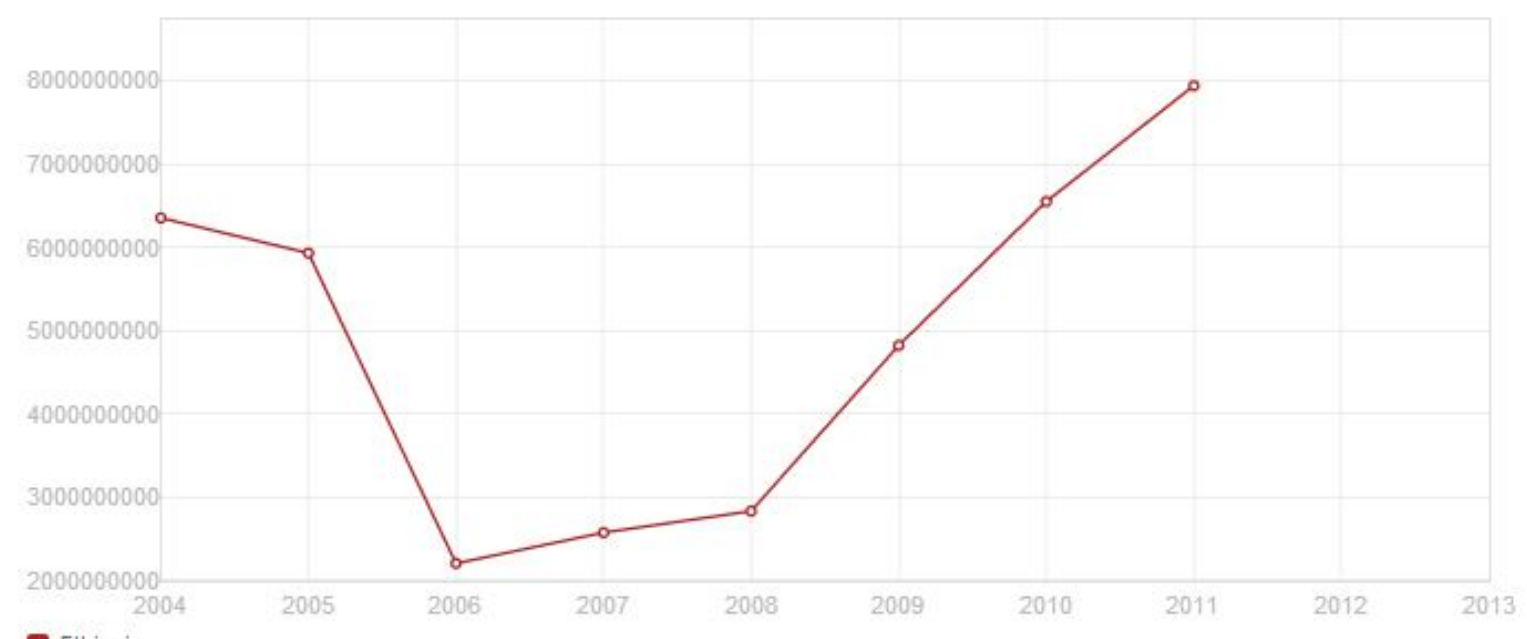

Ethiopia

Figura 10. Evolución de la deuda externa pública y públicamente garantizada de Etiopía en Dolares norteamericanos

(Fuente: Banco Mundial, 2014)

Es importante señalar que Etiopía ya se enfrentó a una crisis de la deuda externa a principios de la década del dos mil, cuando en el año 2002 en medio de una hambruna que azotaba el país el pago de la deuda consumía el $10 \%$ de los recursos del país: 
"Andrew Pendleton, who advises the charity Christian Aid on Ethiopia, pointed out that Ethiopia's ability to cope with the drought was hampered by its continuing foreign debt, which eats up at least $10 \%$ of the state's revenues" (Fuente: http://www.bbc.co.uk/ Recuperado el 28 de Noviembre de 2013 de : http://news.bbc.co.uk/2/hi/africa/2440093.stm).

Otra de las consecuencias negativas de este crecimiento acelerado es las altas tasas de inflación (Figura 11) que están creando y que han provocado un incremento espectacular de los precios en los últimos años y ha puesto en peligro la economía domestica de muchos etíopes:

"High inflation poses a serious threat to poverty reduction and food security. High inflation causes protracted stress on household budgets and increases the vulnerability of any household, especially poor ones" (World Bank, 2012 pág. 15).

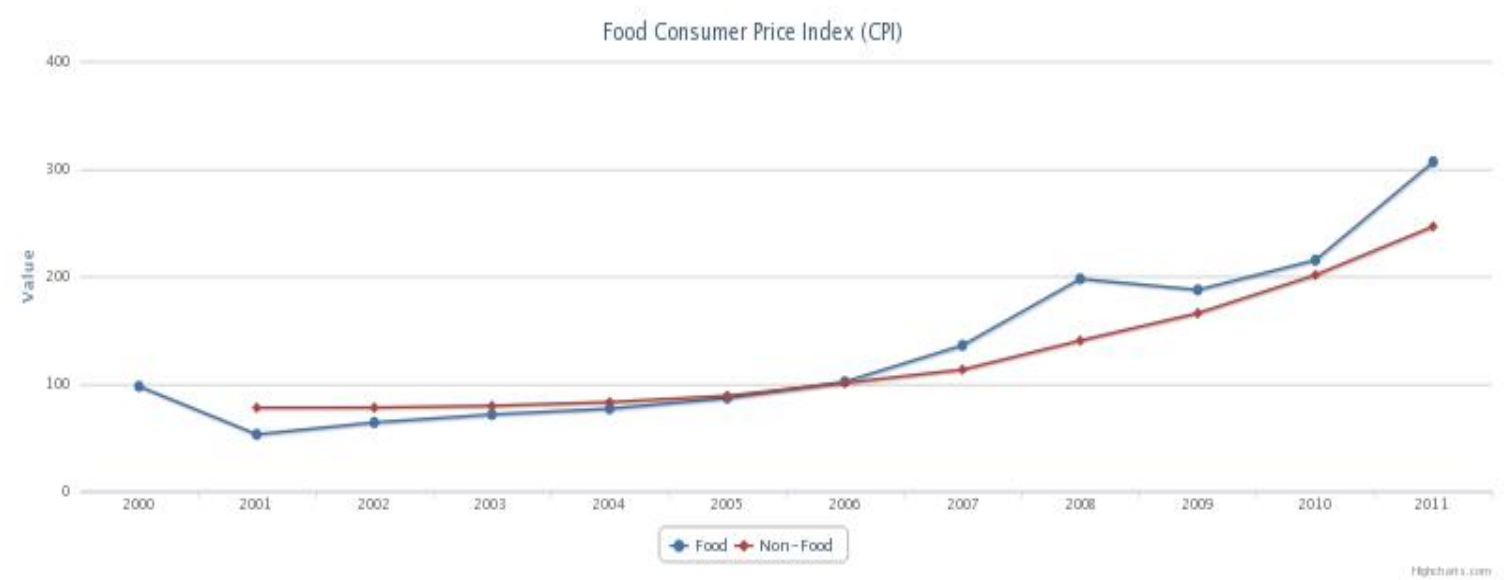

Figura 11. Evolución del índice de precios al consumo en productos alimenticios y no alimenticios durante el periodo 2000-2011 en Etiopía

(Fuente: Banco Mundial, 2014)

En la actualidad el gobierno federal etíope ha adoptado medidas para intentar frenar la inflación que azota el país pero los datos continúan siendo elevados:

"The impact of these efforts has been seen in the reduction of the inflation rate during the year and: annual inflation fell to $7.4 \%$ in June 2013 and $7.9 \%$ in November 2013, in contrast to 39.2\% in November 2011 and 15.6\% in November 2012" (Zerihun, Kibret y Wakiaga, 2014, pág,6 ). 
De los datos se puede desprender una serie de conclusiones. La primera y más importante es que pese al desarrollo económico y al crecimiento del sector secundario y terciario Etiopía sigue siendo en la actualidad un país esencialmente rural y en el que la economía se basa de una manera fundamental en la agricultura, además nuestra experiencia en el país nos ha demostrado que la pequeña explotación agrícola-ganadera familiar es en la gran mayoría de los casos el pilar fundamental de la economía familiar. De hecho, todos los trabajadores de diversos sectores que hemos conocido combinaban su trabajo con la explotación del pequeño terreno familiar, viajando en ocasiones cientos de kilómetros hasta la localidad natal para ayudar en los momentos en los que era necesaria una mayor fuerza de trabajo.

Esta situación es tan evidente que el gobierno otorga vacaciones tanto escolares como laborales en los momentos del año en los que se intensificaba la necesidad de trabajo en el campo como son los momentos de recolección de las cosechas y si no son suficientes estos días la población le da prioridad a las labores agrícolas sobre sus otros trabajos. Por ejemplo en Qillenso el inicio de la escuela se retrasó extraoficialmente un mes para que los niños y los profesores pudieran atender las necesidades de sus explotaciones familiares.

Por otra parte el crecimiento acelerado de estos últimos años esta beneficiando a un número limitado de personas, creando una mayor brecha entre las personas que están logrando beneficiarse de ello y las que están quedando al margen de este crecimiento, las cuales están viendo un empeoramiento relativo de su situación social y económica al quedarse al margen de los beneficios del crecimiento económico pero al tener que asumir sus consecuencias negativas como el aumento de los precios.

Por último este crecimiento se esta realizando a expensas del medio ambiente y de los derechos de ciertos grupos étnicos. 


\subsection{SITUACIÓN SOCIAL Y DEMOGRÁFICA}

Etiopía es el segundo país más poblado de África, con elevados niveles de fertilidad y un rápido incremento en la tasa de nacimientos. Las tasas de planificación familias en mujeres etíopes en edad reproductiva es inferior a la de la mayoría de países del África subsaharia. Es también uno de los países con una mayor tasa de mortalidad materna e infantil del África Subsahariana (Ko et al., 2010; Mohammed, Woldeyohannes, Feleke, y Megabiaw, 2014).

La población etíope se estima en 2013 en unos 93.877 .025 habitantes (www.cia.gov.). Sin embargo, los datos más exactos disponibles son los que aporta el censo llevado a cabo en 2007 que situaban la población en 73.800,000 en ese momento. Como ya hemos expuesto anteriormente, Etiopía es un país principalmente rural, teniendo solo un $17 \%$ de la población viviendo en zonas urbanas y con una tasa de urbanización estimada para el periodo de 2010 a 2015 en un 3,57 anual (www.cia.gov). La población etíope tiene un alto índice de crecimiento anual y durante el último siglo el número de habitantes del país ha aumentado de una manera muy marcada, los datos que aportan los tres únicos censos realizados en el país a este respecto son los siguientes:

"The population has increased steadily over the last three decades, from 42.6 million in 1984 to 53.5 million in 1994 and 73.8 million in 2007. There were slight declines in the population growth rates over these periods, from 3.1 percent per annum in 1984 to 2.9 percent in 1994 and 2.6 percent in 2007" (Central Statistical Agency, 2012, pág 3 ).

Estos datos oficiales reflejan una desaceleración del crecimiento demográfico pero en nuestra experiencia personal varias personas occidentales nos comentaron que los datos que ofrece el gobierno etíope sobre población tienden a revisar el número real de habitantes a la baja y que no se suele registrar a los recién nacidos, lo que dificulta tener un conocimiento real de la situación demográfica del país. Este último punto es confirmado por organizaciones internacionales como UNICEF: 
"In Somalia, Ethiopia, Malawi and Zambia, less than 20 percent of all births are registered. In Ethiopia and Tanzania, more than five times as many children are registered in urban areas than in rural areas" (www.unicef.org Recuperado el 12 de Diciembre de 2013 de: http://www.unicef.org/esaro/factsonchildren 5781.htm/).

Siguiendo los datos de UNICEF que sitúa el registro de niños en las zonas rurales cinco veces por debajo de las zonas rurales (www.unicef.org) y teniendo en cuenta que el $83 \%$ de la población vive en zonas rurales la cantidad de nacimientos no registrados y el efecto distorsionador que esto tiene sobre los datos oficiales de población es evidente. La estructura por edades de la población de Etiopía se caracteriza por la existencia de una población principalmente joven, un $44,4 \%$ de la población es menor de 14 años, mientras que un 49\% de la población se sitúa entre los 15 y los 54 años, esto deja solo un 6,7\% de la población mayor de 54 años en el país y una edad media de la población situada en los 17,5 años (www.cia.gov).

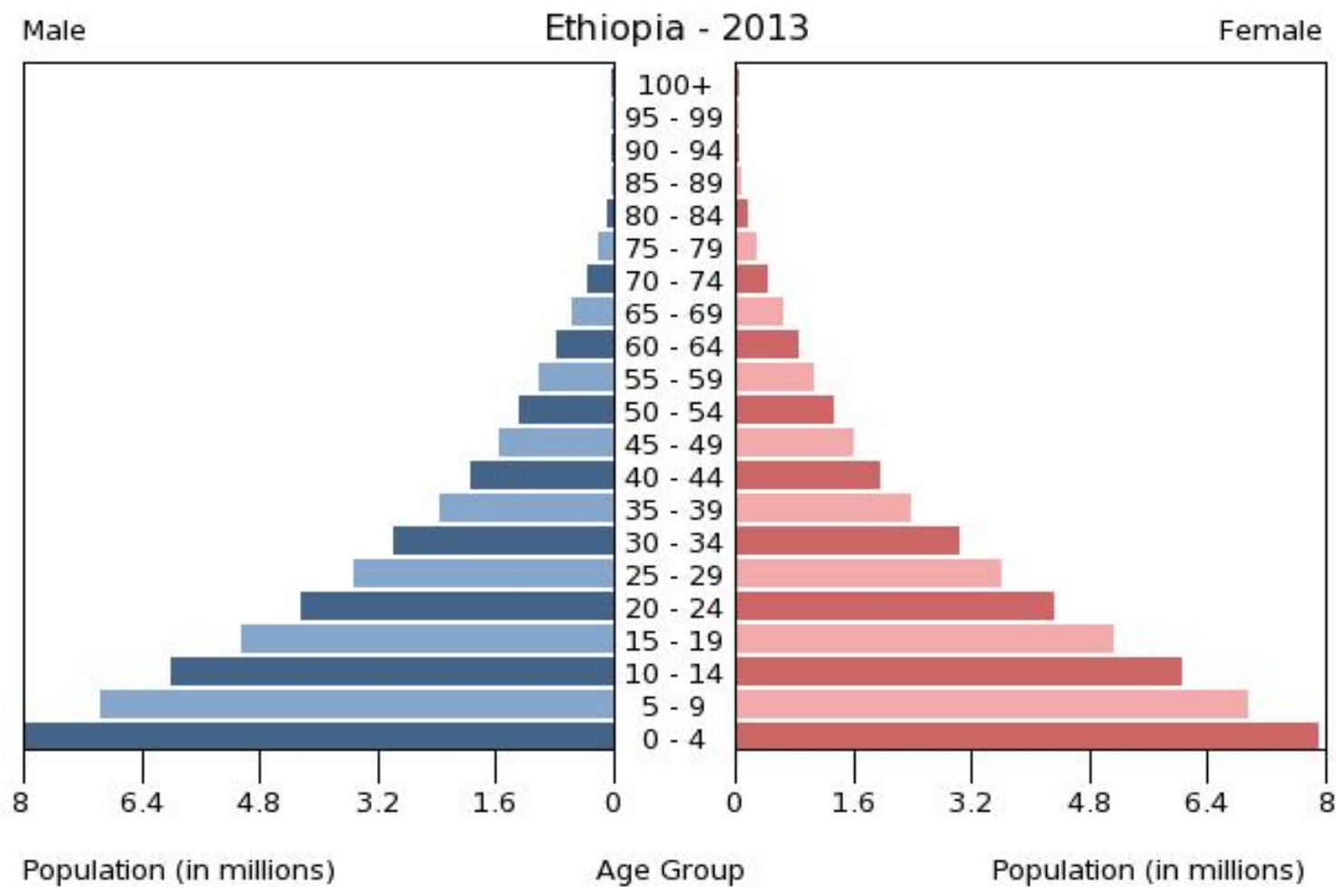

Figura 12. Pirámide poblacional de Etiopía en 2013

(Fuente: CIA)

La pirámide poblacional del país refleja esta realidad (véase Figura 12), dando como resultado una pirámide expansiva, características de los países 
subdesarrollados en las que hay unas altas tasas de mortalidad, natalidad, y un crecimiento natural alto, que en Etiopía son $8,87 / 1000$, 38,07/1000 y 2,9 \% respectivamente (véase: www.cia.gov).

La población etíope se divide en diversas etnias que conviven en el país como ya hemos expuesto anteriormente, la población que aportan cada una de estas 80 etnias al total de los habitantes del país varían de una manera enorme, desde etnias con decenas de millones de individuos a etnias que suman unos escasos miles de habitantes. La distribución étnica se refleja en la Figura 13.

\section{Distribución étinica}

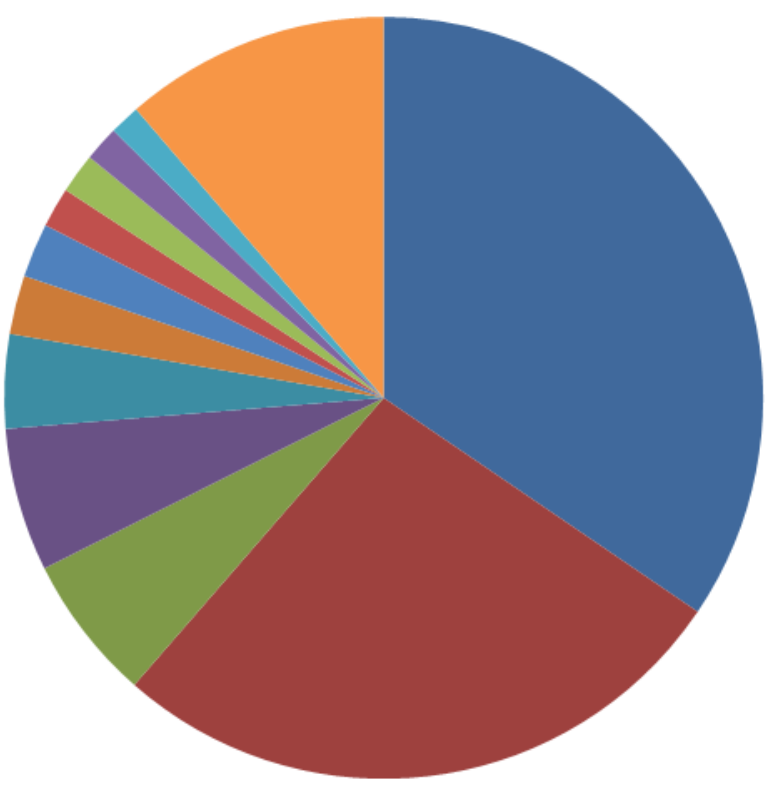

- Oromo: $34,5 \%$

Amhara: $26,9 \%$

- Somali: $6,2 \%$

- Tigray: 6,1\%

- Sidama: $4 \%$

- Gurage: 2,5\%

Welaita: $2,3 \%$

- Hadiya: $1,7 \%$

Afar: $1,7 \%$

- Gamo: $1,5 \%$

- Gedeo: 1,3\%

Otros: $11,3 \%$

Figura 13: Distribución étnica en Etiopía.

(Fuente: Elaboración propia. Datos: obtenidos www.cia.gov)

Debido a la gran diversidad étnica también hay una gran diversidad idiomática:

"The number of individual languages listed for Ethiopia is 89. Of these, 87 are living and 2 are extinct. Of the living languages, 30 are institutional, 12 are developing, 28 are vigorous, 12 are in trouble, and 5 are dying" (http://www.ethnologue.com/ Recuperado el 12 de Diciembre de 2013 de http://www.ethnologue.com/country/ET). 
El idioma oficial del gobierno federal es el amhárico que es el idioma propio de la etnia amhara a la que pertenecen gran parte de los miembros de las élites políticas, sociales y económicas del país como hemos expuesto anteriormente y que en mi experiencia personal pude observar que se había convertido en una lengua franca para el comercio, aunque en las regiones más aisladas gran parte de la población lo desconocía o solo sabía rudimentos básicos.

Personalmente pude observar cómo el amhárico se estaba asociando por los etíopes a la idea del desarrollo, ocurriendo que en ocasiones observé como algunos etíopes mantenían actitudes negativas hacia otros idiomas considerando hablar esos idiomas como sinónimo de subdesarrollo. Este tipo de ideas son fomentadas por el gobierno en su campaña para homogeneizar el país bajo estándares amharas, yo no tengo conocimiento de que se haga de manera oficial, pero a nivel de suelo es la realidad con la que me encontré.

A nivel regional existen otros idiomas que son reconocidos como lenguas oficiales en cada uno de los diferentes estados regionales, siendo el principal del ellos el Oromo, lengua materna de un $33,8 \%$ de la población (consúltese: www.cia.gov).

\subsection{SALUD Y DESARROLLO}

Etiopía es uno de los países más pobres del mundo, pese al ya comentado gran desarrollo económico del país sigue ocupando el puesto número 173 en el Índice de Desarrollo Humano elaborado por el Programa de las Naciones Unidad para el Desarrollo (PNUD) con una puntuación de 0.396 (véase Figura 14). 


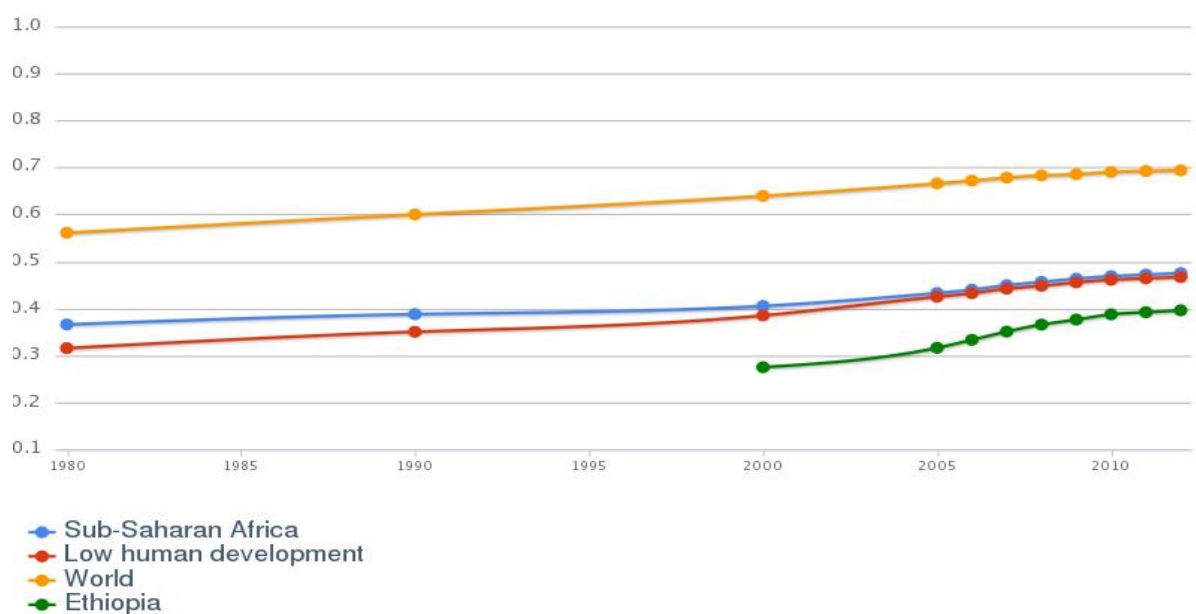

Figura 14. Evolución del IDH de Etiopía comparada con el África Subsahariana, los países con un IDH bajo y la media mundial

(Fuente: PNUD, 2013)

Otro problema importante se relaciona con el bajo estatus que tiene la mujer en Etiopía. Ello obstaculiza o directamente impide la utilización de diferentes servicios de salud (Sathiyasusuman, 2011). De ahí la importancia de promover información sobre salud mental, ofrecer una mayor preparación a los profesionales, así como incrementar los esfuerzos educativos y la confianza en ellos para hacer estos servicios disponibles (Sathiyasusuman, 2011).

\subsubsection{Objetivos de Desarrollo del Milenio}

Los ocho Objetivos de Desarrollo del Milenio fueron acordados por los 191 Estados Miembros de las Naciones Unidas con el fin de internar alcanzarlos en 2015:

"La Declaración del Milenio de las Naciones Unidas, firmada en septiembre de 2000, compromete a los dirigentes mundiales a luchar contra la pobreza, el hambre, la enfermedad, el analfabetismo, la degradación del medio ambiente y la discriminación contra la mujer. Los ODM, dimanantes de esa Declaración, tienen metas e indicadores específicos." (www.who.com Recuperado el 22 de Noviembre de 2013 de http://www.who.int/topics/millennium development goals/es/J. 
Estos ODM son una buena manera de conocer el desarrollo y situación social de un país, por tanto creemos interesante conocer la situación de Etiopía respecto a ellos para lograr una idea de la situación real de la vida diaria en el país.

El primer objetivo alude a la Erradicación de la pobreza extrema. En este sentido, Etiopía está avanzando en la reducción de la pobreza extrema de una manera significativa, pero actualmente todavía un 27,8 \% de la población vive bajo la línea de la pobreza:

"Recent data shows that the proportion of people living below the poverty line in Ethiopia has declined from $45.5 \%$ in 1995/96 to 27.8 in 2011/12 (GTP-APR MoFED, 2011/12). This represents a significant reduction of $38.9 \%$ over the last sixteen years." (Fuente: http://www.undp.org Recuperado el 20 de Noviembre de 2013 de: http://www.et.undp.org/content/ethiopia/en/home/mdgoverview/overview/mdg1 $\Delta$.

Los avances en este objetivo se están produciendo debido a las altas tasas de crecimiento que está sufriendo la economía del país, pero en nuestra experiencia de campo pudimos comprobar que la pobreza sigue estando muy presente en el día a día de la vida en Etiopía. Además gran parte de la población está quedando al margen de esta bonanza económica que esta provocando de manera colateral un incremento del coste de la vida muy significativo, con unas tasas de inflación muy elevadas como ya hemos señalado anteriormente. Algunos estudios lo atribuyen a un aumento del número de personas que viven bajo la línea de la pobreza del país que se sitúa en 0,6 US dólares por día y pronostican que la situación empeorará:

"Overall, the impact of rising consumer prices on expenditures in both rural and urban areas is non-negligible and leads to an estimated increase in the number of poor people of around 1.8 million. Much more, it is to be expected that the consumer price inflation between July 2010 and October 2011 led to a greater increase in both the depth (the average difference between the income of the poor and the poverty line) and the severity of poverty (i.e. the extent to which some of 
the poor are very far from the poverty line) in urban than in rural areas" (World Bank, 2012 pág. 23).

El segundo objetivo del milenio alude a lograr la enseñanza primaria universal. Al respecto, la educación primaria universal ha sido reconocida como una de las claves para conseguir el desarrollo de los países más pobres:

"Lograr el Objetivo relacionado con la educación servirá para promover el progreso de todos los demás objetivos del milenio. Educar a los niños y niñas contribuya a reducir la pobreza y promover la igualdad entre los géneros" (www.unicef.org Recuperado el 12 de Diciembre de 2013 de: http://www.unicef.org/spanish/mdg/education.html).

A nivel mundial las esperanzas de alcanzar este objetivo en 2015 son escasas (www.undp.org) pero Etiopía está cerca de conseguirlo:

"Ethiopia has done quite well in terms of meeting university primary education targets over the last decade and is on track to achieve this goal. The Net Enrolment Ratio (NER) in the lower primary school cycle (grade 1 - 4) increased from $77.5 \%$ in $2004 / 05$ to $92.2 \%$ in $2011 / 12$ and in the upper cycle of primary education (grade $5-8$ ) from $37.6 \%$ to $48.1 \%$ during the same period. Overall, the NER for primary education (Grade 1-8) increased from $77.5 \%$ in $2005 / 06$ to $85.4 \%$ in $2011 / 12$. The primary school attendance ratio has risen from $30.2 \%$ in $2000 / 01$ to $64.5 \%$ in 2010/11. The increase in attendance was disproportionately higher for children from rich families at $70 \%$ compared to $52 \%$ for children from poor families. ." (http://www.undp.org Recuperado el 20 de Noviembre de 2013 de: http://www.et.undp.org/content/ethiopia/en/home/mdgoverview/overview/mdg2 $\Delta$.

En nuestra experiencia de campo en la escuela de Qillenso pudimos comprobar que un patrón muy habitual era la asistencia discontinua a la escuela, habiendo años en que los niños no eran escolarizados para volver a ser escolarizados años después, por lo que el proceso de enseñanza-aprendizaje sufría interrupciones que repercutían negativamente en la educación de los niños. Creemos por tanto que los datos del PNUD sobre asistencia primaria universal 
ocultan una realidad no tan esperanzadora, ya que la calidad de la escolarización deja mucho que desear, y personalmente pude observar que el nivel de conocimientos educativos que los niños obtenían de esta educación era muy inferior al que oficialmente se reconoce.

Por otra parte también hemos observado niños que directamente no habían asistido a la escuela y otros que solo completaban el primer ciclo de educación primaria y abandonaban antes de continuar con el segundo ciclo de educación primaria, es más, en la zona eran mucho más habituales las escuelas que solo impartían el primer ciclo de educación primaria que las que impartían el segundo, que nos indica que la demanda real y las posibilidades de cursar todo el ciclo de primaria son realmente bajas.

Volviendo a los objetivos del milenio, el tercero alude a promover la igualdad entre los géneros y la autonomía de la mujer. En este sentido, en Etiopía la situación de la mujer respecto al hombre es de clara inferioridad, tradicionalmente la primacía masculina ha estado muy presente y todavía lo esta, por lo que en la vida diaria los hombres disfrutan de una posición de clara dominación sobre las mujeres, tanto económica como social. En nuestra convivencia y en las conversaciones que mantuvimos tanto con hombres como con mujeres etíopes pudimos constatar que la mentalidad tradicional que otorga una preponderancia al género masculino sigue estando muy vigente en la sociedad, manteniéndose en gran medida los roles de género tradicionales. Esta preponderancia masculina se ve reflejada en la actitud servil de la mujer, como pudimos observar en todos niveles socioeconómicos, tanto en ciudades como en las zonas rurales. Para luchar contra ello el gobierno etíope introdujo una ley que garantizaba la igualdad de mujeres y hombres, pero la tradición sigue marcando la realidad de la vida de las mujeres en muchos aspectos:

"For example, despite progressive laws introduced in the country, until recently women in Somali Region were barred by backward tradition from owning property without a male guardian"(UNICEF, 2012 pág. 20). 
Una de las causas de esta desigualdad entre los géneros reside en que los hombres en Etiopía siguen en manteniendo de manera general una posición dominante en la aportación de recursos económicos al hogar:

"Lack of assets makes women vulnerable to various forms of violence and affects her decision making power in the family. Although Ethiopian laws give equal property rights to women, in fact tradition and women's low social and economic status limits their ownership of assets." (Central Statistical Agency,2012, pág. 252)

En Etiopía el maltrato físico del hombre sobre la mujer es realmente muy común y existen determinadas situaciones en las que este maltrato es tolerado y justificado por muchas mujeres. En nuestra experiencia de campo pudimos constatar cómo entre los Guji en determinadas situaciones el maltrato físico sobre la mujer no solo no era condenado, sino que estaba bien visto socialmente e incluso se exigía al hombre que maltratara a su mujer para demostrar a esta última que realmente se preocupaba por ella y la quería.

A nivel nacional los estudios realizados en toda Etiopía y plasmados en la encuesta de demografía y salud de 2011 muestran que en al menos una de estas siguientes situaciones: Quemar la comida, discutir con el marido, desatender a los hijos o negarse a mantener relaciones sexuales, un $68 \%$ de las mujeres encuestadas justificaban el maltrato físico mientras que curiosamente solo un $45 \%$ de los hombres manifestaban aprobarlo. Los datos de la encuesta de 2011 muestran que a nivel nacional la justificación del maltrato es más elevada, tanto en hombres como mujeres, en los ambientes rurales y entre los etíopes con un nivel socio-económico más bajo. La educación también se muestra como un factor decisivo a la hora de la justificación del maltrato, cuanto menor es la formación más aceptación del maltrato sobre la mujere se da en hombres y mujeres. Una de las principales causas de esta falta de igualdad entre géneros es la menor presencia de mujeres en el sistema educativo. Así, aunque en el ciclo de primaria los datos han mejorado notablemente, en el ciclo de secundaria las distancias entre géneros son superiores:

"The gender disparity (ratio of girls to boys) in primary education has improved from 0.85 in 2006/07 to 0.93 in 2011/12 and from 0.59 in 2006/07 to 0.83 
in 2011/12 in secondary education. Gender disparity gets broadened as it goes to the higher education level. Gender disparities stand at 0.88 and 0.76 in secondary education first cycle (grade $9-10$ ) and second cycle (grade $11-12$ ), respectively in 2011/12" (http://www.undp.org Recuperado el 20 de Noviembre de 2013 de: http://www.et.undp.org/content/ethiopia/en/home/mdgoverview/overview/mdg3 $\triangle$

Una de las causas de esta menor atención de las chicas a la escuela secundaria son los matrimonios en la adolescencia que llegan a afectar, en algunas zonas del país al $58 \%$ de estas jóvenes:

"Early marriages, especially among children from rural and poor households, tend to inhibit educational progression among girls from primary to secondary level.[...] The number of girls being married by the age of 18 varies across regions, ranging from $12 \%$ in Addis Ababa to $58 \%$ in Beninshangul-Gumuz" (http://www.undp.org Recuperado el 20 de Noviembre de 2013 de: http://www.et.undp.org/content/ethiopia/en/home/mdqoverview/overview/mdq3 $\Delta$.

Esto es un ejemplo de cómo la mentalidad y las costumbres tradiconales siguen marcando la realidad del país, ya que la ley prohíbe los matrimonios de menores de 18 años:

"A new Federal Family Code, based on the principle of gender equality, came into effect in July 2000. It raised the minimum age of marriage from 15 to 18 years and established the rights of women to share any assets the household had accumulated if a couple has been living together for at least three years in an irregular union" (UNICEF, 2012 pág. 20).

El cuarto objetivo del milenio plantea reducir la mortalidad infantil. Según Oyekale (2014), en Etiopía aún queda un largo camino por recorrer al respecto, y es necesario continuar con los esfuerzos destinados a reducir la fertilidad materna y a mejorar la educación de las niñas (Oyekale, 2014). Esta situación es aún más negativa en la zona rural del país (Lakew, Reda, Tamene, Benedict, y Deribe, 2013; Lee et al., 2013). Se ha demostrado la importancia de educar a las parejas para 
mejorar su comunicación e implicación en la planificación familiar (Ko et al., 2010; Mohammed et al., 2014). En este sentido, la lucha contra la mortalidad infantil en Etiopía está arrojando en los últimos años unos resultados claramente positivos:

"In Ethiopia, under-five child mortality has substantially declined to $88 \mathrm{per}$ 1,000 live births in 2010/11 from 123 per 1000 live births in 2004/05, registering a 28.4\% reduction over the period of five years" (Fuente: http://www.undp.org Recuperado el 20 de Noviembre de 2013 de: http://www.et.undp.org/content/ethiopia/en/home/mdgoverview/overview/mdq4 $\triangle$.

Aunque el descenso a nivel global es evidente, hay factores que influyen determinantemente en el nivel de este descenso, manteniéndose en algunos lugares los niveles de mortalidad infantil muy elevados mientras que en otros las tasas de mortalidad infantil han sufrido un desplome. Estos factores son el nivel de ingresos de la familia, el lugar de residencia y el nivel educativo de la madre (www.undp.org). El nivel de ingresos familiares afecta significativamente a la alimentación y los cuidados que reciben los niños. Es por lo tanto un factor determinante del nivel de mortalidad de los niños menores de cinco años:

"According to the result of EDHS conducted in 2010, the under-five mortality rates are higher among children from poor families than those from more prosperous families. For example, under-five mortality rate amongst the children from the richest quintile is only 86/1000 live birth compared to 137/1000 lives for children from the poorest quintile." (Fuente: http://www.undp.org Recuperado el 13 de Diciembre de 2013 de: http://www.et.undp.org/content/ethiopia/en/home/mdgoverview/overview/mdg4 $\Delta$.

La educación que ha recibido la madre se ha mostrado como uno de los factores más determinantes a la hora de reducir la mortalidad infantil:

"As expected, mother's education is inversely related to a child's risk of dying. Under-five mortality among children born to mothers with no education (121 per 1,000 live births) is 2.6 times as high as that of children born to mothers with secondary education (46 per 1,000 live births) and more than five times as high as 
that of mothers with more than a secondary education (24 per 1,000 live births)" (Central Statistical Agency,2012, pág.113).

EI PNUD siguiendo los datos del EDHS también afirma que los niños nacidos en zonas rurales tienen menos posibilidades de sobrevivir que los nacidos en entornos urbanos:

"There are significant variations between rural and urban settings with UMR in urban area estimated at 83/1000 compared to 114 in rural areas" (Fuente: http://www.undp.org Recuperado el 13 de Diciembre de 2013 de: http://www.et.undp.org/content/ethiopia/en/home/mdgoverview/overview/mdg4 $\Delta$

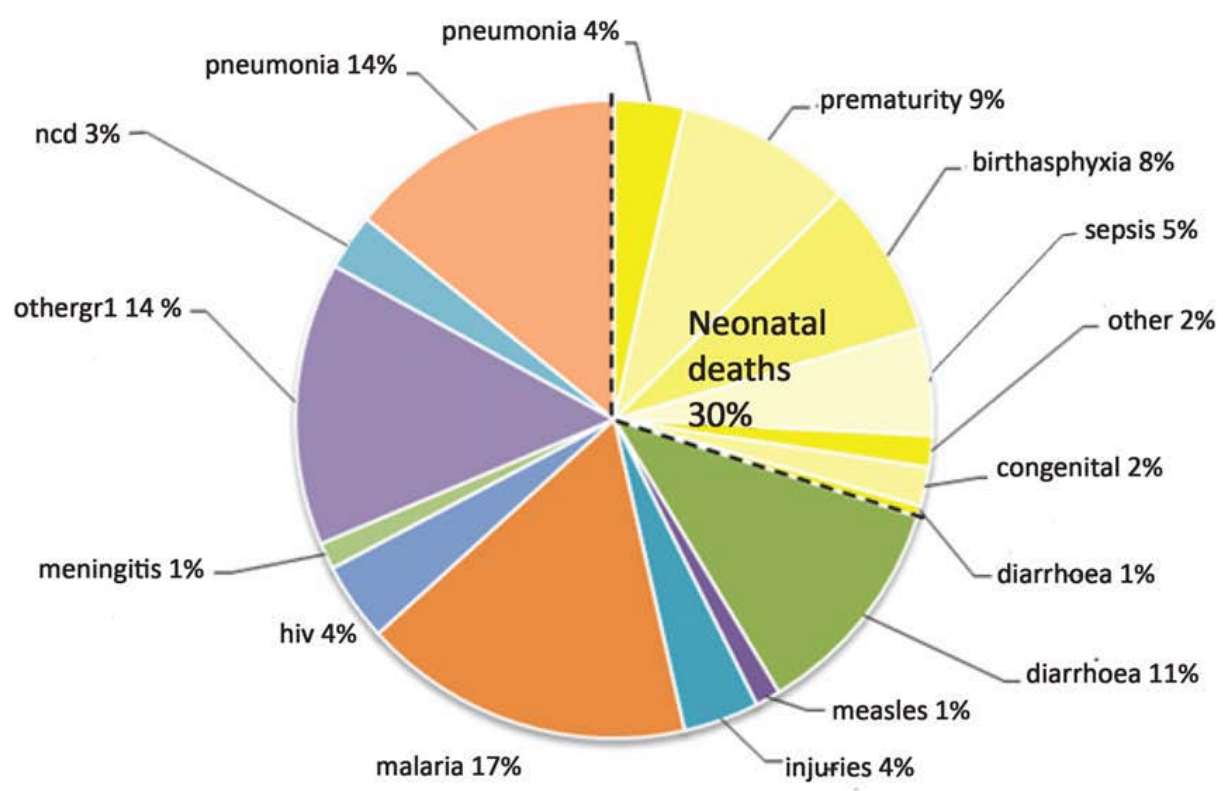

Figura 15: Grafica de las causas de la mortalidad de menores de cinco años en África

El éxito de este descenso en la mortalidad infantil tanto UNICEF como el PNUD lo atribuyen de manera determínate a la implantación de programas de extensión de la asistencia médica:

"The health extension programmes and the expansion of health facilities have played a significant part in reducing child mortality rates in Ethiopia over the last decade" (Fuente: http://www.undp.org Recuperado el 13 de Diciembre de 2013 de:

http://www.et.undp.org/content/ethiopia/en/home/mdgoverview/overview/mdg4 $\Delta$. 
"There has been a significant acceleration in mortality reduction since the introduction of the HEW programme in 2005" (UNICEF, 2012 pág. 35).

Aunque la situación ha mejorado notablemente, todavía hay una serie de medidas que tras su implementación podrían hacer descender mucho más aún la mortalidad infantil en Etiopía:

"The biggest returns will be due to community-based case management of pneumonia, provision of ORS - oral rehydration salts-, exclusive breastfeeding, hand washing, improved sanitation and skilled care because the current coverage of these high, impact interventions is still quite low. Although not featured in the analysis, reduction of malnutrition will also have a major effect since it is an underlying cause of more than half of under-five deaths" (UNICEF,2012, pág. 35).

Pese a todas las mejoras la situación sigue siendo muy mejorable, ya que en 2010 se calculaba en 120.000 el número de niños que morían en Etiopía con menos de un mes (UNICEF, 2012).

Retomando los objetivos del milenio, el quinto alude a mejorar la salud maternal. Debido a la alta natalidad en Etiopía la salud materna es uno de los problemas más acuciantes a los que se enfrenta el país, personalmente fuimos testigos de situaciones en nuestra experiencia de campo que dejaban ver la precaria situación de las madres en el país, la mayoría de los partos se siguen llevando a cabo en casa y solo en caso de complicaciones se acude al médico:

"Ten percent of births in Ethiopia are delivered at a health facility-9 percent in a public facility and 1 percent in a private facility. Nine women in every ten deliver at home" (Central Statistical Agency, 2012 pag. 126).

Esto empeora en las zonas rurales en las que es mucho más difícil obtener atención médica y las costumbres tradicionales están más arraigadas:

"Urban births are notably more likely than rural births to be delivered in a health facility (50 percent versus 4 percent). The percentage of births delivered in health facility ranges from less than 10 percent in SNNP, Affar, Oromiya, Somalia, and Benishangul-Gumuz regions to 82 percent in Addis Ababa" (Central Statistical Agency,2012, pág. 126). 
En cuanto al tipo de asistencia que las madres reciben durante el parto, las costumbres tradicionales siguen estando muy presentes, recibiéndose asistencia de profesionales tan solo en un $10 \%$ de los casos, teniendo un gran peso todavía la asistencia familiar y tradicional:

"Ten percent of births were assisted by a skilled provider-4 percent by a doctor and 7 percent by a nurse or midwife. Less than 1 percent of births were assisted by a HEW, and 57 percent of births were assisted by a relative, or some other person. Twenty-eight percent of births were assisted by a traditional birth attendant, while 4 percent of births were unattended" (Central Statistical Agency, 2012, pág. 127).

La creencia de que no es necesaria la intervención médica para dar a luz junto con el peso de la tradición constituyen algunos de los factores que más influyen a la hora de elegir no acudir a un centro de salud para dar a luz. A ello se ha de añadir la dificultad de asistir a un centro de salud en algunas zonas:

"[...]more than six women in ten (61 percent) stated that a health facility delivery was not necessary, and three in every ten (30 percent) stated that it was not customary. Fourteen percent of women said that the health facility was either too far or that they did not have transportation. Rural woman were more likely than urban women to report that health facility deliveries are not customary, at 31 percent versus 17 percent, or that health facilities were too far or they had no transportation, at 15 percent versus 8 percent" (Central Statistical Agency,2012, pág. 128).

Para empeorar aún más la situación, las madres que deciden asistir a centros de salud, sobre todo en zonas rurales se encuentran con falta de recursos o de preparación del personal sanitario:

"Health facilities are often unable to offer quality services to women during childbirth. Health extension workers often lack the required skills, related to maternal and newborn care and do not respond to emergencies at night nor on weekends. Recent surveys indicate that 68 per cent of the health facilities with childbirth services charge a fee or require women to buy supplies for a normal delivery" (UNICEF, 2012 pág. 36). 
Todas estas características y situaciones tienen su reflejo en los datos en las tasas de mortalidad maternal, que sitúan a Etiopía muy lejos de la consecución del ODM en 2015:

"Ethiopia has one of the highest rates of maternal mortality in Africa. Progress on reducing maternal mortality has stalled since 2005 when the country managed to reduce maternal mortality rate (MMR) to 676 per 100,000 births in 2010/11 from 871 in 2000/01. This means that with the MDG target of 267 per 100,000 births by 2015 , the country is clearly off-track on goal five" (http://www.undp.org Recuperado el 20 de Noviembre de 2013 de: http://www.et.undp.org/content/ethiopia/en/home/mdgoverview/overview/mdg5 $\Delta$.

En nuestra experiencia de campo fuimos testigos del transporte de una mujer embaraza a punto de dar a luz en una moto junto al marido y al conductor camino de la clínica de un pueblo cercano ya que se había complicado el parto y no lo podía llevar a cabo en casa. Cuando preguntamos a algunos de nuestros informantes etíopes sobre cómo daban sus mujeres a luz, todos me contestaron que solo en caso de problemas sus mujeres habían ido o irían al hospital y que lo normal era que dieran a luz en casa. En el año de presencia en Qillenso todos los partos de los que tuvimos noticia se realizaron en casa y con la asistencia de familiares o personal tradicional. También pudimos observar la existencia de niñas muy jóvenes que ya eran madres. Esta maternidad temprana no solo tiene riesgos de salud sino que también, y centrándonos específicamente en el tema de esta investigación, afecta significativamente a la calidad de vida, al desarrollo social, personal y a la escolarización de las madres adolescentes:

"Teenage pregnancy is a major health concern because of its association with higher morbidity and mortality for both mother and child. Childbearing during the teenage years frequently has adverse social consequences as well, particularly on educational attainment, because women who become mothers in their teens are more likely to curtail their education" (Central Statistical Agency,2012, pág. 79). 
El sexto objetivo del milenio plantea Combatir el VIH/SIDA, el paludismo y otras enfermedades. Al respecto, las enfermedades contagiosas son una de las causas del subdesarrollo, ya que cargan a los países con una tasa de morbilidad que lastra sus posibilidades de desarrollo y consume los exiguos recursos sanitarios de estos países, además enfermedades como la malaria provocan una elevada mortalidad infantil. En la lucha contra la malaria se han producido campañas de distribución de mosquiteras impregnadas de insecticida que han reducido notablemente el número de muertes de niños:

"The Ethiopia National Malaria Indicator Survey (2007) showed that malaria-related deaths fell by 55 per cent nationally, in-patient admissions related to malaria went down by 54 per cent and 14,000 child deaths related to malaria were prevented during 2006 and 2007. Forty two per cent of children under five slept under a bed net the night before the survey" (UNICEF, 2012, pág. 36).

Durante el trabajo de campo pude observar que la utilización de mosquiteras en zonas endémicas de malaria no estaba especialmente extendida y que muchos etíopes no sentían una especial preocupación por esta enfermedad. También se apreciaba la elevada prevalencia de algunas enfermedades que en España están erradicadas o son extremadamente raras, o como problemas de salud que en Occidente no son especialmente peligrosos, allí podían costarte la vida, también observamos un miedo a enfermar en muchos etíopes. Por otro lado, en el campo específico de la lucha contra el VIH, Etiopía ha conseguido grandes logros:

"Ethiopia has achieved significant progress towards meeting these targets and it is estimated that HIV/AIDS prevalence amongst the adult population has dropped to $1.5 \%$ in $2010 / 11$ (EDHS, 2011) against the MDG target of 2.5\%, indicating that the country has more than achieved this target2. Malaria control and prevention is one of the core interventions of the country's primary health care system" (http://www.undp.org Recuperado el 20 de Noviembre de 2013 de: http://www.et.undp.org/content/ethiopia/en/home/mdgoverview/overview/mdg6 $\Delta$. 
En este apartado sobre las enfermedades nos parece conveniente hacer una pequeña referencia a las enfermedades mentales, ya que observamos cómo una gran cantidad de personas con enfermedad mental o con discapacidad intelectual eran abandonados en los hospitales de misioneros y misioneras de las distintas creencias y congregaciones religiosas. Muchos otros con estas condiciones vivían de la mendicidad en las calles de las grandes ciudades y cuando una familia decidía cuidar de estas personas en su casa normalmente eran escondidas como algo vergonzante. Tan solo en una ocasión pude observar a un joven con discapacidad intelectual que era llevado a reuniones públicas por su familia y que era protegido por los otros jóvenes de la comunidad. Esta situación es debida a que gran parte de la población etíope asocia las enfermedades y discapacidades intelectuales a la existencia de espíritus, posesiones, o al castigo divino. En la ciudad de Adoola en la zona Guji pude observar como todas las semanas un pastor protestante realizaba exorcismos y como las monjas de Madre Teresa de Calcuta se encargaban de decenas de enfermos mentales abandonados por sus familias. En Addis Ababa y en otras ciudades había también una gran cantidad de enfermos mentales en los que el consumo de una droga legal tradicional, el "khat", parecía que había sido el detonante de su enfermedad, y lo más importante, la gente asociaba el consumo del "khat" al origen de los problemas de esas y otras personas, con lo que se producía una asociación generalizada de enfermedad mental a drogadicción.

Continuando con los objetivos del milenio, el séptimo objetivo plantea Garantizar la sostenibilidad del medio ambiente. Este ODM se divide en cuatro subobjetivos principales en cada uno de ellos los progresos han sido distintos, pero uno de es fundamental a la hora de entender la calidad de vida que disfrutan los etíopes: El acceso a agua potable y a servicios básicos de saneamiento:

"With respect to access to safe drinking water, the review shows that the percentage of households with access to improved and safe drinking water has more than doubled over the last five years and reached 58.25\% in 2011/12 [...] Rural and urban sanitation coverage improved from $60 \%$ and $80 \%$ in $2010 / 11$ to $64 \%$ and $86 \%$ in 2011/12, respectively. Likewise, the national sanitation coverage has 
increased from 63\% in 2010/11 to 67\% in 2011/12" (http://www.undp.org Recuperado el 20 de Noviembre de 2013 de: http://www.et.undp.org/content/ethiopia/en/home/mdgoverview/overview/mdg7 $\Delta$.

En nuestra experiencia de campo pudimos observar cómo en la mayoría de las zonas rurales el agua potable se obtenía de pozos situados en espacios públicos y las casas no disponían de servicio de agua corriente, además el agua necesitaba ser hervida para evitar riesgos para la salud. Diariamente veía a mujeres y a niñas cargando con grandes garrafas amarillas a la espalda en las que transportaban el agua para la familia. El medio ambiente etíope esta sufriendo una clara degradación. Según Waktola (2009), la falta de educación ambiental en los currículos de los maestros es uno de los factores que contribuye a explicar la degradación ambiental que se está experimentando en el país (Waktola, 2009), dado que unos maestros no formados en estos aspectos, tampoco pueden a su vez formar a sus alumnos.

Así pues, Addis Abeba es una ciudad muy contaminada, los grandes lagos del país también sufren una gran contaminación y hay un proceso de deforestación en todo el país:

"Ethiopia has experienced massive deforestation. From a baseline of perhaps $40 \%$ forest cover in the 16th century, the country is down to $4.6 \%$, a result of $0.8 \%$ deforestation a year. Pressure on forests comes from a rapidly growing population - 85 million - with over $80 \%$ living in rural areas, relying on rain-fed agriculture. The 70 million livestock put pressure on land and forests" (Tran, www.theguardian.com Recuperado el 5 de diciembre de 2013 de: http://www.theguardian.com/global-development/2013/apr/15/ethiopia-forestcommunities-reverse-deforestation).

El gobierno está intentado paliar con programas de reforestación, incentivando la participación de las comunidades locales y fomentando la explotación sostenible del bosque: 
"In Bale, forest communities have been taught to grow coffee and bamboo and to become bee-keepers. Of the 23,000 households (an average of five people per household) covered by the Bale project, about 3,500 have taken up these activities" (Tran, www.theguardian.com Recuperado el 5 de diciembre de 2013 de: http://www.theguardian.com/global-development/2013/apr/15/ethiopia-forestcommunities-reverse-deforestation).

Durante nuestra estancia en el país fuimos testigos de una reunión entre miembros de la Cooperación de la UE, técnicos del ministerio de agricultura, miembros del gobierno regional y local y líderes comunitarios para abordar la implementación de uno de estos proyectos en la zona de Qillenso. Personalmente fui invitado a asistir a la reunión ya que ésta tuvo lugar en el patio de nuestro colegio. En dicha reunión puede observar que el proyecto iba con gran retraso y había bastantes problemas a la hora de su ejecución, sobre todo debido a las dudas de cómo explotarlo económicamente de forma viable y evitar la tala ilegal de los árboles de dicho proyecto. En esta reunión pude observar cómo los técnicos extranjeros no entendían la importancia de la cultura tradicional a la hora de implantar el proyecto ya que realizaban peticiones sin sentido cultural, como por ejemplo, intentar que las mujeres tomaran parte en actividades que estaban reservadas para los hombres y viceversa. En otros casos pedían a los granjeros que no talaran los árboles que surgieran en sus tierras de labranza sin comprender que al haber dos cosechas al año no daba tiempo a que los arboles crecieran, como los propios granjeos señalaron. Por otra parte durante nuestra estancia en la zona de Qillenso pudimos observar que la población local necesitaba una gran cantidad de madera y que era una de las materias primas que más deseaban y a la que mayor valor otorgaban. Ésta alcanzaba un elevado precio y era constante el ruido que la tala de árboles producía en la zona.

Para finalizar, el octavo objetivo del milenio se relaciona con el fomento de una alianza mundial para el desarrollo. En este sentido, como señaláramos previamente, Etiopía sigue siendo en la actualidad uno de los países más subdesarrollados del mundo pese al espectacular crecimiento económico que ha 
experimentado el país en los últimos años. El PNUD le otorga un índice de desarrollo humano de 0.363 situando al país en la posición 174 en el ranking mundial. Debido a esta situación de subdesarrollo en este Objetivo del Milenio Etiopía se muestra como un claro receptor de ayuda internacional para el desarrollo, aunque hay países con una mejor situación económica que están recibiendo un nivel de ayudas superior:

"The flow of Official Development Assistance (ODA) to Ethiopia reached USS 2,617.9 million and accounted for approximately $11 \%$ of the country's national budget in 2011/12. While this amount of ODA appears to be large in absolute terms and in comparison to many countries in sub-Saharan Africa, Ethiopia's per-capita ODA is only US\$31.5 compared to US\$52.16 average for Sub-Saharan Africa" (Fuente: http://www.undp.org Recuperado el 10 de Diciembre de 2013 de: http://www.undp.org/content/ethiopia/en/home/mdgoverview/overview/mdg8/).

Al mismo tiempo, en estos últimos años el país ha experimentado un fuerte crecimiento interno, se ha incorporado en mayor medida al comercio internacional y ha creado una mayor base económica como este octavo objetivo promueve para obtener un mayor nivel a desarrollo mundial:

"La globalización brinda oportunidades para el desarrollo cuyo aprovechamiento requiere que en el diseño de las estrategias nacionales se tomen en cuenta las posibilidades que ofrece y los requisitos que exige una mayor incorporación a la economía mundial" (Fuente: www.undp.org Reuperado el 10 de Diciembre de 2013 de: http://www.undp.org/content/undp/es/home/mdgoverview/mdg goals/mdg8/J.

En política exterior Etiopía se ha mostrado como un firme aliado de los EEUU y mantiene una estrecha colaboración en la lucha contra el terrorismo de Al-Qaeda:

"First, under Meles, Ethiopia became a staunch ally of the United States (US), by far (alongside the United Kingdom) the country's largest bilateral donor. Second, the country hosted US bases with their complement of drones for patrolling Somalia and to combat terrorist organisations" (Tijurimo, 2013, Recuperado el 10 de Diciembre de 2013 en http://www.saiia.org.za/opinion-analysis/ethiopiasforeign-policy-one-year-after-meles-zenawi-an-opportunity-for-transformation). 
Al mismo tiempo, el país está jugando un papel fundamental en la estabilidad del Cuerno de África, aportando tropas en misiones de paz en Somalia y participando en las negociaciones de paz entre Sudan del Norte y Sudan del Sur. (Tijurimo, 2013, en: http://www.saiia.org.za/opinion-analysis/ethiopias-foreignpolicy-one-year-after-meles-zenawi-an-opportunity-for-transformation)

En definitiva la situación política, económica y social de Etiopía se encuentra en un momento clave; los graves problemas internos como la falta de democracia real, los problemas étnicos, el crecimiento económico desigual -del que algunas capas de la población se están beneficiando enormemente mientras que grandes masas de población obtienen muy pocos beneficios o incluso son perjudicadas-, la necesidad de seguir avanzando en aspectos de desarrollo social como la extensión de la educación y la mejora de su calidad o la lucha contra enfermedades son problemas que condicionan gravemente el día a día de la vida de los etíopes.

Estas situaciones que azotan al país pese a los últimos años de crecimiento económico sitúan a Etiopía en un punto de inflexión, ya que de no darles solución, los problemas seguirán aumentando y pueden poner en peligro tanto el desarrollo del país como su estabilidad. A esto hay que añadir la incertidumbre creada tras la muerte de Meles Zenawi, que dirigió los designios del país durante 21 años. Y con la vista puesta en las siguientes elecciones de 2015 la solidez interna del partido y su habilidad para seguir manteniendo el control sobre el aparato del Estado junto con la evolución de la oposición van a ser fundamentales a la hora de ver qué camino toma Etiopía. 


\section{CAPÍTULO 2. LOS OROMO: HISTORIA, CULTURA Y ECONOMÍA}

Aunque en el capitulo anterior ya se hizo referencia a la historia del pueblo Oromo, creemos necesario realizar una pequeña exposición de la historia de los Oromo en particular para facilitar la compresión y entender el proceso histórico por el cual los Oromo en general y los Guji en particular han pasado y les ha marcado, hasta la actualidad.

\subsection{INTRODUCCIÓN}

Los Oromo son una de las distintas etnias que habitan la zona del Cuerno de África, a su vez esta dividida en una serie de subtribus independientes pero que conservan unas características culturales comunes y tienen una serie de dialectos muy similares que conforman en su conjunto la lengua oromo, llamada Afan Oromo. Su extensión geográfica por varios paises del cuerno de África como Etiopía y Kenia y su gran número hacen que sean considerados uno de los grandes grupos nacionales de África.

Los Guji, son una de estas ramas y son considerados, junto a los Oromo Borana, una de las ramas Oromo más antiguas y que conserva hasta la actualidad su cultura tradicional de una forma más intensa (Legesse, 2006). Todos los Oromo se consideran descendientes de un antepasado mítico común (Orma) del que toman el nombre y, según su mito fundacional, cada uno de los subgrupos que conforman la "nación" Oromo es descendiente de los distintos hijos de este antepasado común mítico.

Es difícil conocer la historia real de este pueblo debido a la escasez de las fuentes históricas y a la falta de evidencias arqueológicas. Además en mucha de la historiografía más ampliamente difundida se ha ofrecido tradicionalmente la visión de que los Oromo son un pueblo de habla cusítica que invadió el Imperio etíope en 
el Siglo XVI durante una gran migración provocando una gran devastación (Legesse, 2006). Sin embargo, las investigaciones más actuales demuestran la presencia de los Oromos en el territorio de la actual Etiopía en épocas mucho más tempranas y ofrecen un visión de los Oromo como un pueblo originario de Etiopía, en vez de como un pueblo invasor a (Melbaa, 1999). A su vez muchas de las fuentes escritas disponibles tienen el problema de no poderse conocer hasta qué grado son fiables, ya que muchas de ellas están escritas por monjes o historiadores de palacio Amhara y son claramente sesgadas en contra de los Oromos, como indica Legesse (2006):

"There are many traditional Abyssinian historian such as Aleqa Tayye Gebre-mariam or Blatta Heruy Wolde-Sellassie, whose thoughts are direct reflection of the dominant culture. They have discussed Oromo history in the context of Ethiopian and their perspective falls squarely at the base of the intellectual tradition we are examining here" (Legesse, 2006, pag. 4).

Pese que a los Oromo son "conscientes de su origen común", en realidad las tribus se organizaron tradicionalmente de manera independiente y desde hace siglos hasta la actualidad han guerreado entre ellas y muestran claras diferencias unos y otros. La lealtad de un Oromo está por encima de todo ligada a su propia tribu y no al conjunto de la "nación Oromo", aunque en presencia de peligros externos se hayan unido contra ellos. En la actualidad el nacionalismo Oromo puede responder más a un movimiento de reacción ante la conquista y colonialismo por parte de la monarquía amhara tras la subyugación de los distintos reinos Oromo. Así, a continuación distinguiremos entre: (1) Origen y periodo arcaico; (2) Periodo de expansión y asentamiento; (3) Conquista por parte del poder central; (4) Democracía y autonomía)

\subsection{HISTORIA DE LOS OROMO}

\subsubsection{Origen y periodo arcaico}

Este es el periodo más difícil de conocer debido a la falta de fuentes escritas y a la práctica inexistencia de restos arqueológicos. En muchas fuentes historiográficas tradicionales se ha llegado a asegurar que los Oromo no eran 
originarios de la zona del cuerno de África. Por ejemplo, Alaqa Taye que afirmaba que los Ormo provenían de Asia, de la cual emigraron hasta Madagascar y de allí a Etiopía entrando por Mombasa en el continente africano durante los siglos XIV y XVI (Melbaa, 1999). Otras fuentes van más allá y otorgan a los Oromo un carácter subhumano al afirmar que los Oromo tienen su origen en el propio agua:

"Other referents to the Oromo in textbooks of Amharic literature often painted them as cowardly, uncouth, uncivilized, etc., group. When this is added to the theory of a recent aquatic birth of the people, the image of a sub-human category is unmistakable" (Lata, 1999, pág. 181).

Las fuentes más fiables como Legesse o Levine señalan que el origen real de los Oromo se sitúa en la zona sur-este montañosa de la actual Etiopía, alrededor de las montañas Bale. A estas fuentes se unen los relatos de algunos misioneros y viajeros europeos que recogen en sus obras tradiciones orales tanto amháricas como de los Oromos, y que sitúan la presencia de los Oromo en Etiopía en fechas muy anteriores al Siglo XVI:

"The chroniclers and Abyssinian traditionalists mention, for the first time, the presence of a fraction of Oromo of the Arsi tribe in the ancient Kingdom of Bali, as well on the right Banks of the Awash, as a kind of shepherds of the crown. That was in the first century of our era; and their history, up to the $X V^{\text {th }}$ century is lost in the unknown" (de Salviac,2005, pág. 39).

Curiosamente este misionero francés de principios del Siglo XX señala de esta manera el problema con el cual se siguen encontrando los investigadores que centran sus estudios en el pueblo Oromo. Esta localización de la cuna de los Oromo señalada por las pocas fuentes disponibles coincidiría con las tradiciones orales de los Borama y de los Guji, considerados los pueblos Oromo que conservan una cultura ancestral de manera más viva y que se reconocen a sí mismos como los pueblos originales de la nación Oromo, que no recogen procesos de emigración y movimientos de población hacia el norte como sí que hacen las tradiciones de otras tribus. 
Además como ya expusimos en el capítulo anterior el descubrimiento por parte de Lynch y Robbins (1978) de un yacimiento datado en el 300 antes de Cristo en el norte de Kenia al que se atribuye la función de regular el calendario lunar Oromo, es otra prueba de la presencia del origen en el este de África de este pueblo. Estas tradiciones orales junto a los restos arqueológicos encontrados por indicarían que los Oromo llevan asentados en la zona sur de Etiopía desde bastante antes de lo que afirman las fuentes tradicionales amháricas, con lo que quedaría desacreditado uno de los argumentos más usados en contra de los Oromo: que son unos "recién llegados" a Etiopía.

De la cultura y modo de vida Oromo en estos momentos de su historia se tienen muy pocos datos, pero investigadores como Levine apuestan por un posible modo de vida agrícola que fue transformándose en un modo de vida pastoral y nómada:

"Although it is likely that the Oromo had earlier followed a primitive agricultural style, perhaps on the Bale plateau, at the time of their great expansion they were nomadic pastoralists" (Levine, 2000, pag.78).

\subsubsection{Expansión y asentamiento en nuevos territorios}

Aunque las causas de la expansión de los Oromo a partir del Siglo XVI son desconocidas, varios autores como Levine (2000) o Henze (2000) apuntan algunas ideas de estas mismas. Podríamos distinguir las razones de esta expansión o migración entre las causas externas que dieron la oportunidad a los Oromo para expandirse y las causas internas que motivaron a los Oromo a buscar nuevos territorios. Entre las causas externas, la más importante es el agotamiento que tanto los reinos cristianos como los sultanatos musulmanes sufrieron tras las guerras del Grang, situación que daría la oportunidad a los Oromo de avanzar sobre los territorios de unos estados que se encontraban debilitados tras la lucha:

"Grang's invasion and the fighting which followed between the Christians and Muslims opened the way for the great migration of the Oromo" (Henze, 2000, pág. 90). 
Entre las causas internas, Levine señala dos detonantes principales, uno seria un supuesto aumento de población, con el consiguiente aumento de la presión demográfica y la necesidad de buscar nuevos recursos. El segundo detonante sería intrínseco a la cosmovisión de los Oromo, la necesidad cultural de llevar a cabo guerras contra un enemigo de manera periódica:

"Their expansion was triggered by two motives: a need to carry out ritually prescribed military expeditions against enemies and a search for new land to accommodate a rapidly growing population" (Levine, 2000 pág. 79).

Otros autores atribuyen esta necesidad de expansión a la estructura familiar de los Oromo:

"This process of colonization seems to have been linked to the structure of authority and inheritance within the Boran family, witch was based on strict primogeniture and associated with considerable rivalry between brothers. After their conquest as warriors, eldest sons tended to return to the Borana homeland, eventually to take up their inheritance, while younger sons tended to establish themselves within the conquest areas, mending their fortunes and resolving tensions within the family by means of this migration" (Kurimoto y Simonse, 1998, pag 170).

Es importante resaltar que no fue una invasión coordinada por un poder central, sino que fueron varias oleadas protagonizadas por subtribus diferentes y de manera independiente (Levine, 2000). Las tribus Oromo que se expandieron en dirección norte en este periodo se encontraban en un estadio cultural que actualmente es lo que entendemos como cultura tradicional Oromo, caracterizadas por una sociedad igualitaria en el que la Gada regía el destino de cada tribu, una economía basada en la ganadería y un modo de vida nómada:

"The Oromo who began to move northward in the latter part of the 16th century were mostly nomadic pastoralist without a written language. The espoused neither Christianity nor Islam. The had a remarkably egalitarian culture with a complex age-class system, though which all men rotated in their lifetime" (Henze, 2000 pág. 91). 
La primera descripción de los Oromo de este periodo por parte de las fuentes amharas la tenemos gracias a un monje llamado Bahrey, quien los describe como un pueblo salvaje que asalta las fronteras del Imperio Etíope a finales del Siglo XV. En esta primera fuente se describe a los Oromo llamados Galla (manera despectiva) como una fuerza de la naturaleza asemejándoles a una inundación, negando su "condición humana" y sentando un precedente de desprestigio contra el pueblo Oromo que calará muy profundamente en la historiografía durante siglos (Henze, 2000; Levine, 2000; Melbaa, 1999).

Como explicamos más detalladamente en el capítulo anterior, los distintos pueblos Oromo se fueron asentando en diferentes zonas del centro y norte de la actual Etiopía y fueron perdiendo cohesión interna. La gran mayoría de ellos adoptó formas de vida sedentarias, se mezcló con la población de los territorios en los que se asentaron y perdieron su identidad tradicional, sobre todo en los territorios más al norte (Jalata, 2010). Solo los pueblos Oromo que se asentaron en la zona sur del país y que mantuvieron una superioridad demográfica mantuvieron su propia identidad de una manera muchas más fuerte. Con el paso del tiempo en muchos de los pueblos Oromo, en los que el componente étnico dominante seguía siendo el Oromo pero que habían adaptado elementos culturales de los pueblos conquistados y habían pasado de ser pastores nómadas a agricultores y ganaderos sedentarios o semisedentarios, empezaron a surgir clases dominantes y a desarrollar entidades políticas monárquicas o semi-monárquicas que rompían con la tradición democrática:

"The change to cultivation and monarchical rule destroyed the egalitarian and democratic values of tradicional Oromo society. There were preserved only among the clans that remained in the lowlands, mainly the Borana, Guji, Arsi and Gabbra" (Markakis, 2011, pag 38).

Aunque, como señala Legesse, pese al surgimiento de monarquías y clases dominantes estas sociedades Oromo seguían manteniendo elementos democráticos tradicionales (Legesse 1973, 2006) 
Finalmente solo los Borama y los Guji mantuvieron su cultura tradicional de una manera muy viva hasta fechas recientes, salvaguardándose en el caso de los Borama un modo de vida nómada hasta la actualidad aunque amenazado por las campañas del gobierno orientadas a conseguir sedentarizar a la población.

\subsubsection{Conquista por parte del poder central}

Tras este proceso de dispersión y aculturación y siglos de luchas entre las distintas confederaciones Oromo, y los reyes cristianos del norte el acceso de estos últimos a las armas de fuego occidentales cambió las tornas de la contienda y se pasó de una guerra defensiva a una ofensiva y de conquista por parte de estos monarcas (Jalata, 2012). Con la superioridad tecnológica de estas armas, uno a uno los distintos grupos Oromo fueron cayendo, unos tras largas luchas y otros tras rápidos acuerdos. Con la conquista, gran parte de la tierra pasó a manos de los terratenientes y nobles del norte y los Oromo se vieron relegados a la posición de campesinos sin tierras que trabajaban para un señor feudal extranjero. Los menos afortunados fueron reducidos a la esclavitud que durante el Siglo XIX se nutrió enormemente de las poblaciones Oromo conquistadas:

"With the coming of the Abyssinian colonizers, slavery and the slave trade expanded in Oromia" (Melbaa, 1999 pág. 64).

Durante el reinado de Menelik II se extendió la explotación feudal del territorio de la Oromia, con el asentamiento de colonos y de guarniciones militares para el control de la población, además se llevaron a cabo campañas para imponer la amharización del territorio (Melbaa, 1999). Con el reinado de su sucesor Haila Selasi se relajó la política de colonización feudal pero la persecución contra la cultura Oromo y contra otros grupos no amhara se mantuvo debido al miedo al surgimiento de movimientos independentistas y de resistencia, durante esta época surgieron grupos rebeldes especialmente fuertes en la región de Bale.

Esta situación de subyugación política y de persecución cultural se mantuvo durante el régimen del Derg, aunque un principio la llegada del Derg fue celebrada por los Oromo. La alegría inicial ante el nuevo régmine se debió principalmente al 
anuncio de la nacionalización de las tierras por el nuevo gobierno, acabando de esta manera con la explotación feudal. La alegría fue tal que se dió el caso de la elaboración de canciones tradicionales en honor del Derg:

"Since the land proclamation of the Derg regime abolished the relationship between the landlord and tenants, the singer has a reason to praise the Derg. In this song he praises the regime for what it has done. He wishes long life for the Derg regime because, he says, they have made the poor happy" (Nuresu, 2011, pag 33).

Tras esta alegría inicial, la situación para los Oromo Guji se tornó especialmente adversa cuando se empezaron a aplicar los programas de ingenieria social y económica. Las campañas de villagización y sus consecuencias sociales, económicas y sobre la salud de los miembros de esta etnia fueron muy negativas, como veremos más adelante en diversos apartados de este capítulo.

\subsubsection{Los Oromo en la República Democrática Federal Etíope}

Tras la caída del Derg en 1991 y la promulgación de la constitución de 1994 la situación de los Oromo mejoró al menos en su reconocimiento oficial por parte del gobierno como nacionalidad con derecho al autogobierno y la proclamación del estado federal de la Oromia, pero como ya explicamos anteriormente tanto la democracia como el autogobierno de las distintas regiones de Etiopía están seriamente limitados por el partido y el gobierno central. Es indudable que los derechos de los Oromo tras 1994 han aumentado respecto a la situación anterior, siendo especialmente relevante para el tema de esta tesis la posibilidad de recibir la educación primaria y secundaria en el idioma Oromo. Aún así también es evidente que los Oromo siguen discriminados dentro del país y que se les reprime con especial dureza en caso de manifestaciones de descontento como la sucedida recientemente en la localidad de Ambo:

"The $B B C$ reported that a witness in Ambo saw more than 20 bodies on the street, while Voice of America (VOA) reported that at least 17 protesters were killed by "elite security forces" on three campuses in Oromia. Local residents maintain that the figure [of those killed] was much higher" (www.theguardian.com recuperado el 13 de junio de 2014 de http://www.theguardian.com/global- 
development/poverty-matters/2014/may/22/ethiopia-crackdown-student-protest-

education).

Durante nuestra estancia en Etiopía pudimos observar cómo en la actualidad todo lo "oromo" es mirado con cierto recelo desde el gobierno central, debido al tradicional enfrentamiento entre los habitantes semíticos (amharas y tigriños) y cusíticos (ormos) en el país, al miedo a perder el poder por parte de los primeros que son minoría frente a la mayoría oromo y al recelo que provoca un posible incremento del sentimiento nacionalista/independentista entre los oromo.

\subsection{CULTURA OROMO Y GUJII}

Comprender la cultura Guji y por extensión Oromo es fundamental a la hora de poder comprender la cosmovisión de estos grupos y entender los procesos a los que están sometidos, su forma de afrontar el día a día y la educación.

\subsubsection{La Gada}

Podíamos definir la Gada como el núcleo de la cultura y cosmovisión Oromo; este sistema de organización social democrático en el que la población masculina es dividida en diferentes categorías que combinan la edad y la generación con distintas funciones y responsabilidades fue según estudiosos como Legesse (1973), el eje vertebrador y herramienta que permitió a los Oromo alcanzar su gran expansión.

Los Guji, como el resto de las distintas tribus Oromo, se guiaron tradicionalmente por la Gada, este sistema en los Guji es diferente en algunos aspectos respecto a la Gada de los Borama consierada el modelo clásico (Legesse, 1973, 2006). La Gada Guji se caracteriza porque cada uno de los cuatro subgrupos territoriales en los que estan divididos los Guji tiene su propio territorio, su propia independencia política y su propia gada, si bien mantienen una conciencia de unidad entre los distintos grupos Guji y se unen militarmente en caso de peligro externo (Markakis, 2011).

Aunque en la actualidad la Gada ha perdido gran parte de sus funciones en la sociedad Oromo en general y en la Guji en particular, es interesante entender 
cómo funcionaba este sistema de organización social tradicional, ya que aunque en estos momentos solo tiene una mera función folklórica es innegable que el impacto de esta tradición se sigue manteniendo en la sociedad Guji, por ejemplo en el respeto a los mayores o en la búsqueda de la solución de los conflictos sociales mediante la consecución de la nagaa (paz).

En nuestra experiencia en el campo, las referencias que hacían a la Gada se relacionaban con reuniones mantenidas cada ocho años en las que los ancianos se reúnen y los padres van con sus hijos, además comentaban que esos días se comía comida tradicional. También nos señalaban un antiguo bosque sagrado, frente al cual se continúan reuniendo. Cuando preguntaba a cualquier persona menor de 30 o 40 años la respuesta unánime es que no habían sido iniciados en la Gada y lo señalaban como algo de "épocas" anteriores. En conversaciones con el Padre Pedro Pablo, misionero comboniano que lleva varias décadas conviviendo con los Guji me comentó su impresión de que a la reunión de la Gada en la que él estuvo presente le recordaba a "una fiesta norteamericana" con "comida rápida" en el sentido de que era un acto meramente festivo y comercializado, que había perdido su razón de ser original para transformarse en una simple reunión conmemorativa de su tradición pasada.

Pese a la actual decadencia del sistema organizativo de la Gada todavía el Abba Gada es una persona muy respetada en la sociedad Guji y en situaciones excepcionales su figura todavía emerge como un referente. Los valores tradicionales de la Gada, como la solidaridad intertribal o el respeto profundo a los mayores, siguen muy presentes en la sociedad Guji, en mi presencia en el campo apenas vi episodios de violencia entre distintos Guji, y cuando estos se producían se solucionaban siguiendo el método tradicional de acuerdo entre familias. Tradicionalmente la Gada era el núcleo que vertebraba la sociedad dividiendo a la población en diferentes grupos de edad por los que sus iniciados iban pasando a lo largo de su vida. Este sistema proveía a la sociedad Guji de un marco legal, político, cultural y sagrado. Así pues, estaba presente en todos los aspectos de la vida y es fundamental para comprender a los Guji. 
"Real age-sets are organized in such a way that people who are approximately the same age share collective military, economic, political, or ritual responsibilities" (Legesse, 1973, pág., 50).

En las diferentes etapas por las que los miembros varones de la sociedad Guji iban pasando a lo largo de su vida, tenían una serie de derechos y obligaciones cambiantes. Cada etapa duraba ocho años y, según iba aumentando la edad del varón Guji, las responsabilidades a las que tenia que enfrentarse iban creciendo, reservándose para los ancianos las mayores responsabilidades como la mediación en disputas, castigo de los comportamientos socialmente censurados, consejo a los jóvenes o favorecer la cohesión social del grupo (Van de Loo, 1991).

"Each member of the people is conscious of the power and authority vested on the Gada institution and is highly obedient to its directives" (Jaleta, 2004, pag.17).

En concordancia con el aumento de obligaciones, los derechos, privilegios y poder van también aumentando según se iba ascendiendo en la escala de la Gada, en la que hay en total 11 grados de ocho años de duración cada uno. Contamos con varias clasificaciones distintas y diferentes nombres para cada una de estas clases según el autor, personalmente prefiero utilizar la clasificación de Legesse ya que es el mayor experto respecto al tema y quien ha estudiado de una manera más profunda a los Borana, uno de los grupos que conserva la cultura Oromo tradicional más vivamente (Legesse, 1973) (véase Tabla 2).

Tabla 2. Escala de la Gada

\begin{tabular}{ll}
\hline 1- Dabballe & 7-First Yuba \\
2-Gamme Jr. & 8-Second Yuba \\
3-Gamme Sr. & 9- Third Yuba \\
4-Cusa & 10-Fourth Yuba \\
5- Raba Jr. & 11-Gada Moji
\end{tabular}
6-Gada

Fuente: Elaboración propia

Para que un nuevo chico empiece su afiliación al primer grado de la Gada su padre ha de estar en ese momento en el sexto grado llamado Gada, lo que supone que deben haber pasado 40 años. Esto refuerza el sentido de la Gada como organización basada en las generaciones (Baxter,Hultin y Triulzi, 1996). La 
pertenencia a distintos grados de la Gada queda reflejada, además de por las obligaciones y respetabilidad social, por el hecho de que los miembros de un mismo grupo de edad y sus mujeres son enterrados de forma similar. En el sistema de la Gada cuanto mayor es el estatus social más alejado del hogar son enterrados los cuerpos.

Aunque la Gada solo reconoce derechos políticos a los hombres, este derecho de las mujeres a ser enterradas con los mismos honores que sus esposos, junto a otros datos sirve al investigador de la Universidad de Miami, Dejene Debsu para afirmar que la sociedad Guji y el sistema de la Gada otorgan más poder y derechos a las mujeres de lo que a primera vista se podría creer aunque los cambios culturales están debilitando estos espacios de poder tradicional de las mujeres:

"Contrary to the myths and legends, women have continued to provide an important service to their society as links between communities and peace negotiators during and after conflicts. They also enjoy claims to family property in several indirect ways. With changes from pastoralism to agropastoralism, however, women lost some of these economic and customary legal rights and became subjected to more domestic and extra-domestic work burdens" (Debsu, 2009, pag. 15).

En nuestra opinión, aunque la Gada haya desaparecido como fuerza efectiva de organización social, la cosmovisión de los Guji sigue estando muy marcada por ella, en un ejercicio de pervivencia cultural las normas sociales que imponía este sistema, como el matrimonio exogámico o el respeto a los mayores, siguen siendo muy respetados. Otro ejemplo es la necesidad casi patológica que tienen los Guji de discutir en reunión cualquier decisión a tomar y las ganas que tienen todos de aportar su opinión y tomar la palabra aunque su opinión ya haya sido expresada por otro miembro de la reunión.

\subsubsection{La cultura tradicional}

Centrándonos en el tema principal de la presente Tesis Doctoral, es importante comprender el impacto que los valores de la Gada y la cultura 
tradicional tienen a la hora de llevarse a cabo el proceso de enseñanza-aprendizaje, ya que el aprendizaje estaba tradicionalmente regulado por la Gada. Así, pese a la conservación de la cultura tradicional dentro de los Guji, el impacto de la llegada de los nuevos sistemas educativos formales ya se deja notar en la sabiduría popular de este pueblo, recogiéndose en alguno de sus famosos proverbios: "Mana bareessaabaranoota utaalchumaan oli seent" que se traduce por "Nowadays you can enter the houses of writing and learning" (Baxter, Hultin y Triulzi ,1996, pág. 272).

A pesar del impacto de los nuevos sistemas educativos, la cultura tradicional sigue siendo fundamental a día de hoy para entender el proceso de enseñanzaaprendizaje y la socialización de los nuevos Guji. Tradicionalmente los distintos grados del sistema de la Gada por los que iban pasando los niños de la sociedad Guji durante sus primeros años de vida tenían un carácter no solo ligado al aprendizaje, sino también a la religión y a aspectos relativos a la socialización de los niños que eran fundamentales para que estos nuevos miembros de la sociedad Guji aprendieran las habilidades necesarias para el desarrollo de su vida económica y social de adultos.

Gran parte de los elementos religiosos o mágicos atribuidos a los niños en la actualidad han sido sustituidos por los valores de la cosmología cristiana o musulmana, pero todavía se mantienen muchos de los aspectos de la educación tradicional, sobre todo los relacionados con las funciones económicas de los niños, los cuales trabajan diariamente y ejercitan de esa manera habilidades y conocimientos prácticos que necesitarán de adultos. Estas primeras etapas de la vida y de la Gada eran también muy importantes para la estructura de poder de la sociedad Guji, ya que los niños tradicionalmente empezaban a forjar los vínculos sociales necesarios y a demostrar que poseían las habilidades necesarias para poder en un futuro aspirar a obtener una posición relevante en su sociedad (Legesse, 1973).

En la actualidad la estructura del poder tradicional y la forma en la que los miembros de esta etnia forman las alianzas sociales está cambiando con la introducción de nuevos elementos como los partidos políticos o los grupos 
religiosos. En nuestra experiencia de campo fuimos testigos de cómo las distintas iglesias protestantes que han desembarcado con una fuerte presencia en la zona tejen redes de poder e influencia para promocionar a sus miembros a posiciones de poder dentro de la vida económica y política de la zona.

Junto a las distintas confesiones religiosas, otra vía de ascenso social es la afiliación a los partidos Oromo miembros de la coalición de gobierno del partido central. Prácticamente todos los trabajadores públicos en cualquiera de sus ramas, especialmente en la administración y policía, son miembros de uno de estos partidos. Así pues, la afiliación política se ha convertido en un requisito no oficial pero no por ello menos real a la hora de optar a ocupar uno de estos puestos de trabajo. A estos condicionamientos culturales hay que añadir que las circunstancias económicas de las familias pueden suponer una desventaja que límite las posibilidades de que los niños y niñas puedan asistir a clase con regularidad o más allá de la educación básica, al requerirse su aportación para el sostenimiento de la economía familiar. Este aspecto es más influyente en el caso de las niñas, ya que como señala la investigadora Dejene N. Debsu, la carga de trabajo y el tiempo que éstas deben dedicar al mantenimiento de la casa y la economía familiar son más elevados (Debsu, 2009). Todos estos aspectos influyen importantemente en la educación de los niños Guji, no solo en la primaria sino también en las posibilidades de que los alumnos continúen sus estudios hasta alcanzar los estudios universitarios. En nuestra experiencia de campo pudimos observar que todos los niños y niñas en diferente manera aportaban fuerza de trabajo a diario para ayudar a sostener la economía domestica, dependiendo la cantidad de dicha carga de la necesidad de la familia en cada momento.

\subsubsection{Casas y patrón de poblamiento}

Los Guji tradicionalmente fueron una sociedad nómada con unas características similares a las que actualmente mantienen los últimos grupos de Oromo Borana que siguen practicando la forma de vida nómada con los cuales comparten el "honor" de ser considerados los grupos Oromo que mantienen las 
características culturales tradicionales Oromo de una manera más pura, además de ocupar el supuesto territorio originario de los Oromo (Legesse, 1973).

Este pasado nómada o seminomada y el fuerte componente belicoso de la sociedad tradicional Guji explica bajo nuestro punto de vista cómo un grupo de población relativamente pequeño mantiene hasta la actualidad un territorio tan extenso, dando la sensación de estar "vacio".

Según Jhon Markakis, Gujjiland tenía en 2007 1,4 millones de habitantes, incluyendo dentro de este recuento minorías Borana, Gabbra y Somoli, aunque también señala que hay una fuerte presencia Guji en la zona borana (Markakis, 2011). Es muy significativa la impresión que produce pasar de la zona Guji a la zona Sidamo por la carretera que une ambas en sentido a Awasa. Así, en cuanto uno se adentra unos pocos kilómetros en zona Sidamo se observa un incremento de la población y una creciente presencia de centros urbanizados.

Los Guji perdieron definitivamente esta forma de vida seminómada al sufrir la conquista y adhesión al Imperio Etíope por parte del emperador Menelik II en las campañas que finalizaron en 1896, cuya consecuencia fue el cambio de su forma de vida nómada por una sedentaria y en la actualidad están plenamente asentados. Debido a las características ecológicas y climáticas del territorio en el que están asentados los Guji se les puede dividir entre los Guji que viven en zonas de alta montaña y en los que viven en las zonas más bajas, pero en ambos casos el patrón de poblamiento es muy similar (Van de Loo, 1991).

El patrón de poblamiento tradicional de los Guji consistía en una sola casa o un par de casas habitadas por un mismo grupo familiar, rodeadas de sus campos de cultivo y de terreno para el pasto del ganado. Hasta el proceso de villagización impuesto por el Derg, solo en las zonas fronterizas con otras etnias, que podían ser objeto de razzias, la población estaba asentada en agrupaciones mayores (James et al edit, 2002). Las campañas de villanización emprendidas por el Derg en 1986 como medio para "desarrollar" y dotar de servicios a los Guji concentraron la población en villas $\mathrm{y}$ aldeas en las que sus miembros estaban sujetos a un control y a un 
adoctrinamiento ideológico. La concentración de la población provocó sufrimiento y cambios sociales generalmente negativos. Finalmente estas medidas aplicadas entre 1986 y 1991 no dotaron de nuevas infraestructuras y servicios a los Guji como pretendían, provocando en realidad nuevos problemas sociales anteriormente inexistentes o de una importancia muy inferior como las disputas motivadas por los cultivos o el incremento del alcoholismo en la zona (James et al ed, 2002).

Una vez que el gobierno del Derg fue derrocado en 1991, las villas creadas por él mismo fueron abandonadas y en algunos casos destruidas con muestras de rabia y gran parte de los Guji volvieron a sus patrones de asentamiento tradicional disperso. Testigo de ello directo fue uno de los padres combonianos de Qillenso, que me comentó como los habitantes de esas villas creadas por el Derg una vez que cayó el gobierno comunista destruyeron los pueblos hasta los cimientos, de tal manera que en la actualidad no quedan prácticamente rastros que indiquen que allí hubo una aldea (Padre Cavallini, comunicación personal 20 de Enero de 2013).

El modo de asentamiento aislado tradicional todavía está muy presente en la actualidad. Grandes espacios del territorio están poblados siguiendo este patrón; económicamente es un sistema de organización del suelo muy efectivo para la combinación de agricultura y ganadería ya que permite la utilización de grandes espacios para el pasto. A día de hoy con el incremento de población, las nuevas actividades económicas y la implantación de centros organizativos, se observa un desarrollo de núcleos de población concentrada. En este proceso también ha estado presente la inmigración de población de etnia Gedeo y Wolaita principalmente hacia los centros de población más desarrollados. Estos inmigrantes a su vez han traído nuevas actividades económicas y cultivos con ellos lo que ha fomentado aún más los cambios culturales. Un ejemplo de ello es el cultivo del árbol de la falsa banana, desconocido anteriormente para los Guji.

Es importante destacar que pese a la presencia, en ocasiones muy significativa, de miembros de otras etnias, los Guji siguen manteniendo el control de la zona y en ocasiones en las que hay disputas entre los "recién llegados" y Gujis hacen valer "su posesión" del territorio. Ejemplo de ello se encuentra en la zona de 
Qillenso, donde hemos llevado a cabo la mayor parte del trabajo de campo, donde vivían unas familias de etnia Sidamo que se asentaron en la zona durante la gran hambruna de principios de los años 70 y que posteriormente fueron expulsadas al estallar años después las hostilidades entre los Guji y los Sidamo.

Como consecuencia de todo este proceso histórico, en la actualidad los Guji se encuentran divididos entre los que habitan en las zonas rurales asentados de una manera dispersa y los que se encuentran en aldeas y centros urbanos. No es solo una simple separación geográfica sino que además, quienes se encuentran en zonas urbanas están sujetos a un cambio cultural mucho más acelerado que quienes habitan dispersamente de una manera tradicional. Esto es observable claramente en la utilización del Guji o del Amhárico a la hora de entablar comunicación. Mientras que en las zonas más rurales el Oromo es el idioma que preferentemente se utiliza y en muchas ocasiones es el único que se conoce, en las zonas más urbanizadas, el Amhárico ha sustituido al Oromo en muchas ocasiones y está mentalmente asociado en parte de la población al desarrollo y la modernidad.

Bajo nuestro punto de vista, el gobierno federal favorece la creación de estas ciudades de tamaño pequeño o medio siguiendo dos objetivos, el primero la fijación de la población en las zonas rurales para evitar una inmigración masiva a las grandes capitales siguiendo el plan de industrialización mediante la agricultura, tal y como expusimos en el capítulo anterior. El otro objetivo que persigue el gobierno promocionando estas ciudades y la concentración de la población en núcleos es la amharización de la población, tanto en la zona Guji como en otras zonas no amhara. Y ello porque al proveer estas ciudades de servicios, como instituciones educativas superiores o instalaciones sanitarias, logra atraer a la población rural a un contexto en el que la cultura amhara está presente y es además vista como un elemento de desarrollo.

\section{Chozas y casas}

La casa más común en la zona es la choza típica Guji, de construcción circular y con materiales tradicionales aunque en los centros más urbanizados y en los 
márgenes de las carreteras se empieza a encontrar una gran presencia de casas construidas con una forma rectangular y un diseño importado del exterior de Gujiland (véase Figura 16). Estas casas rectangulares también se encuentran en las zonas rurales como añadidos a las casas tradicionales, es un diseño que se encuentra extendido por toda Etiopía cuyo rasgo más destacado es la utilización de placas de metal corrugado para el tejado y son un ejemplo más de proceso de homogenización que está sufriendo el país.

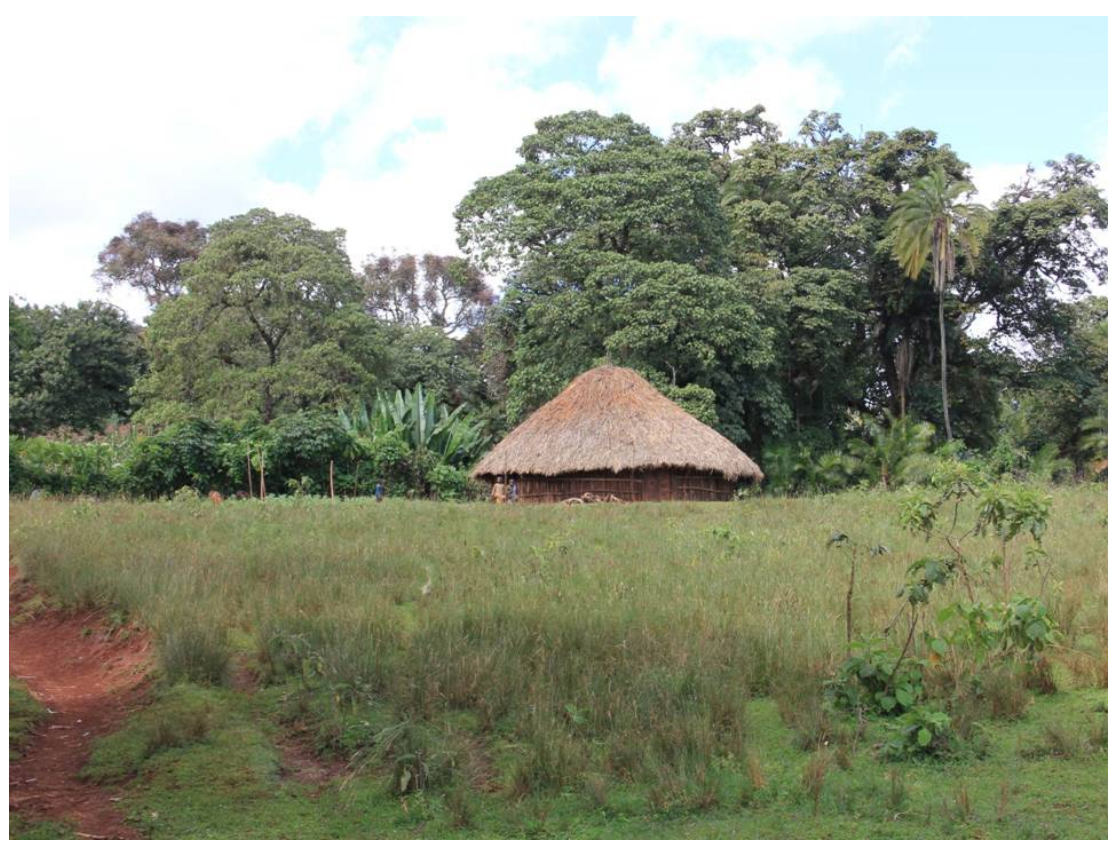

Figura 16. Casa típica Guji siguiendo el patrón de doblamiento disperso

(Fuente: Autor)

Un dato a destacar de las chozas de los Guji y que nos habla de los cambios que ha sufrido este grupo es que las chozas de esta etnia si se las compara con las de sus vecinos los Sidamo, son de un diseño mucho más básico; posiblemente este diseño más primitivo se deba a que los Guji solo han adoptado una forma de vida totalmente sedentaria recientemente mientras que los Sidamo son una cultura sedentaria desde un tiempo muy anterior y esta inferioridad del diseño Guji sería una consecuencia de ello. Los materiales que se empleaban de forma tradicional para la construcción de las chozas son madera, barro u adobe y paja, en la actualidad siguen siendo usados pero es fácil observar la presencia de nuevos materiales como plásticos y placas metálicas. 
A la hora de analizar las chozas tradicionales Guji es importante destacar que el muro exterior está constituido por un armazón de estacas de madera (generalmente de eucalipto o bambú) que posteriormente se recubren con adobe y barro para dar consistencia a los muros aunque hemos observado casas en las que el adobe solo es utilizado para rellenar los huecos entre las distintas estacas de madera y no para recubrirlas completamente. Las aberturas en estos muros normalmente son escasas por lo que la iluminación natural en el interior es exigua; una abertura principal para la puerta y un par de pequeñas ventanas suelen ser todos los orificios al exterior en estas casas. Este muro exterior se encuentra tanto decorado y pintado como dejado sin más remate, aunque a los Guji les gusta pintarlo y decorarlo, escribiendo mensajes deseando la paz (nagaa) o dando la bienvenida a los visitantes, como curiosidad que demuestra el impacto que la cultura occidental está teniendo en todo el mundo es destacable el intento de reproducir mensajes de felicitación en inglés. Como nota personal quiero añadir que la calidad de las puertas y ventanas de madera deja de manera general mucho que desear, observándose que en la gran mayoría encajan de manera bastante imperfecta, lo que sugiere que son elementos añadidos no hace mucho tiempo.

En la parte central de la estructura se levanta un poste principal cuyo extremo más elevado forma el punto desde el cual el tejado desciende hasta asentarse en la parte superior del muro. Es muy común que este poste central sea rematado en el exterior por una estaca de madera de carácter decorativo que puede tener distintas formas, siendo usual la forma de cruz y estar aderezada con elementos como piezas metálicas, latas o botellas de plástico.

El tejado de las casas tradicionales Guji está formado por un entramado de varas de madera recubierto por una techumbre de paja, en algunas casas se puede observar que sus propietarios han añadido grandes piezas de plástico al recubrimiento exterior de paja para ayudar a luchar contra la lluvia. La distribución interna de la casa suele ser muy simple, generalmente hay un espacio principal al que se le da el uso de comedor, sala de estar y en el que también se duerme, luego suele haber uno o dos espacios más pequeños delimitados por muros interiores que 
sirven como lugar de almacenamiento de comida y posesiones y como lugar para preparar los alimentos y cocinar, pero también he observado casas en las que no hay ninguna división interna. Tradicionalmente había pequeñas salas independientes en las que se almacenaba la comida y se preparaba era territorio exclusivo de las mujeres y ningún hombre podía entrar, solo podía entrar el marido para dormir con su esposa (Pedro Pablo, comunicación personal 20 noviembre 2012).

En la actualidad debido al proceso de cambio cultural y a la introducción de nuevos elementos como las camas de diseño occidental, el espacio en el que el matrimonio duerme se ha movido a la sala principal en la que se suelen colocar la cama de matrimonio y en algunos casos si la economía familiar lo permite camas suplementarias para los hijos. El mobiliario suele ser muy escaso y austero, una o varias camas, algún banco largo, algunas sillas y taburetes de madera o plástico, una o varias estanterías y en algún caso un armario. También es común encontrar una pequeña mesa baja utilizada para la ceremonia del café. El menaje y utensilios del hogar también son escasos; en mi experiencia he podido ver cómo los elementos tradicionales del mismo han sido sustituidos por productos de fabricación en masa, principalmente de origen chino y fabricados en plástico de colores.

En la zona central del espacio principal de la choza tiene su lugar el fuego de la casa. Es destacable que las chozas no tienen un orificio de ventilación en el tejado para la salida del humo provocado por el fuego sino que se deja que el humo se filtre por las distintas oquedades entre las cañas de paja del tejado. La inexistencia de un vano de ventilación provoca que haya una gran cantidad de humo en el ambiente con las molestias que esto conlleva para la respiración o la irritación de los ojos. Otra consecuencia de la inexistencia de un agujero de ventilación también es el recubrimiento con una fina capa de hollín de los diversos objetos y superficies en el interior de la casa, pero a su vez tiene consecuencias muy positivas y que compensan estas molestias como son su eficacia para controlar el número de insectos que habitan entre la paja del tejado y para ayudar a su impermeabilización frente a las lluvias. 
Finalmente ante la proliferación de casas de nuevo estilo pregunté a uno de mis informantes clave que vivía anteriormente en una choza tradicional pero que se había mudado a una casa de nuevo estilo, por qué se estaban construyendo en la zona casas de nuevo estilo y se estaba abandonando las chozas tradicionales y me respondió que pese a que las chozas tradicionales eran más baratas, las chozas nuevas eran mejores aunque no me supo razonar más motivos (Waree, comunicación personal, 10 de enero de 2013). Personalmente pude observar que es evidente que las nuevas casas son más fáciles de levantar, tienen una estructura más sencilla que permite que se construyan más rápido que las antiguas. Fui testigo de ello con la construcción por parte del colegio de las casas de los profesores, además generan una sensación de mayor espacio y tienen una mejor iluminación. Lo que suscita mis dudas es si lograrán aguantar tan bien como las tradicionales las Iluvias torrenciales de la zona y las inclemencias como el fuerte sol de la época seca y la constante humedad de la época de lluvias, teniendo en cuenta la mala calidad de los techos metálicos que se están usando.

Como último punto es importante destacar la importancia que para la sociedad Guji tiene la construcción de una nueva casa. Este hecho es un acontecimiento social importante que suele estar relacionado con la formación de un nuevo matrimonio, y como veremos posteriormente en el apartado de parentesco, es la última acción que un padre tiene que hacer por un hijo antes de que éste se independice, lo que bajo nuestro punto de vista constituye una acción que marca un rito de paso dentro de esta sociedad.

\subsection{ECONOMÍA GUJII}

\subsubsection{Economía familiar}

La práctica totalidad de los Guji de la zona rural donde hemos llevado a cabo el trabajo de campo, al igual que los Guji que habitan fuera de los núcleos urbanos de Gujiland, tienen su principal fuente de ingresos en la ganadería y la agricultura. Actualmente la organización y empleo del territorio se basa en parcelas familiares que son explotadas de manera directa por los miembros de la misma. También se 
encuentran campos comunales utilizados para el pasto del ganado. El paisaje se completa con grandes extensiones de bosque y selva de alta montaña, aunque estos espacios naturales durante los últimos decenios han retrocedido debido al aumento de la población Guji y al asentamiento de grupos de población de otras etnias como la Gedeo.

Aunque en la actualidad la implantación de poblaciones ajenas a los Guji en el territorio de los mismos responde a planes del gobierno para reasentar población, tradicionalmente los Guji como el resto de los Oromo han tenido una gran facilidad para aceptar poblaciones extrañas e introducirlas en su sistema organizativo (Levine, 2000). Un ejemplo de ello es la relación estrecha que hay entre los Guji y los Gedeo, que llevan conviviendo pacíficamente desde hace generaciones en una paz solo rota por episodios esporádicos.

\subsubsection{Evolución de la organización del territorio}

Tradicionalmente los Guji habían sido un pueblo nómada o semi-nómada dedicado a la ganadería vacuna; solo después de la conquista amhara y tras el abandono de su forma de vida nómada para asentarse definitivamente y dar paso a un sistema económico agropecuario. Tras la conquista imperial por parte de Menelik II, grandes parcelas del territorio quedaron en manos de grandes propietarios amharas trabajadas por campesinos que se habían visto obligados a entregarles sus tierras para pagar las deudas que contraían al no poder pagar los impuestos que exigía la administración imperial:

"Unsuccessful farmers who failed to pay the quotas were regularly offered assistance by Amhara settlers in the form of cash loans. Those farmers who were unable to restitute the borrowed money in time were forced into a situation of land tenure, woleda aged. The money-lenders, generally of Amhara origin, were thus able to appropriate large portions of both Guji land and livestock. The indebted Guji cattle herders were reduced to the status of chiisanyota, "tenant farmers", and as such were forced to work without payment for a landlord, baalabata, who left but a fourth of the harvest to his tenant"(Van de Loo,1991, pág. 217) 
Frente a esta situación algunos Guji con una situación económica más boyante empezaron a realizar los mismos préstamos a los campesinos en una situación más débil, convirtiéndose a su vez en grandes propietarios y adoptando las mismas características que los grandes propietarios amhara de los que pretendían proteger a la población autóctona, aunque según autores como Van de Loo algunos utilizaron su poder para hacer más soportable el dominio imperial (Van de Loo, 1991). Esta situación cambió con la Revolución de 1974 y la llegada al poder del Derg. Entre sus planes para la modernización y el desarrollo del país se encontraba la reforma agraria. El ideal de esta reforma se basaba en la idea de que la creación de organizaciones de agricultores que debían explotar la tierra de forma conjunta y vivir en comunidades frente al asentamiento disperso tradicional fomentaría el desarrollo económico rural y por ende el del país:

"In countries that followed the socialist route to development, villagization was often considered a means of enhancing rural development in general and agricultural development in particular, being designed as a first step towards the complete collectivization of agriculture" (James et al 2002, pág. 117)

Al principio la llegada al poder del Derg y la reforma agraria no produjo un estallido de violenta resistencia como en otras partes del país. Solo los grandes propietarios intentaron plantear una resistencia armada frente a las nuevas medidas (Van de Loo, 1991). En los registros de la escuela hemos observado que unos años después de la llegada del Derg al poder, el nombre de Menguistu se hizo popular y común entre los alumnos. Teniendo en cuenta la importancia de los nombres que los Guji otorgan a sus hijos, este hecho parece sugerir que la figura de Menguistu Haile Mariam en el momento de su llegada al poder levantó simpatías entre los Guji de la zona, aunque pocos años después igual que el nombre apareció en los registros desapareció sin dejar rastro tras la pérdida de popularidad del dictador como consecuencia de la aplicación de sus medidas de ingeniería social. Los resultados de la aplicación de las medidas del Derg fueron contraproducentes en el campo de la agricultura y la economía: se incrementó la distancia entre los campos y las zonas de hábitat, por lo que los agricultores debían invertir más 
tiempo en llegar a las zonas de trabajo perdiendo de esta manera tiempo dedicado a la producción. En consecuencia, ésta descendió, produciéndose uno de los impactos más perniciosos en la ganadería, ya que el número de cabezas en manos de los Guji descendió de una manera muy marcada debido a enfermedades contagiosas que se extendieron fácilmente debido a la concentración del ganado, la falta de alimentos o el frío (James et al edit, 2002).

\subsubsection{Ganado}

La posesión y explotación de ganado vacuno es para los Guji la fuente de riqueza y sostenimiento económico más importante al mismo tiempo que uno de los pilares más importantes a la hora de ser una persona respetada en la comunidad. El no ser propietario de ganado vacuno hace que los demás no te consideren un Guji propiamente dicho (Baxter, Hultin y Triulzi 1996). Esto llega al extremo de que un dicho tradicional Guji afirma que una vez perdido el ganado lo único que queda por hacer es cortarse el cuello (comunicación personal Robbe, 3 de noviembre de 2012) Además como señala Markakis para los Guji el ganado no solo es importante por sus connotaciones económicas o sociales actuales, sino que les ayuda a mantener un vínculo con su idiosincrasia guerrera tradicional:

"Along with their attachement to livestock, the Guji also retain the pastoralist warrior ethos" (Markakis, 2011, pag. 69)

En nuestra experiencia de campo con los profesores de la escuela o con las personas con las que mantenía un contacto más habitual, la posesión de vacas era el elemento que usaban para definir la riqueza de una persona o familia. Por ejemplo, el profesor Getaanaa de la escuela de Qillenso era definido por sus compañeros como rico debido principalmente a que era propietario de un número superior de vacas a lo habitual en la zona. Este mismo profesor ante la enfermedad de una de sus vacas no dudó en ausentarse el colegio y ninguno de los otros profesores vio nada extraño en ello. Cuando su vaca murió debido a la enfermedad se mostró triste y poco comunicativo durante unos días. 
Otro ejemplo de la importancia que para los Guji tiene su ganado vacuno es el amor que procesan a sus reses. Durante las ceremonias religiosas es común que entonen oraciones pidiendo a Dios que ayude a sanar a alguna de sus vacas enfermas o que conserve la salud de su ganado, y tradicionalmente los Oromo han compuesto y dedicado canciones en honor a sus reses (Nuresu, 2011). Es muy ilustrativo para entender la importancia que el ganado vacuno tiene para los Guji tener en cuenta que en muchos aspectos de su cultura entablan comparaciones y paralelismos entre las propias personas y el ganado. Como ya hemos dicho anteriormente, otro ejemplo de ello es que cuando dos niños nacen el mismo año son dice que son de la misma "camada". También dan nombre propio a algunas de sus vacas y tienen nombres y ceremonias tradicionales especiales para las vacas especialmente fecundas o para conseguir que una vaca estéril se transforme en una vaca prolífica (Van de Loo, 1991). Actualmente debido al impacto del cristianismo estas ceremonias tradicionales han sido abandonadas y sustituidas 0 complementadas con oraciones y ruegos cristianos.

La posesión de vacuno es a su vez una de las razones por las cuales los Guji muestran una alimentación superior a otros pueblos vecinos en los que la ganadería de vacuno tiene un papel mucho menos destacado en su economía ya que les proporciona productos lácteos como leche, yogurt y mantequilla y en ocasiones especiales y grandes festejos se sacrifica algún toro o vaca. Los animales domésticos se completan con la presencia de algunas gallinas y una pequeña cantidad de cabras u ovejas. El consumo de carne se limita en general a celebraciones religiosas y sociales importantes como el Mesquel o el año nuevo etíope. Después de una fiesta importante se aprecia que el número de ovejas y cabras que transitan y atraviesan libremente las carreteras desciende de una manera significativa.

\subsubsection{Agricultura y cultivos}

Actualmente los Guji dedican una gran parte de su actividad a la agricultura. El cambio de la sociedad nómada dedicada al pastoreo de ganado a la sociedad sedentaria que combina tanto la agricultura como la ganadería fue promovido por 
parte de las autoridades imperiales tras la conquista y el asentamiento de terratenientes amhara (Van de Loo, 1991). En este proceso de sendenterización y adopción de la agricultura fue fundamental la epidemia que acabó en el siglo XIX con gran parte del ganado de los Guji, obligando a los Guji a dedicarse a la agricultura para poder sobrevivir y a su vez favoreciendo los planes de sendentarización de la población por parte del poder imperial:

"Sedentarism followed the rindepest epidemic of 1886 that wiped out their heards, and accelerated after the Ethiopian conquest of the region afterwards" (Markakis, 2011, pag. 69).

Sin embargo, socialmente la posesión y el pastoreo del ganado son mucho más valorados que la agricultura ya que para los Guji es la actividad agropecuaria la que proporciona el estatus y el respeto social y aunque la aportación de la agricultura a la economía familiar es realmente muy importante muchos Guji se resistan a admitirlo:

"Cultivation is more important to Guji than they admit, animal husbandry was and still is their favourite economic activity" (James, et al edit, 2002, pág. 70).

Debido a las condiciones climáticas, en las zonas altas de Gujiland se realizan varias cosechas al año, cada una de diferentes productos. Primero es la cosecha de maíz; un par de meses después llega la cosecha del tef. A continuación, a finales de febrero y principios de marzo, empieza la preparación de los campos para una nueva cosecha. Es común observar la quema de rastrojos como paso previo a la siembra antes de que lleguen las primeras Iluvias. Otra importante actividad agrícola en la zona es el cultivo de café. Este producto tiene una gran importancia en todas las celebraciones y en todos los actos de la vida cotidiana de carácter social; siempre que una casa recibe una visita los dueños ofrecerán café a sus invitados. Además es un producto que tiene buena salida en el mercado, ya que desde las zonas productoras de café este se distribuye hacia el resto del país y es a su vez el producto más exportado de Etiopía. 


\section{Producción de miel}

La producción de miel es una actividad económica complementaria al trabajo en los campos y al pastoreo del ganado que ayuda a mejorar los ingresos familiares. Tradicionalmente la miel era necesaria para algunas de las ceremonias religiosas que tenían como objetivo fomentar la fertilidad, lo que nos da una pista de lo apreciada que es la miel, ya que la fertilidad es uno de los valores más importantes en la cultura tradicional Guji (Van de Loo, 1991). La fabricación de las colmenas se lleva a cabo de manera artesanal. El proceso consiste en cortar una sección del tronco de un árbol, a continuación se divide en dos partes y se vacía. Las partes se vuelven a unir mediante fibras de cuerda o piezas metálicas y se introduce una abeja reina en el interior. A continuación la colmena se coloca en las ramas superiores o cerca del tronco de los árboles.

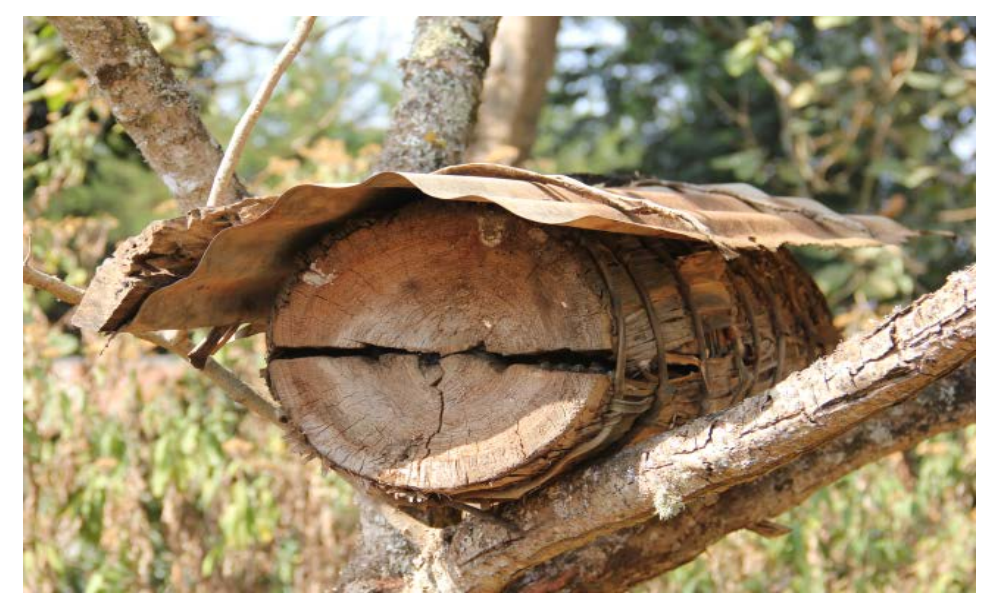

Figura 17. Colmena tradicional

(Fuente: Autor)

La mezcla de miel y de cera de abeja blanca que se obtiene se recolecta generalmente aproximadamente en el mes de abril y se destina para tanto uso doméstico como para la venta en los mercados de la zona. Este trabajo con las abejas es considerado una responsabilidad masculina y las mujeres solo intervienen a la hora de vender la producción en el mercado. En la cultura Guji, regalar miel es uno de los gestos más significativos a la hora de demostrar amistad y es un gesto que hemos visto realizar pocas veces ya que se guarda para ocasiones muy especiales 


\subsubsection{Mercados tradicionales}

Otro de los pilares fundamentales para la economía familiar son los mercados semanales que tienen lugar en las diversas concentraciones de población de mayor importancia en cada zona. En dichos mercados los campesinos venden los excedentes productivos de sus huertas y sembrados y compran productos manufacturados, calzado o ropa, siendo gran parte de estas mercancías de fabricación china con la escasa calidad que ello lleva aparejado, teniendo en cuenta la ausencia de controles de calidad en el país. También es muy común ver pequeños puestos de ropa cuyo origen en muchos casos se encuentra en las donaciones con fines caritativos de los países occidentales. Los días de mercado semanal las carreteras son "tomadas" por grupos de personas, mujeres y muchachas en su gran mayoría, que se desplazan desde sus casas a la población en la que se desarrolla ese día el mercado cargando a la espalda y con burros los productos de sus huertas y plantaciones con la intención de venderlos o para comprar mercancías. Esta producción de pequeños agricultores orientada a su comercialización en los mercados es fomentada por el gobierno etíope ya que uno de los pilares en los que se basan sus planes de desarrollo es llegar a la industrialización del campo mediante la estimulación de la producción agrícola por parte de los pequeños agricultores.

La división de género a la hora de vender los productos es clara: las mujeres y niños son los encargados de vender los productos de la huerta y los productos lácteos, mientras que cuando los pequeños agricultores y ganaderos tienen la intención de vender cabezas de ganado son los hombres los que realizan la transacción económica. El carácter social del mercado también es diferente: para las mujeres es un aspecto más de su trabajo mientras que los hombres acuden en más ocasiones al mercado como centro de reunión social que con la intención de vender productos.

Otro tipo de comercialización de la producción de alimentos es la venta "puerta por puerta" que llevan a cabo generalmente los niños, vendiendo huevos, fruta u otros productos como mazorcas de maíz o caña de azúcar. 


\subsubsection{Nuevas actividades económicas}

De acuerdo con Minney (2010), el incremento del producto interior bruto de Etiopía ha hecho que se configure como el quinto país africano. Su economía está basada fundamentalmente en la producción agrícola y en la inversión pública en infraestructuras. También se ha beneficiado de la inversión extranjera en las minas, así como en la venta de acciones por empresas de nueva creación o en expansión en sectores como la educación, las finanzas, o la construcción (Minney, 2010).

En la actualidad, nuevas actividades económicas se han sumado a las tradicionales o las han expandido a niveles muy superiores a los que tradicionalmente alcanzaban. El comercio también está en pleno desarrollo; las carreteras que atraviesan Gujiland y que entran en el territorio Guji desde Awasaa para luego ramificarse están constantemente transitadas por camiones, generalmente de la marca Isuzu, -llamados Al-qaedas por los lugareños- cargados de mercancías provenientes de Awasa y desde la misma Addis. Estos productos suelen ser manufacturas producidas en otras partes de Etiopía como cerillas y jabón u otros productos importados, teniendo estos últimos su origen en China o en el Sudeste Asiático. También transportan productos de la huerta provenientes principalmente de la zona de Awasa y que durante la estación seca son imposibles de producir en el territorio Guji ya que exigen una gran cantidad de agua. Falta de agua que no tienen que afrontar los agricultores cercanos al lago de Awasa y que el nuevo sector económico del transporte de mercancías permite por primera vez comer productos de época húmeda durante la época seca en Gujiland.

El sector del transporte también está viviendo un gran desarrollo con la mejora de las infraestructuras de comunicación como puentes y asfaltado de carreteras. El transporte de mercancías con las anteriormente citadas Isuzu está posibilitando la llegada de nuevos productos a la zona. El transporte de viajeros por carretera que anteriormente se llevaba a cabo con los grandes autobuses de origen indio o asiático que eran los únicos capaces de soportar y sobrevivir a las carreteras de barro y tierra se encuentran ahora con la creciente competencia de los minibuses Ilamados Abba Dulaa. Su nombre significa literalmente en Oromo "padre 
guerrero" en recuerdo al presidente de la Oromia contemporáneo a su introducción. Este medio de transporte es más rápido y relativamente más cómodo pero requiere la presencia de carreteras asfaltadas. Por ejemplo, en la zona de Qillenso hemos sido testigos de la aparición de estos minibuses cubriendo la ruta hasta Adoola cuando anteriormente era terreno exclusivo de los grandes buses, una vez asfaltada la carretera.

El asfaltado de la carretera también ha traído un nuevo negocio en el transporte de personas y pequeñas cantidades de mercancía en la figura de las moto-taxis conducidas por muchachos y hombres jóvenes -nunca he observado una mujer conduciendo una- en las que se llegan a montar hasta cuatro personas con fardos e incluso en ocasiones con niños pequeños en sus brazos. Estas motos están revolucionando el transporte de personas y mercancías y están empezando a sustituir en alguna de sus funciones a los caballos y burros, aunque su propiedad se limita a pocas personas que contratan a conductores y su presencia está concentrada en los núcleos de población más importantes donde se concentran a su vez los clientes. Sus servicios son muy utilizados para el desplazamiento desde las aldeas y poblaciones pequeñas a los centros de población más importantes los días de mercado.

En los núcleos de población más importantes de la zona como Adoolaa también se ha introducido recientemente y con un gran éxito los Tuc- Tuc como taxis, invento indio que ha demostrado que se adapta muy bien a la necesidad de transporte urbano en estos núcleos de población debido a su rapidez y relativo bajo precio. Este desarrollo de las comunicaciones por su parte también está incrementando el número de accidentes de tráfico con fatales consecuencias, sobre todo por atropello. De hecho, estudios llevados a cabo en Etiopía concluyen que la educación vial es generalmente inapropiada a nivel local. Los programas generalmente se basan en modelos educativos importados de otros contextos. De ahí la importancia de educar a los niños, teniendo en cuenta su cultura para mejorar la seguridad en las carreteras (Salmon y Eckersley, 2010). En nuestra experiencia de campo fuimos testigo de alguno de de estos incidentes (véase Figura 18). 


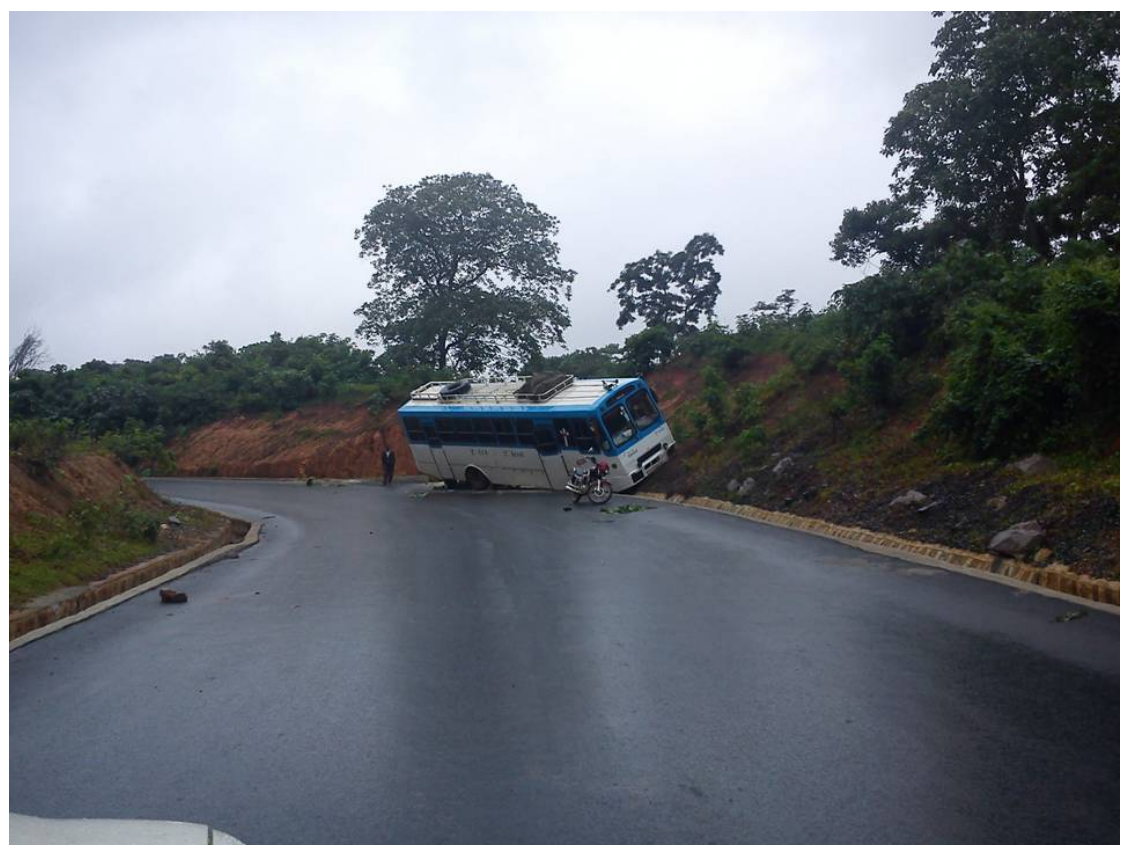

Figura 18. Autobús accidentado en una nueva carretera de Gujiland

(Fuente: Autor)

La presencia de minerales necesarios para la fabricación de las baterías de los teléfonos móviles también ha abierto un nuevo nicho de actividad económica. Este hecho se relaciona especialmente con la calidad de vida infantil, ya que la búsqueda de este mineral en distintos yacimientos en los márgenes de alguno de los ríos que atraviesan Gujiland durante el verano es una actividad llevada a cabo por los niños. Así, en palabras de uno de nuestros informantes: "los niños desaparecen durante el verano para ir a buscar estos minerales" (Donatien, comunicación personal, 12 de Enero 2013). Con los beneficios de esta actividad de búsqueda las familias redondean sus ingresos, siendo este dinero en muchas ocasiones utilizado para pagar los gastos extraordinarios que supone para las familias el inicio del curso académico una vez acabado el verano. A un nivel similar al de la búsqueda de minerales anteriormente comentada también está la búsqueda de oro en el río que atraviesa hasta Saquiso. Lo hacen los niños también en verano y algunos adultos todo el año como actividad complementaria a la agroganadera dejando la prueba de ello en los múltiples agujeros que rodean el cauce del río en algunas zonas. 
Una actividad económica extraordinaria y localizada en la población de Saquiso es la explotación de un yacimiento aurífero propiedad del empresario Alamudi, la persona más rica de Etiopía y muy cercana al gobierno federal, empresario del que ya hablamos en el primer capitulo de esta tesis. Esta mina está a su vez generando una serie de consecuencias para la zona, como la atracción de mano masculina y joven de obra tanto de Gujiland como de otras partes del país. La cara perversa de este proceso es que debido a la numerosa presencia de hombres jóvenes solteros o con sus familias en lugares lejanos hay una gran cantidad de prostitución en la zona con la consecuencia de que algunas de las poblaciones circundantes a la mina, tienen unos de los niveles más elevados de VIH de Etiopía.

En estos momentos, con la gran inversión que está llevando a cabo el gobierno etíope para modernizar las infraestructuras del país principalmente en el apartado de vías de comunicación, se ha abierto una nueva oportunidad de trabajar para las compañías extranjeras concesionarias de las obras. Además, debido a la normativa laboral del gobierno etíope se están contratando tanto hombres como mujeres para trabajar en las obras, aunque en los trabajos más especializados como la conducción de los camiones y la maquinaria pesada la prácticamente totalidad de todos los puestos están ocupados por hombres. Por otra parte cuando visitamos la base de la empresa Turca que está llevando a cabo las obras desde Irba Muda hasta más allá de Adoola, la presencia de trabajadoras como secretarias y otros trabajos de oficina era muy significativa.

Estas nuevas actividades de trabajo no solo están ayudando a dinamizar la economía de la zona sino que están provocando cambios sociales al permitir a las mujeres obtener una "independencia económica" que antes no tenían oportunidad de alcanzar. Cuando menos, el trabajo de las mujeres constituye un aporte a la economía familiar más significativo con su subsiguiente impacto en las relaciones de poder dentro de la familia y demostrando en el caso de las trabajadoras de oficina que invertir en la formación de las hijas de la familia tiene consecuencias positivas, ya que si retrasan la edad de matrimonio y consiguen un buen trabajo pueden aportar dinero a la familia que compensen a sus padres los recursos invertidos en su 
formación que luego tradicionalmente iban a perder al pasar la hija a formar parte de la familia de su marido o al estar mejor formadas y tener un trabajo la familia de la futura esposa puede exigir una mayor dote a la del novio.

Por último, y no por ello menos importante en la vida de los Guji, hay que destacar la aparición de una clase de trabajadores de cuello blanco que trabajan en su gran mayoría para las distintas administraciones del gobierno y que están muy ligados políticamente al mismo. Los cuerpos principales son los formados por los trabajadores de la administración local y los trabajadores de las escuelas. Estos trabajadores son en su mayoría Gujis pero también hay miembros de otros grupos Oromo o de etnias diferentes. Estos trabajadores de origen exterior tienen una presencia muy significativa en el área de sanidad, ya que una vez que los estudiantes acaban sus estudios tienen que servir una serie de años al gobierno, cantidad de años que se ve reducida si trabajan en zonas rurales y aisladas. En nuestra experiencia, en la clínica de Boamba este fenómeno era muy significativo. Ello ha traído consigo el problema de la barrera idiomática que se levanta entre facultativos y pacientes ya que muchos Guji solo hablan su dialecto de Oromo y no comprenden el amhara que utilizan los trabajadores sanitarios.

\subsection{FAMILIA OROMO}

\subsubsection{Parentesco}

Los Guji, a diferencia de otros grupos Oromo que están formados por un solo cuerpo, están constituidos por una confederación de tres grupos de carácter independiente pero fuertemente relacionados: Los Uraga, los Hoku y los Mati. Esta división e independencia de los distintos grupos queda reflejada en que cada uno de ellos tenía tradicionalmente su propio sistema de Gada, sus propios lugares de reunión para las reuniones periódicas de las asambleas de los miembros y sus propios Abba Gada, dando a los Guji una serie de características que los diferencia de otros grupos Oromo: 
"Throughout most of the Oromo nation the general pattern is one Abba Gada and plurality of Qallus, whereas in Guji there is one Qallu and plurality of Abba Gada" (Legesse, 2006, pág. 181).

Estas tres subdivisiones tienen a su vez un marcado carácter territorial y así por ejemplo, nuestro trabajo de campo ha tenido lugar con los Uraga de la zona de Qillenso. Legesse (2006) justifica este marcado carácter territorial de las subdivisiones Guji a que este pueblo debido a la naturaleza del entorno en el que se asienta ha llevado una vida más sedentaria que otros grupos Oromo:

"What distinguishes the Guji system is that is has evolved into a territorial organization, among a people who live around a luxuriant rain forest, and practise a more sedentary, less nomadic form of agropastoralism. In that context, it is reasonable to expect the clans to become more grounded, as indeed they are" (Legesse, 2006 pág. 182).

Las diferencias entre estos tres grupos no son significativas más allá de que en función de la zona donde habiten los Guji existe una mayor o menor dependencia de la agricultura o de la ganadería debido a las condiciones ambientales diferenciadas. A su vez estos tres grupos están divididos en clanes, los clanes Guji Ilamados "Moona" son entidades de parentesco patrilineales exogámicos. La regla de la exogamia se mantiene estricta sin verse alterada por la distancia entre generaciones o lazos de sangre (Van de Loo, 1991).

El nombre elegido para referirse a los clanes "Moona" es significativo para entender la importancia que los Guji dan al ganado vacuno, ya que también es el nombre del corral cercano a la casa en el que se guarda el ganado de la familia extensa o clan. Es otro ejemplo más de la identificación que hacen los Guji entre la familia y el ganado, como veremos más adelante esta identificación entre ganado y personas la vuelven a hacer a la hora de enunciar las formulas tradicionales para concretar un matrimonio por secuestro.

La subdivisión Uraga cuenta con siete clanes: Gola, Sorbortu, Agamtu, Halo, Darartu, Woysitu y Galalca. Por su parte, la subdivisión territorial Hoku cuenta con siete clanes también: Galalca, Oborra, Bala, Hera, Bunditu, Micille y Kin`o. Por 
último la subdivisión Mati solo cuenta con tres clanes: Hirkartu, Insale y Handoa. Otros autores como Negera dividen a los Guji en cuatro grupos:

"Unlike other Oromo groups, which each constitute a single entity, Guji is a confederation of four independent, but by no means exclusive, subgroups known as Uraga, Mati, Hoku and Alabdu. The latter is in turn a confederacy of two interdependent groups called Halo and Woyestu" (James, et al, 2002, pág 119).

Como en todo sistema de parentesco patrilineal, cuando las mujeres se casan entran a formar parte de la familia del marido. Este aspecto cultural tiene la consecuencia negativa de que las familias solo "invierten" por ejemplo en educación, tema de especial interés en nuestra Tesis Doctoral, lo estrictamente necesario en sus hijas ya que una vez que se casen toda inversión pasará a beneficiar solamente a la familia del marido.

\subsubsection{Familia nuclear y familia extensa}

Mana (Casa) o Worra mana (Familia de la casa) son los dos términos con los que los Guji se refieren a la familia nuclear más cercana. Worra también hace referencia a las cinco generaciones que conforman la familia nuclear, siempre teniendo en cuenta que se refieren solo a la línea patrilineal. En esta relación de cinco generaciones queda incluida también la generación de los great-granparents más cercanos que hayan fallecido. Esta realidad está reflejada en el dicho Guji "Worri Guji ii sanan" traducible como "La familia de un Guji son cinco (generaciones)"

Los miembros de la familia extensa siguen siendo considerados familiares consanguíneos. Están sujetos por tanto a la regla de la exogamia y comparten tabúes alimenticios en caso de fallecimiento de un miembro de la familia (Van de Loo, 1991).

\subsubsection{El nombre}

Relacionado con el parentesco está la forma en la que los Guji se nombran. El nombre Guji está compuesto al menos del nombre propio, el nombre propio del 
padre y el nombre propio del abuelo paterno, pero un Guji teóricamente debería recordar al menos los nombres de las ocho generaciones anteriores de su familia, solo por la rama masculina. Los nombres propios suelen elegirse reflejando algún acontecimiento sucedido durante el parto o el embarazo. También hay nombres que surgen de los estados de ánimo provocados por la llegada al mundo del niño o la niña. Otros se eligen por el momento del año en el que se produce el nacimiento, por ejemplo es fácil encontrar persona que se llaman lluvia si han nacido en la época húmeda o llovía el día de su parto (Robee o Robale). Otros nombres tradicionales hacen referencia a cargos de la organización tradicional como serían el nombre de Abba Gadaa o Abba Dula que significan Padre de la Gada y Padre Guerrero, nombres de los más altos cargos de la organización tradicional.

En la actualidad se empiezan a poner nombres de origen cristiano o por influencias culturales externas, pude observar como tanto la Iglesia Ortodoxa había hecho aparecer nombres amháricos en la zona, siguiendo las campañas empezadas por Menelik II (Melbaa, 1999) y especialmente como los protestantes luchaban contra los nombres tradicionales e imponían la utilización de nombres cristianos. Otro tipo de nombres que han aparecido es por las influencias culturales más profanas, como la aparición de niños y niñas llamadas China o con nombres que hacen referencias a marcas de productos occidentales como coches $u$ otros productos que han hecho su aparición en la zona, este fenómeno de la aparición de nuevos nombres ha ocurrido en toda Etiopía, recordando a el fenómeno de la aparición de nombres con origen anglosajón en España o con la utilización de nombres de marcas o de productos norteamericanos en América Latina.

\subsection{CALENDARIO Y MEDICIÓN DEL TIEMPO}

Tradicionalmente el calendario de los Guji lo establecía el Abba Gadaa. El calendario tradicional Guji tenía una base lunar, contaba con meses de 27 días y cada día tenía su propio nombre (Van de Loo, 1991). Actualmente los Guji han adoptado el calendario ortodoxo etíope de base solar. Lo único que queda del calendario lunar anterior es el recuerdo de la existencia del mismo y continuidades 
culturales como utilizar el término "jia", literalmente luna, para referirse al espacio de tiempo de un mes. Más allá de los calendarios astronómicos la verdadera organización del tiempo para los Guji es la que dicta la dicotomía entre la estación de lluvias y la estación seca y el ritmo de las labores en el campo. La estación lluviosa, llamada ganna, comprende desde el mes de Junio al mes de Octubre mientras que la estación seca comprende desde Noviembre hasta Mayo, aunque durante los meses de Febrero y Marzo es habitual que se produzcan algunas precipitaciones. 


\section{CAPÍTULO 3. LA EDUCACIÓN EN ETIOPÍA}

\subsection{INTRODUCCIÓN}

El tema central de esta Tesis es la educación de los niños de la etnia Guji de Etiopía y su relación con la calidad de vida que éstos alcanzan. Es por ello muy importante entender cómo funciona el sistema educativo etíope, qué características lo definen y cuáles son sus puntos fuertes y débiles. Además, debido a la organización administrativa del Estado etíope, es importante conocer la aplicación de este sistema educativo en la región de la Oromía, ya que parte de las competencias y la organización educativa está en manos de las distintas regiones federales del país.

Así pues, en el presente capítulo comenzaremos exponiendo una pequeña introducción a la evolución del sistema educativo etíope, el impacto que este desarrollo ha tenido y su realidad en la actualidad. Procederemos entonces a analizar los distintos indicadores del sistema educativo etíope tanto a nivel nacional como a nivel de la región de la Oromía de los últimos años haciendo especial hincapié en las características de la escolarización femenina para finalmente exponer los problemas que hemos detectado en el sistema educativo etíope

\subsection{EVOLUCIÓN DEL SISTEMA EDUCATIVO}

La educación y el sistema educativo etíope han pasado por distintas fases, desde un periodo de práctica inexistencia a un desarrollo de manera acelerada y con unos objetivos muy específicos desde finales del siglo XIX y principios del siglo $X X$.

Indudablemente durante el periodo preaxumita y anteriormente a la conversión de este imperio al cristianismo debía de existir un sistema educativo muy limitado, que serviría para formar a los miembros de la burocracia de los distintos estados. Prueba de ello es la existencia de inscripciones en yacimientos del periodo protoaxumita, como la que se muestra a modo de ejemplo en la Figura 19. 


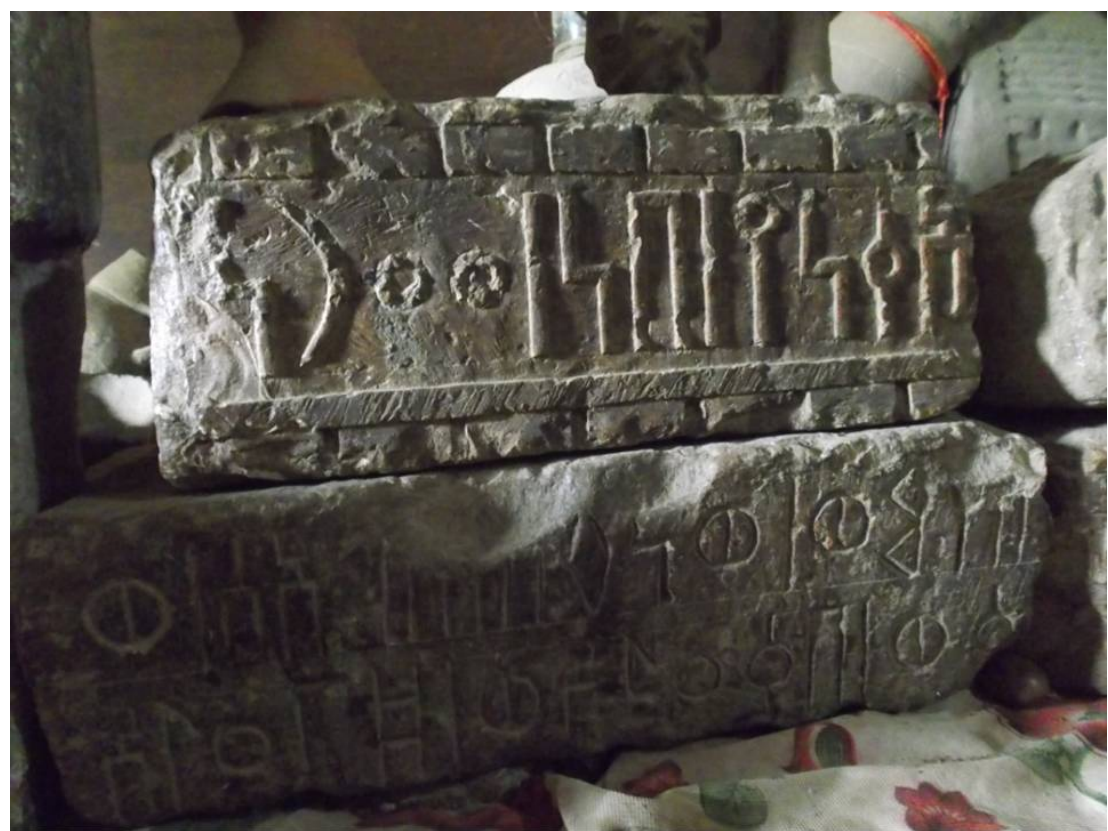

Figura 19. Inscripciones en lengua preaxumita en la ciudad de Yeha

(Fuente: Autor)

Pese a la existencia de esas clases sociales que sabían escribir y que por tanto deberían haber recibido algún tipo de educación formal, en Etiopía se considera que la educación formal surgió con la llegada del cristianismo.

"Education in Ethiopia dates back to the fourth century. For about 1,500 years the church controlled most of the education institutions" (http://www.ethioembassy.org.uk recuperado el 20 de Enero de 2014 de http://www.ethioembassy.org.uk/about us/education.htm).

Este sistema educativo que estaba en manos de la Iglesia Ortodoxa solo alcanzaba a unas capas muy limitadas de población, que eran las clases más ricas y poderosas de las etnias amhara y tigriña principalmente o a sus servidores de palacio. Además la Iglesia Ortodoxa transmitía en sus centros educativos su religión y los valores culturales de los pueblos semíticos del norte, motivo por el cual la Iglesia Ortodoxa sería utilizada por el Estado amhara para aculturizar los nuevos territorios conquistados con su expansión militar (Melbaa, 1999). En el resto del país, los sistemas educativos eran virtualmente inexistentes. En las zonas musulmanas la educación era llevada a cabo en las madrazas de manera tradicional 
repitiendo versículos del Corán., Un ejemplo de ello se expone en el museo de la Universidad de Addis Abeba, donde se encuentran muestras de manuscritos ortodoxos y tablillas musulmanas usadas para la educación tradicional, tal y como tuvimos oportunidad de constatar (véase Figura 20).

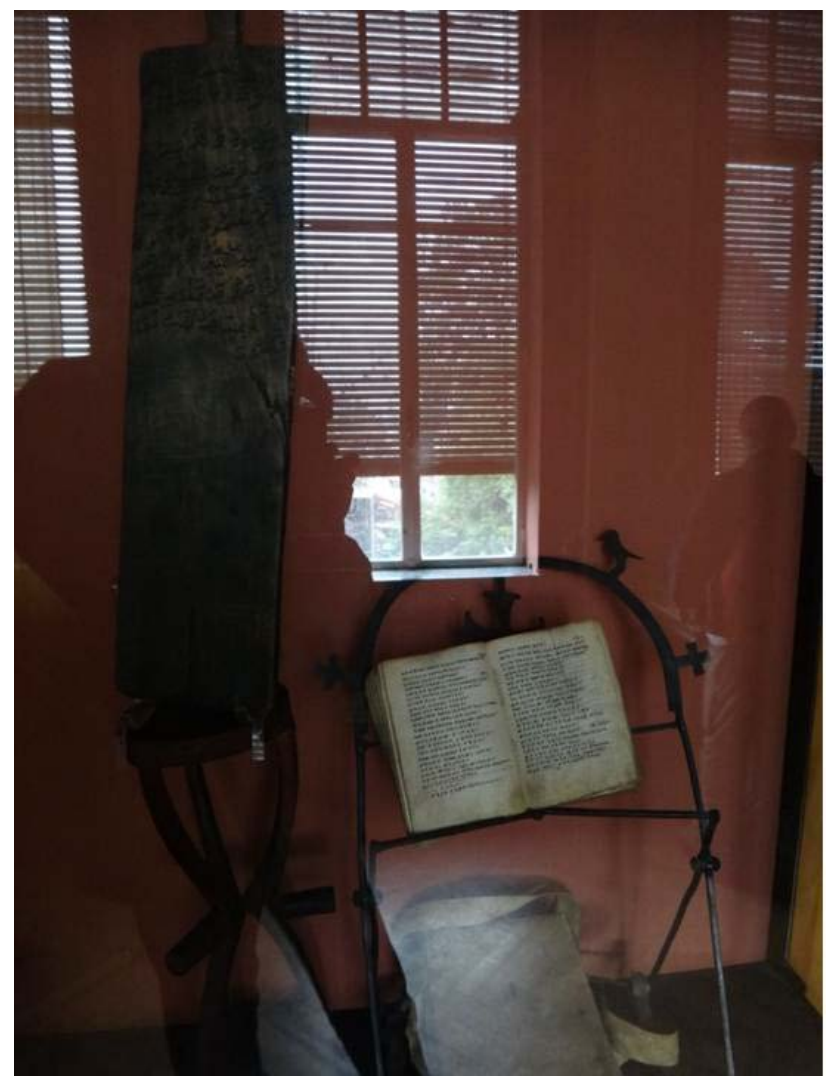

Figura 20. Tablilla coránica y manuscrito ortodoxo utilizados para la educación. Museo de la Universidad de Addis Abeba

(Fuente: Eduardo Hernández Gil)

Sin embargo, en la mayoría de las zonas al sur de la zona de tradicional de presencia amhara no había ningún tipo de sistema educativo formal. Muchas etnias no habían desarrollado la escritura, por lo que esta situación imposibilitaba la creación de un sistema educativo nativo más allá de las escuelas que las misiones de las distintas confesiones religiosas pudieran abrir.

Centrándonos en la etnia Guji, como todos los Oromo, su infancia tradicionalmente estaba reglada por la Gada, y los conocimientos tradicionales que 
se inculcaban a los niños tenían un fuerte componente práctico tanto para la vida diaria como para su desempeño dentro de la vida social del grupo (Legesse, 1973). En los Guji es importante señalar además la importancia que la utilización de los proverbios tradicionalmente tenía a la hora de transmitir los valores sociales y culturales, ya que al no existir la lengua escrita era una poderosa herramienta para la enculturación de los niños y jóvenes (Jaleta, 2004).

El hecho de que hasta el siglo XX no se instaurara un sistema educativo formal y que lo hiciera de una manera muy limitada, como veremos más adelante, es fundamental para entender el origen de alguno de los problemas más importantes a los que se ha enfrentado el sistema educativo etíope desde su origen y que en la actualidad siguen dificultando la consecución de una escolarización universal de calidad. Así, tras la llegada de los primeros misionarios europeos éstos entendieron que la educación era una manera de ayudar a desarrollar el país al mismo tiempo que les daba una oportunidad para expandir las distintas fes que procesaban. Esto fue especialmente significativo a partir del siglo XIX, en el que los monarcas estaban interesados en propagar la educación para conseguir unas clases educadas que les sirvieran como burócratas y como técnicos militares:

"Interest in modern education in Ethiopia goes back to the nineteenth Century. The missionaries, who saw education as an effective means of proselytization, were active in establishing a number of schools and sending the more promising students aboard"' (Zewde, 2001 pág. 103).

Un ejemplo claro de ello fue la instauración de una escuela por misionarios europeos en Gafat bajo el beneplácito de Tewodros, en la que se combinaba la educación con la fabricación de armas:

"At Gafat, a school was established where Ethiopian youths acquired literacy and some technical skills. By trial and error, and under the emperor's ceaseless prodding, the missionaries managed to manufactured some weapons" (Zewde, 2001, pág. 34)

Este interés por la educación aumentó tras la batalla de Adwa y el posterior incremento de las relaciones internacionales, junto al creciente desarrollo del 
aparato del Estado que necesitaba cada vez más personal para funcionar (Zewde, 2001). Menelik II también abrió un número limitado de escuelas centradas en su mayoría en la nueva capital, Addis Abeba (Henze, 2000), pero como veremos a continuación el gran impulsor del sistema educativo durante el principio del siglo XX hasta su derrocamiento fue el emperador Haila Selasi. El sistema educativo moderno que se crea en esta época tiene por tanto una antigüedad de unos 100 años en el país. Además este sistema educativo se va a caracterizar en gran medida por su escasa extensión, y por su elevada inequidad e ineficacia, problemas contra los que todavía se lucha:

"Modern education was introduced to Ethiopia nearly a century ago. However, the education and training offered during these long years had limited positive impact on the lives of the people and national development. The education offered has not enabled to solve the problems of farmers, pastoralist, and change the lives of the over whelming majority of the people" (Ministry of Education, 2002 pág. 1).

El pistoletazo de salida a este sistema de educación formal en Etiopía lo dio Menelik II en 1908, con la fundación de la Menelik II School:

"In terms of formal education, the last years of Menelik saw a significant event the founding in 1908 of the first school set up along modern lines" (Zewde, 2001, pág. 108).

Durante estos primeros años, el nuevo sistema formal de educación estuvo fuertemente influenciado por Francia y la cultura francesa, imponiéndose el francés sobre el inglés como lengua extranjera a la que se daba mayor importancia:

"French was the medium of instruction, and it was remain the lingua franca of Ethiopian intelligentsia until suppressed by English alter 1941" (Zewde, 2001, pág. 108).

Con la llegada de Haila Selasi al poder, el impulso que recibió la creación de escuelas fue mayor aún, pese a ello la presencia de escuelas se centraba casi exclusivamente en la capital y en algunas zonas del norte del país. Así, la situación en Addis Abeba era la siguiente: 
"By 1924, the capital's rudimentary educational system had touched several thousand people, but not enough for a country whose advancement required a cadre educated in Wester ideas. In 1925, the Ras established and financed the quasi-secondary Tafari Makonnen School, which by the end enrolled 160 boys and youths" (Marcus, 2002 pág. 122).

En esta escuela quedó aún más patente la preeminencia que se daba a lo francés como modelo a seguir para desarrollar un sistema educativo formal, tal y como se venía haciendo desde 1912 con la apertura de dos escuelas francesas:

"French cultural paramountcy was further reinforced by the opening alter 1912 of Alliance Franchise schools in Dire Dawa an Addis Ababa. Tafari Makonnen School, opened by Ras Tafari in 1925, was even more French oriented than Menelik II School, with French directors and with the students sitting French Government Certificate examinations" (Zewde, 2001 pág. 108).

Durante nuestra estancia en Etiopía pudimos observar cómo esta presencia tan importante de la cultura francesa en la educación, aunque posteriormente haya sido sustituida por la influencia del mundo anglosajón, ha dejado un recuerdo, ya que en la actualidad el Liceo Francés de Addis Ababa es uno de los colegios más prestigiosos de todo el país y tiene una gran importancia en la vida cultural de la capital. En la década de los 1920 se produjeron varios hechos significativos. Hay que destacar entre éstos el inicio del programa, apoyado personalmente por el propio Haila Selasi, de enviar estudiantes prometedores a completar sus estudios superiores en el extranjero y la implantación de una tasa a partir de 1926 del seis por cierto a las importaciones y exportaciones con el fin de invertir el dinero recaudado en el fomento de la educación (Henze, 2000).

El año 1930 fue también fundamental para la educación en Etiopía, ya que se empezaron a fundar una serie de escuelas más allá de Addis Abeba. De especial importancia fue además la creación de un Ministerio de Educación como un ente independiente, cuando anteriormente había sido una simple oficina dependiente de la iglesia ortodoxa (Zewde, 2001). 
Durante el aproximadamente cuarto de siglo que va desde 1908 hasta 1935 se fue creando una pequeña clase intelectual en Etiopía que trabajaba en las oficinas del gobierno principalmente y que soñaba con lograr que su país se modernizara siguiendo el ejemplo de Japón que había salido de una sociedad feudal para conseguir alcanzar un gran desarrollo industrial y económico (Zewde, 2001). Gran parte de los progresos alcanzados durante estas décadas se perderán con la invasión italiana de Etiopía en 1935 y con la subsiguiente guerra y ocupación. Muchos de los etíopes mejor preparados perecieron en esta guerra y en las sangrientas represiones que se produjeron durante la ocupación como respuesta a los movimientos de resistencia que se produjeron en el país. Aparte de estas muertes, hay que añadir la destrucción material que sufrió el país:

"By the end of 1937 more than 5,000 people has been executed for alleged crimes related to the attempt on Graziani. Among them were practically all the young educated Ethiopians the Italians could lay their hands on and all the officers and cadets of the Holeta Military Academy" (Henze, 2000, pág. 226).

Durante la ocupación, el gobierno italiano no realizó esfuerzos por mejorar la educación de los etíopes debido en parte a las ideas raciales que el gobierno fascista de Mussolini tenía. Por el contrario, se centraron en sacar provecho económico de la ocupación (Henze, 2000). En 1941 con la liberación de Etiopía por las fuerzas británicas y la vuelta del exilio de Haila Selasi se abre un nuevo periodo para el sistema educativo etíope. Como novedad más inmediata, tanto Inglaterra en un primer momento como posteriormente los EEUU desplazaron a Francia como países extranjeros con un mayor peso en Etiopía y el inglés sustituyó al francés como la lengua extranjera más importante para la educación en el país. Esta prominencia de lo anglosajón en la educación pervive hasta la actualidad. Nosotros hemos sido testigos del uso del inglés como lengua en varias conversaciones entre etíopes en la Universidad de Addis Abeba, conversaciones en las que no intervenía ningún extranjero. Nada más retomar el poder, el emperador Haila Selasi organizó personalmente la reconstrucción del sistema educativo etíope y alguna de sus primeras medidas fueron la reinstauración del Ministerio de Educación y la 
expansión de la construcción de escuelas por las provincias del país (Getachew, 2001). En 1941 la necesidad de sustituir a los etíopes mejor educados que habían muerto bajo la ocupación italiana era muy acuciante:

"Modern education also took off in the post-liberation period with the urgent need to replace the educated class killed by the Fascist, and the increasing need for educated and trained individuals to handle the requirements of the modernizing economy" (Getachew, 2001, pág. 125).

La situación era aún más grave ya que, durante la ocupación italiana, las escuelas para etíopes fueron cerradas, haciendo retroceder la implantación de la educación a la situación de varias décadas atrás:

"All schools for Ethiopians had been closed by the Italians Turing the Occupation, so the emperor was starting literally from nothing" (Getachew, 2001, pág. 125).

Además debido a la muerte de la gran mayoría de los etíopes educados el esfuerzo de reconstruir el sistema educativo y otras secciones de la administración recayó casi exclusivamente en personal extranjero reclutado con tal fin:

"Because of their extermination, the post-war effort to Estbaliz and apead modern education had to rely exclusively on expatriate advisers, adninistrators, and teachers" (Milkias y Kebede, 2010, pág. 30).

Esta necesidad fomentará el crecimiento del sistema educativo, pero al mismo tiempo provocará que éste se oriente y organice para la consecución de este objetivo, haciendo que el sistema solo abarque a un número limitado de estudiantes. Además, su fin era crear una clase burocrática, más que expandir la educación a todas las capas de la sociedad:

During both the initial phase and it's the more planned and coordinated expansion of modern education after 1941, the primary objective of education in our country had been to produce trained manpower that could run the emergent government bureaucracy. Particularly after 1941, the government's main concern was to replace expatriates that worked at various levels in public offices by Ethiopian nationals. Hence, the narrow and limited scale of formal education that 
existed, beyond incubating bureaucratic clerks, had hardly any substantial merit (Ministry of Education, 2002 pág. 1).

Esta orientación persistió en gran medida durante las décadas de 1950 y 1960 agravando el problema que esto suponía para el desarrollo del país. Y ello porque al estar la educación tan centrada en la creación de burócratas, los estudiantes dependían del gobierno a la hora de conseguir un trabajo, por lo que la creación de un tejido de empresas privadas que ayudara al crecimiento económico del país quedaba de este modo desincentivado:

"The education of the time nonetheless did little to change trainees" outlook or help them break the cycle of dependency on the government for employment and develop a capacity to create their own jobs in the private sector" (MoE, 2002, pág. 1).

En esta década de los 1940 se fomentó desde el gobierno la expansión de la construcción de escuelas primarias y secundarias. La situación de partida era realmente muy precaria ya que estudios como Henze (2000) sitúan la tasa de analfabetismo por esa época en un $95 \%$ de la población. Ante la imposibilidad de que el gobierno pudiera cubrir la expansión de la educación en solitario y debido a la falta de profesores se invitó a gobierno, organizaciones y personal extranjero a participar:

"There was an acute shortage of teachers. Foreign governments and individuals as well as missionaries were invited to help expand secondary education" (Henze, 2000 pág. 256).

En 1947, debido a estas dificultades y a la necesidad de crear y mantener nuevas escuelas, fue creado un impuesto especial sobre la tierra con el que se pretendía también mantener a los profesores (Marcus, 2002). La realidad en 1950 había mejorado, pero distaba aún mucho de ser una situación de expansión real y significativa del sistema educativo, además se estaba utilizando la educación como medio para asegurar el poder del emperador y el statu quo del imperio, con unas etnias que dominaban al resto de la población: 
"By, 1950 Ethiopia's five hundred school enrolled 52,965, a very small percentage of school-age children to be sure, but they were well taught and thoroughly indoctrinated with loyalty to the throne, respect for the country's traditions, and patriotism" (Marcus, 2002, pág. 160).

Un hito de la educación en Etiopía fue la fundación en 1950 de la Universidad de Addis Abeba, posteriormente renombrada en 1961 Universidad Haile Selasi I (Henze 2000, Marcus 2001). Durante la década de 1950 el crecimiento del sistema educativo fue lento, y principalmente se centró en las grandes ciudades dejando de lado la gran mayoría de la población rural y por ende la gran mayoría de la población, pero en 1960 con la firma de un acuerdo entre Etiopía y los EEUU la expansión de las escuelas de primaria y secundaria recibió un acelerón:

"Primary and secondary education at first expanded slowly, especially in the provinces, but received an enormous boost in the early 1960s when President Kennedy agreed to have the largest Peace Corps contingent in the world assigned to Ethiopia. There were over 900 volunteers, mostly teaching in secondary schools, by the middle of the decade" (Henze, 2000, pág. 257).

A esta presencia de voluntarios norteamericanos hay que añadirle el gran programa de ayudas sueco, que durante la misma década desembarcó en Etiopía:

"During the same period, Sweden undertook a massive school building program and primary and secondary education Spreads rapidly throughout the country, sometimes with local communities raising funds to supplement the central government's budgetary allocations" (Henze, 2000, pág. 257).

Debido al crecimiento del número de escuelas, el gobierno volvió a encontrarse con la imposibilidad de formar suficientes profesores para cubrir la demanda, por lo que se contrató personal de Asia, principalmente de la India para cubrir esta necesidad, sobre todo en las escuelas secundarias (Henze, 2000). Como explicáramos en el primer capítulo de la presente Tesis doctoral, pese a que en ese momento se produjo una expansión de las escuelas de primaria y secundaria por las provincias del imperio, ello no significó que la educación llegara a todos por igual. Las escuelas como el resto de los servicios se concentraron primero en Addis Abeba 
y luego en las capitales de provincia, sobre todo de las regiones del norte del país, favoreciendo a las etnias amhara y tigriña. Además como también expusimos en el primer capítulo y como defienden autores como Melbaa (1999) la educación se ofrecía solo en amhárico y con unos contenidos que promocionaban la cultura del norte y denigraban las culturas diferentes a la amhara y tigriña:

"Instead Amharic was deliberately imposed throughout the country as the official medium of instruction in all primary schools as a tool to deepen and broaden the pattern of ethnic domination" (MoE, 2002, pág. 13).

Sobre estos aspectos más sombríos del sistema educativo durante la época de Haila Selasi y su continuación en la actualidad entraremos en profundidad más adelante cuando hablemos de los problemas del sistema educativo etíope.

La situación continuó desarrollándose en estos parámetros durante toda la década de 1960 hasta 1974 cuando estalló la revolución que acabaría con Haila Selasi e instauraría la dictadura del Derg. Aunque es innegable que bajo el gobierno de Haila Selasi se obtuvieron grandes avances, en el sector de la educación se produjeron situaciones de inequidad y utilización del sistema educativo para la aculturación de las etnias no dominantes que arrojan una sombra a los logros creados y que responden a la propia mentalidad del emperador y de las clases dominantes del momento (Marcus, 2002; Melbaa 1999). Durante la década de 1960 la situación interna del país fue deteriorándose. Un ejemplo de ello fue el intento de golpe de Estado de 1960 en el que los estudiantes y clases intelectuales etíopes tuvieron un gran protagonismo, hastiados de la lentitud de las reformas y la falta de oportunidades (Marcus, 2002).

Es fundamental la importancia que va ganando el movimiento estudiantil durante esta década paralelamente al crecimiento del número de estudiantes. Así, al acabar la década de 1960 éstos habían alcanzado la cifra de unos 700,000, lo que supone un enorme crecimiento desde 1941 aunque seguía siendo un número insuficiente para cubrir las necesidades del país (Marcus, 2002). Este movimiento estudiantil irá radicalizándose con el tiempo hasta que a finales de la década de 1960 y principios de la de 1974 se convertirá en claramente revolucionario y 
abogará por el derrocamiento de Haila Selasi. Esta radicalización de los estudiantes se vio favorecida paradójicamente por una de las medidas adoptadas por el emperador para evitarlo precisamente, la contratación de profesorado universitario religioso y conservador:

"But this prudent policy backfired: the apolitical attitude of the staff drove students to read underground books and pamphlets. Because they were not offered a liberal alternative, neither could they develop a culture of openness, debate, and moderation. Not only did the University fail to defend student's traditional idebtuty, but it also exposed them to the influence of underground radicals by not championing a culture of political debate and openness" (Milkias y Kebede, 2010, pág. 32).

Pese a ello Haila Selasi siguió confiando en la creación de una clase educada devota a el que le ayudara a seguir con sus planes de modernización del país al mismo tiempo que conservaba un poder casi absoluto y se negaba a realizar reformas significativas, situación que acabaría fomentando la revolución (Zewde, 2001).

En 1974 estalló la revolución que derrocó al emperador y con ello llegaron nuevos tiempos para el sistema educativo etíope. Con la llegada del Derg al poder, el sistema educativo recibió de nuevo un duro golpe; es significativo que una de las primeras medidas que tomó el nuevo gobierno fuera el cierre de la Universidad de Addis Abeba para enviar a los estudiantes a promover la revolución por todo el país, siguiendo el ejemplo de la Revolución Cultural China.

Durante el gobierno del Derg el sistema educativo fue puesto al servicio de los objetivos ideológicos y económicos del régimen, siendo fundamental el adoctrinamiento de los estudiantes en la ideología marxista-leninista como el propio régimen expresaba a principio de los años 80 :

"Socialist educational stressed the inculcation of ideology as a prime objective within Marxism and the value of production as its main pillars" (Milkias y Kebede, 2010, pág. 12).

Para ello se reformó el currículum sin una buena planificación: 
"A new curriculum was duly produced where five new subjects namely, agriculture, production technology, political education, home economics and introduction to business were added" (Milkias y Kebede, 2010, pág. 12).

Esto tuvo desastrosas consecuencias educativas, produciéndose un exceso de asignaturas y una bajada de la calidad de la enseñanza (Milkias y Kebede, 2010). Además los occidentales que suponían una parte fundamental del personal educativo fueron rápidamente sustituidos por nuevos expertos llegados del bloque comunista (Milkias y Kebede, 2010). Por ello, gran parte de los conocimientos y experiencia sobre la realidad de Etiopía y de sistema educativo se perdieron de la noche a la mañana. La utilización de la educación y los estudiantes con fines políticos fue más allá aún, un ejemplo de ello es la creación de una campaña a escala nacional en la que el Derg movilizó a los estudiantes de secundaria y de la universidad para implementar la reforma y nacionalización de la tierra en todo el país, mostrando los estudiantes un gran radicalismo (Marcus, 2002).

Este movimiento que en un principio tenía la intención de promover una serie de programas revolucionarios pronto se convertirá en una forma de evitar que los miembros de la oposición al Derg se organizaran mediante su diseminación por el país (Zewde, 2001). Aunque durante los años del Derg el número de niños y niñas que accedieron al sistema educativo aumentó hasta cubrir el 35\% de los niños entre 7 y 16 años lo que no aumentó de igual manera e incluso retrocedió fueron los recursos económicos:

"However, expansion of the education sector was not accompanied by a comparable increase in resources. On the contrary, the Socialist regime intensified the shift system (where students follow all their studies either in the morning or in the afternoon) so as to maximize the utilization of school premises" (Milkias $y$ Kebede, 2010, pág. 13).

Es indudable que la calidad de la educación durante los años del Derg fue resintiéndose cada vez más, un ejemplo de ello es lo ocurrido con el progresivo desconocimiento del inglés por parte de alumnos y profesores: 
"By 1990, one could say English had effectively ceased to be the language of instruction. Despite the fact that it remained the language printed in text books of all subjects for junior and senior secondary education" (Milkias y Kebede, 2010 pág. 14).

La situación en Etiopía se fue volviendo cada vez más insostenible hasta que las guerrillas y grupos étnicos lograron derrocar al Derg en 1991, el legado de este régimen tanto en el país como en el sistema educativo fue desastroso como expresa muy bien Tekeste Negash:

"It portrayed itself as a regime that has done more to spread the benefits of education compared to the imperial rule that it replaced [...] For the great majority of the Ethiopian population, socialism is associated with the spread of the equality of poverty" (Milkias y kebele edit, 2010, pág. 14).

Con la caída del Derg en 1991 todo el Estado etíope sufrió una reestructuración, la educación no fue diferente a ello y lanzó una campaña de reforma y democratización de la educación:

"It was a time when the Ethiopian peoples liberated themselves from a centuries-old system of oppression, and rose up to form a new order of national equality and freedom, of development and democracy. It was therefore necessary to replace the educational system that served the old discarded order by a new one" (MoE, 2002, pág. 4).

Para reformar el sistema educativo el nuevo gobierno reunió a un grupo de expertos encargados de diseñar una nueva política educativa acorde a los nuevos valores democráticos y a las necesidades reales educativas del país. Este grupo se reunió en 1993 y empezó a trabajar:

"As a result, twenty-two government institutions and sixty-two experts from Addis Ababa University served in various committees and contributed to the drafting of the policy. The aim of the study was to formulate a comprehensive and coherent education policy that would be in the service of development and democracy, to assess the problems of modern education in Ethiopia, to recommend solutions, and to broadly analyze all education related issues" (MoE, 2002, pág. 4). 
Como resultado de los trabajos de ese comité de expertos se diseñó una política educativa que satisficiera la democratización de la educación y solventara algunos de los problemas que el sistema educativo de Etiopía llevaba arrastrando durante su siglo de existencia. Esta nueva política entró en vigor en 1994:

"To realize its educational objectives, the government introduced a new Education and Training Policy and an Education Sector Strategy in 1994." (UNICEF, 2012, pág. 55).

Coincidiendo con los planes de cinco años diseñados para el desarrollo económico y social del país, esta nueva política educativa se dividió en programas de cinco años siguiendo la idea del gobierno etíope de conseguir un desarrollo equilibrado entre lo económico y lo social, para a su vez obtener una mano de obra cualificada que ayude a desarrollar la economía del país según ésta se vaya expandiendo e intentando depender lo menos posible de la presencia de extranjeros:

"Subsequently, the government developed a twenty year Education Sector Indicative Plan, which was divided into a series of five-year Education Sector Development Programmes. The duration of these programmes has been adapted so that they fit in with the planning cycles of the national development plan and the time frame for the achievement of the Millennium Development Goals (UNICEF, 2012, pág. 55).

Debido a la nueva estructura federal del gobierno, las distintas regiones también han tenido libertad para implantar los planes de acción de cinco años siguiendo sus propios criterios siempre dentro del marco de actuación a nivel federal:

"In this regard, Regions have been given a free hand to design their own 5 years educational sector development programs based on the specific needs of their region and also the plans of the various departments of the Federal Ministry of Education where included in the program" (MoE, 2002, pág. 59).

Prueba de ello es la utilización como lenguas vehiculares en educación primaria los idiomas de las distintas etnias que conforman el país: 
"The major feature of the new educational policy that became operational in 1994 is the introduction of ethnic languages as mediums of education for primary education. Overnight, more than a dozen languages were deemed fit to function as mediums of instruction" (Milkias y Kebede, 2010, pág. 14).

Aunque, como ya expusimos en el primer capítulo, esta independencia de las regiones está limitada debido a que los recursos económicos están en manos del Estado central y a la propia naturaleza poco democrática del país con las instituciones sometidas a la voluntad del partido político que lleva en el gobierno desde la revolución de 1991. Como consecuencia del impulso que el gobierno ha dado a la educación desde 1994 Etiopía se ha mostrado muy activa en los foros internacionales en todos los temas relacionados con este tema:

"During the latter part of the 20th century, Ethiopia was a signatory of all the relevant global and regional resolutions and declarations" (UNICEF, 2012, pág. $55)$.

Un ejemplo de ello es la utilización del lema "Education for All" o "Quality education for All” en la gran mayoría de las escuelas y la persecución de la universalización de la educación primaria que tiene su origen en la directriz salida de la conferencia de Tailandia de 1990

"Building from the base of these international legal instruments, the 1990 World Conference on Education in Jomtien (Thailand) endorsed 'Education for All' as the rallying cry of the international community. And at the Millennium Summit held at UN headquarters in New York, heads of state and government agreed to work together to ensure that 'children everywhere, boys and girls alike, will be able to complete a full course of primary schooling and that girls and boys will have equal access to all levels of education" (UNICEF, 2012, pag. 55).

En 1999 se dio un paso más con la entrada en vigor del The African Chapter on the Rights and Welfare of the Child que no solo reforzaba el derecho a la educación primaria universal, sino que además tenía en cuenta las características especiales del continente africano, quedando especialmente recogido en varios subapartados del artículo 11 de dicho tratado: 
"(c) The preservation and strengthening of positive African morals, traditional values and cultures; (d) The preparation of the child for responsible life in a free society, in the spirit of understanding tolerance, dialogue, mutual respect and friendship among all peoples ethnic, tribal and religious groups; (e) The preservation of national independence and territorial integrity; (f) The promotion and achievements of African Unity and Solidarity" (UNICEF, 2012, pag. 55).

Esta actividad en los foros internacionales tiene su reflejo en el gran éxito que el gobierno ha tenido a la hora de captar fondos internacionales para financiar el sistema educativo:

"The Ethiopian government in general and the Ministry of Education in particular have been extremely efficient in mobilizing external founds (bilateral and multilateral) for the expansion of the education sector" (Milkias y Kebede, 2010, pág. 14).

Como resultado de todos los esfuerzos de los últimos años el sistema educativo etíope ha sido reformado y reforzado y orientado a dar respuesta a la diversidad interna del país pero, como ya hemos señalado anteriormente, aunque el gobierno etíope afirme que respeta la diversidad étnica y suscriba todos estos tratados internacionales la realidad es que en Etiopía sigue existiendo una desigualdad entre las distintas etnias y el sistema educativo sigue favoreciendo la cultura amhara y a algunas regiones frente a otras.

\subsection{SITUACIÓN EDUCATIVA EN ETIOPÍA}

Una vez que hemos visto las bases históricas y la evolución del sistema educativo de Etiopía ya estamos en condiciones de abordar la realidad de este sistema en la actualidad tras la entrada en vigor de los cambios implementados durante la última década. Para entender esta situación es en primer lugar preciso conocer la evolución de la población susceptible de participar en el sistema educativo etíope y su participación real en el mismo durante los últimos años. En primer lugar, cabe destacar el rápido crecimiento de la población en edad escolar en estos últimos años, como queda de manifiesto en la Figura 21. 


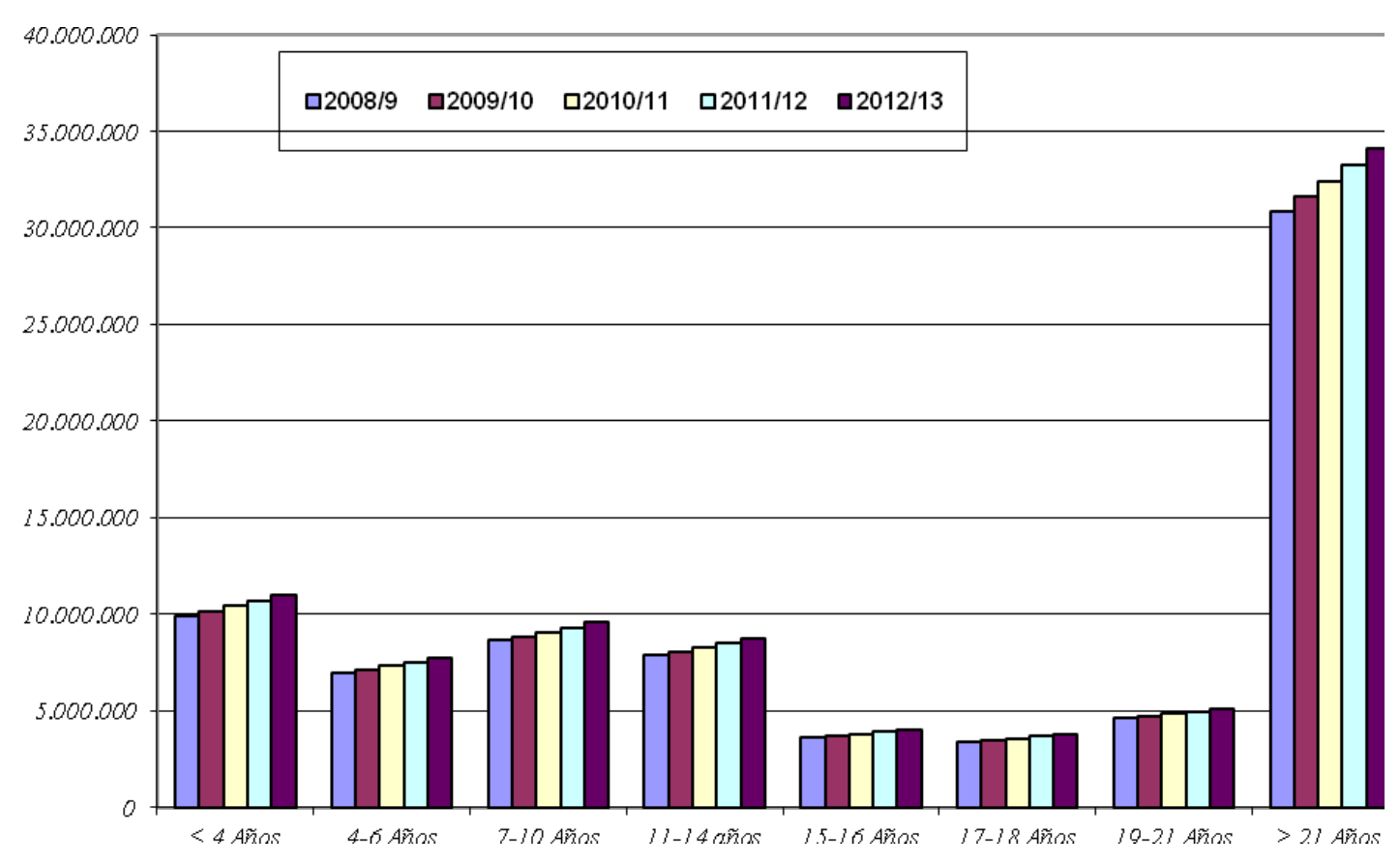

Figura 21. Evolución de la población escolar durante los últimos 5 años

(Fuente: Elaboración propia a partir de datos del MoE)

En la Figura 21 podemos observar un incremento constante de la población en edad educativa a un ritmo del anual medio del 2,6\% aproximadamente. Quizá de estos datos sorprenda la presencia de población mayor de 21 años si bien hay que entenderlo en el contexto de las características e historia reciente de Etiopía. Así, hay programas dentro del sistema educativo destinados exclusivamente a adultos que no han podido acceder a la educación durante su infancia. También es cierto que, debido a la inexistencia de un registro de los nacimientos en el país de una manera sistematizada, estos datos pudieran estar por debajo del número real ya que como denuncia UNICEF hasta un $90 \%$ de los recién nacidos no eran registrados (UNICEF, 2012).

Una vez constatado este incremento constante de la población susceptible de entrar en el sistema educativo es preciso conocer la evolución de la población que efectivamente hace uso de las distintas etapas del sistema educativo (véase Figura 22). 


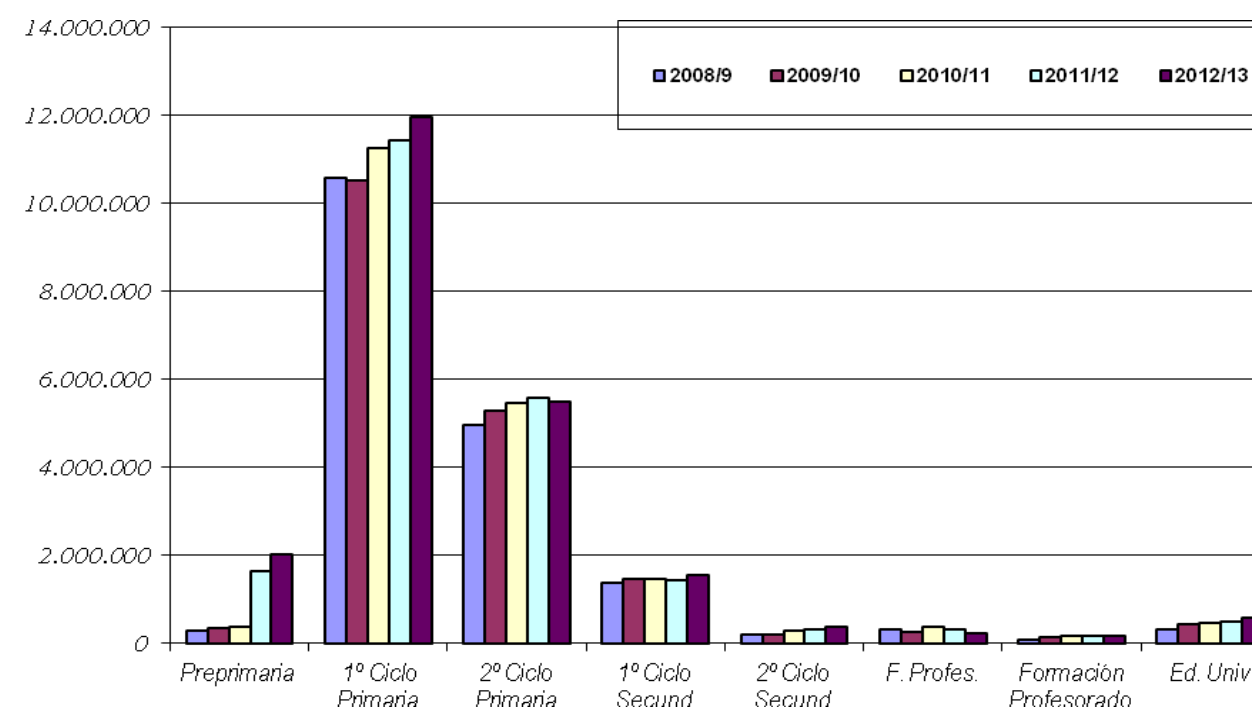

Figura 22. Evolución de los alumnos matriculados en las diversas etapas educativas.

(Fuente: Elaboración propia a partir de datos del Ministerio de Educación)

En la Figura 22 se puede observar el aumento generalizado de alumnos en todos los ciclos educativos el curso 2012/2013 respecto a la situación en el curso 2008/2009 excepto en Formación Profesional. Otros datos destacados son la enorme diferencia de alumnos que asisten a clase entre el primer y segundo ciclo de Primaria, junto a la diferencia entre la educación Primaria y la Secundaria. Todo ello será objeto de un análisis más pormenorizado cuando tratemos cada una de las etapas del sistema educativo.

\subsection{ORGANIZACIÓN ADMINISTRATIVA}

El sistema educativo etíope está organizado distribuyéndose las responsabilidades y competencias entre el nivel federal, el nivel regional y las administraciones locales:

"The Ministry of Education is the executing agency at the federal level. It plays a prominent policy-oriented role and acts as a change agent in leading the education sector towards the realization of its objectives. The regions and woreda are charged with operational responsibilities" (UNICEF, 2012, pág. 60). 
A continuación detallamos de manera más precisa el reparto de las competencias educativas entre los distintos niveles administrativos (UNICEF, 2012). Así, el Ministerio de Educación Etíope tiene las siguientes competencias:

- Desarrollar las políticas y estrategias educativas nacionales

- Fijar los objetivos y estándares nacionales

- Fijar el currículo y las competencias básicas mínimas

- Proveer los libros de texto a las escuelas secundarias

- Fijar los exámenes nacionales

- Evaluar el aprendizaje

- Formar al profesorado de las escuelas secundarias

- Proveer la educación superior

- Promover la inversión privada para el desarrollo de la educación

- Proporcionar apoyo técnico para las oficinas regionales

- Recopilar los datos nacionales del censo escolar.

Por su parte, las regiones tienen las competencias que se indican a continuación:

- Establecer los estándares para las woredas

- Preparar planes y programas regionales

- Formar a los maestros primaria

- Distribuir los libros de texto de primaria

- Preparar y los exámenes finales de octavo grado

- Supervisar las escuelas preparatorias

- Capacitar a las woreda y al personal escolar

- Recopilar datos a nivel regional

Las competencias de las woredas son las siguientes:

- Aplicar las políticas educativas y normativas

- Preparar los planes de la woreda

- Establecer nuevas escuelas

- contratar y pagar al profesorado de primaria 
- Distribuir los libros de texto

- Supervisar las escuelas

- Recoger de datos a nivel de woreda

Como podemos observar, las competencias de cada administración están bien limitadas y definidas. Aún así en nuestra experiencia de campo pudimos observar la existencia de problemas de descoordinación como por ejemplo en el reparto de libros, que ocasionaron que gran parte de los niños no tuvieran libros hasta más de un mes empezado el curso escolar. Además, como ya explicamos en el capítulo primero, al reservarse el gobierno central la mayor parte de los recursos financieros, realmente es éste el que tiene el control y decide en gran parte que políticas o estrategias se implantan simplemente otorgando recursos para ello o negándolos.

\subsection{ESTRUCTURA DEL SISTEMA EDUCATIVO}

En la estructura del sistema educativo etíope están integradas juntas el sistema educativo formal en sí mismo y las alternativas de educación informal para así poder hacer frente a las necesidades e idiosincrasia especiales de parte de la población. De este modo, el sistema está organizado en cuatro niveles: (1) Educación preprimaria, (2) Educación primaria, (3) Educación secundaria, y (4) Educación superior (véase Figura 23). 


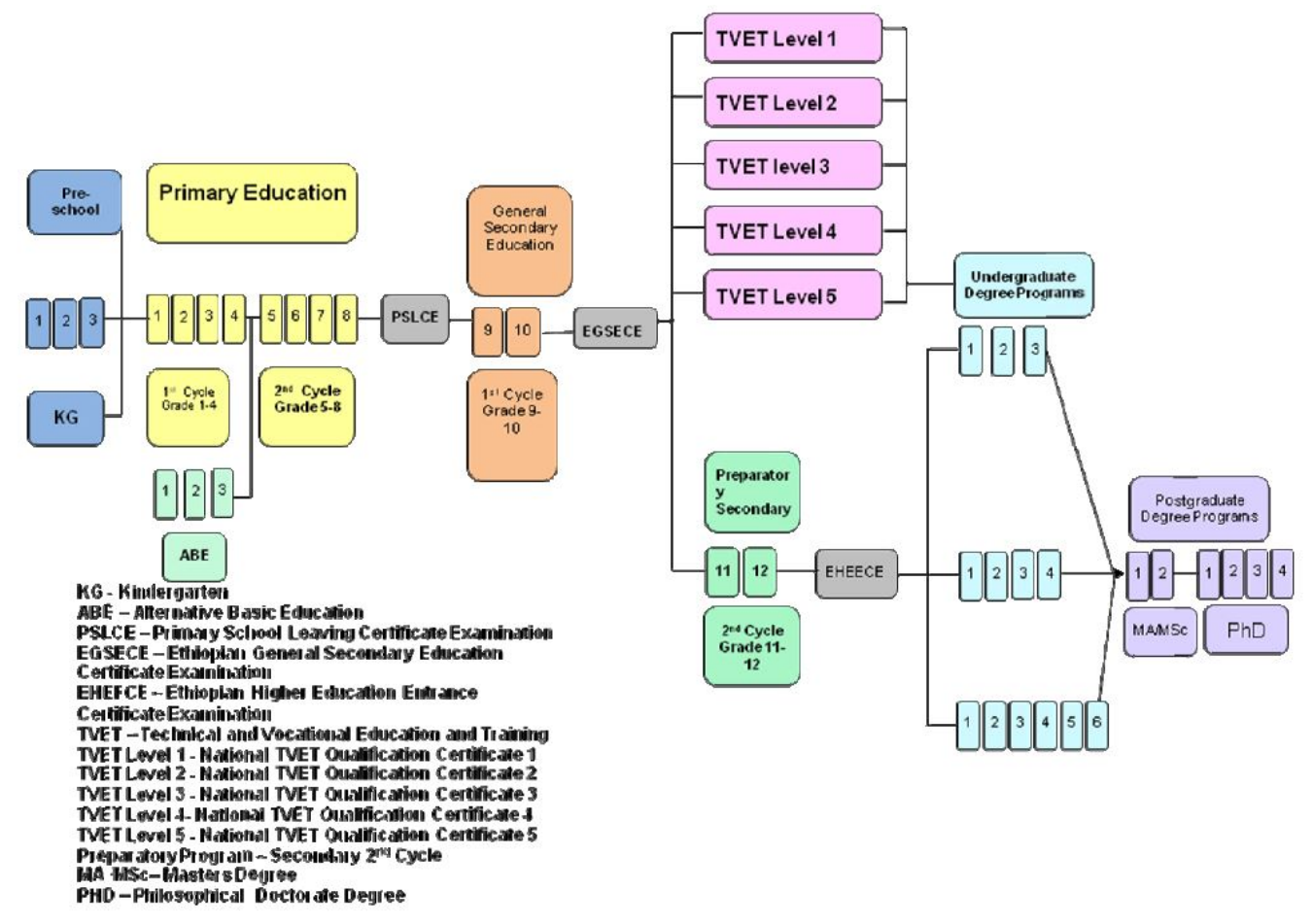

Figura 23. Estructura sistema educativo formal e informal de Etiopía

(Fuente: Ministerio de Educación)

\subsubsection{Educación pre-primaria}

La Educación pre-primaria en Etiopía es vista como una de las soluciones posibles a la gran tasa de abandono escolar, ya que otorga a los alumnos una base que les facilita un mejor desempeño en la escuela:

"Early childhood education is important not only because it is recognized as a child's right in various conventions, but also because there is evidence of the formative significance of early childhood care and education and it plays an important role in the later school success of the child" (UNICEF, 2012, pág. 56).

Otra de sus ventajas es que facilita que las madres puedan incorporarse al trabajo, por lo que los ingresos de las familias aumentan:

"Moreover this type of education enables mothers to enter into the labour force" (UNICEF, 2012 pág. 56).

Por otra parte, y siguiendo con nuestra experiencia en el campo, creemos que este tipo de educación temprana también ayudará a que los hermanos mayores escolarizados, sobre todo las chicas, tengan un nivel menor de abandono escolar, ya 
que igualmente que permite a las madres incorporarse a las tareas productivas previene que los hermanos mayores sean sacados de la escuela para ayudar en el cuidado de los hermanos más pequeños.

1. Tasa de matriculación bruta (GER) y Tasa de Matriculación Neta (NER) en preprimaria

La situación de la educación pre-primaria durante el curso 2012/13 en cuanto a las tasas de matriculación se refleja en la Tablas 3 y 4.

Tabla 3. Tasa de matriculación bruta de educación pre primaria en el curso 2012/13

\begin{tabular}{|c|c|c|c|}
\hline & Chicos & Chicas & Total \\
\hline $\begin{array}{l}\text { Niños entre 4- } \\
6 \text { años }\end{array}$ & 3.924 .540 & 3.790 .416 & 7.714.956 \\
\hline $\begin{array}{l}\text { Alumnos } \\
\text { matriculados }\end{array}$ & 1.046 .177 & 967.037 & 2.013 .214 \\
\hline GER & $26,7 \%$ & $25,5 \%$ & $26,1 \%$ \\
\hline
\end{tabular}

(Fuente: Elaboración propia a partir de datos del Ministerio de Educación)

El GER o tasa de matriculación bruta, nos muestra la relación de alumnos matriculados en pre-primaria sin discriminación por edad respecto a la población total que se encuentra en la edad oficial para cursar la educación de pre-primaria que en Etiopía es de 4 a 6 años. En la Tabla 3 queda claro que la educación preprimaria en Etiopía todavía es minoritaria ya que si comparamos la tasa de matriculación bruta de pre-primaria en 2012/13 con la del primer ciclo de primaria (ver Figura 24) se aprecia que mientras que la primera alcanza solo el $26,1 \%$ I la segunda se sitúa en el $124,9 \%$ lo que es aproximadamente 5 veces más.

Por su parte la tasa de matriculación neta o NER nos permite conocer la relación de alumnos matriculados en pre-primaria que se encuentran en la edad apropiada oficialmente para hacerlo respecto a la población total que se encuentra en la edad oficial para cursar la educación primaria. En la Tabla 4 podemos observar como el NER está muy cercano al GER lo que nos indica que no hay una excesiva 
matriculación tardía en la educación pre-primaria. Las diferencias de género son un poco mayores que en el GER habiendo en este caso una diferencia a favor de los varones de un $1 \%$ lo que supone 73.417 alumnos varones más matriculados en la edad adecuada para ello.

Tabla 4. Tasa de matriculación neta en educación pre primaria en el curso 2012/13

\begin{tabular}{|c|c|c|c|}
\hline & Chicos & Chicas & Total \\
\hline 6 años $\quad$ Niños entre 4- & 3.924 .540 & 3.790 .416 & 7.714 .956 \\
\hline $\begin{array}{l}\text { Alumnos } \\
\text { entre 4-6 años }\end{array}$ & 971.163 & 897.746 & 168.909 \\
\hline NER & $24,7 \%$ & $23,7 \%$ & $24,2 \%$ \\
\hline
\end{tabular}

(Fuente: Elaboración propia a partir de datos del Ministerio de Educación)

Es además necesario tener en cuenta que en Etiopía hay tres tipos de educación preprimaria, dirigida a los niños de edades comprendidas entre los 4 y 6 años:

"The pre-primary education includes kindergartens, " $O$ " class and child to child programs. This level normally involves children of ages 4-6 enrolled in the preprimary education" (MoE, 2013, pág. 21).

A continuación comentaremos cada uno de estos tres programas y las características propias de los mismos.

\section{1) Kindergarden}

El programa de Kindergarden está destinado a los niños entre 4 y 6 años y tiene desarrollado un curriculum y un marco administrativo al igual que cualquier otra etapa educativa:

"Kindergarten is part of the pre-primary education in which children aged 46 are involved. This program has its own curriculum, trained teachers, administrative staff and school compounds" (MoE, 2013, pág. 21). 
Estas escuelas de educación infantil atendían en el año académico 2012/2013 a unos 478.977 niños y niñas de los 2.013.214 alumnos matriculados en los diferentes programas de educación preprimaria (MoE, 2013).

De esta manera los Kindergarden aportan 6,2 puntos del GER en la educación pre-primaria. Teniendo en cuanta que este solo es de un $26,1 \%$ como hemos visto anteriormente supone que los Kindergarden aportan el 23,75\% del GER en esta fase del sistema educativo. Las diferencias de género a la hora de la matriculación de los alumnos en el Kindergarden son mínimas atendiendo a los datos facilitados por el MoE, habiendo una ligera mayor presencia masculina con un GER para los varones de 6,3\% y para las niñas de 6,1\%. Este apenas 0,2\% de diferencia en números absolutos supone que hay 15.391 alumnos varones más matriculados que niñas.

Esto nos da una pista de lo que veremos a continuación repetirse una y otra vez en el sistema educativo etíope, que los alumnos varones tienen siempre una ventaja numérica y proporcional sobre las mujeres en todas las fases educativas. En estas instituciones educativas un dato que contrasta con el resto de las fases educativas es que el profesorado en los Kindergarden está formado en una aplastante mayoría por mujeres frente a la preponderancia masculina en el resto de los niveles educativos. Es más, la presencia masculina podría definirse como anecdótica ya que de los 12.639 profesores solo 734 son hombres, o lo que es lo mismo, el 94,2\% del profesorado está conformado por mujeres y solo un 5,8\% por hombres. Por último hay que destacar que los Kindergarden son un claro ejemplo de la fuerte presencia de las organizaciones internacionales en el sistema educativo etíope, que como hemos ido viendo han tenido y siguen teniendo una fuerte presencia en la educación del país:

"Most kindergarten schools are operated by non-governmental organizations such as communities, private institutions, and faith-based organizations. About 90\% of the Kindergarten enrolment in 2005 E.C. (2012/13) is covered by non-government organizations" (MoE, 2013, pág. 21). 
En nuestra experiencia de campo hemos podido corroborar estos datos, ya que en el país los únicos Kindergarden que logramos ver estaban en manos de organizaciones religiosas como la iglesia católica o iglesias protestantes.

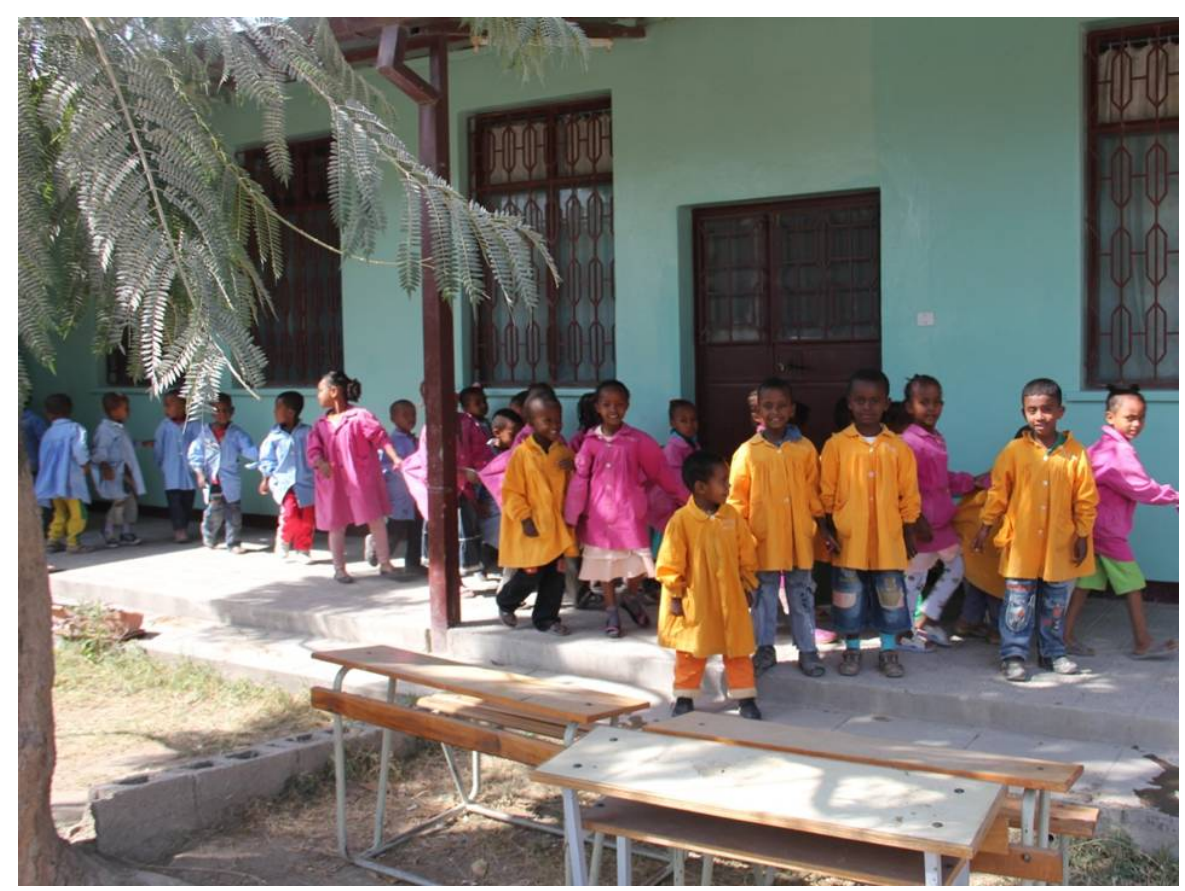

Figura 24. Alumnos del Kindergarden del colegio Mary Help School of Ziway de la misión de las hermanas salesianas en la localidad de Ziway

(Fuente: Autor)

\section{2) “O" Class}

Este programa preescolar esta destinado a los niños de 5 a 6 años que no han tenido acceso al Kindergarden. Estos niños reciben clase por parte del profesorado de la propia escuela de primaria a la que posteriormente asistirán con la intención de preparar a los alumnos para su ingreso en el primer curso de primaria (MoE, 2013).En nuestra experiencia en Qillenso, el supervisor de la zona nos comentó en diversas ocasiones la necesidad de implantar en la escuela este programa de "clase cero", pero nunca pasó más allá de ser un comentario y no había planes específicos para implantarlo 


\section{3) Child to child}

Este último programa podríamos calificarlo como el más informal de los tres, ya que la responsabilidad de ejecutarlo recae sobre los propios niños de primaria:

"Child to child is also a part of the pre-primary education system by which older brother or sisters (younger facilitators of grade 5/6 students) play with their younger siblings and neighbor children. The playing becomes learning as the benefiting child gets to know how for instance, to count or to differentiate colors and identify letters. Through this process the preschool child gets ready for school" (MoE, 2013, pág. 22).

Aún así este programa tiene según UNICEF un gran potencial en Etiopía, ya que consume muy pocos recursos y además ayuda a paliar el problema de la escolarización tardía en la escuela de primaria allí donde no hay posibilidades de acudir a la educación preprimaria:

"The Child-to-Child approach is an especially relevant and low-cost alternative to institutional pre-schools in developing countries. Peer education programmes have shown considerable potential in countries like Ethiopia, where access to pre-schools remains low. The initiative also addresses the problem of overaged enrolment in Ethiopia's primary schools by ensuring that all children in the programme are enrolled the following year into grade one at the appropriate age" (Rana, Abhiyan Recuperado de http://www.unicef.org/infobycountry/ethiopia_48899.html el 4 de Febrero de 2013).

Estos programas han logrado en los últimos años un incremento de la asistencia de los alumnos a los mismos, aún así la situación muestra que falta mucho por hacer a la hora de incrementar la escolarización preprimaria:

"In 2005 E.C. (2012/13) out of the estimated 7.71 million children of the appropriate age group (age 4-6) about 2.01 million children have been reported to have access to pre-primary education all over the country" (MoE, 2013, pág. 21). 
Uno de los problemas que afronta la educación en este estadio es que en gran parte su implantación ha sido dejada en manos de las comunidades locales o el sector privado y el Estado solo se ha centrado en su supervisión, pero no en su establecimiento:

"Although, there is an effort by some regions to start and run the programme, early childhood education is by-and-large left to the communities and the private sector; while the government's direct involvement in the provision of ECCE is limited in maintaining the improvement of quality of the programme and its governance through supervision and inspection" (UNICEF, 2012, pág. 57).

Esto ha provocado que la implantación de esta educación sea muy desigual, dependiendo de cada comunidad o de la presencia de organizaciones internacionales en muchos de los casos ante la falta de recursos económicos locales para llevar estos programas a cabo. Como consecuencia de ello la gran mayoría de los Kindergarden se concentran en las zonas urbanas. Un ejemplo de ello es que de los 2904 Kindergarden que había en el año académico 2009-2010, solo en Addis Ababa se concentraban 968 de ellos. Además muchos padres no tienen la posibilidad de llevar a sus hijos a estos centros debido a los precios de las matriculas a menos de que pertenezcan a instituciones religiosas y no cobren tasas o sean meramente simbólicas (UNICEF, 2012).

El resultado de esta situación queda reflejado en los siguientes mapas y gráficos (véase Figura 25) en los que queda claro que la proporción de niños capaces de leer y escribir en su idioma nativo, idioma en el que recibirán gran parte de la educación primaria, es bastante baja. Destacan tan solo tres ciudades, Addis Ababa, Harar y Dire Dawa con una tasa de un $60 \%$ o superior y predominando en las zonas rurales del país unas tasas de alfabetización inferiores al 50\% de manera generalizada, con zonas especialmente atrasadas como la somalí o la afar, zonas poco pobladas y en las que se concentra población nómada lo que dificulta la escolarización de los alumnos. 

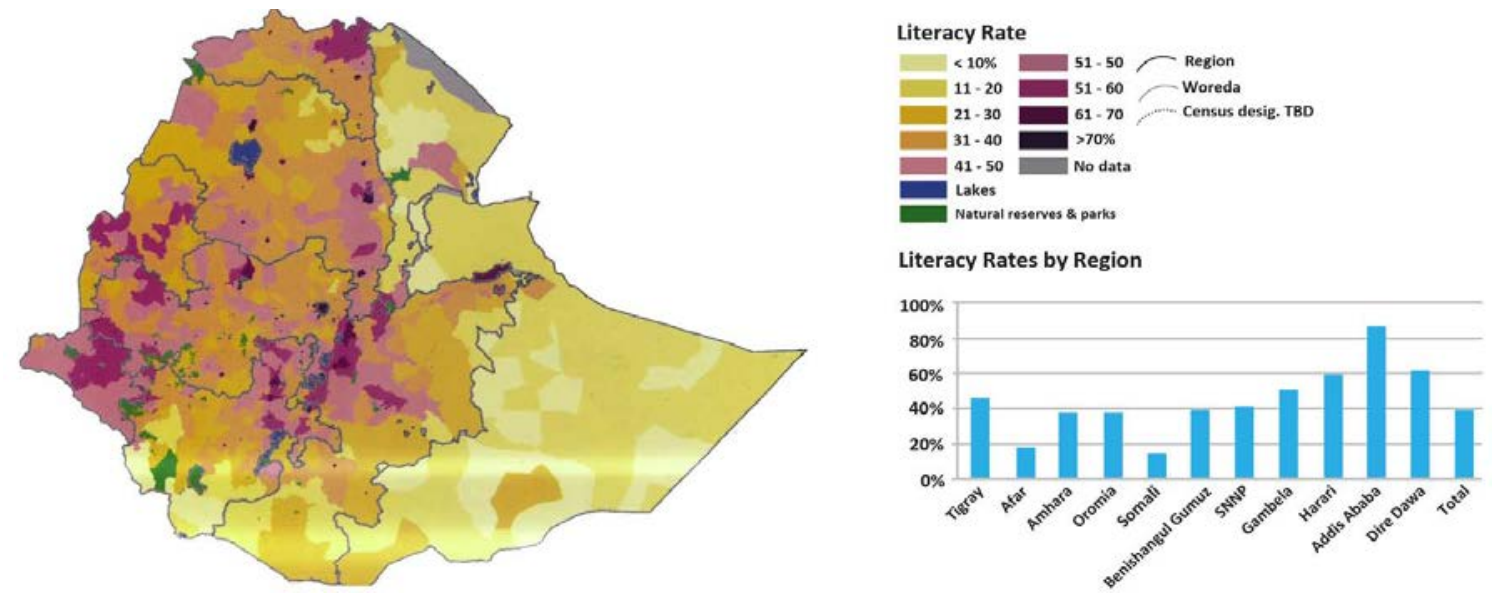

Figura 25. Mapa de Etiopía con la proporción mayores de cinco años de edad capaces de leer y escribir en la lengua nativa

(Fuente: UNICEF, 2012)

En nuestra experiencia de campo pudimos corroborar esta situación al observar cómo muchos niños incluso en los primeros grados de educación primaria tenían autenticas dificultades para leer y escribir.

\subsubsection{Educación primaria}

La educación primaria en Etiopía está dividida en dos ciclos que abarcan desde el grado 1 으 hasta el grado 8 음 ambos incluidos. El primer ciclo está formado por los cursos del 1ㅇ al 4ㅇ y el segundo ciclo consta del los cursos del 5으 al 8ㅇ.. Esta educación primaria ha sido reconocida por el estado etíope como una pieza fundamental a la hora de lograr el desarrollo del país:

"Primary education is critical to a nation's development, providing the highest public return to investment for the state, and the keystone for later education and economic growth" (MoE, 2013 pág. 23).

Como veremos más adelante la educación primaria se lleva más del $50 \%$ del presupuesto de educación en Etiopía, (UNICEF, 2012) pero la situación es menos positiva de lo que da a parece este dato a primera vista. Uno de los problemas a los que se ha de hacer frente se relaciona con la capacitación de los maestros. Así, en Etiopía se ha puesto en marcha un programa en las escuelas para mejorar los conocimientos, habilidades y motivación de los maestros y, en consecuencia, mejorar el aprendizaje y rendimiento de los estudiantes (Gemeda, Fiorucci, y 
Catarci, 2014). Y ello porque los datos indican que existe una amplia brecha entre lo que en teoría se debiera poner en marcha con estos maestros y las prácticas que en realidad se llevan a cabo en las escuelas. Una de las principales barreras para el desarrollo de estos profesionales es su concepción limitada del desarrollo profesional, el enfoque excesivamente burocrático a la hora de poner en marcha iniciativas para la mejora del desarrollo de carrera de estos profesores. Barreras adicionales se relacionan con la falta de un liderazgo educativo, numerosas necesidades experimentadas por el personal, falta de motivación y aumento de la carga de trabajo de los maestros (Gemeda, Fiorucci, y Catarci, 2014).

Volviendo a la organización de este nivel educativo, el ciclo completo de educación primaria está diseñado para niños y niñas de edades comprendidas entre los 7 y 14 años, pero debido a las características culturales, económicas y sociales de Etiopía estas edades son en muchos casos meramente orientativas, ya que un porcentaje muy alto de alumnos tienen edades superiores a las que oficialmente están reconocidas como edades para estar escolarizados en primaria. Como veremos más adelante alguno de los problemas de la educación primaria son el alto índice de abandono escolar y la escolarización tardía o intermitente de muchos alumnos.

Lo primero que debemos conocer es el número de alumnos que hay en la educación primaria, en la Tabla 5 podemos observar la evolución entre los cursos 2008/09 y 2012/13. Se observa un crecimiento del número de alumnos matriculados de 1.877 .152 lo que supone un incremento aproximado de un $12 \%$.

Tabla 5. Evolución del número de alumnos matriculados en educación primaria (incluyendo ABE y evening class) entre $2008 / 9$ y $2012 / 13$

\begin{tabular}{|cccccc|}
\hline Año & $2008 / 09$ & $2009 / 10$ & $2010 / 11$ & $2011 / 12$ & $2012 / 13$ \\
\hline Alumnos & 15.553 .142 & 15.792 .103 & 16.718 .111 & 16.989 .784 & 17.430 .294 \\
\hline
\end{tabular}

(Fuente: Elaboración propia a partir de datos del Ministerio de Educación)

Es importante destacar que durante nuestra estancia en el país hemos podido observar que aunque la educación primaria está oficialmente compuesta de 
dos ciclos, las diferencias entre el primer ciclo son tan marcadas como veremos más adelante que provocan que solo el primer ciclo actúe como educación primaria y el segundo ciclo empiece a actuar ya como educación secundaria. Este fenómeno es fácilmente observable en los distintos datos y estadísticas que iremos revisando a lo largo de este capítulo.

\section{Escuelas de primaria e instalaciones disponibles}

Para hacernos una idea más completa de la situación es importante conocer es el número de escuelas de educación primaria que existen en el país, en la actualidad. Así, según los datos del Ministerio de Educación de Etiopía hay 30.534 escuelas de primaria en el país (MoE, 2013) Como podemos ver en la Tabla 6, la construcción de escuelas de primaria durante los últimos años ha sido constante, pasando de 25.212 centros en el curso 2008/09 a 30.534 durante el curso 2012/2013.

Tabla 6. Escuelas de primaria existentes en el periodo 2008-2013

\begin{tabular}{lccccc}
\hline Año & $2008 / 09$ & $2009 / 10$ & $2010 / 11$ & $2011 / 12$ & $2012 / 13$ \\
\hline Escuelas & 25.212 & 26.951 & 28.349 & 29.643 & 30.534 \\
& & & & & \\
\hline
\end{tabular}

(Fuente: Elaboración propia a partir de datos del Ministerio de Educación

Estos datos nos arrojan un incremento anual de las escuelas existentes del $4,9 \%$ de media en estos último cinco cursos académicos. Si comparamos este crecimiento con el aumento en el número de alumnos en los últimos 5 años, se puede apreciar que mientras las escuelas han aumentado un 4,9\% de media anualmente, los alumnos lo han hecho en un 2,8\% anual de media. (MoE, 2013) Este aumento superior de las instalaciones educativas disponibles en educación primaria al aumento de los alumnos es reflejo de los intentos del gobierno etíope para mejorar la calidad de la educación primaria, siendo uno de sus objetivos bajar la ratio de alumnos por clase.

En conversaciones con el supervisor de educación de las escuelas de la zona me comentó cómo año tras año iban bajando el número de alumnos que podían 
estar matriculados en la misma clase, recordando que hace unos años podían superar los 100 alumnos y que ahora no querían superar los 80 alumnos pero había flexibilidad dependiendo de los recursos disponibles. Es más, al principio de curso hasta que no superamos los 100 alumnos matriculados en primer ciclo no mandaron un profesor extra desde la oficina de educación de la woreda.

Etiopía es un país eminentemente rural pese al desarrollo económico y la emigración de población a las ciudades que se ha producido en los últimos años, como vimos en el primer capítulo de la presente tesis. Debido a ello gran parte de las escuelas del país están en zonas rurales, de las 30.534 escuelas del país solo 4536 están en zonas urbanas frente a las 25.998 que están en zonas rurales. Esto supone que el $85 \%$ de las escuelas de primaria del país están en ambientes rurales. Otro aspecto importante a la hora de hablar de la educación primaria es entender en qué condiciones se lleva a cabo el proceso de enseñanza-aprendizaje de los alumnos, para ello es fundamental conocer el tipo de instalaciones que las escuelas de primaria disponen. El gobierno etíope considera que dotar a las escuelas de instalaciones no es solo beneficioso para la educación de los alumnos, sino que también es una forma de atraerlos a la escuela:

"School facilities have an impact on access, quality, efficiency and equity. School facilities are tools to attract students in general and girls in particular" (MoE, 2013, pág. 37)

En la Tabla 7 ofrecemos una imagen general de la situación de las instalaciones disponibles en las más de 30.500 escuelas de primaria durante el curso escolar 2012/2013 (MoE, 2013). 
Tabla 7. Instalaciones disponibles en las escuelas de primaria durante el curso 2012/2013

\begin{tabular}{|c|c|c|c|c|c|c|c|c|c|c|c|}
\hline \multirow[b]{2}{*}{ Region } & \multirow[b]{2}{*}{ Schools } & \multirow[b]{2}{*}{$\begin{array}{c}\text { No of } \\
\text { Clusters }\end{array}$} & \multicolumn{3}{|c|}{ Water. } & \multicolumn{3}{|c|}{ Iatrine } & \multirow[b]{2}{*}{ Clinic } & \multirow[b]{2}{*}{ Library } & \multirow[b]{2}{*}{$\begin{array}{c}\text { Pedagogy } \\
\text { Center }\end{array}$} \\
\hline & & & $\begin{array}{c}\text { Access to } \\
\text { Water }\end{array}$ & Tap & Well & $\begin{array}{l}\text { Boys' } \\
\text { Pits }\end{array}$ & $\begin{array}{l}\text { Girls' } \\
\text { Pits }\end{array}$ & $\begin{array}{l}\text { Boys' \& } \\
\text { Girls' }\end{array}$ & & & \\
\hline Tigray & 2,017 & 432 & 786 & 381 & 93 & 4,652 & 4,615 & 1,388 & 523 & 991 & 1,014 \\
\hline Afar & 539 & 90 & 192 & 82 & 75 & 556 & 523 & 81 & 84 & 75 & 53 \\
\hline Amhara & 7,493 & 1,631 & 2,678 & 625 & 323 & 9,312 & 9,050 & 2,925 & 1,533 & 3,773 & 3,471 \\
\hline Oromiya & 12,060 & 2,336 & 4,500 & 1,944 & 2,079 & 24,634 & 22,173 & 6,357 & 1,569 & 6,024 & 8,119 \\
\hline Somali & 1.091 & 586 & 272 & 5 & 13 & 1.017 & 1.146 & 896 & 187 & 15 & 4 \\
\hline Ben Gumuz & 497 & 140 & 214 & 32 & 14 & 992 & 933 & 365 & 52 & 127 & 206 \\
\hline SNNP & 5,685 & 1,325 & 2,310 & 837 & 607 & 17,338 & 15,779 & 1,386 & 1,286 & 1,383 & 2,672 \\
\hline Gambela & 237 & 86 & 91 & 17 & 11 & 253 & 261 & 73 & 24 & 28 & 39 \\
\hline Harari & 70 & 16 & 41 & 38 & 1 & 220 & 175 & 28 & 42 & 49 & 34 \\
\hline Addis & 745 & 240 & 1,248 & 393 & 19 & 4,900 & 4,707 & 888 & 1,116 & 694 & 560 \\
\hline Dire Dawa & 100 & 16 & 95 & 19 & 3 & 315 & 318 & 67 & 64 & 57 & 65 \\
\hline rotal & 30,534 & 6.898 & 12,427 & 4,373 & 3,238 & 64,189 & 59,680 & 14,454 & 6,480 & 3,216 & 6,237 \\
\hline
\end{tabular}

(Fuente: Ministerio de Educación, 2013)

Como se puede observar, respecto al agua, casi el $41 \%$ de las escuelas tienen una fuente de acceso al agua disponible para los alumnos. En nuestra experiencia de campo hemos podido comprobar cómo este acceso al agua de los alumnos es utilizado por los mismos no solo para beber, sino que también para lavarse y asearse. Debido a los cortes de agua frecuentes muchas veces estas fuentes de agua no funcionan, como todos los servicios en Etiopía estas fuentes son mucho más comunes en las zonas urbanas en las que hay agua corriente disponible para las casas que en las zonas rurales.

En cuanto a las letrinas, el $92 \%$ de las escuelas de primaria tiene algún tipo de letrinas, generalmente estas son simples agujeros practicados en el suelo, cubiertos por una caseta de contrachapado, ya que en muchas escuelas del país no hay agua corriente y por lo tanto no es posible la instalación de sanitarios. Un ejemplo de ello lo tenemos en la Figura 26. 


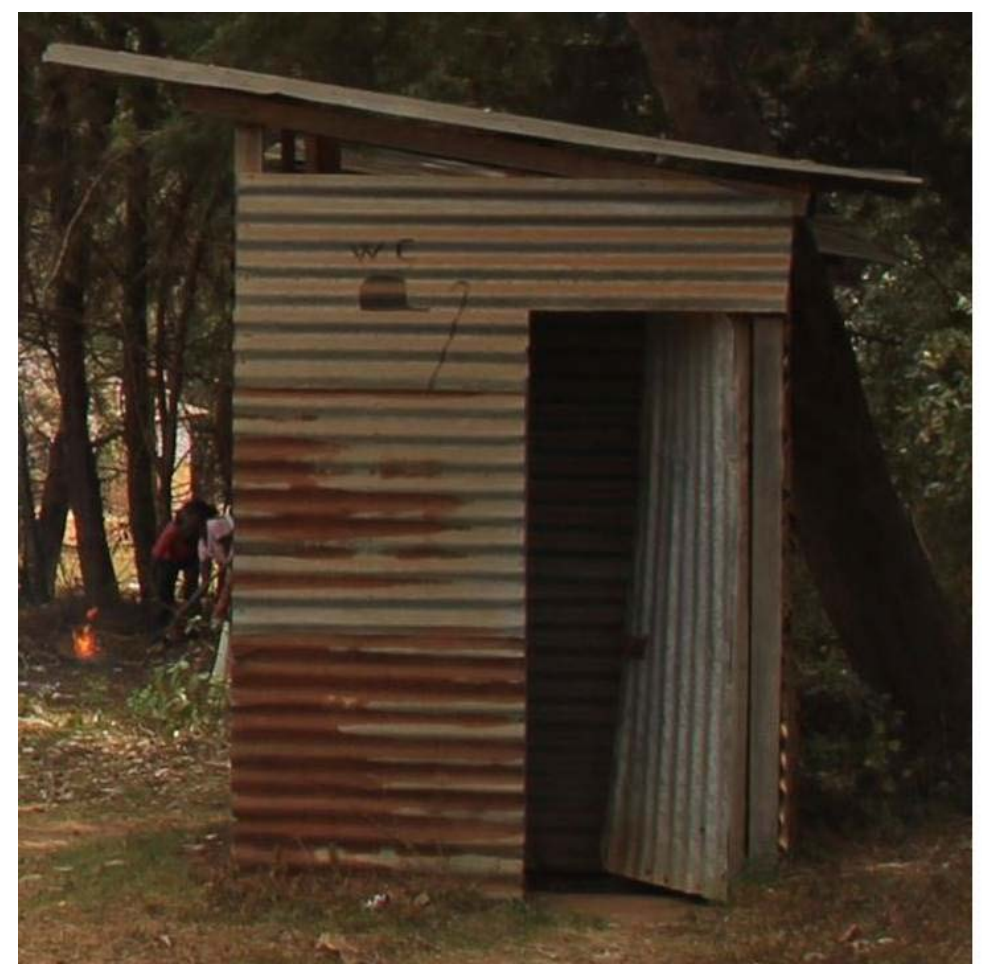

Figura 26. Letrina de una escuela de primaria

(Fuente: Autor)

Por lo que se refiere a las clínicas e instalaciones sanitarias, el $21 \%$ de las escuelas tienen clínicas o instalaciones sanitarias asociadas para el uso de los alumnos. En nuestra presencia en el país solo fuimos testigos de la presencia de clínicas asociadas a centros educativos en grandes escuelas que pertenecían a compañías internacionales como parte de su obra social o en escuelas fundadas por ONGD o entidades religiosas

En cuanto a las aulas o centros pedagógicos, más de un $50 \%$ de las escuelas del país tiene aulas dedicadas a la pedagogía. En ellas los profesores deben guardar y elaborar materiales pedagógicos para su utilización en clase. En nuestra experiencia de campo pudimos observar que la falta de presupuesto en las escuelas públicas provocaba una infrautilización de estas aulas, además los profesores no mostraban un interés muy marcado por utilizar materiales didácticos. Incluso, en más de una ocasión el supervisor de la escuela de Qillenso se quejó de que los 
profesores, pese a tener los materiales didácticos a su disposición, no hacían uso de ellos.

Respecto a las bibliotecas, aproximadamente un $43 \%$ de las escuelas contaban con bibliotecas en el curso 2012-2013 según los datos del MoE. Las bibliotecas escolares a las que he tenido acceso suelen tener pocos libros a la disposición de los alumnos, entre otras limitaciones.

Bajo nuestro punto de vista un problema que afecta a todos estos datos es que la presencia de las instalaciones no garantiza su funcionamiento real o su utilización por parte de alumnos y profesores. Un problema que vimos en Etiopía fue que tanto actividades como instalaciones existían o se utilizaban solo sobre el papel, en los planes de la escuela que era obligatorio elaborar y presentar en caso de inspección de educación, pero que más allá de estar reflejados en el papel no se llevaban a cabo.

Una vez conocidas los servicios que ofrecen las escuelas de primaria es necesario conocer el número de aulas disponibles en las mismas para llevar a cabo el proceso de enseñanza-aprendizaje como vemos en la Tabla 8. Así, se puede observar cómo hay disponibles un total de 313,784 aulas en las 30,534 escuelas del país para los alumnos de primaria, lo que supone que las escuelas disponen de media de 10 aulas aproximadamente.

Tabla 8. Número de clases disponibles por curso en 2013

\begin{tabular}{|ccccccccccc|}
\hline Grado & 1 & 20 & 30 & 40 & 50 & 60 & 70 & 8 o & Total \\
Aulas & 62.550 & 52.949 & 46.693 & 40.378 & 33.477 & 29.579 & 24.831 & 23.327 & 313.784 \\
\hline
\end{tabular}

(Fuente: Elaboración propia a partir de datos del Ministerio de Educación)

Sin embargo, en nuestra experiencia constatamos que solo las grandes escuelas de las zonas más urbanizadas tienen más de 10 aulas, las escuelas rurales que hemos visitado a lo largo de nuestra experiencia en Etiopía tendrían de media unas cinco o seis aulas. Es interesante analizar el número de aulas disponibles para cada curso en las escuelas de primaria. Así, el primer ciclo de primaria tiene asignadas el $64,5 \%$ de las aulas mientras que el segundo ciclo tiene disponibles el 
$35,5 \%$ restante. Esto nos vuelve a demostrar la mayor importancia de este primer ciclo de primaria respecto al segundo ya que las aulas asignadas al primer ciclo están cerca de doblar en número a las del segundo ciclo. Además queda claro en los datos el descenso de aulas disponibles según se va avanzando en los cursos desde primero hasta el octavo claro reflejo de la progresiva pérdida de estudiantes según avanza la primaria.

La comprensión del funcionamiento y características de la educación primaria en Etiopía requiere también conocer cómo los alumnos se acercan por primera vez a la misma. Por ello es importante conocer algunas estadísticas, ya que el primer grado condicionará en gran medida la situación de la educación primaria en general. Y ello porque, dependiendo del tipo de alumnado que acceda en primer grado, así se verá afectado el resto de la educación primaria.

\section{Tasa de ingreso neto (NIR)}

Esta tasa recoge el porcentaje de niños de 7 años que son matriculados en el primer grado de primaria sobre el total de niños de 7 años del país, la edad oficial de admisión el sistema educativo etíope. En la Tabla 9 presentamos los datos relativos a los últimos años.

Tabla 9. Tasa de ingresos netos en los cursos $2008 / 8$ hasta $2012 / 13$

\begin{tabular}{|cccc||}
\hline AÑO ACADEMICO & NIÑOS \% & NIÑAS \% & TOTAL \% \\
\hline $2008-2009$ & 84,3 & 80,1 & 82,2 \\
\hline $2009-2010$ & 78,8 & 74,5 & 76,7 \\
\hline $2010-2011$ & 94,2 & 88,4 & 91,3 \\
\hline $2011-2012$ & 94,6 & 89,7 & 92,2 \\
\hline $2012-2013$ & 97,9 & 93,0 & 95,5 \\
\hline
\end{tabular}

(Fuente: Elaboración propia a partir de datos del Ministerio de Educación)

Los datos muestran cómo se ha producido un incremento en los últimos años de la escolarización de los niños y niñas de 7 años en país. El crecimiento, tanto en niños como en niñas, es de unos 13 puntos porcentuales a lo largo de estos 
últimos cinco cursos académicos situando a Etiopía en el camino correcto para conseguir la educación primaria universal en 2015 como pretenden los Objetivos del Milenio. Además este aumento de la tasa de ingreso neto es positivo ya que es importante que los niños y niñas accedan a la educación primaria en el momento preciso para facilita una mejora de la calidad de la educación ya que reduce la disparidad de edades en el aula y por lo tanto homogeniza los ritmos del proceso de enseñanza-aprendizaje ya que hay más niños con las mismas capacidades potenciales.

\section{Tasa de ingreso con independencia de la edad (AIR)}

Este sistema de medición refleja el porcentaje de alumnos matriculados en primer grado de primaria sin tener en consideración su edad respecto al número de niños y niñas de siete años, por lo que recoge la presencia de los alumnos que no fueron matriculados a la edad de siete años por diversos motivos y que han accedido a la educación primaria de forma tardía (véase Tabla 10). Ello explica la existencia de tasas de ingreso superiores al $100 \%$.

Tabla 10. Tasa de ingreso con independencia de la edad para los cursos 2008/9 hasta 2012/13

\begin{tabular}{||cccc|}
\hline AÑO ACADEMICO & NIÑOS \% & NIÑAS \% & TOTAL \% \\
$2008-2009$ & 169,4 & 155,4 & 162,5 \\
$2009-2010$ & 150,4 & 135,2 & 142,9 \\
$2010-2011$ & 171,9 & 154,5 & 163,4 \\
$2011-2012$ & 156,0 & 142,4 & 149,3 \\
$2012-2013$ & 150,2 & 137,8 & 144,4 \\
\hline
\end{tabular}

(Fuente: Elaboración propia a partir de datos del Ministerio de Educación)

En los datos podemos observar que los valores del AIR han fluctuado de manera muy significativa estos años pero que muestran una tendencia a la baja solo rota durante el curso 2010/11 que en parte puede deberse a la tendencia al alza del NIR. Es importante señalar que al analizar los datos anteriores queda patente uno de los problemas más graves del sistema educativo etíope, la tardía escolarización de muchos alumnos que afecta muy gravemente al desarrollo de la educación 
primaria y satura los centros educativos, pero esto lo trataremos más adelante a lo largo de este capítulo. También muestra que sigue habiendo una inferior escolarización de niñas respecto a los niños.

Una vez conocida la situación y la forma en la que los alumnos acceden por primera vez a la educación primaria es el momento de ver la situación de toda la primaria, tanto en general como en sus dos ciclos más detalladamente.

\section{Tasa de matriculación bruta (GER) en primaria}

Lo primero que debemos conocer es el GER, es decir la relación de alumnos matriculados en primaria sin discriminación por edad respecto a la población total que se encuentra en la edad oficial para cursar la educación primaria, esto es, la población comprendida entre los 7 y 14 años de edad (véase Figura 27).

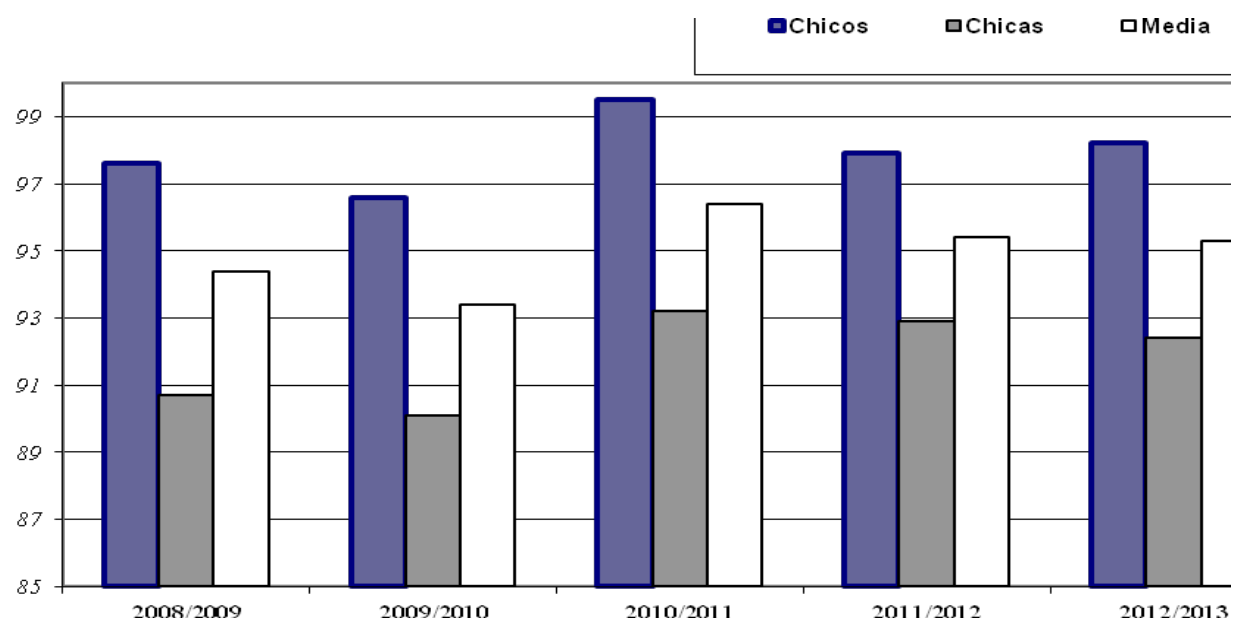

Figura 27. Evolución del GER en Primaria (1-8)

(Fuente: Elaboración propia a partir de datos del Ministerio de Educación)

Los datos reflejados en esta Figura 27 pueden inducir al error, ya que al mostrar unas cifras inferiores al $100 \%$ puede parecer que el número de alumnos en primaria está ajustado a la población entre 7 y 14 años, lo que indicaría que los alumnos entran en la primaria a la edad oficial de 7 años y la abandonan al completar el ciclo a los 14 años. Sin embargo, como hemos señalado anteriormente, la tasa de ingreso con independencia de la edad tiene una media en los últimos cinco años de un 152,5\% lo que imposibilita esta explicación. La razón de estos 
datos tan bajos en la tasa de matriculación bruta (GER) se debe en realidad al gran abandono escolar que se produce en el cambio del primer al segundo ciclo de primaria como veremos a continuación. Así y como podremos observar a continuación, durante el primer ciclo de primaria la tasa de matriculación bruta supera de media en 20 puntos porcentuales el 100\% (véase Figura 28).

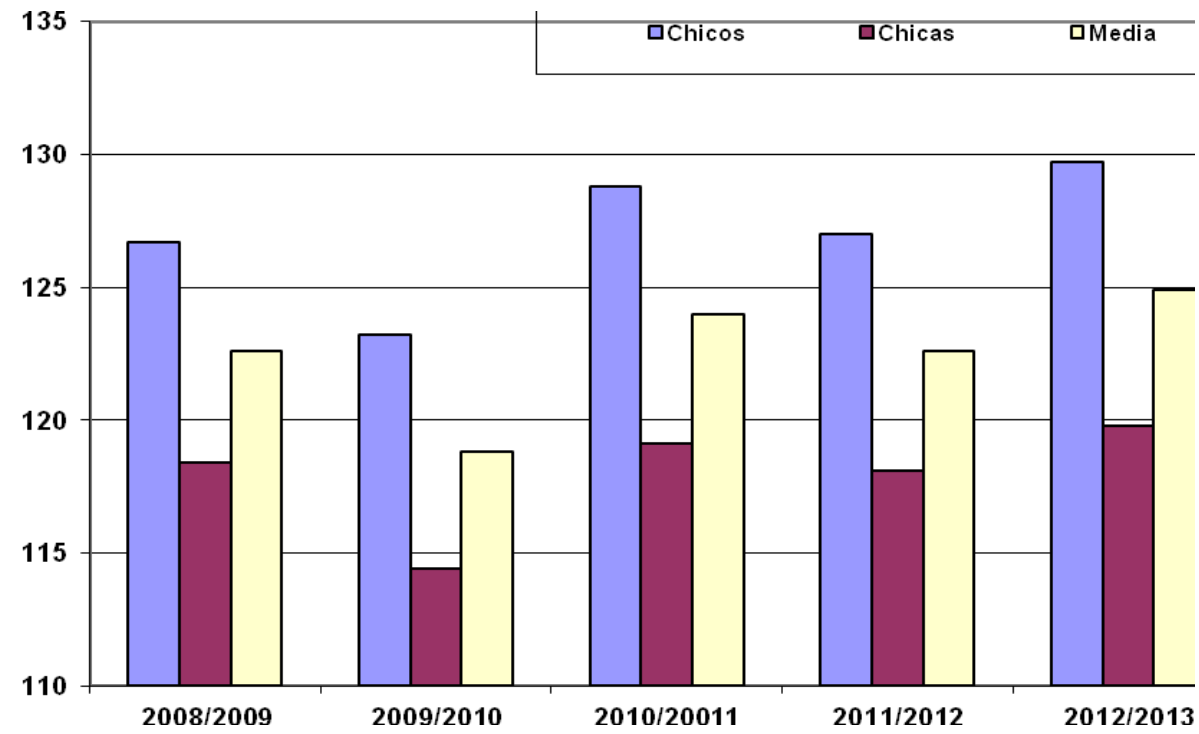

Figura 28. Evolución de la tasa de matriculación bruta en el Primer Ciclo de la Educación Primaria (1-4)

(Fuente: Elaboración propia a partir de datos del Ministerio de Educación)

Estos datos reflejan uno de los problemas del sistema educativo etíope, la carga extra de alumnado durante el primer ciclo de primaria debido a diferentes causas, que veremos más adelante, como la gran cantidad de alumnos que acceden de manera tardía al sistema educativo o la escolarización intermitente. Estas situaciones provocan entre otras cosas el descenso de recursos disponibles por alumno y el empobrecimiento de la calidad de la educación. A diferencia de los datos del primer ciclo de primaria, los del segundo ciclo muestran unos datos muy inferiores (véase Figura 29). 


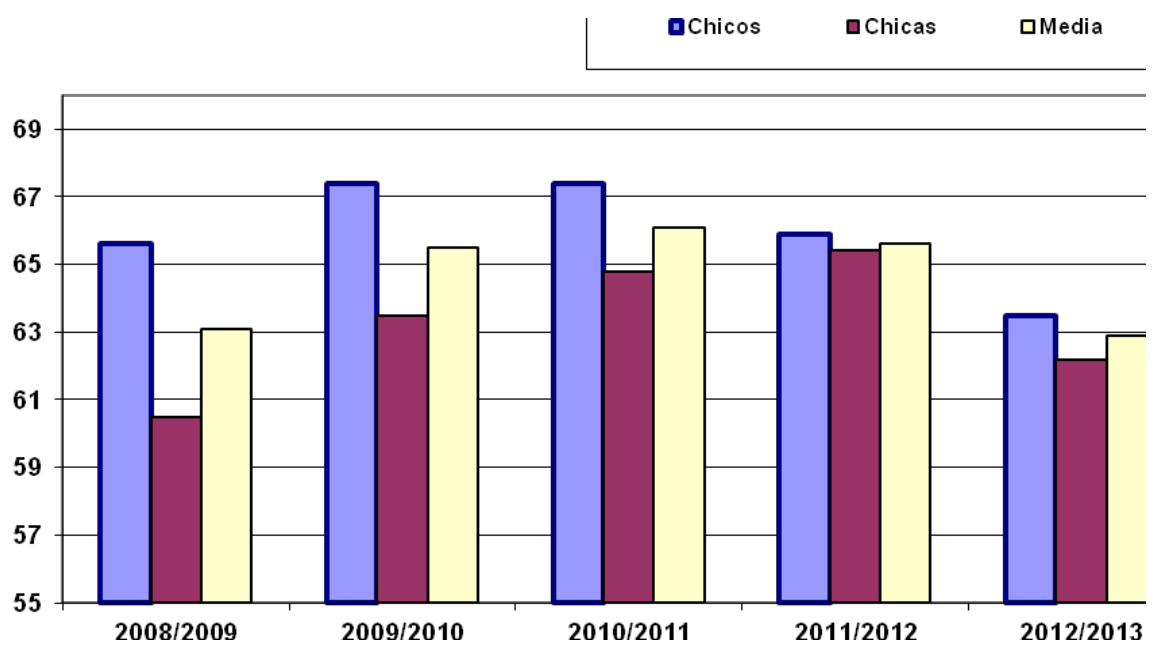

Figura 29. Evolución de la tasa de matriculación bruta en el Segundo Ciclo de la Educación Primaria (1-4)

(Fuente: Elaboración propia a partir de datos del Ministerio de Educación)

Como podemos observar la diferencia entre el GER entre el primer ciclo de primaria y el segundo ciclo es muy significativa, de media durante el periodo de 2008-2013 la diferencia ha sido de 57,92 puntos. Lo que viene a significar que durante el primer ciclo de primaria prácticamente hay el doble de alumnos que en el segundo.

Este descenso de alumnos en el segundo ciclo de primaria nos muestra que esta segunda parte de la primaria actúa realmente como una educación secundaria, ya que como vemos en estos datos y como veremos más adelante, en el momento de acabar el primer ciclo y empezar este segundo ciclo existe una gran tasa de abandono escolar. En nuestra experiencia de campo pudimos observar en varias de las escuelas de la zona Guji la poca cantidad de alumnos que había en los cursos del segundo ciclo comparados con los del primer ciclo.

\section{Tasa de Matriculación neta (NER) en primaria}

La tasa de matriculación neta es otro indicador que nos permite por su parte conocer la relación de alumnos matriculados en primaria que se encuentran en la edad apropiada oficialmente para hacerlo respecto a la población total que se encuentra en la edad oficial para cursar la educación primaria. Como podemos ver a 
en la Figura 30, durante el periodo 2008/9 -2012/13 el Net ha aumentado un 2,9\% situándose en la actualidad en un $85,9 \%$

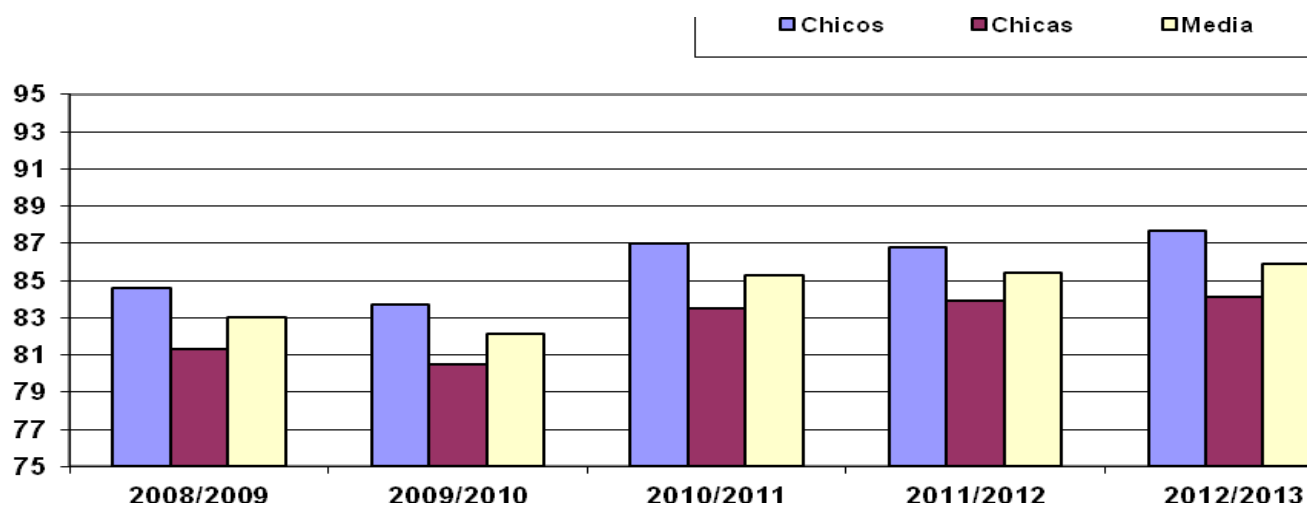

Figura 30. Evolución NET en Primaria (1-8)

(Fuente: Elaboración propia a partir de datos del Ministerio de Educación)

Según se aprecia en la Figura 30, la evolución del porcentaje de matriculación neta en primaria durante los últimos cinco cursos escolares 2008/9 2012/13 ha mantenido una tendencia a un aumento de la escolarización primaria tanto de niños y niñas en edad oficial excepto durante el curso 2009/10 en el que se produjo un descenso respecto al año anterior.

Igual que en el caso anterior de la matriculación bruta, los datos de matriculación neta esconden una realidad más compleja de lo que puede parecer a simple vista. Si hacemos una distinción entre el primer y segundo ciclo de primaria se produce una situación muy similar a la que ocurre con la matriculación bruta como podemos ver en la Tabla 11.

Tabla 11. Comparativa NER entre el primer y Segundo ciclo de primaria en 2012/13

\begin{tabular}{|c|c|c|c|}
\hline & Chicos & Chicas & Media \\
\hline 10 Ciclo primaria & $98,2 \%$ & $92,8 \%$ & $95,5 \%$ \\
\hline 20 Ciclo primaria & $46,5 \%$ & $48,1 \%$ & 47,3 \\
\hline
\end{tabular}

(Fuente: Elaboración propia a partir de datos del Ministerio de Educación)

En el año 2012/13, último del que están los datos disponibles queda claro que las diferencias de matriculación neta entre el primer y segundo ciclo de 
primaria son muy marcadas. La matriculación neta en el primer ciclo es mayor del doble de la del segundo ciclo, además en el segundo ciclo ni la mitad de los alumnos en edad oficial de estar matriculados lo está efectivamente, ya que la media es de un $47,3 \%$ en el segundo ciclo mientras de un $95,5 \%$ en el primero. Pese a esta gran diferencia entre los dos ciclos el aumento que se ha producido desde 2008/2009 es positivo en la medida que indica que los alumnos cada vez más acceden al sistema educativo con la edad apropiada. Esto facilita el proceso de enseñanza aprendizaje al homogenizar las edades de los alumnos y así lograrse un entorno en el que las capacidades de los alumnos son similares y que al menos en el primer ciclo parece que se está más cerca de conseguir la escolarización universal.

Esto supone, siguiendo la teoría del Ministerio de Educación de Etiopía, que al menos se conseguirá que las siguientes generaciones de etíopes logren obtener las herramientas básicas para defenderse en la vida diaria al saber leer, escribir y las técnicas matemáticas básicas (MoE, 2013) pero que al mismo tiempo dejará a una gran parte de esas generaciones sin la posibilidad de acceder a unos estudios superiores y por tanto cualificarles para desempeñar trabajos especializados o técnicos. Tanto el estudio del GER como del NER dejan claro que existe una importante brecha en el sistema educativo etíope entre el primer y segundo ciclo de primaria Fenómeno que también veremos más adelante en otros indicadores como las tasas de repetición o de abandono. Los dos ciclos de primaria tienen unas características tan distintas que de hecho se comportan como dos períodos educativos distintos y como no dos partes de la misma fase. Esta realidad es una de los problemas más fundamentales de la educación en Etiopía y la veremos aparecer a lo largo de este capítulo en más ocasiones.

\section{Tasa de repetición}

La tasa de repetición es una medida que nos indica el porcentaje de alumnos que han permanecido dos o más años en el mismo curso, habiendo repetido tanto por sus malos resultados académicos o por haber abandonado prematuramente el curso y posteriormente haberse matriculado de nuevo en ese curso. En Etiopía hay 
varias políticas educativas respecto a la repetición de cursos, una de las más importantes es la siguiente:

"Current national policy requires that promotion is based on students' continuous assessment results for the first three grades of primary" (MoE, 2013 pág. 32).

Esta política implica que los alumnos que se mantienen matriculados y asisten a clase durante todo el curso académico tienen garantizada la promoción al siguiente curso independientemente de que hayan alcanzado los conocimientos mínimos impartidos durante los primeros años de su escolarización en la educación primaria. Pese a ello como podemos observar en la Figura 31, la media de repetidores por curso es de un 7,8\% a lo largo de los 8 cursos de primaria.

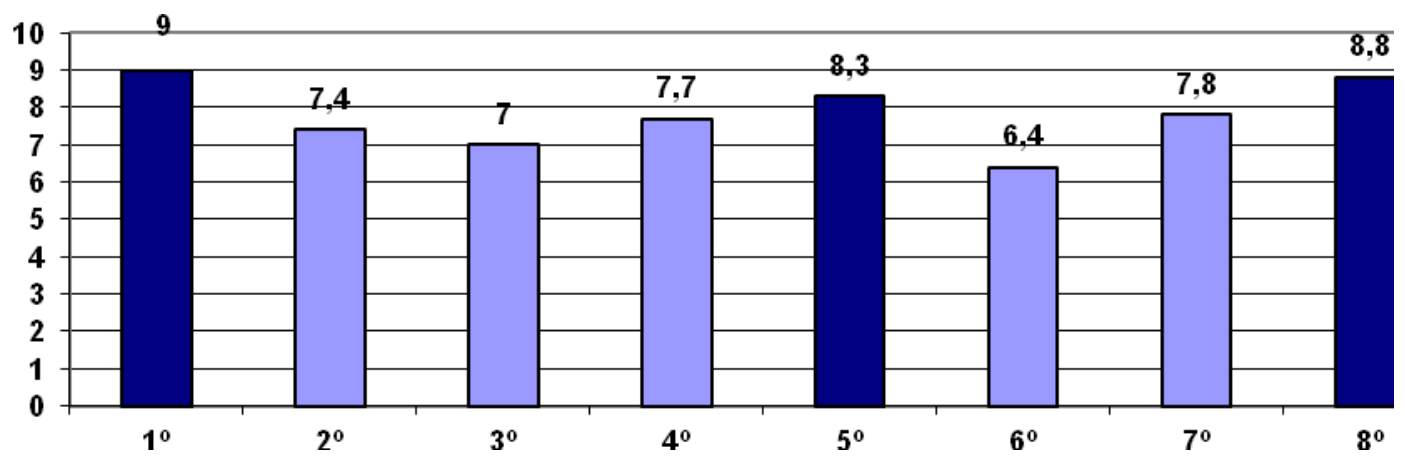

Figura 31. Porcentaje de alumnos repetidores en cada curso de primaria curso 2011/2012

(Fuente: Elaboración propia a partir de datos del Ministerio de Educación)

Estas tasas de repetición se deben a dos factores principales, primero el factor que forman los alumnos que repiten curso debido a que abandonaron el mismo antes de finalizar el año académico y deben volver a cursarlo y segundo el grupo de los alumnos que han sido incapaces de superar el curso por motivos académicos. En la Figura 31 hemos resaltado en color más oscuro los cursos en los que se produce una mayor tasa de repetición. El más alto es el primer grado, debido a que la promoción durante los primeros cursos de primaria es automática este $9 \%$ 
de repetidores se deben exclusivamente a alumnos que abandonaron el sistema educativo antes de terminar este curso escolar antes y volvieron a matricularse en años posteriores.

A continuación los dos cursos con mayor tasa de repetición son 5으 y 8oㅡ, esto se debe a que a partir de 50 la promoción no es automática y al llegar muchos alumnos con un nivel muy bajo de los primeros cursos de primaria son incapaces de alcanzar los objetivos mínimos del curso. En octavo el aumento de la tasa de repetidores se debe a que al tener que pasarse un examen nacional, con un carácter similar al que tendría nuestra revalida, los alumnos que no logran aprobarlo han de repetir octavo curso para poder volver a presentarse al examen y de esta manera conseguir el certificado que les acredita haber terminado la educación primaria:

"This is not a surprising, the pattern show greater repetition before transition from first to second cycle and higher repetition at the end of primary as national policy requires those who do not pass the Primary School Certificate Examination to repeat grade 8 and retake the examination" (MoE, 2013, pág. 33).

Es importante señalar que el Ministerio de Educación contabiliza en una figura especial llamada readmitidos a los alumnos que repiten más de un año. Esto tiene dos efectos, el primero hacer descender las tasas de repetición y el segundo hacer aumentar las de abandono escolar en las estadísticas:

"In Ethiopia, if a child repeats a grade more than one year after they first started the grade, then they are considered "readmits" rather than a repeater. In international terms, this approach "artificially" reduces repetition rates, but also increases perceived Drop Out rates. For purposes of international comparison, "readmits" are combined with repeaters to reflect the more widespread international approach to calculating repetition" (MoE, 2013 pág. 319).

\section{1) Tasa de abandono escolar}

La discontinuidad en la educación se encuentra asociada a menores niveles de aprendizaje y son indicadores clave de desventaja. En estudios donde se comparan los niveles educativos y los aprendizajes en diferentes países en 
desarrollo, se ha puesto de manifiesto que en Etiopía los progresos educativos son más bajos. Tanto la tasa de matriculación como la mejora de la calidad continúan siendo tareas pendientes (Rolleston, 2014).

La tasa de abandono escolar recoge los alumnos que a lo largo de un curso abandonan el sistema escolar. Este abandono puede ser definitivo o puede que se dé el caso de que en unos años parte de estos alumnos vuelvan a matricularse en el sistema educativo o busquen alternativas a la educación formal (Figura 32).

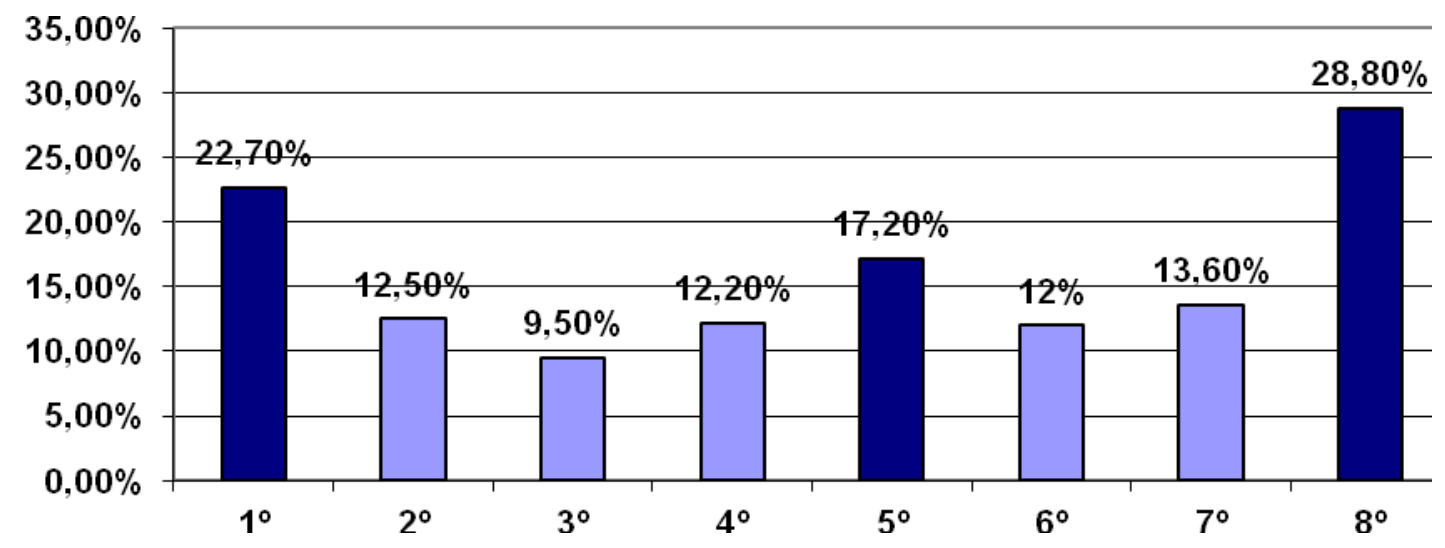

Figura 32. Porcentaje de alumnos que abandonan el sistema educativo en cada curso de primaria durante el curso 2011/2012

(Fuente: Elaboración propia a partir de datos del Ministerio de Educación)

Al igual que en la Figura 31, en esta Figura 32 hemos marcado de color más oscuro los cursos en los que, en este caso, se produce una mayor tasa de abandono escolar. Es especialmente preocupante la tasa de abandono escolar que se produce en el primer curso ya que significa que un $22,7 \%$ de los alumnos abandonan el sistema escolar nada más acceder a la educación primaria, debido a esto el gobierno etíope está poniendo una atención especial para luchar contra el abandono escolar en el primer grado:

"Therefore, to decrease dropout at primary school (grades 1 to 8), the Ethiopian education system has to focus on decreasing grade 1 dropout students because, if grade 1 students are kept in the system the probability of dropping out in future grades is much less" (MoE,2013, pág. 34). 
El alto grado de abandono escolar en 8ㅇ curso puede deberse entre otros factores a que los alumnos que son incapaces de lograr aprobar el examen obligatorio que hay al final del segundo ciclo de primaria simplemente abandonan el sistema educativo antes de conseguir obtener el título. Si comparamos los datos de abandono escolar en el curso 2011/12 con los del curso 2008/2009, como podemos observar en la Figura 33, la situación ha mantenido la misma tendencia pero se han producido algunas variaciones y fenómenos que merece la pena que analicemos.

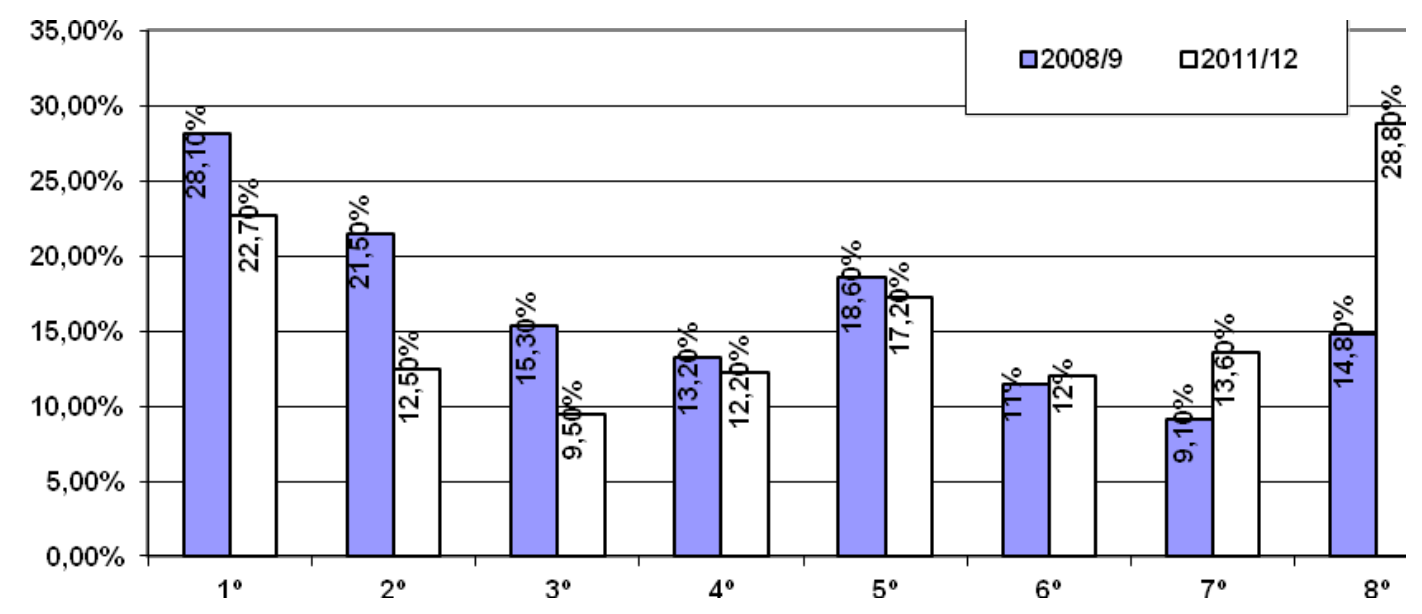

Figura 33. Comparativa del porcentaje de alumnos que abandonan el sistema educativo en cada curso de primaria durante el curso 208/2009 y 2011/12

(Fuente: Elaboración propia a partir de datos del Ministerio de Educación y UNICEF

Tanto en el año académico 2008/2009 como en el 2011/12 los cursos que mantienen un mayor tasa de abandono escolar son 10 , 50 y $8^{\circ}$ aunque en el 2008/2009 también el segundo curso tiene una alta tasa de abandono escolar, siendo el curso con mayor abandono tras 10 y como señalábamos anteriormente esto es reflejo de uno de los problemas de la educación en Etiopía, la alta tasa de abandono escolar nada más empezar la primaria. Aunque en la Figura 33 se puede observar que las tasas de abandono han disminuido de primero a cuarto curso un $5,3 \%$ de media, también se puede observar que excepto 50 curso en el que la tasa de abandono ha descendido ligeramente durante todo el segundo ciclo de primaria las tasas de abandono han aumentado siendo especialmente significativo el caso de 
8o curso en el que el grado de abandono escolar prácticamente se ha doblado pasando de un $14,4 \%$ a un $28,8 \%$.

Este fenómeno de bajada de las tasas de abandono en el primer ciclo de primaria y aumento en el segundo ciclo se debe entre otros factores a que al descender el número de alumnos que abandonan la educación de 1ㅇ a 4을 muchos de ellos progresan hasta el segundo ciclo y allí es cuando abandonan el sistema educativo, esto se puede observar en el aumento de un $10 \%$ en la tasa de supervivencia a 5o curso que se ha producido entre 2008/9 y 2011/12 (ver Figura 34).

Otra razón muy poderosa del aumento del abandono escolar en segundo ciclo es que la presión de la necesidad de dejar los estudios para ponerse a trabajar va aumentando según los alumnos van teniendo mayor edad por lo que al haber llegado al segundo ciclo alumnos que antes no llegaban y tener que abandonar de igual manera la educación para incorporarse al trabajo esto ha hecho aumentar las tasas. El aumento espectacular del abandono escolar en 8 o curso creemos que se debe en gran parte en que a que aunque más alumnos logran llegar a octavo curso en realidad tienen un nivel de conocimientos muy inferior a lo exigido por el gobierno, y al tener que enfrentarse a un examen controlado por las oficinas de educación y no por los propios colegios, esto queda patente y se produce un gran abandono escolar. Además, al fracasar en el examen muchos abandonan para trabajar en el mantenimiento económico de las familias. Estas causas de abandono escolar junto con otras a las que aludiremos posteriormente serán analizadas a lo largo de estas páginas.

Volviendo a la situación actual podemos observar tanto en la Figura 31 como en la Figura 32 cómo los cursos con mayor abandono escolar coinciden con los cursos en los que se produce una mayor tasa de repetición. De esta manera podemos deducir que estos cursos, 19 , $5^{\circ}$ y y $8^{\circ}$ son realmente una especie de cuellos de botella en el sistema educativo etíope, ya que si seguimos los datos del año 2011/12 y sumamos las cantidades de la tasa de repetición y la tasa de abandono escolar arrojan los siguientes resultados, en 1 을 solo un $68,3 \%$ de los alumnos 
consigue terminar el curso, en 50 solo un $74,5 \%$ consigue hacerlo y finalmente en 8 은 un $62,4 \%$ de los alumnos consiguen finalizar el octavo de manera satisfactoria.

\section{2) Tasa de supervivencia hasta el 5 curso}

Esta tasa nos proporciona una estimación de los alumnos que al menos logran completar los cuatro primeros grados de la educación primaria, es decir el primer ciclo de educación primaria. Esto es importante ya que el completar estos años es considerado una garantía de haber alcanzado un nivel de alfabetización aceptable:

"The completion of at least 4 years of schooling is considered as a prerequisite for a sustainable level of literacy" (MoE, 2013, pág. 34).

Esta tasa se obtiene mediante un método de cohorte sintética en la que se toma generalmente a un grupo de 1.000 alumnos que se matriculan conjuntamente y progresan hasta 5으, recogiéndose entonces el número de alumnos de esos 1.000 que consiguen hacerlo. Entre los alumnos que lo logran se incluyen aquellos que lo hayan conseguido sin repetir y aquellos que lo hayan conseguido repitiendo hasta en dos ocasiones (MoE, 2013).

Como vemos en la Figura 34, esta tasa en los últimos años de los que se tienen datos ha sido bastante irregular pero ha arrojado una media del $48,16 \%$, lo que viene a significar que menos de la mitad de los alumnos que empiezan la educación primaria logran acabar el primer ciclo. 


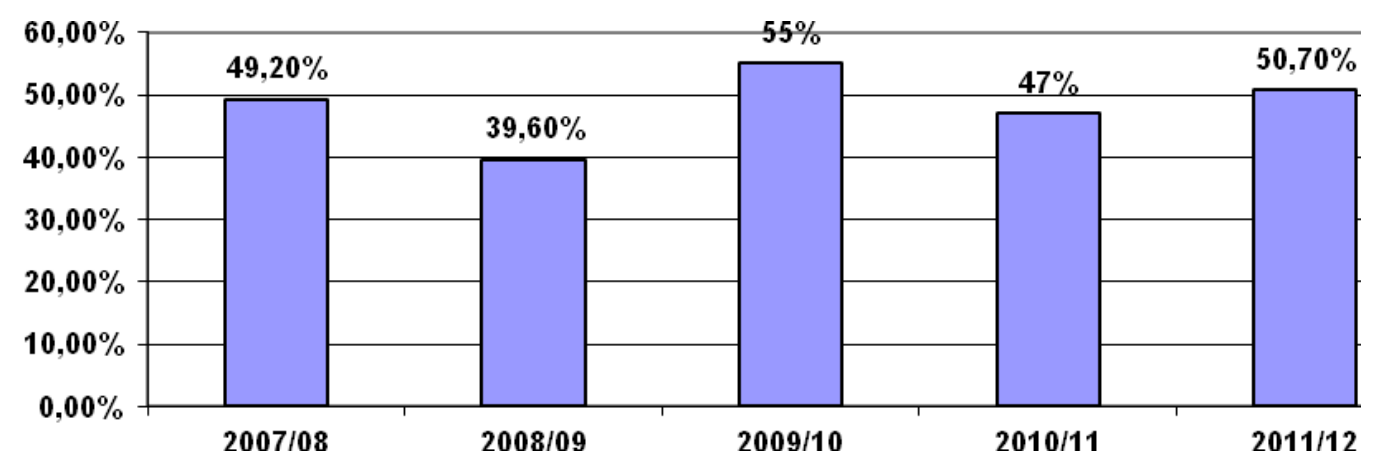

Figura 34. Porcentaje de supervivencia hasta 5o entre los cursos académicos 2007/08 y 2011/12 (Fuente: Elaboración propia a partir de datos del Ministerio de Educación)

\section{3) Tasa de finalización de primaria}

Esta tasa es utilizada internacionalmente para conocer los resultados educativos que los distintos sistemas escolares logran conseguir, además ha sido elegida por la ONU como uno de los indicadores para conocer el grado de consecución del objetivo 2 del milenio:

"It has been specified as one of the two major education indicators for the Millennium Development Goals" (MoE, 2013, pág. 35).

El método para calcular esta tasa consiste en dividir los nuevos alumnos que llegan al último curso por el número de niños y niñas que están en la edad oficial para estar escolarizados en ese curso. En Etiopía estas tasa se calcula tanto en el 50 curso que supone el inicio de la segunda etapa de primaria como en el 8 o curso, por lo que las edades oficiales son 11 y 14 años respectivamente (MoE, 2013).

En Etiopía se calculan en estos dos cursos ya que el primero de ellos, 5으, supone el curso inmediatamente posterior al primer ciclo de primaria y nos aporta información muy valiosa de los alumnos que han logrado acabar el primer ciclo de primaria y además continúan su educación. Como ya hemos señalado con anterioridad una de las características de la educación primaria en Etiopía es el alto grado de abandono escolar tras acabar el primer ciclo de primaria. Como se puede apreciar en la Figura 35, la tasa de finalización en 5o curso descendió desde 
2008/2009 en la que se situaba en un 78,9\% hasta 2010/2011 en la que se situó en un $69,4 \%$ y a partir de ese año ha vuelto a recuperarse pero todavía no ha alcanzado los valores de 2008/2009 situándose en un $76,4 \%$ lo que supone todavía un $2,5 \%$ menos.

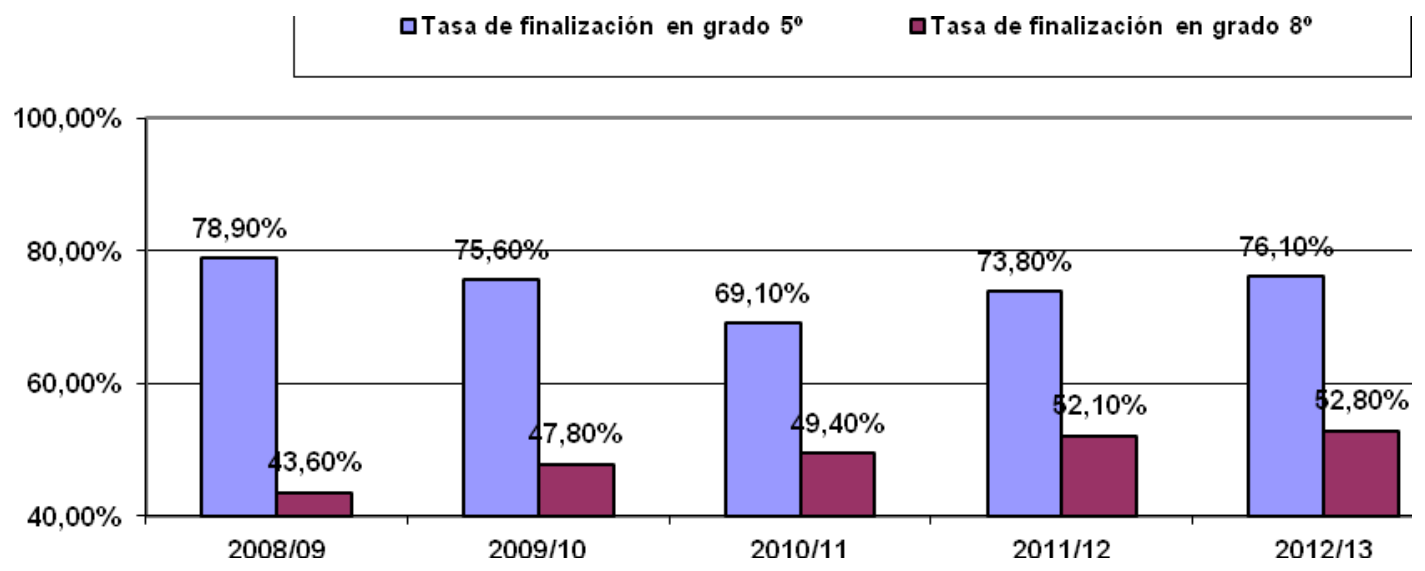

Figura 35. Evolución de la tasa de finalización en 5ㅇ y 8ㅇ Grado durante los cursos 2008/9- 2012/13

(Fuente: Elaboración propia a partir de datos del Ministerio de Educación)

Para el octavo curso los valores son muy inferiores, situándose en el curso 2012/13 en un $52,8 \%$, lo que supone un incremento de un $9,2 \%$ desde el curso 2008/09. Esto muestra un aumento medio anual de un $2,3 \%$ de esta tasa. Debido a la alta frecuencia con la que los alumnos repiten curso o abandonan el sistema escolar en Etiopía (MoE, 2013) el número de niños y niñas que realmente logran acabar los estudios de primaria es inferior, ya que en cada año se acumulan una gran cantidad de alumnos con edades superiores a la edad oficial para estar matriculados en los cursos con los que se calcula esta tasa. Además debido al abandono escolar tan marcado, aunque estén matriculados, no supone en un gran porcentaje ni que asistan todo el curso a clase ni que logren finalizarlo satisfactoriamente.

\section{4) Ratio de alumno por sección}

El ratio de alumnos por sección sustituye a la ratio de alumnos por clase ya que debido a las características de las escuelas etíopes este tipo de medición es más 
precisa que la tradicional ratio de alumnos por clase. Una sección, según el MoE, es una de las clases que se forman en un mismo grado, ya que en muchas ocasiones el número de alumnos matriculados en un colegio para cursar un mismo grado es muy superior al que puede alojar:

"Sections are multiple streams of a single grade. For example, if there are 120 Grade One enrolees, and classrooms can only accommodate 60 children, then 2 sections will be formed" (MoE, 2013 pág. 319).

Como hemos dicho con anterioridad esta ratio de alumnos por sección es más precisa debido a que en una gran cantidad de veces las aulas en Etiopía son compartidas por distintas clases ya que muchas escuelas son usadas por distintos turnos. Así pues, debido a la escasez de escuelas o de aulas en una misma escuela algunos cursos han de tener más de una clase o un alua ha de servir a más de un curso:

"Pupil Section Ratio is the average number of pupils, at a given educational level, in a given section. It is calculated by dividing the total number of pupils at a given level by the total number of sections available for that level. In a multi-shift school environment (such as Ethiopia has at both the Primary and Secondary levels), since classrooms are shared, the PSR is effectively the Student Classroom Ratio" (MoE, 2013 pág. 318).

Durante el curso 2012/13 esta ratio en la educación primaria se ha mantenido en 53,7 alumnos por sección, lo que mejora ligeramente la media de los años anteriores habiendo descendido desde 2008/9 en 5,1 alumnos por sección como podemos ver en la Tabla 12.

Tabla 12. Evolución de la tasa de alumnos por sección en primaria entre los cursos 2008/9 y 2012/13

\begin{tabular}{|c|c|c|c|c|c|}
\hline Curso & $2008 / 9$ & $2009 / 10$ & $2010 / 11$ & $2011 / 12$ & $2012 / 13$ \\
\hline Proporción & 58.8 & 56.6 & 57.2 & 54.5 & 53.7 \\
\hline
\end{tabular}

(Fuente: Elaboración propia a partir de datos del Ministerio de Educación)

Hay que tener en cuenta que en estos cálculos computan todos los cursos de primaria desde primer grado hasta octavo, lo que baja la ratio sensiblemente, ya 
que como en nuestra propia experiencia de campo hemos podido constatar, el número de alumnos en los primeros cursos de primaria es muy superior al existente en los últimos.

\section{5) Ratio de alumno-profesor}

La ratio de alumnos por profesor nos indica la proporción de alumnos por cada profesor, una ratio baja facilita que el profesorado pueda atender de una manera más individualizada a los alumnos y por tanto mejore la calidad de la educación que éstos reciben. Cada país establece una ratio máxima que garantiza un nivel de calidad e igualdad en la educación que los alumnos reciben. En Etiopía esta ratio se ha fijado en 50 alumnos por clase. En la Figura 36 podemos observar cómo en los últimos años esta ratio de profesores por alumno ha ido bajando paulatinamente debido a la incorporación de nuevo profesorado. Así, a pesar del aumento de la incorporación de niños al sistema educativo, durante el curso 2012/13 se ha llegado a lograr bajar del propio ratio máximo que establece el país.

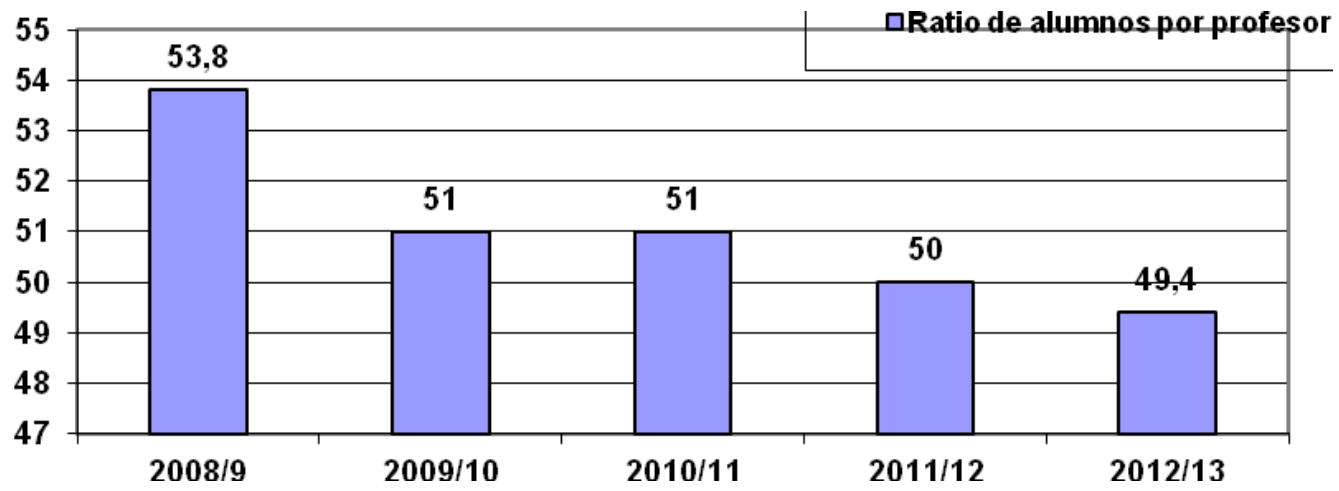

Figura 36. Evolución del Ratio de alumnos por profesor en los últimos 5 cursos académicos

(Fuente: Elaboración propia a partir de datos del Ministerio de Educación)

Pese a estos datos de la bajada de la ratio de alumnos por profesor queda mucho camino por hacer, ya que como veremos a continuación, la formación de estos profesores no es siempre la ideal y en bastantes ocasiones carecen de una titulación especializada que les habilite como profesores. 


\section{6) Profesorado de primaria}

El profesorado es una de las claves más importantes a la hora de analizar un sistema educativo y a la hora de lograr que éste alcance una buena calidad y forme correctamente a los alumnos que pasen por él. En Etiopía durante el curso 2012/13 había un total de 190.130 profesores en el primer ciclo de educación primaria y 144.979 en el segundo ciclo. (MoE, 2013). Como ya nos han mostrado anteriormente otros indicadores como el descenso de la ratio de alumnos por profesor, se ha producido un incremento del número de profesores trabajando en la educación primaria. Este aumento, como podemos ver en la Tabla 13, ha sido constante en los últimos años.

Tabla 13. Evolución del número de profesores en los dos ciclos de primaria entre 2006/7 y 2012/13

\begin{tabular}{|c|ccc|}
\hline Ciclo/ año & $2006 / 7$ & $2009 / 10$ & $2012 / 13$ \\
Primer ciclo & 145.359 & 175.334 & 190.130 \\
\cline { 2 - 3 } Segundo ciclo & 79.960 & 116.796 & 144.979 \\
Total & 225.319 & 292.130 & 335.109 \\
\hline
\end{tabular}

(Fuente: Elaboración propia a partir de datos del Ministerio de Educación y Unicef)

El profesorado de primaria ha aumentado desde 225.319 en el año 2006// hasta 335.109 en el curso 2012/13 lo que supone un ampliación del 32,77\% de la plantilla de profesores trabajando en las escuelas de primaria del país. Este crecimiento no se ha repartido por igual entre el profesorado de primer ciclo y segundo ciclo de primaria, ya que mientras el primero ha pasado de 145.359 profesores en $2006 / 7$ hasta 190.130 en $2012 / 13$, lo que supone un aumento del 23,55\%, el profesorado del segundo ciclo de primaria ha aumentado desde 79.960 en $2006 / 7$ hasta 144.979 en $2012 / 13$, lo que supone un crecimiento de un $44,85 \%$ durante ese periodo de tiempo.

Respecto al género de estos profesores, es claro el dominio del profesorado de género masculino ya que de los 335.109 docentes 210.975 son hombres y 124.134 son mujeres lo que arroja unas proporciones aproximadas de un $63 \%$ de 
profesorado masculino frente a un $37 \%$ de profesorado femenino. Esta diferencia es mucho más marcada en el segundo ciclo de primaria que en el primero, ya que mientras en los primeros cuatro cursos las diferentes proporciones son de $56,7 \%$ y $43,3 \%$ de profesorado masculino y femenino respectivamente en el segundo ciclo la diferencia de género aumenta hasta que los hombres suponen el $71,2 \%$ del profesorado y las mujeres solo el $28,8 \%$ del mismo. En nuestra experiencia de campo hemos podido constatar esta preponderancia del profesorado masculino en varios colegios a los que hemos asistido como podemos ver en la siguiente imagen (véase Figura 37).

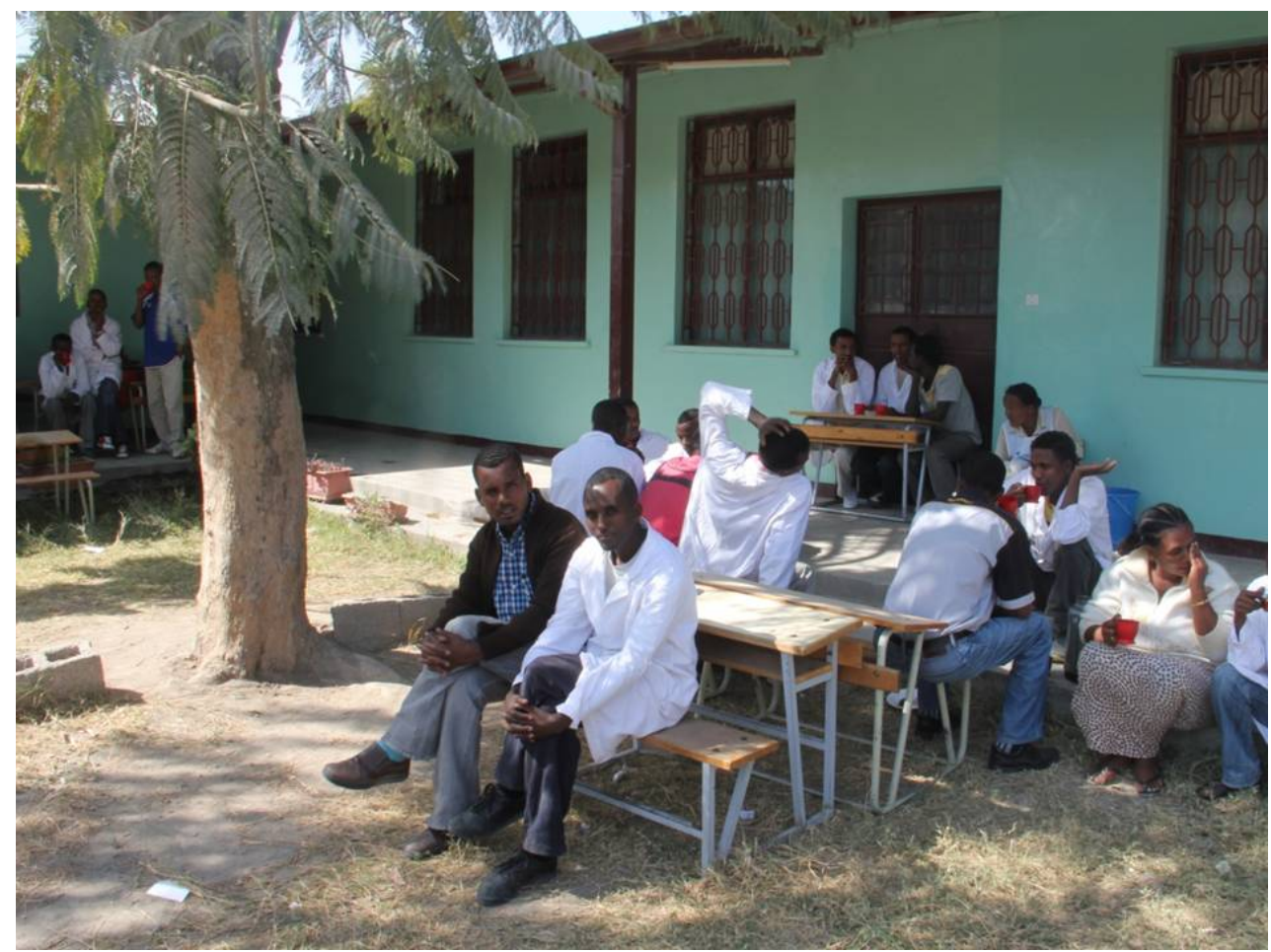

Figura 37. Profesorado de una escuela de primaria relajándose durante un periodo de descanso (Fuente: Autor)

Además observando los datos de estos últimos cinco años parece que las proporciones se mantienen bastante estables en la educación primaria rondando la proporción entre el $36 \%$ y $37 \%$ de profesorado femenino (véase Figura 38). 


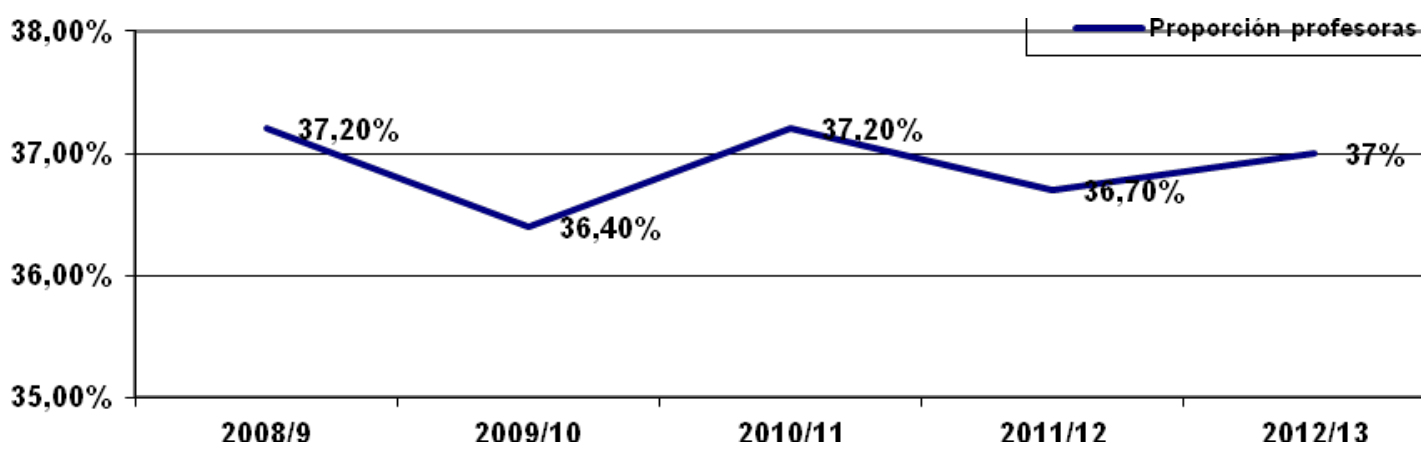

Figura 38. Evolución de la proporción de profesorado femenino en primaria entre los cursos 2008/9 y 2012/13

(Fuente: Elaboración propia a partir de datos del Ministerio de Educación)

No solo el aumento del profesorado es importante, la formación del mismo es otro de los aspectos que en los últimos años se han intentado mejorar. Varios de los profesores de la escuela de Qillenso nos relataron cómo cuando eran niños las aulas estaban completamente masificadas y el profesor no solía prestar una especial atención a los niños en clase. El supervisor de la zona me llegó a contar cómo él recordaba que uno de sus profesores de primaria se dedicaba a mirar por la ventana durante el horario lectivo y no daba la clase día tras día.

En el año 2009 se estableció un cambio de política por el cual se empezó a exigir a todos los profesores de primaria tener una formación mínima obtenida en un College of Teachers Education y se empezó a considerar no suficientemente formados a los profesores que se habían estudiado solo en una Teaching Training Institution (TTI) (MoE, 2013) Anteriormente al curso 2009/10 con un título obtenido en un TTI se consideraba que los profesores estaban suficientemente formados para impartir clase el primer ciclo de primaria, esto explica como veremos a continuación que se pasara de un porcentaje de profesores suficientemente formados de un 89,4\% en el primer ciclo de primaria en 2008 a un 15,5\% en 2009 (Figura 39). 


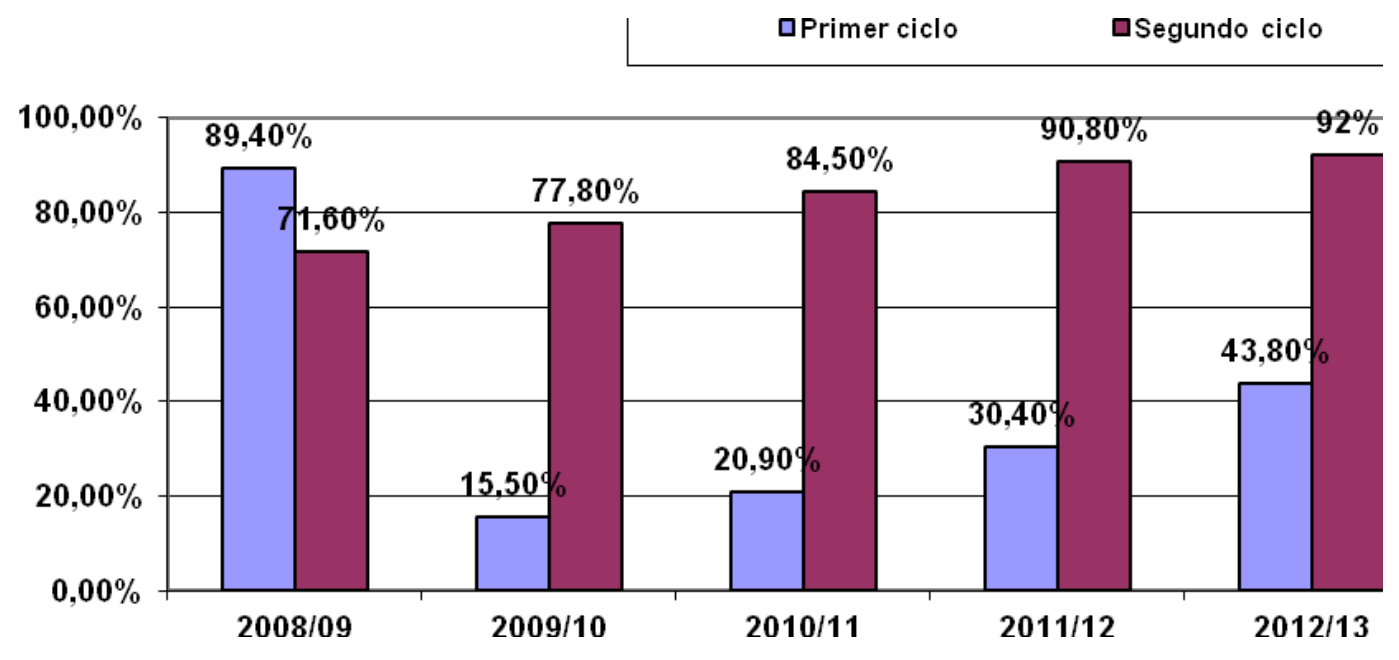

Figura 39. Evolución del porcentaje de profesores suficientemente cualificados en primer y segundo ciclo de primaria entre el 2008 y 2013

(Fuente: Elaboración propia a partir de datos del Ministerio de Educación)

Como se puede apreciar en la Figura 39 , desde $2009 / 10$ hasta $2012 / 13$ se ha experimentado un aumento constante del porcentaje de profesores que tienen una titulación en un CTE en el primer ciclo de primaria. Esto no se debe solo a la incorporación de nuevo profesorado sino también y en gran medida al reciclado del profesorado antiguo que durante las tardes o durante los veranos asisten a CTE para así lograr un diploma en un CTE. El gobierno etíope está facilitando que los antiguos profesores que no alcanzaban los requisitos mínimos de formación tras el cambio de normativa en 2009 logren obtener el diploma. Por ello los CTEs tienen varios tipos de programa para hacer que la asistencia a estos centros sea flexible y que los profesores que ya trabajen puedan conseguirlo:

"CTES give the three years and above diploma program in regular, evening and summer programs. There are more than 20 different departments, or streams, in most CTEs, categorized under two modalities; linear and cluster" (MoE, 2013 pág. 51).

Esto se hace evidente si tenemos en cuenta que de los 175.142 alumnos matriculados en los distintos CTEs repartidos por Etiopía, 92.929 asistían en la modalidad de verano, modalidad elegida preferentemente por los profesores que 
durante el año trabajan en las escuelas de primaria y en el verano van a ampliar su formación (MoE,2013).

En nuestra experiencia de campo pudimos constatar cómo en verano varios de los profesores de la escuela de Qillenso que no tenían un diploma en un CTE durante el verano iban a distintas localidades para asistir a cursos de verano. Además en las remuneraciones que recibían del gobierno por su trabajo como profesores los que tenían una titulación superior recibían un salario superior a los que no la tenían, ya que el mismo estaba expuesto en la dirección de la escuela para que el público pudiera ver los salarios de los profesores como indican las normas del MoE.

En el segundo ciclo de primaria el porcentaje de profesores con la titulación mínima exigida lleva aumentando constantemente desde el curso 2008/09 habiéndose incrementado un $20 \%$ aproximadamente el porcentaje de profesores en estas condiciones. Las diferencias de género en este aspecto de la formación necesaria para ejercer el trabajo son en este caso en los dos ciclos de la primaria favorables a las mujeres ya que las profesoras tienen unas proporciones más elevadas que los hombres habiendo un $65,4 \%$ de mujeres con la titulación necesaria frente a un $64,2 \%$ de hombres en la misma situación en el conjunto de la primaria.

Si analizamos los datos por ciclos en el primero de ellos de los 107.765 profesores trabajando durante el curso $2012 / 13$ solo 41.877 tienen la titulación exigida lo que supone el 38,9\% mientras que de las 82.365 profesoras 41.459 la tenían lo que supone el 50,3\%. En el segundo ciclo las proporciones están mucho más igualadas ya que de los 103.201 hombres 93.616 tienen la formación necesaria lo que es un $90,7 \%$ frente a las 39.712 profesoras formadas de las 41.769 que trabajan en el segundo ciclo de secundaria lo que supone que el $95,1 \%$ de las profesoras ha cursado los estudios necesarios para desempeñar su trabajo. Esta proporción mayor de mujeres tituladas no significa que haya más mujeres que hayan realizado los estudios necesarios ya que en realidad durante el curso 2012/13 había 54.418 profesores más que profesoras con los estudios mínimos exigidos para desempeñar su profesión. 
Es importante destacar que aunque son varios los estímulos que están recibiendo los profesores para mejorar su formación en la actualidad, esto no significa que automáticamente se traduzca en un mejor desempeño de la actividad docente como veremos más adelante cuando analicemos los problemas detectados en el sistema educativo etíope.

\section{7) Educación primaria alternativa}

Incluimos en este apartado una breve referencia a la educación básica alternativa $(A B E)$ y a la educación para adultos. Así, en primer lugar y por lo que se refiere a la Educación básica alternativa $(A B E)$, Etiopía es un país con enormes diferencias internas y con la presencia de poblaciones nómadas o con un tipo de asentamiento muy disperso por lo que el gobierno diseñó la $A B E$ para poder dar una educación primaria básica a niños que no podrían haberla conseguido con el sistema educativo normal:

"To realize the goal of providing universal access to primary education by 2008 E.C. (2015/16), ESDP III envisaged provision of basic education through alternative modes" (Moe, 2013, pág. 38).

Esta educación alternativa está orientada a alumnos con una edad similar a los alumnos que cursan la educación primaria regular y desde el curso 2005/6 se incluye a sus alumnos en los datos oficiales de la educación primaria. Durante estos años ha supuesto un 4\% del GER en educación primaria (MoE, 2013). Esta educación alternativa también ha servido como un puente para acercar la educación primaria formal a zonas en las que anteriormente no se encontraba y prueba de ello es el descenso del alumnado de estos centros y su incorporación al sistema educativo formal:

"The ABE enrolment shows a decreasing trend especially for the last four years and this is because many $A B E$ centers are being upgraded to formal primary schools" (MoE, 2013, pág. 38).

En segundo lugar y por lo que respecta a la Educación no formal para adultos, dichos programas tienen como objetivo proporcionar una educación básica 
a personas que están muy por encima de la edad oficial en la que los niños deberían cursar la educación primaria (MoE, 2013). El propio Ministerio de Educación de Etiopía reconoce que no dispone de unos datos especialmente completos sobre el número de alumnos matriculados en estos programas ya que muchos son llevados a cabo por organizaciones internacionales y la forma y duración de esos mismos programas hace muy difícil la recolección de datos:

"Reporting accuracy and completeness is uneven and this might be due to the fact that duration of registration and data collection doesn't match for adult education" (MoE, 2013, pág. 39).

Aún así los datos que ha podido recopilar el MoE indican que durante el curso 2012/13 son que un total de 3.415.776 adultos estaban apuntado a alguno de estos programas, de los que 2.116 .620 eran hombres y 1.299 .156 eran mujeres. En nuestra experiencia de campo pudimos conversar con un anciano Guji que había asistido a uno de estos programas y comentó que le enseñaron a leer y escribir en amhárico pero no en Oromo; también se quejó de que cuando era el niño no había escuela y por eso tuvo que aprender de mayor a leer y escribir.

\section{8) Estudiantes con necesidades especiales}

En Etiopía, como en otros países pobres, los niños con discapacidad se encuentran en un mayor riesgo de exposición a situaciones peligrosas para su integridad física y moral:

"In Ethiopia, children and women with disabilities are more likely to be abused and neglected than other children" (UNICEF, 2012, pág. 31).

Las causas de estas discapacidades son varias, desde razones puramente genéticas hasta causas relacionadas con la falta de educación de las madres o la pobreza:

"The underlying causes include insufficient access to food, inadequate maternal and childcare practices, poor water and sanitation and inadequate health services" (UNICEF, 2012, pág. 31). 
El número de estos niños con discapacidades según el último censo disponible con datos del año 2007, se situó en 231.192 (UNICEF, 2012). En realidad creemos que la cifra será muy superior ya que todavía en la cultura etíope muchos tipos de discapacidad como la mental son considerados vergonzantes y los enfermos son escondidos en casa o abandonados. Hay que tener en cuenta que la prevalencia media de los trastornos mentales en Etiopía es de un 18\% para adultos y de un $15 \%$ en el caso de los niños. Sin embargo, los servicios de salud mental sólo están disponibles en Addis Abeba. Por tanto, un gran número de estos chicos está sin hogar y vive en la calle (Sathiyasusuman, 2011).

En nuestra experiencia de campo conocimos varios casos de abandono de niños con alguna alteración como la epilepsia. Además muchos de estos niños acaban siendo utilizados para mendigar en las grandes ciudades como pudimos observar y como denuncia en un informe UNICEF:

"Many unscrupulous individuals also bring disabled children to urban centres and force them to beg for a living or work for low wages" (UNICEF, 2012, pág. 31).

Que estos niños y niñas logren acudir al sistema educativo es fundamental para que se visibilice y normalice su situación y ayudar así a acabar con la discriminación que sufren en muchas ocasiones las personas discapacitadas en Etiopía. En este sentido, el número de alumnos con necesidades especiales matriculados en la educación primaria durante el curso 2012/13 fueron 68.404 , de los cuales 39.293 eran chicos y 29.111 chicas (MoE, 2013). Si comparamos este número de alumnos con el número total de alumnos matriculados en la educación primaria que es de 17430294 podemos observar que los alumnos con necesidades especiales solo suponen el 0,39\% del total. En la Tabla 14 podemos observar cómo se distribuyen estos mismos alumnos dependiendo del tipo de discapacidad que presentan. 
Tabla 14. Distribución por discapacidad y género de los alumnos discapacitados en educación primaria durante el curso 2012/13

\begin{tabular}{|c|c|c|c|}
\hline Discapacidad & Chicos & Chicas & Total \\
\hline Ceguera & 5.020 & 3.678 & 8.698 \\
\hline Física & 10.864 & 7.768 & 18.632 \\
\hline Sordera & 8.686 & 6.783 & 15.469 \\
\hline Intelectual & 10.247 & 7.608 & 17.855 \\
\hline Otras & 4.476 & 3.274 & 7.750 \\
\hline Total & 39.293 & 29.111 & 68.404 \\
\hline
\end{tabular}

(Fuente: Elaboración propia a partir de datos del Ministerio de Educación)

En la Tabla 14 podemos observar cómo las discapacidades físicas con un $27,2 \%$ e intelectuales con un $26,1 \%$ son las más numerosas, seguidas en tercer lugar de la sordera que aporta un $22,6 \%$ de los alumnos con algún tipo de discapacidad. También queda patente que los alumnos varones con discapacidad son más numerosos que las alumnas aportando los primeros un $57,4 \%$ y las segundas un $42,6 \%$ del total de alumnos con algún tipo de discapacidad.

Tabla 15. Distribución por grado de los alumnos con discapacidad durante el curso 2012/13

\begin{tabular}{|c|c|c|c|c|c|c|c|c|c|}
\hline Curso & 19 & 29 & 30 & 40 & 50 & 60 & 70 & 80 & Total \\
\hline Número & 17.250 & 11.344 & 9.622 & 7816 & 6.345 & 4951 & 5688 & 5408 & 68.404 \\
\hline$\%$ & $25,21 \%$ & $16,58 \%$ & $14,06 \%$ & $11,42 \%$ & $9,27 \%$ & $7,23 \%$ & $8,31 \%$ & $7,9 \%$ & $100 \%$ \\
\hline
\end{tabular}

(Fuente: Elaboración propia a partir de datos del Ministerio de Educación)

Respecto a la evolución de los alumnos con discapacidad a lo largo de los dos ciclos de primaria (véase Tabla 15), podemos observar cómo al igual que ocurre con los alumnos generales de la educación primaria se observa un descenso paulatino de alumnado desde el primer ciclo hasta el octavo, excepto en este caso entre el sexto curso y el séptimo que aumenta ligeramente. Este alumnado con necesidades especiales se concentra en los primeros cursos de primaria, podemos observar en la tabla que el $67.27 \%$ de todos los alumnos con algún tipo de discapacidad cursan en 
los cuatro primeros cursos de primaria mientras que solo el $32.73 \%$ están matriculados en el segundo ciclo de educación primaria.

\section{9) Género y educación}

El acceso a la educación por parte de las niñas es fundamental para el desarrollo de un país, esto es especialmente importante a la hora de la educación primaria. El gobierno etíope recoge en sus informes (MoE, 2013) que el GPI (Índice de paridad de genero) para la educación primaria es de un 0.94. Este dato aisladamente no es a nuestro entender suficientemente explicativo y por ello para facilitar la comprensión de la situación de las niñas en la educación primaria respecto a la de sus compañeros varones hemos decidido analizar tomando el género como el eje fundamental de nuestro análisis los distintos datos que hemos ido viendo a lo largo de los distintos apartados de este capítulo relacionados con la educación primaria.

Como primer dato y aunque no parezca muy importante, creemos que es muy simbólico que si bien el gobierno etíope tiene la igualdad de géneros en la enseñanza como uno de sus ejes para la mejora de la educación, en las escuelas del país hay solo 59.686 letrinas para niñas frente a 64.189 letrinas para niños, lo que demuestra que el propio gobierno infravalora la presencia y las necesidades de las niñas en las escuelas.

Entrando ya en el análisis de los datos el primer punto que hemos de conocer es la evolución del número de niñas que están asistiendo a la educación primaria durante estos últimos años y el porcentaje del alumnado que representan. Como podemos ver en la Tabla 16, durante estos años el porcentaje de alumnas matriculadas se ha mantenido aproximadamente en un $47 \%$ del total lo que viene a demostrar que pese al aumento de la escolarización en primaria nivel general en Etiopía parece que han llegado a un punto de estabilidad que es difícil de superar para acabar de lograr introducir en la educación al remanente de niñas que no acceden a la misma (véase Tabla 16). Esta impresión queda reforzada en la misma Tabla 16 ya que vemos que pese a que el 49,1\% de la población en edad escolar es 
de género femenino el alumnado femenino se mantiene alrededor del $47 \%$ anteriormente citado por lo que queda claro que una pequeña parte de la población femenina en edad escolar queda sistemáticamente fuera del sistema educativo.

Tabla 16. Evolución porcentaje alumnas matriculadas en educación primaria (incluyendo ABE) y su comparación respecto al porcentaje de población femenina en edad escolar

\begin{tabular}{|c|ccccc|}
\hline Año & $2008 / 09$ & $2009 / 10$ & $2010 / 11$ & $2011 / 12$ & $2012 / 13$ \\
\% población & $49,1 \%$ & $49,1 \%$ & $49,1 \%$ & $49,1 \%$ & $49,1 \%$ \\
\% escuela & $47,3 \%$ & 47,6 & 47,5 & 47,8 & 47,6 \\
\hline
\end{tabular}

(Fuente: Elaboración propia a partir de datos del Ministerio de Educación)

Tasa de ingreso neto

La situación estos años muestra que de media las niñas son matriculadas de media un $4 \%$ menos aproximadamente que los niños a la edad de 7 años para empezar el primer curso de primaria y esa tendencia se ha mantenido todos los últimos años, mostrando la matriculación femenina el mismo patrón que la masculina, aunque inferior a éstos, en todos los años analizados como podemos ver en la Figura 40.

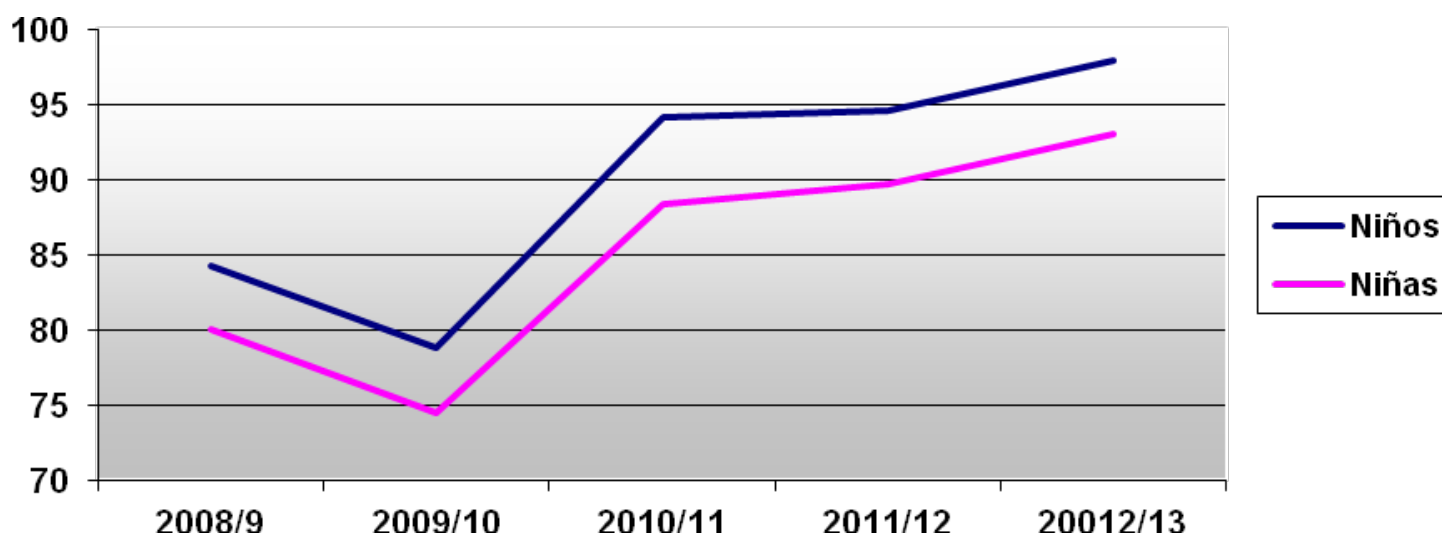

Figura 40. Comparación de la evolución de la tasa de ingreso neto entre niños y niñas entre 2008/9 y 2012/13

(Fuente: Elaboración propia a partir de datos del Ministerio de Educación) 
Tasa de ingreso con independencia de la edad (AIR)

Las diferencias entre niños y niños en este caso son más marcadas que el anterior, habiendo una diferencia media de 13,28 puntos durante estos cinco años académicos aunque igualmente que el caso anterior la evolución de niños y niñas sigue un patrón similar, como queda reflejado en la Figura 41.

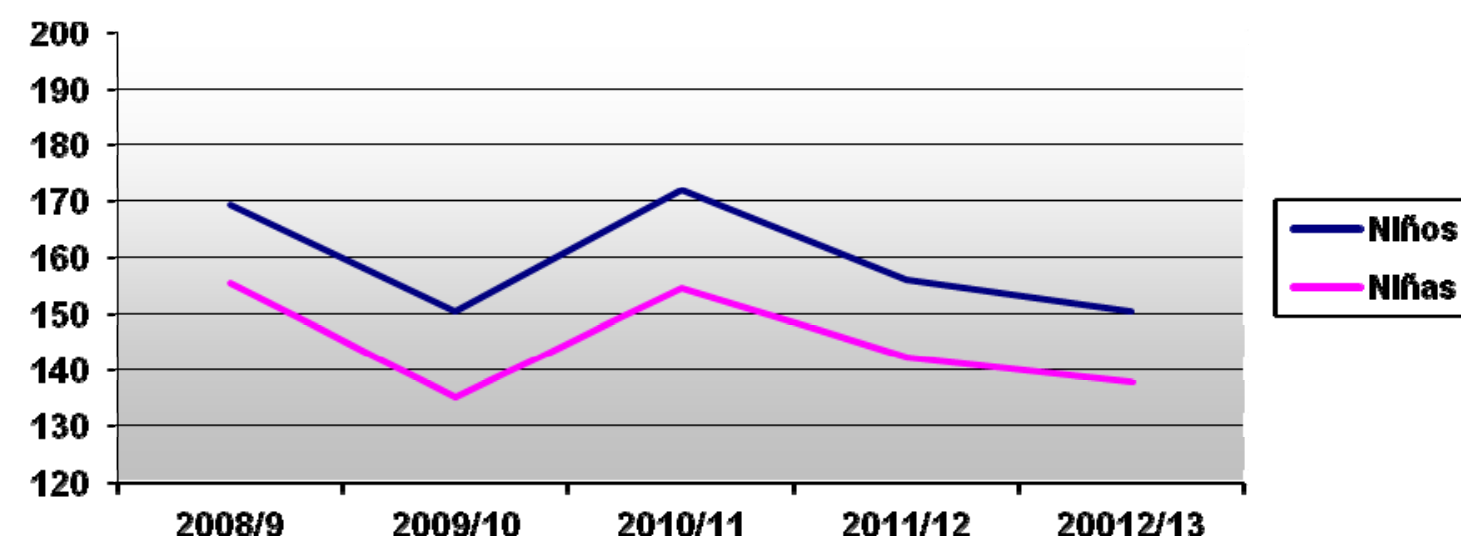

Figura 41. Evolución de la tasa de ingreso con independencia de la edad diferenciada por género (Fuente: Elaboración propia a partir de datos del Ministerio de Educación)

De estos datos se puede deducir que las niñas acceden en un porcentaje inferior por primera vez al primer curso de primaria, situación que ya compromete negativamente la educación de las niñas ya que las sitúa en una desventaja respecto a sus compañeros masculinos. Personalmente pienso que esta menor primera matriculación de las niñas se debe a ciertos factores económicos, sociales y culturales que afectan negativamente al papel de la mujer en la sociedad y que analizaremos más adelante.

Tasa de escolarización bruta (GER)

Como podemos ver en la Figura 42, la tasa de escolarización bruta a nivel general de toda Etiopía para las chicas es de media un 6,1 \% inferior a la de los chicos en el periodo de 2008/9 hasta 2012/13 


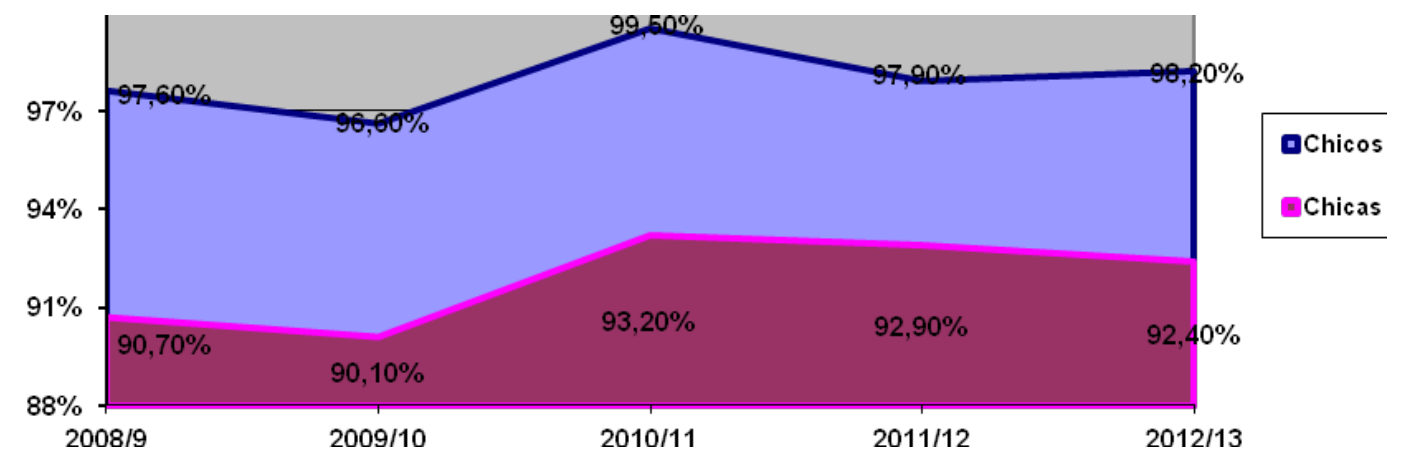

Figura 42. Comparativa de las tendencias entre $2008 / 9$ y 2012/13 de la tasa de escolarización bruta en primaria (10-8ㅇ) dependiendo del género

(Fuente: Elaboración propia a partir de datos del Ministerio de Educación)

Podemos observar en la Figura 42 que las diferencias por género se han acortado de un $6,9 \%$ en el curso $2008 / 9$ a un 5,8\% en el $2012 / 13$ pero esta tendencia parece que, aunque está en camino de consolidarse, todavía puede sufrir un retroceso ya que mientras las diferencias por genero bajaron de manera constante entre 2008/9 y 2011/12 hasta situarse solo en un 5\% en 2012/13 volvieron a aumentar hasta el 5,8\% anteriormente citado.

Si analizamos más en detalle la tasa de escolarización bruta comparando los datos del primer ciclo de primaria con los del segundo ciclo podemos observar unas diferencias muy interesantes. En el primer ciclo, como vemos en la Figura 43, durante el periodo comprendido entre $2008 / 9$ y 2012/13 la tasa media ha sido un $9,12 \%$ inferior en el caso de las niñas que en el caso de los niños. Lo preocupante es que los datos muestran la tendencia de que la brecha de género se está ensanchando ya que mientras que en $2008 / 9$ era de un $8,3 \%$ en 2012/13 la diferencia era ya de un $9,9 \%$ lo que supone un aumento de un $1,6 \%$ en estos cinco años lo que es un claro retroceso ya que excepto entre los cursos 2010/11 y 2011/12 el resto de los años esta diferencia ha ido aumentando paulatinamente. 


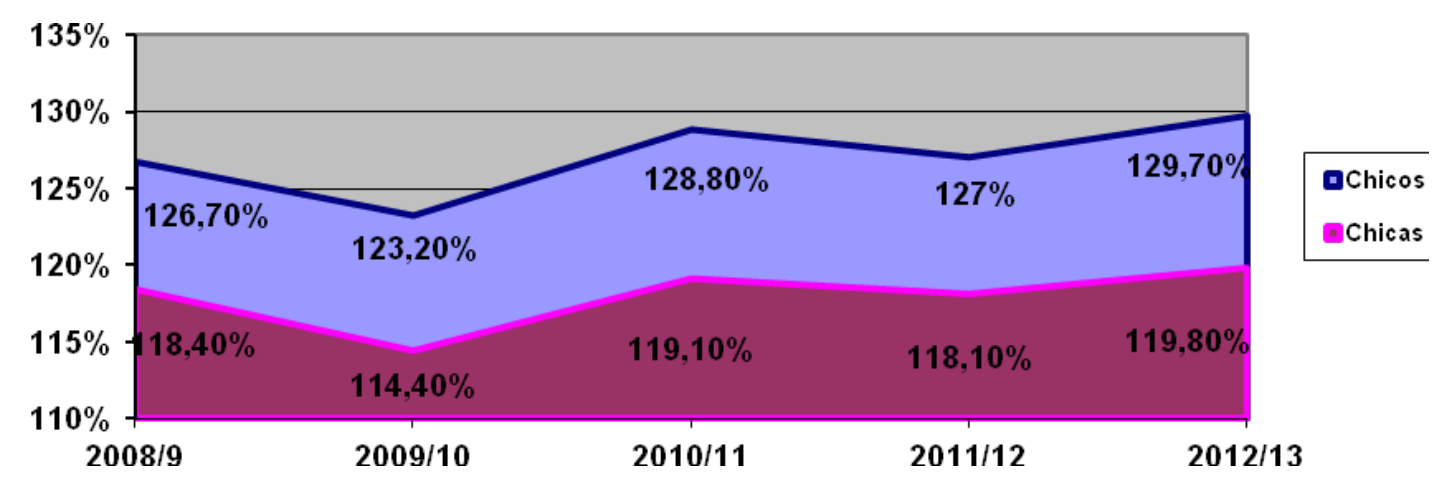

Figura 43. Comparativa de la tendencia tasa de matriculación bruta en el primer ciclo de primara (10-4ㅇ) dependiendo del género

(Fuente: Elaboración propia a partir de datos del Ministerio de Educación)

Si comparamos estos datos del primer ciclo con los del segundo ciclo de primaria (ver Figura 44) las diferencias no pueden ser más significativas. Durante el periodo de 2008/9 hasta 2012/13 la diferencia de género ha sido de un 2,68\% de media. Además la tendencia muestra un claro retroceso de las diferencias de género ya que en el año 2008/9 la diferencia se situaba en un 5,1\% mientras que en el 2012/13, pese a que ese año aumento la diferencia por género en un $0,8 \%$ respecto al anterior, la diferencia se situaba en un $1,3 \%$

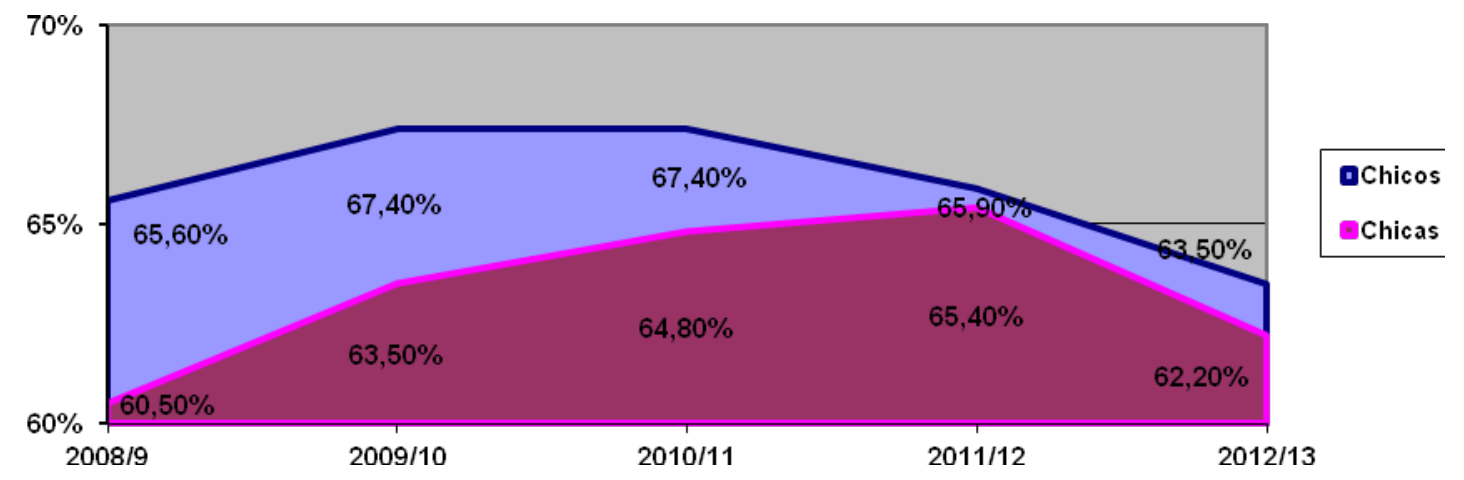

Figura 44. Comparativa de la tendencia tasa de matriculación bruta en el segundo ciclo de primara (5-8ㅇ) dependiendo del género

(Fuente: Elaboración propia a partir de datos del Ministerio de Educación)

Aunque esta es una buena noticia, la situación no es tan positiva como en un principio se puede creer. Y ello porque aunque se esté reduciendo la distancia en el segundo ciclo de primaria una vez que se entra en la educación secundaria, sobre 
todo en el segundo ciclo de la misma, esta separación entre géneros crece de una manera muy marcada como se puede comprobar en los datos del Ministerio de Educación de Etiopía (MoE, 2013) y como denuncian diversos informes internacionales (UNICEF, 2012) Si además continuamos estudiando los datos y nos fijamos en la educación superior las diferencias de género se hacen enormes, siendo la presencia femenina en los programas de posgraduado de un solo $19,5 \%$ (MoE, 2013). Además este estrechamiento de la disparidad en la matriculación en el segundo ciclo de primaria no se debe solo al aumento de la matriculación femenina, sino al gran abandono escolar que se produce una vez finalizado el cuarto curso de primaria y como veremos a continuación afecta más a los chicos que a las chicas.

En la Tabla 17 se puede observar que este abandono ha sido superior entre los chicos que entre las chicas en todos los años estudiados excepto en el curso 2008/9 y que esta diferencia ha ido acrecentándose año tras año menos en 2012/13 que ha retrocedido ligeramente.

Tabla 17. Comparativa de la tendencia durante el periodo 2008/9-2012/13 del descenso de alumnos matriculados en segundo ciclo de primaria respecto al primer ciclo según el género

\begin{tabular}{|c|c|c|c|c|c|c|c|c|c|c|}
\hline Año & \multicolumn{2}{|c|}{$2008 / 9$} & \multicolumn{2}{c|}{$2009 / 10$} & \multicolumn{2}{c|}{$2010 / 11$} & \multicolumn{2}{c|}{$2011 / 12$} & \multicolumn{2}{c|}{$2012 / 13$} \\
\hline Genero & Chicos & Chicas & Chicos & Chicas & Chicos & Chicas & Chicos & Chicas & Chicos & Chicas \\
\hline 1 ciclo & 5.570 .497 & 5.018 .155 & 5.545 .577 & 4.966 .962 & 5.947 .467 & 5.307 .229 & 6.022 .357 & 5.402 .698 & 6.320 .632 & 5.630 .825 \\
\hline 2 ciclo & 2.626 .001 & 2.338 .489 & 2.764 .312 & 2.515 .253 & 2.831 .621 & 2.631 .794 & 2.843 .134 & 2.721 .595 & 2.812 .742 & 2.666 .095 \\
\hline \% descenso & 52,86 & 53,4 & 50,15 & 49,36 & 52,39 & 50,41 & 52,79 & 49,63 & 55,5 & 52,65 \\
\hline
\end{tabular}

(Fuente: Elaboración propia a partir de datos del Ministerio de Educación)

Además si comparamos la evolución de los datos de la Tabla 16 con los de la Tabla 17 vemos que hay una correspondencia en la evolución del descenso de la diferencia de la tasa de matriculación bruta entre chicos y chicas y el aumento de la diferencia del porcentaje de abandono tras la finalización del primer ciclo. O dicho de otra manera se está produciendo una progresiva diferenciación en la Tasa de abandono de modo que los chicos tienden a abandonar más que las chicas, pero es importante tener en cuenta que debido al hecho de que en realidad, hay más chicos que chicas que se benefician de la oportunidad de ir a la escuela sigue habiendo una 
mayoría de alumnos varones en las clases tanto de primer ciclo como de segundo ciclo de primaria (Figura 45).

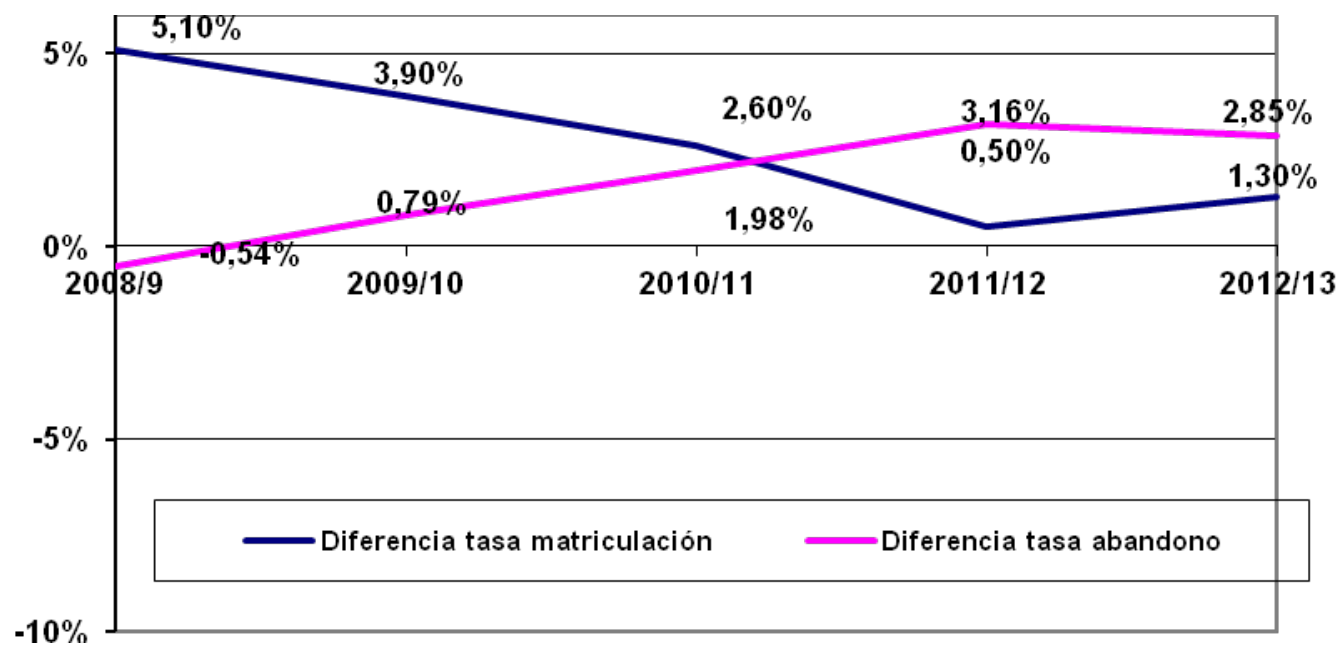

Figura 45. Grafica comparativa de las diferencias por género en la tasa de matriculación bruta en el segundo ciclo de primaria y la tasa de abandono al finalizar el primer ciclo de primaria

(Fuente: Elaboración propia a partir de datos del Ministerio de Educación)

\section{Tasa de escolarización neta}

La tasa de escolarización neta de las niñas durante los dos ciclos de educación primaria se ha mantenido de media un 3,3\% inferior a la de los alumnos varones durante el periodo de tiempo comprendido entre $2008 / 9$ y 2012/13. En la Figura 46 queda claro que las diferencias de género se han mantenido en el mejor de los casos bastante estables durante estos años alrededor del 3\% y que de hecho han aumentado ligeramente desde $2008 / 9$ en un $0,3 \%$ lo que es justo lo contrario al objetivo de lograr una paridad en la educación. 


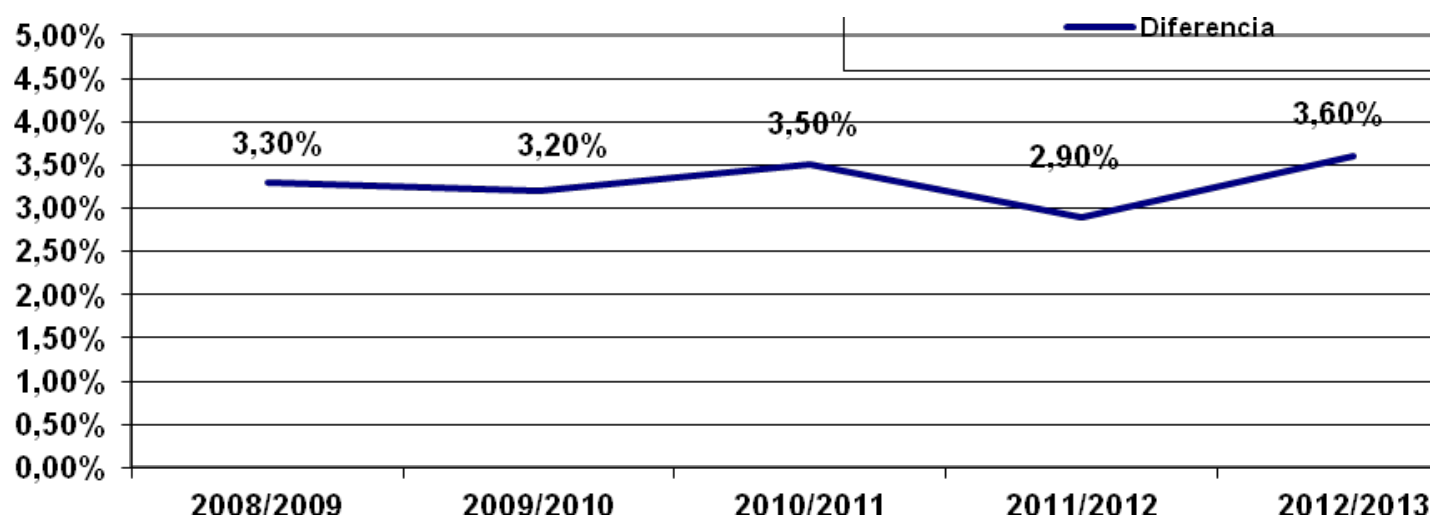

Figura 46. Evolución de la diferencia de la NET en primaria dependiendo del género

(Fuente: Elaboración propia a partir de datos del Ministerio de Educación)

Si estudiamos las tasas de matriculación neta de manera diferenciada entre los dos ciclos de primaria observamos que en el segundo ciclo de primaria la escolarización neta femenina es superior a la masculina en un 1,6\% durante el curso 2012/13 (MoE, 2013). Esto se debe a como hemos dicho anteriormente a múltiples factores ya explicados en el apartado anterior y pese a ello en el ciclo de primaria de manera global la diferencia en $2012 / 13$ se situaba en un $3,6 \%$ a favor de los varones. Las consecuencias de ello son que en el primer ciclo de primaria, educación que en muchos casos es la única que los alumnos logran terminar satisfactoriamente, las diferencias de género no solo se mantienen sino que se están acrecentando ligeramente y provocaban que durante el curso 2012/13 las niñas tuvieran unas tasas de matriculación neta de un 5,4\% inferiores a los niños. Esto se debe entre otros motivos a que pese al aumento de la incorporación de las niñas al sistema educativo se ha producido paralelamente un aumento superior de la matriculación de los niños ya que durante el periodo 2008/9-2012/13 la matriculación neta de los varones ha aumentado un 3,1\% mientras que la de las niñas lo ha hecho en un $2,8 \%$.

\section{Tasa de repetición y abandono escolar}

A continuación analizaremos el impacto del género a la hora de producirse tanto la repetición entre cursos como el abandono del sistema educativo. 
En primer lugar la tendencia de caer en la repetición de un curso durante todo el ciclo de primaria durante desde el curso 2007/8 hasta el curso 2011/12 dependiendo del género la podemos observar en la Figura 47.

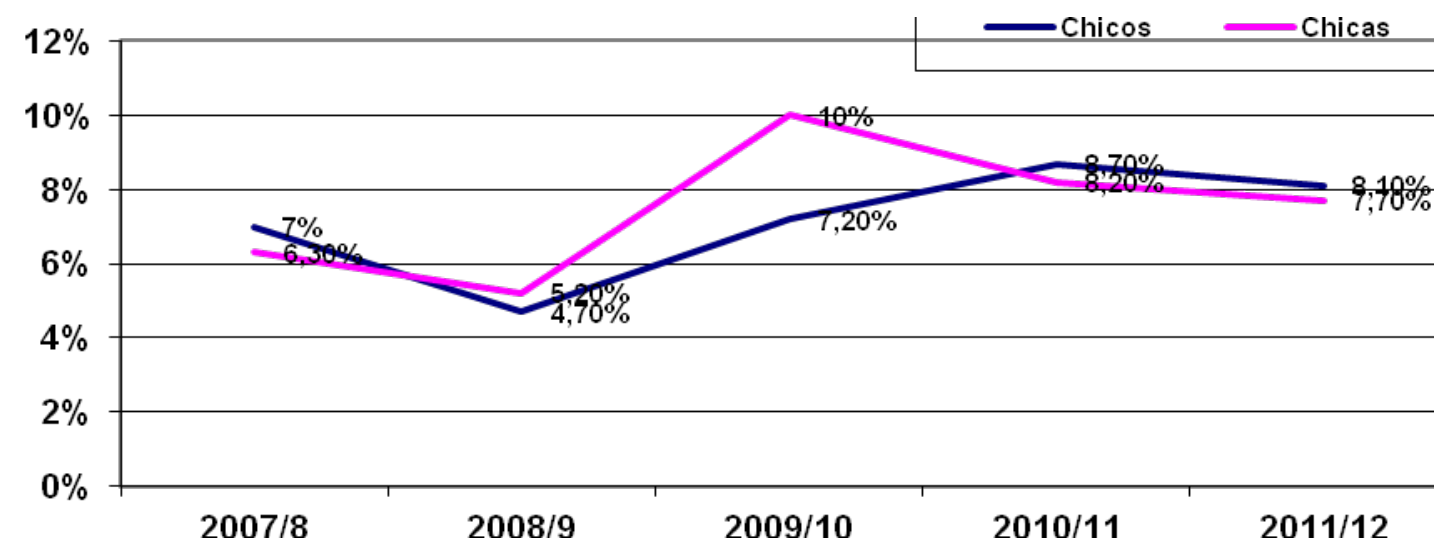

Figura 47. Tendencias en grado de repetición según el género durante la primaria entre 2007/8 y 2011/12

(Fuente: Elaboración propia a partir de datos del Ministerio de Educación)

Como podemos apreciar, tanto alumnos como alumnas mantienen la misma tendencia aunque durante el curso 2009/10 el incremento del porcentaje de repetición fue notablemente superior entre las estudiantes que entre los estudiantes. Si analizamos más a fondo los datos más actuales disponibles que son los del curso 2011/12 y separamos las tasas de repetición curso por curso el resultado obtenido queda reflejado en la Figura 48.

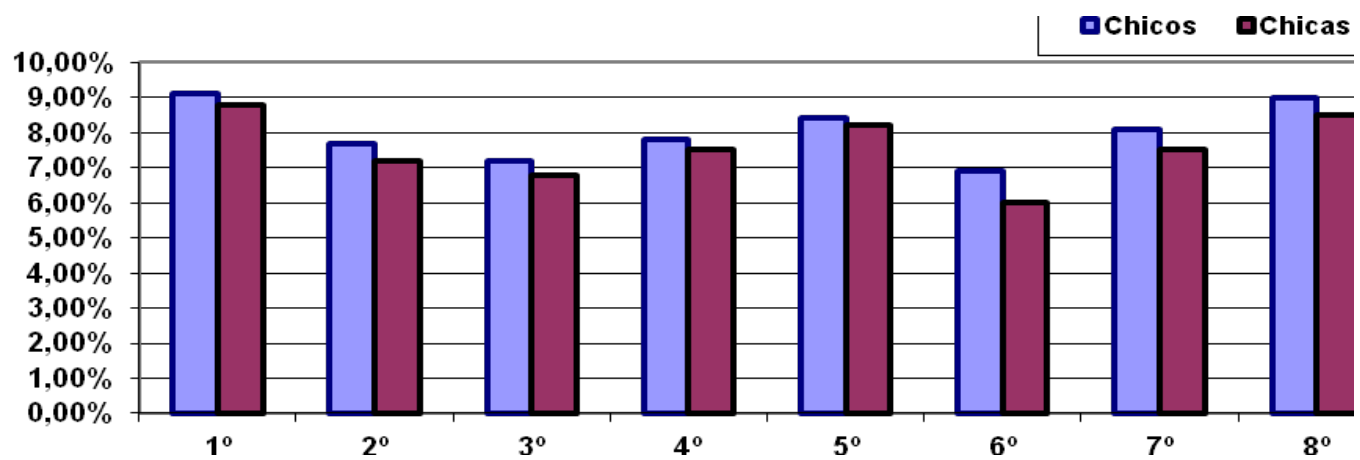

Figura 48. Comparativa según el género de la tasa de repetición en cada curso de primaria durante el año académico 2011/12

(Fuente: Elaboración propia a partir de datos del Ministerio de Educación) 
Queda claro al observar la Figura 48 que las diferencias de género no son sustanciales a la hora de repetir algún curso, alumnos y alumnas repiten los mismos cursos en proporciones muy igualadas. A la hora de analizar el abandono escolar en la educación primaria según el género de los alumnos la situación es muy similar. En la evolución de la tendencia del abandono escolar durante los últimos años académicos podemos observar que siguen un patrón muy similar a la tasa de repetición, con los dos géneros siguiendo una misma tendencia y con diferencias mínimas (véase Figura 49).

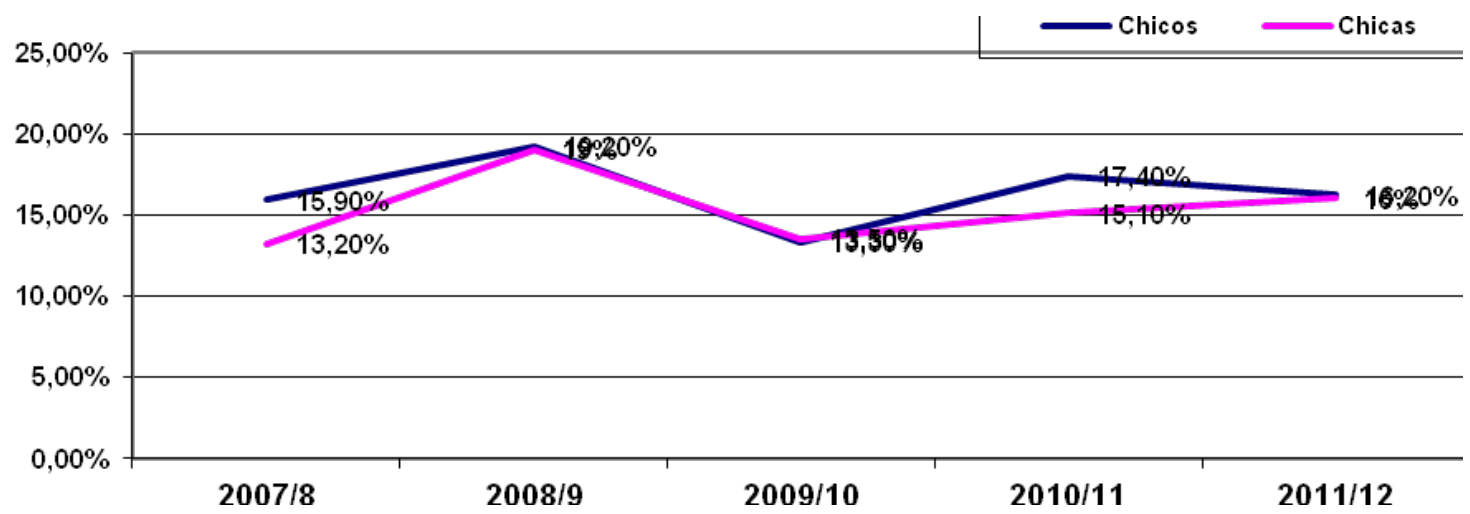

Figura 49. Tendencia según el género de la tasa de abandono escolar entre el curso 2007/8 y 2011/12 en primaria

( Fuente: Elaboración propia a partir de datos del Ministerio de Educación)

Si analizamos los datos del año 2011/12 podemos observar en la Figura 50 cómo el abandono escolar es muy similar entre chicas y chicos siendo ligeramente superior el abandono de todos los chicos durante todos los cursos excepto en 7으 $\mathrm{y}$ 8 ㅇ en el que el abandono de las chicas es superior. 


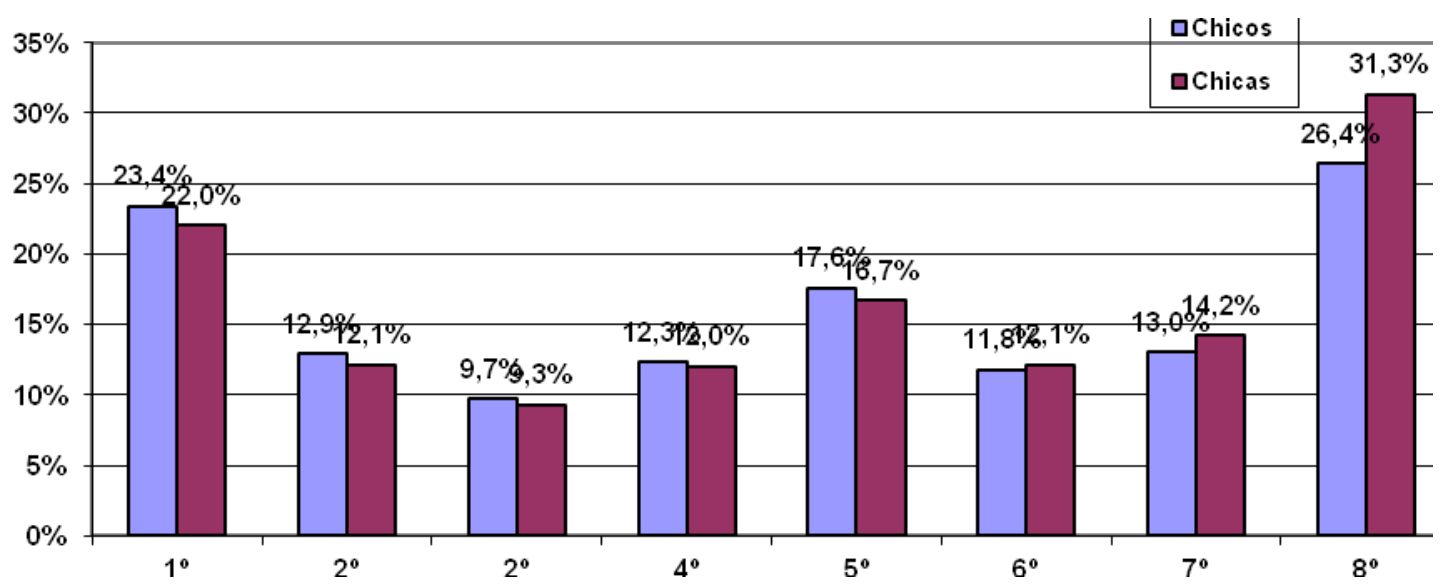

Figura 50. Tasa de abandono escolar según el género durante los distintos cursos de la educación primaria durante el curso $2011 / 12$

(Fuente: Elaboración propia a partir de datos del Ministerio de Educación)

Tasa de supervivencia hasta 5 을 grado

La tasa de supervivencia hasta el quinto curso, como dijimos anteriormente, es una medida que sirve para conocer una estimación del número de alumnos que al menos completan los primeros cuatro cursos de primaria lo que se supone que es un requisito para conseguir una alfabetización mínima que les ayude a sobrevivir en el día a día. Como vemos en la Figura 51, tanto la tasa de supervivencia hasta el 5 o curso de los chicos como la de las chicas se ha comportado de una manera muy irregular en los últimos años por lo que es difícil lograr vislumbrar una tendencia en ella

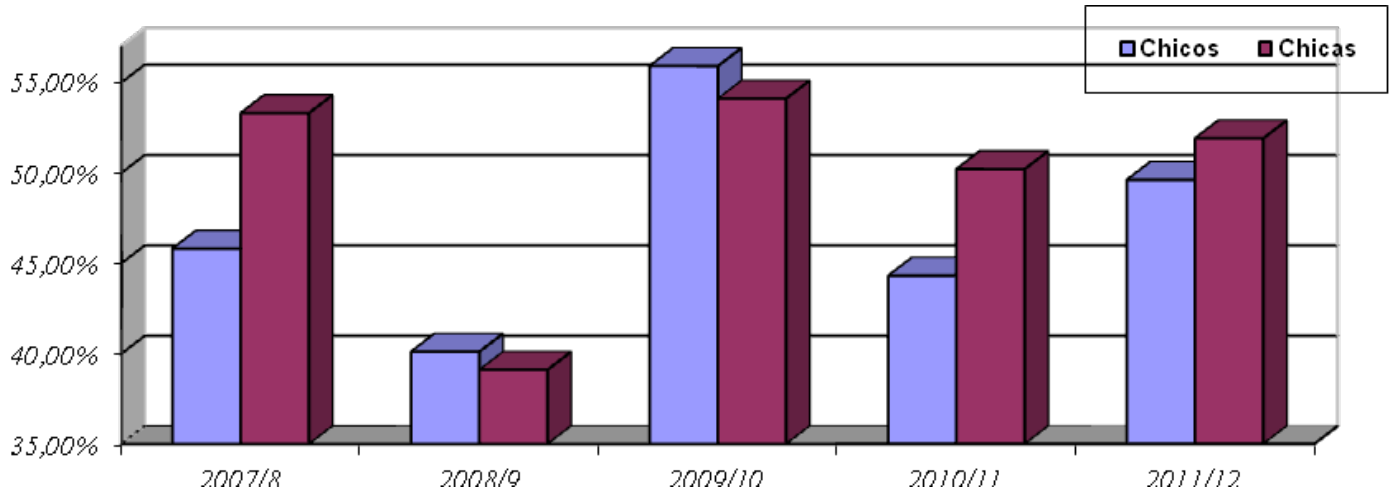

Figura 51. Evolución de la Tasa de supervivencia entre 2007/8 y 2001/12 según el género

(Fuente: Elaboración propia a partir de los datos del Ministerio de Educación Etíope) 


\section{Tasa de finalización de primaria}

Como vimos anteriormente esta tasa, elegida por la ONU como una de los sistemas de medición más importantes para analizar el desempeño de un sistema educativo, (MoE, 2013) se calcula en Etiopía tanto en grado 5o y grado 8o y nos puede ayudar para vislumbrar diferencias de género a la hora de acabar el primer ciclo y segundo ciclo de primaria.

En la Figura 52 podemos ver que la diferencia debido al género que nos arroja esta tasa para quinto grado es relativamente pequeña aunque desde el curso 2008/9 la tasa de finalización en los varones se ha mantenido siempre por superior a la de las chicas. De media esta tasa masculina ha sido 2,08 puntos más elevada que la femenina. Todo ello nos indica que la relación entre chicos y chicas a la hora de finalizar el primer ciclo de primaria es favorable a estos primeros y parece que la progresión femenina ha llegado a un punto de estancamiento y la diferencia por género pese a ser pequeña no se consigue finalmente cerrar, es más en el último año ha aumentado en 1,3 puntos respecto al anterior.

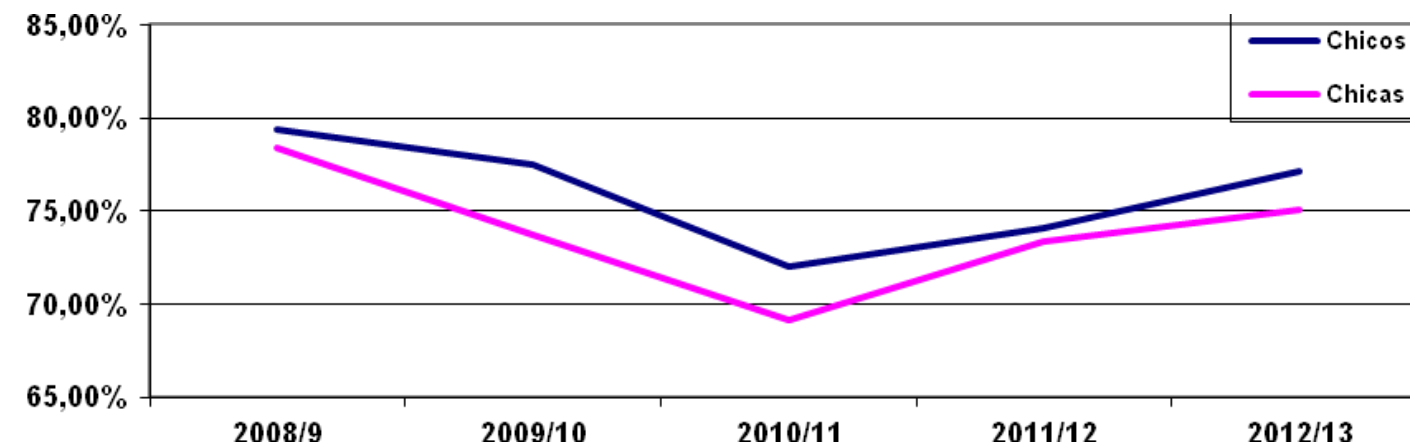

Figura 52. Tendencia entre $2008 / 9$ y 2012/13 según el género en la tasa de finalización de primaria en 5 ㅇ

(Fuente: Elaboración propia a partir de datos del Ministerio de Educación)

Por otra parte si echamos un vistazo a los datos de los mismos años para la tasa de finalización de primaria en 8 o curso (véase Figura 53) podemos observar una serie de diferencias. 


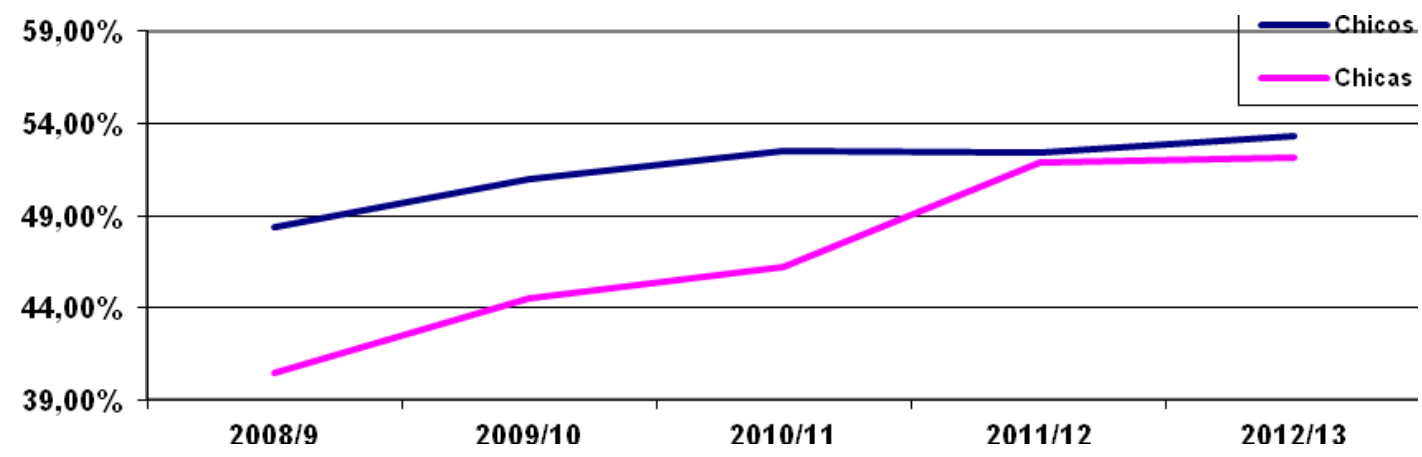

Figura 53. Tendencia entre $2008 / 9$ y 2012/13 según el género en la tasa de finalización de primaria en 8 ㅇ

(Fuente: Elaboración propia a partir de datos del Ministerio de Educación)

En primer lugar podemos observar que las diferencias por género han sido mucho mayores que en la tasa de finalización en 50 curso, ya que mientras que en 5 o curso la diferencia media durante estos último 5 años ha sido de 2,08 puntos en 8 o la diferencia ha sido de media 4,4 puntos, por lo tanto más del doble. También es muy clara la reducción de la distancia entre chicos y chicas. Durante estos últimos años la distancia entre los dos géneros se ha acortado de una manera muy significativa, pasando de una diferencia de 8,1 puntos a favor de los varones en 2008/9 a solo 1,1 puntos a favor de los mismos en 2012/13 lo que supone una reducción de un $86 \%$ de la distancia entre los géneros en estos 5 años.

Por otra parte igual que en el caso anterior queda patente que pese a la reducción de la distancia llega un momento en el que la situación se estabiliza y no se logra alcanzar la paridad entre alumnos y alumnas, manteniéndose estas últimas siempre un poco por debajo de los varones.

\section{Genero en los alumnos con necesidades especiales}

Entre el alumnado con necesidades especiales matriculado en la educación primaria también hay diferencias de género y además están más acentuadas que entre el alumnado general. Mientras que en el alumnado general el 52\% del alumnado es masculino y el $42 \%$ es femenino en el alumnado con necesidades especiales esta diferencia de género se agranda y el $57,4 \%$ son niños y solo un 
$42,6 \%$ son niñas, (Moe, 2013) lo que viene a significar que la diferencia aumenta en 5,4 puntos. Esto es reflejo de la menor valoración que tiene la mujer en la sociedad etíope, ya que estas alumnas con necesidades especiales aparte de sufrir la discriminación por su discapacidad se une la discriminación por su género.

Además, estudiando todos los datos analizados en este apartado, da la sensación de que la presencia de alumnas en las escuelas de primaria se ha encontrado en los últimos años con un techo de cristal ya que pese a que la situación actual muestre una enorme mejoría respecto a la situación de hace años en las escuelas las diferencias de género parecen haber llegado a una estabilidad y no logran ser erradicadas completamente.

\subsubsection{Educación secundaria}

Aunque la educación secundaria excede los propósitos de la presente tesis doctoral, la educación en la etapa secundaria igual que hicimos con la educación pre-primaria ha de ser expuesta aunque sea de una manera somera, ya que contienen una serie de datos y aspectos que nos ayudan a comprender de una manera más global la situación en el terreno educativo y las consecuencias directas de lo que sucede en la educación primaria.

La educación secundaria en Etiopía está formada por dos ciclos de dos cursos cada uno de ellos. El primer ciclo lo componen el 90 y 10 으 curso y el segundo ciclo lo forman el 11 y y 12 o curso. Al finalizar el 10 o curso hay a su vez un examen de carácter nacional que selecciona a los alumnos dependiendo sus resultados para una educación universitaria o para una educación técnica:

"A national examination (the Ethiopian General Secondary Education Certificate Examination) is given in grade 10, to certify completion of general secondary education and to select students that qualify for the next higher level of education" (MoE, 2013, pág. 40).

Debido a este examen que separa la educación secundaria en dos el primer ciclo es definido como la Educación Secundaria General y es común a todos los estudiantes que se matriculan en enseñanza secundaria mientras que el segundo 
ciclo de la educación secundaria se divide en dos itinerarios distinto. Según la calificación que hayan logrado en el examen nacional, los alumnos con mejor nota pasarán a cursar el programa preparatorio para la educación superior mientras que los alumnos con las notas más bajas pasan directamente a la educación técnica.

Como podemos observar en la Figura 54, una vez seleccionado el itinerario tras el examen en grado 10 o los alumnos que siguen los cursos preparatorios para la educación superior han de cursar dos cursos más y realizar un examen nacional más mientras que los alumnos que sigan el itinerario de la educación técnica pueden realizar una formación profesional de hasta cinco niveles.

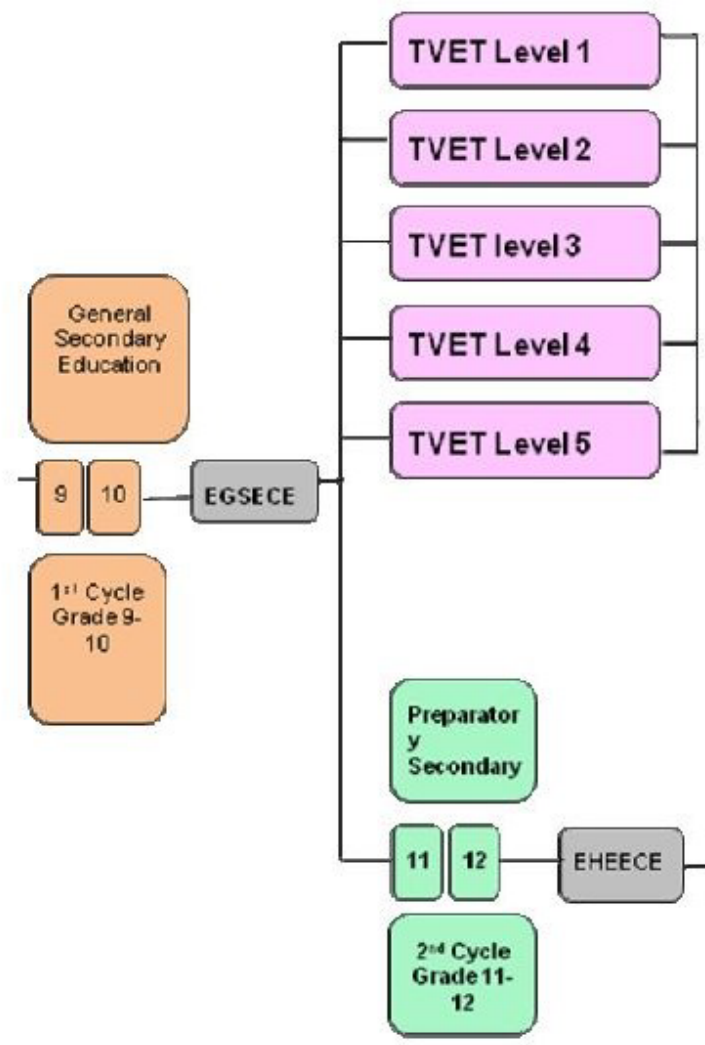

Figura 54. Esquema de la educación secundaria en Etiopía y sus distintos itinerarios. Fuente: MoE

En la actualidad durante el curso 2012/13 hay matriculados 1.900 .735 alumnos en los dos ciclos de ecuación secundaria, de ellos 1.542 .242 corresponden al primer ciclo y 358.493 al segundo ciclo en sus diversas modalidades. Estas cifras aunque bajas si las comparamos con la educación primaria suponen que desde el curso 2008/9 ha aumentado anualmente la matriculación en secundaria (9-12) en un $4,6 \%$ siendo mucho más pronunciado el crecimiento en el segundo ciclo con un 
$15 \%$ anual frente al 2,8\% del primer ciclo. Pese al aumento anual tan marcado en el segundo ciclo de la educación secundaria todavía en este segundo ciclo el número de alumnos matriculados suponían en el año $2012 / 13$ solo el $18,8 \%$ de los alumnos de secundaria.

\section{Escuelas de secundaria e instalaciones disponibles}

El número de escuelas de secundaria ha experimentado un crecimiento constante durante estos años, durante el curso 2012/13 el número de escuelas de educación secundaria disponibles era de 1912 lo que supone que desde el curso $2008 / 9$ se ha producido un incremento anual del $12,4 \%$ frente al $4,9 \%$ que han crecido anualmente las escuelas de primaria (MoE, 2013).

Pese a ello si comparamos el número de escuelas de primaria durante el curso 2012/13 con el número de escuelas de secundaria nos da una idea de lo débil que es todavía la educación secundaria en el país, ya que frente a esas 1912 escuelas de secundaria se levantan 30.534 escuelas de primaria lo que supone que por cada 100 escuelas de primaria que hay en el país solo hay 6,26 escuelas de secundaria.

Por otra parte, a diferencia del caso de la educación primaria, en la educación secundaria el grueso de las escuelas se concentra en zonas urbanas situándose 1.451 escuelas de secundaria en las ciudades frente a solo 461 en zonas rurales. Esto significa que casi un $76 \%$ de las escuelas de secundaria del país están en zonas urbanas cuando en primaria esta proporción desciende al $15 \%$ y revela uno de los problemas de la educación en Etiopía, como es la dificultad que tienen muchos alumnos para continuar los estudios debido a la necesidad de desplazarse a las ciudades próximas para poder asistir a clase.

Estas escuelas de secundaria atienden de media a 994 alumnos por centro, lo que según defiende el Ministerio de Educación de Etiopía es un tamaño excesivo comparado con los estándares internacionales y puede tener un efecto negativo en la calidad de la educación (MoE, 2013). 
Tabla 18. Instalaciones disponibles en las escuelas de secundaria durante el curso 2012/13

\begin{tabular}{|c|c|c|c|c|c|c|c|c|c|c|c|c|c|}
\hline \multirow[b]{2}{*}{ Region } & \multirow[b]{2}{*}{$\begin{array}{c}\text { No of } \\
\text { Schools }\end{array}$} & \multicolumn{3}{|c|}{ Water } & \multicolumn{3}{|c|}{ Boys_Pits } & \multirow[b]{2}{*}{ Clinic } & \multirow[b]{2}{*}{ Library } & \multirow[b]{2}{*}{$\begin{array}{l}\text { Tech } \\
\text { Labs }\end{array}$} & \multirow[b]{2}{*}{$\begin{array}{l}\text { Inter } \\
\text { net }\end{array}$} & \multirow[b]{2}{*}{$\begin{array}{l}\text { Electri } \\
\text { city }\end{array}$} & \multirow[b]{2}{*}{ Plasmas } \\
\hline & & $\begin{array}{c}\text { Accces } \\
\text { to } \\
\text { Water }\end{array}$ & Tap & Well & $\begin{array}{l}\text { Boys' } \\
\text { Pits }\end{array}$ & $\begin{array}{l}\text { Girls' } \\
\text { Pits }\end{array}$ & $\begin{array}{c}\text { Boys' \& } \\
\text { Girls' } \\
\text { Pits }\end{array}$ & & & & & & \\
\hline Tigray & 148 & 107 & 98 & 5 & 890 & 862 & 179 & 38 & 121 & 220 & 38 & 121 & \\
\hline Afar & 16 & 15 & 16 & 1 & 61 & 54 & 18 & 10 & 15 & 23 & & 13 & 91 \\
\hline Amhara & 316 & 237 & 190 & 5 & 1,483 & 1,347 & 258 & 101 & 324 & 606 & 78 & 244 & 4,027 \\
\hline Oromiya & 718 & 517 & 469 & 43 & 3,762 & 3,016 & 760 & 147 & 604 & 686 & 90 & 603 & 5,426 \\
\hline Somali & 78 & 40 & 1 & - & 82 & 75 & 34 & 22 & 8 & 13 & 2 & 32 & 91 \\
\hline Ben. Gumuz & 46 & 25 & 5 & 2 & 115 & 140 & 48 & 5 & 30 & 10 & 4 & 22 & 151 \\
\hline SNP & 365 & 237 & 142 & 30 & 2,340 & 1,955 & 253 & 116 & 83 & 435 & 75 & 276 & 2,632 \\
\hline Gambella & 32 & 15 & 1 & 1 & 61 & 60 & 32 & & 19 & 5 & & 10 & 23 \\
\hline Harari & 11 & 10 & 9 & 2 & 40 & 42 & 14 & 6 & 12 & 14 & 11 & 11 & 9 \\
\hline Addis Ababa & 163 & 383 & 103 & 6 & 2,525 & 2,547 & 878 & 352 & 147 & 480 & 70 & 269 & 1,660 \\
\hline Dire Dawa & 19 & 17 & & - & 151 & 153 & 47 & 16 & 21 & 20 & 3 & 18 & 99 \\
\hline lotal & 1,912 & 1,603 & 1,034 & 95 & 11,510 & 10,251 & 2,521 & 820 & 1,384 & 2,512 & 378 & 1,619 & 5,281 \\
\hline
\end{tabular}

(Fuente: Ministerio de Educación, 2013)

Como se puede observar en la Tabla 18 , respecto al agua, casi el $84 \%$ de las escuelas de secundaria tienen una fuente de acceso al agua disponible para los alumnos, siendo un porcentaje muy superior al de las escuelas de primaria que como vimos con anterioridad solo disponen de acceso al agua en un $41 \%$ de los casos. Todas las escuelas de secundaria, siguiendo los datos oficiales (MoE , 2013), tienen letrinas disponibles para los alumnos.

Por lo que se refiere a las clínicas e instalaciones sanitarias, el $42,9 \%$ de las escuelas tienen clínicas o instalaciones sanitarias asociadas para el uso de los alumnos. Respecto a las bibliotecas, aproximadamente un $72 \%$ de las escuelas contaban con bibliotecas en el curso 2012-2013 según los datos del MoE. Es importante destacar respecto a este dato que por norma como nos explicó el supervisor de educación asignado a la zona de Qillenso la biblioteca es obligatoria en las escuelas a partir de cuarto grado de primaria, por lo que en las escuelas de secundaria su presencia debería ser obligatoria y aún así más de un cuarto de las escuelas de secundaria no la tienen.

Teniendo en cuenta los datos expuestos en la Tabla 18, el número de laboratorios disponibles en las 1.912 escuelas de secundaria del país es de 2.512 , lo que implica que algunas escuelas de secundaria tienen más de un laboratorio 
disponible para los alumnos. En nuestra experiencia de campo los únicos laboratorios escolares que hemos podido visitar estaban en algunas escuelas que pertenecían a misiones religiosas o instituciones internacionales. El acceso a Internet según el informe del MoE durante el curso 2012/2013 estaba disponible en un $19,4 \%$ de las escuelas de secundaria del país. Este dato es realmente sorprendente ya que en nuestra experiencia de campo los únicos centros educativos que tenían acceso a Internet que conocimos eran los de educación superior como universidades o colegios de formación de profesorado.

La disponibilidad de energía eléctrica se encuentra en casi un $85 \%$ de las escuelas, pero teniendo en cuanta la gran cantidad de cortes de electricidad que se sufren a diario en Etiopía la disponibilidad real de la luz es intermitente, ya que en cualquier momento se puede ir la luz e inutilizar los aparatos electrónicos que dependen de ella para funcionar, provocando retrasos en el trabajo administrativo de las escuelas o dificultades para poder impartir materias como la informática, como pudimos constatar en nuestra presencia en el país. En cuanto a las Televisiones de plasma, según los datos del MoE (2013) hay una media de ocho televisores de plasma en cada centro de secundaria, lo que resulta muy extraño cuando teniendo en cuenta el dato anteriormente expuesto un 15\% de las escuelas de secundaria no tienen electricidad. En nuestra experiencia de campo no logramos ver ninguna escuela de secundaria que tuviera más de uno o dos televisores, y solo en escuelas pertenecientes a organizaciones internacionales.

Al igual que cuando analizamos los datos de las instalaciones de las escuelas de primaria creemos que la supuesta presencia de instalaciones y servicios en las escuelas no garantiza ni su presencia real ni su funcionamiento y más cuando estos servicios suponen una fuerte inversión económica, la importación de productos tecnológicos y exigen un mantenimiento constante. Estas 1912 escuelas cuentan a su vez con 32.173 aulas que estaban repartidas de la siguiente manera durante el curso 2012/13 como podemos observar en la Tabla 19. 
Tabla 19. Distribución de las clases disponibles en las escuelas de secundaria durante el curso 2012/13

\begin{tabular}{|c|c|c|c|c|c|}
\hline Grado & $9 \circ$ & 10 일 & 11 \% & 12 & Total \\
\hline Aulas & 15.053 & 10.281 & 3.616 & 3.223 & 32.173 \\
\hline
\end{tabular}

(Fuente: Elaboración propia a partir de datos del Ministerio de Educación)

Es interesante comprobar cómo al igual que ocurría en la educación primaria hay muchas más aulas disponibles en el primer ciclo de la educación secundaria que en el segundo ciclo, lo que es reflejo del abandono progresivo de la educación por parte del alumnado que va ocurriendo tanto en primaria como en secundaria según se avanza en los cursos.

\section{Ner y Ger en secundaria}

Las edades oficiales para la matriculación y cursado de la educación secundaria en Etiopía son 15 y 16 años para el primer ciclo y 17 y 18 para el segundo ciclo (MoE, 2013). Tomando este marco de edades como referencia podemos calcular tanto el GER como el NET. El Ger en el primer ciclo de educación secundaria se situaba en el año $2012 / 13$ en un $38,4 \%$ de media, siendo esta misma tasa para los varones un $39,9 \%$ y para las mujeres de un $36,9 \%$. En el segundo ciclo de secundaria el GER en el mismo año fue de un 9,5\% siendo el de los varones de un $10,5 \%$ y el de las mujeres de un $8,5 \%$ como podemos ver más claramente en la Tabla 20.

Tabla 20. GER de 1ㅇ y 2o ciclo de educación secundaria durante el curso 2012/13

\begin{tabular}{|c|c|c|c|c|c|c|}
\hline Ciclo & \multicolumn{3}{|c|}{1 C Ciclo } & \multicolumn{3}{c|}{ 20 Ciclo } \\
\hline Género y Media & Varones & Mujeres & Media & Varones & Mujeres & Media \\
\hline Porcentaje GER & $39,9 \%$ & $36,9 \%$ & $38,4 \%$ & $10,5 \%$ & $8,5 \%$ & $9,5 \%$ \\
\hline
\end{tabular}

(Fuente: Elaboración propia a partir de datos del Ministerio de Educación)

Por su parte el Ner para la educación secundaria queda muy afectado debido a varias de las características y problemas que hemos visto anteriormente que se producen en la educación primaria en Etiopía: 
"It is clear that there is a large discrepancy between GER and NER for the first cicle, indicating that secondary education is highly dominated by over-aged students. This may be due to delayed graduation from primary school, or it might be because of examinations barriers, supply barriers, or financial barriers to promote from grade 8 of primary to grade 9 of secondary education" (MoE, 2013, pág. 42).

Estos problemas tienen su reflejo en los datos que se muestra en la Tabla 21.

Tabla 21. NER de 1ㅇ y 2 ciclo de secundaria durante el curso 2012/13

\begin{tabular}{|c|c|c|c|c|c|c|}
\hline Ciclo & \multicolumn{3}{|c|}{1 10 Ciclo } & \multicolumn{2}{c|}{ 20 Ciclo (Programa preparatorio) } \\
\hline Género y Media & Varones & Mujeres & Media & Varones & Mujeres & Media \\
\hline Porcentaje NER & $18,8 \%$ & $20,1 \%$ & $19,4 \%$ & $5,4 \%$ & $5,2 \%$ & $5,3 \%$ \\
\hline
\end{tabular}

(Fuente: Elaboración propia a partir de datos del Ministerio de Educación)

En esta Tabla 21 queda reflejado que en el curso 2012/13 el NER durante el primer ciclo de secundaria no llegó al 20\% y en el segundo ciclo apenas superó el 5\% lo que supone que en los dos últimos cursos de secundaria apenas algo más del $5 \%$ de los alumnos matriculados tienen la edad apropiada para cursas dichos cursos.

Es destacable que durante el primer ciclo de la educación secundaria haya un porcentaje superior de alumnas matriculadas en la edad apropiada que de alumnos pero esto no nos indica que haya más alumnas que alumnos ya que de hecho hay en números totales 82.386 varones más que mujeres matriculados en el primer ciclo de educación secundaria aunque hay 15.070 alumnas más que alumnos en edad apropiada.

\section{Tasa alumno por sección}

A continuación debemos estudiar la tasa de alumnos por sección para comprender en que entorno se desarrolla el proceso de enseñanza aprendizaje (véase Tabla 22). A primera vista resulta sorprendente que pese a las menores tasas de matriculación en secundaria que en primaria la tasa de alumnos por sección es más elevada en educación secundaria que en primaria, situándose en 2012/13 en 59,3 lo que supone 5,6 alumnos por sección más que en educación primaria en el mismo año. 
Tabla 22. Evolución de la tasa de alumnos por sección en secundaria entre los cursos 2008/9 y 2012/13

\begin{tabular}{|c|c|c|c|c|c|}
\hline Curso & $2008 / 9$ & $2009 / 10$ & $2010 / 11$ & $2011 / 12$ & $2012 / 13$ \\
\hline Proporción & 67.9 & 63.9 & 58.1 & 56.1 & 59.3 \\
\hline
\end{tabular}

(Fuente: Elaboración propia a partir de datos del Ministerio de Educación)

Por otra parte el descenso de alumnos por sección ha sido mayor en secundaria desde 2008/9 que en primaria, disminuyendo en secundaria en 8,6 alumnos frente al descenso de 5,1 alumnos en primaria. Pese a esta elevada tasa de alumnos por sección la tasa de alumnos-profesor no se ha visto perjudicada y como veremos en el siguiente apartado los datos del Ministerio de Educación son realmente buenos.

\section{Tasa alumno-profesor}

A diferencia del problema que nos encontrábamos en educación primaria en la educación secundaria no hay una sobrecarga de alumnado por lo que la proporción de alumnos por profesor esta mucho más ajustada a lo que entenderíamos en occidente como una proporción aceptable (véase Tabla 23 ).

Tabla 23. Evolución P.A.P entre en curso $2008 / 9$ y 2012/13

\begin{tabular}{|c|c|c|c|c|c|}
\hline Curso & $2008 / 9$ & $2009 / 10$ & $2010 / 11$ & $2011 / 12$ & $2012 / 13$ \\
\hline Proporción & 41 & 36 & 31 & 29 & 28,7 \\
\hline
\end{tabular}

(Fuente: Elaboración propia a partir de datos del Ministerio de Educación Etíope)

En la Tabla 23 podemos ver como la situación ha ido mejorando año tras año hasta situarse en 28,7 alumnos por profesor durante el curso 2012/13, lo que supone que esta proporción ha descendido en un 30\% desde 2008/9

\section{Profesorado de secundaria}

El número de profesores en educación secundaria durante el curso 2012/13 fue de 65,116 de los que 55,353 eran hombres y 9,763 mujeres lo que arroja unas proporciones de un $85 \%$ de profesorado masculino frente a un $15 \%$ de profesorado femenino, lo que muestra una abrumadora descompensación a favor de los hombres. En la educación secundaria la formación del profesorado es superior a la 
educación primaria y además el porcentaje de profesores con la formación necesaria para ejercer su profesión es del 91\%:

"In contrast with primary education, the percentage of qualified teachers is higher in secondary education. Nationally, of all the secondary teachers, $91.5 \%$ are qualified for their level of secondary teaching" (MoE, 2013, pág. 44).

Este nivel de formación es bastante homogéneo entre hombres y mujeres y parece que el género no marca especiales diferencias entre hombres y mujeres a la hora del porcentaje de formación ya que frente al $90,8 \%$ de profesoras con la cualificación necesaria hay $91,7 \%$ de profesores suficientemente cualificados lo que supone una diferencia de menos de un $1 \%$.

\section{Genero en la educación secundaria}

Al igual que en la educación primaria la igualdad de género no se ha alcanzado todavía en las escuelas de educación secundaria de Etiopía, es más mientras que el en la educación primaria el GPI fue de 0,94 durante el curso 2012/13 la situación en educación secundaria es peor. Durante este curso el GPI para el primer ciclo de secundaria era de un 0,92 pero para el segundo ciclo solo alcanzaba un 0,81 (MoE, 2013). Estos datos nos muestran uno de los problemas que ya habíamos visto en la educación primaria y que se repite una y otra vez se avanza en el sistema educativo etíope las diferencias de género van aumentando y cada vez las chicas se encuentran en peor posición respecto a sus compañeros varones.

\subsection{FINANCIACIÓN DEL SISTEMA EDUCATIVO}

Como señala Unicef, el grado de compromiso de un estado con la educación se puede observar en el porcentaje de los recursos que el gobierno destina a financiar la educación:

"Increasing access as well as improving the quality of education requires budgetary allocation. The proportion of the education expenditure to the total government expenditure reflects the states commitment to education" (UNICEF, 2012, pág. 61). 
En el caso del gobierno Etíope, el compromiso del gobierno con la educación parece fuera de toda dura atendiendo a los datos, que reflejan que una importante parte del presupuesto es destinado a la educación (véase Figura 55).

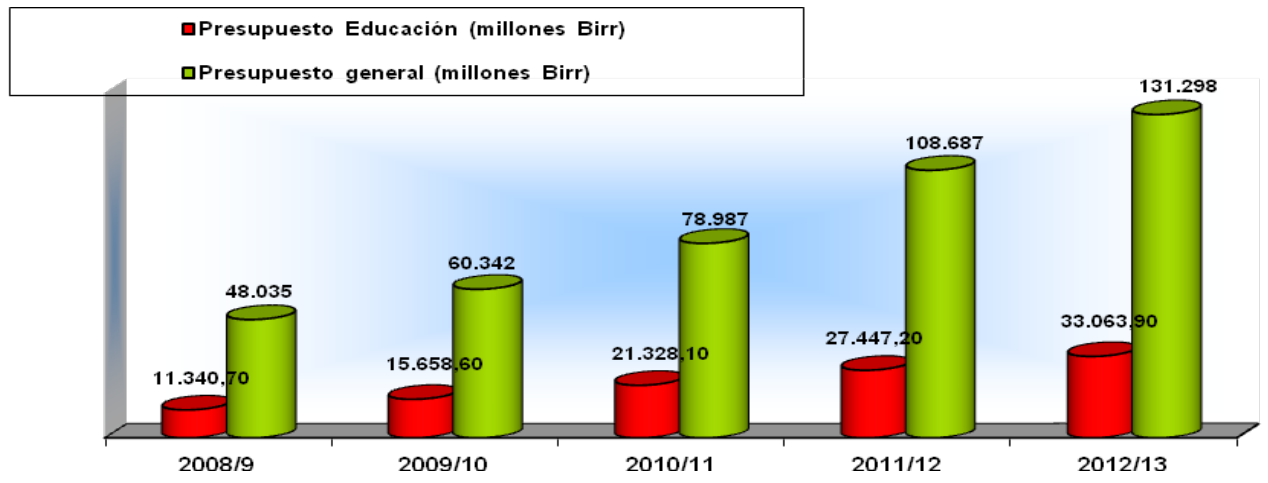

Figura 55. Presupuesto de educación y Presupuesto general del gobierno de Etiopía entre los años 2008-2013

(Fuente: Elaboración propia a partir de datos del Ministerio de Educación)

Si comparamos estos datos con España, es posible apreciar la gran cantidad de recursos económicos que está destinando a la educación el gobierno Etíope y el empeño real que se está poniendo por parte del gobierno para mejorar el sistema educativo (véase Figura 56).

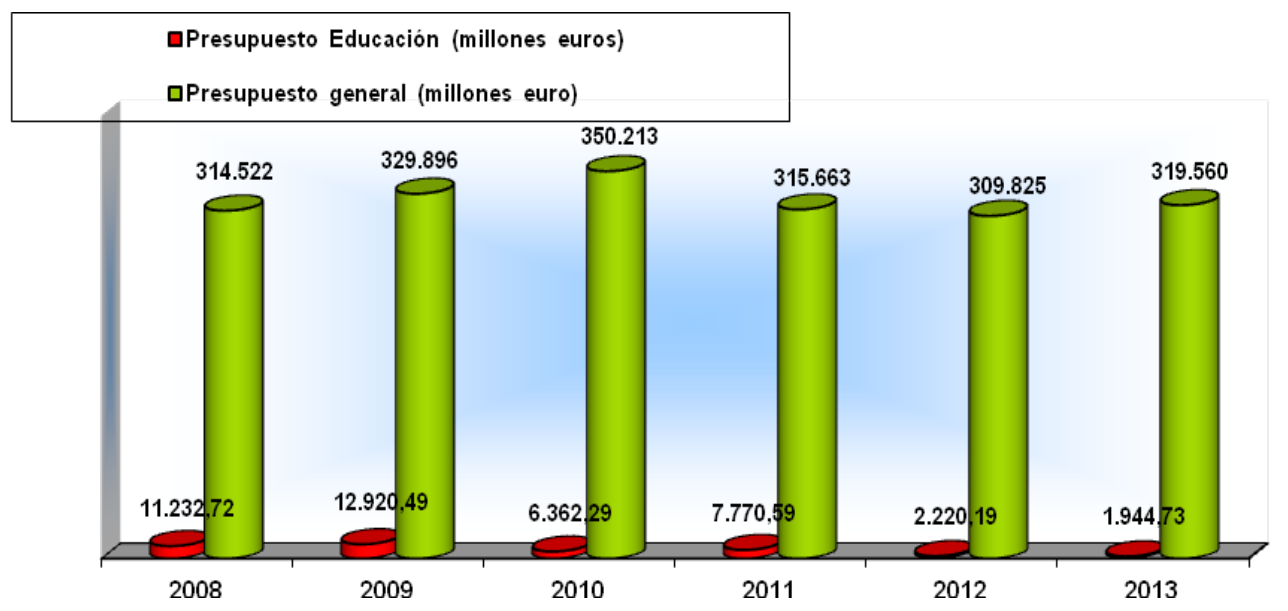

Figura 56. Presupuesto de educación y Presupuesto general de España entre los años 2008-2013 (Fuente: Elaboración propia a partir de datos del Ministerio de Educación)

Esta financiación del sistema educativo por parte del gobierno etíope se divide entre los distintos niveles administrativos del mismo, repartiéndose entre el 
gobierno central, el gobierno regional y las woredas. Aparte del dinero que sale de las arcas del estado etíope, no es desdeñable el apoyo financiero que terceros países, organizaciones financieras internacionales como el Banco Mundial, ONGDS, La Unión Europea o la USAID aportan al sistema educativo. (UNICEF, 2012). Este dinero es utilizado para una gran variedad de servicios y proyectos dentro del sector de la educación, tanto en la construcción de infraestructuras como en programas de formación:

"The funds cover a variety of projects including service-delivery, teacher development, capacity building, school construction, alternative basic education, and support for higher education, school grants and technical assistance" (UNICEF, 2012 pág. 60).

No faltan tampoco voces críticas al respecto de estas contribuciones de ONGs. Por ejemplo, Pillay (2010) manifiesta que el papel de las ONGs en la defensa del desarrollo de una política educativa en Etiopía está cambiando. Así, estas organizaciones están modificando su papel que inicialmente se centraba en la provisión de servicios, a otro centrado en el desarrollo de políticas. Esta tendencia está teniendo un efecto negativo en las perspectivas lingüísticas, culturales y educativas del país. Mientras que las ONGs se han ganado la aceptación del país por sostener que están hablando en nombre de sus gentes, voces críticas indican que en realidad las ONGs internacionales son instituciones dominantes que trabajan fundamentalmente en colaboración con los intereses sociopolíticos de las clases sociales altas del Estado, así como de las agencias de desarrollo multilaterales. Por tanto, están contribuyendo a la penetración neocolonial del país, ayudando al proceso de reproducción políticas educativas/escolares importadas y manejadas desde fuera (Pillay, 2010).

Aunque como hemos visto el esfuerzo del gobierno de Etiopía a la hora de financiar la educación es evidente el aumento de la escolarización a un ritmo superior al aumento de los recursos disponibles ha provocado un retroceso en los fondos disponibles por alumno: 
"However, since the growth in education expenditure has not kept pace with the rapid expansion in enrolment, in absolute terms per pupil recurrent expenditure has declined" (UNICEF, 2012 pág. 62).

A la hora de distribuir los gastos entre los distintos niveles educativos los datos nos muestran que más de la mitad de los recursos son dedicados a la educación primaria, seguidos por los destinados a la educación superior y finalmente la secundaria. Es destacable que hasta un 13\% de los recursos no está claro a qué se dedican según UNICEF en el año 2012 (véase Figura 57).

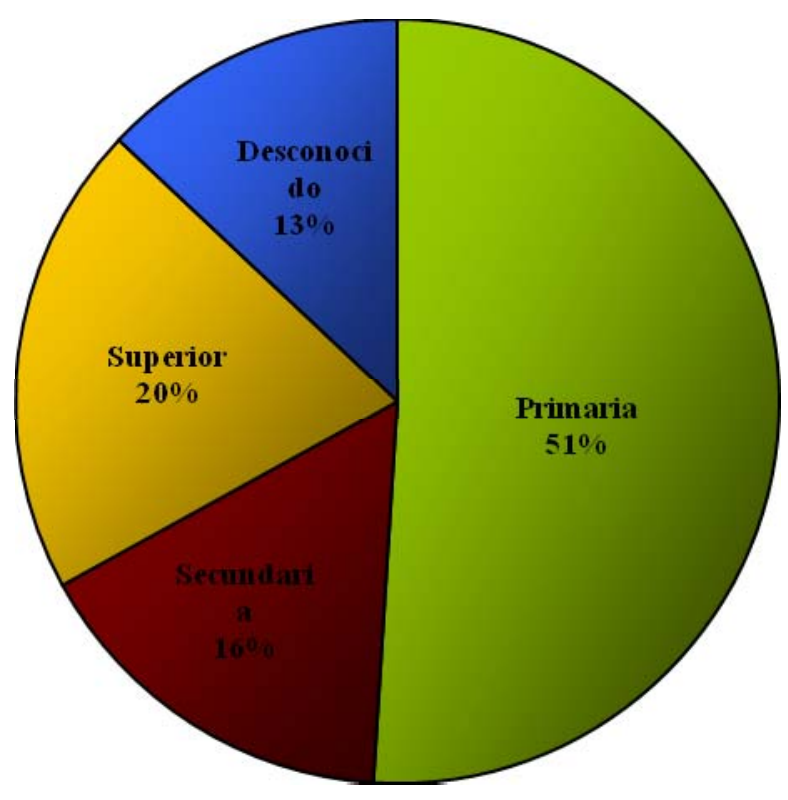

Figura 57. Distribución de los fondos de educación según el nivel educativo en Etiopía

(Fuente: Elaboración propia a partir de datos de UNICEF, 2012)

Aunque la gran mayor parte de los recursos se destinan a educación primaria, los recursos que se destinan por alumno son mucho menores en educación primaria que en otros de los tramos educacionales (véase Figura 58). 


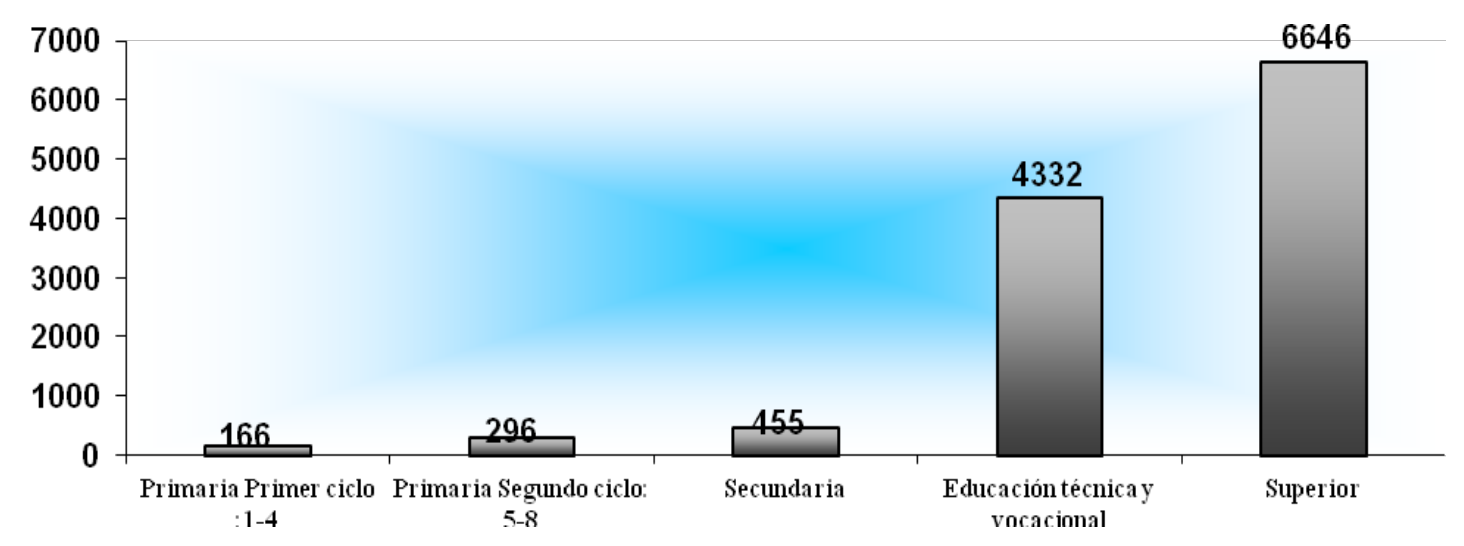

Figura 58. Birrs estimados destinados por alumno y año en Etiopía

(Fuente: Elaboración propia a partir de datos de UNICEF 2012)

Como podemos observar en la Figura 58, la inversión del Estado en los alumnos de primaria es insignificante si la comparamos con los recursos invertidos en un alumno de educación técnica o superior. Esto, bajo nuestro punto de vista y experiencia en el campo, crea un problema de base ya que la educación primaria es tan de baja calidad que condiciona todo el desarrollo posterior de la vida educativa de los alumnos y hace que los conocimientos que adquieren los alumnos realmente estén muy por debajo de los estándares esperados. Especialmente preocupante es la baja inversión anual en los alumnos de primer ciclo de primaria, debido a que como veremos más adelante muchos alumnos no llegan si quiera a completar más allá del primer ciclo de primaria y es la poca educación que van a recibir en su vida más allá de posibles programas alternativos como programas de alfabetización para adultos. Como consecuencia de ello la calidad de la educación primaria se resiente:

"The cost per pupil at the primary level is too tiny resulting in inadequate inputs to key school investment priorities" (UNICEF, 2012 pág. 63).

Posteriormente cuando analicemos los problemas de la educación en Etiopía veremos más en profundidad los problemas que la financiación del sistema educativo tiene y su efecto en la educación en el país, principalmente en la educación primaria. 


\subsection{ESCUELAS EN GUJILAND}

Antes de pasar a centrarnos en el análisis del contexto particular objeto de nuestr presente Tesis Doctoral, es importante insistir en que, a nivel de todo el país, estudios recientes que han analizado la política en la educación primaria etíope (Frost y Little, 2014) han puesto de manifiesto: (1) el desajuste entre la pedagogía prescrita por el gobierno y las prácticas educativas reales; y (2) la relación entre estas prácticas y condicionantes tanto de los centros educativos como de los maestros (Frost y Little, 2014). Así, el mencionado estudio pone de manifiesto que la puesta en marcha de actividades orientadas al alumno es más probable en maestros con un título universitario, que no haya estado ausente recientemente y que haya recibido supervisión durante el último mes. Está también asociado a clases con un número de alumnos inferior a 26.

Estos problemas que afectan en general al país, encuentran un reflejo aún más precario en la Oromía en general y en particular en Gujiland. Así, la infraestructura de las escuelas de la zona es muy pobre si la comparamos con los estándares occidentales a los que estamos acostumbrados. Las escuelas de misiones católicas suelen estar mejor equipadas pero, aún así, a un observador occidental le dan la sensación de estar vacías. Los edificios de las escuelas públicas primarias de la zona suelen ser edificios construidos con postes de madera de eucalipto generalmente recubiertos de barro y pintados. El tejado es de placas metálicas corrugadas, el suelo puede ser de cemento o de tierra aplastada. Por ejemplo en la zona de Qillenso una escuela un poco más metida en el interior del campo la era directamente una gran nave de postes de madera con el techo de placas finas metálicas, dando al edificio aspecto de una nave industrial o de una chabola grande.

Los alumnos se sientan en bancos que comparten dos, tres o más alumnos cuando la utilización optima sería solo para uno o dos alumnos, con los niños más pequeños el problema de espacio es menor pero alumnos de cuarto o quinto que ya han crecido tienen claros problemas de espacio en estas mesas. El número de alumnos por clase puede llegar hasta los 80 pero ahora el gobierno intenta que 
haya un profesor cada 50 alumnos. Por ejemplo, en la escuela donde se sitúa nuestro estudio ese es el número que nos dijeron pero al principio del curso cuando solicitábamos más profesores nos dijeron que hasta que no alcanzáramos los 100 alumnos en una clase no nos mandarían un segundo profesor, hecho que solo ocurrió cuando el curso ya llevaba en marcha más de dos meses.

Una cosa a la que dan una gran importancia en las escuelas es el aspecto estético; gran parte de las quejas que hemos recibido por parte de los profesores se centran en este tema. Piden que se planten flores, que se pinten y cuelguen eslóganes motivacionales en placas metálicas y que se pinten también eslóganes en las paredes. La verdad es que en las escuelas públicas sí se ven pintadas de este tipo.

\subsubsection{La dotación de las escuelas}

\section{Equipamiento deportivo y educación física en las escuelas}

En teoría todas las escuelas tienen que contar con una zona para realizar deportes habilitada, al menos con un campo de futbol y una pista de balonmano. La realidad dista bastante de ello. En nuestra escuela recibimos quejas por el mal estado del campo de hacer deporte pero en realidad es mucho más grande del que suelen contar las demás escuelas. Las instalaciones típicas consisten en un pequeño campo de tierra sin mucho césped, más o menos plano en el que hay una red de voleibol y a veces dos porterías que en ocasiones son sustituidas por unas hechas de palos.

La clase de educación física dista mucho de lo que consideraríamos una clase estructurada y se asemeja más bien al tiempo de recreo. Lo típico es que el profesor entregue un balón a los niños y les deje jugar libremente. Las niñas suelen preferir jugar a la comba durante este tiempo. Pocas veces se ve al profesor participar con ellos y muchas veces no pasan todo el periodo con ellos en el campo, sino que se vuelven a la escuela. Por ejemplo, cuando en la misión donde nos encontrábamos les hacíamos calentar antes de jugar al futbol, pudimos apreciar que es una actividad que no realizaban en clase a menudo. Aunque las escuelas, como era 
nuestro caso, cuentan a veces con otro equipamiento como vallas para saltar, nunca durante nuestra estancia vimos que éstas fueran utilizadas.

\section{Biblioteca, laboratorio, sala de psicopedagogía}

En este aspecto, las escuelas difieren sustancialmente de las que estamos acostumbrados. Así, pudimos confirmar en Qillenso por dos profesores de la zona que ninguna escuela de la Wooredaa (centro administrativo) cuenta con biblioteca, laboratorio o sala de pedagogía. Y ello pese a que las escuelas de educación secundaria deberían en teoría contar con instalaciones completas.

En caso de tenerlas su utilización es nula, aspecto que hemos constatado, tanto por experiencia directa como a través de las conversaciones con profesores y con la observación de sus acciones día a día. A modo de ilustración, el supervisor de las escuelas de la zona me aseguró un día que en Qillenso contábamos con más material que en ninguna otra escuela, refiriéndose a la biblioteca y a los materiales pedagógicos, pero que éstos no eran utilizados, aspecto en el que coincidimos. Muy pocas veces se ve a los profesores emplear materiales de refuerzo como pósters con vocabulario y la biblioteca no es utilizada nunca más allá de emplearse como sala suplementaria para alguna reunión de profesores. Algo similar sucede con los laboratorios. La ley exige que se usen a partir de sexto grado de primaria, pero su uso, al menos en nuestra experiencia, fue nulo.

\section{Equipación informática y nuevas tecnologías}

En los ambientes educativos occidentales hay actualmente una decidida apuesta por la incorporación de las nuevas tecnologías al proceso de enseñanzaaprendizaje como una respuesta a la superlativa importancia que la informática y las nuevas tecnologías tienen en el día a día y en desarrollo económico de nuestras sociedades. En las zonas rurales de Gujilan la presencia de equipos informáticos en las escuelas primarias es inexistente. No solo no existe un aula o una asignatura de informática sino que la administración de la escuela se sigue llevando a cabo a mano, con los retrasos y las inconveniencias que ello conlleva. Cabe no obstante señalar que pese a esta falta de material informático la administración educativa de 
Irba, la Wooreda de la zona, exige al director que entregue los informes hechos con ordenador.

Esta falta de educación en las nuevas tecnologías durante el periodo de enseñanza primaria se debería ver contrarrestado en teoría con la existencia de clases y equipamiento informático durante el proceso de enseñanza secundaria, pero debido al elevado nivel de abandono escolar y a la falta de continuidad de los estudios una vez superada la enseñanza primaria la realidad es que los jóvenes Guji son en una aplastante mayoría "analfabetos" informáticos.

Otro factor a tener en cuenta es que debido a la pobreza de la zona, a la falta de infraestructuras y al elevado coste de los equipos informáticos en el país, ninguna familia "normal" puede permitirse el poseer un ordenador. Los únicos ordenadores que vimos en la zona en manos particulares pertenecían a personas que trabajaban en la administración o que tenían contacto con extranjeros, como era el caso de familiares emigrantes o que trabajaban para organizaciones internacionales.

Como hemos expuesto previamente, esta falta de acceso a ordenadores provoca que los jóvenes de la zona sean en su gran mayoría "analfabetos" informáticos ya que pese a la formación que puedan recibir durante la escuela secundaria, el prácticamente inexistente acceso y utilización de equipos informáticos en etapas posteriores hace que, en el mejor de los casos, las habilidades aprendidas se pierdan.

\section{Libros y material escolar}

Los libros de texto que usan los alumnos son proporcionados por las escuelas. En teoría todos los alumnos tienen que tener sus propios libros de texto pero hemos sido testigos de los problemas acaecidos debido a que no siempre hay libros disponibles para todos los alumnos, sobre todo a principios de curso.

Un aspecto positivo es la gratuidad de los libros de texto, que deben pasar de año en año a las siguientes promociones de alumnos que se matriculan en la escuela. La calidad del papel de los libros es de un nivel básico. Por otro lado, un 
problema es que el nivel de conocimientos reflejado en los libros es superior o muy superior al nivel que realmente los alumnos poseen. Esto es fácilmente observable en los libros de inglés donde queda reflejado un nivel de exigencia que está muy por encima del nivel real que los alumnos alcanzan. Los alumnos suelen llevar los libros a clase en bolsas de plástico, y no hemos visto ninguna mochila. Los bolígrafos son un artículo que escasea y los alumnos los compran a los profesores en la oficina.

\section{Viviendas de los profesores}

Por ley, los profesores deben vivir junto a las escuelas. Por ello el gobierno les habilita unas pequeñas casas junto al terreno de la escuela. Estas casas son totalmente básicas, se las podría definir como una serie de habitaciones grandes construidas con barro y postes de madera y con techo de placas metálicas. Cuando los profesores tienen la oportunidad de vivir en un centro urbano cercano a la escuela con mayores servicios, se resisten claramente a la hora de tener que habitar estas casas.

La idea de que los profesores vivan junto a la escuela se basa en la teoría de que esta cercanía les permite atender a los niños en horas extraordinarias y para actividades que no se ciñan al horario escolar estándar como tutorías, clases de recuperación, clases de refuerzo para alumnos con problemas de aprendizaje, o educación para adultos, entre otras actividades.

\subsubsection{Actividades en las Escuelas}

\section{Competiciones académicas}

Un par de veces por semestre se organiza una competición entre las distintas escuelas de la zona. Una escuela es elegida como sede cada año y allí acuden los profesores de las otras escuelas involucradas en la competición con sus mejores alumnos. La idea es fomentar el espíritu competitivo tanto entre los alumnos como entre los profesores y así obtener un mejor desarrollo del proceso de enseñanza-aprendizaje. 
La competición versa sobre los conocimientos de las distintas asignaturas centrándose en Oromo, Amhárico, Matemáticas, Ciencia, Geografía e Inglés. Dos alumnos compiten en cada asignatura por cada escuela. Los profesores los días anteriores o ese mismo día se reúnen para diseñar una serie de preguntas. Los profesores de cada escuela aportan cuestiones y luego se hace una lista definitiva. La competición se lleva a cabo en el exterior ya que todos los alumnos están presentes y sería imposible que entraran en un aula. Todos los alumnos deben asistir a la competición en silencio y aplaudir cada acierto.

Las veces que hemos asistido, he oído acusaciones de trampas por parte de unos profesores a los de otras escuelas ya que aseguran que preparan sus preguntas con sus alumnos para obtener unos mejores resultados y dar a entender que su escuela es superior al resto. A los tres mejores alumnos de cada curso se les premia con algo de material escolar como libretas, bolígrafos o lápices.

\section{Competiciones deportivas}

También de vez en cuando se realizan competiciones deportivas entre los distintos colegios de la zona. Generalmente consisten en carreras y en competiciones de voleibol. En la zona de Qillenso cuando un alumno destaca se le lleva a competir a nivel regional a Negele Borana. Participan tanto niños como niñas, pues los deportes de grupo son mixtos.

\section{Competición y colaboración dentro de cada clase}

La legislación etíope y los planes educativos contemplan varios incentivos dentro de la rutina diaria de clase diseñados para que los alumnos mejoren su rendimiento académico. Se dividen en dos tipos: el trabajo de grupo y la competición individual. El trabajo en grupos o rayia, consiste en que se divide a los alumnos en grupos de cinco miembros en los que cada uno tiene una responsabilidad específica atribuida como el control de la puntualidad, el apoyo en clases por parte del alumno más aventajado que sus compañeros, o el control de los deberes realizado en casa. Por otra parte todos los alumnos tienen una corresponsabilidad en todos los aspectos. 
La competición individual consiste en premiar con un reconocimiento público semanal a los alumnos que muestren mejor desempeño académico y mejor comportamiento durante esa semana en su clase. El reconocimiento consiste en escribir sus nombres junto a sus notas en un papel que se cuelga en la puerta de la clase, a la vista de todos.

\section{Otras actividades de los alumnos dentro del ambiente escolar}

Los alumnos realizan en las escuelas actividades y trabajos que bajo un punto de vista occidental están más allá de lo exigible a un alumno o a un niño. Por ejemplo, los alumnos actúan como recaderos de los profesores, no solo para cuestiones relacionadas con la escuela sino también para aspectos privados. Así también, los alumnos son los encargados de la limpieza tanto de las clases, como del recinto de la escuela y de los servicios sanitarios de la misma.

Las escuelas públicas cuentan con una parcela de terreno adyacente en la que se cultivan distintos vegetales y en la que los alumnos tienen que trabajar algunos días. Con la producción de este terreno se ayuda al mantenimiento económico de la escuela, sobre todo para pagar los desplazamientos de los maestros y su asistencia a reuniones en los centros administrativos, al mismo tiempo que se enseña a los alumnos las técnicas y habilidades propias del trabajo en el campo.

\subsubsection{La Actividad Docente}

\section{Castigos físicos en la escuela}

Los castigos físicos están prohibidos por ley en las escuelas, pero todos los días tienen lugar. El más común es el golpe en las manos o nalgas con un palo de madera, con un trozo de cable o con un trozo de cinturón a los alumnos que llegan tarde. Dentro de la clase en ocasiones los profesores lanzan tizas contra los alumnos, les golpean con el libro, con un palo o les dan collejas. Otros castigos que se imparten contra los alumnos consisten en obligarles a conservar posturas humillantes o dolorosas enfrente del resto de los alumnos. 


\section{Programas de mejora de la escuela}

Hay una serie de programas de mejora para la escuela que se dividen en seis categorías principales. Cada profesor es el encargado de una o de varias de ellas según sus habilidades, voluntad y tiempo. En gran medida estos programas solo existen sobre el papel y los protocolos y programas solo se actualizan una vez al año, copiando los anteriores introduciendo pequeños cambios -la fecha principalmente- y archivándolos en un cajón. Sin embargo y como comentáramos previamente es muy destacable el gran interés que muestran en el embellecimiento exterior de la escuela, y la presencia de plantas y de carteles y pinturas con eslóganes exaltando la educación como uno de los aspectos más importantes.

\section{Reuniones de control en la Woreda}

Las reuniones para controlar el desarrollo del curso académico y otros aspectos de las escuelas son bastante comunes, prácticamente todos los meses el supervisor de las escuelas de la zona tiene que asistir a alguna de estas reuniones más los informes que envían mediante el móvil. En estas reuniones, según el supervisor de la zona me explicó, le dan una serie de puntos fijos que ha de controlar siempre más algunos que le añaden para constatar algún aspecto sobre el que deseen trabajar en ese momento.

El director de la escuela acude cada mes o mes y medio a Irba a reuniones de manera general durante el curso, pero en momentos en los que se incrementaba la actividad administrativa de la escuela estas visitas eran semanales. Todas las semanas tiene que enviar distintos informes a Irba. También los profesores tienen que acudir en ocasiones a reuniones de carácter político. Por ejemplo, poco después de la muerte del anterior Primer Ministro Meles Zenawii, los supervisores de la zona acudieron a una reunión de cuatro días donde les explicaron lo qué había hecho Meles Zenawi por Etiopía y cómo ellos debían continuar trabajando para que su visión se completara. 


\section{Supervisión}

La figura del supervisor es la de un intermediario entre la escuela y la oficina de educación de la "Woreda". Su función es controlar varias escuelas bajo su supervisión y asegurarse que los planes educativos del gobierno se apliquen, también debe asesorar y evaluar a los profesores y corregir los problemas que detecte entre el profesorado.

En nuestra experiencia con el supervisor de la escuela en la que hicimos las prácticas, su función se centraba en preocuparse sobre todo por la asistencia de los profesores a su puesto de trabajo y porque la "escuela de papel" (i.e. burocracia) estuviera al día. Así pues, su actitud dejaba traslucir una preocupación por asegurarse que los aspectos burocráticos estuvieran en reglan ante una posible inspección.

\subsubsection{Problemas principales de la educación}

Existen ciertas circunstancias y situaciones que afectan negativamente a la calidad de la educación que los niños de las zonas rurales de Gujiland reciben. Así, aunque el gobierno etíope en los últimos años ha realizado una fuerte apuesta por la expansión y mejora del sistema educativo del país todavía queda un largo camino por recorrer para alcanzar la meta que el propio gobierno etíope se ha marcado y que queda definida en el eslogan que puede verse en gran cantidad de escuelas: "Educación de calidad para todos"

"Education is central for rural development. It is an instrument for reducing poverty, improving the living conditions of rural people and building a food-secure world. Education is a basic right in itself. In spite of this, children's access to education in rural areas is still much lower than in urban areas, adult illiteracy is much higher and the quality of education is poorer. Expanding access to quality education for rural people is thus of crucial importance in the realization of human rights and in achieving the Millennium Development Goals" (Government of Ethiopia, 2005). 


\section{Problemas más destacados del sistema educativo respecto a los Guji}

El sistema educativo etíope está organizado en dos ciclos de primaria; el primero comprende de primer a cuarto grado, el segundo comprende de quinto a octavo. A continuación en octavo grado los alumnos pasan un examen de carácter nacional que selecciona a los alumnos entre los que acudirán a educación secundaria general de 8 a 10 y los que accederán a centros de educación secundaria superior de 8 a 12 que les dará posteriormente la posibilidad de continuar los estudios hacia el college o la universidad.

Aunque la educación primaria oficialmente abarca desde primer grado a octavo en el día a día el primer ciclo es el que actúa como educación primaria real y el segundo ya actúa como una educación secundaria. En esto están de acuerdo tanto el personal extranjero con el que he hablado de educación como los profesores y en el día a día de las escuelas de la zona se puede observar que la gran mayoría de las escuelas de primaria solo cubren desde el primer grado hasta el cuarto o quinto.

La calidad real de la educación se encuentra muy por debajo de la que los registros oficiales indican. Los libros aunque son de un nivel asequible están muy por encima del nivel real de los alumnos, las calificaciones de los alumnos son irreales y están muy "infladas". Así y en nuestro trato diario con los alumnos de la escuela en la asignatura de inglés, los chicos que conocía personalmente y de los cuales sabía que su nivel de conocimiento de esta lengua era muy escaso obtenían muy buenas calificaciones en la escuela. De hecho, algunos autores ponen de manifiesto que el desarrollo en África se ve ralentizado porque la comunicación se basa en gran medida en lenguas extranjeras de la época colonial y por tanto, las partes implicadas en el proceso de desarrollo no pueden interactuar eficazmente (Kanana, 2013).

En la zona de Qillenso las escuelas que ofrecen más allá de segundo grado se encuentran aproximadamente a 12 kilometros una de la otra y se encuentran en las zonas más urbanizadas mientras que en la zona intermedia hay varias escuelas 
primarias que solo cubren hasta grado cuatro. Este hecho sugiere que la demanda de educación más allá de grado cuarto o quinto es mucho más limitada y que los alumnos una vez acabado el primer ciclo suelen abandonar el sistema educativo. En los registros de la escuela es notable como los últimos grados 3 y 4 siempre tienen un número inferior de alumnos matriculados.

Otro de los problemas fundamentales es el idioma. Las clases son impartidas en Oromo oficial, mientras que los alumnos tienen como lengua materna el Oromo Guji, uno de los múltiples dialectos de la lengua Oromo, esto crea dificultades en clase a la hora de la compresión. Nosotros mismos hemos sido testigos de que la utilización de palabras de "oromo oficial" confundía a los alumnos ya que desconocían que significaban. Con vistas al futuro de las nuevas generaciones Guji y observando la evolución del país, es posible anticipar que el desconocimiento general del amhárico va a suponer un duro hándicap para los miembros de esta tribu a la hora de conseguir un trabajo más allá de las fronteras de Gujiland.

\subsection{Comparativa de LA SITUACIÓN EDUCATIVA ENTRE Etiopía y LA OROMÍA}

Una vez conocida la situación general del sistema educativo etíope es necesario que nos centremos en la situación del mismo en la Oromía, región a la que pertenecen los participantes de nuestro estudio. Lo primero que debemos destacar es la importancia que tiene la Oromía en el sistema educativo de Etiopía, como ya hemos visto anteriormente este estado federal es uno de los más grandes y poblados del país y esta condición tiene un claro reflejo en la importancia del volumen de alumnado que aporta al sistema educativo nacional de Etiopía que como iremos viendo oscila de alrededor de un $20 \%$ en educación pre-primaria a cerca de un $40 \%$ en educación primaria.

Por lo tanto conocer la situación de la educación en la Oromía no solo nos servirá para comprender en qué contexto inmediato se encuentran los alumnos Guji, sino que es fundamental para conocer la situación del sistema educativo Etíope en sí. 


\subsubsection{Educación pre-primaria en la Oromía}

La población total en edad oficial de cursar la educación pre-prima en la Oromía es 3.143 .818 lo que supone el $40,74 \%$ de la población total en ese mismo rango de edad de Etiopía que asciende a 7.714.956 (MoE, 2013). Esto debería suponer que 4 de cada 6 alumnos de pre-primaria deberían ser Oromos pero en realidad la Oromía solo aportó 472.988 alumnos de los 2.013.214 que cursaron la educación pre-primaria durante el curso $2012 / 13$ lo que supone tan solo el $23,5 \%$. Así pues, la tasa de matriculación bruta de la Oromía está más de 10 puntos por debajo de la media nacional, ya que mientras el TMB de la Oromía es de $15 \%$ el nacional es de un $26,1 \%$.

Si analizamos estos datos dependiendo del género de los alumnos podemos observar cómo a nivel de la Oromía y a nivel nacional las diferencias entre los chicos y chicas son muy similares ya que mientras a nivel nacional la diferencia es de 1,2 puntos de desventaja en el TMB de las chicas respecto al de los chicos a nivel de la Oromía esta diferencia es de 1,1.

\section{Kindergarden}

Centrándonos en los Kindergarden que suponen la educación más formal dentro de la preprimaria la situación en la Oromía es la siguiente. 146.531 alumnos acuden a Kindergardens en la Oromía lo que significa que solo Addis Abeba con 170.559 aporta más estudiantes a los 478.977 del total nacional. Aunque esto supone que el $30,6 \%$ de los alumnos de todo el país de Kindergarden acuden a clase en la Oromía la Tasa de Matriculación bruta en esta región solo es de un 4,7\% frente al $6,2 \%$ nacional.

En lo que sí tienen una mejor situación la Oromía que el resto de Etiopía es en la tasa de alumnos por profesor, ya que mientras que a nivel nacional la tasa se sitúa en 43 alumnos por cada profesor en la Oromía se sitúa en 40,7.

En resumidas cuentas la situación de la pre-primaria en la Oromía supone por una parte una clara desventaja para los alumnos de etnia Oromo ya que, como hemos visto anteriormente, la educación preprimaria tiene un impacto muy 
significativo a la hora del desempeño que los alumnos lograrán luego en la educación primaria, y al tener una tasa inferior de matriculación que la media nacional un porcentaje mayor de alumnos acuden a la educación primaria sin la base que otorga la educación pre-primaria. Por otra parte la existencia de una ratio inferior de alumnos por profesor en los Kindergarden podría suponer que los alumnos que si acuden a estos centros deberían obtener una atención más personalizada del profesorado y por tanto una mejor formación, aunque la diferencia en la ratio no es especialmente grande por lo que puede que su impacto sea bastante limitado.

\subsubsection{Educación primaria en la Oromía}

La comprensión de la situación de la educación primaria tanto en Etiopía como en la Oromía es uno de los puntos fundamentales de la presente Tesis, por lo tanto debemos conocer como es la situación de esta fase educativa en la Oromía y su situación respecto a la educación primaria en todo el estado etíope.

En primer lugar debemos de conocer algunos datos generales sobre la población susceptible de matricularse en la educación primaria y la que llega a hacerlo en la Oromía y la proporción que aportan a los mismos contingentes de población a nivel nacional. Así, la población de la Oromía en edad oficial de cursar la educación primaria 7-14 es de 7.036.942 personas, lo que supone un 38,48\% del total de las18.287.214 personas que se encuentran en ese arco de edad en Etiopía. Si analizamos las cifras de alumnos matriculados en primaria en la Oromía había 6.414.327 alumnos cursando la educación primaria durante el curso 2012/13, es decir que esta región aporta un 36,8\% de los 17.430.294 alumnos de primaria que hay a nivel nacional.

De estos datos se desprenden varias conclusiones, que iremos analizando a lo largo de este apartado. En primer lugar, es importante señalar que, como ya hemos visto a nivel nacional y como volveremos a ver cuando analicemos el GER y el NER de la Oromía, estas cifras tan próximas entre la población en edad oficial de ser matriculada en la educación primaria y el número de estudiantes de educación 
primaria puede llevar a error si no se entiende que responde de una manera importantísima a la presencia de un gran número de alumnos con edades superiores a la oficial más que a la matriculación en primaria de todos los niños y niñas en edad oficial de hacerlo. Por lo tanto pese a la inferior aportación en proporción de alumnado de la Oromía en comparación con su peso demográfico, $36,8 \%$ de alumnos de primaria frente a $38,48 \%$ de población- hay que analizar los datos de una manera más detallada para obtener conclusiones acertadas y precisas.

Lo primero que debemos comprobar es si la tendencia en la matriculación de alumnado en la Oromía presenta alguna diferencia significativa con la tendencia a nivel nacional. En este sentido, en la Figura 59 podemos observar que tanto Etiopía como la Oromía han seguido un patrón muy similar pero las fluctuaciones han sido mucho más marcadas en la Oromía, con un aumento record entre el curso de $2009 / 10$ y $2010 / 11$ de un $10,3 \%$. A diferencia de la tendencia acumulativa siempre en positivo de Etiopía, la Oromía perdió estudiantes entre el año 2010/11 y 2011/12 aunque este retroceso fue mínimo, de un 0,07\% lo que en la práctica supuso el descenso de unos 5.000 alumnos aproximadamente.

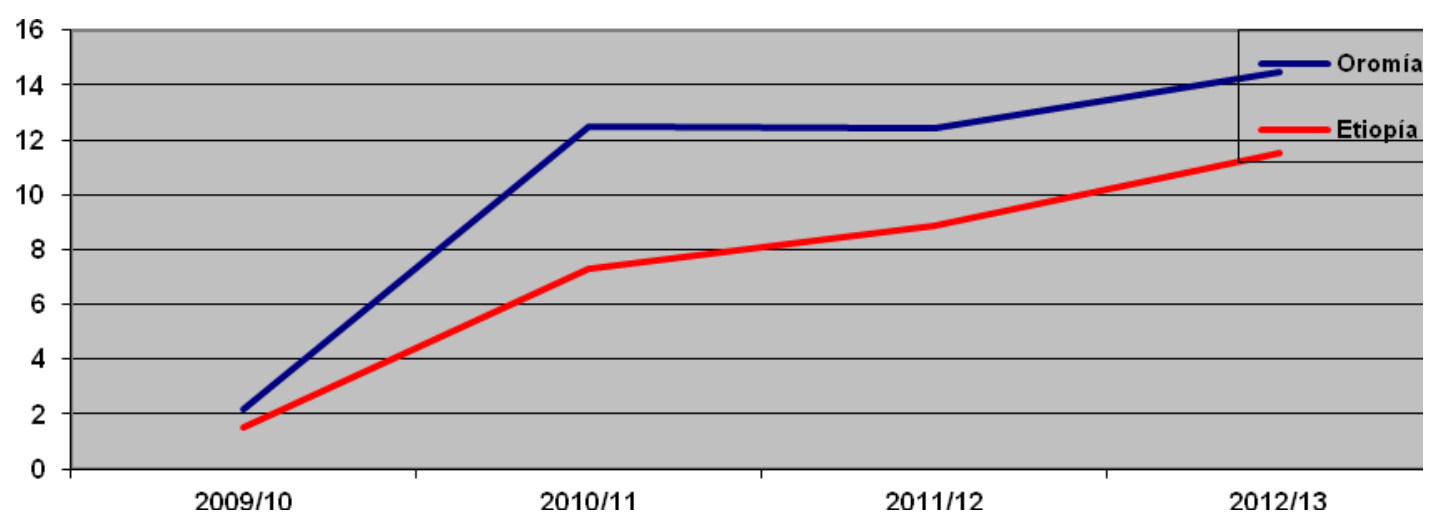

Figura 59. Comparativa de las tendencias acumuladas de Etiopía y la Oromía en el aumento anual de alumnos matriculados en educación primaria

(Fuente: Elaboración propia a partir de los datos del Ministerio de Educación Etíope)

La media de crecimiento anual de matriculación en la Oromía ha sido por tanto superior a la nacional, situándose la primera en un 3,6\% mientras que la 
segunda se ha quedado en un $2,8 \%$. A continuación es importante comparar el porcentaje de alumnado femenino del total tanto de Etiopía como de la Oromía y ver la evolución de los mismos a lo largo de estos años (Tabla 24).

Tabla 24. Comparativa de la evolución del porcentaje de alumnado femenino en primaria entre el curso 2008/9 y 2012/13 en Etiopía y en la Oromía

\begin{tabular}{|c|c|c|c|c|c|}
\hline Año & 2008/09 & $2009 / 10$ & $2010 / 11$ & $2011 / 12$ & $2012 / 13$ \\
\hline $\begin{array}{c}\text { \% alumnas } \\
\text { Oromía }\end{array}$ & 46,2 & 46,5 & 46,6 & 47,1 & 46,9 \\
\hline $\begin{array}{c}\text { \% alumnas } \\
\text { Etiopía }\end{array}$ & 47,3 & 47,6 & 47,5 & 47,8 & 47,6 \\
\hline
\end{tabular}

(Fuente: Elaboración propia a partir de datos del Ministerio de Educación Etíope)

En la Tabla 24 queda claro que tanto en la Oromía como en Etiopía la composición por género del alumnado es muy similar, siendo ligeramente inferior en la Oromía que la media estatal. En los dos casos queda claro que como habíamos comentado anteriormente parece haberse llegado a una especie de techo de cristal respecto a la incorporación de las niñas al sistema educativo que no logran equiparar su porcentaje como alumnas al tanto por ciento de la población que suponen.

\section{Escuelas en la Oromía}

Una vez conocidos estos datos es necesario analizar la situación de las escuelas en la Oromía y las condiciones en las que estos 6.414 .327 alumnos de primaria acuden a clase. En primer lugar si realizamos una comparativa de la evolución del número de escuelas disponibles tanto en Etiopía como en la Oromía queda patente que en ambos casos ha habido un incremento continuado durante los últimos años de las escuelas disponibles siendo el crecimiento en la Oromía algo inferior a la media nacional, como podemos ver en la Tabla 25. 
Tabla 25. Evolución del número disponible de escuelas de primaria en la Oromía y Etiopía entre los cursos $2008 / 9$ y 2012/13

\begin{tabular}{|c|c|c|c|c|c|c|}
\hline & $2008 / 9$ & $2009 / 10$ & $2010 / 11$ & $2011 / 12$ & $2012 / 13$ & $\%$ anual \\
\hline Oromía & 10.083 & 10.742 & 11.381 & 11.729 & 12.060 & $4,6 \%$ \\
\hline Etiopía & 25.212 & 16.951 & 28.349 & 29.482 & 30.534 & $4,9 \%$ \\
\hline
\end{tabular}

(Fuente: Elaboración propia a partir de datos del Ministerio de Educación Etíope)

Por otra parte queda patente que en ambos casos el crecimiento anual de escuelas disponibles es superior al crecimiento anual del número de estudiantes que como vimos anteriormente era de $3,6 \%$ y $2,8 \%$ para la Oromía y Etiopía respectivamente. Por lo tanto aunque el crecimiento del alumnado es mayor en la Oromía que en el resto del país y el ritmo de apertura de escuelas es inferior en esta región que la media nacional lo que sin duda debe afectar negativamente a los ratios de alumnos/aula aunque este impacto negativo sea mitigado en cierta medida por el hecho de que pese a que el alumnado de la Oromía suponga solo el $36,8 \%$ del total nacional las escuelas de la Oromía supongan el 39\% de todas las escuelas de primaria del país.

De igual manera, la proporción de escuelas de primaria en zonas rurales es muy similar entre la Oromía y Etiopía, ya que según los datos del Ministerio de educación Etíope, el 85\% de las escuelas de primaria a nivel nacional están en zonas rurales mientras que en la Oromía esta proporción sube casi hasta un $88 \%$ por lo que la diferencia no creemos que sea suficientemente significativa para provocar diferencias entre la Oromía y el resto de país.

\section{Tasa de ingreso con independencia de la edad (AIR)}

El primer dato a comparar en la educación primaria es el AIR. Como podemos observar en la Tabla 26, Oromía está por encima de la media en el AIR en el caso de los chicos pero tanto en el caso de las chicas como en el Índice de Paridad de Género es ligeramente inferior al nacional. 
Tabla 26. Comparativa del AIR entre la Oromía y Etiopía durante el curso 2012/13

\begin{tabular}{|c|c|c|c|c|}
\hline & Chicos & Chicas & Media & I.P.G \\
\hline Oromía & 151.1 & 137.7 & 144.5 & 0.91 \\
\hline Nacional & 150.2 & 137.8 & 144.1 & 0.92 \\
\hline
\end{tabular}

(Fuente: Elaboración propia a partir de los datos del Ministerio de Educación Etíope)

\section{Tasa de ingreso neto (NIT)}

Como ya hemos expuesto anteriormente la NIT lleva desde el curso 2008/9 creciendo año tras año hasta haber alcanzado en 2012/13 una tasa del 95,5\% (MoE, 2013). Si comparamos los datos de la Oromía con los datos a nivel estatal este último curso, la situación es que la Oromía está 1,1 puntos por debajo de la media nacional. Como podemos ver en la Tabla 27 la diferencia entre la Oromía y Etiopía a nivel general en el caso de los niños es mínima, situándose esta región solo 0.3 decimas por debajo de la media nacional. En el caso de las niñas la diferencia es más acusada ya que las niñas Oromo son matriculadas a la edad de siete años en primero de primaria 1,8 puntos por debajo de la media nacional.

Tabla 27. Comparativa de la NIT entre la Oromía y Etiopía durante el curso 2012/13

\begin{tabular}{|c|c|c|c|}
\hline & Chicos & Chicas & Media \\
\hline Oromía & $97.6 \%$ & $91,2 \%$ & $94.4 \%$ \\
\hline Etiopía & $97.9 \%$ & $93.0 \%$ & $95.5 \%$ \\
\hline
\end{tabular}

(Fuente: Elaboración propia a partir de los datos del Ministerio de Educación Etíope)

Tanto el AIR como el NIT nos indican que los alumnos de la Oromía acuden por primera vez a la educación primaria ligeramente en peores condiciones que la media nacional, en un primer lugar que el AIR de la Oromía esté por encima del nacional mientras que el NIT esté por debajo es una muestra de que hay una proporción mayor de alumnos Oromo que acuden a clase por primera vez con una edad superior a la ideal para ello que a nivel nacional En esta primera matriculación en la edad primaria las chicas de la Oromía están ligeramente peor situadas que la media Etíope, ya que tanto en el AIR como en el NIT sus cifras son inferiores a la media nacional, siendo mayor la desventaja en el NIT por lo que empeora aún más 
la situación al significar que no es que solo sean matriculadas por primera vez de una manera inferior, sino que lo hacen de manera más tardía que la media.

\section{Tasa de Matriculación bruta (GER)}

La tasa de matriculación bruta es inferior en la Oromía que la media nacional, como podemos ver en la siguiente figura esta diferencia es de 4.1 puntos, lo que nos indica que en la Oromía una menor proporción de alumnos son matriculados que de media en el país (véase Tabla 28).

Tabla 28. Comparativa de la Tasa de Matriculación bruta entre la Oromía y Etiopía en el curso 2012/13

\begin{tabular}{|c|c|c|c|}
\hline & Chicos & Chicas & Media \\
\hline Oromía & 95.6 & 86.6 & 91.2 \\
\hline Etiopía & 98.2 & 92.4 & 95.3 \\
\hline
\end{tabular}

(Fuente: Elaboración propia a partir de los datos del Ministerio de Educación Etíope)

De igual manera, si analizamos los datos de la Tabla 28 más detenidamente podemos observar que en la Oromía hay una mayor brecha de género que en el resto del país, ya que mientras que a nivel estatal esta diferencia es de 5,8 puntos en la Oromía la diferencia sube significativamente hasta los 9 puntos, situándose la matriculación bruta masculina 2,6 puntos por debajo de la estatal mientras que la femenina lo hace 5,8 puntos por detrás. Si diferenciamos los datos de los dos ciclos de la educación primaria podemos deducir una serie de conclusiones interesante (véanse Tablas 29 y 30 ).

Tabla 29. Comparativa de la Tasa de Matriculación bruta entre la Oromía y Etiopía en el primer ciclo de educación primaria durante el curso 2012/13

\begin{tabular}{|c|c|c|c|}
\hline & Chicos & Chicas & Media \\
\hline Oromía & 127 & 115.7 & 121.4 \\
\hline Etiopía & 129.7 & 119.8 & 124.9 \\
\hline
\end{tabular}

(Fuente: Elaboración propia a partir de los datos del Ministerio de Educación Etíope) 
El primer dato destacable es que mientras en Etiopía la diferencia en la tasa de matriculación bruta entre el primer ciclo y el segundo ciclo de primaria se sitúa en 62 puntos porcentuales en la Oromía esta diferencia es de 64,9. Esto nos muestra que la Oromía siguiendo el mismo patrón de Etiopía sufre un gran descenso de alumnado en el segundo ciclo de primaria el que como explicamos anteriormente actúa realmente como una etapa educativa diferente al primer ciclo de primaria y no como una segunda fase de la misma etapa como debería hacer.

Pese a esta similitud no hay que dejar de observar que las diferencias de matriculación bruta entre la Oromía y Etiopía crecen significativamente entre el primer y segundo ciclo de primaria, ya que mientras en los cuatro primeros cursos de primaria la Oromía se sitúa 3,6 puntos por debajo de la media nacional en el segundo ciclo las diferencias crecen hasta situarse en 6,4 puntos lo que deja claro que en la Oromía por diversos motivos, que iremos viendo a continuación, el segundo ciclo de educación primaria es más débil que a nivel nacional y esta menor matriculación bruta inferior ya va indicándonos que los alumnos de la Oromía son menos proclives a continuar sus estudios al terminar el primer ciclo de primaria.

Tabla 30. Comparativa de la Tasa de Matriculación bruta entre la Oromía y Etiopía en el segundo ciclo de educación primaria durante el curso 2012/13

\begin{tabular}{|c|c|c|c|}
\hline & Chicos & Chicas & Media \\
\hline Oromía & 59.5 & 53.4 & 56.5 \\
\hline Etiopía & 63.5 & 62.2 & 62.9 \\
\hline
\end{tabular}

(Fuente: Elaboración propia a partir de los datos del Ministerio de Educación Etíope)

Por otra parte las diferencias de género entre un ciclo y otro son también muy significativas en ambos casos aunque en la Oromía las diferencias de género son más marcadas, ya que frente a los 9,9 en el primer ciclo y 1,3 puntos en el segundo de diferencia a favor de los chicos en Etiopía respectivamente en la Oromía estas diferencia son de 11,3 y 6,1 puntos. Esto nos indica no solo que hay una menor tasa de matriculación bruta femenina en ambos ciclos en la Oromía que en Etiopía como hemos podido observar en las tablas, sino que además en el segundo ciclo de primaria las chicas Oromo están en una desventaja mucho más marcada 
que a nivel nacional, ya que la diferencia por género en la tasa de matriculación bruta en la Oromía durante el segundo ciclo de primaria es casi cinco veces superior lo que supone que mientras que a nivel estatal las chicas son un $48,6 \%$ del alumnado del segundo ciclo de primaria mientras que en la Oromía solo aportan un $46,7 \%$.

\section{1) Tasa de matriculación neta (NER)}

Respecto a la matriculación en la primaria de los alumnos en la edad oficial para hacerlo como podemos observar en la siguiente tabla la Oromía también está por debajo de Etiopia aunque en este caso las diferencias son menos marcadas, situándose la Oromía dos puntos porcentuales por debajo de la media nacional (Tabla 31).

Tabla 31. Comparativa de la Tasa de Matriculación neta entre la Oromía y Etiopía en el curso 2012/13

\begin{tabular}{|c|c|c|c|}
\hline & Chicos & Chicas & Media \\
\hline Oromía & 87,2 & 80,6 & 83,9 \\
\hline Etiopía & 87,7 & 84,1 & 85,9 \\
\hline
\end{tabular}

(Fuente: Elaboración propia a partir de los datos del Ministerio de Educación Etíope)

Es destacable que, igual que en la matriculación bruta, en la matriculación neta hay una gran diferencia por género que en la Oromía que sitúa la matriculación neta femenina 6,8 puntos por debajo de la masculina en esta región y 3,5 puntos por debajo de la matriculación femenina neta nacional. Como en el apartado anterior estudiar los datos de la matriculación neta de manera individualizada para los dos ciclos de primaria nos aportará una información más precisa.

Como podemos ver en la Tabla 32, la tasa de matriculación neta de la Oromía para el primer ciclo de primaria es ligeramente inferior a la media nacional, solo 0,5 puntos porcentuales por debajo, es más en el caso de los chicos es superior a la media nacional en 0,3 puntos pero en las alumnas de la Oromía están 1,3 puntos por debajo de la tasa de matriculación bruta de Etiopía. 
Tabla 32. Comparativa de la Tasa de Matriculación neta entre la Oromía y Etiopía en el primer ciclo de educación primaria durante el curso 2012/13

\begin{tabular}{|c|c|c|c|}
\hline & Chicos & Chicas & Media \\
\hline Oromía & 98.5 & 91.5 & 95 \\
\hline Etiopía & 98.2 & 92.8 & 95.5 \\
\hline
\end{tabular}

(Fuente: Elaboración propia a partir de los datos del Ministerio de Educación Etíope)

En el caso del segundo ciclo de primaria las cosas cambian significativamente, en la Oromía igual que en Etiopía se pasa de una matriculación neta cercana al $100 \%$ a cifras inferiores al $50 \%$ lo que como explicamos anteriormente a lo largo de la presente tesis es una consecuencia de varios de los grandes problemas del sistema educativo etíope. Si comparamos los datos de la Oromía con Etiopía disponibles en la Tabla 33 podemos observar que la matriculación neta en la Oromía está 4,2 puntos por debajo de la media nacional mientras que en el primer ciclo solo estaba 0,5 puntos por debajo. Este aumento de diferencias entre la Oromía y Etiopía también se daba en la Tasa de Matriculación bruta por lo que queda claro que en la Oromía por diversos motivos los niños y niñas tienden a continuar de una manera inferior los estudios después de finalizar el primer ciclo de educación primaria o a abandonar los estudios en mayor medida que de media en el país. La confirmación de esta idea la veremos más adelante cuando analicemos las tasas de finalización de primaria y de abandono escolar.

Tabla 33. Comparativa de la Tasa de Matriculación neta entre la Oromía y Etiopía en el segundo ciclo de educación primaria durante el curso 2012/13

\begin{tabular}{|c|c|c|c|}
\hline & Chicos & Chicas & Media \\
\hline Oromía & 44.3 & 41.9 & 43.1 \\
\hline Etiopía & 46.5 & 48.1 & 47.3 \\
\hline
\end{tabular}

(Fuente: Elaboración propia a partir de los datos del Ministerio de Educación Etíope)

Volviendo a los datos de la tasa de matriculación bruta en el segundo ciclo de educación primaria es especialmente significativo el caso de las chicas en la Oromía, ya que mientras a nivel nacional las chicas tienen una ventaja sobre los 
chicos de 1,6 puntos en la Oromía las chicas están 2,2 puntos por debajo de los chicos, o lo que es lo mismo 6,2 puntos por debajo de las media nacional de las chicas. Esto nos indica no solo que en la Oromía el segundo ciclo de primaria es más débil que en el resto del país como acabamos de ver, sino que las diferencias de género son mayores y las chicas por lo tanto están en una situación más precaria aún que sus congéneres del resto del país

\section{2) Tasa de repetición}

Anteriormente ya explicamos la especial idiosincrasia de la repetición en Etiopía y como las repeticiones se concentraban en varios puntos de los dos ciclos de educación primaria. Al no tener datos disponibles para la Oromía de donde se producen estas repeticiones nos vemos obligados a analizar solamente la tasa de repetición media entre 10 y $8^{\circ}$ curso de primaria.

Tabla 34. Comparativa de la tasa de repetición en primaria (1-8) en la Oromía y Etiopia

\begin{tabular}{|c|c|c|c|}
\hline & Chicos & Chicas & Media \\
\hline Oromía & 9.3 & 8.7 & 9 \\
\hline Etiopía & 8.1 & 7.7 & 7.9 \\
\hline
\end{tabular}

(Fuente: Elaboración propia a partir de los datos del Ministerio de Educación Etíope)

Como podemos ver en la Tabla 34, en la Oromía la tasa de repetición es de un $9 \%$, lo que es superior en un 1,1 puntos a la media nacional, igual que a nivel nacional, los chicos de la Oromía tienden más a repetir que las chicas pero las diferencias entre los géneros son de menos de un $1 \%$ por lo que como ya explicamos anteriormente no creemos que el género sea muy significativo en este caso.

\section{3) Tasa de abandono escolar}

Igual que en el caso anterior de la tasa de repetición no tenemos para la tasa de abandono escolar información suficiente para conocer en los diferentes cursos en los que los alumnos de la Oromía abandonan el sistema educativo por lo que 
tendremos que limitarnos a comparar la media de abandono escolar a lo largo de toda la primaria entre la Oromía y Etiopía, esto lo podemos ver en la Tabla 35.

Tabla 35. Comparativa de la tasa de abandono escolar en primaria (1-8) en la Oromía y Etiopia

\begin{tabular}{|c|c|c|c|}
\hline & Chicos & Chicas & Media \\
\hline Oromía & 18.6 & 18.6 & 18.6 \\
\hline Etiopía & 15.9 & 14.4 & 15.7 \\
\hline
\end{tabular}

(Fuente: Elaboración propia a partir de los datos del Ministerio de Educación Etíope)

La tasa de abandono escolar durante la educación primaria es superior en la Oromía que la media nacional, como podemos (Tabla 35), en 2,9 puntos. Las diferencias de género para la Oromía en este caso son inexistentes ya que tanto chicos como chicas tienen una tasa de abandono escolar del $18.6 \%$ lo que confirma la idea que ya habíamos visto al analizar esta tasa en el caso de Etiopía de que el género no parece tener un impacto muy significativo a la hora de abandonar el sistema educativo a lo largo de la primaria.

\section{4) Tasa de finalización de primaria}

Como ya explicamos anteriormente esta tasa es uno de los estándares internacionales elegidos para conocer los resultados obtenidos por un sistema educativo por lo que la comparación de los datos entre Etiopía y la Oromía es especialmente interesante en este caso. En la Tabla 36 podemos observar cómo la tasa de finalización de primaria en 5으 curso es 5,7 puntos inferior en la Oromía que la media nacional de Etiopía. Es especialmente significativo el caso de las chicas que están en la Oromía 8,3 puntos por debajo de la media de las alumnas a nivel nacional y 7,2 puntos por detrás de sus compañeros masculinos en la Oromía.

Tabla 36. Comparativa de la tasa de finalización de primaria en 5o curso del año 2012/13 en la Oromía y Etiopía

\begin{tabular}{|c|c|c|c|}
\hline & Chicos & Chicas & Media \\
\hline Oromía & 74.1 & 66.9 & 70.5 \\
\hline Etiopía & 77.2 & 75.2 & 76.2 \\
\hline
\end{tabular}

(Fuente: Elaboración propia a partir de los datos del Ministerio de Educación Etíope) 
Esto nos indica que más de un $30 \%$ de las chicas de la Oromía son incapaces de finalizar el primer ciclo de educación primaria.

Tabla 37. Comparativa de la tasa de finalización de primaria en 8 o curso del año 2012/13 en la Oromía y Etiopía

\begin{tabular}{|c|c|c|c|}
\hline & Chicos & Chicas & Media \\
\hline Oromía & 46.3 & 40.7 & 43.5 \\
\hline Etiopía & 53.4 & 52.2 & 52.8 \\
\hline
\end{tabular}

(Fuente: Elaboración propia a partir de los datos del Ministerio de Educación Etíope)

Para la tasa de finalización en 80 curso, los datos de la Oromía (Tabla 37) son aún más bajos que los de Etiopía. En este curso la tasa de finalización en la Oromía está 9,3 puntos por debajo de la media nacional, lo que supone que casi un $10 \%$ menos de alumnos de la Oromía no logran terminar octavo curso en comparación con el resto de Etiopía. Especialmente preocupante es la situación de las alumnas en la Oromía, aproximadamente solo 4 de cada 10 logran terminar octavo curso y además se sitúan 11,5 puntos por debajo de la media nacional femenina y 5,6 puntos por debajo de sus compañeros de la Oromía.

\section{5) Ratio de alumnos por sección}

Como ya explicamos anteriormente debido a las características organizativas del sistema escolar etíope la tasa de alumnos por sección es un indicador especialmente útil a la hora de conocer la situación real de la utilización de las aulas del país. Si comparamos los datos de la Oromía con los de Etiopía para el año escolar 2012/13 podemos ver que la Tasa de alumnos por sección tiene una media nacional de 53.7 mientras que en la Oromía esta tasa se sitúa en 58.9.

Como se aprecia en la Tabla 38, la Oromía ha tenido una tasa de alumnos por sección siempre por encima de la media nacional y además el descenso de alumnos por sección desde el curso 2008/9 ha sido menor en la Oromía que en el resto del país por lo que la distancia entre esta región y la media nacional ha aumentado de 2,5 alumnos más por sección a 5,2. 
Esto nos indica que las clases en la Oromía están más saturadas de alumnos que en el resto del país pese a que como vimos anteriormente esta región cuente con un $39 \%$ del total de las escuelas del país aportando solamente el $36.8 \%$ de los alumnos de primaria del país. Esta contradicción que se produce entre el que haya más escuelas disponibles para menos alumnos y las clases estén más saturadas se debe entre otros factores a como veremos a continuación el mayor ratio de alumnos por profesor.

Tabla 38. Comparativa de la ratio de alumnos por sección entre la Oromía y Etiopía entre los cursos 2008/9 y 2012/13

\begin{tabular}{|c|c|c|c|c|c|}
\hline Curso & $2008 / 9$ & $2009 / 10$ & $2010 / 11$ & $2011 / 12$ & $2012 / 13$ \\
\hline Ratio Etiopía & 58.8 & 56.6 & 57.2 & 54.5 & 53.7 \\
\hline Ratio Oromía & 61.3 & 60.2 & 61.7 & 57.4 & 58.9 \\
\hline
\end{tabular}

(Fuente: Elaboración propia a partir de datos del Ministerio de Educación Etíope)

\section{6) Ratio de alumnos por profesor}

El RAP de la región de la Oromía fue de 56.2 durante el curso 2012/13, esto no solo lo sitúa sensiblemente por encima de la media nacional que es de 49.4 , sino que es necesario recordar que la ratio máxima reconocida por el gobierno etíope para la primaria es de 50 alumnos por profesor (MoE, 2013).

En la Tabla 39 podemos observar cómo la Oromía ha mantenido siempre durante los últimos cursos un ratio de alumnos por profesor superior a la media nacional y mientras esta última ha descendido en 4.4 alumnos en la Oromía este descenso ha sido solo de 1.2 alumnos, por lo que no solo la Oromía se encuentra en una posición peor que la media nacional, sino que la brecha ha aumentando.

Tabla 39. Comparativa de la ratio de alumnos- profesor entre la Oromía y Etiopía entre los cursos $2008 / 9$ y 2012/13

\begin{tabular}{|c|c|c|c|c|c|}
\hline Curso & $2008 / 9$ & $2009 / 10$ & $2010 / 11$ & $2011 / 12$ & $2012 / 13$ \\
\hline Ratio Etiopía & 53.8 & 50.4 & 50.9 & 50 & 49.4 \\
\hline Ratio Oromía & 57.4 & 54 & 58.7 & 56.9 & 56.2 \\
\hline
\end{tabular}

(Fuente: Elaboración propia a partir de datos del Ministerio de Educación Etíope) 
Este dato junto al dato anterior de el Ratio de Alumnos por Sección nos dan una clara imagen de que los alumnos de primaria en la Oromía se encuentran lo primero más afinados que sus compañeros de otras partes del país y lo segundo sus profesores tienen que atender en la clase a un número superior de alumnos por lo que es evidente que la calidad de la educación que estos alumnos de la Oromía reciben tienen que resentirse. Si analizamos todos estos datos, queda claro que en la Oromía el sistema educativo es más débil que en otras zonas de Etiopía ya que casi todos sus indicadores como tasas de matriculación bruta, neta, tasas de repetición, de abandono escolar o de finalización de primaria arrojan unos datos peores que la media nacional del país.

Además también queda patente en estos indicadores que la situación de las niñas en la Oromía está por debajo de los alumnos varones y además en muchas ocasiones muy por debajo de la situación de las niñas en otras partes del país.

\section{7) Profesorado de primaria}

En la Oromía había durante el curso 2012/13 110.850 profesores de primaria, de ellos 65.467 trabajaban en el primero ciclo y 45.383 en el segundo ciclo. De los 65.476 profesores del primer ciclo de primaria el $57,2 \%$ eran hombres y el $42,7 \%$ eran mujeres. En el segundo ciclo de primaria las proporciones son de un $71,5 \%$ de profesorado masculino y un $28,5 \%$ femenino. De todos ellos el $69.4 \%$ poseían la titulación requerida para ejercer su profesión, lo que sitúa al profesorado de la Oromía por encima de la media nacional en cerca de 5 puntos porcentuales.

La comparativa del porcentaje del profesorado que tiene la formación exigida para trabajar en los distintos ciclos de la educación primaria entre la Oromía y Etiopía es favorable a esta región en los dos ciclos, como vemos en la Figura 60, y puede aliviar en cierta medida la situación que acabamos de analizar en el apartado anterior. 


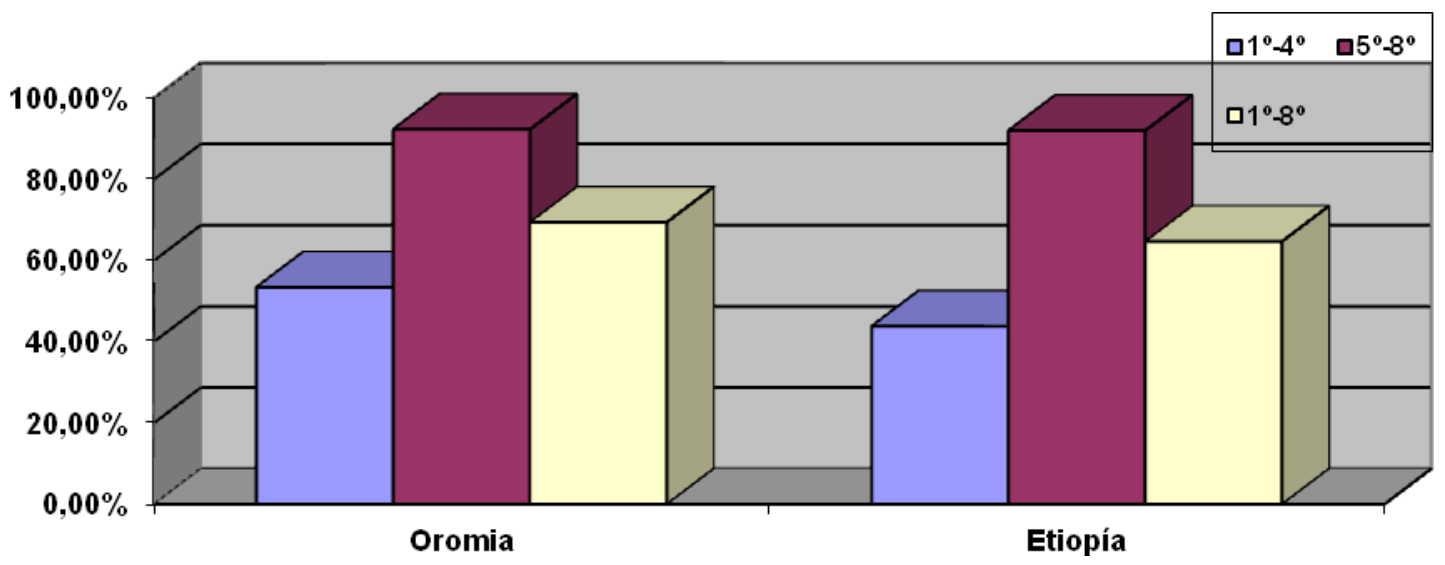

Figura 60. Comparativa de la formación del profesorado durante el curso 2012/13 entre la Oromía y Etiopía

(Fuente: Elaboración propia a partir de los datos del Ministerio de Educación Etíope)

Como se aprecia en la Figura 60, el porcentaje de profesores con una titulación suficiente para ejercer su profesión es un 10\% superior en la Oromía que la media nacional, esto es importante ya que como hemos visto anteriormente el primer ciclo de la educación primaria es en muchos casos la única educación que los alumnos van a recibir y más aún en el caso de la Oromía en la que los alumnos tienden a continuar de una manera menor escolarizados una vez acabado este ciclo. Por lo tanto, contar con un profesorado con una buena formación en el primer ciclo de primaria se vuelve fundamental en este caso, sobre todo por el mayor número de alumnos por profesor y sección que hay en esta región respecto a la media nacional.

El segundo ciclo de secundaria la ventaja de la Oromía respecto al resto del país se mitiga enormemente siendo los datos prácticamente iguales, 92,3\% en la Oromía y $90 \%$ de media nacional por lo que a efectos prácticos la Oromía está en la media del país en esta segunda fase de la educación primaria. Si atendemos a la composición de género de estos profesores de la Oromía a la hora de tener la titulación requerida la situación es la siguiente, un $44.9 \%$ de los profesores que ejercen su profesión en el primer ciclo de primaria posee la titulación necesaria para ello frente a un $64.9 \%$ de las mujeres mientras que en el segundo ciclo de la educación primaria los datos son que un $90.7 \%$ del profesorado masculino y un 96.4\% del femenino poseen dicha titulación. 


\section{8) Educación primaria alternativa}

En la Oromía igual que en el resto de Etiopía están instaurados unos sistemas de educación primaria alternativa que pretender llegar a la población que no puede o no ha podido acceder a la educación primaria formal. En el primero de estos sistemas alternativos, el ABE, la Oromía aportó durante el curso 2012/13 152.879 de los 731.600 alumnos que hay a nivel nacional inscritos en este programa. Es más interesante el caso de la educación no formal para adultos, en la que la Oromía aportó durante este mismo curso 1.442.917 alumnos del total de 3.415.776 que acuden a este programa en Etiopía. Esto nos indica que este segundo programa es todo un éxito en la Oromía como afirman los propios informes del MoE:

"Adult and non-formal education programs are running by government and non-governmental organizations in which Oromiya and Amhara account about 70\% of the total enrolment" (MoE, 2013, pág. 39).

\subsubsection{Educación secundaria}

Una vez conocida la situación de la educación primaria en la Oromía es importante conocer cómo se encuentra la educación secundaria para poder extraer conclusiones de cómo la situación de la primera afecta a la segunda y así poder diseñar posibles soluciones.

La población de la Oromía en edad oficial de cursar la educación secundaria que es la que se encuentra entre los 15 y 18 a los es de 2.859 .264 personas, lo que supone un $36,75 \%$ del total de las 7.778 .360 personas que se encuentran en ese arco de edad en Etiopía. De los 1.900 .735 alumnos de educación secundaria que había en el país durante el curso 2012/13 642.281 estudiaban en la Oromía. Esto supone que los estudiantes de la Oromía aportan el 33,79\% del alumnado. Igual que ocurría en la educación primaria, en esta educación secundaria la Oromía aporta un porcentaje menor de alumnado al total de los estudiantes de secundaria en Etiopía en relación a su peso demográfico, ya que solo aporta el 33,79\% de alumnos de 
secundaria cuando en realidad tiene un $36,75 \%$ de población en edad oficial de asistir a la educación secundaria.

Una vez conocidos estos datos es importante comprobar si la tendencia en la matriculación de los alumnos en la educación secundaria en la Oromía muestra un patrón similar a lo que ocurre a escala nacional en Etiopía como sucedía en la educación primaria o si por el contrario hay diferencias significativas entre esta región y el país en la educación secundaria (véase Figura 61).

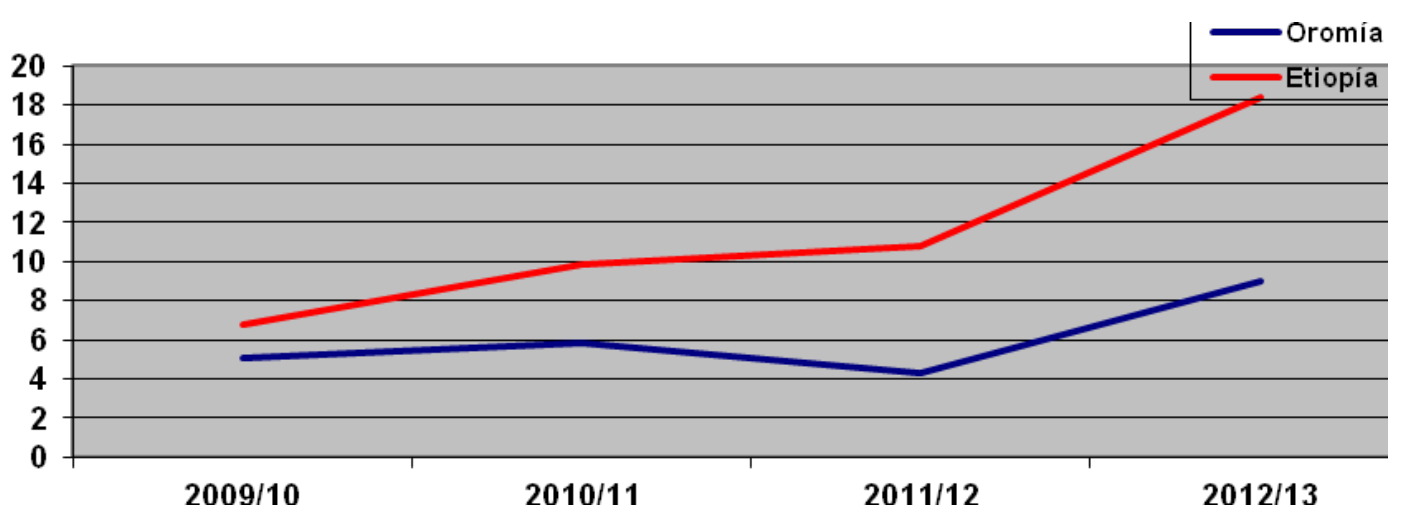

Figura 61. Comparativa de las tendencias acumuladas de Etiopía y la Oromía en el aumento anual de alumnos matriculados en educación secundaria

(Fuente: Elaboración propia a partir de los datos del Ministerio de Educación Etíope)

Como podemos ver en Figura 61, las tendencias acumuladas entre la Oromía y Etiopía son bastante similares, si bien es cierto la Oromía en el curso 2011/12 sufrió un fuerte retroceso perdiendo el $1,5 \%$ de los alumnos respecto al curso anterior. También queda patente que, a diferencia de lo que ocurría en la educación primaria, en la educación secundaria el crecimiento medio anual de la matriculación de alumnos en la Oromía ha sido durante estos últimos años inferior al de la media nacional, por lo que la Oromía esta quedándose atrás en la matriculación de alumnos en secundaria respecto al resto del país. De esta forma la media de crecimiento anual de matriculación en la Oromía ha sido por tanto inferior a la nacional, situándose en un $0,5 \%$ en el primer ciclo de educación secundaria y en un $14,9 \%$ en el segundo mientras que el aumento anual de matriculación a nivel nacional ha sido de un $2,8 \%$ en el primer ciclo y un $15 \%$ anual en el segundo ciclo de 
educación secundaria. Los datos para todo el ciclo de educación secundaria han sido los siguientes, el crecimiento anual de la Oromía ha sido de un 2,25\% mientras que el crecimiento medio anual de Etiopía ha sido de un 4,6\%

El siguiente paso que debemos de dar es comparar la evolución del porcentaje de alumnado femenino del total tanto de Etiopía como de la Oromía. Como podemos observar en la Tabla 40, el porcentaje de alumnado femenino en la Oromía ha crecido de un $36,8 \%$ en el curso $2008 / 9$ a un $44,7 \%$ en el curso $2012 / 13$, esto lo sitúa por debajo de la media nacional que era en $2012 / 13$ de un $46,8 \%$. Aún así en los datos facilitados por el Ministerio de Educación queda claro que el crecimiento anual del porcentaje de alumnado femenino en la educación secundaria durante el periodo comprendido entre los cursos anteriormente citados ha sido superior en la Oromía que de media en Etiopía ya que en el caso de esta región ha aumentado un 1,58\% de media anualmente frente al crecimiento a escala nacional que se ha situado en un $1,34 \%$ anual.

Tabla 40. Comparativa de la evolución del porcentaje de alumnado femenino en educación secundaria entre el curso $2008 / 9$ y 2012/13 en Etiopía y en la Oromía

\begin{tabular}{|c|c|c|c|c|c|}
\hline Año & $2008 / 09$ & $2009 / 10$ & $2010 / 11$ & $2011 / 12$ & $2012 / 13$ \\
\hline $\begin{array}{c}\text { \% alumnas } \\
\text { Oromía }\end{array}$ & $36,8 \%$ & $39,7 \%$ & $41,2 \%$ & $43,5 \%$ & $44,7 \%$ \\
\hline $\begin{array}{c}\% \text { alumnas } \\
\text { Etiopía }\end{array}$ & $40,1 \%$ & $42,5 \%$ & $44,2 \%$ & $45,6 \%$ & $46,8 \%$ \\
\hline
\end{tabular}

(Fuente: Elaboración propia a partir de datos del Ministerio de Educación Etíope)

Si comparamos estos datos con los reflejados para la educación primaria, queda claro que la incorporación de las chicas a la educación se ha producido posteriormente a esa misma incorporación a la educación primaria ya que el porcentaje de alumnado femenino en 2008/9 en educación primaria eran superiores o similares a los porcentajes de alumnas en educación secundaria durante el curso 2012/13 tanto en la Oromía como en Etiopía en general. Por otra parte viendo la desaceleración del crecimiento anual del porcentaje de alumnas matriculadas en educación primaria creemos que ya se está empezando a producir el mismo fenómeno de techo de cristal que provoca que la presencia femenina en 
las aulas siempre sea un poco inferior a la masculina y que evita que se logre acabar con la brecha de género de manera definitiva.

\section{Escuelas de secundaria en la Oromía}

Una vez conocidos los datos anteriores es necesario conocer la situación de las escuelas de educación secundaria en la Oromía y las condiciones en las que los 642.281 alumnos de esta región matriculados en la secundaria acuden a clase. Como en el caso de las escuelas de primaria, hemos comenzado realizando es una comparativa de la evolución del número de escuelas disponibles tanto en Etiopía como en la Oromía. En esta comparativa queda patente que en ambos casos ha habido un incremento continuado de la puesta en funcionamiento durante los últimos cursos de escuelas de secundaria disponibles, siendo el crecimiento en la Oromía un 2,1\% superior a la media nacional (véase Tabla 41).

Tabla 41. Evolución del número disponible de escuelas de secundaria en la Oromía y Etiopía entre los cursos $2008 / 9$ y 2012/13

\begin{tabular}{|c|c|c|c|c|c|c|}
\hline & $2008 / 9$ & $2009 / 10$ & $2010 / 11$ & $2011 / 12$ & $2012 / 13$ & $\%$ anual \\
\hline Oromía & 418 & 461 & 528 & 615 & 718 & $14,5 \%$ \\
\hline Etiopía & 1197 & 1355 & 1517 & 1710 & 1912 & $12,4 \%$ \\
\hline
\end{tabular}

(Fuente: Elaboración propia a partir de datos del Ministerio de Educación Etíope)

En la Tabla 41 también queda patente que durante el curso 2012/13 la Oromía contaba con el $37,5 \%$ de las escuelas de secundaria del país, que es un porcentaje superior a la proporción de alumnos de secundaria que aporta esta región al total del país que solo se sitúa en el 33,79\% como vimos anteriormente. Este porcentaje mayor de escuelas disponibles que de alumnos matriculados provoca que en el curso 2012/13 la media de alumnos por centro de estudios en Etiopía fuera de 994, mientras que en la Oromía esta media bajaba a 895. (MoE, 2013). Esto, junto al crecimiento superior del número de escuelas disponibles a lo largo de estos años en la Oromía respecto al resto del país, nos indica que la Oromía está realizando un esfuerzo para lograr mejorar una mayor expansión de la 
educación secundaria en la región, posiblemente para intentar paliar la desventaja en escolarización secundaria en esta región frente a otras regiones del país.

Pasando ahora a la localización de estas escuelas de secundaria en la Oromía, asistimos a una situación completamente opuesta a la que vimos en la educación primaria, ya que en el caso de la secundaria la gran mayoría de las escuelas disponibles se localizan en centros urbanos y no en zonas rurales, tanto es así que solo un $16,1 \%$ de las escuelas de secundaria se encuentran en esta región en zonas rurales. Si comparamos esta proporción con la media nacional podemos constatar que el porcentaje de escuelas de secundaria rurales en la Oromía está 8 puntos por debajo de la media nacional. (MoE, 2013) Como ya hemos expresado anteriormente esta baja presencia de infraestructuras educativas en zonas rurales en un país como Etiopía con una población joven, con pocos recursos económicos y en su gran mayoría asentada en zonas rurales dificulta en gran medida que la gran mayoría de la población pueda completar los estudios secundarios, situación aún más difícil en la Oromía por la presencia aún menor de escuelas de educación secundaria en zonas rurales.

\section{Ger y Ner en educación secundaria en la Oromía}

El Ger para la educación secundaria en la Oromía es de un 22,5\% frente a la media nacional que es de un $24,5 \%$, lo que significa que igual que pasaba en la educación primaria la matriculación bruta en la Oromía es inferior a la nacional en 2 puntos porcentuales de media. Pero este dato del $22,5 \%$ no es realmente representativo de la realidad de la educación secundaria en la Oromía ya que esta, igual que ocurría con la primaria, está dividida en dos ciclos con características muy diferentes como podemos ver en la Tabla 42. 
Tabla 42. Comparativa entre la Oromía y Etiopía del GER 1 y 20 ciclo de educación secundaria durante el curso 2012/13

\begin{tabular}{|c|c|c|c|c|c|c|}
\hline \multirow{2}{*}{ Ciclo } & \multicolumn{3}{|c|}{1 . Ciclo } & \multicolumn{3}{c|}{ 20 Ciclo } \\
\hline Género y Media & Varones & Mujeres & Media & Varones & Mujeres & Media \\
\hline Porcentaje GER Etiopía & $39,9 \%$ & $36,9 \%$ & $38,4 \%$ & $10,5 \%$ & $8,5 \%$ & $9,5 \%$ \\
\hline Porcentaje GER Oromía & $39,3 \%$ & $33,4 \%$ & $36,4 \%$ & $8,9 \%$ & $6 \%$ & $7,5 \%$ \\
\hline
\end{tabular}

(Fuente: Elaboración propia a partir de datos del Ministerio de Educación Etíope)

Durante el primer ciclo de secundaria el Ger de la Oromía fue de un 36,4\% frente al $38,4 \%$ de la media nacional, esto es dos puntos por debajo, pero como veremos a continuación esta diferencia es mucho más marcada entre las chicas que entre los chicos ya que durante este primer ciclo la diferencia entre los varones que cursaban sus estudios en la Oromía y la media nacional es muy pequeña, de solo 0,6 puntos, mientras que las chicas de la Oromía están 3,5 puntos por debajo de la media femenina nacional. Además las diferencias de género son más marcadas en la Oromía que a escala nacional, ya que las chicas de la Oromía están casi 6 puntos por debajo de sus compañeros masculinos en matriculación bruta, lo que es prácticamente el doble que la media nacional.

Si nos centramos en el segundo ciclo de la educación secundaria, es posible apreciar que la Oromía también se encuentra dos puntos porcentuales por debajo de la media nacional, pero en este caso la situación es aún más preocupante ya que el GER a escala nacional no alcanza ni un $10 \%$, por lo que una diferencia de dos puntos es mucho más significativa y supone un 20\% menos de alumnos matriculados. La situación de la matriculación bruta de las chicas en este segundo ciclo de secundaria en la Oromía es de casi 3 puntos por debajo de sus compañeros varones y 2,5 puntos por debajo de la media nacional femenina, por lo que podemos concluir que las alumnas de la Oromía se encuentran en los dos ciclos de secundaria en una situación de desventaja no solo respecto a los varones de su región, sino también frente a las chicas de muchas otras regiones del país.

Ya habíamos constatado anteriormente cómo, a escala nacional, alguno de los problemas de la educación primaria como la tardía escolarización afectaban 
negativamente a la tasa NER en Etiopía, a continuación veremos en la siguiente tabla como estos mismos problemas tienen su reflejo en la matriculación neta en la educación secundaria en la Oromía. Igual que ocurría anteriormente con la matriculación bruta, en la matriculación neta las tasas de la Oromía están por debajo de la media nacional, 2,5 puntos en el primer ciclo y 1,6 en el segundo.

Tanto en la Oromía como en Etiopía las chicas tienen una matriculación neta superior en el primer ciclo, pero mientras en Etiopía aún así había 15.070 chicos más matriculados en la edad oficial de hacerlo son las chicas las que son mayoría, aportando 125,692 alumnas frente a los 124,855 chicos, lo que supone 837 chicas más que chicos.

Tabla 43. Comparativa entre la Oromía y Etiopía del NER 1ㅇ y 2을 clo de educación secundaria durante el curso 2012/13

\begin{tabular}{|c|c|c|c|c|c|c|}
\hline \multirow{2}{*}{ Ciclo } & \multicolumn{3}{|c|}{1 10 Ciclo } & \multicolumn{2}{c|}{ 20 Ciclo (Programa preparatorio) } \\
\hline Género y Media & Varones & Mujeres & Media & Varones & Mujeres & Media \\
\hline Porcentaje NER Etiopía & $18,8 \%$ & $20,1 \%$ & $19,4 \%$ & $5,4 \%$ & $5,2 \%$ & $5,3 \%$ \\
\hline Porcentaje NER Oromía & $16,7 \%$ & $17,1 \%$ & $16,9 \%$ & $4 \%$ & $3,4 \%$ & $3,7 \%$ \\
\hline
\end{tabular}

(Fuente: Elaboración propia a partir de datos del Ministerio de Educación Etíope)

En el segundo ciclo las tornas cambian y los varones tienen tanto en Etiopía como en la Oromía unas tasas de matriculación neta superiores a las femeninas. Por otra parte, pese presencia de 837 chicas más que de chicos en el primer ciclo de secundaria, los datos nos muestran que durante toda la educación secundaria las chicas de la Oromía se encuentran en una situación de inferioridad respecto a la situación media de las alumnas en todo el país, ya que en el primer ciclo la ventaja de las chicas de la Oromía frente a los varones es de 0,4 puntos cuando en el país esta ventaja es de 1,3 puntos porcentuales. De igual manera en el segundo ciclo de secundaria las chicas están de media en Etiopía 0,2 puntos por debajo de los chicos 
mientras que en la Oromía esta desventaja se amplía hasta los 0,6 puntos en matriculación neta.

De esta manera los datos del NER confirma lo que ya habíamos visto al estudiar el GER, que la matriculación de los alumnos en el Oromía es inferior a la media del país, siendo la situación de las chicas especialmente precaria al tener una matriculación inferior no solo a la media de la matriculación femenina en Etiopía sino además al soportar una brecha de género respecto a sus compañeros de la Oromía superior a la brecha de género media del país.

\section{Ratio de alumnos por sección}

Como vimos anteriormente en el caso de educación primaria también en educación secundaria la Oromía ha tenido desde el curso 2008/9 hasta la actualidad una tasa de alumnos por sección superior a la media nacional, situándose en el último curso en 63.6 frente a los 59.3 del resto del país (véase Tabla 44).

Tabla 44. Comparativa de la ratio de alumnos por sección en educación secundaria entre la Oromía y Etiopía entre los cursos $2008 / 9$ y 2012/13

\begin{tabular}{|c|c|c|c|c|c|}
\hline Curso & $2008 / 9$ & $2009 / 10$ & $2010 / 11$ & $2011 / 12$ & $2012 / 13$ \\
\hline Ratio Etiopía & 67.9 & 63.9 & 58.1 & 56.1 & 59.3 \\
\hline Ratio Oromía & 73.5 & 65.5 & 62.6 & 57.7 & 63.6 \\
\hline
\end{tabular}

(Fuente: Elaboración propia a partir de los datos del Ministerio de Educación Etíope)

A diferencia de en educación primaria en secundaria la desventaja de la Oromía respecto a la media del país se ha recortado ligeramente pero aún así durante el curso 2012/13 hay 4.3 alumnos más por sección en esta región que de media en Etiopía.

\section{Ratio de alumnos-profesor}

Respecto a la ratio de alumnos por profesor la situación en las escuelas de secundaria de la Oromía durante el curso 2012/13 era la presencia de 63.6 alumnos por profesor, lo que situaba a esta región en cuatro alumnos por encima de la media nacional. 
Tabla 45. Comparativa de la ratio de alumnos-profesor en educación secundaria entre la Oromía y

Etiopía entre los cursos 2008/9 y 2012/13

\begin{tabular}{|c|c|c|c|c|c|}
\hline Curso & $2008 / 9$ & $2009 / 10$ & $2010 / 11$ & $2011 / 12$ & $2012 / 13$ \\
\hline Ratio Etiopía & 67.9 & 63.9 & 58.1 & 56.1 & 59.3 \\
\hline Ratio Oromía & 73.5 & 65.5 & 62.6 & 57.7 & 63.6 \\
\hline
\end{tabular}

(Fuente: Elaboración propia a partir de los datos del Ministerio de Educación Etíope)

En la Tabla 45 podemos observar como la Oromía ha tenido desde 2008/9 un ratio de alumnos por profesor superior a la media de Etiopía pero como la distancia entre esta región y el resto del país ha disminuido en 1.6 alumnos.

\section{Profesorado de secundaria}

En la Oromía ejercían durante el curso 2012/13 21.235 profesores de secundaria, de estos profesores el $86,6 \%$ eran hombres y el $13,4 \%$ eran mujeres. La comparativa del porcentaje del profesorado que tiene la formación exigida para trabajar en la educación secundaria entre la Oromía y Etiopía es desfavorable para esta región, ya que mientras la media nacional se establece en un $91.5 \%$ en la Oromía solo el $\mathbf{9 0 . 5 \%}$ del profesorado tiene dicha formación. Por otra parte esta diferencia de un $1 \%$ no es especialmente grande por lo que no creemos que provoque una situación de desventaja a los alumnos de educación secundaria de la Oromía.

Por lo tanto el contar con un profesorado con una buena formación en el primer ciclo de primaria se vuelve fundamental en este caso, sobre todo por el mayor número de alumnos por profesor y sección que hay en esta región respecto a la media nacional. Si atendemos a la composición de género de estos profesores de la Oromía a la hora de tener la titulación requerida la situación es la siguiente, un 90.9\% de los profesores que ejercen su profesión posee la titulación necesaria para ello frente a un $\mathbf{8 7 . 9 \%}$ de las mujeres, esta brecha por género es superior a la del resto del país en 2.1 puntos porcentuales. 


\subsection{PRINCIPALES PROBLEMAS DE LA EDUCACIÓN EN ETIOPÍA}

Una vez conocida tanto la evolución del sistema educativo de Etiopía y en la Oromoía como los datos más actuales de los mismos es hora de analizar los problemas que les atenazan y sus posibles soluciones. La educación etíope presenta una serie de problemas que minan los esfuerzos por su ampliación, mejora y limitan los efectos beneficiosos para la sociedad que una buena educación produce. Algunos de ellos son de larga duración mientras otros han surgido en los últimos años al calor de la expansión de la red educativa por todo el país al presentarse situaciones nuevas.

Los problemas de larga duración son realmente graves y condicionan todas las medidas de mejora del sistema educativo que se produjeron desde la introducción de los cambio en la política educativa en 1994, ya que por una parte determinaron en gran parte las medidas que se implantaron y por otra parte es tal la gravedad de esos problemas que han provocado que gran parte de los esfuerzos para mejorar el sistema educativo no hayan tenido el efecto deseado o no logren alcanzar sus objetivos al $100 \%$. Tradicionalmente los problemas que ha ido arrastrando el sistema educativo etíope han sido problemas de acceso al mismo, diferencias de género y baja calidad de la enseñanza impartida:

"The long-standing problems associated with the Ethiopian education system were essentially limited and inequitable access, lack of quality and relevance, and continuous decline in quality and standard" (MoE, 2002, pág. 8).

Por ello cuando el nuevo gobierno accedió al poder en 1991 fue muy consciente de las necesidades apremiantes que tenía el sistema etíope de educación y por ello como ya explicamos anteriormente reclutó a un grupo de expertos para que identificara las debilidades y fallos del sistema educativo y buscara cómo solucionarlos:

"To this effort, various strategies and methods have been devised to rectify the problems identified above and fully implement the new education policy. It is useful, however, to look at the strategy employed to correct each of the basic 
problems of the old educational system in order to better understand the new policy" (MoE, 2002, pág. 15).

Paradójicamente y pese al esfuerzo de dichos expertos para mejorar el sistema educativo alguna de las soluciones que plantearon han provocado nuevos problemas como veremos más adelante, además el gobierno ha sucumbido a la tentación de perseguir objetivos políticos propios con el sistema educativo desvirtuando alguna de las medidas propuestas y adaptándolas o implantando medidas nuevas para conseguirlo. Por otra parte no podemos dejar de observar los problemas y condicionantes que están relacionados con la realidad socioeconómica del país y que afectan de una manera determinante a la escolarización de los alumnos.

Es posible agrupar los problemas del sistema educativo en tres grandes grupos: (1) culturales; (2) económicos, y (3) estructurales. Esta clasificación nos servirá de hilo conductor para exponer dichos problemas, sus consecuencias y las posibles soluciones de los mismos.

\subsubsection{Problemas culturales}

Todas las sociedades tienen su idiosincrasia y su cosmovisión que condiciona el modo en que sus miembros son enculturados, clasifican los conocimientos y valoran la educación. Así, la forma de acercarse a la escuela es condicionada por la cultura de cada sociedad y tiene su reflejo en los sistemas educativos de cada uno de los países. En la actualidad, debido a la influencia cultural occidental sobre el resto del mundo, el modelo educativo de corte occidental se ha expandido e implantado en todo el globo. No debemos olvidar que este modelo fue diseñado para servir y dar respuestas a las necesidades de Occidente por lo que, pese al éxito obtenido en muchos casos, ha producido desajustes en países de otras regiones del mundo donde este modelo choca con las tradiciones y culturas existentes.

En el caso de Etiopía, debido a sus diferencias étnicas y culturales internas, esta situación se vuelve aún más compleja. Para facilitar la comprensión de la misma, haremos referencia a los condicionantes que afectan a la mayoría de las 
culturas que conviven en el país haciendo especial mención a la cultura Oromo entre cuyos miembros hemos realizado la presente investigación. El propio gobierno etíope en colaboración con Unicef reconoce que las distintas culturas tradicionales que conviven en Etiopía, en muchas ocasiones, no favorecen especialmente la escolarización de los niños ya que la escuela choca en muchos aspectos con las prácticas y creencias:

"Among the various socio-cultural values, some, such as violence against women and children, early marriage, and negative attitude towards education are common to most of the ethnic groups" (MoE y UNICEF, 2012, pág. 41).

Por ejemplo durante nuestra estancia en el país hemos sido testigos de lo que un occidental calificaría como violencia contra los niños o de comportamientos y creencias sobre las mujeres que en nuestra cultura serían reprobados como discriminatorios. Revisamos a continuación los principales problemas culturales constatados, a saber: (1) escasa valoración social de la escuela; (2) actitudes negativas frente a las discapacidades; (3) violencia contra los niños; (4) orfandad; (5) migraciones estacionales y éxodo a las ciudades; (6) problemas de género.

\section{Escasa valoración social de la escuela}

El primero de estos condicionantes, y que consideramos uno de los más importantes, es la escasa valoración social que en algunos ámbitos de Etiopía tiene la escuela:

"However, many parents, particularly those who live in rural Ethiopia, do not have the proper knowledge regarding the benefit of education due to the fact that they are illiterate" (MoE y UNICEF, 2012, pág. 47).

Dado que muchas de las personas de edad más avanzada, que en la sociedad etíope tienen un gran prestigio, no han ido nunca a la escuela, tampoco apoyan ni valoran la educación de las nuevas generaciones y consideran más importante que los niños ayuden en el trabajo diario de las casas y adquieran los conocimientos necesarios para ser agricultores o ganaderos en la edad adulta. 
En nuestra experiencia de campo fuimos testigos además de cómo, por ejemplo, aunque entre los Guji el maestro era respetado socialmente al igual que las personas que tenían estudios, la persona más valorada era la que lograba poseer un número superior de vacas que el resto de sus vecinos. Otros elementos como la participación en las distintas iglesias eran elementos que otorgaban a las personas un prestigio superior.

\section{Actitudes negativas frente a las discapacidades}

En Etiopía existe una autentica discriminación de las personas con discapacidad. En muchas ocasiones son maltratadas y ridiculizadas y las familias esconden a estos miembros en sus casas como algo vergonzante. En el peor de los casos los abandonan en instituciones religiosas, como fuimos testigos al visitar distintas misiones de las Hermanas de Teresa de Calcuta.

En el caso de los niños y niñas, estas actitudes sociales tienen como consecuencia lógica de los alumnos con discapacidad tengan muchas menos posibilidades de asistir a la escuela; si lo hacen, los profesores y compañeros no tienen una actitud positiva hacia ellos. En cuanto a los primeros, no creemos que tengan las herramientas necesarias para dar respuesta las necesidades especiales de estos alumnos:

"As a result, children with various kinds of disabilities are enrolled in schools but the public attitude towards these children has not yet changed. Accordingly, many children are kept in their homes and are not allowed to go to school" (MOE y UNICEF 2012, pág. 49).

En nuestra experiencia de campo no vimos ningún niño con discapacidad asistiendo a una escuela, aunque sí vimos a muchos de ellos pidiendo en las calles de las grandes ciudades del país.

\section{Violencia contra los niños}

La violencia contra mujeres y niños está muy extendida en Etiopía y es una práctica que es considerada aceptable por la gran mayoría de la sociedad. A modo 
de ilustración, entre los Guji la figura paterna representa para los niños una mezcla entre una figura respetada y temida ya que ante actitudes y comportamientos de los niños que sus progenitores consideren inapropiados o censurables es muy probable que utilicen la violencia física.

Estas prácticas tradicionales que se dan en las familias tienen su reflejo en la escuela donde tanto niños y niñas sufren violencia por parte de sus profesores y compañeros mayores. Si bien la utilización de castigos físicos por parte del profesorado está prohibida por ley, como padres y profesores los siguen considerando aceptables, se siguen empleando. Esta utilización de la violencia contra los niños en el ambiente escolar favorece directa e indirectamente la menor asistencia a clase y finalmente el abandono escolar. En el caso de las chicas esta violencia tiene una segunda vertiente que analizaremos en el apartado de los problemas relacionados con el género.

\section{Orfandad}

En Etiopía debido a enfermedades como el VIH/SIDA hay un gran número de huérfanos. Estos niños y niñas se encuentran en una situación mucho más vulnerable que quienes proceden de familias con ambos progenitores vivos ya que tienen menos recursos económicos y una situación social y afectiva más frágil, lo que a su vez afecta negativamente a su escolarización. Esta situación es aún más precaria en las zonas rurales o cuando los huérfanos no tienen una familia extensa que les apoye:

"Orphan children living in rural areas with poor households are compelled to be engaged in incoming-generating activities which are sometimes beyond their capacity. Most of the time boys are employed in laborious work while girls are either hired as domestic workers or become commercial sex workers" (MOE y UNICEF, 2012, pág. 52).

Además los huérfanos son más susceptibles de sufrir abusos físicos, psicológicos o sexuales por parte de sus nuevos cuidadores y, en el caso de que las 
familias de acogida cuenten con pocos recursos económicos, es más probable que sean sacados de la escuela para ponerlos a trabajar y pagar así su sustento.

En nuestra experiencia de campo conocimos el caso de una familia cuyo padre había muerto asesinado por un vecino debido a un conflicto por las tierras de labor. Su viuda e hijos, al no tener familia que les ayudara, se encontraban en una autentica situación de pobreza y tan solo gracias al apoyo económico que obtenían de una misión católica podían salir adelante y los hijos podían asistir a la escuela.

\section{Migraciones estacionales y éxodo a las ciudades}

En Etiopía hay poblaciones como los Oromo Borana o pequeños grupos de los Guji cuya economía familiar se basa en el pastoreo trashumante de ganado. Ello obliga a que las familias se desplacen siguiendo los pastos y las fuentes de agua para su ganado lo que dificulta enormemente que los niños y niñas puedan asistir a la escuela. En otros casos en los que solo los progenitores se desplazan y ausentan durante meses de la casa familiar, el impacto emocional y la falta de supervisión paterna también son causantes del abandono escolar:

"Moreover, when parents are far apart for long periods, children can be severely affected emotionally due to the lack of remittances, which can create family stress in relation to children's education. Not having a parent around to monitor the child's progress can adversely affect his/her chances of succeeding in school. Children can also decide on their own volition whether to attend school or not" (MoE y UNICEF, 2012, pág. 53).

Por otra parte el éxodo que se está produciendo actualmente de población rural a las ciudades está también afectando negativamente a la escolarización de los niños. Así, en muchas ocasiones, niños que estaban anteriormente escolarizados en sus lugares de origen tienen que ponerse a trabajar para ayudar a mantener a sus familias en las ciudades o, en el peor de los casos, acaban como niños de las calles con la problemática que esto trae consigo, ya que hay que en muchas ocasiones los niños se desplazan a las ciudades solos y sin ningún adulto que se encargue de ellos. 


\section{Problemas de género}

En este apartado de los problemas y condicionantes culturales es fundamental hacer hincapié en las desigualdades de género y en cómo la imagen tradicional de la mujer en Etiopía afecta de una madera determinante a la escolarización de las niñas y a su presencia en la escuela. Como hemos podido apreciar a lo largo de este capítulo, las chicas se encuentran en una clara situación de desventaja respecto a sus compañeros masculinos. En la inmensa mayoría de los indicadores analizados, las chicas obtienen unos resultados inferiores a sus compañeros varones, incluyendo inferiores tasas de matriculación tanto bruta como neta o inferiores tasas de finalización de primaria.

Además, aunque se ha producido un acercamiento entre las chicas y los chicos en los últimos años, todos los indicadores muestran que la situación se ha estabilizado y no se logra acabar con la diferencia entre los géneros. Incluso, en algunos casos donde estas diferencias se habían reducido, se han vuelto a agrandar. Es posible aludir a una serie de prácticas, creencias y tradiciones que afectan negativamente a la escolarización de las niñas y que expondremos a continuación. La primera de ellas es la actitud negativa que hay en parte de la sociedad acerca de la escolarización de las chicas. Y ello porque no se ve la utilidad de escolarizar durante muchos años a una persona que va a acabar siendo madre y ama de casa:

"Parents assume that educating a female child is a waste of time and resources because when she is old enough, she will marry someone and star taking care of her children and husband" (MOE y UNICEF, 2012, pág. 49)

Además, en caso de sociedades patrilineales como los Guji, a este aspecto se une el hecho de que, en su concepción del parentesco, las mujeres una vez casadas pasan a formar parte de la familia del esposo, por lo que invertir recursos en su educación supone derrochar recursos económicos para que luego otra familia se beneficie de ellos.

La segunda de estas creencias es la idea de que las chicas son menos inteligentes y hábiles que los chicos y que su paso por la escuela es menos brillante, 
he incluso que son más holgazanas que sus compañeros varones (MoE y UNICEF, 2012). En nuestra experiencia de campo fuimos testigos en una ocasión de cómo una alumna que vivía enfrente de la escuela estaba, en horario escolar, sentada con su madre y otros familiares en la puerta de su casa y no había acudido a clase. Ante nuestra insistencia de que se incorporara a las clases, los miembros de su familia se rieron y dijeron que ya iría otro día, que no era importante. Además estas ideas provocan que en caso de que sea necesario que alguno de los niños de la casa trabaje para ayudar al sostenimiento económico de la familia, los padres tiendan a elegir en mayor medida a las chicas que a los chicos para quedarse en casa y cuidar a sus hermanos pequeños. Ejemplo de ello lo vemos en la siguiente fotografía (véase Figura 62) en la que aparecen dos niñas en edad escolar que se encontraban fuera de la escuela durante el periodo lectivo. La niña mayor había recibido el encargo de sus padres de llevar agua a casa y de cuidar de su hermana pequeña.

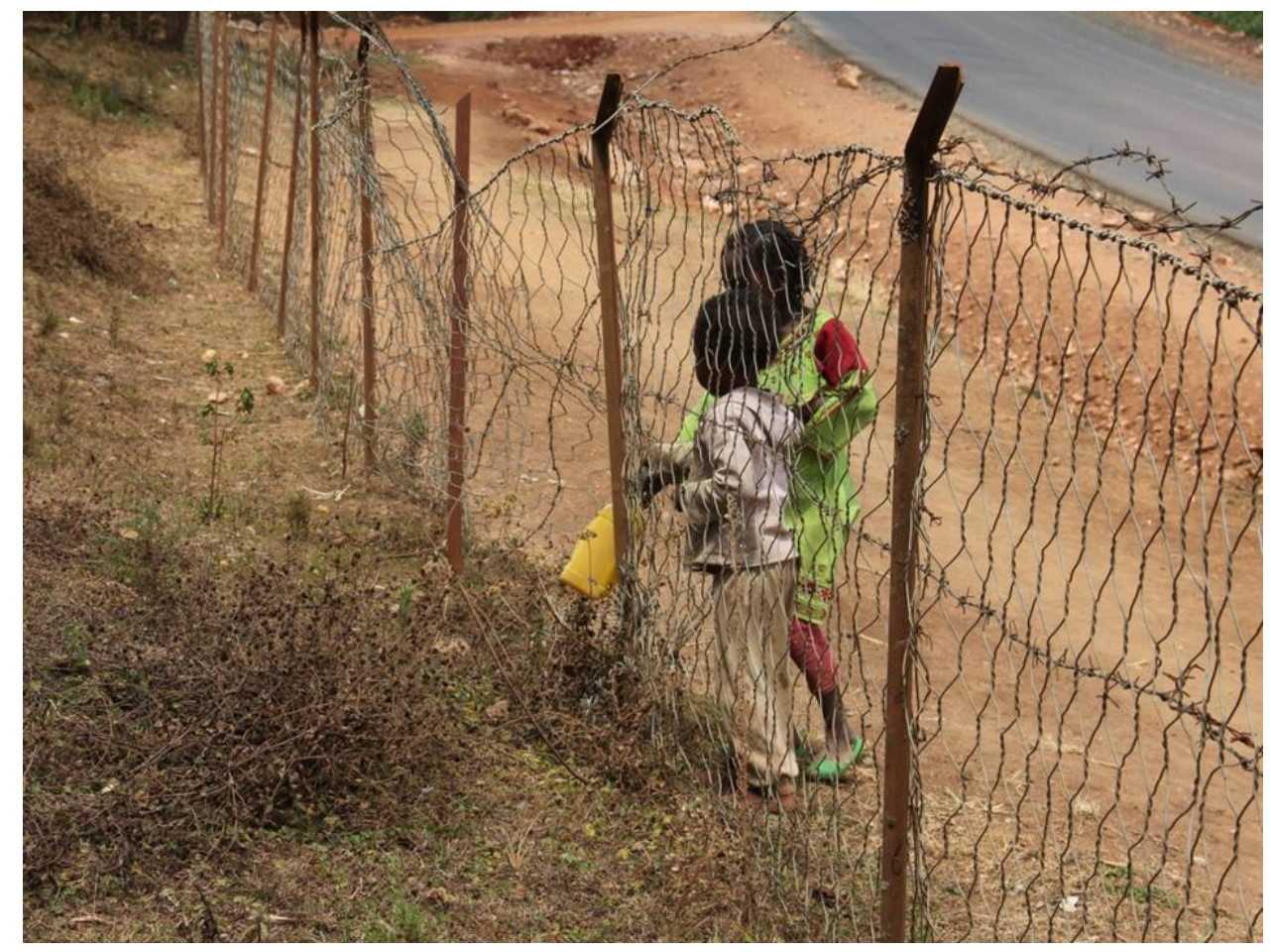

Figura 62. Niñas con recipiente para transportar agua fuera de la escuela durante el horario escolar (Fuente: Autor)

Otra de las situaciones que dificulta la escolarización de las chicas es el miedo a las violaciones, secuestros y actividad sexual antes del matrimonio. Este problema se acrecenta cuanto más lejos esté la escuela del hogar y cuando las 
chicas llegan a la pubertad. Es importante tener en cuenta que en la sociedad etíope todavía son comunes los tabúes sobre la actividad sexual antes del matrimonio, lo que provoca que el precio de la novia sea inferior. Los matrimonios por secuestro son forzados o pactados y tristemente jóvenes menores de edad son asaltadas sexualmente en los caminos solitarios hacia la escuela.

La última de estas tradiciones que tiene un impacto realmente negativo en la escolarización de las chicas es el matrimonio a temprana edad. Este fenómeno se produce por diversas causas como el miedo a las relaciones prematrimoniales, a los secuestros, a la necesidad de alianzas o a razones económicas como el cobro del precio de la novia o incluso, por el interés de la familia del novio de incorporar mano de obra extra a la familia. Esta situación de discriminación de las mujeres es más intensa en las zonas rurales, como ilustramos seguidamente. En las zonas urbanas la paridad de género en el número de alumnos matriculados en educación primaria es casi total con un $50,23 \%$ del alumnado masculino y un $49,77 \%$ femenino frente a las zonas rurales en las que un $52,74 \%$ es masculino frente a un $47,26 \%$ es femenino (MoE, 2013). Esta diferencia de un 2,51\% de alumnas menos matriculadas en zonas rurales respecto a las alumnas matriculadas en zonas urbanas puede parecer no muy grande pero traducida a números absolutos supone que en las zonas urbanas hay 14.871 más niños que niñas escolarizadas mientras que la diferencia entre niños y niñas matriculadas en las zonas rurales es de 733.359. Además, como hemos visto anteriormente, la calidad de la escolarización de chicos y chicas favorece a los primeros respecto a las segundas.

\subsubsection{Problemas económicos}

La educación en Etiopía enfrenta una serie de problemas y condicionantes económicos fundamentales divididos en dos vertientes; el primero se relaciona con la financiación del sistema educativo por el gobierno. El segundo y no menos importante es el impacto de la educación en la economía familiar. 


\section{Financiación del sistema educativo}

El sistema educativo etíope, sobre todo en educación primaria, presenta graves problemas financieros y de recursos monetarios y materiales que afectan a la educación de los alumnos. Anteriormente en este capítulo expusimos el tremendo esfuerzo económico que el gobierno etíope está realizando a la hora de financiar el sistema educativo. Sin embargo, como bien sabemos, no solo invertir más dinero es la clave para obtener una educación de calidad sino que además es importante analizar cómo se invierten estos recursos, y en esto precisamente radica el problema de la financiación de la educación en Etiopía.

En primer lugar es necesario destacar, como ya hicimos con anterioridad al hablar de la financiación de la educación, que pese al incremento anual del presupuesto en educación en Etiopía, el incremento del número de alumnos que acceden al sistema educativo año tras año ha provocado que los recursos disponibles por alumno hayan descendido (UNICEF, 2012). El segundo de estos problemas se relaciona con la descompensada distribución de estos recursos a lo largo de todo el sistema educativo. Como señalamos previamente, la inversión por alumnos en primaria es ínfima respecto a la inversión por alumno en educación universitaria. Es tal la descompensación de las inversiones por alumno que los recursos invertidos en un alumno de primaria suponen apenas el $3 \%$ de los recursos destinados a la educación de un alumno universitario.

Si examinamos los datos por ciclos resulta que el presupuesto disponible por alumno en el primer ciclo de primaria tan solo supone el $2,5 \%$ de la inversión por alumno universitario, mientras que los recursos invertidos por alumno de segundo ciclo de educación primaria representan el 4,45\% de lo invertido en la educación de un alumno universitario. Esto agrava aún más la situación ya que, como hemos venido señalando, una gran cantidad de los alumnos tan solo asiste al primer ciclo de educación primaria, en el mejor de los casos.

Si bien es lógico que haya una inversión superior por alumno de universidad que de primaria, la descompensación es tan excesiva que no deja lugar a dudas de 
que está mal distribuida. Conociendo además la idiosincrasia de la educación en Etiopía y el hecho de que una gran parte de los alumnos no logrará siquiera terminar la educación primaria, es evidente que sería necesario reforzar los recursos disponibles en este ciclo para ofrecerles al menos una educación de buena calidad durante los escasos años que muchos de ellos estarán escolarizados. Además si observamos cómo se invierte el dinero destinado a educación primaria, se hace patente otro de los grandes problemas de la financiación del sistema, como es el hecho de que la gran mayoría de los recursos de la educación primaria se destine directamente al pago de los salarios de los profesores:

"A worrying feature of the countries education budget is that the bulk of the expenditure is allocated for staff salaries" (UNICEF, 2012, pág. 63).

De hecho, en 2010 el 93\% de los recursos de educación primaria se destinó al pago de salarios de profesores (MoE y UNICEF, 2012); si analizamos los datos que nos ofrece UNICEF del curso 2006/2007, podemos apreciar cómo el 84\%de los recursos destinados a educación a nivel regional y el $94 \%$ de los mismos a nivel local se destinaron al pago de los salarios de los profesores. Estos datos dejan claro que los elevados niveles de gasto en salarios son una constante en la educación del país (UNICEF, 2012). Una de las razones que contribuyen a explicar esta situación es la necesidad de contratar cada vez más profesores para hacer frente a una creciente demanda de profesorado ante el aumento del número de alumnos, evitando así las ratios alumnos-profesor se disparen. El problema es que el porcentaje de recursos disponibles para otros gastos descendió de un 7\% en 2006 a un 4\% en 2010 (MoE y UNICEF, 2012). Ello demuestra que el problema no solo no está en vías de solucionarse sino que además se está agravando. Esto provoca que haya grandes problemas para cubrir las necesidades materiales y de infraestructuras en las escuelas del país. A su vez, ello hace que se resienta la calidad de la educación como veremos cuando analicemos los problemas y condicionantes materiales y estructurales.

Además, como la financiación de la educación por parte del Estado es inviable, se han establecido fuentes de financiación alternativas como la 
recaudación de dinero entre las familias para sufragar gastos como la asistencia de los profesores a las reuniones en las oficinas de educación o el trabajo de los alumnos en campos adyacentes a la escuela para sufragar, con la venta de la producción de esas explotaciones, parte de los gastos de la escuela. Por otra parte la distribución de los recursos económicos entre las distintas regiones del país es injusta; Hay regiones como la Amhara o el Tigray de donde provienen los altos cargos del gobierno federal que son claramente favorecidas a la hora de recibir recursos, tanto en educación como en otros aspectos que inciden directa e indirectamente en la educación, como son las infraestructuras o servicios. Recursos como las carreteras o los pozos de agua favorecen que los alumnos vayan a la escuela o que puedan llegar a ella mucho más rápido. En nuestra presencia en el país pudimos constatarlo cómo las carreteras del Tigray eran de una calidad muy superior a las de la Oromia.

\section{Impacto económico}

La segunda vertiente de los problemas y condicionantes económicos es la del impacto, positivo y negativo, que la educación primaria produce en las familias y la necesidad de éstas de contar con la mano de obra infantil. La economía familiar es posiblemente uno de los factores que afectan de una manera más determinante la escolarización de los alumnos en Etiopía, sobre todo en las familias con escasos recursos económicos:

"When we see poverty as a barrier for school enrolment and attendance, although school enrolment has increased dramatically in Ethiopia, there are more than three million children who are out of school" (MoE y UNICEF, 2012, pág. 50).

Para luchar contra ello el gobierno de Etiopía convirtió la educación primaria en totalmente gratuita; en los colegios privados pertenecientes a misiones y organizaciones no gubernamentales las tasas son meramente simbólicas y no cubren prácticamente nada de los costes reales de la educación que se imparte. Por ejemplo, en el colegio de los hermanos combonianos de Qillenso donde realizamos nuestro estudio, la tasa escolar era de 20 Birs por alumno y año, lo que al cambio en 
esos momentos suponía unos 80 céntimos de euro. Pese a la gratuidad de la educación primaria hay una serie de gastos indirectos derivados de la asistencia de los alumnos a la educación primaria que muchas familias no pueden costear:

"Even though Ethiopia has made primary education free, due to the indirect cost involved, children are deterged from being enrolled in primary school since their parents cannot afford to cover the indirect costs, which include the cost of purchasing uniforms, stationary, other learning materials, transport cost, etc." (MoE y UNICEF, 2012, pág. 50).

Además no solo los gastos directos e indirectos afectan a la economía familiar de manera negativa, sino también los ingresos que las familias dejan de percibir al perder la mano de obra que representan los niños para la unidad familiar:

"In Ethiopia, children as young as 7 years old are required to perform various task related to domestic and farm activities" (MOE y UNICEF 2012, pág. 51).

Este problema de la necesidad de la mano de obra infantil para el sostenimiento de la economía familiar es especialmente significativo en las zonas rurales del país, en las que recordemos que vive aproximadamente el $85 \%$ de la población del país:

"This is especially true of rural school children who have to work on farms before and after school and also during weekends" (MoE y UNICEF, 2012, pág. 51).

Muchas familias con varios hijos tienen que elegir quién podrá asistir a la escuela y quién tendrá que quedarse en casa para ayudar al sostenimiento de la familia. En nuestra experiencia de campo fuimos testigos del caso de un niño de unos 12 o 13 años que nunca había asistido a la escuela y trabajaba cuidando el ganado de la familia, mientras que sus hermanos sí asistían. También hemos sido testigos de varios casos en los que matriculaban a sus hijos de manera intermitente, turnando a los diferentes hijos e hijas entre la asistencia a la escuela y el trabajo para la familia. 
También hay que tener en cuenta el cálculo coste/beneficio que realizan las familias cuando se plantean enviar o no a sus hijos a la escuela. En muchas ocasiones las familias concluyen que el gasto inmediato que supone prescindir de la mano de obra infantil es superior al beneficio futuro o bien, es simplemente inasumible. Además tristemente en nuestra experiencia de campo fuimos testigos de que en zonas rurales como en las que estuvimos realizando nuestra investigación muy pocos alumnos lograban alcanzar los estudios superiores no solo debido a la falta de recursos económicos de las familias sino también por la falta de oportunidades futuras. Así, dado que la gran mayoría de los niños y niñas iban a continuar con la vida de agricultores/ganaderos de sus padres, invertir en la educación de los hijos más allá de unos estudios básicos para muchas familias constituía un desperdicio de recursos y tiempo. Esta misma situación ha sido denunciada por Unicef y el Ministerio de Educación en uno de sus informes:

"Parents who do not see the immiedate and long-term benefits of sending their children to school because they expect poor quality education and/or becasue children do not meet the social and economic success marker in the community are unlikely to invest on education" (MoE y UNICEF, 2012, pág. 48).

Finalmente, es preciso señalar que la necesidad del trabajo infantil no solo afecta a las posibilidades de escolarización, sino que además provoca que los niños no puedan realizar las tareas y ejercicios que les mandan sus profesores o estudiar, con las consecuencias académicas negativas que ello supone en cuanto a favorecimiento del fracaso escolar y por tanto al abandono de los estudios.

\subsubsection{Problemas estructurales}

La educación primaria de Etiopía presenta una serie de problemas estructurales que hemos detectado durante nuestra experiencia de campo y que hemos corroborado al estudiar los distintos informes sobre la educación tanto del Ministerio de Educación de Etiopía (MoE, 2013) como de distintos organismos internacionales (UNICEF, 2012). Para facilitar su exposición, los hemos agrupado en once factores. 


\section{Distribución de las escuelas}

El primero de estos problemas estructurales se relaciona con la dispar distribución ciudad/campo de las escuelas tanto de primaria como de pre-primaria y secundaria, en un país eminentemente rural como Etiopía donde los alumnos de zonas rurales suponen la aplastante mayoría:

"A comparison of urban and rural enrolment indicates that about $81 \%$ of primary learners are in rural areas; only the rest are in urban areas" (MoE, 2013 pág. 29).

Pese a ello, tanto las escuelas de pre-primaria (UNICEF, 2012) como las de educación secundaria (MoE, 2013) se concentran en los núcleos urbanos del país por lo que la gran mayoría de los niños tienen muy difícil el acceso tanto a la educación de pre-primaria como a la educación secundaria. Ya expusimos anteriormente cómo el acceso a la educación pre-primaria era enormemente beneficioso no solo para el desempeño académico de los alumnos en educación primaria sino también para la mejora de las tasas de matriculación bruta y neta en primaria.

Además en las zonas rurales, debido al patrón de poblamiento disperso presente en muchas zonas, la escolarización de los niños y niñas es aún más dificultosa ya que los alumnos tienen que caminar enormes distancias hasta las escuelas con la pérdida de tiempo que supone. Ello a su vez se traduce en un mayor impacto económico negativo de la educación en la economía familiar y en la exposición de los niños y niñas a peligros como los secuestros y las violaciones en su camino al colegio.

Por otra parte la necesidad de que los alumnos se trasladen a un núcleo urbano para continuar la educación secundaria dificulta de una manera muy marcada las posibilidades de que los chicos y chicas de zonas rurales continúen sus estudios, no solo por el impacto económico que supone para las familias la necesidad de alquilar una habitación en la ciudad y suplir de comida y dinero a los hijos e hijas sino también por la pérdida de fuerza de trabajo que aportan en el día a 
día sus hijos, una vez terminan las clases. En nuestra experiencia de campo fuimos testigos de cómo esta necesidad de trasladarse a una ciudad era especialmente problemática en el caso de las chicas ya que las familias eran especialmente reticentes a ello por motivos culturales como el miedo a las relaciones sexuales prematrimoniales o a posibles embarazos.

Como nota final a este apartado es importante destacar que durante nuestra estancia en el país no solo fuimos testigos de la desigual distribución entre el campo y la ciudad de las escuelas de los distintos ciclos educativos, sino que además, dentro del propio ciclo de primaria, las escuelas que ofertaban el segundo ciclo de primaria eran escasas en las zonas rurales, cubriendo la gran mayoría de las escuelas tan solo el primer ciclo de primaria.

\section{Escuelas compartidas}

Uno de los problemas más importantes y que se encuentra a caballo entre los problemas materiales y los estructurales es el abuso que se hace del shift system o la utilización de las escuelas hasta para tres turnos:

"Shifts are a second or third full school activity, in the same school building, at a different time of the day. Because of limited school buildings, some schools operate a Morning and Afternoon Shift as well as an Evening shift" (MoE, 2013, pág. 319).

Esto no solo provoca una sobreutilización de los recursos como pizarras, pupitres u otros materiales didácticos con su consiguiente desgaste acelerado sino que además provoca que las jornadas escolares sean más cortas, con la pérdida de tiempo dedicado a la enseñanza-aprendizaje y el impacto negativo que esto supone para la calidad de la educación de los alumnos:

"A Full Day School provides 5.25 hours of instruction per day, in contrast with the 4 hours per day in a Shift school" (MoE, 2013, pág. 318). 


\section{Problemas materiales}

La falta misma de escuelas pese a su construcción continuada es un problema estructural del sistema educativo etíope. Se necesita un número mayor de centros para reducir las tasas de alumnos por sección y el número de escuelas que se emplean en distintos turnos (MoE, 2013). Por otra parte, toda escuela necesita tener unas infraestructuras mínimas para garantizar su funcionamiento y calidad. Además el estado de estas instalaciones afecta de manera directa a la escolarización de los niños:

"Insufficient and poor school infrastructure and limited classroom space affect to schooling because parents do not send their children in such schools even if they are poor" (MoE y UNICEF, 2012, pág. 56).

En Etiopía la situación de las escuelas respecto a infraestructuras y servicios mínimos, como expusimos previamente, no es especialmente bueno y las escuelas de primaria presentan deficiencias muy notables. Uno de sus principales problemas es la falta de agua en las escuelas de primaria:

"The availability of drinking water also has an impact $n$ children's school enrolment as well as attendance because water is essential at any time and at any place for hygiene as well as for drinking" (MoE y UNICEF, 2012, pág. 59).

Tan solo el $41 \%$ de las escuelas de primaria tiene acceso al menos a una fuente de agua en el recinto (MoE, 2012). Esto tiene un efecto muy negativo para el proceso de la enseñanza-aprendizaje. Los alumnos más pequeños tienen dificultades para aguantar una jornada escolar sin beber y muchos salen del recinto en busca de agua o la traen cargando desde casa.

Nosotros mismos fuimos testigos de la falta de agua en las escuelas y de sus consecuencias. Aunque en la zona donde estábamos no era un problema especialmente acuciante debido a la altura y climatología de la zona en la que abundaban las fuentes de agua, en otras zonas del país mucho más cálidas y secas esta falta de agua en las escuelas puede llegar a ser peligroso por las altas temperaturas que se alcanzan. 
La falta de electricidad en las escuelas es otro de los problemas más importantes, ya que esta se estima que solo llega al 5\% de los centros educativos del país (UNICEF y MOE, 2012). Esta falta de electricidad imposibilita la utilización de equipos electrónicos tanto en las aulas como en la administración del centro con el consiguiente impacto en la calidad de la educación. Además cuando la luz natural es reducida, es difícil cuando no imposible, dar clase.

La ausencia o infrautilización de las bibliotecas, laboratorios y centros pedagógicos es el tercer gran problema de las infraestructuras educativas de primaria de Etiopía. En nuestra experiencia de campo pudimos observar cómo en muchas ocasiones se construyen infraestructuras e incluso se dotan de materiales que luego no se utilizan. En otros casos no se tienen recursos para mantener su funcionamiento ya que, por ejemplo, es casi imposible de conseguir recambios necesarios para reparar material de laboratorio.

\section{Ratios elevadas y matrículas tardías}

De entre los problemas que hemos venido señalando a lo largo de este capítulo destacan las elevadas tasas de alumnos por sección y la elevada ratio de alumnos por profesor. Estos dos elementos afectan de manera negativa a la calidad de la enseñanza ya que provocan que los profesores se vean sobrecargados de alumnos a los que atender.

En esta línea, otro de los problemas que acucian el desarrollo del proceso de enseñanza-aprendizaje y para el funcionamiento normal de las propias escuelas es la tendencia que existe en el país a matricular a los niños y niñas tardíamente superando la edad oficial para hacerlo. Además, una vez que han accedido al sistema educativo, muchos niños son matriculados intermitentemente o por turnos entre los distintos hermanos. Esta situación tiende a provocar una saturación de alumnos en algunos cursos, haciendo que las clases tengan alumnos con ritmos de aprendizaje muy diferentes por sus distintas edades. Sobre todo hace que los niños y niñas tiendan a abandonar el sistema educativo antes de finalizar siquiera la 
primaria al alcanzar una edad en la que pueden y deben trabajar o, en el caso de las chicas, casarse antes de haber terminado incluso este ciclo educativo.

\section{Organización en ciclos escolares}

Otra dificultad que hemos vivido se relaciona con las marcadas diferencias entre los distintos ciclos escolares que rompen el sentido de proceso continuo de la educación. Esta diferencia la hemos percibido especialmente al pasar del primer al segundo ciclo ciclo de primaria, ya que funcionan como dos ciclos educativos totalmente distintos y no dos partes conectadas del mismo. De esta manera la educación primaria queda dividida en dos lo que, unido a otras características como la localización de los distintos tipos de escuelas o la promoción automática, hace que una gran cantidad de alumnos abandonen la educación primaria durante el cambio de ciclo y no se muestren interesados en continuar la escolarización una vez superado el cuarto grado.

\section{Promoción automática y exámenes}

Relacionado con el problema anterior está la promoción automática de los alumnos en los primeros cursos de primaria hasta quinto grado, independientemente de su desempeño y de los conocimientos que hayan adquirido. Esto ha provocado una elevada tasa de repetición en quinto curso y un gran abandono escolar, pues los alumnos llegan con un nivel muy inferior al que deberían haber adquirido teóricamente a un curso donde no hay promoción automática. Para muchos este moemento marca el final de su andadura dentro del sistema educativo.

En Etiopía hay además una enorme diferencia entre el nivel de conocimientos que teóricamente los alumnos han de adquirir durante su escolarización y el que realmente logran alcanzar. En nuestra opinión, esto se debe entre otras razones a la promoción automática, a la falta de medios y recursos educativos adecuados o a la poca preparación de los profesores. Todo ello tiene repercusiones muy negativas y favorece el abandono escolar o la poca valoración de la educación por parte de los padres que no ven resultados reales en sus hijos. 
Estrechamente unido a los dos aspectos anteriores, y como consecuencia de la organización de los ciclos escolares, está el problema del examen nacional que hay al final del octavo grado. La superación de dicho examen es requisito para obtener el certificado de educación primaria. Como este examen responde al nivel teórico que los alumnos debieran haber conseguido, gran parte del alumnado es incapaz de superarlo o lo suspenda varias veces. Ello les obliga a repetir curso, lo hace que en muchas ocasiones abandonen el sistema educativo sin haber obtenido el diploma de primaria.

\section{Altas tasas de abandono escolar y de repetición}

Un claro ejemplo de problema estructural y que es a su vez consecuencia de otros factores señalados a lo largo de esta sección, es la alta tasa de abandono escolar que existe en el país. Según las estadísticas presentadas previamente, la escolarización completa en el ciclo de primaria se encuentra todavía en unos niveles muy bajos. Además este problema hace que los niños y niñas que han abandonado la escuela antes de completar el ciclo de primaria no hayan adquirido las competencias básicas que posteriormente necesitarán para ser independientes:

"Con frecuencia, estos niños no han adquirido las competencias básicas de lectura, escritura o utilización de números (numeracy), hecho que limita sus capacidades y oportunidades en la vida" (UNESCO, 2012, pág. 32).

El abandono escolar prematuro afecta además de manera desigual a las distintas capas de la sociedad, siendo los niños de familias más pobres quienes más lo sufren, niños que por otra parte serían los más beneficiados al recibir la educación:

"Sin embargo, los estudiantes provenientes de familias de escasos recursos que más podrían beneficiarse de este derecho son los que, probablemente, nunca lo reciban debido a una salida prematura" (UNESCO, 2012, pág. 32).

Recientemente, un estudio llevado a cabo en Etiopía pone de manifiesto el impacto que la educación de los hermanos tiene en la educación de los otros (Lindskog, 2013). Dicho estudio destaca la existencia de efectos negativos del 
acceso a hermanos más pequeños en la asistencia a la escuela de las niñas. También el estudio pone de manifiesto que a la larga se aprecian efectos positivos en cuanto a la asistencia a la escuela, de aquellos niños cuyos hermanos han terminado la escuela, probablemente debido a un cambio en las percepciones sobre los beneficios de la educación, o bien debido al hecho de que los hermanos mayores que han recibido educación pueden contribuir económicamente en la familia y aumentar por tanto las posibilidades de que sus hermanos puedan también asistir. El mencionado estudio pone también de manifiesto que los hermanos mayores suelen recibir menos educación que sus otros hermanos, probablemente porque se da por hecho que estos hijos deben hacerse cargo de la granja de la familia, de modo que las habilidades agrícolas son más apreciadas (Lindskog, 2013).

Otro problema relacionado es la repetición. Así, en Etiopía en la educación primaria se producen altas tasas de repetición en algunos puntos clave que, como hemos visto anteriormente, son causadas por otros problemas estructurales de la educación primaria en el país. Estas altas tasas de repetición tienen varias consecuencias negativas como son favorecer el abandono escolar o el derroche de los ya de por sí escasos recursos económicos existentes. Además las tasas de repetición afectan a la Esperanza de vida escolar de los alumnos, provocando que por ejemplo en el África subsahariana, de los 7,9 años de media que un alumno está matriculado en educación primaria 0,7 años los dediquen a repetir curso (UNESCO, 2012).

\section{Escasez o inadecuación de los libros de texto y otros materiales didácticos}

Los libros de texto en Etiopía son en muchas ocasiones suministrados y financiados por organizaciones internacionales o por gobiernos extranjeros como parte de sus proyectos de ayuda al desarrollo. Por esta razón, en muchas ocasiones no se adaptan a la idiosincrasia ni a la realidad Etíope pues parecen diseñados para responder a los estándares internacionales de lo que constituye una "buena educación", más que para hacer frente a la realidad del país. De ello se desprende que el nivel de los contenidos de los libros está muy por encima del nivel real que 
los alumnos logran alcanzar acrecentándose curso a curso la brecha entre el nivel de los libros de texto y el nivel real de los alumnos.

Otro ejemplo de la inadecuación de los libros lo vivimos cuando, impartiendo clases de inglés a los niños de la escuela de Qillenso nos encontramos con que el libro hacía referencias a elementos como piscinas u otras instalaciones y realidades de la vida cotidiana occidental que raramente son conocidos por un niño de Etiopía.

Pero es que no solo los libros de texto son poco adecuados a la realidad etíope, sino que además su número es escaso con los problemas que ello acarrea:

"An adequate supply of textbooks and other teaching and learning materials is a pre-requisite for effective teaching and learning processes; however, children at primary schools are in short of these books" (MoE y UNICEF, 2012, pág. $60)$.

La presencia de libros y materiales didácticos no solo es beneficioso para los alumnos, sino que su efecto positivo se extiende a los profesores a quienes ayuda a mejorar su formación (MoE y UNICEF, 2012). La necesidad de que cada alumno tenga su propio libro de texto es clara, pero como denuncia el informe de UNICEF en colaboración con el Ministerio de Educación de Etiopía, en 2010 en las escuelas de primaria del país había un libro por cada 1,5 alumnos solamente (UNICEF y MoE, 2012).

Además este informe (MoE y UNICEF, 2012) mencionaba que la falta de libros y la presión que los profesores ejercían a los alumnos sin libro para que lo consiguieran era una de las causas de abandono escolar en el país. En el caso de quienes no abandonaran la escuela, los resultados de los alumnos sin libro de texto eran más bajos que los de sus compañeros con dicho material.

Nosotros mismos pudimos comprobar cómo la falta de libros de texto era un problema real de la educación primaria. A principios de curso hubo muchos problemas para conseguir los libros necesarios para un alumno. Se tuvieron que realizar varias visitas a la oficina del distrito para conseguir los libros necesarios. Ya 
estaba avanzado en curso cuando se obtuvieron todos los libros y la falta de los mismos había ocasionado varias peleas entre los alumnos.

Además la falta de libros está tan normalizada que ante la insistencia de la dirección de la escuela para que se facilitaran desde la oficina de educación los libros necesarios, el propio supervisor de las escuelas de la zona sugería que compráramos los libros de segunda mano en algún sitio de la ciudad.

\section{Utilización excesiva del inglés en la educación}

En un intento por aparentar un nivel educativo superior al existente ante las organizaciones e informes internacionales, en las escuelas de primaria y sobre todo de secundaria se produce una sobreutilización del inglés. En Etiopía, a partir de séptimo curso de primaria el inglés se convierte en la lengua vehicular de la educación y todos los conocimientos han de impartirse en esa lengua excepto el amhárico y la lengua propia de cada región.

Este hecho, que en un principio pudiera parecer una buena idea para conseguir una sociedad multilingüe que domine tanto sus idiomas nativos como una lengua internacional de la importancia del inglés, dado el bajo conocimiento de este idioma que manejan los alumnos se convierte en una barrera para alcanzar conocimientos más que en una herramienta y una ventaja.

\section{Profesorado poco preparado}

Durante nuestra estancia en el país pudimos apreciar cómo muchos profesores estaban poco preparados para ejercer su trabajo, tanto en métodos pedagógicos como en conocimientos de las materias que debían enseñar. Era muy común ver a profesores de inglés que no conocían realmente ese idioma y que no comprendían cuando uno intentaba comunicarse con ellos en este idioma.

La escasa preparación afectaba también a las metodologías docentes. Así, era muy común verles utilizar el castigo físico antes comportamientos inadecuados. Igualmente habitual era la utilización de métodos pedagógicos basados en el 
aprendizaje por repetición y memorización en vez de la promoción de aprendizajes significativos.

En otras ocasiones, su compromiso con el rol de maestros era cuestionable. Por ejemplo, era común que utilizaran a los alumnos como mano de obra para asuntos personales propios de los profesores ajenos a la actividad educativa del centro. También lo era que los profesores llegaran tarde a clase o que no impartieran realmente las clases y se limitaran a esperar a cumplir el horario, o que dejaran a los alumnos solos en clase mientras se iban a hablar con otros docentes.

A todo lo expuestos previamente se ha de añadir el hecho de que debido a la necesidad de dar cabida a las distintas etnias del país en el sistema educativo, en ocasiones el factor étnico es más importante que la preparación real del maestro a la hora de contratarlo:

"A teacher in an Awassa school, for instance, argued that the regional government was too concerned with a balanced ethnic composition of the regional administration, so ethnicity became more important than skill when people were employed"(Aalen , 2002, pág. 70).

\section{Utilización política de la educación}

Un grave problema para que las distintas etnias del país sientan que la educación reglada es algo que les pertenece y que no es ajeno a su cultura es la utilización de la educación como una herramienta para la amharización del país que se ha venido produciendo y se produce en la actualidad en Etiopía. Un ejemplo claro de ello pudimos observarlo en los libros de texto de historia en los que la cultura amhara era la clara protagonista, identificándose de manera implícita lo amhara con lo etíope.

Por otra parte aunque legalmente Etiopía no tiene idioma oficial, el amhara es impartido en los colegios como tal, generando rechazo en algunos alumnos, como tuvimos ocasión de comprobar entre los Oromo de los pueblos de alrededor de Ziway que se negaban a estudiar en amhárico. 
Estrechamente relacionado con el proceso de amharización del país está la utilización con fines políticos de la educación por parte del gobierno federal y de los partidos políticos regionales afines a él, que son en realidad los que gobiernan ante la inexistencia de oposición oficial en el país. Esta realidad no es nueva ni originaria de Etiopía. Como señalan Montes y Martínez (2012), el sistema educativo en muchas ocasiones es utilizado con fines ajenos a los que supuestamente debería perseguir:

"[...] es preciso reconocer la evidencia del control social, económico y político ejercido sobre el sistema educativo por parte del Estado, de forma que la apropiación de ambos por parte de diferentes clases, grupos o estratos sociales hegemónicos relativiza en la práctica social la declaración de buenas intenciones que los programas, planes o reformas educativas rezuman" (Montes y Martínez, 2012, pág. 340).

En nuestra experiencia de campo fuimos testigos de situaciones de adoctrinamiento político de los niños e incluso de los maestros. Ejemplo de ello eran las reuniones para exaltar al recientemente fallecido primer ministro o la obligatoriedad de comprar biografías alabando al mismo. En una ocasión presenciamos cómo el profesorado fue obligado a asistir a unas jornadas de una semana en las que se les informó de todo lo que había hecho el antiguo primer ministro por el país y todo lo que iba a seguir haciendo el gobierno al respecto.

Unido a esto se encuentra el problema de la contratación como profesorado y la promoción dentro de la administración y los colegios de personas militantes o cercanas a los partidos oficialistas más allá de sus capacidades como docentes y trabajadores. 


\section{CAPÍTULO 4. ANÁLISIS DE LA SITUACIÓN EDUCATIVA EN LA ESCUELA PRIMARIA DE QILLENSO. UNA ETNOGRAFÍA}

\subsection{Presentación}

Las grandes estadísticas educativas planteadas en los informes que organizaciones internacionales como la ONU con sus distintas secciones o los propios gobiernos a través de sus ministerios de educación exponen al mundo sirven en muchas ocasiones para "señalar o tapar las vergüenzas". Más allá de todo ello están las realidades del día a día a nivel local.

Como señala Clifford Geertz en su obra "La Interpretación de las culturas" (2013) existe una dicotomía entre lo local y lo general en las investigaciones antropológicas. Como este autor indica acertadamente, y pese a que muchas investigaciones así lo pretendan, un estudio local no debe extrapolarse y convertirse en una imagen de lo general; la escuela de una pequeña aldea en las montañas del sur del país jamás podrá ser una representación de toda la realidad educativa de Etiopía, pero sí nos ayudará a comprender cómo los grandes datos y estadísticas se plasman finalmente en un recóndito lugar del país.

Bajo nuestro punto de vista, y como hemos pretendido reflejar en la presente Tesis Doctoral, tanto las grandes estadísticas generales como las realidades etnográficas más locales constituyen las caras de una misma moneda. Por tanto, es muy interesante conocer ambas para tener una imagen tanto de lo global como de lo local y, de esta manera, comprender lo que millones de niños etíopes de zonas rurales encuentran día a día en sus escuelas.

Así pues, en este capítulo y en el siguiente vamos a centrarnos en la realidad más local del día a día de la escuela de Qillenso y de sus alumnos. De esta manera veremos cómo los datos a nivel nacional y regional expuestos en los capítulos precedentes tienen su reflejo en la pequeña escuela de primaria de Qillenso. 
Previamente, realizaremos unas consideraciones para contextualizar el estudio dentro de la Antropología Educativa.

\subsection{Antropología Educativa: Consideraciones PREVIAS}

Antes de adentrarnos más en los aspectos empíricos de esta investigación consideramos oportuno llevar a cabo, sin ánimo de ser exhaustivos, una pequeña reflexión sobre la Antropología de la Educación ya que esta disciplina es uno de los marcos teóricos en el que se fundamenta la presente Tesis.

En primer lugar, según afirma Carmen Ortiz (2003), una idea paradigmática en el campo de la antropología de la educación es el interés por el estudio comparativo de otras "culturas" para enseñarnos así más sobre la nuestra. De este modo, la antropología de la educación al igual que la antropología en general, se interesa por el estudio de la otredad -o la diferencia social y cultural- en cualquier ámbito de dominación y espacio temporal en que ésta se produzca. Se ocupa tanto de nosotros como de otros y emplea para su estudio herramientas y análisis propios que tienen que ver con la observación de conductas grupales y aprendizajes sociales y culturales con un nivel de detalle relativamente elevado (Ortiz, 2003).

Esta definición preliminar nos sirve para comenzar por señalar el diverso origen de la Antropología de la Educación y las diversas ramas en la que esta se divide:

"La Antropología de la Educación, en cuanto que antropológica puede aparecer tener variedad como la Antropología misma y así podemos advertir una Antropología de la Educación que arranca de la Antropología biológica, una Antropología de la Educación que se fundamenta en la Antropología sociocultural o una Antropología de la Educación que sigue la Antropología filosófica" (Bernal, 2006, pag,155). 
La diversidad de orígenes previamente señalada hace que cada una de estas ramas tenga sus propias características y contribuya de una manera determinada al saber total de la Antropología de la Educación:

"Eso supone tener en cuenta el proceso de maduración, desarrollo y crecimiento -temas mas elaborados gracias a los trabajos de la antropología biológica-; la relación educativa, la comunicación y el uso del lenguaje; la autorrealización y la libertad -temáticas que se impulsan desde diferentes corrientes filosóficas contemporáneas, entre las que sobresale el existencialismo-, así como comprender que tanto la formación del ser humano, como la relación educativa que impulsa ese proceso, se producen en un tiempo, en un espacio y en una cultura." (Bernal, 2006, pág., 131)

En el desarrollo de la Antropología de la Educación es importante destacar el hecho de que en el mundo anglosajón la Antropología de la Educación tiene un largo recorrido sentando sus bases en la Antropología Cultural:

"Tanto en Estados Unidos como en el Reino Unido, lo que empezó como etnografías infantiles y estudios de los efectos de la cultura en los niños, se fue aplicando poco a poco a la solución de los problemas educativos, especialmente los que resultaban del contacto entre diferentes culturas" (Perez, 1998, pág., 207)

Mientras tanto en España los primeros estudios sobre antropología de la educación empezaron a surgir a mediados de los años 70 del Siglo XX pero no fue hasta la década de los 90 del mismo siglo que empezó a despegar la producción bibliográfica (Bernal, 2008; Jociles, 2007a, 2007b; Jociles Rubio, 2007; Latapí, 2005; Ortiz, 2003; Pallma y Sinisi, 2004):

"No obstante, tal como se ha visto, a partir de los años noventa experimenta un importante desarrollo que lleva a que se presente una media de una tesis doctoral por año en las universidades españolas y a que, en general, las obras socioantropológicas acerca de la educación o de la etnografía escolar se multipliquen de manera considerable respecto a las dos décadas anteriores..."(Jociles, 2007a, pág., 89) 
Esto ha llevado a que, tras el incremento de la producción de investigaciones y trabajos aplicados, se hayan conformado en España grupos de antropólogos trabajando en distintos puntos de interés dentro de la antropología de la educación. En nuestro país son además tratados con especial interés los temas relacionados con forma adecuada de llevar a cabo etnografías educativas o de escuela y los desafíos surgidos con la llegada de inmigrantes al sistema educativo español (Jociles, 2007a, 2007b).

Este foco sobre la forma de llevar a cabo etnografías de la escuela ha provocado que se hayan publicado en España excelentes investigaciones sobre el tema, destacando los trabajos de Velasco y Díaz de Rada (2009) los cuales hemos seguido a la hora de diseñar nuestra investigación. Respecto a la corriente de la Antropología de la educación relacionada con la inmigración y la educación en ambientes multiculturales, nos han servido de gran ayuda los análisis de Dolores Juliano (1993) aunque centradas en el contexto de la educación occidental. Y ello porque la realidad multiétnica y multilingüística de la educación en Etiopía hace que el sistema educativo etíope y sus alumnos se enfrenten a situaciones análogas.

En el campo de la educación multicultural y sus desafíos para los sistemas educativos caben destacar las ya tradicionales aportaciones de Montes, Pulido y García (1997). Éstas nos han resultado muy útiles a la hora de abordar la realidad del sistema educativo de Etiopía, el cual tiene que dar respuesta a una serie de grupos étnicos con diferentes culturas a los que, por desgracia y como hemos podido apreciar, no trata de la igual manera.

También son muy interesante las aportaciones que al campo de la educación en ambientes multiculturales de la antropología latinoamericana. Ejemplo de ello son las publicaciones de Ossola (2013), Gomes (2006) o Ibáñez, Díaz, Druker y Rodríguez (2012).

Volviendo a la aplicación práctica del marco teórico al presente caso, debido a las características de esta investigación, a los objetivos que pretendemos alcanzar y a nuestra propia formación previa, hemos seguido la rama sociocultural de la 
Antropología de la Educación. Esta aproximación es más cercana al entendimiento de una antropología de la educación de carácter "cultural" (Juliano, 1991). En este sentido, nuestro estudio, al igual que sucede con un gran número de estudios realizados en España -y, en general, en los países occidentales-, la etnografía educativa es más bien siendo una etnografía escolar del mismo modo que la antropología de la educación es más bien una antropología de la escuela (Jociles, 2007b). Ello no ha supuesto sin embargo rechazar las aportaciones de las ramas filosófica y biológica, pues éstas que han ayudado a completar y mejorar la investigación, de igual manera que nos hemos servido de otras disciplinas ajenas a la Antropología de la Educación. Esta postura es además, en palabras de Bernal (2008) bastante común cuando se enseña antropología de la educación:

"subrayándose la metodología de investigación; la relación de la antropología con otras ciencias afines; los conceptos y categorías nucleares. En este conjunto de temas descuella la etnografía aplicada a contextos educativos, especialmente escolares. Entre las categorías centrales, son dos las que alcanzan un mayor protagonismo: la educabilidad y la cultura -el proceso de adquisición y transmisión de la cultura" (Bernal, 2008, pág., 130).

Por ello, la metodología que hemos adoptado principalmente para llevar a cabo nuestra investigación ha sido la etnografía. Ello a su vez coincide con la afirmación de Bernal (2006), quien señala que es el método de recogida clásico del enfoque sociocultural:

“La metodología adoptada en este enfoque es la etnografía -denominación tanto del método de recogida y análisis de los datos socioculturales como del informe descriptivo de un sistema sociocultural o de una dimensión de un sistema concreto" (Bernal, 2006, pág., 158)

Esta aplicación de la etnografía dentro del marco de la escuela la hemos llevado a cabo como dijimos con anterioridad siguiendo uno de los modelos propuestos por Velasco y Díaz de Rada en su obra "La lógica de la investigación etnográfica: un modelo del trabajo para etnógrafos de escuela" (Velasco y Díaz de Rada, 2009). Para nosotros también fue importante la lectura del libro "Lecturas de 
antropología para educadores: El ámbito de la antropología de la educación y de la etnografía escolar" (Díaz de Rada , Velasco , y García, 1993) para ayudarnos a tener una visión más precisa de la antropología de la educación. Además, según señala Bernal (2008), la cultura es el fenómeno que aglutina la atención de gran parte de las investigaciones actuales en antropología de la educación, lo que coincide con nuestro interés investigador.

A la hora de llevar a cabo nuestro estudio y la forma de enfocar el mismo tuvimos muy en cuenta las teorías de Bourdieu y Passeron (2001) sobre la reproducción del poder y la violencia simbólica en la escuela ya que consideramos que eran fundamentales para comprender la realidad educativa etíope. Consideramos que esta vigencia de las ideas de Bourdieu y Passeron en el sistema educativo de Etiopía esta fundamentada en las relaciones de poder y dominación que se dan dentro del país. Creemos que el modelo de dominación y reproducción del poder que estos autores demostraron en el caso de la escuela francesa es completamente aplicable al caso de Etiopía, sustituyendo la dominación entre las distintas clases sociales por las relaciones de dominación y violencia simbólica, y en muchas ocasiones real, entre las distintas etnias de Etiopía.

Una vez expuesto el marco teórico de la Antropología de la Educación en el que hemos enmarcado nuestra investigación es el momento de pasar a analizar los métodos y técnicas que hemos usado para obtener la información y poder responder a las hipótesis y los objetivos que nos hemos planteado.

\subsection{OBJETIVOS}

Con el presente estudio pretendemos profundizar en el funcionamiento de la escuela de los Padres Combonianos de Qillenso mediante la elaboración de una etnografía sobre la misma. Tratamos así de generar un conocimiento experto que permita conocer los puntos fuertes y débiles de esta institución educativa. Este objetivo general se traduce en los siguientes objetivos específicos: 
1) Realizar una etnografía de la escuela de Qillenso, describiendo y analizando tanto su situación geográfica, instalaciones y principales actores involucrados en su funcionamiento.

2) Conocer el grado en que los datos de la escuela coinciden con las estadísticas regionales y nacionales.

3) Determinar semejanzas y diferencias en cuanto a los problemas y puntos fuertes detectados.

4) Determinar puntos fuertes que puedan servir de apoyo para actuaciones que ayuden a mejorar su funcionamiento.

5) Determinar el grado en que la educación altera o modifica la cultura Gujii.

6) Identificar el tipo de modelo educativo que se sigue o promueve en la escuela de Qillenso

\subsection{MÉTOdO}

\subsubsection{Diseño del estudio}

A la hora de diseñar este estudio etnográfico sobre la escuela de Qillenso tuvimos en cuenta que, pese a nuestra experiencia previa en el sector de la educación en Etiopía, al ir a encontrarnos con una zona para nosotros desconocida del país y cambiar de entorno sociocultural, geográfico e incluso climático no debíamos dar por sentado nada y debíamos diseñar un estudio concienzudo, no dejando aspectos al azar y no dejándonos llevar por las ideas preconcebidas que pudiéramos tener. Pretendíamos así evitar condicionar el estudio y provocar que los resultados obtenidos estuvieran sesgados y no representaran la realidad de la escuela de Qillenso, o en palabras de Anastasia Téllez:

"El antropólogo, si bien puede establecer contactos anteriores y llevar a cabo parte de observación exploratoria en el terreno, debe diseñar un borrador de proyecto de investigación en el que establece las preguntas a modo de hipótesis que guiarán su estudio" (Téllez, 2007, pág. 74). 
Para diseñar el estudio de la institución escolar hemos seguido el modelo de laberinto propuesto por Wallance (en Velasco y Díaz de Rada, 2009) que nos permite conocer el quién, el cómo, el qué y el por qué de los distintos aspectos de la escuela. Tenemos además en cuenta los elementos externos que proporcionan el marco jurídico, político, geográfico, cultural y la forma en el que los distintos miembros de la comunidad educativa se acercan a la escuela, hacen uso de ella y se relacionan entre sí (véase Figura 63).

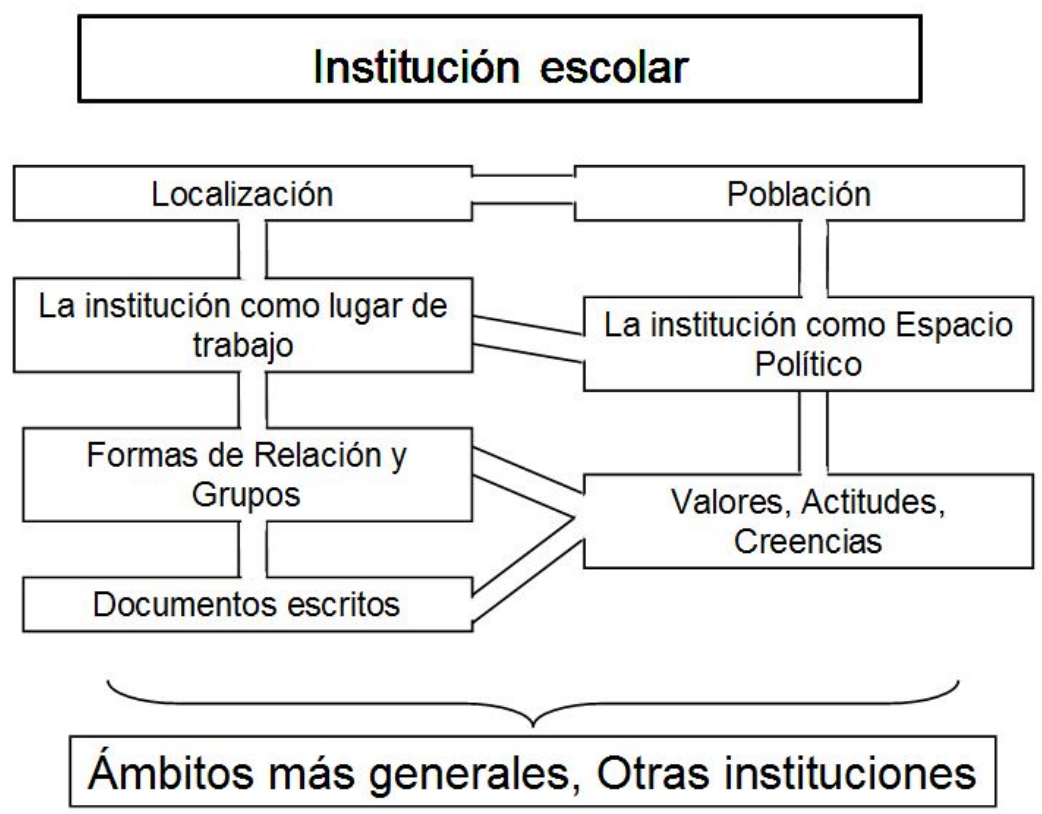

Figura 63. Esquema diseño etnografía escuela de Qillenso

(Fuente: Elaboración propia. Datos: Velasco y Díaz de Rada 2009)

Para poder llevar a cabo este estudio etnográfico nos planteamos cuatro etapas bien definidas. Las tres primeras fases se encuentran separadas temporalmente de manera muy clara, ya que mientras la primera y la tercera se han llevado a cabo en España, la segunda, la correspondiente a la recolección de información sobre el terreno, fue llevada a cabo en Etiopía. Por último destacar que entre la tercera y cuarta etapa las barreras fueron difusas, ya que se produjo una sinergia entre el análisis de información y la síntesis de la misma. 


\section{1․ Etapa de planificación}

Durante esta primera fase realizamos la planificación completa del estudio. Empezamos seleccionando la bibliografía disponible sobre el tema, llevamos a cabo un análisis de las investigaciones similares y procedimos a la búsqueda de información actualizada sobre el país. También comenzamos el estudio de la zona en la que íbamos a llevar a cabo la investigación, realizamos una lectura de los trabajos más importantes sobre las características culturales de la población con la que íbamos a convivir y seleccionamos y/o diseñamos los instrumentos y técnicas necesarias para llevar a cabo la etnografía. Finalmente, procedimos a la selección de material, a la estimación de los recursos económicos necesarios para llevar a cabo el estudio y a la obtención de permisos y planificación de nuestra estancia, entre otras gestiones.

\section{Etapa de trabajo de campo}

En esta segunda fase y ya sobre el terreno nos centramos inicialmente en nuestra adaptación al campo, tanto física como psicológica y posteriormente empezamos con la recogida de datos mediante las técnicas de la observación participante, la toma de notas en el diario de campo, la recolección de materiales audiovisuales, las entrevistas y la recolección de información derivada de las fuentes documentales disponibles en la zona.

\section{Etapa de análisis de datos}

Durante esta tercera fase y una vez de vuelta a España, comenzamos con el análisis y clasificación de la información obtenida de las técnicas aplicadas en la fase anterior. Una vez clasificada, analizada y valorada la información y tras obtener una serie de datos y resultados, finalizamos esta fase con la interpretación de los mismos.

\section{Etapa de síntesis y redacción}

La última etapa se caracterizó por el proceso de transcripción, composición y redacción de la información obtenida tanto en la segunda como en la tercera fase. 


\subsubsection{Acceso al campo}

Nuestro acceso a la escuela de Qillenso se llevó a cabo tras una experiencia previa en el campo de la educación en Etiopía. Esta experiencia anterior nos facilitó el conocimiento de primera mano del sistema educativo etíope y nos puso en contacto con personas e instituciones que fueron fundamentales para el acceso a la escuela de Qillenso.

Una vez en Etiopía contactamos con los Padres Combonianos en su sede provincial de Addis Abeba y llegamos a un acuerdo para que pudiéramos realizar los estudios recogidos en la presente Tesis Doctoral, en la escuela que estos misioneros tienen en la localidad de Qillenso a cambio de colaborar con ellos en varios aspectos de la escuela y de una ayuda económica para ayudar a sufragar los gastos de los vuelos internacionales, además de proceder a la firma de un acuerdo sobre dichos aspectos. Los Padres Combonianos también me hicieron entrega de un documento en el que quedaba reflejado que ellos se harían cargo de mis gastos de vivienda y manutención en el país, lo que era necesario para que la Universidad de Addis Abeba aceptara mi petición de afiliación a la misma y secundara mi petición de un permiso de residencia ante la Oficina de Inmigración del gobierno etíope.

Una vez de vuelta en España redactamos un proyecto de investigación el cual presentamos al Departamento de Antropología de la Universidad de Addis Abeba para su aprobación y para obtener nuestra posterior afiliación en base a dicho proyecto. Dicha afiliación era condición necesaria para optar a un permiso de residencia como investigador en Etiopía, permiso que de otra manera era imposible de obtener y que era un requisito indispensable para poder realizar nuestros estudios en el país.

Tras la aprobación por la Universidad de Addis Abeba de nuestro proyecto y nuestra petición de afiliación a la misma volvimos a Etiopía y nos dirigimos a la Oficina de Inmigración con el documento que señalaba nuestra afiliación como profesor-investigador al departamento de antropología en la Universidad de Addis 
Abeba y dicha Universidad rogaba se nos concediera un permiso para residir e investigar durante un año en el país.

Una vez concluidos los trámites burocráticos en la capital y con nuestro permiso de residencia e investigación por un año recién concedido nos dirigimos en todoterreno a Qillenso en compañía de uno de los padres combonianos de la misión católica en la que se encontraba la escuela en la que íbamos a llevar a cabo nuestra investigación.

La misión de Qillenso se localiza en la carreta que parte de Awasa hacia el Este finalizando en la frontera de Somalia, a unos 15 minutos en coche tras el pueblo de Boamba y a 40 minutos de la ciudad más cercana, Kibre Menguist. El viaje desde Addis Abeba dura un día en todoterreno y entre uno y dos en transporte público, aunque con la mejora de las carreteras en la zona se está recortando esta duración. En esta misión llevamos a cabo tanto el presente estudio como fijamos nuestro lugar de residencia, de esta manera obteníamos una posición optima, ya que la misión no solo disponía de infraestructuras que facilitaban nuestro trabajo sino que también era un foco de atracción de población y lugar donde se llevaban a cabo varios tipos de actividades lo que nos facilitaba poder observar y participar en varios aspectos de la vida cotidiana más allá de la escuela tanto de niños y adultos.

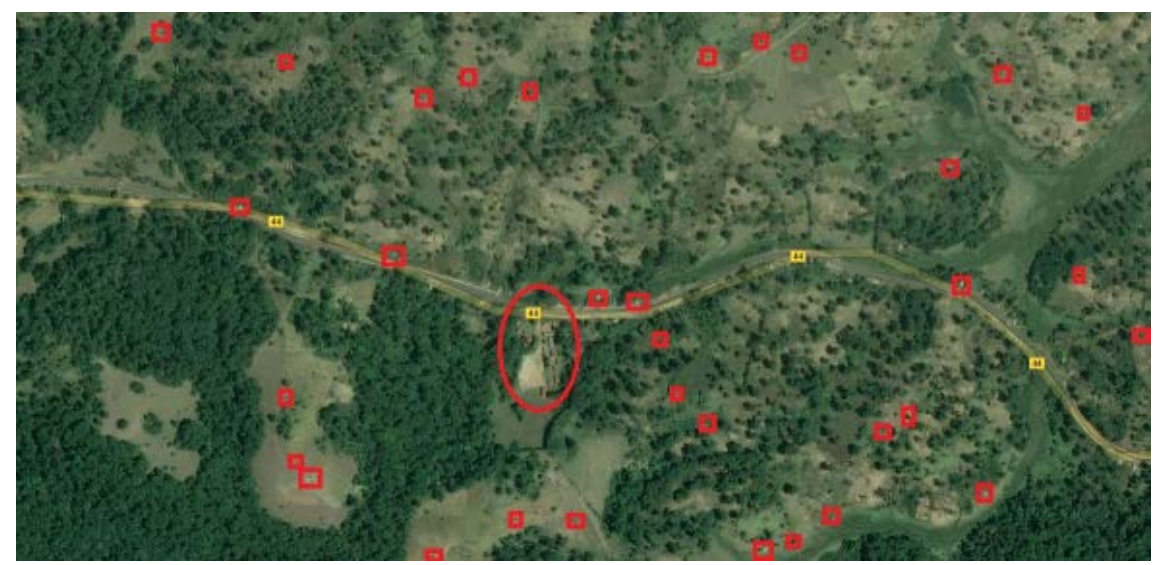

Figura 64. Vista De Qillenso por Satélite en la que se resaltan la misión y algunas casas.

(Fuente: Elaboración propia. Imagen: GoogleMaps)

Como podemos observar en la Figura 64, la misión (rodeada por un círculo rojo) estaba rodeada por una serie de casas solitarias (cuadrados rojos) que seguían 
el patrón de poblamiento disperso tradicional de los Guji (aunque se empiezan a concentrar en los alrededores de la carretera). Este patrón de poblamiento y la ausencia de centros de población concentrada en las cercanías hacía aún más ideal la selección de la misión como centro de residencia ya que aunque de esta manera no podíamos alejarnos del campo en nuestro tiempo libre para tomar perspectiva, las características de la propia misión hacían posible interponer una barrera mental y física entre el campo y la residencia cuando era necesario, como explicaremos más adelante.

Por otro lado, al vivir con la comunidad religiosa pudimos acompañar a sus miembros en las visitas a aldeas alejadas y aisladas lo que nos permitió acceder a una mayor cantidad de fuentes de información, conocer más en profundidad la zona y a sus habitantes y, en consecuencia, formamos una idea más completa de la realidad del área y de sus características.

Además al vivir en la misión de Qillenso pudimos beneficiarnos del prestigio de sus miembros en la comunidad local, lo que nos facilitó ganarnos la confianza de la población de la zona. Por otra parte debido a la relación personal que establecimos con los miembros de la comunidad religiosa y gracias a su experiencia en la zona nos ayudaron como "gatekeepers" proporcionándonos toda una gama de consejos y advertencias que nos ayudaron a evitar desde malentendidos culturales a problemas de salud.

A la hora de seleccionar un rol con el que presentarnos a la comunidad nos encontramos con que nuestra presencia allí dependía no solo de nuestra investigación sino también de nuestro trabajo voluntario en la escuela de Qillenso, por lo que decidimos adoptar una serie de roles múltiples que nos permitieran movernos por distintos ambientes y situaciones de la manera más favorable posible. De esta manera entre otros roles adoptamos el de investigador de la universidad de Addis Abeba, el de profesor del colegio, el del miembro de la comunidad misionera católica, etc.... 
De esta manera pudimos además seguir una estrategia de marginalidad (Téllez, 2007) que nos permitió lograr un equilibrio entre el extrañamiento y la familiaridad y realizar así una recogida de datos optima evitando conflictos o llevar a cabo acciones que no encajaban con nuestra ética y moral, cosa que hubiera sucedido si hubiéramos seguido de manera incondicional las normas sociales del grupo investigado y nos hubiera llevado por ejemplo a utilizar el castigo físico contra los niños.

Además siguiendo los consejos de Taylor y Bodgan (Téllez, 2007) no especificamos a nuestros informantes clave cuál era exactamente el objetivo de nuestra investigación para evitar condicionar sus repuestas y su comportamiento teniendo en cuenta además la idea generalizada que hay en Etiopía de que el gobierno tiene espías e informantes distribuidos en todos los lugares, con el subsiguiente temor que ello suscita a criticar al gobierno o a algunas de sus medidas como pudieran ser, en nuestro caso, las concernientes a la educación.

\subsubsection{Recogida de datos}

Durante el trabajo de campo, la intención de todo antropólogo es compilar todos los datos posibles, ya que cualquier elemento que se esté estudiando está condicionado por el contexto cultural en el que se encuentra. En palabras de Velasco y Díaz de rada (2009):

"La pretensión que anima el trabajo de campo es la aprehensión de la totalidad. Ésta recibe nombres genéricos, globalizadores: el contexto, la historia, la sociedad, la cultura. E incluso cuando la investigación se dirige hacia algún tema específico o hacia algún problema concreto, su comprensión exige la contextualización, es decir, dimensionarlo respecto al conjunto de factores o elementos que inciden o intervienen en él y que finalmente se revelan en extensión casi indefinida, como un conjunto estructurado, como un todo" (Velasco y Díaz de Rada, 2009, pág. 32).

En nuestro caso, para realizar la etnografía de la escuela de Qillenso necesitábamos comprender el contexto, social, geográfico y cultural en el que este 
centro educativo estaba inscrito. Así, fue necesario seleccionar una serie de herramientas y técnicas para que nos proporcionaran información no solo de la escuela de su funcionamiento y de la composición y comportamiento de su alumnado, sino también de las causas subyacentes a todo ello.

Al tratarse de un estudio etnográfico consideramos fundamental la recogida de datos mediante la utilización de múltiples técnicas o herramientas que nos permitieran adaptarnos a las distintas situaciones. De nuevo, en palabras de Velasco y Díaz de Rada (2009):

"La tendencia a la aprehensión de totalidad implica que las técnicas empleadas, las fundamentales, deben ser tan flexibles como para acomodarse a la heterogénea naturaleza de las situaciones de trabajo y a la no menos heterogénea naturaleza de los datos" (Velasco y Díaz de Rada, 2009, pág. 33).

La primera técnica consistió en la utilización de notas de campo. También empleamos la creación de registros permanentes como fotos o vídeos tanto de personas como de lugares y documentos que ayudaran a proporcionar un contexto visual a dichas notas o permitieran registrar elementos y sus características que fueran difíciles de reflejar mediante el uso de la palabra escrita.

El análisis de la documentación de la escuela es otra de las técnicas utilizadas para la recolección de datos y junto con la realización de entrevistas, tanto estructuradas como informales, completan la serie de técnicas principales que hemos utilizado para llevar a cabo la presente etnografía.

\section{Notas de campo}

El trabajo de campo y la creación de un diario de campo son elementos intrínsecos a una investigación de antropología y sirve como base para el posterior trabajo de análisis y elaboración:

"En la concepción tradicional el TC es entendido preferentemente como descripción etnográfica. El contacto del antropólogo con la comunidad o grupo social a investigar, se establece generalmente sobre la base de la recogida de datos. Con posterioridad y lejos del grupo estudiado, el antropólogo interpreta los datos, 
busca explicación a la información recogida y elabora teorías en el marco de la teoría antropológica" (Montes del Castillo y Martínez, 2012, pág. 39).

La técnica del diario de campo se estableció como un estándar a partir del trabajo de Malinowski con los nativos de las islas Trobriand y su intercambio de la Kula (Malinowski, 1973). Posteriormente se han elaborado teorías y trabajos de cómo ha de llevarse a cabo un correcto diario de campo:

"La técnica del diario de campo, en su versión más conocida, es de uso general en la antropología de principios del siglo XX acá, siendo quizá Malinowski el ejemplo más conocido, si bien la obra de Paul Rabinow resulta especial adecuada para ilustrar esta práctica" (Martínez, 2008, pág. 29).

En el presente estudio hemos llevado un doble diario de campo; uno de carácter más amplio en el que recogíamos todos los aspectos del día a día de nuestra presencia en el campo y un segundo diario centrado únicamente en los acontecimientos que se producían en la escuela o que estaban directamente relacionados con el funcionamiento diario del centro aunque se produjeran fuera del horario escolar.

La finalidad de mantener este segundo registro de los acontecimientos diarios en forma de "diario de la escuela" ha sido tanto por exigencia de nuestro trabajo para los Padres Combonianos en la escuela, como para dejar en la misma, tras nuestra marcha, un documento preciso y descriptivo que contuviera información que pudiera ser útil en cursos posteriores.

Además, dentro de este apartado de notas de campo debemos destacar que siempre llevamos con nosotros un cuaderno de notas en el que apuntábamos ideas y frases principales para posteriormente usarlo de base en la elaboración del diario de campo o de la escuela. Además en este cuaderno de notas también registramos dibujos explicativos o lo utilizamos para apuntar vocabulario, o para comunicarnos mediante escritura con informantes cuando era imposible por medio de la palabra hablada (véase Figura 65). 


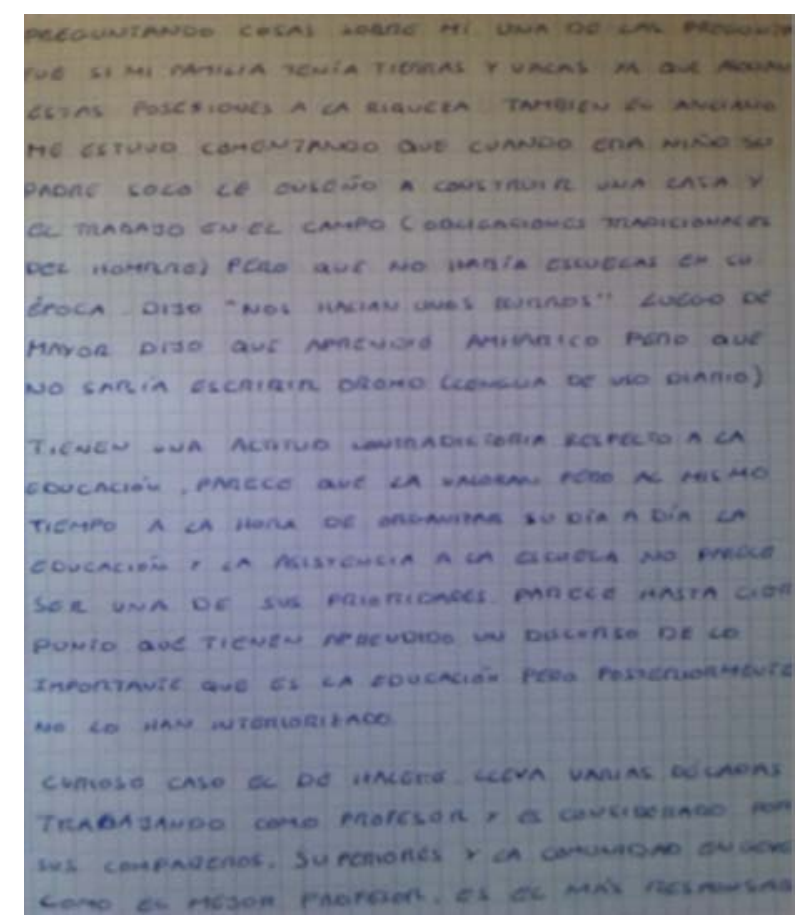

Figura 65. Imagen de una página del cuaderno de notas

(Fuente: Autor)

\section{Registros permanentes (fotos, videos...)}

La fotografía y el vídeo son dos técnicas fundamentales a la hora de recoger información en antropología, especialmente cuando se está llevando a cabo una etnología, ya que como afirma Alvar (citado en Téllez 2007):

"para la etnología, toda documentación acumulada en el terreno y en especial la información gráfica, fuera de la escritura, como el dibujo, la fotografía y el cine, tiene una importancia primordial" (Téllez, 2007, pág. 289).

En la presente investigación es muy clara la utilidad de la imagen a la hora de registrar datos o situaciones que habrían sido muy difíciles de reflejar de otra manera. Además, en otros casos una imagen nos servía para dar sentido y completar la descripción y el análisis escrito. Un ejemplo de ello es la importancia de la imagen a la hora de reflejar el exceso de burocracia y la importancia superlativa que otorgaba el supervisor de la escuela de Qillenso a tener a la vista información sobre la escuela y sobre su organización. Así, más que un verdadero interesaba porque los programas educativos a los que hacían referencia esas imágenes se llevaran a cabo, existía un claro interés porque estuvieran escritos en 
papel y expuestos, por si venía una inspección del Ministerio de Educación (véase Figura 66), situación a la que, por otra parte, tampoco es ajena nuestro país.

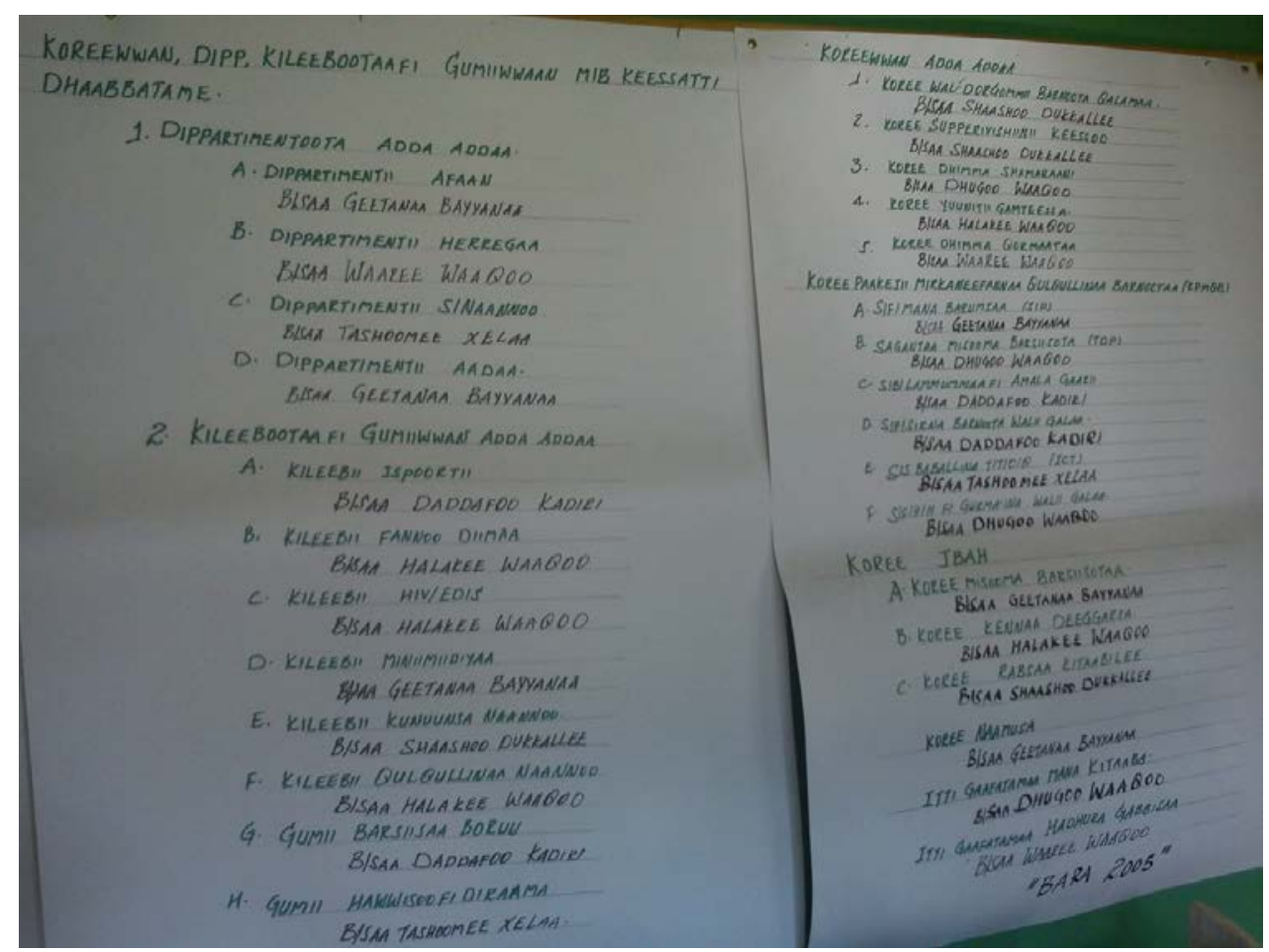

Figura 66. Posters con información sobre la organización de la escuela

(Fuente: Autor)

\section{Análisis de documentos}

Un aspecto fundamental a la hora de llevar a cabo esta etnografía ha sido el estudio de la documentación a la que hemos tenido acceso en los archivos de la escuela de Qillenso. Ello nos ha permitido obtener datos cuantitativos tanto del presente como del pasado, lo que nos ha facilitado el análisis de la evolución de una serie de indicadores que a su vez, nos han ayudado a obtener una imagen precisa de la evolución de esta institución y de los alumnos que han pasado por ella (véase Figura 67).

Entre los documentos que hemos analizado se encontraban todos los registros de matriculación de alumnos. También hemos analizado documentos como modelos de exámenes, cartillas de matriculación, documentos internos del colegio o como podemos ver en la Figura 68, registros de notas de la historia de la escuela. 


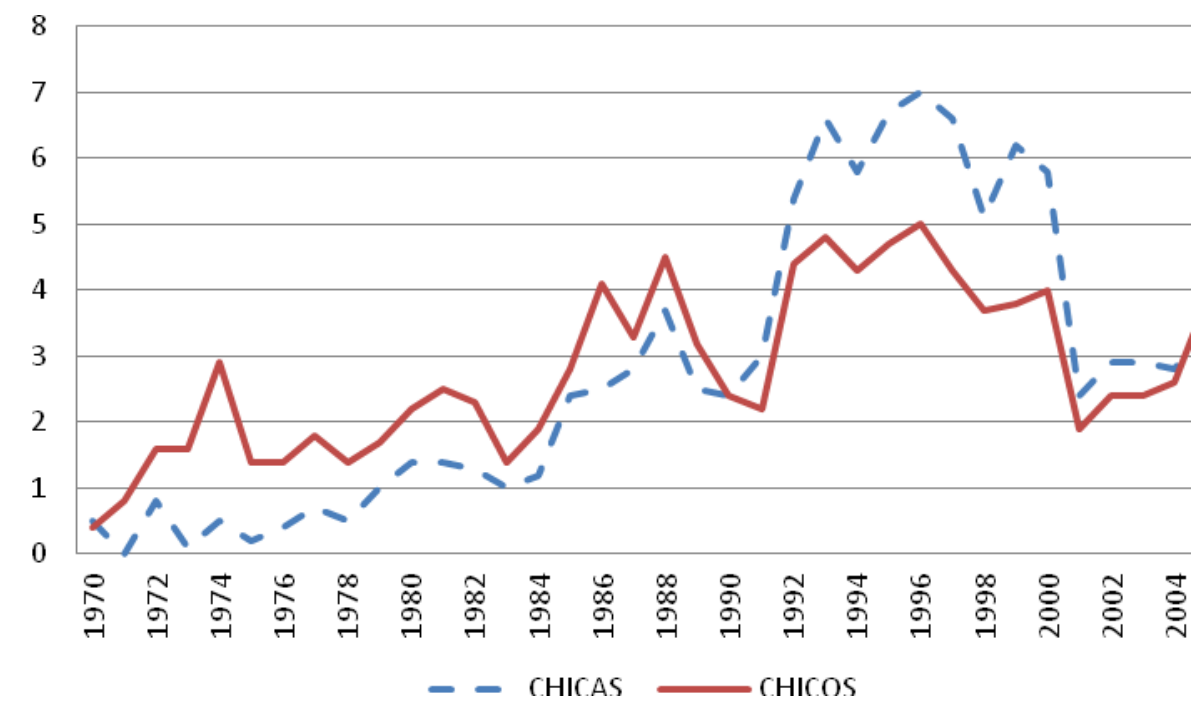

Figura 67. Representación de los alumnos y alumnas de la escuela de Qillenso

Con todos estos documentos hemos podido no solo conocer la realidad de la escuela de Qillenso en particular, sino que al trabajar sobre ellos a su vez hemos podido elaborar tablas y estadísticas que nos han permitido, como veremos en el apartado de resultados de este capítulo, comparar los datos entre la escuela de Qillenso y los informes a nivel regional del gobierno etíope y de instituciones internacionales y de esta manera dar respuesta a alguno de los objetivos de esta investigación.

\subsection{Resultados}

\subsubsection{Etnografía de la Escuela de Qillenso}

\section{La escuela}

Uno de los objetivos principales del estudio etnográfico de la escuela de Qillenso era descubrir si los datos sobre educación que arrojan los informes de organismos internacionales se corresponden con la realidad de esta pequeña escuela o si, por el contrario, la realidad del día a día en una escuela es muy distinta a esa supuesta radiografía de la educación que los distintos informes muestran. Para ello primero realizaremos una pequeña descripción de la escuela de Qillenso, 
sus instalaciones y su personal para después continuar comparando los datos de esta escuela con los que mostramos en el segunda capítulo de esta tesis.

Comenzaremos por tanto por un análisis y descripción de la Misión y de la propia Escuela de Qillenso, esto nos servirá tanto para tener claro el cuadro físico en el que se ha llevado a cabo la investigación como para ir conociendo datos de la escuela que nos ayudarán posteriormente a contextualizar los resultados que posteriormente iremos mostrando.

El complejo en el que se engloba la misión y la escuela de Qillenso se puede diferenciar entre dos áreas, la pública y la privada, en la Figura 68 en esta zona privada quedarían englobados los edificios 3,4 y 5 de la zona D. Esta es una división tanto física, mediante vallas y setos, como mental, ya que los habitantes de la zona sabían que por norma general no tenían permiso de adentrarse en la misión más allá de la puerta de la casa en la que viven los misioneros por lo que la parte posterior de la misión era una zona completamente privada.

Para una mejor comprensión hemos dividido el complejo de la misión en cuatro espacios como se puede ver en la Figura 68.

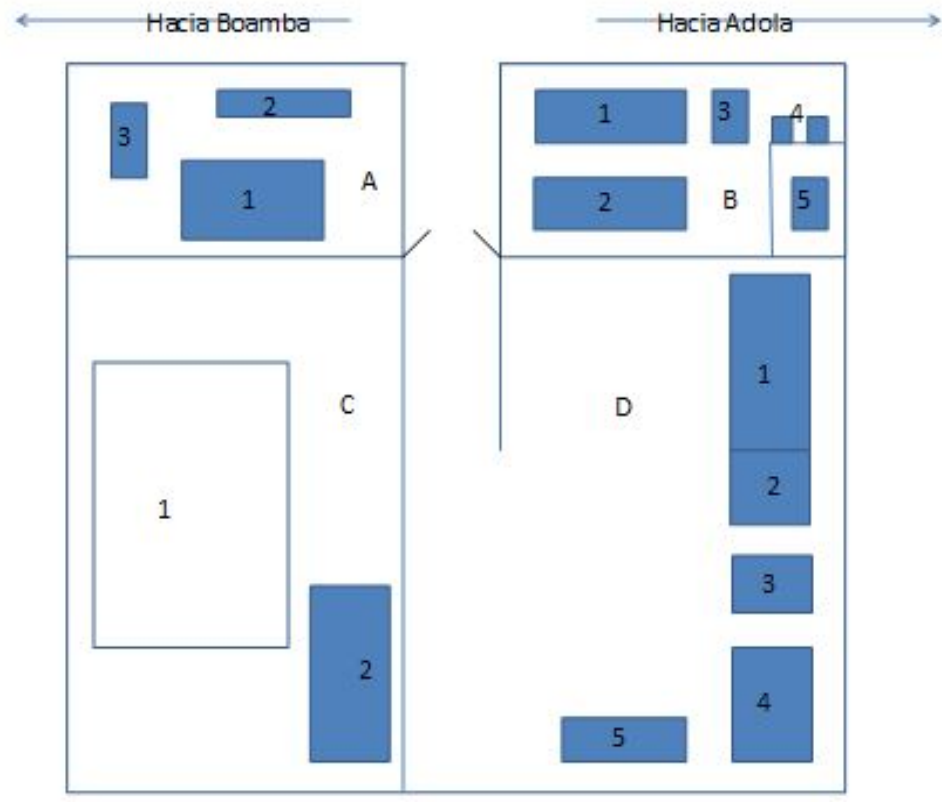

Figura 68. Esquema de la misión de Qillenso 
La zona A: Esta zona es la que ocupa la antigua clínica que está siendo de nuevo rehabilitada para que vuelva a entrar en servicio. Está delimitada toda ella por una valla metálica que la separa del resto del complejo. En ella se encuentra la propia clínica (1), varios edificios auxiliares en los que se encuentran las cocinas (2), y habitaciones para enfermos de tuberculosis que deben permanecer aislados (3).

La zona B: Esta zona es ocupada por la escuela. En ella se encuentran los edificios de las aulas ( 1 y 2 ), el centro pedagógico (3), las letrinas (4) y una antigua aula-casa destinada a la educación de adultos (5). La escuela está separada del resto del complejo mediante una valla metálica combinada con arbustos lo que da a la escuela algo más de privacidad.

La zona C: Esta sección de la misión está conformada por un campo de futbol (1) y por la Iglesia (2) además de por un extenso terreno de pasto y arboles.

La zona D: En esta zona se encuentran los edificio de hábitat ( 2 y 4) y mantenimiento de la misión ( 3 y 5) además de una nave (1) que se utiliza en las reuniones escolares y de la comunidad y en la que hay una pequeña oficina.

Centrándonos en nuestro lugar de trabajo principal, la escuela se sitúa a la entrada del "compound" de la Misión Comboniana de Qillenso, lindando con la carretera que atraviesa la zona y justo enfrente de la antigua clínica de las hermanas combonianas, que en los momentos de realización del presente estudio estaba siendo acondicionada para volver a ser puesta en funcionamiento.

Las instalaciones de la escuela las conforman dos naves de aulas y oficinas (1 y 2), una cabaña de madera (3) y unas letrinas de chapa (4). Todo este conjunto está rodeado por una valla metálica baja que forma un espacio aislado del exterior y al mismo tiempo diferenciado del resto del conjunto de la misión. Dentro de esta valla que delimita el espacio de la escuela y en una partición interna se encuentra un edificio donde se impartían anteriormente talleres de trabajo y educación para mujeres y que en la actualidad está en desuso.

Los dos bloques de aulas son paralelos, por lo que forman un espacio al aire libre rectangular entre ellas que es utilizado como "patio" de la escuela en el que 
los niños juegan y forman en fila todas las mañanas para cantar el himno de la Oromía o de Etiopía antes de entrar en clase.

Las paredes y el suelo de las aulas están formados por cemento mientras que el techo está construido con madera y chapas metálicas corrugadas. Esto la diferencia del resto de las escuelas de la zona que están construidas generalmente de manera tradicional con madera, caña y adobe.

El interior de las aulas es austero si lo comparamos con una escuela española pero está mejor equipado que la escuela media pública de la zona. La escuela cuenta con un pupitre grande por cada dos o tres alumnos, una pizarra y una mesa y silla para el profesor. En las aulas también hay posters educativos, folios con información de las distintas actividades de la escuela y alguna pieza de mobiliario auxiliar (véase Figura 69).

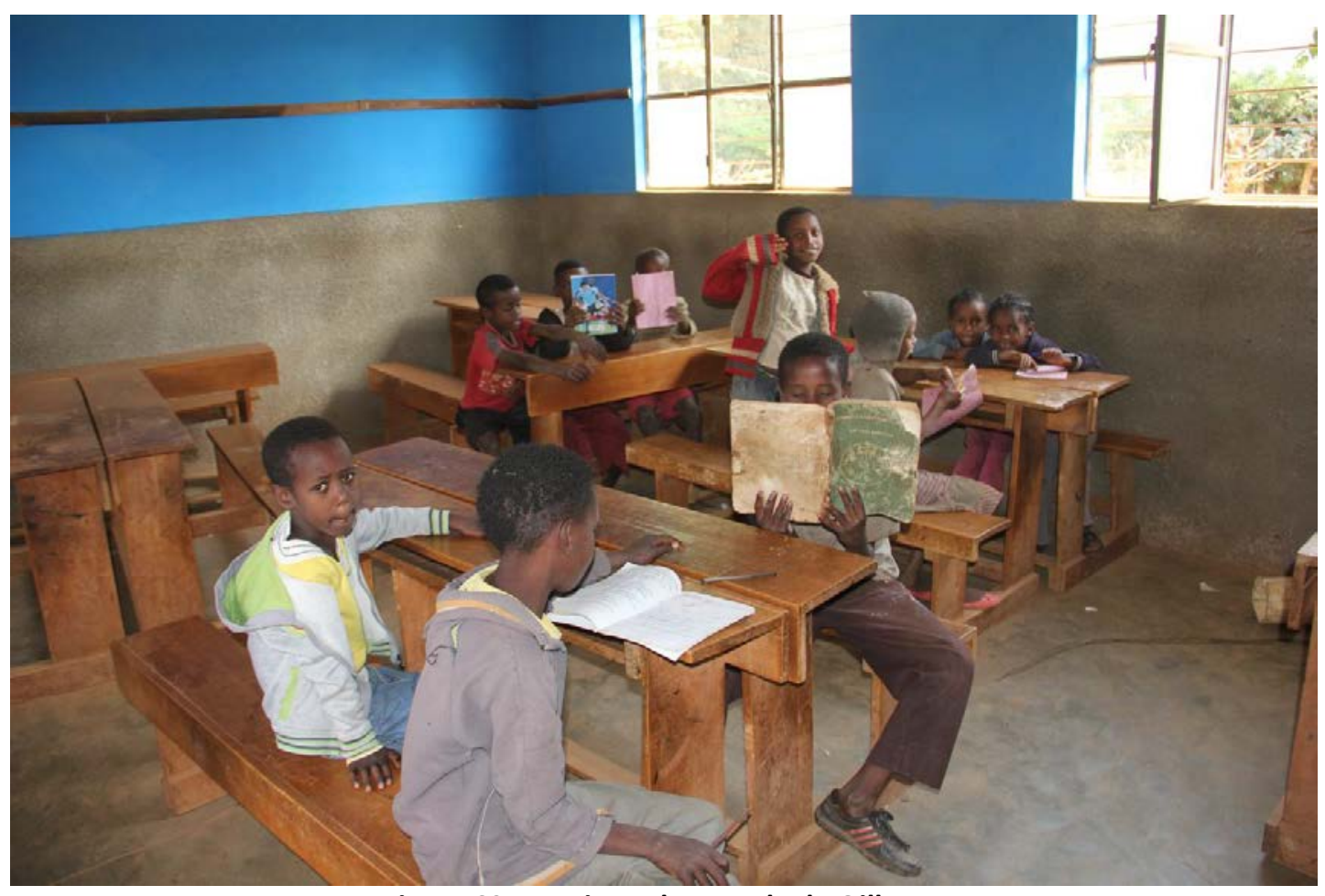

Figura 69. Interior aula escuela de Qillenso

(Fuente: Autor)

En las aulas hay cableado eléctrico pero, al no haber suministro en la zona, éste es inútil. Por tanto, las clases se deben realizar en horario con luz natural 
suficiente, impidiendo de esta manera que las instalaciones puedan ser utilizadas para alguno de los programas educativos vespertinos o nocturnos que el Ministerio de Educación ha diseñado. Las ventanas se encuentran en ambos lados de las aulas y disponen de cristales semi-abatibles protegidos por una serie de barrotes; dejan pasar una luz suficiente pero en días nubosos o con fuerte niebla hay sensación de penumbra en las salas.

En el primero de los bloques de aulas (1) está compuesto por dos aulas, la oficina del subdirector y una biblioteca. La oficina del subdirector también es utilizada como sala de profesores y en ella trabaja tanto el subdirector en solitario como se realizan las reuniones entre éste y el profesorado. En dicha sala tienen también sus taquillas los profesores y el supervisor de las escuelas de la zona tiene un pequeño espacio compuesto por una mesa y una silla para su trabajo. Esto último se debe a que el supervisor eligió la escuela de Qillenso como su base de trabajo cuando no estaba visitando las cuatro escuelas a su cargo. Una características llamativa de esta oficina es que esta "forrada" de documentos (véase Figura 70), organigramas y esquemas que recogen y sobre todo mantienen a la vista las actividades, cargos y responsabilidades que el profesorado tiene y realiza, aunque en muchas ocasiones, como ya hemos indicado, ese trate más bien de una simple exhibición de papel que de una constatación del trabajo realizado. 


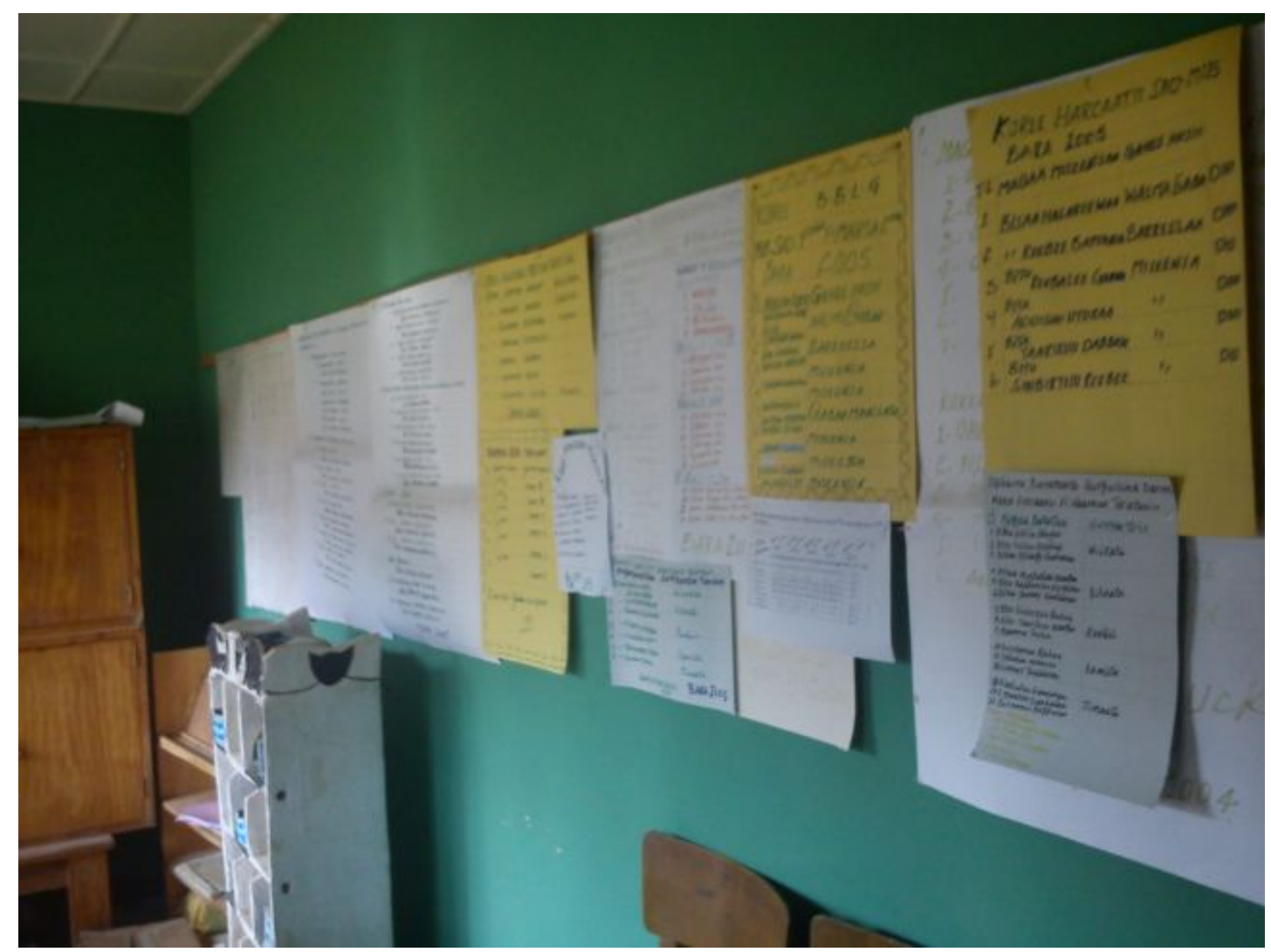

Figura 70. Interior de la oficina del subdirector en la escuela de Qillenso

(Fuente: Autor)

Esta oficina está siempre rebosante de actividad ya que debido a las características de la administración de la educación en Etiopía, siempre hay informes que rellenar y numerosas reuniones. Además los profesores la utilizan como sala de descanso por lo que siempre hay alguien trabajando o simplemente charlando.

La biblioteca se encuentra a continuación de la oficina del subdirector. Ocupa el antiguo espacio del aula de pedagogía, ya que el año de realización del presente estudio hubo que ampliar en una el número de aulas disponibles debido al gran número de estudiantes de primer grado. En esta aula reconvertida se colocaron inicialmente estanterías con libros y un pequeño número de pupitres, pero al final de nuestra estancia en el campo fue equipada con nuevas mesas y bancos al recibir la escuela una ayuda económica por parte del gobierno destinada a tal fin. En realidad este dinero tenía que haber sido entregada a la escuela a 
principios del año escolar, pero al igual que sucedía con otras subvenciones, las demoras en la recepción de las mismas podía ser de un año. Dos aulas finalizan este primer bloque.

En el segundo bloque (2) encontramos en primer lugar la oficina de dirección y almacén. En esta oficina se archivan los documentos de años anteriores del colegio y los archivos del mismo. Además en el almacén hay toda clase de material escolar, desde tizas a libros pasando por cartulinas o folios. A continuación hay cuatro aulas.

Al lado del primer bloque (1) hay una casa (3) de madera y piezas metálicas que sirve tanto de aula de psicopedagogía como de almacén de material escolar de años anteriores. Sin embargo, no fue utilizada en todo el año que duró nuestra estancia, pese a que se animó a los profesores, tanto desde la dirección del colegio como desde el supervisor de las escuelas de la zona, a que hicieran uso de los materiales que en ella se almacenaban

Otros elementos con que cuenta la escuela son un par de casetas metálicas (4) que sirven de letrinas. Más allá hay un hueco en el suelo que sirve de depósito de basura del material escolar que se estropea o que una vez utilizado (folios o basura en general) no se puede recuperar para un uso posterior. Cuando el agujero rebosa se recurre a la quema para deshacerse de la basura, ya que es el único espacio disponible a tal efecto en el lugar (Figura 71). 


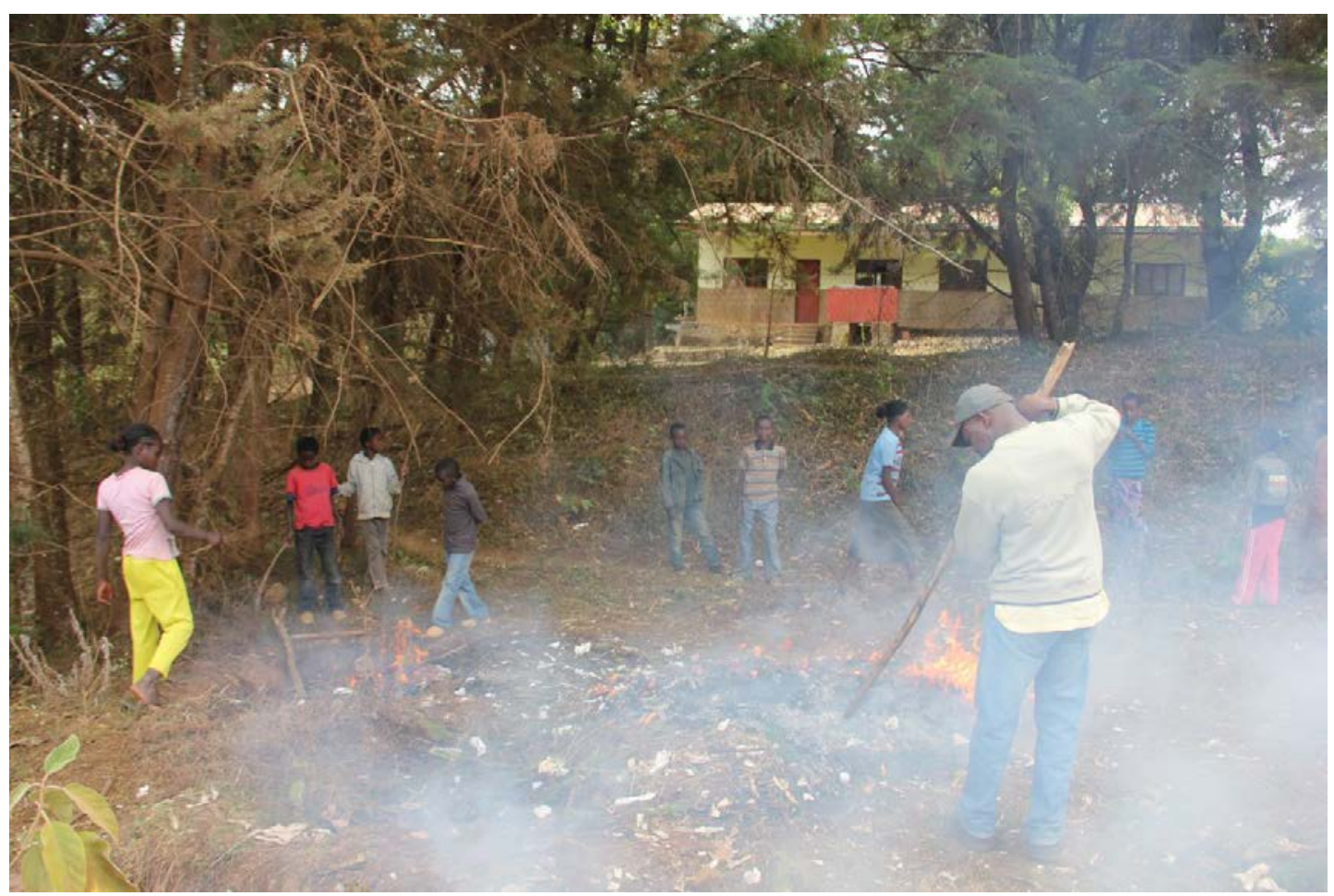

Figura 71. Quema de basura por parte de profesores y alumnos

(Fuente: Autor)

Siguiendo con la exposición de otros elementos que hay en la escuela, cabe destacar una fuente de cemento que se encuentra en el patio que forman las dos alas de aulas. Esta fuente no está operativa puesto que el agua está cortada para evitar un uso indebido de la misma por parte de los vecinos de la zona que se colaban en horario extraescolar. Un problema similar se produce con las letrinas ya que es en ocasiones los vecinos del área entran para utilizarlas aunque está prohibido. En el patio, en un punto central entre los dos bloques de aulas, hay un mástil para izar una única bandera pero, como la ley exige que se ice tanto la bandera de la Oromía como la de Etiopía, se ha proyectado la instalación de un segundo mástil para izar simultáneamente ambas enseñas.

Junto a la pared de la oficina del subdirector también hay unos bancos para el descanso de los profesores. Siguiendo la línea que delimita los edificios de las aulas y el patio interior, hay una serie de viejas ruedas de coche que son utilizadas como macetas. 
Aunque separado del complejo de la escuela, es importante mencionar que tanto los profesores como los alumnos tienen acceso a un campo de fútbol que se encuentra junto a la iglesia de la misión (C1) (véase Figura 72).

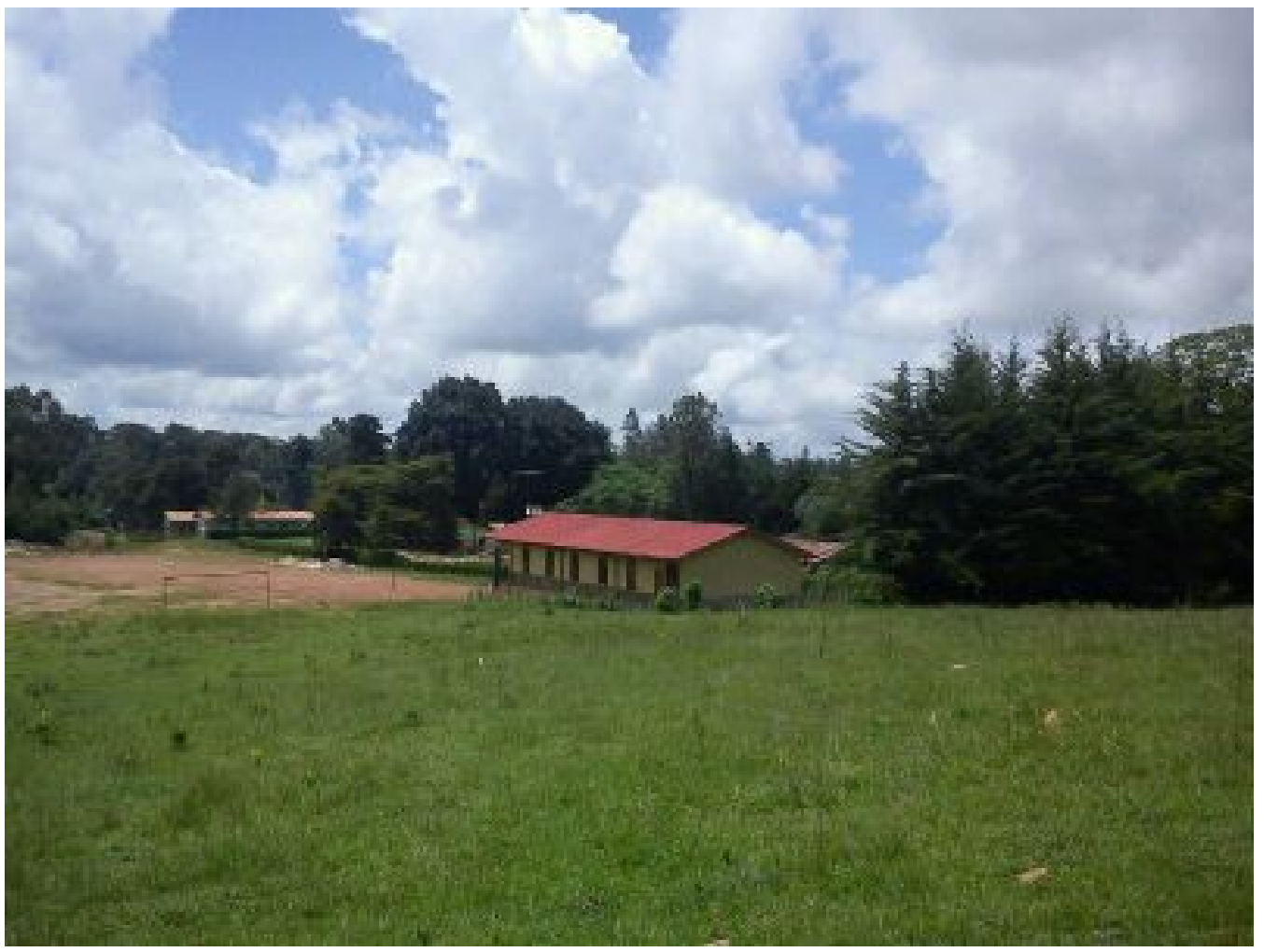

Figura 72. Imagen del campo de futbol, iglesia (primer plano) y escuela de Qillenso (segundo plano)

(Fuente: Autor)

En este campo de futbol se practica deporte en los periodos lectivos de educación física. Debido a problemas del firme del terreno ocasionados por las lluvias, su estado no es el ideal para practicar deporte pero aún así es más amplio y está en mejores condiciones que los campos de deporte de las escuelas públicas vecinas.

El edificio (D1) que es utilizado normalmente para reuniones de la parroquia de la misión es también utilizado en ocasiones especiales tanto por padres de alumnos como por estos mismos y por los profesores para distintos eventos. Dichos eventos pueden consistir en la inauguración del curso, la clausura del mismo, 
reuniones de los padres de alumnos y otras actividades extraordinarias (véase Figura 73).

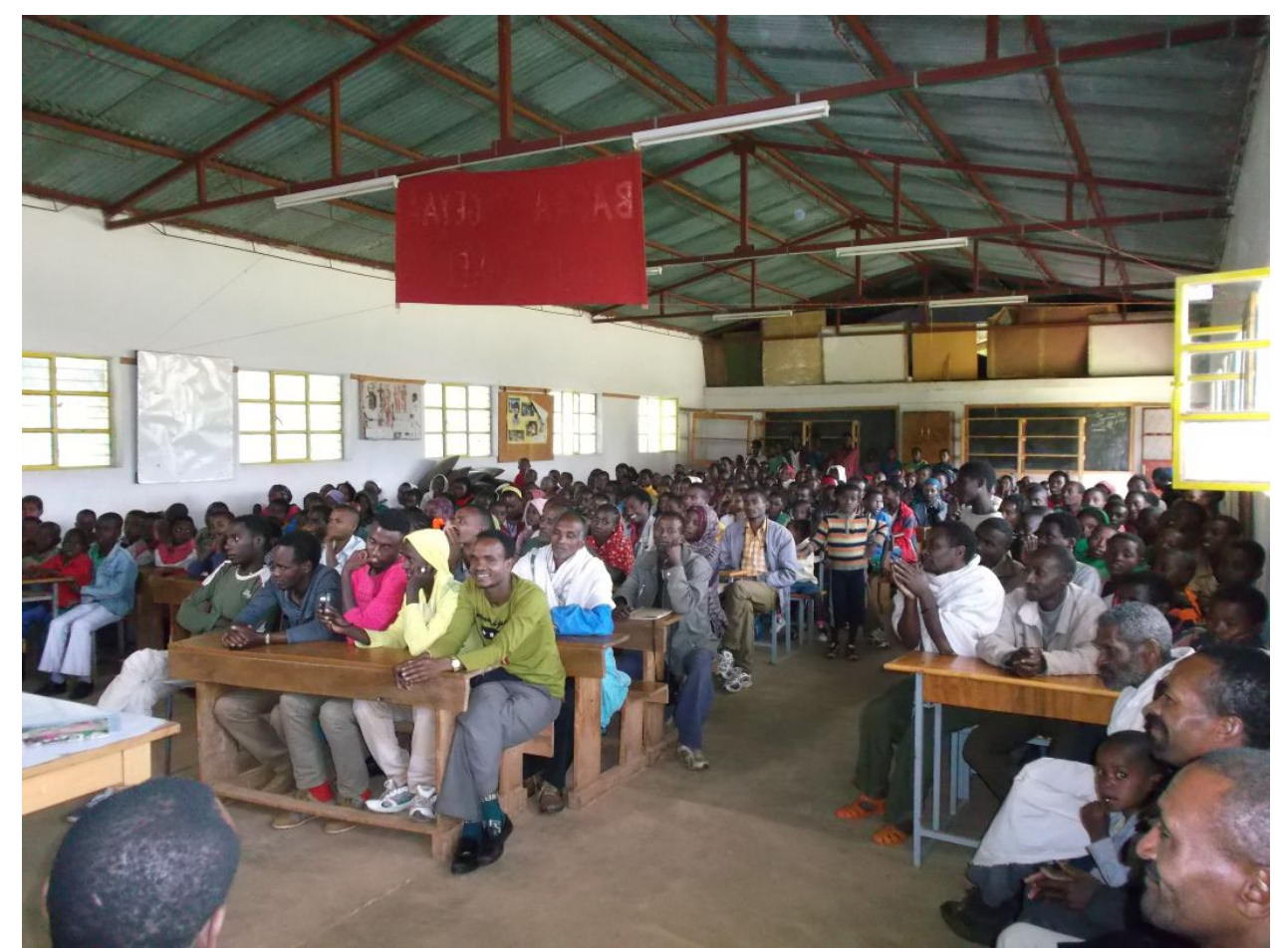

Figura 73. Reunión de padres, alumnos y profesores al finalizar el curso

(Fuente: Autor)

Por último, pertenecen a la escuela una serie de casas que se encuentran a unos cinco minutos andando en dirección a Boamba. Estas pequeñas edificaciones construidas con adobe, madera y planchas metálicas, siguiendo el nuevo modelo de casa que se está extendiendo por el país, están destinadas a los profesores. Fueron pagadas y construidas por parte de la Misión durante mi presencia en la zona por imperativo de las autoridades educativas. Sin embargo, los profesores se negaban a utilizarlas como vivienda pese a ser obligatorio que los profesores vivan cerca de la escuela, ya que preferían seguir viviendo en el pueblo de Boamba aunque esto supusiera que muchos días llegaran tarde y no estuvieran disponibles para realizar actividades en la escuela por la tarde. 


\section{El personal}

A continuación realizaremos una somera descripción del personal que trabajaba en la escuela de Qillenso, ya que entraremos más en detalle a analizar sus características posteriormente. Así pues, el personal que trabajaba en la escuela era el siguiente:

- Un director: Era un misionero de los Padres Combonianos pero delegaba la gran mayoría de sus funciones en el subdirector

- El subdirector: Se encargaba de la gran mayoría de la administración de la escuela y asistía a las reuniones en la oficina de educación de la zona

- Personal docente: Estaba formado por siete profesores, todos hombres

- Personal auxiliar: El Guardia de Seguridad de la misión también ejercía sus funciones en la escuela.

- Supervisor: Técnicamente no era un trabajador de la escuela, pero debido a su presencia habitual y a que su trabajo consistía en supervisar las escuelas de la zona lo incluimos en esta sección ya que, como veremos más adelante, influía con su presencia y con sus decisiones en el funcionamiento de la escuela.

\section{El alumnado de Qillenso}

Una vez conocida la situación de la escuela, sus instalaciones y su personal es hora de pasar a analizar el alumnado que acude a este centro educativo. Para ello contaremos no solo con nuestras observaciones in situ sino también con los datos que nos ha proporcionado el estudio de los diferentes documentos de la escuela y que junto a las observaciones nos permitirán cuando sea posible y oportuno compararlos con los datos a nivel nacional y regional de Etiopía y la Oromía.

En primer lugar debemos conocer el número de alumnos matriculados en la escuela de Qillenso en su historia, este número alcanza los 5900 de los cuales 2207 
eran chicas y 3693 chicos. Lo que significa que a lo largo de los años un $62,6 \%$ de los alumnos han sido chicos frente a un $37,4 \%$ que han sido chicas.

Esto concuerda con los datos generales del país y de la Oromía en los que queda reflejado una preponderancia del alumnado masculino frente al femenino tanto en los indicadores del GER como del NER como vimos en el segundo capítulo de esta tesis, pero si analizamos de una manera más detallada los datos de la escuela de Qillenso podemos observar que la proporción entre alumnado femenino y masculino ha cambiado significativamente a lo largo de los años de funcionamiento de la escuela como podemos observar en la Figura 74.

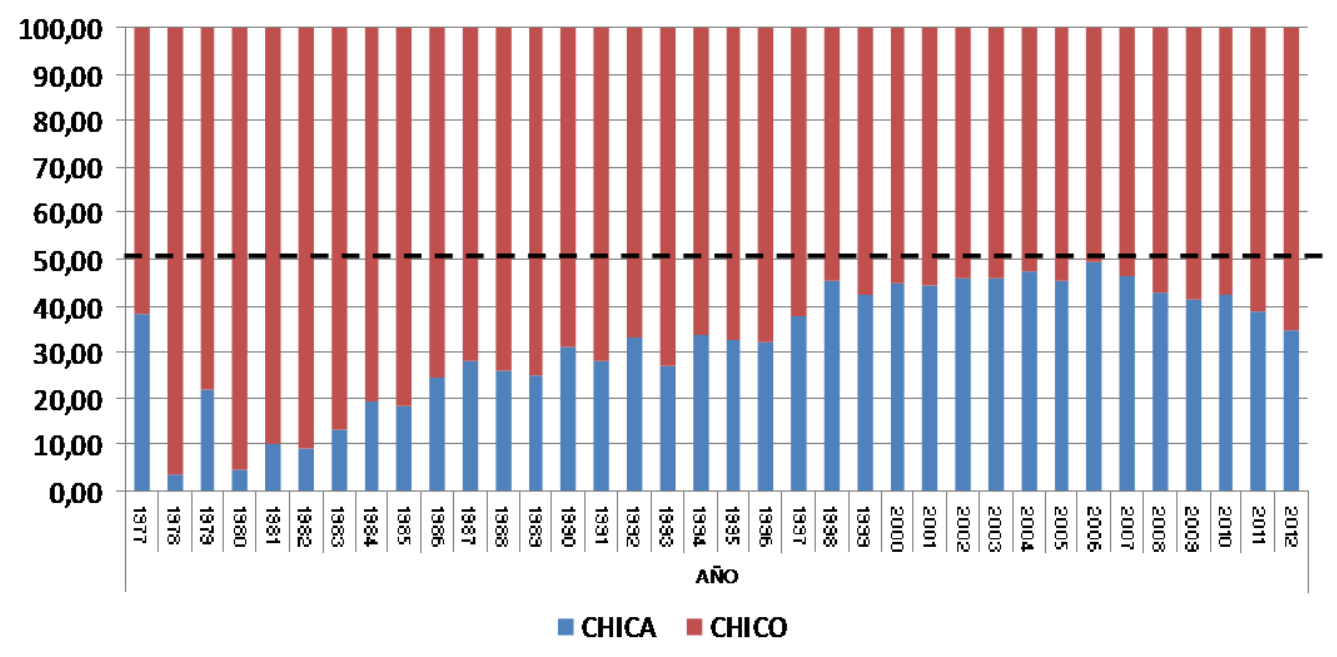

Figura 74. Proporción anual del alumnado dependiendo del género en la escuela de Qillenso.

(Fuente: Elaboración propia)

Lo primero que llama la atención de la figura es que en todos los años que ha estado funcionando la escuela de Qillenso siempre ha habido una mayoría de alumnado masculino, solo durante el curso 2006 los dos géneros llegaron a estar prácticamente igualados con un $49,28 \%$ de chicas frente a un $50,72 \%$ de chicos.

A continuación, si analizamos la gráfica queda patente cómo durante los primeros años de funcionamiento de la escuela la presencia femenina es, quitando 1977, muy reducida, con una media en los primeros diez años de solo un $19,18 \%$ de alumnado femenino. Por otra parte en la figura puede observarse como desde 1980 
ha ido aumentando esta presencia femenina en la escuela de manera continua hasta que entre los años 200 y 2006 la proporción de alumnado femenino era muy cercano al masculino con una media durante estos años de un $45,16 \%$ de alumnas, pero partir del año 2006 la tendencia ha cambiado completamente y durante el periodo entre 2007 y 2012 la proporción de alumnado femenino ha vuelto a descender, situándose en un $41 \%$.

De esta manera queda claro como en Qillenso ha sucedido un fenómeno muy similar al producido en la Oromía y el resto de Etiopía respecto a la escolarización primaria femenina. Este fenómeno se ha caracterizado por un incremento notable de la proporción de alumnas en las aulas respecto a la situación de partida de décadas atrás, pero este aumento nunca ha logrado ni que se igualen las cifras de los grandes indicadores GER, NET ni en las aulas como podemos ver en el caso de Qillenso. Es más esta escuela es un claro ejemplo del techo de cristal con el que se encuentra la matriculación femenina. Un límite que no solo se caracteriza por que las chicas nunca alcancen los niveles masculinos de matriculación manteniéndose unos puntos porcentuales por debajo de los masculinos, sino que en algunas ocasiones se está produciendo un descenso de la presencia femenina en las aulas como podemos ver en el caso de Qillenso.

Para analizar más a fondo la evolución de los alumnos dependiendo de su género en la escuela de Qillenso tenemos la Figura 75. En ella podemos observar el porcentaje anual de matriculación dependiendo del género respecto al total de alumnos de cada género matriculados en la historia de Qillenso. 


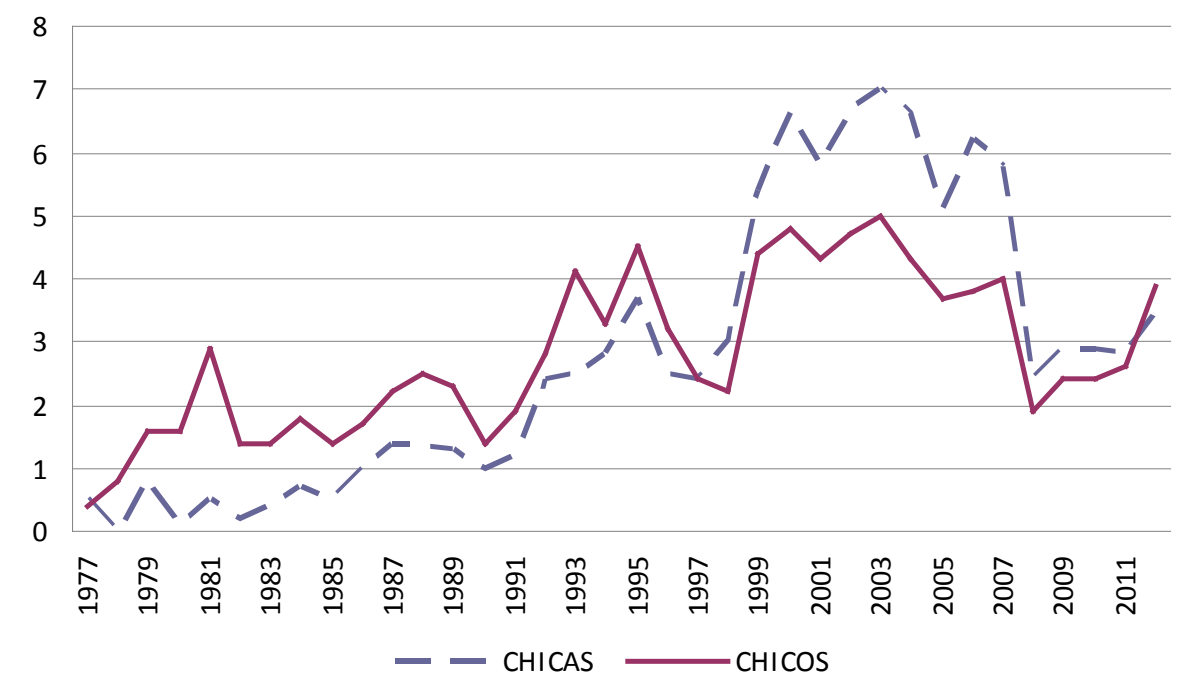

Figura 75. Evolución del número de alumnos dependiendo de su sexo en la escuela de Qillenso. (Fuente: Elaboración propia)

La grafica a simple vista muestra que las curvas de chicos y chicas han tenido un comportamiento muy similar y se desarrollan prácticamente en paralelo, pero si se estudia de una manera más detallada podemos distinguir dos etapas principales a la hora de la matriculación de alumnado según el género, una primera dominada por el género masculino y una segunda etapa en la que las alumnas han accedido a la escuela de una manera mucho más marcada. La primera de estas etapas abarcaría desde 1977 hasta 1997. Durante estos primeros veinte años de funcionamiento de la escuela aparte del dominio masculino se puede observar un incremento progresivo del número de alumnos de ambos sexos, que se invierte significativamente entre 1988 y 1990 y entre 1995 y 1997.

Este descenso de alumnos puede estar provocado entre 1988 y 1990 por el recrudecimiento de la guerra entre el gobierno del Derg y los grupos rebeldes con la posterior caída del primero, mientras que para la caída de alumnos entre 1995 y 1997 no tenemos una explicación satisfactoria.

En 1997 el porcentaje de varones y mujeres que se matricularon en la escuela respecto al total de todo su funcionamiento es el mismo, este año además marcará el inicio de una nueva tendencia en la matriculación femenina ya que 
podemos ver en la gráfica como durante la década que contenida entre 1997 y 2007 se produce un incremento muy marcado de la matriculación de alumnas, tanto es así que durante estos diez años se matriculó el $60 \%$ de todas las alumnas que han pasado por la escuela de Qillenso en toda su existencia. Este aumento de la matriculación femenina además tiene su reflejo en la Figura 75 , ya que si nos fijamos en la misma década en la dicha figura podemos observar como son los años en los que la proporción de chicos y chicas en la escuela está más igualada.

Las razones que llevaron a que se produjera este aumento no las conocemos, pero sospechamos que seguramente este fenómeno estuvo muy influenciado por el cambio de política que el nuevo gobierno del FDRPE implantó tras su llegada al poder y que pretendía favorecer la matriculación de las niñas en la educación primaria.

Este aumento tan marcada de la matriculación femenina se ha ido mitigando año tras año después de 2007 y durante el curso 2012, en el que realizamos nuestra investigación en Qillenso, la proporción de alumnos masculinos respecto a su matriculación histórica total era superior de nuevo a la misma proporción en el caso de las chicas.

Este descenso de la matriculación femenina coincide de nuevo con los datos expuestos en la figura 75, y es reflejo del mismo fenómeno de techo de cristal y retroceso que sufren las alumnas etíopes como comentamos anteriormente en este apartado.

Una vez conocidos los porcentajes anuales y los datos totales de matriculación tanto de chicos como de chicas en la escuela de Qillenso es la hora de conocer como se han repartido los alumnos dependiendo del curso en la escuela. Aludiremos por tanto a la escolarización según el curso.

De esta manera si estudiamos los años en los que se concentra la escolarización de los alumnos, podemos observar como más de la mitad del alumnado a lo largo de todo el tiempo que ha funcionado la escuela se ha concentrado en los dos primeros cursos de primaria, acumulando un $62,3 \%$ de las 
matrículas de alumnos, mientras que los restantes cursos se reparte el $37,7 \%$ de manera descendente como podemos ver en la Figura 76.

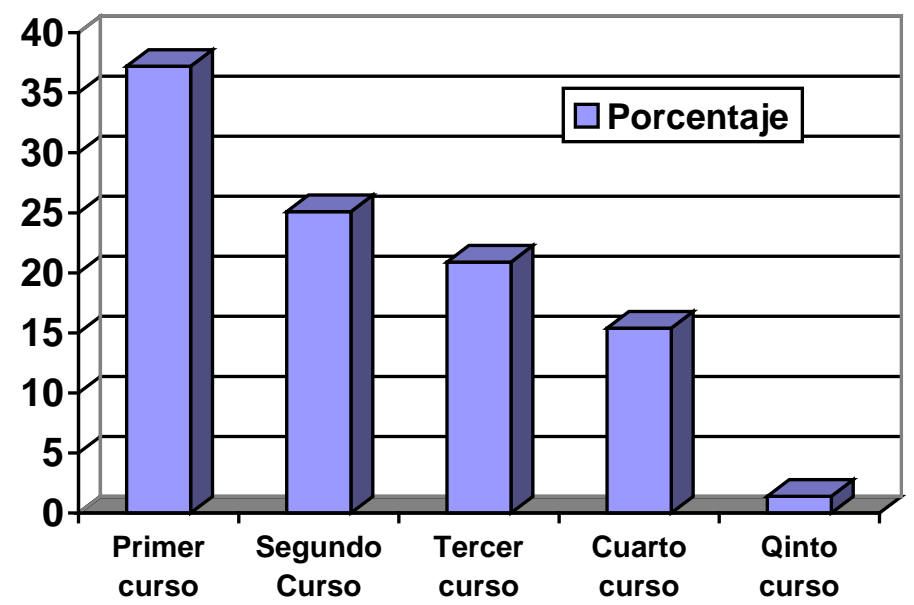

Figura 76. Distribución de los alumnos matriculados por curso entre 1977 y 2012 en la escuela de Qillenso

(Fuente: Elaboración propia)

Además en la Figura 76 podemos observar de igual manera la mínima proporción de los alumnos matriculados en quinto curso, esto se debe principalmente a que han sido muy pocos años los que se ha ofertado el quinto curso de primaria a los alumnos. Esto es un indicador muy claro del fenómeno de la falta de interés o de oportunidades a la hora de continuar los estudios una vez finalizado el primer ciclo de primaria ya que al preguntar a los Misioneros Combonianos por la desaparición del quinto curso tras su implantación nos confirmaron que tomaron la decisión de dejar de impartir este quinto curso de educación primaria por la falta de interés en el mismo. Pese a ello en el curso académico que estuvimos presentes en Qillenso habían vuelto a ofertar el quinto curso ya que la escuela se encuentra en un plan de transformación que iba a llevar al centro a pasar de ser una escuela de primer ciclo de primaria a una escuela exclusivamente de segundo ciclo de primaria.

Esta transformación se debe a que con la próxima apertura de una nueva escuela pública muy cercana a Qillenso y ante la falta de escuelas que ofertaran el segundo ciclo de primaria en la zona (la más cercana está a más de una hora andando) los Padres Combonianos junto a las autoridades educativas han llegado al 
acuerdo de que sería bueno para la zona este cambio, al posibilitar de esta manera que los alumnos puedan seguir sus estudios una vez acabado el primer ciclo de primaria.

Por otra parte, y tras hablar con un padre comboniano destinado en otra misión entre los Guji en la que la escuela de primaria solo ofertaba el segundo ciclo de primaria (grados 5ㅇ a 8은 no estamos muy convencidos de que esta decisión haya sido muy acertada, ya que como nos contó este otro padre en la escuela de su misión, que solo oferta de 50 a 8o curso, casi no hay alumnos y los profesores prácticamente no tenían trabajo debido a la falta de demanda entre la población de una escuela de segundo ciclo de primaria (Padre Ramón Navarro, comunicación personal Noviembre de 2012).

Si analizamos estos datos según el género podemos observar que tanto en el caso de los varones como en el de las mujeres las tendencias son muy similares (Ver figura 78) aunque si es posible ver como el porcentaje de la matriculación femenina es superior en los dos primeros cursos respecto a los mismos datos de matriculación femenina. Mientras el $63,6 \%$ de las matriculaciones femeninas se concentran en primero y segundo solo el $61 \%$ de las matriculas correspondientes a chicos se corresponden a estos dos primeros cursos, invirtiéndose por tanto la tendencia en los tres cursos restantes, concentrándose en este caso el 39\% de las matriculas masculinas frente a un $36,4 \%$ de las matriculas femeninas. 


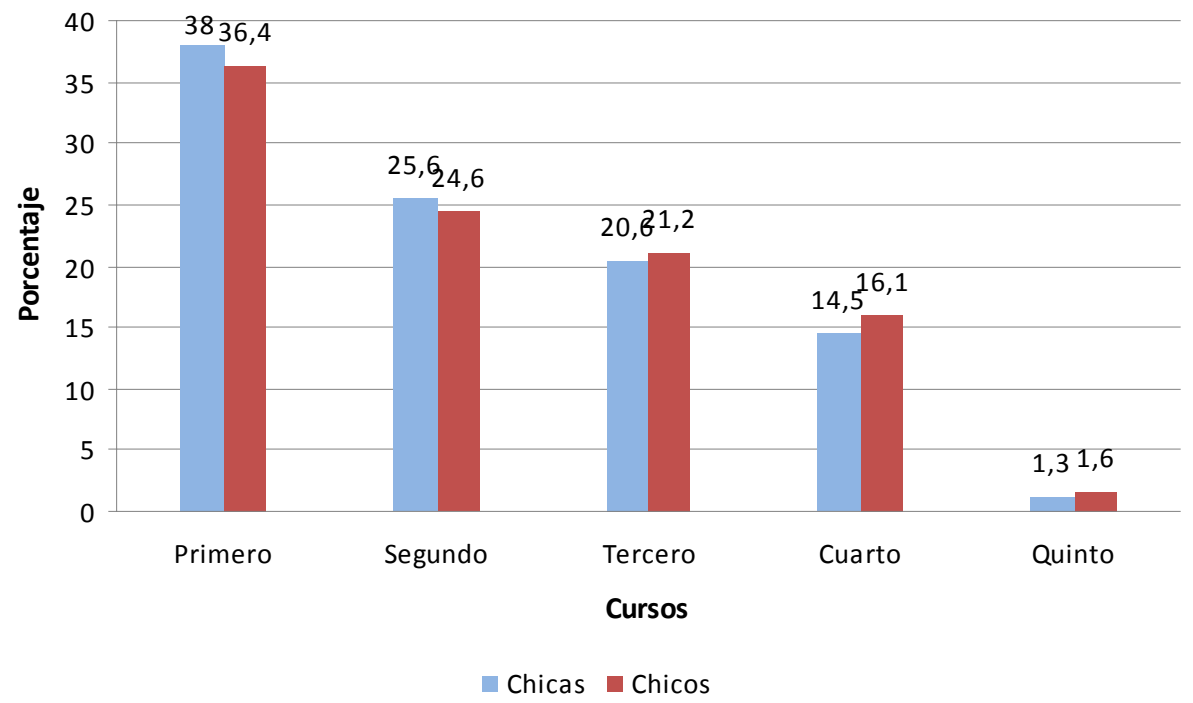

Figura 77. Distribución por curso dependiendo del género del porcentaje de alumnos en la escuela de Qillenso entre 1977 y 2012

(Fuente: Elaboración propia)

De esta manera tanto la Figura 77 como la Figura 78 vienen a confirmar que en Qillenso se ha estado produciendo los mismos fenómenos que en el resto de la Oromía y Etiopía, a saber, una mayor matriculación en los primeros cursos de primaria con el posterior abandono de la escuela y una menor presencia femenina en las aulas según avanzan los cursos.

Pero para obtener una imagen más ajustada a la realidad vamos a pasar a analizar la evolución de esta distribución del alumnado según el curso a lo largo de los 37 años de funcionamiento de la escuela de Qillenso.

En la Figura 78 podemos observar varios hechos que llaman la atención. Como comentábamos anteriormente el primo de estos hechos es la poca importancia que ha tenido el quinto curso a lo largo del funcionamiento de la escuela, solo ha sido ofertado de manera intermitente un total de cinco años. Además el porcentaje mayor de alumnos que ha tenido durante uno de los cursos que ha funcionado ha sido del $16,22 \%$.

De manera general y corroborando los datos que hemos expuesto anteriormente queda claro que a lo largo de todo el tiempo que ha estado funcionando la escuela de Qillenso el tándem formado por primero y segundo de 
primaria ha tenido un alumnado que suponía, exceptuando algún año puntual, entre un $50 \%$ y un $60 \%$ del total de chicos y chicas que asistían a la escuela, llegando hasta más de un 92\% en alguna ocasión.

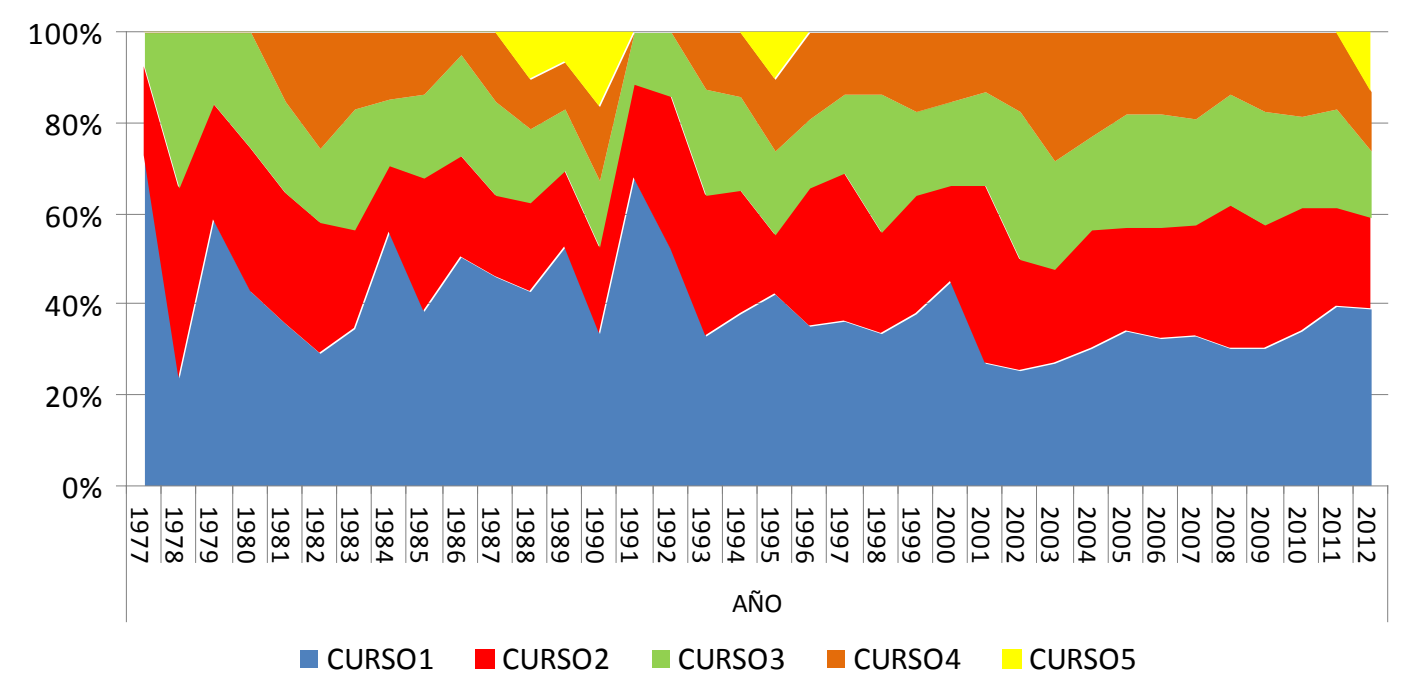

Figura 78. Evolución anual del porcentaje de alumnos según el curso

(Fuente: Elaboración propia)

En la Figura 78 podemos distinguir dos etapas o periodos, el primero de ellos transcurre entre 1977 y 1990 y el segundo entre 1993 a 2012.

La primera Etapa está caracterizada por una fuerte inestabilidad en los porcentajes de alumnos que cursan cada uno de los diferentes niveles y una dominación especialmente marcada del primer y segundo grado que durante varios años superan el $80 \%$ del alumnado de la escuela. También es destacable como durante los primeros cuatro años de funcionamiento de la escuela de Qillenso no existía siquiera el cuarto grado y como solo entre 1988 y 1990 estuvo presente el quinto grado en la escuela. De esta manera al analizar los primeros años de la gráfica es evidente que los porcentajes de alumnos que cursan cada nivel fluctúa en razón de la incorporación de los alumnos que el año anterior habían cursado un nivel inferior, esto queda muy claro al observar detenidamente los datos de 1977 y 1978 en los que claramente queda reflejado como el transvase de alumnos de primer a segundo curso es muchísimo más importante que la incorporación de 
nuevos alumnos, ya que se pasa de un $73,08 \%$ de alumnos de primero y un $19,23 \%$ de alumnos de segundo en 1977 a un $24,14 \%$ y un $41,38 \%$ respectivamente en 1978, unas diferencias que no podrían darse si el nivel de incorporación de alumnos a primer grade fuera constante. Esta inestabilidad parecía que se estaba corrigiendo a mediados de la década de los ochenta pero el periodo comprendido entre 1989 y 1993 volvió a regirse por unas fluctuaciones muy marcadas, estos años de vuelta a la inestabilidad conceden a su vez con los años de cambio de régimen político en Etiopía y la introducción de reformas educativas como ya hemos visto en los capítulos anteriores.

Por su parte la segunda etapa que comprende entre 1993 y 2012 se caracteriza por la consecución de una estabilidad de las distintas proporciones de alumnos que suponen cada curso. En esta nueva etapa el conjunto de primer y segundo curso se mantienen en valores alrededor del $60 \%$ mientras que tercer y cuarto curso se reparten el $40 \%$ restante. Finalmente durante los últimos años se ha producido un aumento de los alumnos que cursan primer curso de primaria bastante llamativo, esto podría achacarse a varios factores como la implantación de campañas para introducir a la escuela a los niños fuera del sistema educativo o ser el reflejo del a nivel local de la tendencia nacional a una mejora de la escolarización en primaria, pero bajo nuestro punto de vista este fenómeno se debe a una causa meramente local: La conversión de la escuela de Qillenso en una escuela de segundo ciclo de primaria. Esta conversión de la escuela ha espoleado a las familias de la zona a matricular a sus niños en la escuela ante la perspectiva de que si no lo hacen tendrán que enviar en los próximos años a sus hijos a escuelas distintas, posiblemente de peor calidad, y más alejadas de sus casas, ya que según el plan de conversión la escuela irá cerrando los niveles de primer ciclo de primaria según vaya abriendo los del segundo ciclo de primaria.

Si a continuación analizamos estos mismos datos dependiendo no solo del año sino también del género de los alumnos la visión que obtendremos será aún más completa y nos ayudará a comprender algunas de las diferencias entre los 
chicos y chicas una vez que están dentro de la escuela de Qillenso. Para ello mostramos las Figuras 79 y 80.

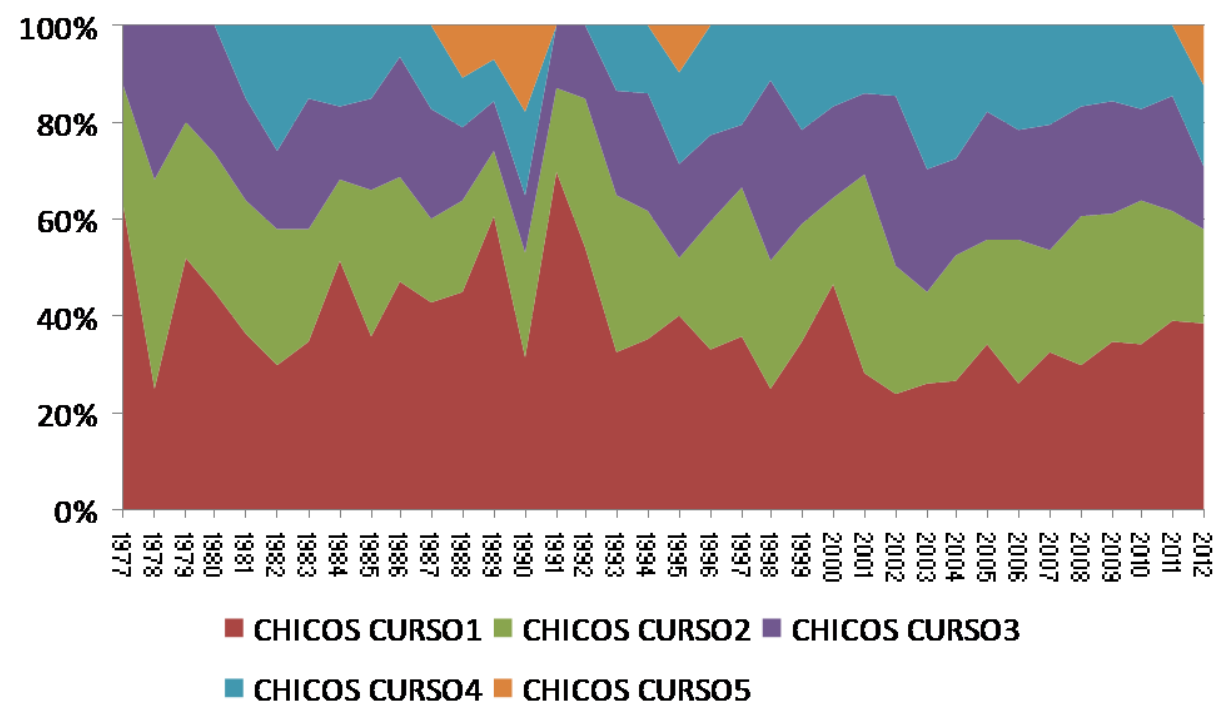

Figura 79. Evolución anual de la matriculación según el curso de los alumnos de la escuela de Qillenso

(Fuente: Elaboración propia)

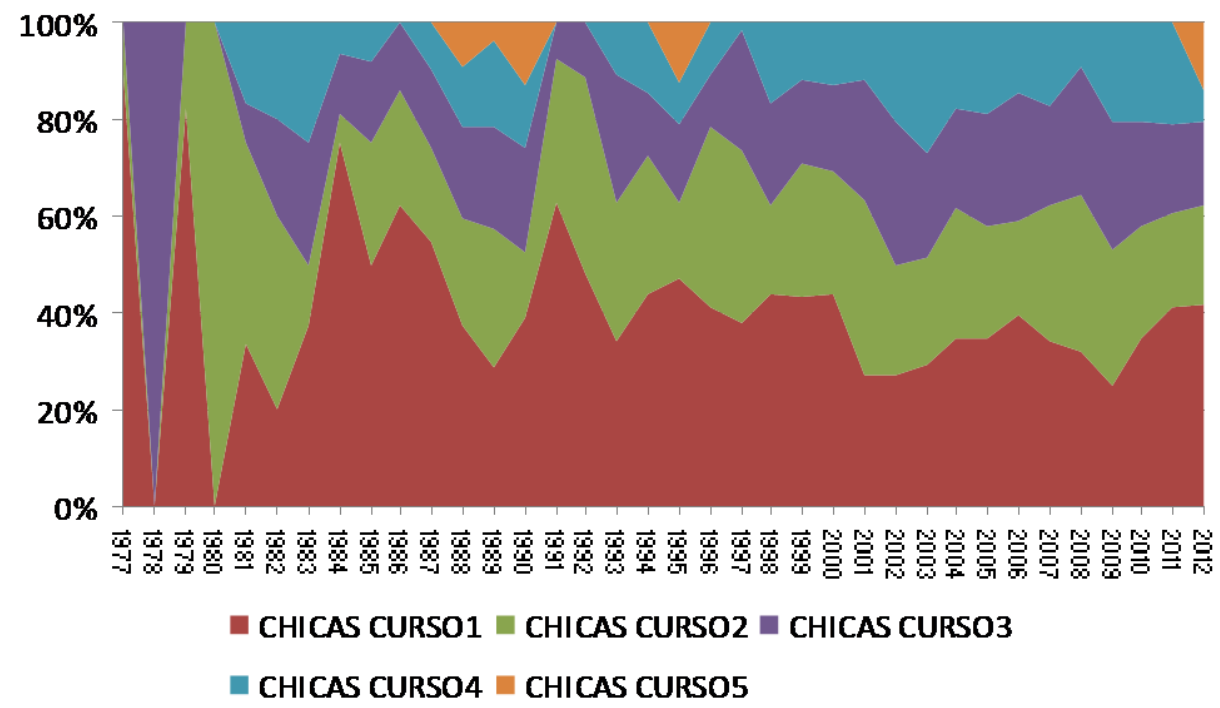

Figura 80. Evolución anual de la matriculación según el curso de las alumnas de la escuela de Qillenso

(Fuente: Elaboración propia) 
Si comparamos los primeros años de las dos figuras anteriores queda patente que se ha producido una mayor inestabilidad en el caso de las chicas que en el caso de los chicos, ejemplo de ello es como fluctúan los porcentajes de primero, segundo y tercero entre 1977 y 1979 en el caso de las chicas frente a una relativa estabilidad de los mismos en el caso de los chicos. Además en el caso de las chicas en estos primeros años podemos observar como durante varios años no hay alumnas matriculadas más allá de segundo grado, lo que es una prueba de la mayor debilidad de la escolarización femenina frente a la masculina, ya que ni siquiera las alumnas tenían la oportunidad de continuar más allá de segundo grado. Por lo demás y una vez superados los años 80 se puede observar una evolución similar en ambos géneros, siguiendo la línea que hemos comentado anteriormente al hablar de los datos en general sin tener en cuenta el género. Aún así hasta la actualidad todavía puede observarse como en el caso de las alumnas el primer y segundo grado tienen un peso superior al que suponen estos cursos para los chicos, ya que estos últimos muestran una distribución más uniforme entre todos los cursos frente a la menor presencia femenina una vez se va escalando cursos.

Como nota final a este apartado diremos que pese a la evolución hacia una pérdida de importancia relativa de primer y segundo curso desde el inicio del funcionamiento de la escuela es evidente que todavía tanto el primer como el segundo curso de primaria son los que tienen un mayor número de alumnos y continúa el fenómeno de abandono escolar que provoca la disminución del número de alumnado en las escuelas según se van avanzando por el primer ciclo de primaria. Que esta situación se sigue dando y que tristemente muchas veces los únicos a los que acuden los niños y niñas son primero y segundo tiene su reflejo en los datos del año 2012 en la escuela de Qillenso. Durante este año en el que realizamos nuestro trabajo de campo de las 6 aulas disponibles en la escuela la mitad estaban destinadas a primero y segundo de primaria y además el número de alumnos en estos dos cursos era de 87 en el caso de 10 y 44 en el caso de 20 lo que suponía un 59,2\% de los 221 alumnos que estudiaban durante ese curso en Qillenso alguno de los cinco cursos que la escuela ofertaba. Como afectará este fenómeno a 
la escuela de Qillenso no lo sabremos hasta dentro de unos años cuando se haya transformado completamente en una escuela de segundo ciclo de primaria, pero viendo otros ejemplos personalmente creemos que el número de alumnos que atenderán a esta escuela será muy inferior al actual una vez que solo se impartan de 5ㅇ a 8 o curso.

A continuación pasaremos a analizar las edades en las que los alumnos han estado matriculados en la escuela de Qillenso. Lo primero que destaca al ver la Figura 81 es la presencia de alumnos con edades de hasta 27 años, pero esto se debe a que cuando los Padres Combonianos abrieron la escuela lograron convencer a algunos adultos para que asistieran a la misma y aprendieran a leer y escribir.

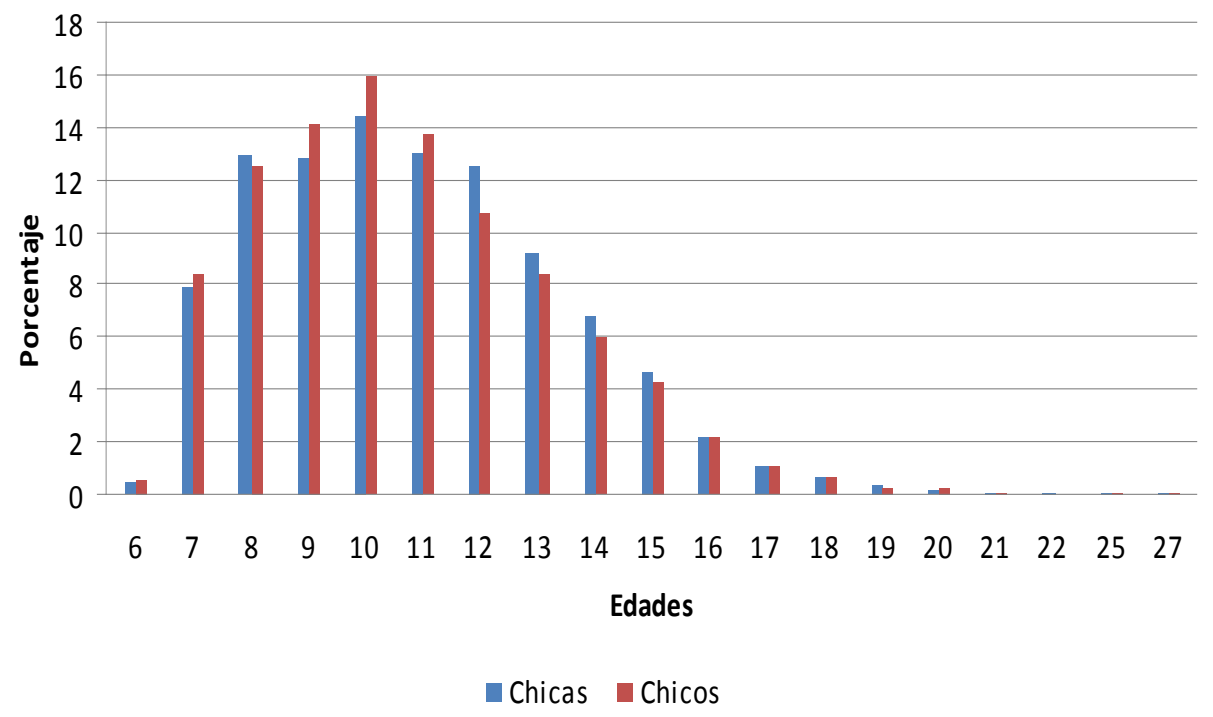

Figura 81. Escolarización según la edad y el género en la escuela de Qillenso

(Fuente: Elaboración propia)

Por otra parte en la gráfica queda claro cómo pese que el arco de edad oficial de escolarización en primer ciclo de primaria es el comprendido entre los 7 y 10 años (MoE, 2013) una gran cantidad de los estudiantes de Qillenso han sido matriculados en rangos de edad distintos a la oficial.

En el caso de los varones solo el 51,2 \% estaban en la escuela en la edad oficial de hacerlo mientras que en el caso de las alumnas solo el $48,3 \%$ fueron matriculadas en la edad oficial, esto nos muestra claramente que un gran 
porcentaje de los alumnos de la escuela de Qillenso acceden a la misma con una edad superior a la que deberían hacerlo (Figura 82).

Hay varias razones para ello que expondremos cuando tratemos de los problemas detectados en la escuela, pero como apunte diremos que se engloban en cuestiones de distancia, economía familiar y condicionantes culturales.

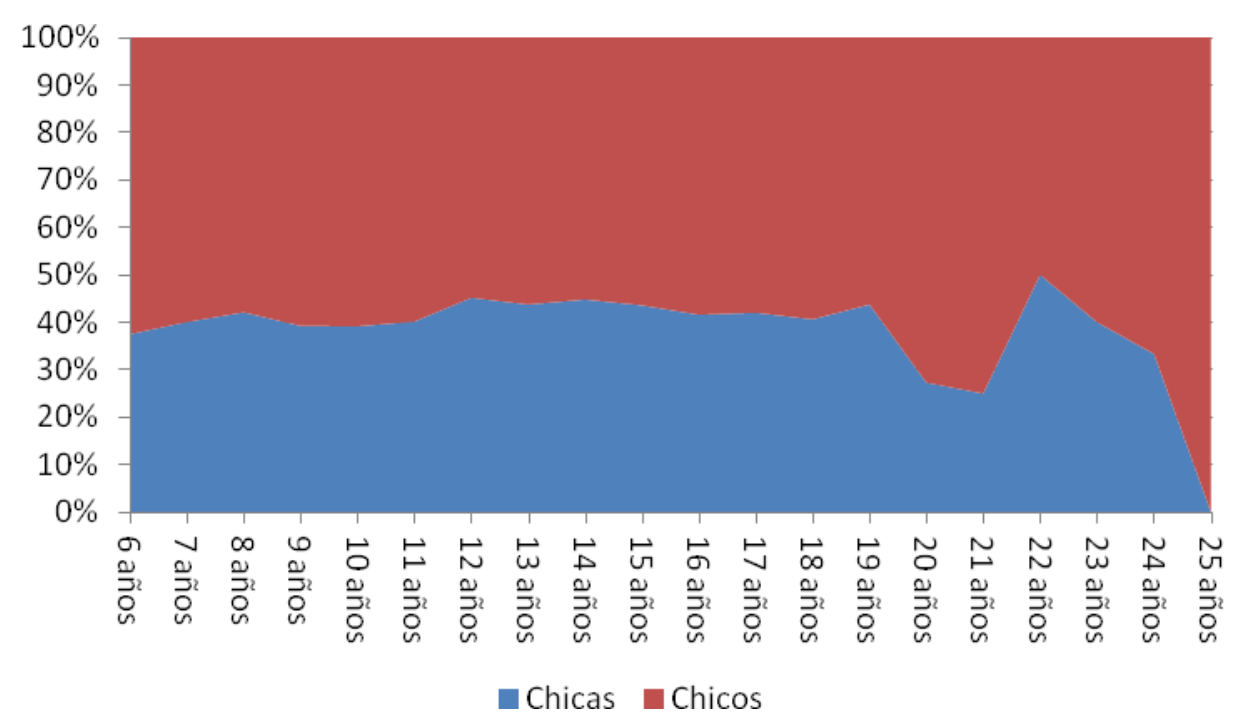

Figura 82. Escolarización según la edad y el género en la escuela de Qillenso.

(Fuente: Elaboración propia)

Si a continuación analizamos a los alumnos que se encuentran dentro del rango de edad oficial para la matriculación dentro del primer ciclo de primaria (7 a 10 años) podemos observar cómo dentro de este rango de edad desde mediados de los años ochenta del siglo pasado hasta el inicio del nuevo milenio más del $50 \%$ de los alumnos tenían 9 o 10 años, llegándose algunos años a un $80 \%$ del alumnado de estas edades. Si juntamos este dato con las estadísticas de la escuela en las que tanto 10 como 20 curso (En los que teóricamente los alumnos han de tener 7 y 8 años respectivamente) son dominantes nos deja muy claro como en Qillenso se reproduce uno de los problemas de la educación en Etiopía, la tardía escolarización de los niños y niñas en primaria (Figura 83). 


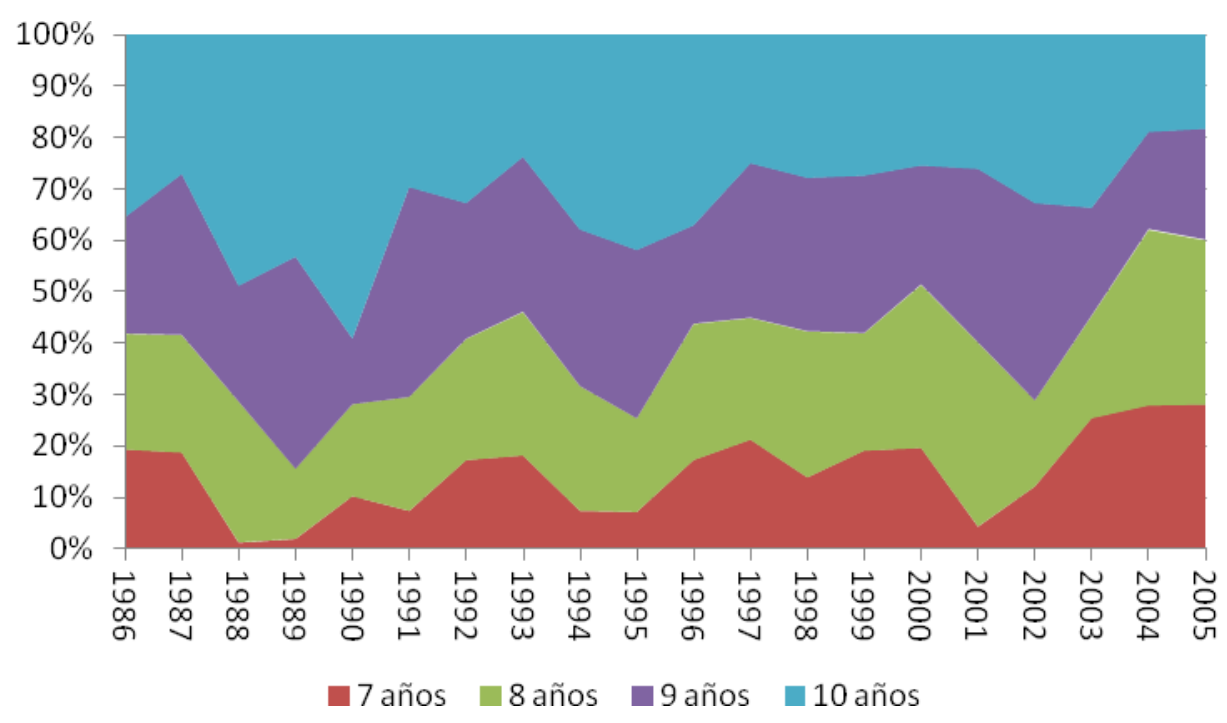

Figura 83. Escolarización según la edad de la escolarización obligatoria, y años, en la escuela de Qillenso

(Fuente: Elaboración propia)

\subsubsection{Retos presentes y futuros en la escuela de Qillenso}

En esta sección expondremos los problemas y condicionantes que afectan de una manera negativa al proceso de enseñanza-aprendizaje que hemos detectado durante nuestra presencia en el campo y que hemos podido confirmar tanto con los datos que hemos expuesto en esta capítulo como con algunas de las respuestas de los autoinformes que los alumnos de la escuela de Qillenso rellenaron y que analizaremos en el quinto capítulo de la presente investigación.

En primer lugar hay que señalar que parte de estos problemas en gran medida son iguales a los que hemos ido exponiendo en capítulos anteriores y que no solo ocurren en Qillenso, sino que también se dan a nivel nacional en Etiopía y a nivel regional en la Oromía. Esto nos indica que la escuela de Qillenso está en línea con el resto del sistema educativo etíope, pero al mismo tiempo en Qillenso varios de estas problemáticas que se producen a nivel general en el país se dan de una forma más intensa debido al aislamiento geográfico y a la pobreza de la zona. 
Por otra parte, y pese a la situación de especial vulnerabilidad que el sistema educativo tiene en la zona de Qillenso, hay que señalar el efecto positivo que ejerce sobre la escuela de Qillenso que sea propiedad y este gestionada por parte de los misioneros combonianos, ya que estos aportan unos fondos económicos y una experiencia profesional que ayuda a mitigar parte de estos problemas.

El análisis realizado a lo largo de estas páginas y que complementamos a continuación, nos permite afirmar que la educación altera o modifica la cultura Gujii. La educación reglada de corte occidental que se ha implantando en Etiopía y por tanto en Gujiland es un claro factor de cambio cultural y tiene un impacto en la identidad Guji.

Por otro lado, los datos recogidos con diversas fuentes dejan claro que el modelo educativo que se sigue en Qillenso, al igual que en el resto de Etiopía esta muy influenciado por la educación anglosajona. Este modelo se ha tomado como referencia a la hora de montar el sistema educativo del país. Para comprender este proceso hay que tener en cuenta la importancia histórica que ha tenido tanto Inglaterra como EEUU en el desarrollo del sistema educativo etíope tras la Segunda Guerra Mundial.

Con todo y dado que en las conclusiones finales de la presente Tesis Doctoral abundaremos en estas conclusiones, exponemos a continuación un análisis más específico de los problemas y puntos fuertes detectados en la Educación de estos niños.

\section{Falta de infraestructuras o infrautilización de las mismas}

En la escuela de Qillenso hemos podido observar de primera mano dos de los problemas más significativos dentro del sistema educativo etíope y que afectan en gran medida a la calidad de la enseñanza. El primero es la falta de infraestructuras, el segundo es la nula o muy escasa utilización de las infraestructuras disponibles. 
En Qillenso la falta de electricidad afectaba tanto a la posibilidad de un programa de educación por la tarde o por la noche tanto de primaria como de educación para adultos como por ejemplo a la apertura y utilización de la biblioteca por las tardes para favorecer hábitos de estudio entre los estudiantes.

Esta falta de electricidad en la escuela también afectaba al trabajo organizativo y administrativo de la misma ya que todo el papeleo debía realizarse a mano en un primer momento y después ser mecanografiado por nuestra parte - debían enviarse los documentos al pueblo de Boamba para que en establecimientos privados los copiaran a ordenador con la pérdida de tiempo y el gasto económico que eso suponía. En muchas ocasiones había que dejar cuestiones administrativas paralizadas a la espera de recibir los documentos mecanografiados ya que la oficina de educación de la que dependía la escuela de Qillenso en numerosos casos exigía que se le entregara la documentación transcrita a ordenador.

A su vez esta falta de electricidad impedía que se utilizaran recursos didácticos que necesitaran de esa energía como películas, programas de radio o televisión y la utilización de recursos informáticos a la hora de impartir las clases.

Esta utilización de nuevas tecnologías es uno de los programas que ha implantado el Ministerio de Educación de Etiopía y la oficina de educación de la Oromía, pero como denuncia esta propia oficina el problema que detectamos en Qillenso está muy extendido por el resto de las escuelas rurales:

"On the other hand there is educational media program which is conducted by the bureau in order to improve quality of primary education. But when compared with the area of the region and distribution of schools, the existing centers can't cover all the schools" (Oromia Education Bureau, 2005, pág. 23).

Por otra parte la falta de agua corriente también afectaba negativamente a la higiene y salud de los alumnos ya que provocaba que durante todo el horario escolar no pudieran beber agua o no pudieran realizar aseos básicos como lavarse las manos. 
Pasando ya a la infrautilización de las infraestructuras que si que tenía la escuela de Qillenso el caso más llamativo era el de la biblioteca, un aula equipada con todo el material necesario para su funcionamiento, única en su entorno como señalaba el Supervisor de la zona, y no fuimos testigos de que ni una vez un profesor usara la biblioteca para impartir clase a sus alumnos o solicitara su apertura para realizar actividades de estudio.

El aula de pedagogía por su parte, al haber sido trasladada a principios de curso por necesidades de espacio a la caseta auxiliar de madera quedaba de esta manera prácticamente inutilizable debido al mal estado de esta edificación. Por ello se convirtió más que nada, como ya explicamos anteriormente, en un almacén de materiales escolares y libros de texto de años pasados que ya no se podían seguir utilizando. La utilización de esta sala se redujo durante toda nuestra presencia a su apertura en busca de algún libro y para almacenar material que ya no se necesitaba o que estaba en mal estado.

\section{Problemas relacionados con el material didáctico}

En el apartado anterior hemos tratado el problema que suponía la falta de algunas infraestructuras que nosotros damos como básicas y como la presencia de otras no suponía su utilización. En este nos centraremos en un problema que comparte algunas características con el anterior, la poca disposición de material didáctico y su falta de adecuación al entorno.

Ya hemos señalado con anterioridad como los libros de texto utilizados en la educación primaria en Etiopía son proveídos por donantes internacionales. La gran mayoría de los libros escolares que examiné tenían el sello de USAID. Aunque pudimos observar que los libros de texto estaban escritos por etíopes y adaptados por tanto a la realidad de Etiopía había grandes problemas. El primero de ellos era la poca disponibilidad de libros, en Etiopía los libros son propiedad del estado que los distribuye por las escuelas según la necesidad de las mismas, ya que la gran mayoría de las familias no podría hacer frente a la compra de los libros. 
Este sistema que en principio no debería suponer un inconveniente provocaba en realidad una serie de problemas. El primero de ellos era que el número de libros disponibles era inferior a los necesario, sobre todo a principios de curso, lo que en nuestra experiencia de campo en Qillenso originó problemas entre los alumnos y que en determinadas asignaturas nos encontráramos con que un elevado número de niños tenían que compartir libro o que los profesores no tuvieran el llamado "libro del profesor", problemas que tardaron varias semanas en ser totalmente solucionados y que provocaron desajustes en el normal funcionamiento de la escuela.

Además esta escasez de libros creaba oportunidades para la corrupción como eran las situaciones de entregar los libros antes o después a determinada escuela dependiendo de las relaciones personales y favoritismos o la existencia de un mercado paralelo en el que se podían comprar los mismos libros que la oficina de educación no entregaba a la escuela ya que estaban supuestamente agotados.

Otro de los problemas más importantes era que pese que los libros estaban escritos por etíopes su adaptación a la realidad cultural etíope era en ocasiones deficiente, un ejemplo de ello lo vimos cuando en una unidad didáctica de un libro de inglés una de las preguntas que tenían que contestar los alumnos era que peligros creían que podía haber en una piscina cuando ninguno de ellos sabe siquiera que era una piscina y menos aún la ha utilizado. Por otra parte había capítulos muy bien adaptados a la situación de Etiopía, por ejemplo los que trataban del VIH y otras enfermedades.

Finalmente el último gran problema que detectamos en los libros de texto fue la significativa diferencia entre el nivel de contenidos que recogían los libros y por tanto nivel del conocimiento teóricamente exigido a los alumnos y el nivel real de los mismos. Donde mejor pudimos detectar este problema fue en los libros de texto de inglés, los cuales recogían un nivel de conocimientos muy superior al que los alumnos eran capaces de alcanzar. Sospechamos que este nivel tan elevado de conocimientos exigidos frente a los conocimientos reales se debe entre otros 
factores a que el gobierno de Etiopía sigue, en el tema de educación, estándares internacionales que poco tienen que ver con la realidad del alumnado en el país.

\section{Problemas relacionados con el profesorado}

Alguno de los problemas más importantes que pudimos observar en la escuela de Qillenso tenía que ver con sus profesores y el subdirector.

Los profesores en la escuela de Qillenso no están especialmente motivados para cumplir su trabajo, es una situación que ya vivimos en nuestra anterior experiencia en el sistema educativo etíope. Era muy común observar que los profesores llegaran tarde al trabajo, especialmente representativo de este problema es el ejemplo que nos otorga el saber cómo un día que llegaron una hora tarde ya que habían ido todos juntos a tomar té a una casa cerca de la escuela desde la que podían observar claramente como los alumnos les estaban esperando y estaban vagando y jugando en la escuela a la espera de la llegada de los profesores. Otro de los problemas cuyo origen era el profesorado es el que se producía al negarse estos a vivir en las cercanías de la escuela por lo que de esta manera no estaban disponibles para actividades que se tuvieran que llevar a cabo después del horario lectivo ordinario y que en época de lluvias con el empeoramiento del estado de las carreteras los profesores que vivían más alejados llegan generalmente tarde.

Para evitar este problema de la impuntualidad de los profesores el colegio constaba con un libro en el que tenían que firmar a su llegada pero o falsificaban la hora de entrada u otro profesor firmaba por ellos con la complicidad del subdirector que teóricamente debía asegurar el control riguroso de la asistencia. Solo el supervisor llevaba de una manera más estricta el control de la asistencia y puntualidad de los profesores pero al contar con una nula colaboración del subdirector esta tarea de control no era efectiva y cuando trataba de que se cumpliese era motivo de disputas entre ambos.

Otro ejemplo de la poca motivación o compromiso de los profesores para cumplir con su trabajo era que aunque según la normativa cuando se perdía 
horario lectivo por alguna situación como fuertes tormentas, actividades extraordinarias o simplemente por la enfermedad del profesor era obligatorio impartir clases de "Make up" es decir, recuperar los periodos lectivos perdidos. En todo el año, solo uno de los profesores realizó estas actividades, y solo el acudió a la escuela por las tardes para preparar sus clases o exámenes con el material que en el centro tenía disponible para ello.

También era muy común que los profesores perdieran tiempo lectivo quedándose en la oficina del subdirector charlando, saliendo de sus aulas a hablar entre ellos y lo que era especialmente habitual es que los periodos de educación física se limitaran a dar un balón a los alumnos y sentarse en los bancos de la oficina del subdirector dejando a los alumnos sin supervisión.

Por otra parte era fácil observar situaciones en las clases que destacaban por su falta de adecuación pedagógica, un profesor en particular utilizaba de una manera muy intensiva la técnica de la repetición constante por parte de los alumnos de frases que él decía como método para dar clases. Además el nivel de conocimientos de los profesores de algunas materias que debían enseñar no era el adecuado, claro ejemplo de ello era que alguno de los profesores que debían enseñar inglés no eran capaces de hablar este idioma sin encontrarse en dificultades.

Además para los profesores su trabajo en la escuela no era su principal fuente de ingresos o necesitaban llevar a cabo otras actividades económicas para completar los ingresos familiares. Puede que si fuera su principal fuente de dinero liquido pero con sus explotaciones agrícolas y ganaderas era con las que realmente subsistían. Los salarios que cobraban los profesores dependían de su nivel de estudios y de sus años trabajados, la media estaba situada en unos 1750 Birs brutos, unos 67 euros aproximadamente. Debido a la presión fiscal los salarios sufrían un recorte de un $25 \%$ aproximadamente y quedaban finalmente en unos 1300 Birs netos o lo que lo mismo unos 50 euros al mes y para empeorar la situación la alta inflación que vive el país junto a los sobrecostes de los productos debido al precio del transporte de las mercancías hasta una zona 
remota como Qillenso hacía que los salarios perdieran gran parte de su poder adquisitivo. De esta manera los profesores en muchas ocasiones estaban más preocupados por sus animales y cultivos que por impartir las clases, ausentándose de la escuela cuando sus explotaciones agropecuarias necesitaban su atención y dedicando más atención y energía a sus asuntos privados.

Ejemplo de la importancia superior de lo privado sobre la escuela para los profesores es que utilizaban a los alumnos como recaderos de sus asuntos privados, llegando en una ocasión un profesor a utilizar a los alumnos como porteadores de sacos de hierba que necesitaba para el tejado de su nueva casa durante el horario escolar.

\section{Problemas relacionados con las técnicas didácticas}

Aunque en el apartado anterior ya hemos señalado algún problema relacionado con las técnicas didácticas empleadas por los profesores creemos que es necesario reservar a estos problemas un apartado propio, ya que su importancia así lo requiere.

El primero de estos problemas como ya señalamos anteriormente es que muchos de los profesores utilizaban preferentemente como técnica para impartir conocimientos la repetición y memorización de los contenidos, lo que solo desarrolla la capacidad memorística y no favorece que los alumnos realicen el proceso de aprendizaje por autodescubrimiento que se ha demostrado como el mejor para conseguir un aprendizaje significativo y duradero en el tiempo. Ejemplo de ello era el del profesor anteriormente citado que utilizaba preferentemente la técnica de hacer repetir en voz alta a los alumnos todo lo que él decía una y otra vez.

El segundo problema que observamos fue la poca utilización de la escritura más allá de copiar al pie de la letra cualquier cosa que el profesor escribiera en la pizarra, esto provocaba que muchos de los alumnos tuvieran grandes dificultades a la hora de leer y sobre todo de escribir y lo hicieran de forma muy lenta. Ejemplo de esta poca utilización de la escritura es que todos los 
exámenes fueran tipo test y los alumnos tuvieran simplemente que señalar la opción elegida. Además este problema se agravaba ya que los alumnos de Qillenso tenían no solo que aprender a leer y a escribir con el abecedario occidental utilizado en la lengua Oromo, sino que además debían aprender también con el abecedario amhárico, con la dificultad que ello conlleva añadida.

Otro de los problemas didácticos detectados fue la gran cantidad de periodos lectivos que se perdían por diversos motivos a lo largo del curso escolar, casi todas las semanas por algún motivo los alumnos salían antes de tiempo del colegio o se suspendían las clases para que los alumnos colaboraran en alguna labor como la limpieza de las instalaciones. Ejemplo de ello era que todos los meses algún profesor, sino todos, se ausentaban de la escuela para ir a la oficina de educación para solucionar algún problema con su nómina pese a que los misioneros les ayudaban transportándoles en coche hasta la oficina de educación un día al mes por la tarde para evitar que lo hicieran en horario lectivo. Además en caso de que un profesor se ausentara por enfermedad o asuntos personales en muchas ocasiones no había ningún profesor disponible para cubrir su puesto o en caso de que si hubiera algún profesor libre normalmente este se limitaba a dejar que los niños y niñas jugaran por el patio. Hay que señalar que las ausencias de profesores eran mucho más frecuentes de lo que estamos acostumbrados en nuestras escuelas occidentales y debido a todos estos factores expuestos al final de curso la cantidad de horas perdidas de clase eran muy elevadas.

Otro problema que detectamos fue el provocado por la realidad sociolingüística de la zona y la utilización de los idiomas en la escuela. Los Guji utilizan su propio dialecto del Oromo, el Oromo Guji (OG) para comunicarse, dialecto que tiene algunas diferencias significativas, tanto en vocabulario como en gramática con el Oromo normalizado (ON) que se utiliza como lengua vehicular en las escuelas de la Oromía. Esto provocaba irónicamente que pese a que tanto en las clases como en los libros se utilizara el Oromo (ON) como método para defender el derechos lingüísticos de los Oromo a estudiar en su 
propia lengua los alumnos se encontraran en ocasiones con dificultades para entender sus libros ya que las diferencias entre el Oromo Guji y el Oromo Normalizado son suficientemente importantes para provocar problemas de comprensión. Es más los profesores de origen Guji tenían en ocasiones los mismos problemas para encontrar palabras en Oromo Normalizado o discutían entre ellos y con los profesores de otras partes de la Oromía sobre cómo era gramaticalmente correcta alguna frase en Oromo Normalizado.

Otro grave problema que detectamos fue el provocado por el deficiente conocimiento del amhárico. Este idioma que ejerce de facto como idioma oficial de de Etiopía es de enseñanza obligatoria en las escuelas, pero en la Oromía por motivos principalmente ideológicos no se empieza enseñar hasta el 4ำ curso. Ya hemos visto anteriormente el alto grado de abandono escolar que hay antes de ni siquiera alcanzar cuarto curso por lo que como consecuencia de ello muchos alumnos en Qillenso y en la Oromía jamás dan clase de amhárico y si la reciben solo consiguen unos conocimientos muy limitados, con el problema que ello supone para su día a día en el futuro sobre todo si pretenden salir de la Oromía o encontrar trabajo en las ciudades donde el amhárico está desplazando al Oromo en la propia Oromía. De todas maneras de este problema sociolingüístico y de la utilización de la escuela como arma política hablaremos más adelante en las conclusiones.

Por último cabe señalar que, al igual que sucediera hace años en las aulas de nuestro país, el recurso a los castigos físicos como método para corregir los comportamientos de los alumnos, sobre todo la falta de puntualidad o las faltas de respeto a los profesores en clase, sigue están vigente en algunos casos. Y ello pese a que su utilización esté prohibida por la legislación etíope. Pero como antes indicamos, el castigo físico es habitual y socialmente aceptado y utilizado también por los padres por lo que no hay gran oposición social a su utilización. 


\section{Problemas relacionados con el Supervisor}

Aunque podríamos haber incluido al Supervisor de la zona en los problemas de personal de la escuela, debido a sus características especiales hemos considerado analizar los problemas relacionados con este actor en un apartado exclusivo.

Así, la figura del Supervisor fue introducida con la intención de asistir a los profesores en las escuelas, asegurarse de que el proceso de enseñanza aprendizaje fuera realizado correctamente y cerciorarse de que las escuelas tenían los recursos necesarios para funcionar:

"To ensure whether the educational process has met it's goals or not, continuous educational supervision has to be conducted by professionals. The major purpose of school supervision was focused on identifying shortcomings of the process and coming up with constructive suggestions" (OEB, 2005, pág 23).

El problema en Qillenso es que la figura del Supervisor llegó a ser tan intrusiva que provocaba problemas en el funcionamiento de la escuela. Entre otras acciones, el supervisor realizaba comentarios o peticiones que provocaban malestar en los profesores y afectaban al desarrollo normal de la actividad en la escuela, suscitando enfrentamientos y pérdida de tiempo en los horarios lectivos.

Entre sus funciones se incluían entrar en clase con los profesores y supervisar cómo ejercían su trabajo, hablar con los docentes tras las clases y elaborar informes. Sin embargo, tuvimos ocasión de contemplar cómo en alguna ocasión accedía a las clases, corregía al profesor, le interrumpía y cuestionaba su modo de impartir las clases, lo que provocaba el enfado del profesor al verse desautorizado e interrumpido enfrente de sus alumnos. Hay que entender que la autoridad de los profesores en Etiopía en clase es incuestionable y que este comportamiento por parte del Supervisor es claramente humillante para el docente.

Por otra parte, el enfrentamiento personal que tenía con el subdirector de la escuela era muy marcado; las peleas entre ambos llegaban a tal nivel que el 
subdirector amenazó con dejar de realizar su trabajo si no se ponía en su sitio al Supervisor desde la oficina de educación o desde la propia escuela. Además, al tener que compartir la misma oficina, la presencia del supervisor y su forma de inmiscuirse en los asuntos de la administración de la escuela en los que no tenía potestad ni competencia provocaba que los enfrentamientos entre subdirector y supervisor fueran continuos y ralentizaran el funcionamiento de la escuela ya que invertían gran cantidad de tiempo en discutir o simplemente el subdirector dejaba para más adelante cuestiones para poder abordarlas sin que estuviera el supervisor presente.

Otra de las actuaciones cuestionables del supervisor eran los informes comparativos entre las escuelas. Así, si bien la escuela de Qillenso era la mejor de la zona e incluso el año anterior a nuestra estancia había recibido un premio por ello, debido a sus enfrentamientos personales con los profesores o incluso con algunos de los Padres Combonianos de la misión, el supervisor puntuaba varios aspectos de la escuela con extrema dureza y así bajaba su nota media en los informes. Un ejemplo de ello era fue la penalización que sufrió en su informe la escuela por el mal estado de la cancha deportiva mientras que otra escuela que no contaba con un espacio para realizar deporte (más allá de un prado sin ningún tipo de preparación) había sido puntuada de manera superior a la escuela de Qillenso en dicho apartado.

En otras ocasiones sus consejos y advertencias sobre las carencias de la escuela sobrepasaban los límites de sus funciones, exigiendo que la escuela tuviera servicios más allá de toda posibilidad realista. Ejemplos de ello fue cuando solicitaba que se le habilitara una sala como oficina para él solo o cómo semana tras semana pedía que se contratara maquinaria pesada para reparar el firme del campo de futbol estropeado por las lluvias torrenciales, cuando esto hubiera supuesto acabar con el presupuesto de la escuela de varios años.

Otra característica de sus peticiones era que se preocupaba en mayor medida por la imagen externa de la escuela y por sus instalaciones que por el funcionamiento real de la misma. Tanto en nuestras notas de campo como en el diario de la escuela gran parte de sus requerimientos estaban centrados en 
aspectos externos que no afectaban prácticamente a la calidad del proceso de enseñanza-aprendizaje. No obstante y como señaláramos previamente, esto no es solo achacable al supervisor sino que la preocupación por la imagen es una constante en el sistema educativo etíope.

Personalmente creemos tras nuestra experiencia en Qillenso y la experiencia previa que los supervisores de educación tienden a exigir una gran cantidad de requisitos a las escuelas gestionadas por organizaciones extranjeras ya que tienen la mentalidad de que "los blancos" tienen dinero y pueden permitirse una gran cantidad de gastos, lo que les permitiría a la postre, presumir en la oficina de educación de las buenas infraestructuras y servicios que tienen las escuelas bajo su supervisión.

Pese a lo dicho, es también fácil adivinar que los supervisores se encuentran bajo la presión de las oficinas de educación para que mejore el desempeño de las escuelas bajo su supervisión y para que estas mismas oficinas puedan mostrar buenos datos a las inspecciones de educación que manda el Ministerio. El temor al superior, rasgo de la cultura etíope, puede contribuir a explicar su comportamiento.

También hemos de añadir que, por otra parte en ocasiones la presencia del supervisor era beneficiosa para la escuela ya que añadía presión a los profesores y subdirector para realizar su trabajo de forma correcta. No obstante, el exceso de celo del supervisor, su tendencia a controlarlo todo, sus enfrentamientos personales con el profesorado y su mayor preocupación por la imagen que por el funcionamiento real de la escuela reducía en gran medida la calidad de su trabajo.

\section{Falta de aplicación de los planes y programas:}

En nuestra presencia en el terreno pudimos observar cómo, pese a la constante elaboración de planes y reuniones para diseñar $u$ organizar estrategias y actuaciones educativas en la zona, a la hora de la verdad no se llevaban a cabo casi ninguna de ellas. Ejemplos de ellos son que jamás se realizó ninguna actividad para favorecer la educación en pre-primaria con el plan conocido como "Zero-class". De hecho, ni siquiera los profesores intentaron localizar a niños en la zona fuera del 
sistema educativo. Tampoco se impartieron clases de educación para adultos, ni se llevaron a cabo prácticamente sesiones de recuperación o "Make-up" como ya comentamos anteriormente.

Otro ejemplo de ello fue que pese a que se organizaron los distintos departamentos educativos (departamento de ciencias, sociales, inglés...) y se nombró a distintos profesores como directores de los mismos, en ningún momentos durante nuestra estancia se coordinó desde estos departamentos la impartición de las materias y cada profesor iba por libre en cuanto a los contenidos que impartía y al tiempo que le dedicaba a cada uno de ellos. Así pues, los departamentos son otro ejemplo de energía, tiempo y recursos gastados en organizar programas sobre el papel para adaptarse a las exigencias del Ministerio de Educación, sin que ello fuera seguido por actividad real alguna.

Los únicos programas que vimos realizar fueron las competiciones escolares entre las cuatro escuelas de la zona en las que alumnos escogidos tenían que responder a cuestiones de diversas materias y los ganadores recibían un premio en forma de material escolar.

\section{Problemas relacionados con los usuarios de la escuela}

En este apartado haremos referencia a los problemas detectados que tienen su origen en los alumnos y en sus familias, ya que no hay que olvidar que la escolarización y la asistencia a clase de los niños de primaria depende casi exclusivamente de la voluntad de sus padres. Por esta razón hemos decidido tratar a los alumnos y a sus familias como un todo, ya que los condicionantes que afectan a la escolarización de los niños y niñas tienen su origen en las familias y en el entorno cultural, económico y social en el que unos y otros se mueven.

\section{1) Condicionantes económicos}

El primero y posiblemente más determinante de estos impedimentos que detectamos fue el relacionado con la economía familiar y la necesidad de la fuerza de trabajo que suponían los niños. Tanto niños como niñas realizaban labores 
domésticas, de trabajo en el campo y con el ganado. Estas labores eran tanto de tipo diario como de tipo estacional y variaban en cuanto al tiempo y esfuerzo que requerían.

Según lo observado durante nuestra estancia, la gran mayoría de las tareas diarias eran realizadas por los alumnos en las tardes, por lo que en un principio no tendría por qué afectar a la escolarización de los niños. No obstante, hay algunas tareas encargadas a los niños que sí afectan directamente o impiden la escolarización, como es la necesidad de cuidar de los hermanos pequeños.

El cuidado de los hermanos pequeños provocaba, especialmente en el caso de las niñas, la escolarización tardía o el abandono prematuro de la escuela. Otras tareas diarias como la recogida de leña o el cuidado de los animales aunque se realizaran fuera del horario escolar acababan teniendo un impacto negativo en la escolarización y rendimiento de los alumnos. Ejemplo de ello fue la conversación que mantuvimos con una chica que aunque había logrado alcanzar la educación secundaria se quejaba, tras relatar un extensa lista de tareas que tenía que realizar a diario, de cómo sus obligaciones domesticas le impedían estudiar lo suficiente. Además debido a que estas tareas se debían realizar durante las horas de luz solar los alumnos tenían que estudiar y realizar las tareas encomendadas por sus maestros cuando la luz natural no era suficientemente intensa como para poder leer y escribir con comodidad, situación agravada por la falta de luz eléctrica en las casas del área de Qillenso.

Por otra parte, las tareas que los alumnos habían de realizar fuera de horario escolar afectaban a la posibilidad de participar en programas educativos especiales de refuerzo como el que llevamos a cabo para fomentar el conocimiento del inglés. Así pues, nos veíamos obligados a reducir el tiempo en estas actividades para evitar interferir con el trabajo de los niños en sus casas; en otros casos, los padres les prohibirían acudir por estas razones.

Otro grupo de tareas fundamentales para la economía familiar en las que los niños tienen que participar junto al resto de los miembros de la familia, están 
relacionadas con periodos específicos del calendario agrícola. Se trata de los momentos en los que se lleva a cabo la siembra y recolección de las cosechas. Durante esos días el gobierno etíope otorga vacaciones especiales y a la vez intenta ajustar el inicio y final del curso para facilitar la conciliación entre la escolarización y los momentos de mayor carga de trabajo en el campo. Sin embargo, normalmente estas tareas acaban causando la perdida de varios días lectivos, ya que los profesores suelen alargar los días libres que otorga el gobierno para realizar ellos mismos estas tareas de recolección en sus tierras. De hecho, durante los días anteriores y posteriores a los días libres decretados por el gobierno pudimos observar una notable reducción de la asistencia a clase por parte de los alumnos.

Además, debido al respeto por la cultura tradicional, muchos padres no solo ven necesario sino deseable que los niños y niñas trabajen para ayudar a mantener a la familia ya que así se forman y conocen las técnicas que necesitarán en su vida adulta para trabajar en el campo, cuidar al ganado y, en el caso de las niñas, cuidar del hogar y de los hijos, aparte de saber llevar a cabo las tareas económicas tradicionales de las mujeres. Esta importancia otorgada tradicionalmente a que niños y niñas aprendan desde muy jóvenes las técnicas de trabajo en la casa y el campo necesarias para su vida de adulto queda reforzada además con la falta de perspectivas de un futuro mucho mejor si se completan los estudios. Y ello porque prácticamente la totalidad de los niños de la zona al llegar a su vida adulta se dedicarán a las mismas actividades económicas tradicionales que sus padres.

Un ejemplo de cómo el trabajo infantil es visto como algo normal en la sociedad Guji es que en los colegios públicos de la zona (al igual que sucede en otras áreas de Etiopía) los alumnos tienen que trabajar algunos días en campos adyacentes cuya producción es vendida, tanto para ayudar a sostener económicamente el colegio como para dar respuesta a otras necesidades. Por ejemplo, los profesores de Qillenso organizaban a los alumnos para realizar tareas como la limpieza de las instalaciones o el transporte de maderos para la construcción de la nueva escuela de primaria sin que ello provocara queja alguna por parte de los padres o de la oficina de educación de la zona. Esta aceptación del 
trabajo infantil está unida a la situación económica de las familias; situación que afecta además a la asistencia de los alumnos a la escuela de otras maneras distintas a las que acabamos de explicar. Así, debido a los limitados recursos monetarios de las familias es muy común que éstas no puedan permitirse que sus hijos tengan un periodo de escolarización en primaria completo si ello supone prescindir de su trabajo. En Qillenso tuvimos oportunidad de ver cómo, una vez finalizado el primer ciclo de primaria, muchas familias dejaban de enviar sus hijos al colegio ya que éste se encontraba en una localidad cercana lo que obligaba a que los alumnos tuvieran que desplazarse a diario o directamente alquilar una habitación y vivir allí durante el curso. Durante nuestra presencia conocimos de primera mano el caso de una chica que asistía a clase gracias al apoyo económico de la misión católica y al hecho de que trabajara los fines de semana y los periodos de vacaciones para sufragar los gastos del colegio.

Esta situación, ya de por sí complicada, empeoraba a la hora de continuar y asistir a la educación secundaria. Así, mientras que el colegio de educación primaria de segundo ciclo estaba en una localidad relativamente cercana (hora y media andando) el instituto de educación secundaria más cercano se encontraba a 40 kms. Por tanto y respecto al segundo ciclo de primaria, mientras que algunos alumnos de la zona Qillenso se desplazaban a diario al colegio, otros optaban por alquilar una habitación en la localidad donde estaba el colegio permaneciendo allí durante los días de actividad lectiva. En el caso del instituto, debido a la distancia, al tiempo necesario para el desplazamiento y al coste del transporte, era indispensable el alquiler de una casa, cosa que muchas familias no podían permitirse, tanto por la pérdida de esta fuerza de trabajo como por la imposibilidad de pagar los altos gastos que suponen el alquiler y la manutención de una persona en un centro "urbano" donde los precios son más elevados.

Otra evidencia de cómo la situación económica de las familias es un condicionante importante en la escolarización de los niños y de cómo el trabajo infantil es socialmente aceptado es el hecho de que en todas la reuniones de padres siempre surgían protestas por tener que pagar 25 Birs para matricular a los alumnos 
a principio de curso mientras que en los colegios públicos no había que pagar nada. Esta supuesta gratuidad de los colegios públicos es irreal ya que, como hemos señalado anteriormente, los alumnos deben contribuir con su trabajo al sostenimiento del colegio, situación que no levanta ninguna protesta por parte de los padres. Por otra parte, aunque 25 Birs no supongan una cantidad muy significativa de dinero no hay que olvidar que muchas familias Guji siguen manteniendo una economía de subsistencia en la que conseguir dinero líquido supone tener que invertir parte de su producción agrícola que podría ser utilizada más eficientemente si se consumiera directamente por la familia. Así pues, es comprensible que muchas familias prefieran el trabajo infantil en la escuela a tener que desembolsar cualquier cantidad de dinero.

\section{2) Condicionantes culturales}

Un condicionante cultural que perjudica especialmente la escolarización femenina es el tipo de parentesco patrilineal de los Guji. Así, las chicas están destinadas a ser entregadas en matrimonio y a formar parte de la familia de su marido. Por ello los padres son más reticentes a invertir recursos en la educación de sus hijas ya que todos estos recursos los "perderán" cuando, al casarse sus hijas, los beneficios de tal inversión, si es que se producen, sean disfrutados por la familia del marido.

Por otra parte en la escala de valores de la sociedad Guji dedicarse a la ganadería esta altamente estimado por lo que muchas padres prefieren que sus hijos aprendan las técnicas agropecuarias y modo de vida tradicional antes que mandarlos a la escuela ya que consideran que el mejor futuro posible es el que les puede ofrecer dedicarse a las actividades agropecuarias, además es impotante comprender que dentro de la propia identidad Guji el ganado tiene un rol fundamental, como ya hemos expresado con anterioridad un hombre Guji sin ganado no es considerado propiamente un Guji "completo" por lo que la presión para formarse desde niño en el modo de vida tradicional es aún mayor. 
A ello se añade el hecho de que los padres de los niños etíopes creen que enviar a sus hijos a la escuela no garantiza su aprendizaje debido a la baja calidad del sistema educativo (Asselin y Doiron, 2009).

Otro condicionante a tener en cuenta a la hora de analizar el rendimiento de los alumnos en la escuela se relaciona con el hecho de que muchos padres tienen una formación mínima o nula, por lo que es más difícil que puedan ayudar a sus hijos con sus estudios o que entiendan la importancia de la escuela para el futuro de sus hijos. Sobre este punto hay que señalar no obstante que, en varios de los casos que conocimos más profundamente, los padres y madres estaban concienciados de la importancia de la escuela aunque también conocimos muchos casos que no valoraban realmente la escuela y no les importaba que sus hijos no asistieran a clase.

Aún así se producían situaciones que chocaban con nuestro punto de vista occidental. Por ejemplo, uno de los profesores, posiblemente el más profesional y concienciado de su labor y de la importancia de la educación, no tuvo inconveniente en que uno de sus hijos dejara la escuela un año pese a sus buenos resultados para así "esperar" a uno de sus hermanos y acudir juntos el siguiente año a la misma clase.

Como hemos visto en este apartado, en la escuela de Qillenso pudimos observar cómo los alumnos y sus familias han de hacer frente a una serie de condicionantes sociales, económicos y culturales que afectan tanto a las posibilidades de escolarización de los niños como sobre todo a los años y modo que esta escolarización es llevada a cabo.

\section{Puntos fuertes detectados en la escuela de Qillenso}

Pese a que en las secciones precedentes nos hemos centrado en el análisis de los problemas detectados en la escuela objeto de estudio, hemos también de indicar que nuestra estancia nos ha permitido identificar una serie de puntos fuertes que pueden ser utilizados como base para mejorar la educación en la escuela de Qillenso. 
El principal punto fuerte es la presencia de los Padres Combonianos en el lugar. Ellos son la llave para canalizar recursos del exterior como fondos económicos, materiales didácticos o la presencia de profesores extranjeros que pueden ayudar en gran medida a mejorar el proceso de enseñanza-aprendizaje en la escuela. Esta presencia beneficiosa de los combonianos ya es palpable en el hecho de que por ejemplo la escuela sea en términos objetivos y esté considerada la mejor de la zona, tenga las mejores instalaciones y posea una gran cantidad de materiales y recursos disponibles. La canalización de recursos del exterior no está exenta de dificultades relacionadas con la obtención de permisos de trabajo y de estancia para voluntarios, la existencia trabajadores expatriados, elevados impuestos y problemas burocráticos que obstaculizan la importación de materiales.

Además como líderes en la comunidad también favorecen la valoración de la educación entre los Guji de la zona e introducen ideas y valores que son favorables a la educación de los niños. Así, en varias ocasiones nos informaron de casos en los que habían logrado convencer a familias de que llevaran a los niños a la escuela y también fuimos testigo de uno de estos intentos.

Por otra parte también hemos conocido varios casos en los que la misión sufragaba los gastos de escolarización de varios niños, no solo en la escuela de Qillenso sino también de chicos y chicas que acudían a clase a centros de secundaria en localidades vecinas.

Tras el análisis de una realidad compleja y que se ha de enfrentar a numerosos retos y condicionantes culturales, sociales, económicos, etc., pasamos en el capítulo siguiente a indagar en la percepción de los propios alumnos de la escuela de Qillenso. 


\section{CAPÍTULO 5. LA SITUACIÓN DE ALUMNOS DE PRIMARIA OROMO GUJII EN LA ESCUELA DE QILLENSO DESDE SU PROPIA PERSPECTIVA}

\subsection{PRESENTACIÓN}

A lo largo de esta investigación hemos pretendido utilizar de una manera equilibrada tanto el punto de vista "etic" como el punto de vista "emic". Para ello hemos utilizado técnicas de investigación antropológica variadas que pretendían dar voz tanto al punto de vista del investigador como al de los agentes o usuarios que participan en el proceso de enseñanza-aprendizaje en la escuela de Qillenso.

En este capítulo sin embargo hemos decidido centrarnos casi exclusivamente en la perspectiva "emic" y dar la voz a los alumnos de la escuela de Qillenso. Consideramos este aspecto especialmente importante por varias razones. Primero porque como principales usuarios del servicio educativo analizado, su opinión ha de ser tenida en cuenta. Segundo, porque creemos necesario conocer las fortalezas y debilidades de la educación desde su propia perspectiva ya que, como futuros padres y madres, la opinión sobre la importancia y utilidad que los niños de hoy en día tengan de su paso por la escuela será fundamental para que en un futuro estén concienciados de la necesidad de que sus hijos asistan a la escuela el máximo tiempo posible y adopten medidas acordes con dichas creencias.

\subsection{OBJETIVOS}

Con el presente estudio, pretendemos responder a los siguientes objetivos:

1. Conocer el perfil y circunstancias de los alumnos que asisten a la escuela de Qillenso.

2. Conocer sus percepciones sobre la satisfacción con la escuela.

3. Conocer su percepción de su calidad de vida. 
4. Conocer la asociación entre calidad de vida y satisfacción con la escuela.

5. Identificar la percepción de la satisfacción de los estudiantes en función de variables sociodemográficas (edad, género, etc.).

\subsection{HIPÓTESIS}

1. Los alumnos de la escuela de Qillenso mostrarán características sociodemográficas similares a las observadas en las estadísticas locales y nacionales.

2. Los alumnos mostrarán una elevada satisfacción con la escuela.

3. Los alumnos mostrarán una elevada valoración de su calidad de vida.

4. Existirán asociaciones positivas y significativas entre satisfacción con la escuela y calidad de vida.

5. Las variables socioculturales afectarán a la valoración de la satisfacción con la escuela.

6. Las variables socioculturales afectarán a la valoración de la satisfacción con la calidad de vida.

\subsection{Aspectos MetodolóGicos}

\subsubsection{Diseño del estudio}

Al igual que en el capítulo anterior el diseño del estudio lo dividimos en una serie de fases, como indicaremos a continuación.

\section{1․ Etapa de planificación}

Durante esta primera fase realizamos una planificación completa del estudio, analizamos la bibliografía disponible, realizamos una búsqueda y estudio de investigaciones similares y recogimos información actualizada sobre el país y zona en la que se íbamos a trabajar. También analizamos las etnografías sobre los Oromo Guji. Posteriormente llevamos a cabo la selección y diseño de las técnicas e 
instrumentos necesarios para llevar a cabo el estudio y de los cuestionarios a completar. Además, como en el caso anterior, seleccionamos el material que íbamos a utilizar, llevamos a cabo una estimación de los recursos económicos que íbamos a necesitar, establecimos una planificación temporal y obtuvimos los permisos necesarios para llevar a cabo el estudio.

\section{2o Etapa de trabajo de campo}

En esta segunda fase, al igual que en el estudio anterior, pasamos por una fase de adaptación física y psicológica al terreno. Una vez preparados, comenzamos con la recogida de datos mediante el uso de técnicas clásicas de la antropología. Ello sirvió para adaptar los cuestionarios que llevábamos previamente preparados a la lógica cultural de los Guji y a la realidad en la que nos encontrábamos evitando así que las preguntas carecieran sentido para los participantes. Además llevamos a cabo una traducción de los cuestionarios con la ayuda de nuestros informantes clave (véanse Anexos 8.2 y 8.3).

\section{3o Etapa de análisis de datos}

En esta fase realizamos el análisis y clasificación de la información obtenida mediante las entrevistas autocompletables y propia observación. Con la información ya procesada pasamos a la cuarta fase de síntesis y redacción.

\section{Etapa de síntesis y redacción}

Esta última etapa se caracterizó por el proceso de transcripción, composición y redacción de la información obtenida, tanto en la segunda como en la tercera fase.

\subsubsection{Acceso al campo}

Por tratarse del mismo proceso expuesto en el capítulo precedente y en aras de la brevedad, remitimos al lector interesado a dicho capítulo. 


\subsubsection{Recogida de datos mediante cuestionarios: Aspectos previos}

En el presente estudio mostramos en primer lugar los análisis realizados con los cuestionarios para analizar sus propiedades psicométricas. Dichos análisis se basan en la denominada Teoría de Respuesta al Ítem o Modelo Rash. En segundo lugar, hemos empleado estadísticos descriptivos y análisis de frecuencias para determinar las percepciones de los participantes sobre aspectos relativos a la escuela y a su satisfacción vital. En tercer lugar, para el contraste de hipótesis relativo a la diferencias entre grupos en función de variables sociodemográficas, hemos empleado pruebas paramétricas (análisis múltiple de varianza y análisis de varianza).

El enfoque émic considera las manifestaciones de un fenómeno (p.e. la satisfacción escolar) desde distintas vertientes. Por un lado, emplea diversos grupos de informantes. Además, requiere realizar un análisis cualitativo basado en las opiniones de los expertos para definir un constructo o tema de interés y construir un conjunto amplio de ítems que formen parte de un cuestionario (Wong, Wu, Guo, Lam, \& Snowden, 2012).

El desarrollo de una escala o autoinforme desde una perspectiva émic supone dar los pasos siguientes: (1) definir el constructo basado en la concepción del mismo por parte de la población de interés; (2) diseñar ítems acordes con la descripción del contenido; (3) definir el "espacio de resultados", esto es, el conjunto de respuestas a los ítems significativo para los respondientes y que proporcione información para distintos grupos de respondientes en función de sus diferentes características (p.e. género, edad, etnia..), (3) utilizar el análisis de Rasch para ajustar un modelo a los datos que represente el constructo definido (Wong, et al., 2012).

El modelo de Rasch (1960) es útil para entender el papel que tienen los ítems ante diferentes niveles de una variable, en nuestro caso la satisfacción con la escuela. Permite detectar diferencias entre grupos definidos sociodemográfica y culturalmente, y desarrollar escalas no sesgadas y eficientes. El análisis Rasch 
permite estimar la ubicación de los ítems en un continuo (p.e. de satisfacción con la escuela) y detecta, mediante el análisis del funcionamiento diferencial de los ítems (FDI), diferencias en el grado en que los ítems se ajustan a los grupos, tras controlar sus niveles de, por ejemplo, satisfacción escolar.

El FDI captura las diferencias en experiencia, deseos de informar, interpretación u otros factores relativos a la relevancia de un elemento o un ítem para cada grupo sociodemográfico o cultural. Con esta información es posible determinar si, por ejemplo, un ítem supone el mismo nivel de percepción de satisfacción con la escuela y con su situación de inclusión en alumnos con diferentes niveles educativos, o de distinto género. También permite elegir ítems menos sesgados, seleccionando aquellos que cubran un rango más amplio o relevante y que no sean conceptualmente repetitivos, para así desarrollar un instrumento de evaluación más eficiente.

El modelo de Rasch tiene entre otras ventajas que permite obtener un modelo fiable con medidas objetivas - i.e. que no dependan del instrumento o de los participantes concretos en un estudio- a partir de una muestra pequeña y poco representativa (Bond y Fox, 2001). Dicho modelo asume además la unidimensionalidad del concepto, constructo o rasgo latente bajo estudio (Wong, et al., 2012). También permite analizar un conjunto de respuestas en escala tipo Likert de fenómenos psicológicos (Embretson y Reise, 2000).

En el análisis Rasch, la probabilidad de que una persona responda de una determinada manera a un determinado ítem se establece como una función logística (i.e. curva en forma de S) de la distancia relativa entre el ítem y la ubicación de la persona en el rasgo latente (Bond y Fox, 201). Dicho de otro modo, permite ubicar la habilidad (u otra cualidad) de una persona y la dificultad de un ítem.

Estos análisis ofrecen unos estadísticos de ajuste denominados Infit y Outfit cuyos valores tienen una media de 1,0 . Valores entre 0,66 y 1,33 indican un buen ajuste de los datos al modelo (Wilson, 2005), aunque otros autores plantean que valores entre 0,5 y 1,5 son aceptables (Linacre y Wright, 1994). Estadísticos de 
ajuste más elevados denotan un escaso ajuste y por el contrario, más bajos indican un mayor ajuste del esperado. Por lo general se considera que valores inferiores a 2.0 denotan un adecuado ajuste.

El estadístico de ajuste infit se centra en las observaciones diana (Linacre, 2002), es decir, en el comportamiento general de un ítem o una persona. El estadísticos Outfit muestran la influencia de observaciones fuera del rango o no diana, es decir, es un estadístico sensible a los casos atípicos. Los coeficientes de fiabilidad de Rasch son conceptualmente análisis al alfa de Cronbach (Bond y Fox, 2001), que se consideran adecuados de 0,80 a 0,90 y óptimos cuando son superiores a 0,90 (Traub, 1994; Wong, et al., 2012).

La evaluación final del modelo se realiza comparando el mapeado de la distribución estimada de ítems y personas, que se denomina Mapa de Wright, y el mapa del constructo. Se ha de prestar atención a las diferencias en la localización de los ítems, en el número de ítems por nivel de severidad y por dimensión y en el número de ítems que se solapan (Wong, et al., 2012).

Además de puede analizar el FDI en función del género, edad, nivel educativo o cualquier otra variables sociodemografica o cultural. En los análisis de FDI se estiman los modelos separados para cada subgrupo, con objeto de analizar el tamaño de las diferencias entre las estimaciones de los ítems. Las diferencias en la dificultad de los ítems se pueden analizar (con una alfa =0,05), empleando los errores estándar conjuntos para calcular el estadístico T. Las diferencias en las estimaciones de los ítems, denominadas tamaños de los efectos, son consideradas grandes si son superiores a 0,638 logits; intermedias si están entre 0,426 y 0,638 logits, y pequeñas si son menores que 0,426 logits. Los tamaños de los efectos intermedios y grandes se interpretan como una fuente de sesgo importante (Wong, et al., 2012).

Una vez aclarado el enfoque seguido para el análisis de las propiedades de los cuestionarios, acorde con un enfoque emic, pasamos a exponer los resultados obtenidos en cada caso. 


\subsubsection{Escala de Satisfacción con la Escuela}

La Escala de Satisfacción con la Escuela está compuesta por 20 ítems a los que se han añadido dos más (números 21 y 22). Se trata de un cuestionario adaptado del Cuestionario de Inclusión de Booth y Ainscow (2002). El instrumento indaga sobre la satisfacción del alumno con distintas condiciones (maestro, compañeros, condiciones físicas de la escuela y del hogar, apoyo de padres, etc.) relacionadas con su escolarización. La adaptación del cuestionario requirió la simplificación de los ítems así como su traducción al Oromo (véase cuestionario en Anexo 8.2). Tras la recogida de datos se comenzó por analizar la fiabilidad de la escala, y se obtuvo una consistencia interna de $\alpha=0,892$, plenamente satisfactorio.

De modo complementario y de acuerdo con los principios de la teoría de respuesta al ítem, hemos comprobado el ajuste de datos al modelo. En primer lugar, el ajuste de los ítems y en segundo lugar, el ajuste de los participantes. En la Tabla 46 se indican los datos de ajuste de los ítems al modelo. Se puede apreciar cómo los valores medios de Infit $(M=1,04)$ y Outfit $(M=1,01)$ no superan el valor de 2,0 , lo que indica un buen ajuste. El error de medida fluctúa entre 0,14 y 0,20 , muy bajos todos ellos, lo que avala la precisión de la medida. La fiabilidad de la escala atendiendo a los ítems fue de 0,90.

Tabla 46. Propiedades psicométricas de la muestra de ítems de satisfacción con la escuela ( $\mathrm{N}=\mathbf{2 0}$ )

\begin{tabular}{|l|l|l|l|l|}
\hline & Localización & Error & INFIT & OUTFIT \\
\hline Media & 0,00 & 0,16 & 1,04 & 1,01 \\
\hline D.T. & 0,49 & 0,02 & 0,30 & 0,27 \\
\hline Máximo & 0,91 & 0,20 & 1,55 & 1,48 \\
\hline Mínimo & $-0,92$ & 0,14 & 0,58 & 0,56 \\
\hline
\end{tabular}

En la Tabla 47 se presentan los resultados relativos al ajuste de las personas al modelo. Los valores medios Infit $(M=0,98)$ y Outfit $(M=1,01)$ son adecuados, si bien, la puntuación máxima de Infit y Outfit es superior a 2,0, lo que indica que aunque por término medio los participantes se ajustan al modelo, hay participantes con patrones de respuesta desajustados. Concretamente, dos personas (2,9\%) 
mostraron valores extremos. La fiabilidad de las personas fue de 0,83 , lo que avala un elevado ajuste de las personas al modelo.

Tabla 47. Propiedades psicométricas de la muestra de participantes en la escala de satisfacción con la escuela $(\mathrm{N}=68)$

\begin{tabular}{|l|l|l|l|l|l|}
\hline & Total & Localización & Error & INFIT & OUTFIT \\
\hline Media & 59,1 & 0,58 & 0,30 & 0,98 & 1,01 \\
\hline D.T. & 8,1 & 0,76 & 0,09 & 0,46 & 0,49 \\
\hline Máximo & 79,0 & 4,27 & 1,02 & 2,26 & 2,25 \\
\hline Mínimo & 26,0 & $-2,02$ & 0,25 & 0,15 & 0,16 \\
\hline
\end{tabular}

En el mapa de Wright (Figura 84) se presenta la localización de los participantes y los ítems en la variable latente medida. La línea central de la figura representa el continuo de satisfacción con la escuela. En la parte inferior se sitúan los ítems que miden aspectos más básicos o "fáciles" de satisfacción, mientras que en la parte superior se encuentran los aspectos más exigentes o "difíciles" de la misma. También se aprecia cómo los participantes que ocupan la parte inferior de la Figura experimentan una menor satisfacción, mientras que los de la parte superior experimentan una mayor satisfacción con la escuela. 


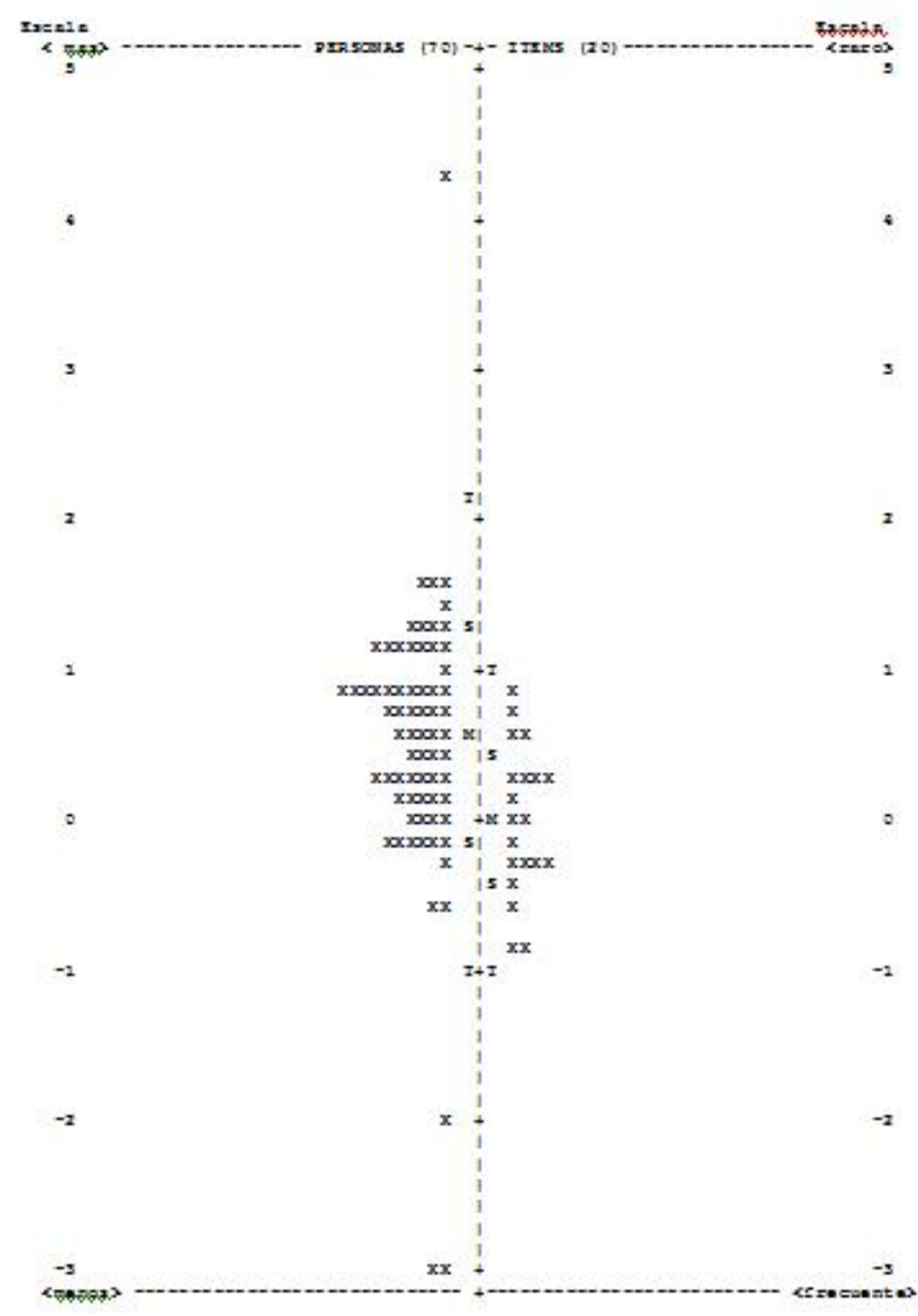

Figura 84. Mapa de Wright. Localización de los participantes y los ítems en la variable latente medida

En la Figura 85 se reproduce la misma imagen pero en este caso, identificando los ítems y las personas. Así, se puede apreciar cómo en cuanto a los participantes, quienes muestran puntuaciones más extremas se corresponden con alumnos de tercer curso (identificables por el primer dígito que indica el curso). Respecto a los ítems, se aprecia cómo los más difíciles son el número 16 ("Me siento contento cuando hago un buen trabajo"), mientras que el más fácil o indicador de aspectos más básicos de la satisfacción escolar es el 11 ("Se meten conmigo") 


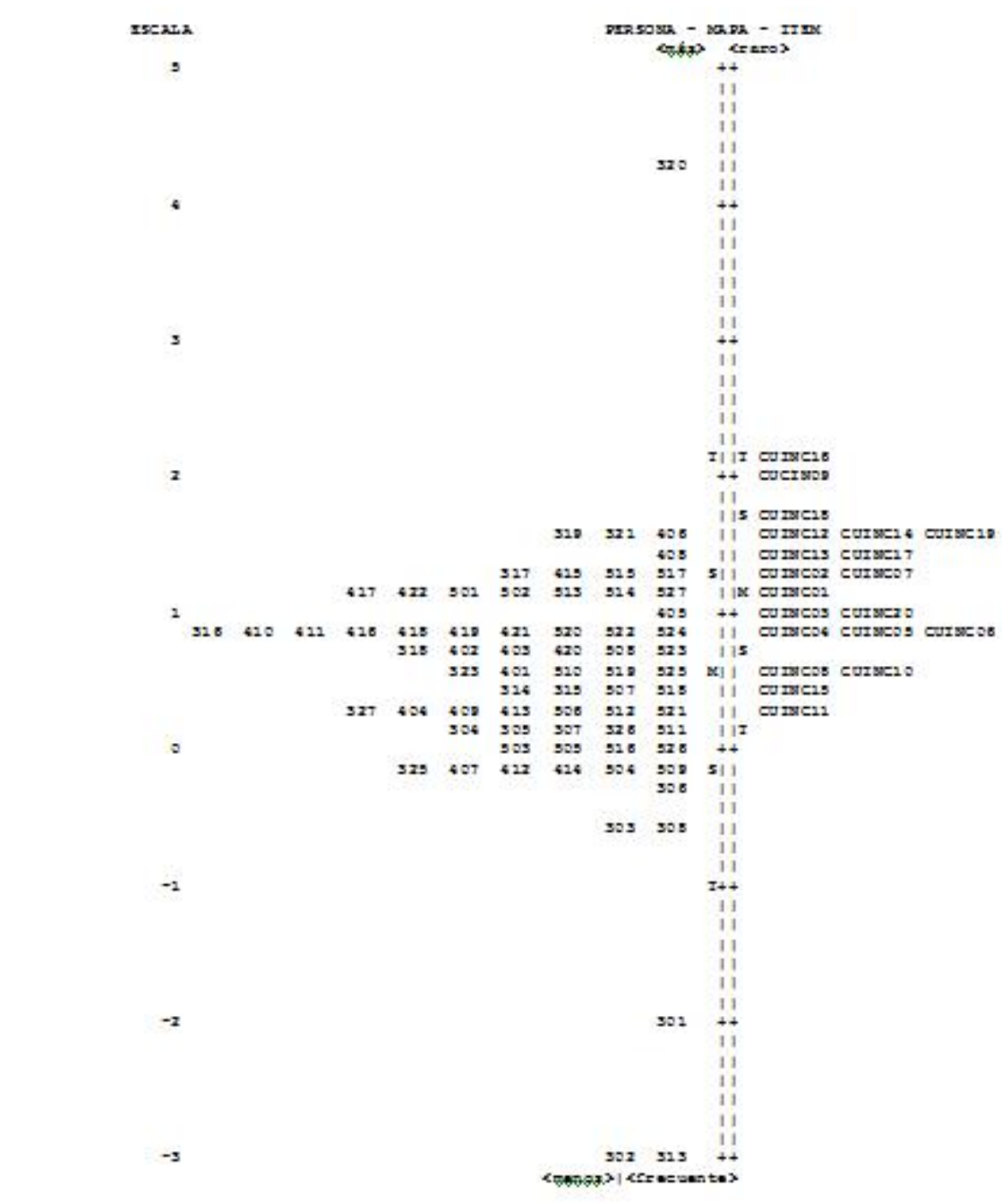

Figura 85. Mapa de Wright. Identificación de los participantes y los ítems en la variable latente medida

Por tratarse de una escala con ítems politómicos, presentamos en la Figura 86 la distribución de personas e ítems. La variable está dispuesta verticalmente, de modo que las personas con más satisfacción y los ítems más difíciles aparecen en la parte superior. Cada ítem aparece tres veces en la escala. En la columna central, cada ítem está ubicado en su calibración media (i.e. localizado en el centro de la escala, es decir, el lugar donde puntuar en las categorías inferior y posterior es igualmente probable).

En la columna de la parte izquierda, el ítem aparece en su nivel de medida (Rash-Thurstone threshold), que corresponde a la probabilidad del 50\% de ser 
valorado en la parte inferior de la categoría de la escala. En la columna de la parte derecha, el ítem se muestra en el nivel de probabilidad del $50 \%$ de ser valorado en la parte superior de la categoría de la escala.

Cada persona o ítem aparece señalado con una X. La columna de la izquierda localiza la habilidad (o en este caso su satisfacción con la escuela) de la persona en la variable. Por ejemplo, podemos observar que hay un participante en la columna de la izquierda cuya puntuación está bastante por encima del ítem más difícil (es decir, la columna de la derecha del todo), pero también hay participantes con puntuaciones por debajo de la categoría del ítem más fácil ( $x$ de la parte inferior en la columna de la derecha del todo. Por debajo significa que tienen menos de un $50 \%$ de posibilidades de puntuar menos.

En la segunda columna aparecen reflejadas las posiciones de la variable latente donde un participante tiene un $50 \%$ de posibilidades de ser observado en la categoría inferior y otro $50 \%$ de ser observado en una categoría superior. Es equivalente a la "dificultad del ítem" de la categoría inferior. Por su parte, en la cuarta columna se localizan los puntos donde una persona tiene un $50 \%$ de posibilidades de ser observado en la categoría superior y otro $50 \%$ de ser observado en una categoría más alta. Así, sería equivalente a la "dificultad del ítem" de la categoría superior. Por lo tanto, la dificultad del ítem de cada ítem cubre todo el rango desde donde su $\mathrm{x}$ se encuentra en la segunda columna hasta donde se encuentra en la cuarta. 


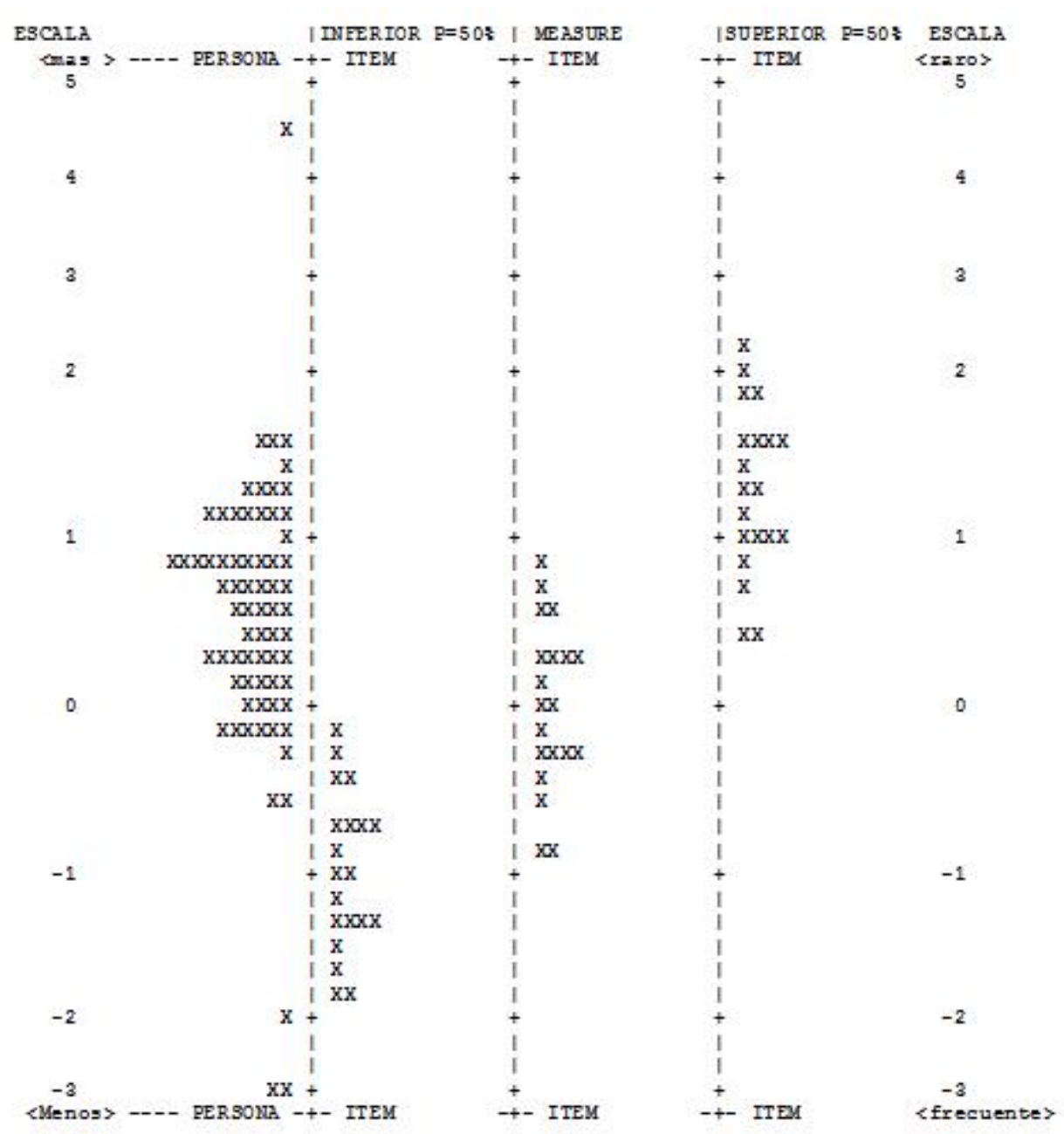

Figura 86. Distribución de personas e ítems en la Escala de Satisfacción Escolar

Respecto a las propiedades psicométricas de los ítems de la escala de satisfacción con la escuela según el modelo de Rash, en la Tabla 48 se indican los valores obtenidos para cada uno de los ítems. Se puede apreciar cómo ninguno de los valores de Infit y Outfit supera el valor de 2.0, lo que indica un buen ajuste. Como antes señaláramos, todos los errores de medida (CSEM) son pequeños, especialmente los de los ítems 11 al 4 (parte superior de la Tabla). Los valores de correlación obtenidos frente a los esperados son muy similares en la mayoría de los ítems, así como los valores obtenidos frente a los esperados. 
Tabla 48. Propiedades psicométricas de los ítems de la escala de satisfacción con la escuela según el modelo de Rash

\begin{tabular}{|c|c|c|c|c|c|c|c|c|c|c|c|c|}
\hline $\begin{array}{l}\text { Ite } \\
\text { m }\end{array}$ & $\begin{array}{l}\text { Puntuació } \\
\mathrm{n}\end{array}$ & $\begin{array}{l}\text { Localizació } \\
\mathrm{n}\end{array}$ & $\begin{array}{l}\text { CSE } \\
M\end{array}$ & INFIT & & $\begin{array}{l}\text { OUTFI } \\
T\end{array}$ & & $\begin{array}{l}\text { Point- } \\
\text { measure } \\
\text { correlatio } \\
\mathrm{n}\end{array}$ & $\begin{array}{l}\text { Valor } \\
\text { esperado } \\
\text { de la } \\
\text { correlació } \\
\mathrm{n}\end{array}$ & $\begin{array}{l}\text { Exac } \\
\mathrm{t} \\
\text { obs. } \\
\%\end{array}$ & $\begin{array}{l}\text { Esper } \\
\%\end{array}$ & Item \\
\hline & & & & $\begin{array}{l}\text { MNS } \\
Q\end{array}$ & $\begin{array}{l}\text { ZST } \\
\text { D }\end{array}$ & MNSQ & $\begin{array}{l}\text { ZST } \\
\text { D }\end{array}$ & & & & & \\
\hline 11 & 161 & .91 & .14 & .78 & -1.7 & .78 & -1.5 & .48 & .46 & 50.0 & 38.8 & CUINC11 \\
\hline 15 & 173 & .68 & .14 & 1.09 & .7 & 1.07 & .5 & .44 & .48 & 42.6 & 41.6 & CUINC15 \\
\hline 8 & 177 & .60 & .14 & 1.08 & .6 & 1.01 & .1 & .46 & .49 & 55.9 & 42.8 & CUINC08 \\
\hline 10 & 178 & .58 & .14 & .79 & -1.5 & .78 & -1.4 & .50 & .49 & 52.9 & 42.9 & CUINC10 \\
\hline 4 & 189 & .36 & .14 & .75 & -1.7 & .75 & -1.5 & .51 & .51 & 58.8 & 45.5 & CUINCO4 \\
\hline 5 & 191 & .31 & .15 & 1.02 & .2 & 1.11 & .7 & .51 & .51 & 45.6 & 46.5 & CUINC05 \\
\hline 6 & 192 & .29 & .15 & 1.26 & 1.6 & 1.16 & .9 & .56 & .51 & 39.7 & 46.5 & CUINC06 \\
\hline 3 & 195 & .23 & .15 & .58 & -3.0 & .56 & -2.9 & .59 & .52 & 60.3 & 47.1 & CUINCO3 \\
\hline 20 & 199 & .14 & .15 & 1.03 & .2 & 1.26 & 1.4 & .50 & .52 & 45.6 & 47.2 & CUINC20 \\
\hline 1 & 202 & .07 & .15 & .79 & -1.3 & .73 & -1.5 & .57 & .53 & 64.7 & 48.6 & CUINC01 \\
\hline 7 & 207 & -.05 & .16 & .95 & -.2 & .88 & -.6 & .59 & .54 & 47.1 & 50.2 & CUINC07 \\
\hline 2 & 211 & -.15 & .16 & .58 & -2.7 & .60 & -2.3 & .64 & .55 & 60.3 & 50.6 & CUINCO2 \\
\hline 17 & 214 & -.23 & .16 & .75 & -1.4 & .75 & -1.3 & .59 & .55 & 57.4 & 50.6 & CUINC17 \\
\hline 13 & 216 & -.28 & .17 & 1.42 & 2.1 & 1.29 & 1.4 & .51 & .56 & 36.8 & 50.4 & CUINC13 \\
\hline 12 & 218 & -.34 & .17 & .93 & -.3 & .90 & -.4 & .54 & .56 & 60.3 & 50.8 & CUINC12 \\
\hline 19 & 218 & -.34 & .17 & 1.52 & 2.5 & 1.48 & 2.1 & .45 & .56 & 42.6 & 50.8 & CUINC19 \\
\hline 14 & 221 & -.42 & .17 & 1.52 & 2.4 & 1.37 & 1.7 & .56 & .57 & 41.2 & 52.3 & CUINC14 \\
\hline 18 & 227 & -.61 & .18 & 1.06 & .3 & 1.03 & .2 & .54 & .58 & 47.1 & 53.2 & CUINC18 \\
\hline 9 & 233 & -.81 & .19 & 1.55 & 2.4 & 1.35 & 1.5 & .58 & .60 & 44.1 & 55.4 & $\begin{array}{l}\text { CUCINCO } \\
9\end{array}$ \\
\hline 16 & 236 & -.92 & .20 & 1.34 & 1.6 & 1.29 & 1.2 & .60 & .61 & 55.9 & 56.6 & CUINC16 \\
\hline
\end{tabular}

La Tabla 49, relativa a la polaridad de los ítems, presenta los estadísticos de las categorías de respuesta de los ítems de satisfacción con la escuela ordenados según el tamaño de la correlación. De acuerdo con la medición según Rash, es de esperar que cuanto más alto puntúe una persona, más altas serán las valoraciones de los ítems, y a la inversa. La correlación punto-medida refleja el grado en que esto es verdad para cada ítem. Esperamos así que las categorías más altas (es decir, la 4, que denota más satisfacción con la escuela), sean elegidos por los niños que puntúen más alto (es decir, que se sientan más satisfechos). En los casos en los que no sucede, aparece un asterisco para señalar que las habilidades promedio se encuentran desordenadas. Como se puede apreciar, en nuestro caso tan solo aparece en el ítem 8 ("ayudo a mi profesor"). Respecto a las correlaciones, esperamos que la categoría más alta (i.e. 4) muestre una correlación elevada y positiva con la variable evaluada (satisfacción con la escuela) y que la categoría más baja (i.e. 1) tenga una correlación elevada y negativa con dicha variable. 
Tabla 49. Polaridad de los ítems de la escala de satisfacción con la escuela

\begin{tabular}{|c|c|c|c|c|c|c|c|c|c|}
\hline $\begin{array}{l}\text { numero } \\
\text { de item }\end{array}$ & $\begin{array}{l}\text { código de } \\
\text { la } \\
\text { puntuación }\end{array}$ & valor & Frecuencia & porcentaje & $\begin{array}{l}\text { Habilidad } \\
\text { promedio }\end{array}$ & $\begin{array}{l}\text { E.T. } \\
\text { Media }\end{array}$ & $\begin{array}{l}\text { Outfit } \\
\text { MNSQ }\end{array}$ & $\begin{array}{l}\text { PTMA } \\
\text { Corr }\end{array}$ & Item \\
\hline \multirow[t]{4}{*}{15} & 1 & 1 & 16 & 23 & -.51 & .45 & 1.0 & -.44 & CUINC15 \\
\hline & 2 & 2 & 15 & 21 & .56 & .12 & 1.1 & .06 & \\
\hline & 3 & 3 & 29 & 41 & .62 & .10 & 1.1 & .14 & \\
\hline & 4 & 4 & 10 & 14 & 1.19 & .39 & 1.2 & .27 & \\
\hline \multirow[t]{4}{*}{19} & 1 & 1 & 7 & 10 & -1.44 & .93 & 1.4 & -.54 & CUINC19 \\
\hline & 2 & 2 & 9 & 13 & .41 & .19 & 1.3 & -.01 & \\
\hline & 3 & 3 & 23 & 33 & .60 & .10 & .9 & .10 & \\
\hline & 4 & 4 & 31 & 44 & .73 & .16 & 1.2 & .23 & \\
\hline \multirow[t]{4}{*}{8} & 1 & 1 & 15 & 21 & -.65 & .46 & .9 & -.48 & CUINC08 \\
\hline & 2 & 2 & 14 & 20 & .38 & .11 & .7 & -.02 & \\
\hline & 3 & 3 & 30 & 43 & .87 & .07 & .4 & .33 & \\
\hline & 4 & 4 & 11 & 16 & $.78^{*}$ & .41 & 1.7 & .13 & \\
\hline \multirow[t]{4}{*}{11} & 1 & 1 & 16 & 23 & -.53 & .45 & .9 & -.45 & CUINC11 \\
\hline & 2 & 2 & 21 & 30 & .46 & .12 & .9 & .01 & \\
\hline & 3 & 3 & 29 & 41 & .79 & .09 & .8 & .26 & \\
\hline & 4 & 4 & 4 & 6 & 1.52 & .96 & 1.3 & .23 & \\
\hline \multirow[t]{4}{*}{20} & 1 & 1 & 9 & 13 & -1.30 & .70 & .7 & -.57 & CUINC20 \\
\hline & 2 & 2 & 13 & 19 & .35 & .17 & 1.1 & -.03 & \\
\hline & 3 & 3 & 28 & 40 & .76 & .16 & 3.8 & .23 & \\
\hline & 4 & 4 & 20 & 29 & .80 & .09 & 1.0 & .20 & \\
\hline \multirow[t]{4}{*}{10} & 1 & 1 & 11 & 16 & -1.02 & .60 & .8 & -.54 & CUINC10 \\
\hline & 2 & 2 & 17 & 24 & .57 & .12 & 1.2 & .07 & \\
\hline & 3 & 3 & 35 & 50 & .65 & .08 & .9 & .19 & \\
\hline & 4 & 4 & 7 & 10 & 1.30 & .55 & 1.0 & .25 & \\
\hline \multirow[t]{4}{*}{13} & 1 & 1 & 9 & 13 & -1.05 & .71 & 1.1 & -.49 & CUINC13 \\
\hline & 2 & 2 & 6 & 9 & -.05 & .09 & .5 & -.13 & \\
\hline & 3 & 3 & 25 & 36 & .59 & .14 & 2.0 & .10 & \\
\hline & 4 & 4 & 30 & 43 & .84 & .15 & 1.0 & .30 & \\
\hline \multirow[t]{4}{*}{4} & 1 & 1 & 8 & 11 & -1.33 & .81 & 1.0 & -.54 & CUINCO4 \\
\hline & 2 & 2 & 12 & 17 & .46 & .16 & 1.2 & .01 & \\
\hline & 3 & 3 & 43 & 61 & .62 & .07 & .8 & .21 & \\
\hline & 4 & 4 & 7 & 10 & 1.22 & .58 & 1.3 & .23 & \\
\hline \multirow[t]{4}{*}{5} & 1 & 1 & 13 & 19 & -.77 & .50 & .8 & -.49 & CUINCO5 \\
\hline & 2 & 2 & 9 & 13 & .35 & .13 & .8 & -.03 & \\
\hline & 3 & 3 & 32 & 46 & .61 & .12 & 2.7 & .14 & \\
\hline & 4 & 4 & 16 & 23 & 1.09 & .24 & 1.0 & .31 & \\
\hline \multirow[t]{3}{*}{18} & 1 & 1 & 5 & 7 & -2.30 & 1.08 & .9 & -.65 & CUINC18 \\
\hline & 2 & 2 & 3 & 4 & .12 & .40 & .9 & -.06 & \\
\hline & 3 & 3 & 32 & 46 & .62 & .10 & 1.3 & .15 & \\
\hline
\end{tabular}




\begin{tabular}{|c|c|c|c|c|c|c|c|c|c|}
\hline & 4 & 4 & 30 & 43 & .71 & .15 & 1.1 & .21 & \\
\hline \multirow[t]{4}{*}{12} & 1 & 1 & 4 & 6 & -2.48 & 1.33 & .9 & -.62 & CUINC12 \\
\hline & 2 & 2 & 7 & 10 & .16 & .21 & .9 & -.08 & \\
\hline & 3 & 3 & 36 & 51 & .52 & .10 & 1.4 & .08 & \\
\hline & 4 & 4 & 23 & 33 & .88 & .19 & 1.0 & .27 & \\
\hline \multirow[t]{4}{*}{6} & 1 & 1 & 19 & 27 & -.58 & .36 & .8 & -.53 & CUINC06 \\
\hline & 2 & 2 & 3 & 4 & -.04 & .19 & .2 & -.09 & \\
\hline & 3 & 3 & 25 & 36 & .71 & .08 & .5 & .18 & \\
\hline & 4 & 4 & 23 & 33 & 1.02 & .17 & 1.0 & .35 & \\
\hline \multirow[t]{4}{*}{14} & 1 & 1 & 10 & 14 & -1.26 & .62 & .8 & -.59 & CUINC14 \\
\hline & 2 & 2 & 6 & 9 & .26 & .28 & 1.1 & -.05 & \\
\hline & 3 & 3 & 17 & 24 & .65 & .13 & 1.1 & .11 & \\
\hline & 4 & 4 & 37 & 53 & .81 & .12 & 1.0 & .35 & \\
\hline \multirow[t]{4}{*}{1} & 1 & 1 & 8 & 11 & -1.35 & .79 & .9 & -.55 & CUINC01 \\
\hline & 2 & 2 & 6 & 9 & .28 & .20 & .9 & -.04 & \\
\hline & 3 & 3 & 42 & 60 & .54 & .08 & .8 & .12 & \\
\hline & 4 & 4 & 14 & 20 & 1.18 & .27 & .9 & .32 & \\
\hline \multirow[t]{4}{*}{9} & 1 & 1 & 7 & 10 & -1.88 & .78 & .7 & -.66 & CUCINCO9 \\
\hline & 2 & 2 & 6 & 9 & .26 & .19 & 1.1 & -.04 & \\
\hline & 3 & 3 & 14 & 20 & .69 & .13 & 1.3 & .11 & \\
\hline & 4 & 4 & 43 & 61 & .74 & .11 & 1.0 & .34 & \\
\hline \multirow[t]{4}{*}{17} & 1 & 1 & 4 & 6 & -2.90 & 1.15 & .5 & -.71 & CUINC17 \\
\hline & 2 & 2 & 8 & 11 & .30 & .19 & 1.0 & -.04 & \\
\hline & 3 & 3 & 38 & 54 & .55 & .08 & .8 & .11 & \\
\hline & 4 & 4 & 20 & 29 & .93 & .21 & 1.0 & .27 & \\
\hline \multirow[t]{4}{*}{7} & 1 & 1 & 7 & 10 & -1.70 & .84 & .7 & -.61 & CUINCO7 \\
\hline & 2 & 2 & 13 & 19 & .12 & .13 & .7 & -.13 & \\
\hline & 3 & 3 & 26 & 37 & .69 & .08 & .7 & .17 & \\
\hline & 4 & 4 & 24 & 34 & .94 & .18 & 1.0 & .32 & \\
\hline \multirow[t]{4}{*}{3} & 1 & 1 & 5 & 7 & -2.36 & 1.04 & .5 & -.67 & CUINC03 \\
\hline & 2 & 2 & 14 & 20 & .37 & .11 & .9 & -.03 & \\
\hline & 3 & 3 & 42 & 60 & .60 & .09 & 1.0 & .18 & \\
\hline & 4 & 4 & 9 & 13 & 1.27 & .40 & .9 & .28 & \\
\hline \multirow[t]{4}{*}{16} & 1 & 1 & 6 & 9 & -1.82 & 1.01 & 1.5 & -.59 & CUINC16 \\
\hline & 2 & 2 & 3 & 4 & -.25 & .22 & .5 & -.12 & \\
\hline & 3 & 3 & 20 & 29 & .44 & .11 & .9 & .01 & \\
\hline & 4 & 4 & 41 & 59 & .80 & .11 & 1.0 & .38 & \\
\hline \multirow[t]{4}{*}{2} & 1 & 1 & 4 & 6 & -2.94 & 1.12 & .4 & -.71 & CUINCO2 \\
\hline & 2 & 2 & 8 & 11 & .25 & .17 & .9 & -.06 & \\
\hline & 3 & 3 & 41 & 59 & .51 & .08 & .9 & .08 & \\
\hline & 4 & 4 & 17 & 24 & 1.12 & .21 & .9 & .34 & \\
\hline
\end{tabular}

* la habilidad promedio no aumenta de acuerdo a lo esperado. 
En la Figura 87 se muestra cómo los participantes se han comportado como sería de esperar en todos los ítems, salvo en el ítems 8 ("Ayudo a mi profesor"): categoría más alta-> mayor puntuación promedio. En el ítem 8 las categorías 3 y 4 aparecen desordenadas.

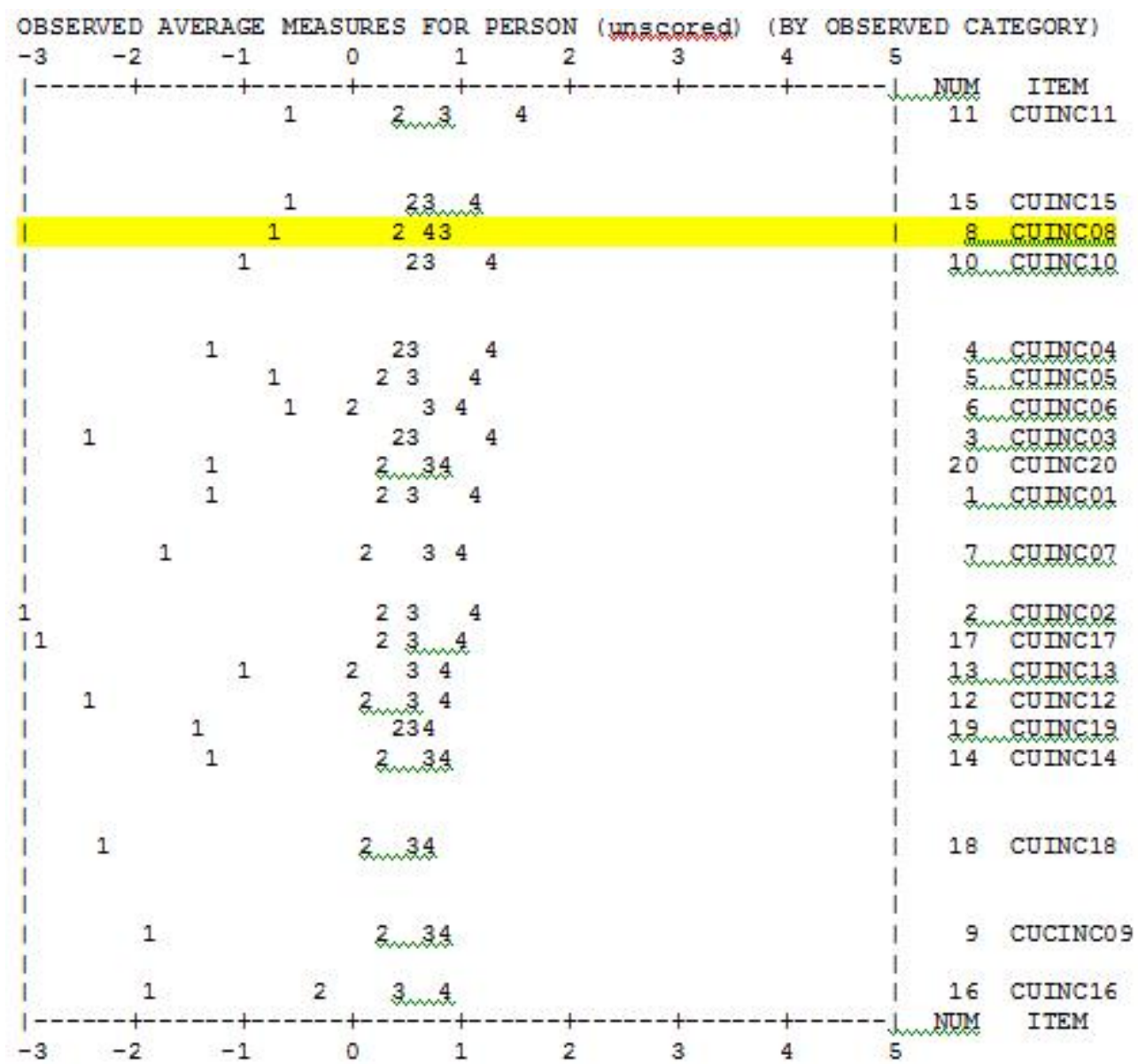

Figura 87. Representación gráfica del comportamiento de los ítems (escala de satisfacción)

El gráfico de burbujas (Figura 88) presenta los ítems. Un tamaño más grande de las burbujas indica mayor error típico. Se aprecia cómo las burbujas de los ítems son aproximadamente del mismo tamaño. Los valores infit son sensibles a patrones extraños no extremos, mientras que los outfit son sensibles a valores extremos. Los valores esperados en todos los casos son de 1 o cercanos. Los valores estandarizados se deben encontrar entre $-2 y+2$ y un ajuste perfecto implica valores cercanos a 0 . Se puede apreciar cómo la gran mayoría de los ítems se 
encuentran en los niveles de ajuste y bastante agrupados, con la ligera excepción del ítem 2 ("Trabajamos en grupos") y el ítem 3 ("Ayudo a mis compañeros").

\section{ITEM}

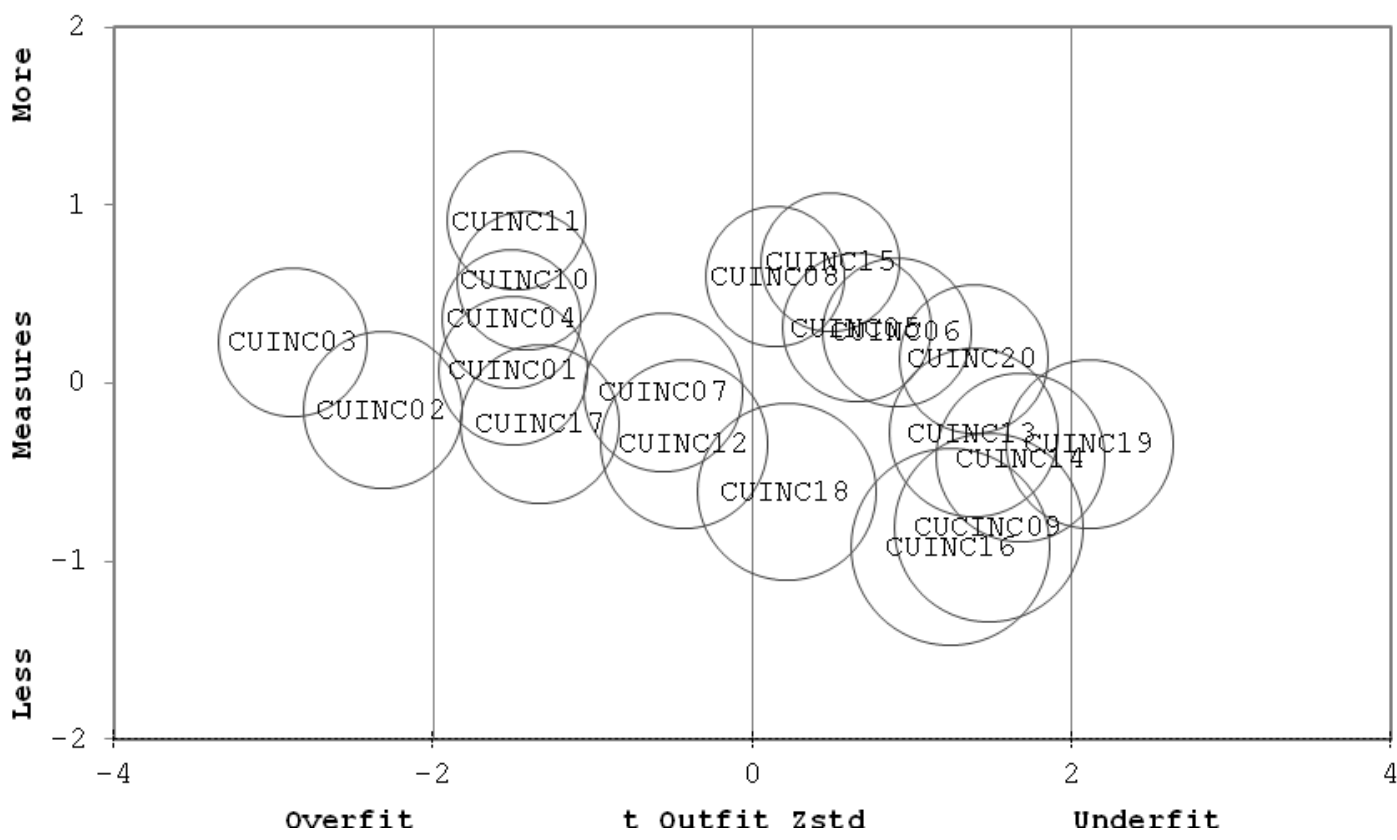

Figura 88. Gráfico de burbujas de los ítems (Escala de satisfacción escolar)

En la Figura 89 se puede apreciar cómo la calibración de los pasos 1 al 4 no es perfecta, dado que la categoría de respuesta 2 no es la más probable en ninguna región de la variable. Sin embargo, hemos optado por respetar la configuración inicial de las categorías, para no perder información derivada de agrupar varias en una. 


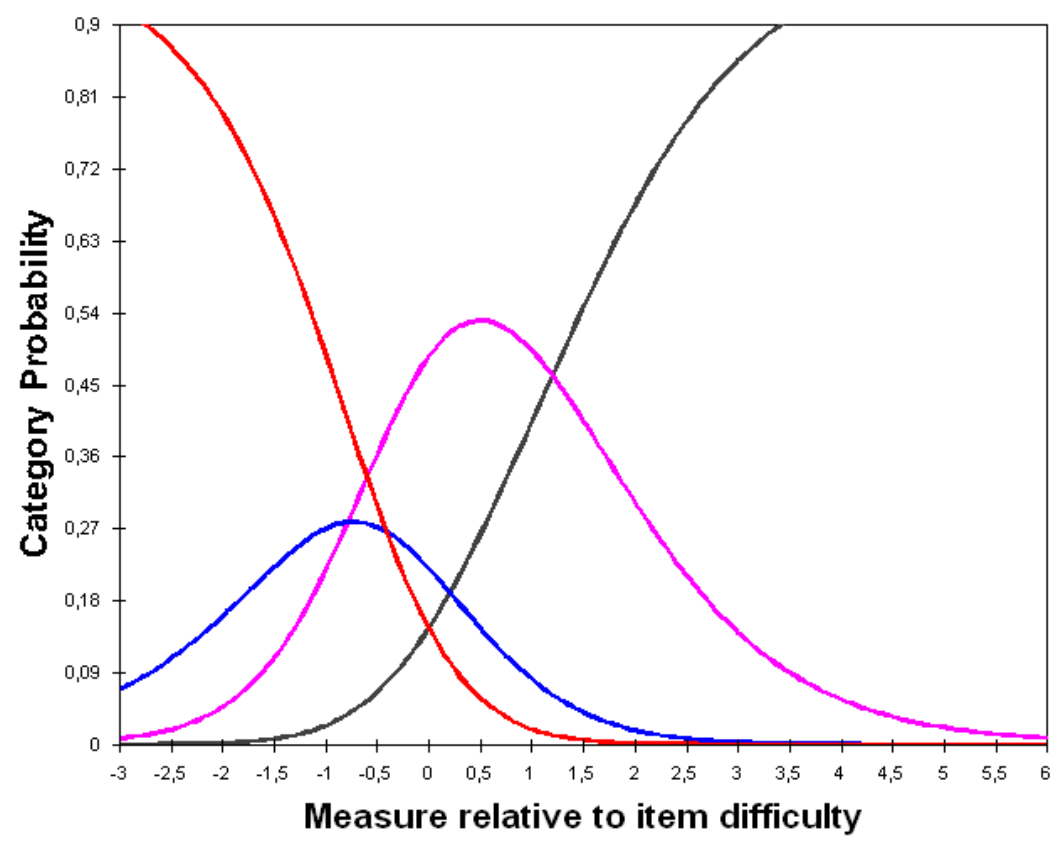

- Category probability: $1-$ Category probability: $2-$ Category probability: $3 \quad-$ Category probability: 4

Figura 89. Calibración de los ítems (escala de satisfacción escolar)

En la Figura 90 se presentan las curvas características de los ítems en términos absolutos respecto a la variable latente satisfacción con la escuela. Se puede apreciar una cierta variación en la dificultad de distintos ítems, pero con similares pendientes 


\section{Item Characteristic Curves}

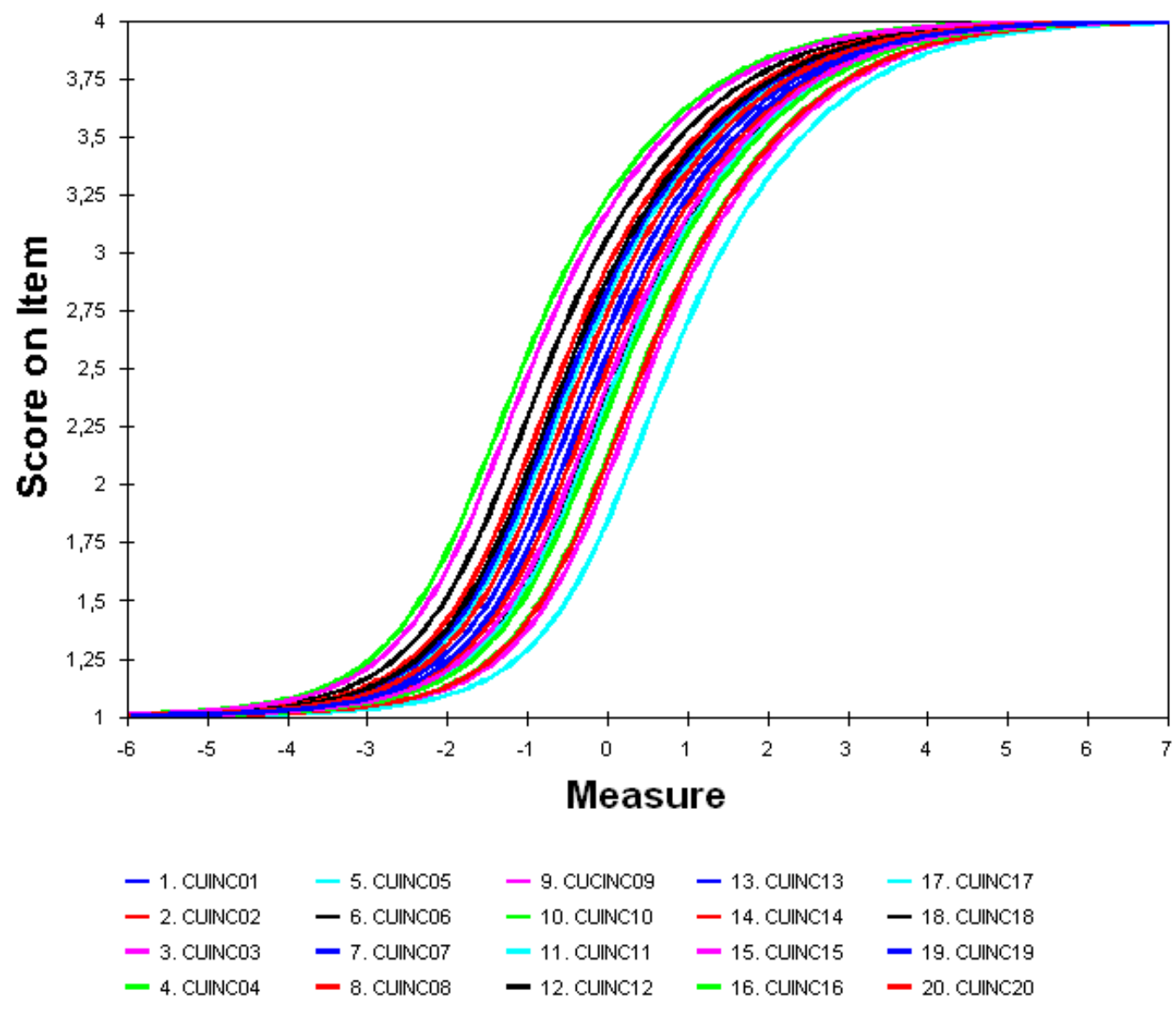

Figura 90. Curvas características de los ítems (Escala de Satisfacción Escolar)

A modo de ejemplo, se presenta la curva característica del ítem esperada por el modelo de Rasch (véase Figura 91). Dicho modelo predice cómo los participantes que obtienen diferentes puntuaciones en la variable latente (eje $\mathrm{x}$ ) puntuarán en el ítem (eje y) en promedio. La línea azul refleja la curva empírica característica del ítem. Se puede ver cómo dicha línea se encuentra próxima a la línea azul. Las líneas verdes reflejan las bandas a ambos lados de los niveles de confianza al 95\%. Dichas bandas se sitúan a 1,96 errores típicos de la línea roja. Cuantas más observaciones hallen en un intervalo, más cerca se encuentran las líneas verdes a la roja. 


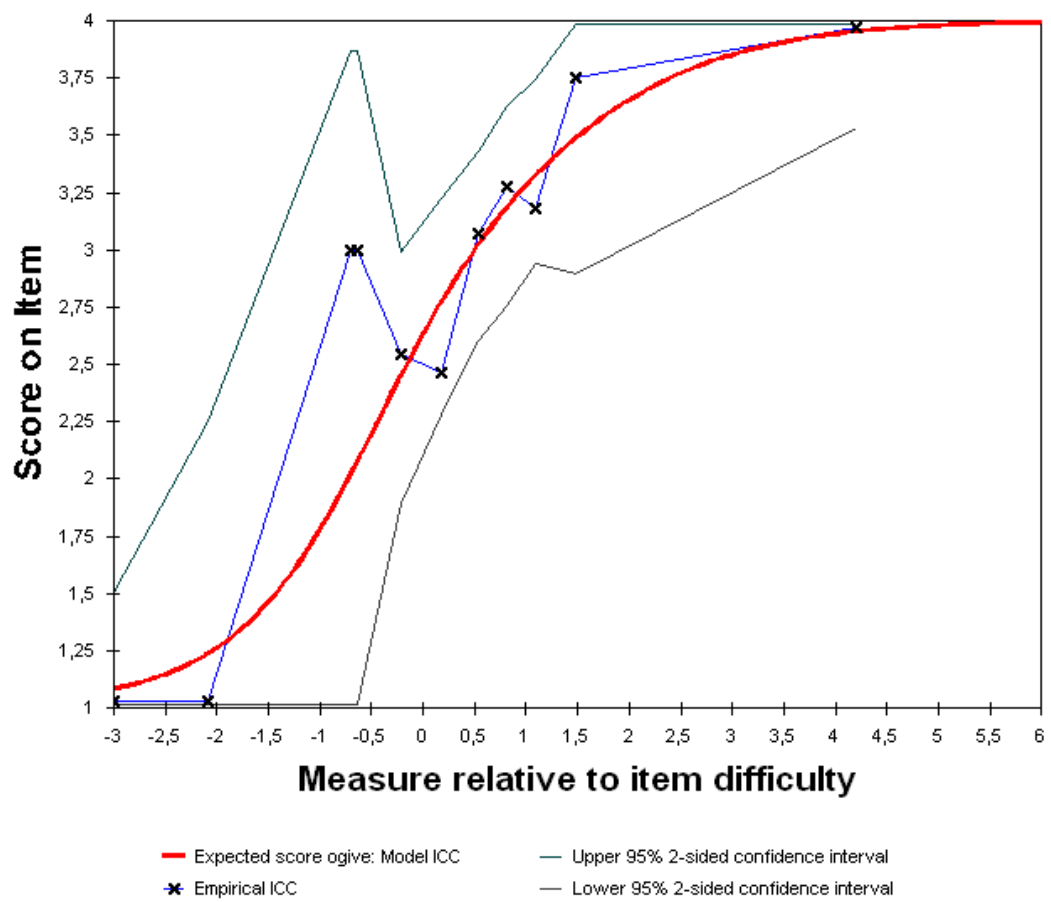

Figura 91. Ejemplo de curva característica del ítem 1 según el modelo Rash, en la escala de Satisfacción con la escuela

\section{1) Funcionamiento diferencial del test (FDT)}

El análisis del funcionamiento diferencial del test pretende determinar si el test, formado por todos los ítems, funciona igual para los participantes atendiendo a alguna variable relevante, en nuestro caso, el género. Ello requiere comparar la dificultad de los ítems en ambas submuestras (hombres y mujeres). En el gráfico de dispersión (scatterplot) se presentan los ítems (véase Figura 92). El eje y refleja la dificultad de los ítems para las mujeres. El eje $\mathrm{x}$ refleja las dificultades de los ítems para los hombres. La línea de puntos refleja la media de ambos grupos de ítems. Las líneas continuas reflejan las bandas al $95 \%$ del intervalo de confianza. Las puntuaciones de ambos grupos no parecen diferir sustancialmente (i.e. no quedan fuera de los niveles de confianza), aunque parece que los ítems 1,5, 13 y 14 son los que más difieren. El eje y muestra las dificultades de los ítems para las mujeres y sugiere que el ítem 1 ("trabajo con compañeros") es más difícil para este grupo. EI 
eje $\mathrm{x}$ muestra las dificultades para los hombres y sugiere que el ítem 5 ("muestran nuestros trabajos para que los demás lo vean") es más difícil para éstos. Podemos decir por tanto que el test no muestra sesgos en función del género y que en todo caso, estos pequeños sesgos quedan contrarrestados por el hecho de que en un ítem los hombres puntúen más alto y en otro, las mujeres.

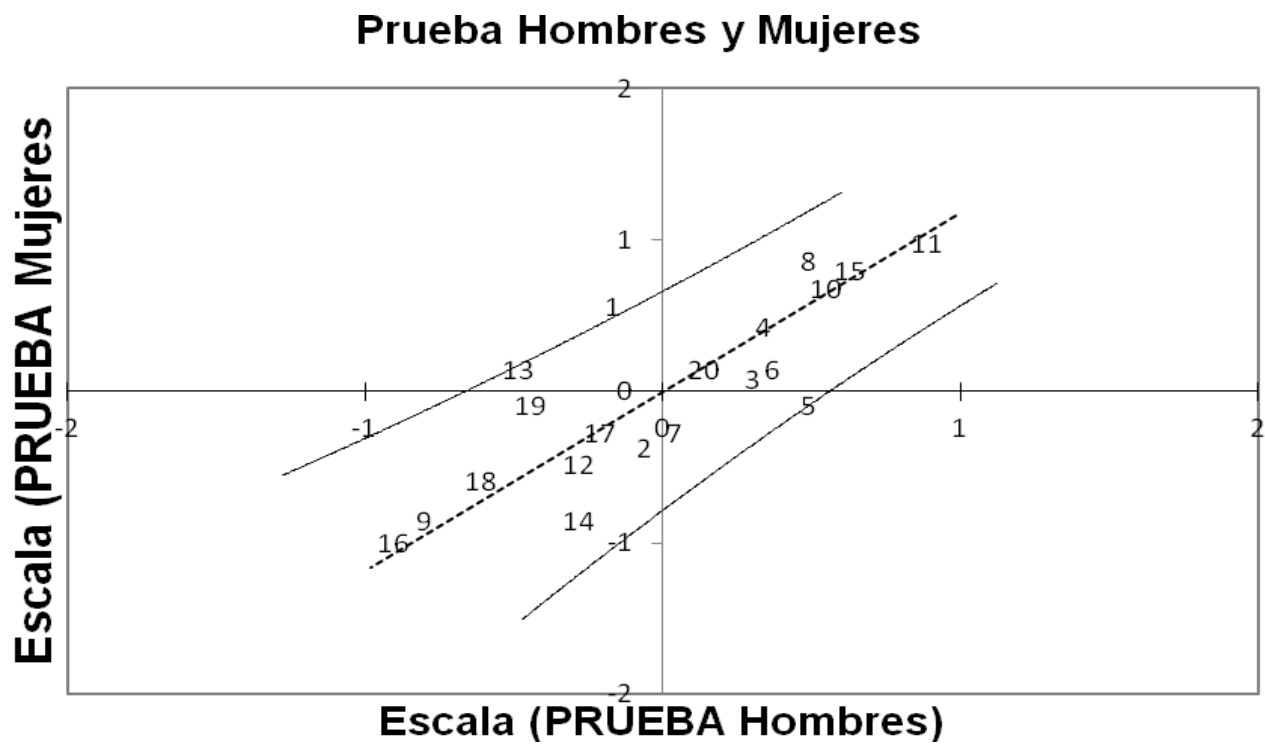

Figura 92. Funcionamiento diferencial del test para hombres y mujeres (Escala de Satisfacción con la escuela)

\section{2) Funcionamiento diferencial de los ítems (FDI)}

Se presenta a continuación el tamaño del efecto del funcionamiento diferencial de los ítems. Se puede comprobar la ausencia de puntuaciones con tamaños de los efectos grandes (i.e. logits superiores a 0,638), si bien, varios ítems muestran tamaños de los efectos intermedios (entre 0,426 y 0,638), como es el caso de los ítems 1, 5, 13 y 14 . 


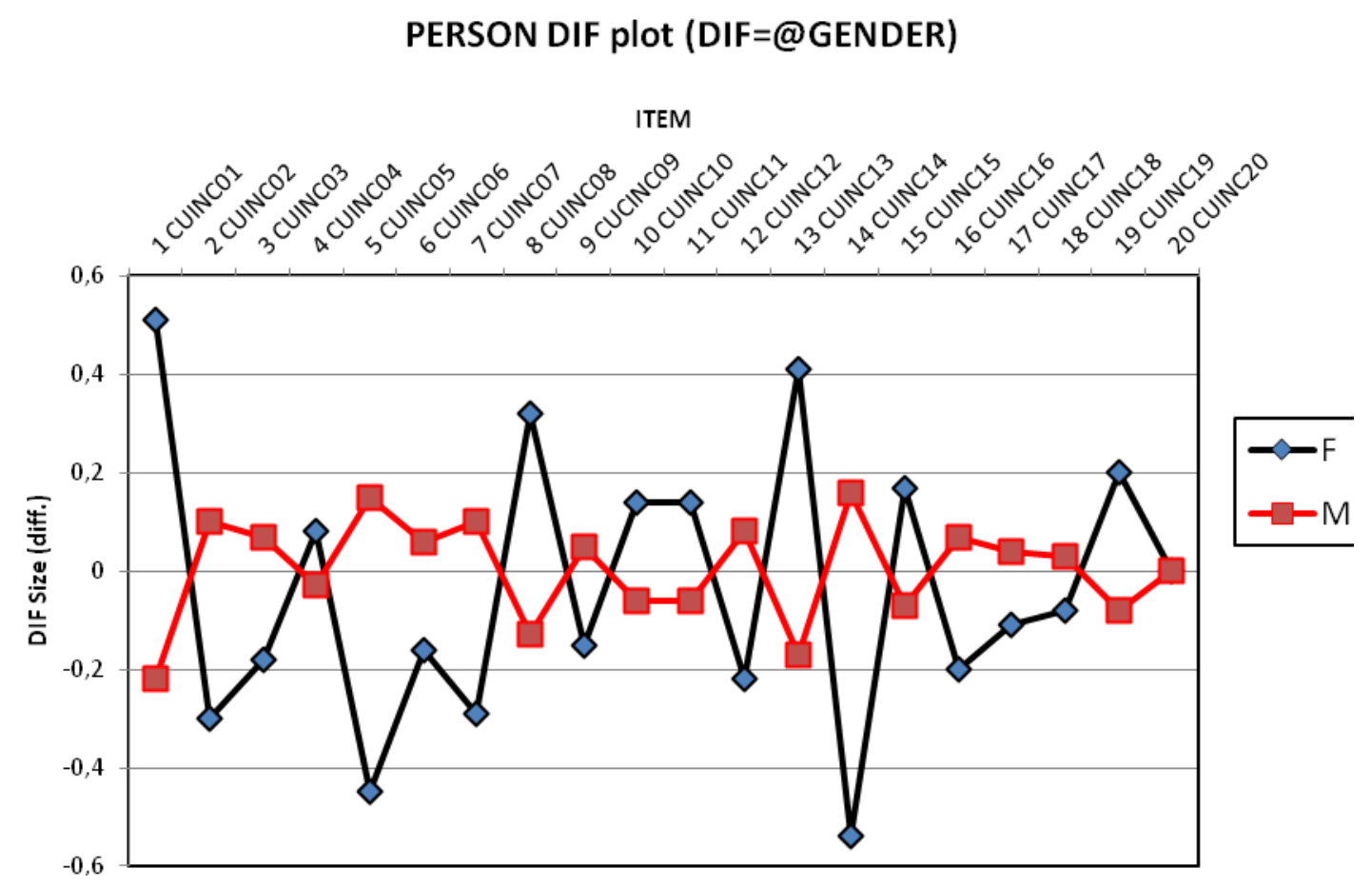

Figura 93. Tamaño de las diferencias del FDI en función del género (Escala de satisfacción con la escuela)

Un análisis más detallado puso de manifiesto que el único ítem en el que se obtienen diferencias significativas (pruebas $t$ de Rasch-Welch y Chi cuadrado de Mantel-Haenszel) es en el ítem 1 ("trabajo con compañeros"), es decir, que el sesgo que supone para las mujeres respecto a la dificultad general del ítem 1 no es explicado por el azar y es 0,74 logits más difícil para las mujeres. 


\subsubsection{Cuestionario de datos sociodemográficos}

Incluye 31 preguntas elaboradas ad hoc tras nuestra primera estancia en el país y tras consultar con informantes sobre la adecuación o relevancia de las mismas (véase Anexo 8.1). Otras preguntas están inspiradas en el Documento de Objetivos del Milenio en incluyen variables como el género, la procedencia rural o urbana, el abandono escolar o la presencia de discapacidad. Todas estas variables han sido identificadas como factores de riesgo para la consecución del objetivo de la educación universal, pues, como se indica en dicho Informe (MDG Report, 2010, p.18), las desigualdades obstaculizan el avance hacia el logro de dicho objetivo. Añadimos también algunos ítems de Global School-based Student Health Survey (GSHS): 2006 Ethiopia GSHS Questionnaire, o La Encuesta Mundial de Salud a Escolares (GSHS) (OMS, 2006). Otros ítems se han derivado de la encuesta de calidad de vida infantil para padres o tutores (Sabeh, Verdugo, Prieto y Contini de González, 2009). El cuestionario fue cuidadosamente revisado para asegurarnos de la pertinencia de los ítems. Agradecemos en este sentido la ayuda del Padre Pedro, de la orden de los Misioneros Combonianos del Corazón de Jesús, por su intestimable colaboración en la valoración de la adecuación del dossier de evaluación. A modo de ilustración, se incluyen algunas variables inicialmente propuestas para su inclusión en el cuestionario y que fueron eliminadas, a tenor de los comentarios de nuestro colaborador.

Tabla 50. Ejemplo de preguntas y valoración de su pertinencia

\begin{tabular}{|l|l|}
\hline Preguntas & Observaciones \\
\hline $\begin{array}{l}\text { Nivel económico de los padres (alto, medio, } \\
\text { bajo,..) }\end{array}$ & $\begin{array}{l}\text { ¿Cómo saberlo? ¿Sobre el número de vacas o } \\
\text { extensión de tierra? }\end{array}$ \\
\hline Coste de acudir a la escuela (gratis, pagan, etc.) & $\begin{array}{l}\text { No hay 'fee' en Escuelas Públicas ni en las } \\
\text { católicas. Pero sí se pide un "parental } \\
\text { contribution". }\end{array}$ \\
\hline Tiene alguna enfermedad crónica (si o no) & $\begin{array}{l}\text { Ninguno. Ninguna visible y debido a la } \\
\text { mentalidad Pentecostal se avergonzarían de } \\
\text { contestar afirmativamente. Por ejemplo la } \\
\text { semana pasada una mujer se estaba muriendo } \\
\text { simplemente por ser diabética y no haber } \\
\text { tratamiento de insulina en la zona. Los crónicos } \\
\text { duran muy poquito (VIH más Tuberculosis los } \\
\text { mata rápido) }\end{array}$ \\
\hline
\end{tabular}




\begin{tabular}{|l|l|}
\hline Preguntas & Observaciones \\
\hline Su alimentación semanal es equilibrada (si o no) & $\begin{array}{l}\text { Hmm... cómo valorizarlo? Comen siempre "lo } \\
\text { mismo" }\end{array}$ \\
\hline Se alimenta en cantidades adecuadas (si o no) & $\begin{array}{l}\text { ¿cómo valorizarlo? Generalmente los Guji están } \\
\text { mejor alimentados que muchos otros etíopes ya } \\
\text { que tienen vacas que les proporcionan leche, } \\
\text { yogurt y mantequilla. Carne solo comen los días } \\
\text { de fiesta muy importantes. Casos de "hambre" } \\
\text { conozco algunos. Hambre se ve en familias sin el } \\
\text { padre. }\end{array}$ \\
\hline Vive con ambos padres (si o no) & $\begin{array}{l}\text { En la cultura Guji, también puede ser que un } \\
\text { pariente los 'crece' aunque tenga a los dos } \\
\text { padres. }\end{array}$ \\
\hline Ingresos de la familia (nada, muy bajos, bajos, \\
medios, altos, muy altos) \\
$\begin{array}{l}\text { La economía aquí tiene muy poco circulante } \\
\text { monetario, es en gran parte basada en } \\
\text { "agricultura de subsistencia". Tener vacas es lo } \\
\text { que indica la riqueza, las mujeres llevan los } \\
\text { productos lácteos y de la huerta a los mercados } \\
\text { de la zona y allí los venden. Los que tienen otras } \\
\text { profesiones como maestros, carpinteros.. } \\
\text { siempre las combinan con trabajo en la tierra y } \\
\text { tener animales. }\end{array}$
\end{tabular}

\subsubsection{Cuestionario de Calidad de vida infantil}

El cuestionario, elaborado por Sabeh y cols., (Sabeh, Verdugo, Prieto y Contini de González, 2009) ha sido desarrollado para ser utilizado con niños entre 8 y 11 años. Evalúa la calidad de vida en cinco factores: bienestar emocional (10 ítems), relaciones interpersonales (13 ítems), bienestar físico (5 ítems), desarrollo personal y actividades (9 ítems), y bienestar material (6 ítems). Para el presente estudio se optó por eliminar varios ítems que, a juicio de nuestro colaborador de los Misioneros Combonianos, eran no pertinentes o inadecuados culturalmente.

Tabla 51. Ítems de calidad de vida infantil eliminados para el presente estudio

\begin{tabular}{l}
\hline Ítems eliminados \\
\hline 18. Quisiera que cambiaran muchas cosas en mi vida \\
22. Quisiera que mis compañeros fueran diferentes \\
26. Mis compañeros me invitan a celebraciones \\
28. Me gusta y me siento bien con mi cuerpo \\
29. En mi cumpleaños puedo invitar a quien quiero \\
31. Tengo familia (tíos, primos, abuelos) que nos visitan \\
37. Me gustaría que mi maestra fuera diferente \\
41. Me preocupa lo que me pueda suceder cuando sea grande
\end{tabular}


Está compuesto por 43 ítems que se han de valorar en una escala tipo likert de cuatro puntos, que fluctúa desde "casi siempre" a "casi nunca" y puntuaciones más elevadas denotan mayor calidad de vida. En la Tabla 52 se presentan los resultados del análisis de fiabilidad obtenidos.

Tabla 52. Consistencia interna de la escala y los factores de Calidad de Vida Infantil

\begin{tabular}{ll}
\hline Factores & Alfa de Cronbach \\
\hline F1. Bienestar Emocional & 0,594 \\
F2. Relaciones Interpersonales & 0,779 \\
F3. Desarrollo Personal y Autonomía & 0,650 \\
F4. Bienestar Físico & 0,558 \\
F5. Bienestar Material & 0,737 \\
Total & 0,935 \\
\hline
\end{tabular}

En la Tabla 53 se presentan las asociaciones entre los factores y el total de la escala. Se puede apreciar la existencia de correlaciones medias entre escalas y más elevadas con el total de la misma. También se aprecia cómo por ejemplo, no existe asociación entre bienestar físico y material. Todo ello indica que es posible experimentar diferentes niveles de bienestar en las diversas áreas vitales relevantes.

Tabla 53. Correlaciones de Pearson entre las dimensiones y total de la escala de Calidad de Vida infantil

\begin{tabular}{|c|c|c|c|c|c|c|}
\hline & $\begin{array}{l}\text { Bienestar } \\
\text { Emocional }\end{array}$ & $\begin{array}{l}\text { Relaciones } \\
\text { Interpersonales }\end{array}$ & $\begin{array}{l}\text { Desarrollo } \\
\text { Personal y } \\
\text { Actividades }\end{array}$ & $\begin{array}{l}\text { Bienestar } \\
\text { Físico }\end{array}$ & $\begin{array}{l}\text { Bienestar } \\
\text { Material }\end{array}$ & Total CVI \\
\hline $\begin{array}{l}\text { Bienestar } \\
\text { Emocional }\end{array}$ & 1 & $0,434 * *$ & $0,487^{* *}$ & $0,486 * *$ & $0,322 * *$ & $0,721 * *$ \\
\hline $\begin{array}{l}\text { Relaciones } \\
\text { Interpersonales }\end{array}$ & & 1 & $0,605^{* *}$ & $0,581 * *$ & $0,407 * *$ & $0,842 * *$ \\
\hline $\begin{array}{l}\text { Desarrollo Personal } \\
\text { y Actividades }\end{array}$ & & & 1 & $0,392 * *$ & $0,488 * *$ & $0,826 * *$ \\
\hline Bienestar Físico & & & & 1 & 0,053 & $0,657 * *$ \\
\hline Bienestar Material & & & & & 1 & $0,621 * *$ \\
\hline Total CVI & & & & & & 1 \\
\hline
\end{tabular}

** La correlación es significativa al nivel 0,01 (bilateral).

\section{Análisis Rash de la Escala de Calidad de Vida Infantil}

De modo complementario y de acuerdo con los principios de la teoría de respuesta al ítem, hemos comprobado el ajuste de datos al modelo. En primer 
lugar, el ajuste de los ítems y en segundo lugar, el ajuste de los participantes. En la Tabla 54 se indican los datos de ajuste de los ítems al modelo. Se puede apreciar cómo los valores de Infit y Outfit no superan el valor de 2,0, lo que indica un buen ajuste. El error de medida fluctúa entre 0,13 y 0,19 , muy bajos todos ellos, lo que avala la precisión de la medida. La fiabilidad de la escala fue de 0,90.

Tabla 54. Propiedades psicométricas de la muestra de ítems de calidad de vida ( $\mathrm{N}=43$ )

\begin{tabular}{|l|l|l|l|l|}
\hline & Localización & Error & INFIT & OUTFIT \\
\hline Media & 0,00 & 0,15 & 1,04 & 1,02 \\
\hline D.T. & 0,60 & 0,02 & 0,26 & 0,24 \\
\hline Máximo & 1,13 & 0,19 & 1,51 & 1,43 \\
\hline Mínimo & $-1,00$ & 0,13 & 0,47 & 0,46 \\
\hline
\end{tabular}

En la Tabla 55 se presentan los resultados relativos al ajuste de las personas al modelo. Los valores medios infit y outfit son adecuados, si bien, la puntuación máxima de infit y outfit es superior a 2,0, lo que indica que aunque por término medio los participantes se ajustan al modelo, hay participantes con patrones de respuesta desajustados. Concretamente, dos personas $(2,9 \%)$ mostraron valores extremos. La fiabilidad de las personas fue de 0,89 , lo que avala un ajuste adecuado de las personas al modelo.

Tabla 55. Propiedades psicométricas de la muestra de participantes en la escala de calidad de vida $(\mathrm{N}=67)$

\begin{tabular}{|l|l|l|l|l|l|}
\hline & Total & Localización & Error & INFIT & OUTFIT \\
\hline Media & 121,7 & .38 & 0,18 & 1,00 & 1,02 \\
\hline D.T. & 11,3 & .37 & 0,01 & 0,44 & 0,46 \\
\hline Máximo & 152,0 & 1,54 & 0,25 & 2,17 & 2,30 \\
\hline Mínimo & 103,0 & $-0,21$ & 0,17 & 0,26 & 0,31 \\
\hline
\end{tabular}

En el mapa de Wright (Figura 93) se presenta la localización de los participantes y los ítems ${ }^{1}$ en la variable latente medida. La línea central de la figura representa el continuo de calidad de vida. En la parte inferior se sitúan los ítems que miden aspectos más básicos o "fáciles" de la calidad de vida, es decir, en aquéllos en los que es más fácil obtener la máxima puntuación (p.e. ítem 35: “Me gusta mi casa o mi habitación" e ítem 53: "Me siento bien en la escuela"), mientras

\footnotetext{
${ }^{1}$ Si bien los análisis tan solo incluyen los 43 items utilizados para el presente estudio, hemos mantenido la denominación inicial de los ítems, por lo que la numeración de los mismos no coincide con la numeración que hemos presentado en el Anexo 7.3.
} 
que en la parte superior se encuentran los aspectos más exigentes o "difíciles" de la calidad de vida, esto es, en los que es más difícil obtener la máxima puntuación (p.e. ítem 30: "Mis compañeros me pegan o me gritan más que a otros" o ítem 8: "En la escuela las cosas me salen mal"). También se aprecia cómo los participantes tienden a experimentar una media-alta calidad de calidad de vida.

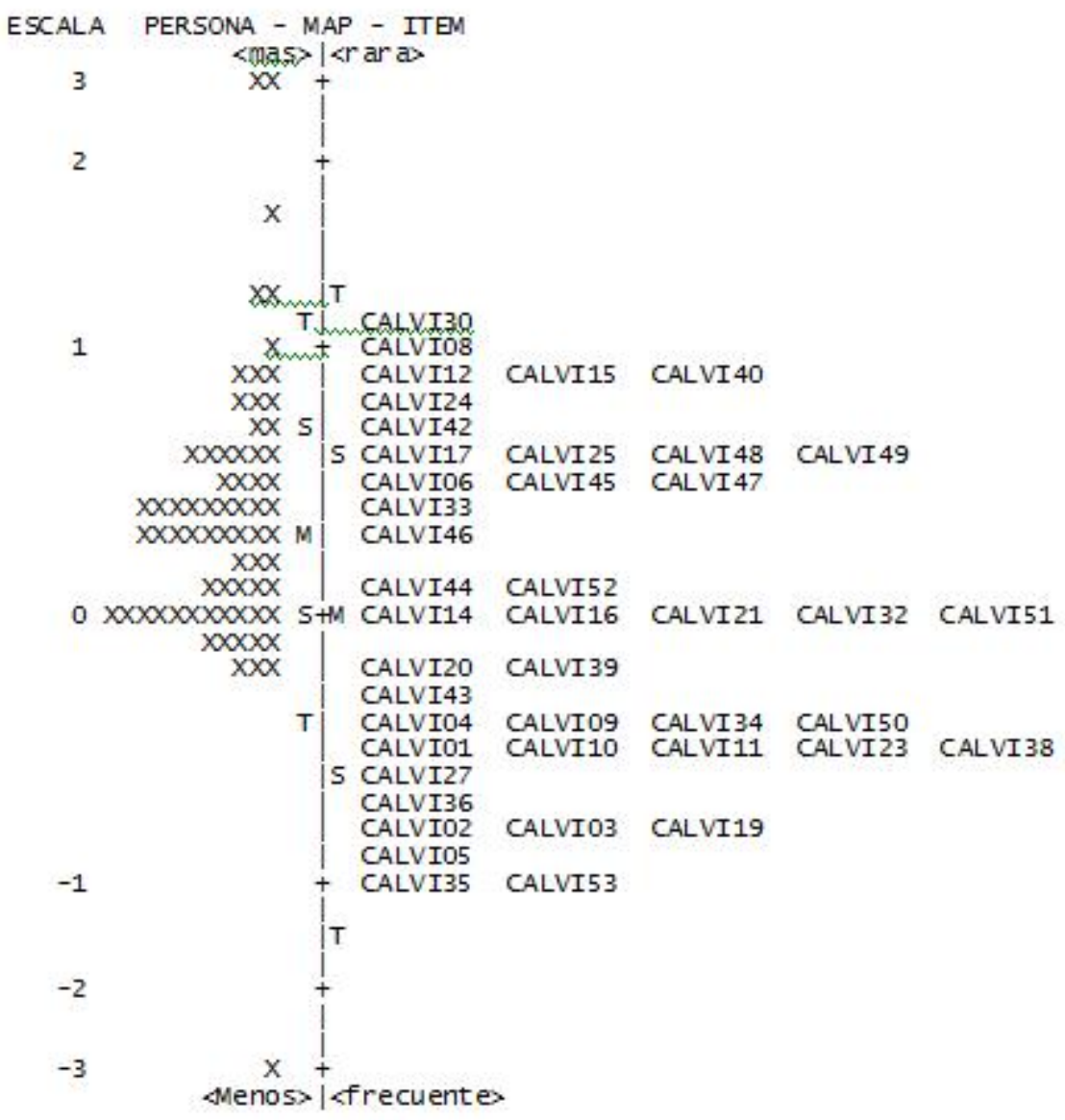

Figura 94. Mapa de Wright. Identificación de los participantes y los ítems en la variable latente medida (Calidad de vida)

Por tratarse de una escala con ítems politómicos, presentamos en la Figura 95 la distribución de personas e ítems. 


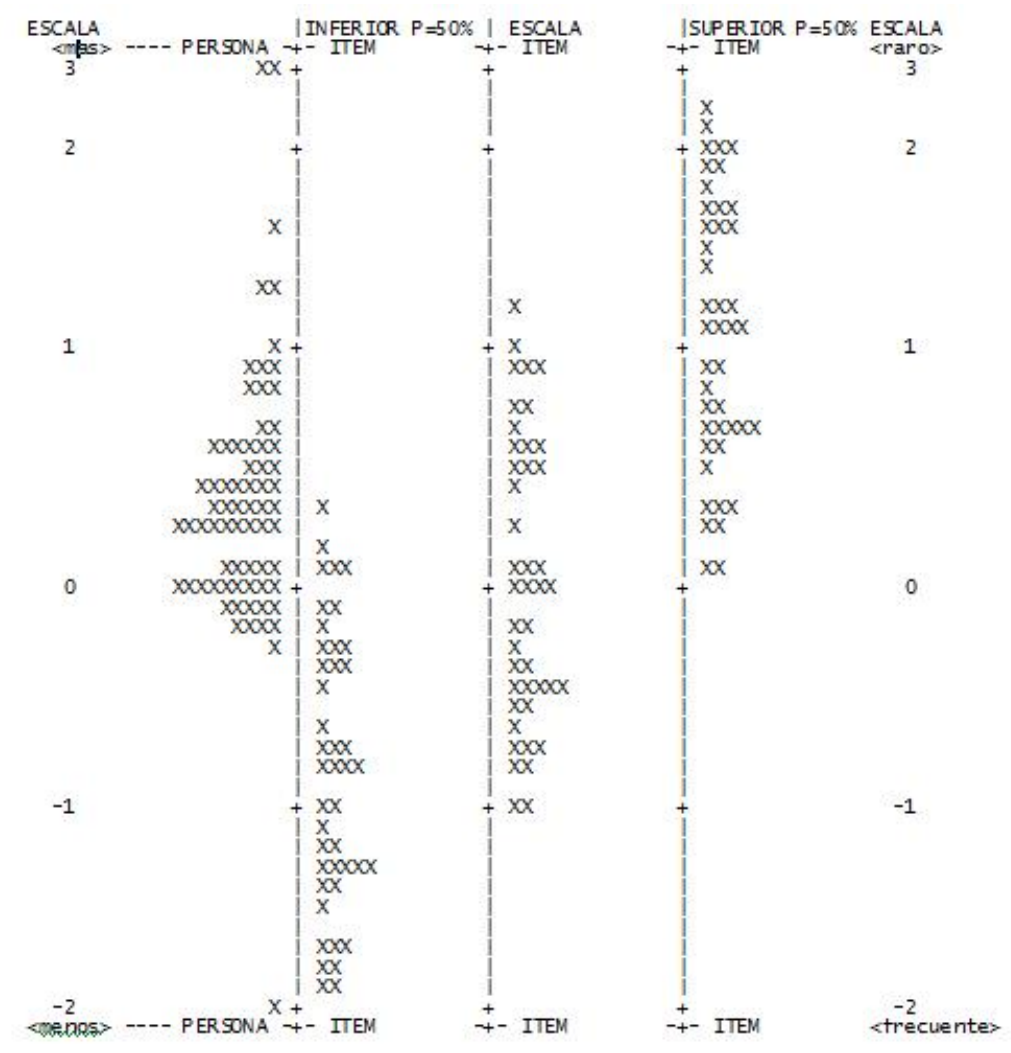

Figura 95. Distribución de personas e ítems en la Escala de Calidad de vida

Respecto a las propiedades psicométricas de los ítems de la escala de satisfacción con la escuela según el modelo de Rash, en la Tabla 56 se indican los valores obtenidos para cada uno de los ítems. Se puede apreciar cómo ninguno de los valores de Infit y Outfit supera el valor de 2.0, lo que indica un buen ajuste. Como antes señaláramos, todos los errores de medida son pequeños, especialmente los que aparecen en la parte superior de la Tabla (p.e. ítems 30: "Mis compañeros me pegan o me gritan más que a otros", 8: "En la escuela las cosas me salen mal", 12: "Mi maestra/o me trata de forma diferente que a los demás compañeros", 40: "Estoy triste, con ganas de llorar", etc.). Los valores de correlación obtenidos frente a los esperados son muy similares en la mayoría de los ítems, así como los valores obtenidos frente a los esperados. 
Tabla 56. Propiedades psicométricas de los ítems de la escala de calidad de vida según el modelo de Rash

\begin{tabular}{|c|c|c|c|c|c|c|c|c|c|c|c|c|}
\hline & & & & infit & & outfit & & & & & & \\
\hline Puntuación & $\mathrm{N}$ & Measures & $\begin{array}{l}\text { Error } \\
\text { tpicio }\end{array}$ & MNSQ & ZSTD & MNSQ & ZSTD & $\begin{array}{l}\text { point- } \\
\text { measure } \\
\text { correlation }\end{array}$ & $\begin{array}{l}\text { Valor } \\
\text { esperado } \\
\text { de la pm } \\
\text { correlación }\end{array}$ & $\begin{array}{l}\text { Exact } \\
\text { obs. } \\
\%\end{array}$ & Esper\% & item \\
\hline 135 & 70 & 1.13 & .14 & 1.20 & 1.4 & 1.21 & 1.4 & .39 & .43 & 19.4 & 27.6 & CALVI30 \\
\hline 144 & 70 & .97 & .13 & 1.21 & 1.6 & 1.30 & 2.1 & .33 & .41 & 25.4 & 26.9 & CALVI08 \\
\hline 147 & 70 & .92 & .13 & 1.10 & .8 & 1.09 & .7 & .39 & .41 & 26.9 & 27.6 & CALVI12 \\
\hline 147 & 70 & .92 & .13 & 1.31 & 2.2 & 1.41 & 2.8 & .33 & .41 & 22.4 & 27.6 & CALVI40 \\
\hline 149 & 70 & .89 & .13 & 1.13 & 1.0 & 1.16 & 1.2 & .36 & .40 & 28.4 & 27.9 & CALVI15 \\
\hline 157 & 70 & .76 & .13 & 1.31 & 2.3 & 1.33 & 2.4 & .32 & .39 & 29.9 & 28.6 & CALVI24 \\
\hline 158 & 70 & .74 & .13 & 1.05 & .4 & 1.09 & .8 & .34 & .39 & 35.8 & 28.6 & CALVI42 \\
\hline 164 & 70 & .64 & .13 & .90 & -.8 & .90 & -.8 & .40 & .39 & 34.3 & 30.2 & CALVI49 \\
\hline 167 & 70 & .59 & .13 & .74 & -2.2 & .73 & -2.3 & .42 & .38 & 43.3 & 31.0 & CALVI17 \\
\hline 167 & 70 & .59 & .13 & .89 & -.8 & .90 & -.7 & .39 & .38 & 41.8 & 31.0 & CALVI25 \\
\hline 168 & 70 & .58 & .13 & .74 & -2.3 & .73 & -2.3 & .46 & .38 & 41.8 & 31.0 & CALVI48 \\
\hline 172 & 70 & .51 & .13 & .77 & -1.9 & .75 & -2.1 & .44 & .38 & 41.8 & 31.8 & CALVI06 \\
\hline 174 & 70 & .48 & .13 & 1.02 & .2 & .99 & .0 & .36 & .38 & 37.3 & 32.9 & CALVI45 \\
\hline 174 & 70 & .48 & .13 & 1.12 & .9 & 1.13 & 1.0 & .36 & .38 & 32.8 & 32.9 & CALVI47 \\
\hline 177 & 70 & .43 & .13 & .94 & -.4 & .92 & -.5 & .38 & .38 & 44.8 & 34.6 & CALVI33 \\
\hline 188 & 70 & .25 & .13 & .92 & -.6 & .88 & -.8 & .36 & .37 & 44.8 & 37.5 & CALVI46 \\
\hline 197 & 70 & .10 & .13 & .96 & -.2 & 1.09 & .6 & .33 & .37 & 53.7 & 40.7 & CALVI44 \\
\hline 197 & 70 & .10 & .13 & .75 & $\begin{array}{l}-1.8 \\
\end{array}$ & .76 & -1.7 & .43 & .37 & 52.2 & 40.7 & CALVI52 \\
\hline 200 & 70 & .04 & .13 & .57 & -3.4 & .57 & -3.2 & .44 & .36 & 55.2 & 42.5 & CALVI51 \\
\hline 202 & 70 & .01 & .14 & .75 & -1.7 & .75 & $\begin{array}{l}-1.7 \\
\end{array}$ & .41 & .36 & 50.7 & 43.5 & CALVI32 \\
\hline 203 & 70 & -.01 & .14 & 1.22 & 1.4 & 1.19 & 1.2 & .33 & .36 & 37.3 & 43.5 & CALVI14 \\
\hline 203 & 70 & -.01 & .14 & .98 & -.1 & .95 & -.3 & .36 & .36 & 37.3 & 43.5 & CALVI21 \\
\hline 204 & 70 & -.03 & .14 & .98 & .0 & 1.06 & .4 & .35 & .36 & 46.3 & 44.1 & CALVI16 \\
\hline 211 & 70 & -.17 & .14 & .86 & -.8 & .89 & -.6 & .36 & .36 & 50.7 & 45.9 & CALVI20 \\
\hline 212 & 70 & -.19 & .14 & .47 & -3.9 & .46 & -3.9 & .49 & .36 & 61.2 & 46.0 & CALVI39 \\
\hline 215 & 70 & -.25 & .15 & 1.26 & 1.5 & 1.21 & 1.1 & .38 & .36 & 31.3 & 46.0 & CALVI43 \\
\hline 220 & 70 & -.36 & .15 & .79 & -1.2 & .75 & -1.4 & .43 & .36 & 53.7 & 46.1 & CALVI04 \\
\hline 220 & 70 & -.36 & .15 & .95 & -.2 & 1.03 & .2 & .39 & .36 & 46.3 & 46.1 & CALVI09 \\
\hline 222 & 70 & -.41 & .15 & .83 & -.9 & .83 & -.9 & .39 & .37 & 49.3 & 46.2 & CALVI34 \\
\hline 223 & 70 & -.43 & .15 & 1.51 & 2.5 & 1.43 & 2.1 & .34 & .37 & 26.9 & 46.1 & CALVI50 \\
\hline 224 & 70 & -.45 & .16 & 1.35 & 1.8 & 1.26 & 1.3 & .34 & .37 & 35.8 & 46.6 & CALVI11 \\
\hline 224 & 70 & -.45 & .16 & .70 & -1.7 & .69 & -1.8 & .44 & .37 & 56.7 & 46.6 & CALVI23 \\
\hline 224 & 70 & -.45 & .16 & 1.07 & .4 & 1.03 & .2 & .38 & .37 & 40.3 & 46.6 & CALVI38 \\
\hline 227 & 70 & -.53 & .16 & .78 & -1.2 & .77 & -1.2 & .42 & .37 & 53.7 & 47.2 & CALVI01 \\
\hline 227 & 70 & -.53 & .16 & .84 & -.8 & .82 & -.9 & .39 & .37 & 50.7 & 47.2 & CALVI10 \\
\hline 228 & 70 & -.55 & .16 & .94 & -.2 & .94 & -.2 & .36 & .37 & 49.3 & 47.2 & CALVI27 \\
\hline 235 & 70 & -.74 & .17 & 1.31 & 1.4 & 1.14 & .7 & .38 & .37 & 37.3 & 47.8 & CALVI36 \\
\hline 236 & 70 & -.77 & .17 & 1.36 & 1.6 & 1.23 & 1.1 & .33 & .37 & 31.3 & 48.6 & CALVI02 \\
\hline 236 & 70 & -.77 & .17 & 1.35 & 1.6 & 1.24 & 1.1 & .36 & .37 & 40.3 & 48.6 & CALVI19 \\
\hline 238 & 70 & -.84 & .18 & 1.49 & 2.1 & 1.36 & 1.6 & .33 & .38 & 37.3 & 49.3 & CALVI03 \\
\hline 239 & 70 & -.87 & .18 & 1.27 & 1.2 & 1.18 & .8 & .36 & .38 & 43.3 & 49.5 & CALVI05 \\
\hline 242 & 70 & -.97 & .19 & 1.32 & 1.4 & 1.23 & 1.1 & .36 & .38 & 46.3 & 52.3 & CALVI53 \\
\hline 243 & 70 & -1.00 & .19 & 1.48 & 2.0 & 1.32 & 1.4 & .38 & .38 & 55.2 & 53.4 & CALVI35 \\
\hline
\end{tabular}

En la Tabla 57 relativa a la polaridad de los ítems, presenta los estadísticos de las categorías de respuesta de los ítems de satisfacción con la escuela, ordenados según el tamaño de la correlación. Como sucediera con la escala previa, es de esperar que cuanto más alto puntúe una persona, más altas serán las valoraciones de los ítems, y a la inversa. La correlación punto-medida refleja el grado en que esto es verdad para cada ítem. Esperamos así que las categorías más altas (es decir, la 4, que denota más calidad de vida), sean elegidos por los niños que puntúen más alto (es decir, que se sientan más satisfechos al respecto). En los 
casos en los que no sucede, aparece un asterisco para señalar que las habilidades promedio se encuentran desordenadas. Como se puede apreciar, en nuestro caso tan solo aparece en los ítems 3 ("me llevo bien con mis hermanos") y 27 ("Estoy contento con mis notas o rendimiento en la escuela"). Respecto a las correlaciones, esperamos que la categoría más alta (i.e. 4) tenga una correlación elevada y positiva con la variable evaluada (calidad de vida) y que la categoría más baja (i.e. 1) tenga una correlación elevada y negativa con dicha variable.

Tabla 57. Polaridad de los ítems de la escala de calidad de vida

\begin{tabular}{|c|c|c|c|c|c|c|c|c|c|}
\hline $\begin{array}{l}\text { numero } \\
\text { de item }\end{array}$ & $\begin{array}{l}\text { código de } \\
\text { la } \\
\text { puntuación }\end{array}$ & valor & Frecuencia & porcentaje & $\begin{array}{l}\text { Habilidad } \\
\text { promedio }\end{array}$ & $\begin{array}{l}\text { E.T. } \\
\text { Media }\end{array}$ & $\begin{array}{l}\text { Outfit } \\
\text { MNSQ }\end{array}$ & $\begin{array}{l}\text { PTMA } \\
\text { Corr }\end{array}$ & item \\
\hline 23 & 1 & 1 & 36 & 51 & .10 & .16 & 1.0 & -.27 & CALVI 30 \\
\hline & 2 & 2 & 10 & 14 & .24 & .12 & 1.3 & -.06 & \\
\hline & 3 & 3 & 17 & 24 & 58 & .11 & 9 & .07 & \\
\hline & 4 & 4 & 7 & 10 & 2.00 & 1.05 & 1.3 & .43 & \\
\hline 7 & 1 & 1 & 29 & 41 & .13 & .20 & 1.1 & -.21 & CALVI 08 \\
\hline & 2 & 2 & 14 & 20 & .27 & .09 & .9 & -.06 & \\
\hline & 3 & 3 & 21 & 30 & .51 & .10 & .9 & .05 & \\
\hline & 4 & 4 & 6 & 9 & 1.96 & 1.29 & 2. 2 & .38 & \\
\hline 11 & 1 & 1 & 29 & 41 & 06 & .20 & 1.0 & -.25 & CALVI 12 \\
\hline & 2 & 2 & 14 & 20 & .20 & .08 & 8 & -.09 & \\
\hline & 3 & 3 & 18 & 26 & .53 & .11 & 1. 0 & .05 & \\
\hline & 4 & 4 & 9 & 13 & 1. 77 & .81 & 1.0 & .42 & \\
\hline 31 & 1 & 1 & 30 & 43 & 09 & .20 & 1.1 & -.24 & CALVI 40 \\
\hline & 2 & 2 & 12 & 17 & 36 & .09 & .8 & -.02 & \\
\hline & 3 & 3 & 19 & 27 & 50 & .10 & 9 & .04 & \\
\hline & 4 & 4 & 9 & 13 & 1.49 & .87 & 1.7 & .33 & \\
\hline 13 & 1 & 1 & 28 & 40 & .08 & .21 & 1.1 & -.23 & CALVI 15 \\
\hline & 2 & 2 & 12 & 17 & .22 & .07 & 4 & -.08 & \\
\hline & 3 & 3 & 23 & 33 & 49 & .09 & 1.0 & .04 & \\
\hline & 4 & 4 & 7 & 10 & 1.96 & 1.06 & 1.5 & .42 & \\
\hline & & & & & & & & & \\
\hline 20 & 1 & 1 & 26 & 37 & .04 & .22 & 1.0 & -.24 & CALVI 24 \\
\hline & 2 & 2 & 13 & 19 & .26 & .07 & .5 & -.06 & \\
\hline & 3 & 3 & 19 & 27 & .59 & .11 & 8 & .08 & \\
\hline & 4 & 4 & 12 & 17 & 1. 19 & .66 & 1.5 & .28 & \\
\hline 32 & 1 & 1 & 21 & 30 & .06 & .28 & 1.3 & -.20 & CALVI 42 \\
\hline & 2 & 2 & 17 & 24 & .21 & .07 & .6 & -.10 & \\
\hline & 3 & 3 & 25 & 36 & .47 & .08 & .9 & .03 & \\
\hline & 4 & 4 & 7 & 10 & 1. 90 & 1.07 & 1.5 & .40 & \\
\hline 39 & 1 & 1 & 19 & 27 & -.11 & .30 & 9 & -.27 & CALVI 49 \\
\hline & 2 & 2 & 16 & 23 & 27 & .07 & 8 & -.07 & \\
\hline & 3 & 3 & 27 & 39 & 47 & .08 & 9 & .03 & \\
\hline & 4 & 4 & 8 & 11 & 1.85 & .92 & 1. 2 & 42 & \\
\hline 15 & 1 & 1 & 14 & 20 & -.29 & 39 & 8 & -.29 & CALVI 17 \\
\hline & 2 & 2 & 22 & 31 & .30 & .07 & 9 & -.07 & \\
\hline & 3 & 3 & 27 & 39 & 53 & .08 & 8 & .06 & \\
\hline & 4 & 4 & 7 & 10 & 1.89 & 1.07 & 1.3 & .40 & \\
\hline 21 & 1 & 1 & 17 & 24 & -.06 & .34 & 1.1 & -.22 & CALVI 25 \\
\hline & 2 & 2 & 17 & 24 & .15 & .05 & .3 & -.13 & \\
\hline & 3 & 3 & 28 & 40 & .48 & .07 & .8 & .04 & \\
\hline & 4 & 4 & 8 & 11 & 1.85 & .93 & 1. 3 & .42 & \\
\hline 38 & 1 & 1 & 18 & 26 & -.15 & .31 & 9 & -.28 & CALVI 48 \\
\hline & 2 & 2 & 15 & 21 & .07 & .05 & 2 & -.15 & \\
\hline & 3 & 3 & 28 & 40 & 50 & .05 & .7 & .05 & \\
\hline & 4 & 4 & 9 & 13 & 1.96 & .78 & .8 & .48 & \\
\hline 6 & 1 & 1 & 18 & 26 & -.18 & .31 & .9 & -.29 & CALVI 06 \\
\hline & 2 & 2 & 10 & 14 & .01 & .05 & .1 & -.14 & \\
\hline & 3 & 3 & 34 & 49 & 52 & .06 & 7 & .07 & \\
\hline & 4 & 4 & 8 & 11 & 1. 92 & .91 & 1. 0 & 44 & \\
\hline 35 & 1 & 1 & 17 & 24 & -.10 & .33 & 1.0 & -.24 & CALVI 45 \\
\hline & 2 & 2 & 12 & 17 & .23 & .09 & .8 & -.07 & \\
\hline
\end{tabular}




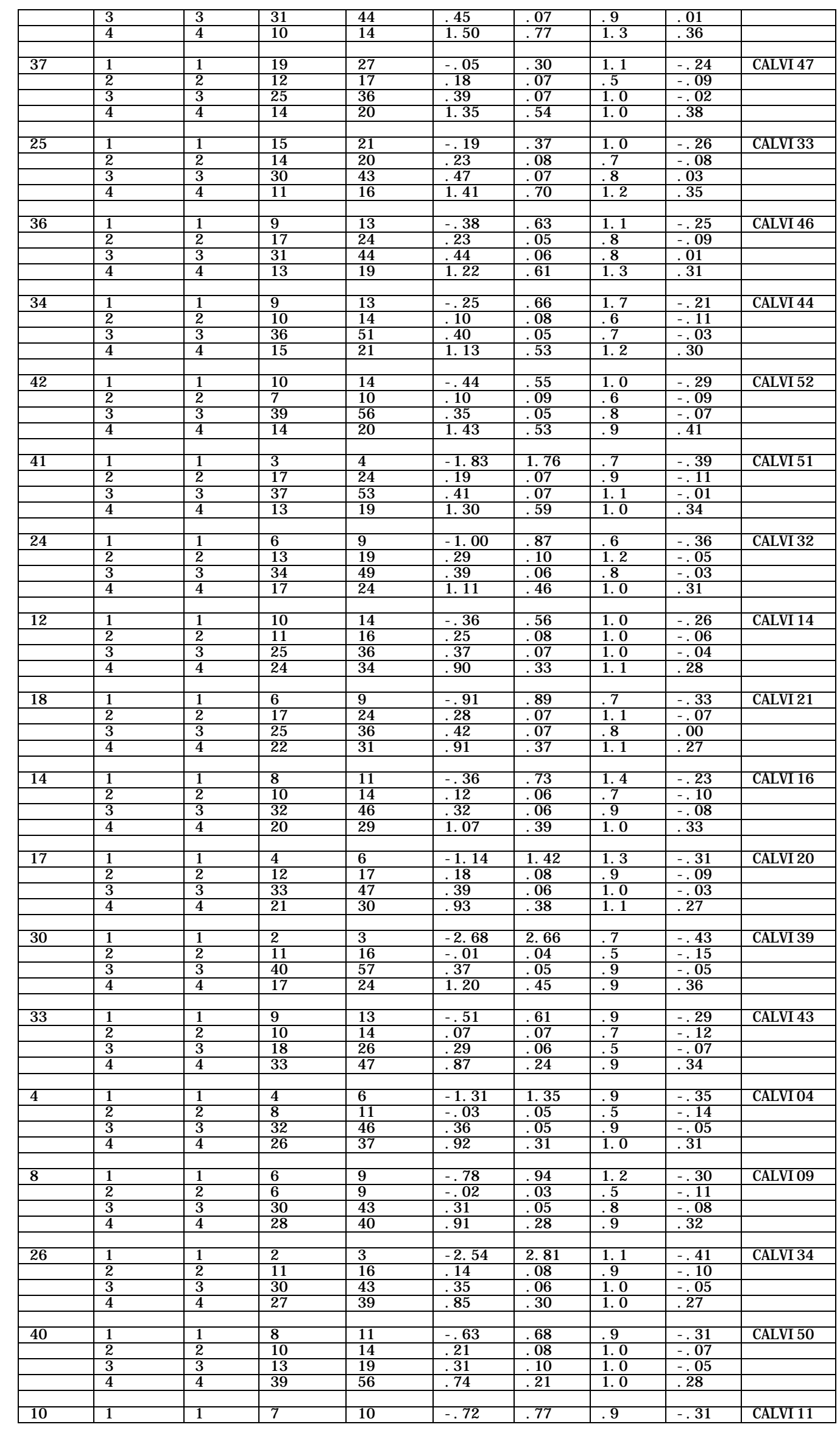




\begin{tabular}{|c|c|c|c|c|c|c|c|c|c|}
\hline & 2 & 2 & 7 & 10 & .19 & .09 & 9 & -.07 & \\
\hline & 3 & 3 & 21 & 30 & .39 & .08 & 1. 2 & -.02 & \\
\hline & 4 & 4 & 35 & 50 & .73 & .23 & 1.0 & .25 & \\
\hline \multirow{4}{*}{19} & 1 & 1 & 3 & 4 & -182 & 1.76 & 7 & -39 & CAlVI 23 \\
\hline & 2 & 2 & 6 & 9 & .02 & .08 & .7 & -.10 & \\
\hline & 3 & 3 & 35 & 50 & .32 & .06 & 1. 2 & -.09 & \\
\hline & 4 & 4 & 26 & 37 & .93 & .30 & .9 & .31 & \\
\hline \multirow[t]{4}{*}{29} & 1 & 1 & 4 & 6 & -1.36 & 1.33 & .8 & -.36 & CALVI 38 \\
\hline & 2 & 2 & 11 & 16 & .20 & .06 & 9 & -.08 & \\
\hline & 3 & 3 & 22 & 31 & .28 & .08 & 1.0 & -.08 & \\
\hline & 4 & 4 & 33 & 47 & .82 & .24 & 1.0 & .30 & \\
\hline \multirow[t]{4}{*}{1} & 1 & 1 & 3 & 4 & -1.70 & 1.83 & 1.0 & -.37 & CALVI 01 \\
\hline & 2 & 2 & 5 & 7 & .11 & .11 & .8 & -.07 & \\
\hline & 3 & 3 & 34 & 49 & .28 & .05 & 8 & -.12 & \\
\hline & 4 & 4 & 28 & 40 & .90 & .28 & 1. 0 & .31 & \\
\hline \multirow[t]{4}{*}{9} & 1 & 1 & 3 & 4 & -1.69 & 1.83 & 10 & -37 & CALVI 10 \\
\hline & 2 & 2 & 5 & 7 & .12 & .08 & .8 & $\frac{-.51}{-.07}$ & \\
\hline & 3 & 3 & 34 & 49 & .33 & .06 & 1.1 & -.07 & \\
\hline & 4 & 4 & 28 & 40 & .82 & .29 & 1.0 & .26 & \\
\hline \multirow[t]{4}{*}{22} & 1 & 1 & 3 & 4 & -1.64 & 1.85 & 1.1 & -.36 & CALVI 27 \\
\hline & 2 & 2 & 6 & 9 & .24 & .14 & 1.1 & -.05 & \\
\hline & 3 & 3 & 31 & 44 & .30 & .06 & .9 & -.09 & \\
\hline & 4 & 4 & 30 & 43 & .80 & .27 & 1. 0 & .26 & \\
\hline \multirow[t]{4}{*}{28} & 1 & 1 & 5 & 7 & -1.15 & 1. 05 & .7 & -.36 & CALVI 36 \\
\hline & 2 & 2 & 6 & 9 & .01 & .01 & .7 & -.10 & \\
\hline & 3 & 3 & 18 & 26 & .35 & .07 & 1. 1 & -.04 & \\
\hline & 4 & 4 & 41 & 59 & .71 & .20 & 1.0 & .28 & \\
\hline \multirow{4}{*}{2} & 1 & 1 & 5 & 7 & -1.11 & 1.06 & 8 & -.35 & CALVI 02 \\
\hline & 2 & 2 & 4 & 6 & .02 & .15 & .8 & $\frac{-.50}{-.08}$ & \\
\hline & 3 & 3 & 21 & 30 & .48 & .08 & 1. 6 & .03 & \\
\hline & 4 & 4 & 40 & 57 & .63 & .21 & 1. 1 & .19 & \\
\hline \multirow{5}{*}{16} & & & & & & & & & \\
\hline & 1 & 1 & 5 & 7 & -1.14 & 1.05 & .7 & -.35 & CALVI 19 \\
\hline & 2 & 2 & 5 & 7 & .24 & .11 & 1.0 & -.04 & \\
\hline & 3 & 3 & 19 & 27 & .30 & .08 & 1. 1 & -.06 & \\
\hline & 4 & 4 & 41 & 59 & .70 & .20 & 1.0 & .26 & \\
\hline \multirow[t]{4}{*}{3} & 1 & 1 & 6 & 9 & -.91 & .89 & 8 & -.33 & CALVI03 \\
\hline & 2 & 2 & 2 & 3 & .41 & .05 & 1.3 & .00 & \\
\hline & 3 & 3 & 20 & 29 & $.37 *$ & .09 & 1.3 & -.03 & \\
\hline & 4 & 4 & 42 & 60 & .65 & .20 & 1. 0 & .22 & \\
\hline \multirow[t]{4}{*}{5} & 1 & 1 & 4 & 6 & -1.35 & 1.33 & 8 & -.36 & CALVI 05 \\
\hline & 2 & 2 & 4 & 6 & .04 & .11 & 8 & -.08 & \\
\hline & 3 & 3 & 21 & 30 & .37 & .09 & 1.3 & -.03 & \\
\hline & 4 & 4 & 41 & 59 & .67 & .20 & 1. 0 & .23 & \\
\hline \multirow[t]{4}{*}{43} & 1 & 1 & 2 & 3 & -2.65 & 2.69 & 9 & -43 & CALVI 53 \\
\hline & 2 & 2 & 9 & 13 & .13 & .07 & 9 & -.09 & \\
\hline & 3 & 3 & 14 & 20 & .30 & .10 & 1. 1 & -.05 & \\
\hline & 4 & 4 & 45 & 64 & .66 & .18 & 1. 0 & .26 & \\
\hline \multirow[t]{4}{*}{27} & 1 & 1 & 4 & 6 & -1.37 & 1.32 & 8 & -.36 & CALVI 35 \\
\hline & 2 & 2 & 6 & 9 & .16 & .10 & .9 & -.07 & \\
\hline & 3 & 3 & 13 & 19 & $.14^{*}$ & .07 & 6 & -.11 & \\
\hline & 4 & 4 & 47 & 67 & .69 & .17 & 1.0 & .31 & \\
\hline
\end{tabular}

* la habilidad promedio no aumenta de acuerdo a lo esperado.

En la Figura 96 se muestra cómo los participantes se han comportado en todos los ítems como cabría esperar: a mayor categoría, mayor puntuación promedio. 


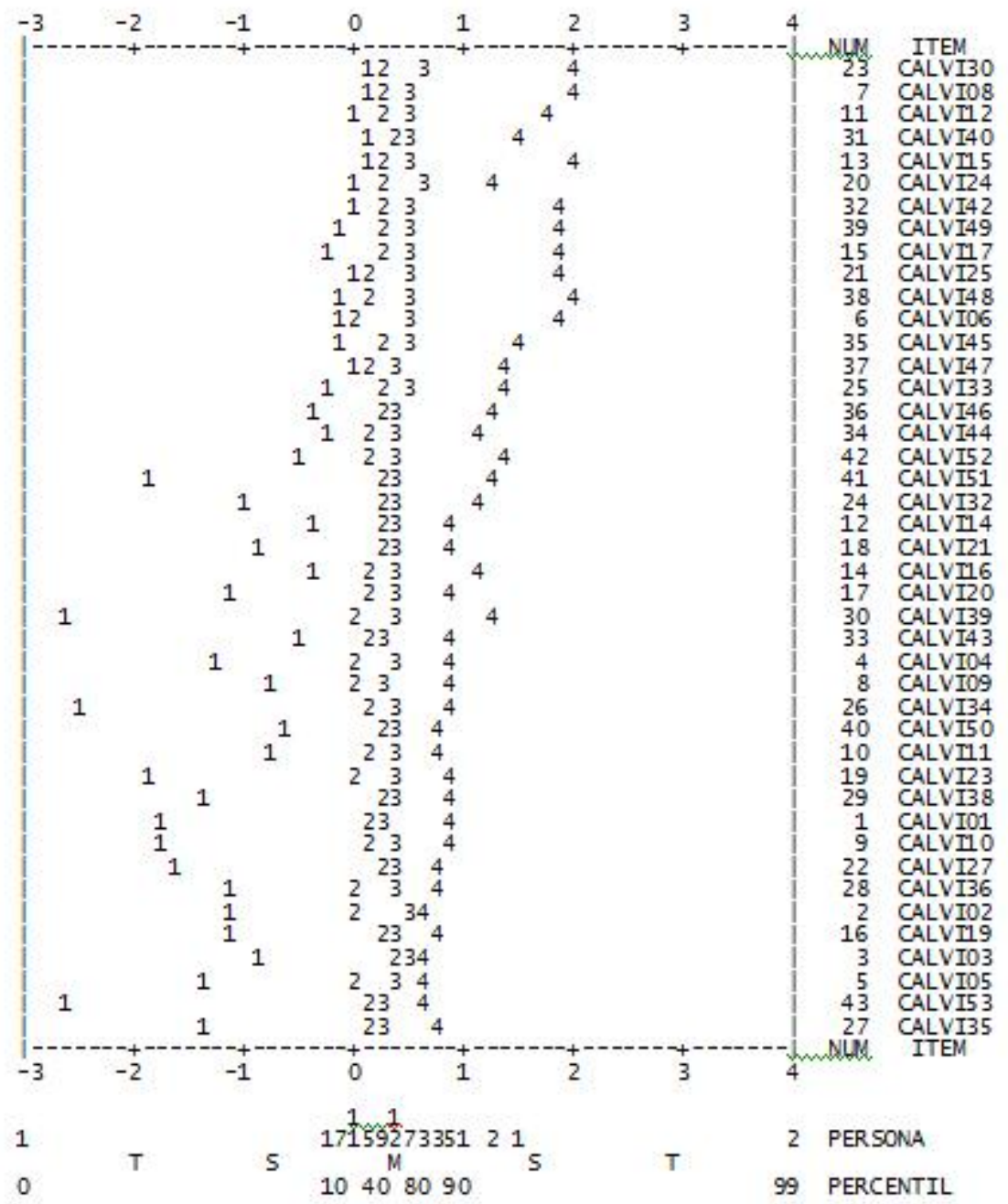

Figura 96. Representación gráfica del comportamiento de los ítems (escala de calidad de vida)

El gráfico de burbujas (Figura 97) presenta los ítems. Un tamaño más grande de las burbujas indica mayor error típico. Se aprecia cómo las burbujas de los ítems son aproximadamente del mismo tamaño. Los valores infit son sensibles a patrones extraños no extremos, mientras que los outfit son sensibles a valores extremos. Los valores esperados en todos los casos son de 1 o cercanos. Los valores estandarizados se deben encontrar entre $-2 y+2 y$ un ajuste perfecto implica valores cercanos a 0 . Se puede apreciar cómo la gran mayoría de los ítems se encuentran en los niveles de ajuste y bastante agrupados, con la excepción de los ítems 39 ("A mis compañeros les gusta estar conmigo"), 51 ("Tengo tiempo libre 
suficiente"), 40 ("Estoy triste, con ganas de llorar") y el ítem 24 ("En la escuela me siento solo").

ITEM

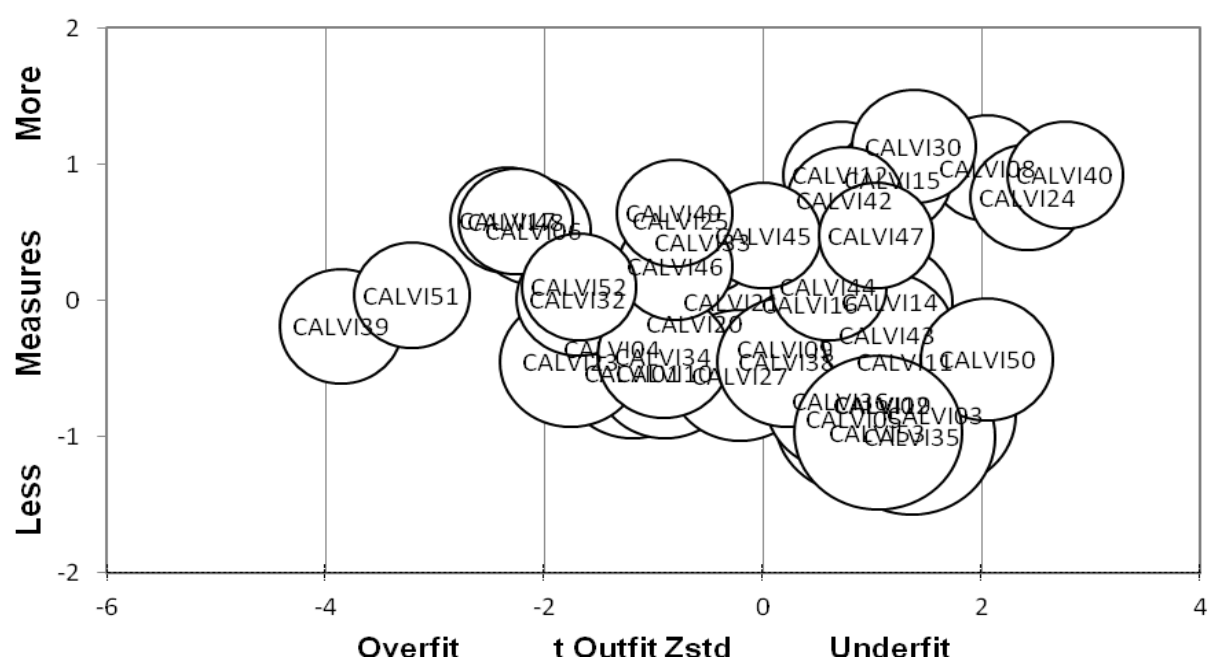

Figura 97. Gráfico de burbujas de los ítems (Escala de Calidad de Vida)

En la Figura 98 se puede apreciar cómo, al igual que sucediera con la anterior escala, la calibración de los pasos 1 al 4 no está perfectamente calibrada, dado que la categoría de respuesta 2 no es la más probable en ninguna región de la variable. Sin embargo, hemos optado por respetar la configuración inicial de las categorías, para no perder información derivada de agrupar varias en una. 


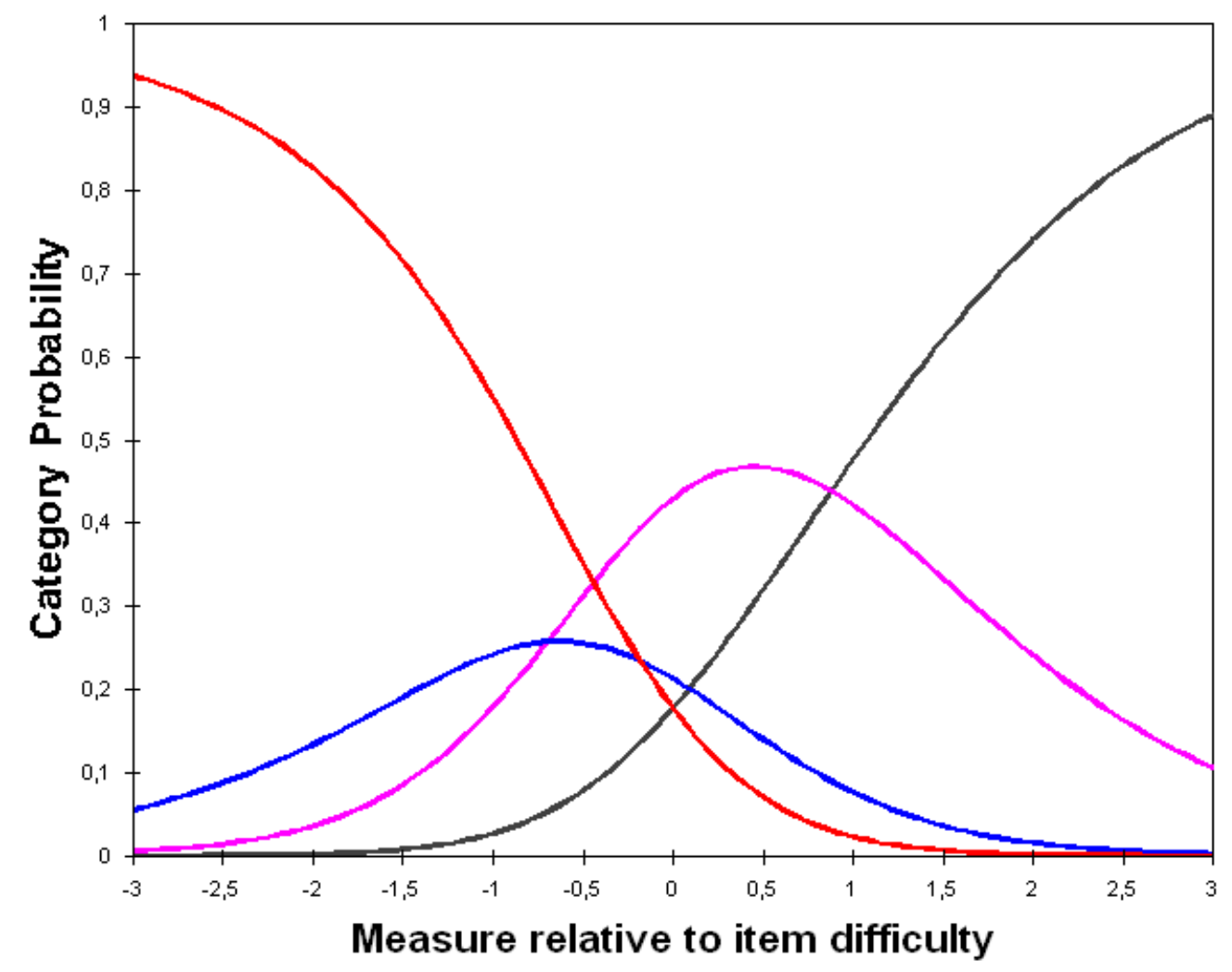

- Category probability: $1 \quad$ - Category probability: 2 - Category probability: 3 - Category probability: 4

Figura 98. Calibración de los ítems (escala de calidad de vida)

En la Figura 99 se presentan las curvas características de los ítems en términos absolutos respecto a la variable latente satisfacción con la escuela. Se puede apreciar una cierta variación en la dificultad de distintos ítems, pero con similares pendientes 


\section{Item Characteristic Curves}
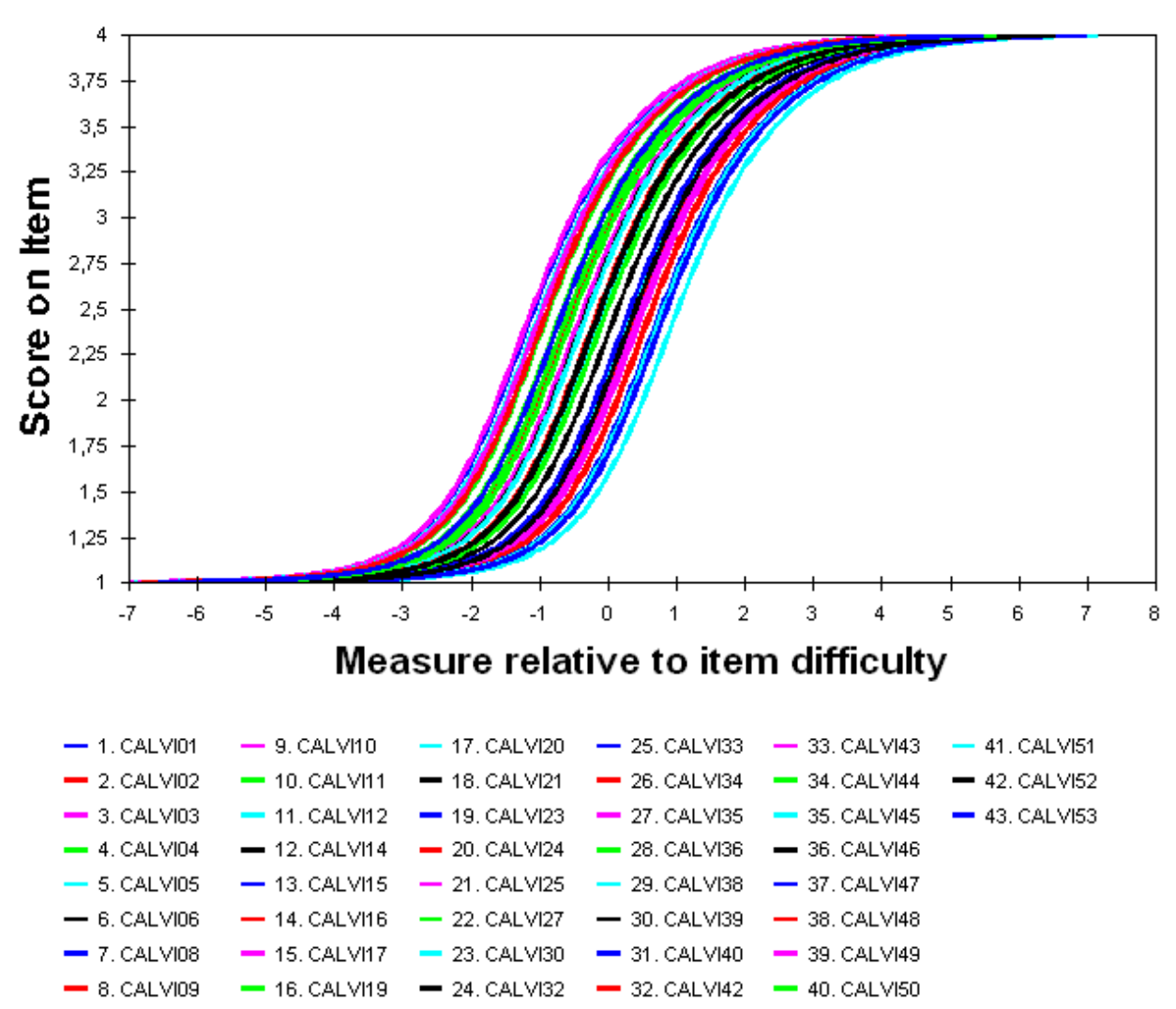

Figura 99. Curvas características de los ítems (Escala de Calidad de Vida)

A modo de ejemplo, se presenta la curva característica del ítem esperada por el modelo de Rasch (Figura 100). Dicho modelo predice cómo los participantes que obtienen diferentes puntuaciones en la variable latente (eje $x$ ) puntuarán en el ítem (eje y) en promedio. La línea azul refleja la curva empírica característica del ítem. Se puede ver cómo dicha línea se encuentra próxima a la línea azul. Las líneas verdes reflejan las bandas a ambos lados de los niveles de confianza al 95\%. Dichas bandas se sitúan a 1,96 errores típicos de la línea roja. Cuantas más observaciones hallen en un intervalo, más cerca se encuentran las líneas verdes a la roja. 


\section{CALVI01}

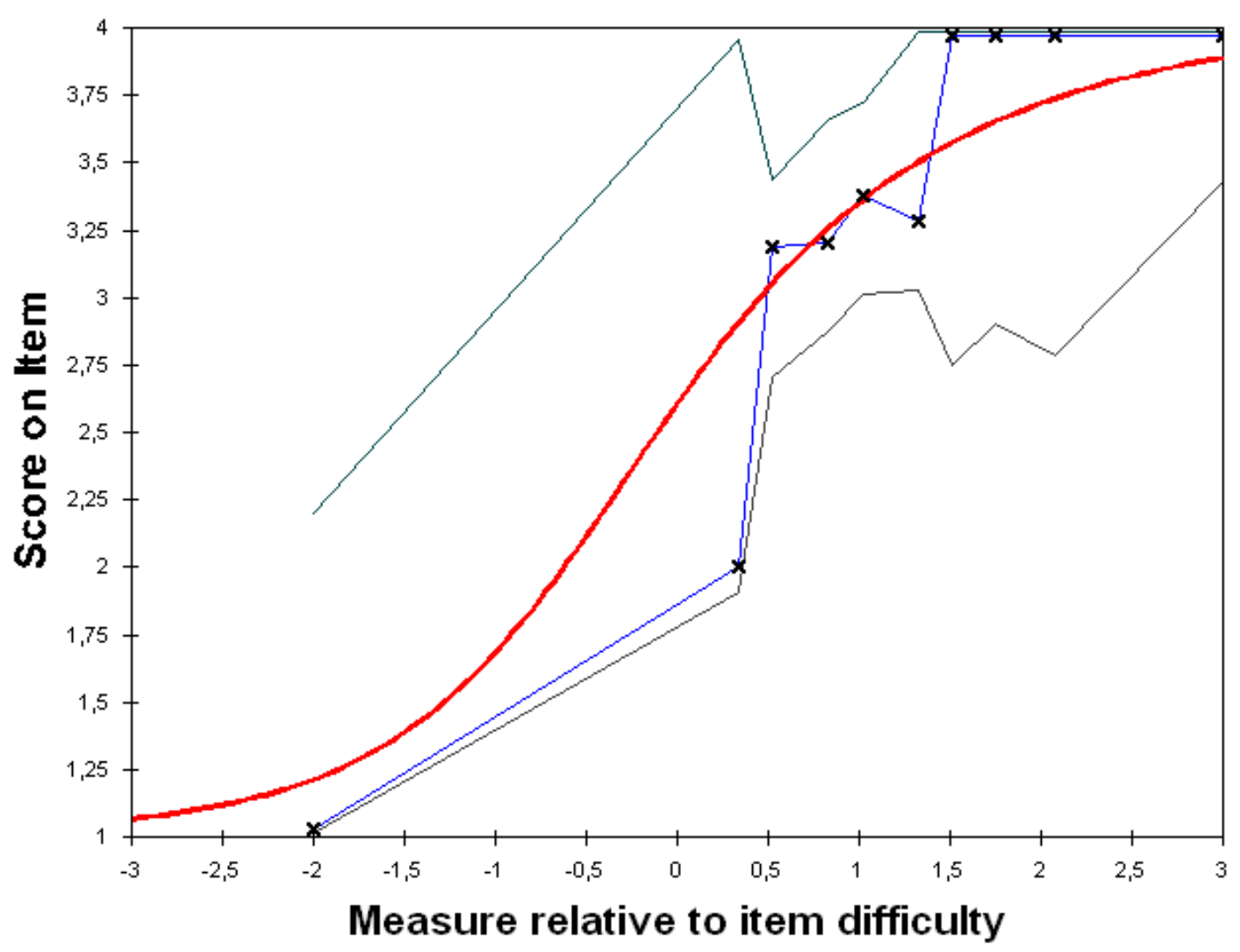

- Expected score ogive: Model ICC

- Upper $95 \% 2$-sided confidence interval

* Empirical ICC

- Lower $95 \%$ 2-sided confidence interval

Figura 100. Ejemplo de curva característica del ítem 1 según el modelo Rash, en la escala de Calidad de Vida

\section{3) Funcionamiento diferencial del test(FDT)}

El análisis del funcionamiento diferencial del test pretende determinar si el test, formado por todos los ítems, funciona igual para los participantes atendiendo a alguna variable relevante, en nuestro caso, el género. En la Figura 101 se puede apreciar que el ítem 23 ("Juego con mis amigos") es bastante más difícil para los hombres que para las mujeres, mientras que por ejemplo, el ítem 27 ("Estoy contento con mis notas o rendimiento en la escuela") es más fácil para las mujeres que para los hombres. 


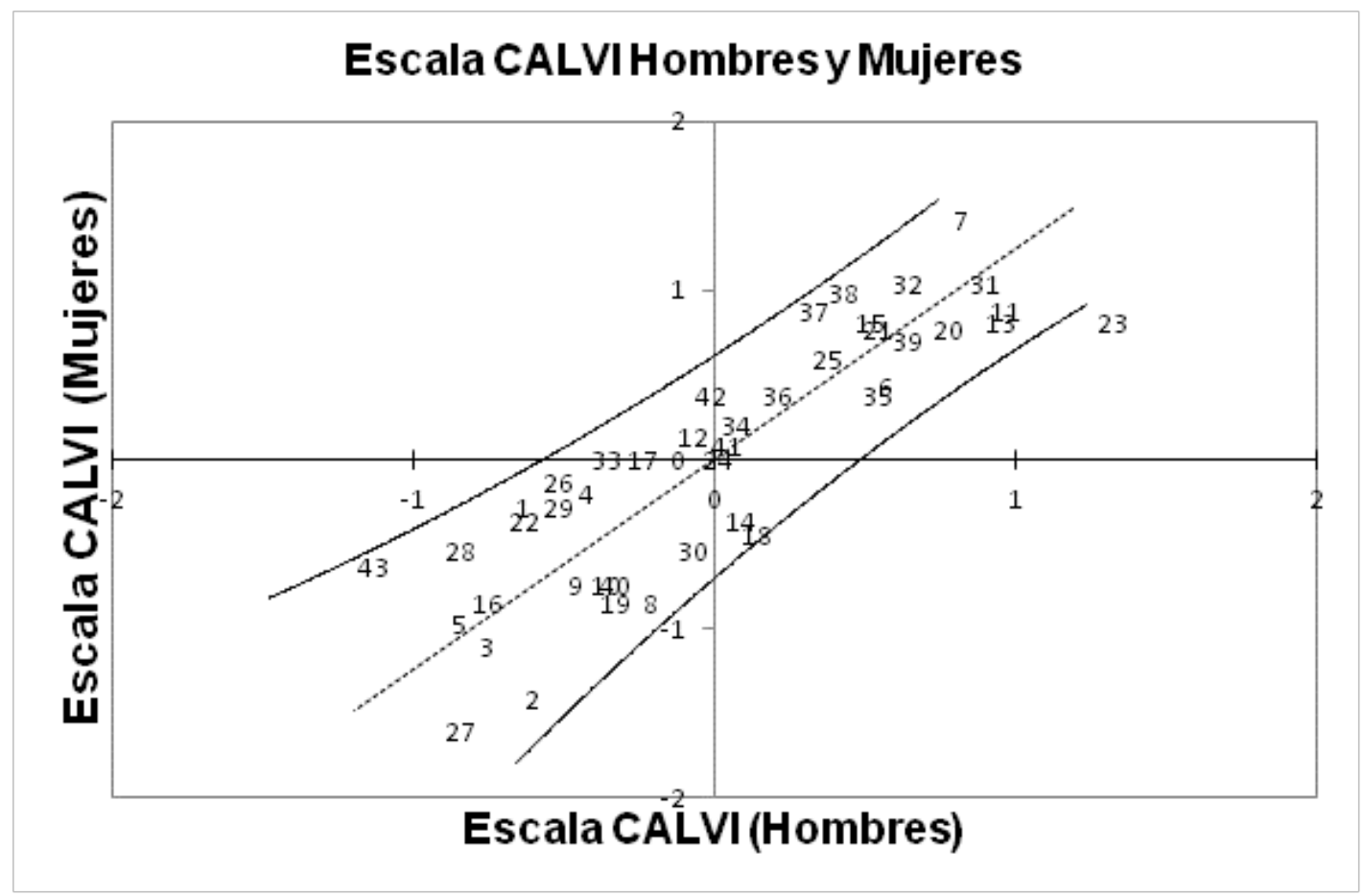

Figura 101. Funcionamiento diferencial del test para hombres y mujeres (Escala de Calidad de Vida)

\section{4) Funcionamiento diferencial de los ítems (FDI)}

Se presenta a continuación el tamaño del efecto del funcionamiento diferencial de los ítems (véase Figura 102). Se puede comprobar la presencia de algunas puntuaciones con tamaños de los efectos grandes (i.e. logits superiores a 0,638 ) Ítems 2 ("Duermo tranquilo") y 9 ("Los fines de semana hago cosas que me gustan"), siendo en ambos casos más fáciles para las mujeres, dicho de otro modo, es más probable que las mujeres obtengan puntuaciones más elevadas en ambos ítems.

Además, varios ítems muestran tamaños de los efectos intermedios (entre 0,426 y 0,638); en algunos casos los ítems son más difíciles para las mujeres, como sucede con los ítems 8 ("En la escuela las cosas me salen mal"), 47 ("Los demás 
piensan que hago todo mal") y 53 ("Me siento bien en la escuela"). En otros casos los ítems son más fáciles para las mujeres, cosa que sucede con los ítems 16 ("Estoy preocupado"), 21 ("Puedo contar a alguien de mi familia las cosas feas/malas que me pasan"), 39 ("A mis compañeros les gusta estar conmigo") y 50 ("Mi familia tiene suficiente dinero").

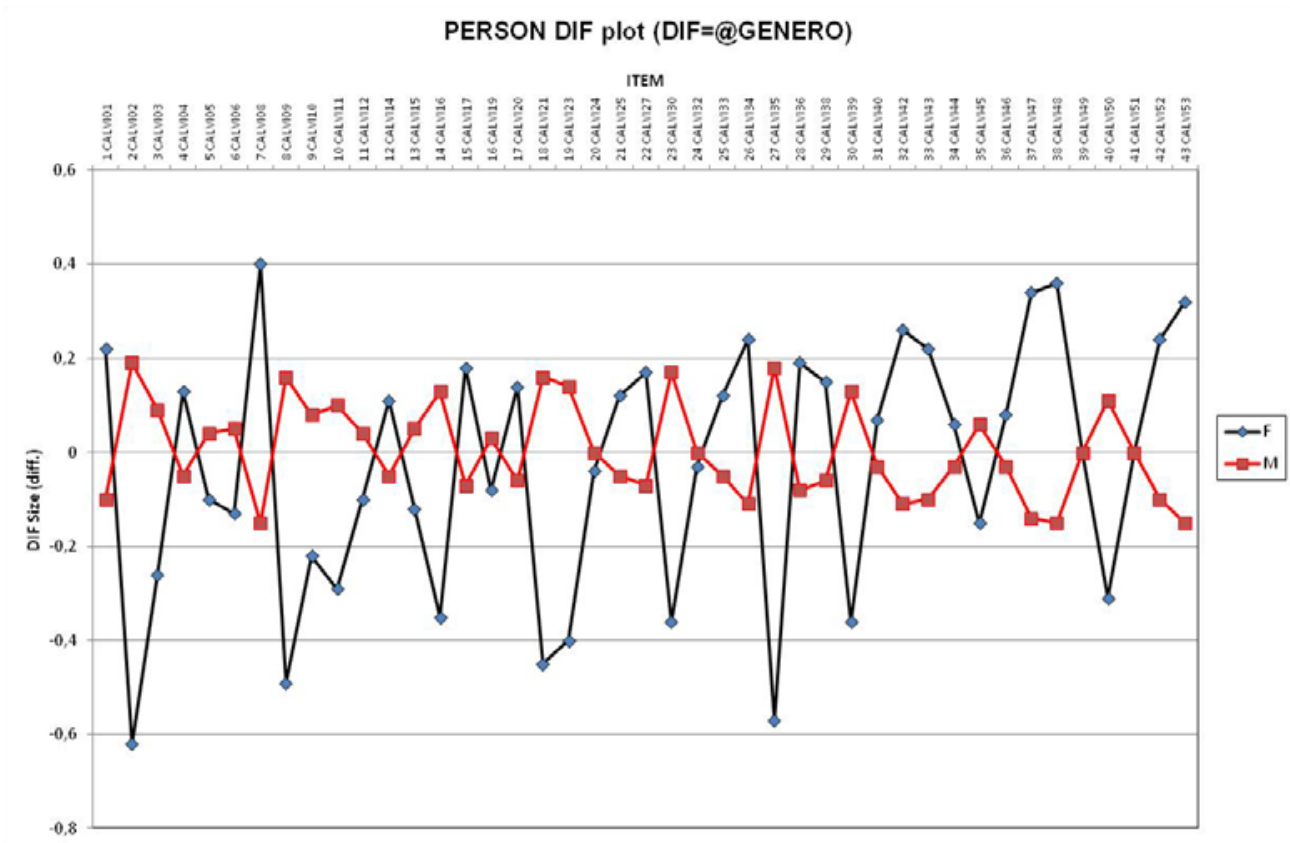

Figura 102. Tamaño de las diferencias del FDI en función del género (Escala de satisfacción con la escuela)

Un análisis más detallado puso de manifiesto la ausencia de diferencias significativas (pruebas t de Rasch-Welch y Chi cuadrado de Mantel-Haenszel) en los diferentes ítems en función del género. Es decir, que las posibles diferencias en la dificultad de los ítems asociadas al sexo se explican por el azar.

\subsection{ENTREVISTAS DE CAMPO}

La metodología que utilizamos para llevar este estudio de satisfacción escolar y su relación con la calidad de vida fueron las entrevistas de campo autocompletables. A través de estos cuestionarios hemos conseguido dar voz a los que en muchos estudios sobre educación o sobre calidad de vida infantil paradójicamente no se concede la voz a los propios niños y niñas. 


\subsubsection{Participantes}

En el presente estudio participaron 70 alumnos de los cursos de tercero a quinto de la escuela de Qillenso. Los análisis previos nos indicaron que los alumnos de primero y segundo no eran capaces de entender las preguntas que se les formulaban en los cuestionarios, incluso aunque se les tradujeran y leyeran en voz alta. Dado que parte de nuestro estudio se centra en el análisis de las características sociodemográficas de los alumnos, pasamos en el apartado siguiente a profundizar sobre los resultados que se desprenden de dicho análisis.

\subsection{ResUltados}

\subsubsection{Perfil sociodemográfico y circunstancias que rodean a los estudiantes de la escuela de Qillenso}

Los 70 alumnos participantes tienen una edad promedio de 11,13 (DT=1,8), con un rango entre los 8 y los 15 años. En la Tabla 58 podemos ver la distribución de alumnos por edad. Esta media de edad de 11,13 años nos indica que en la escuela de Qillenso hay una matriculación tardía de los niños en primaria.

Tabla 58. Distribución de los participantes por edades

\begin{tabular}{llll}
\hline edad & $\mathrm{N}$ & $\%$ & \% Acum. \\
\hline 8 & 2 & 2,86 & 2,86 \\
9 & 12 & 17,14 & 20,00 \\
10 & 17 & 24,29 & 44,29 \\
11 & 11 & 15,71 & 60,00 \\
12 & 12 & 17,14 & 77,14 \\
13 & 8 & 11,43 & 88,57 \\
14 & 4 & 5,71 & 94,29 \\
15 & 4 & 5,71 & 100,00 \\
Total & 70 & 100,00 & \\
\hline
\end{tabular}

A continuación y en cuanto al género, encontramos que al colegio acuden 20 chicas frente a 50 chicos. Así y como se refleja en la Figura 103, casi tres cuartos de la matrícula corresponde a chicos. Esta diferencia tan marcada a favor de los chicos 
se encuentra dentro del marco de que la asistencia masculina a la escuela de primaria de Qillenso es superior a la femenina.

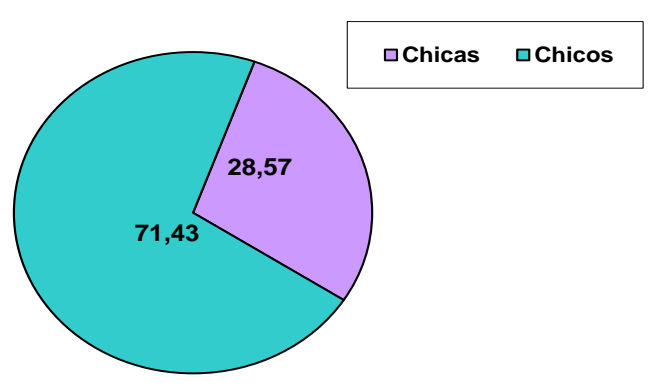

Figura 103. Distribución de los participantes por género.

En la Tabla 59 se aprecia la distribución de los alumnos dependiendo del curso en el que se encontraban matriculados. Se puede observar que se entrevistó a alumnos de tercer, cuarto y quinto grado y las proporciones que cada clase aportó al total de entrevistas. Descartamos realizar entrevistas a los alumnos de primer y segundo grado por razones que expondremos más adelante

Tabla 59. Distribución de participantes en niveles educativos

\begin{tabular}{llll}
\hline grado & $\mathrm{N}$ & $\%$ & $\%$ Acum. \\
\hline Tercero & 21 & 30,00 & 30,00 \\
Cuarto & 22 & 31,43 & 61,43 \\
Quinto & 27 & 38,57 & 100,00 \\
Total & 70 & 100,00 & \\
\hline
\end{tabular}

Los análisis revelaron una ausencia de asociación entre género y grado (Chi cuadrado =5,802; $g l=2 ; p=0,055)$, es decir, que chicos y chicas se distribuyen de un modo similar en los diferentes cursos analizados. No obstante y dado lo próximo a la significación del estadístico Chi cuadrado, es interesante destacar cómo en tercer grado había un $14,3 \%$ de chicas, cifra que asciende a un $22,7 \%$ de chicas en cuarto y que alcanza un $44,4 \%$ de chicas en quinto. 
En cuanto al número de participantes en el estudio que contaban con hermanos o hermanas en el mismo centro escolar, el 77,14\% de los encuestados tenía algún hermano o hermana en el mismo colegio de Qillenso mientras que solo el $22,86 \%$ no lo tenía, estos datos refuerzan nuestra creencia de que la presencia de un primer niño o niña de una familia en la escuela favorece la posterior matriculación de sus hermanos, además también pensamos que confirma la idea de que muchas familias de la zona esperan a que varios hermanos tengan la edad suficiente para asistir a la escuela para matricularlos conjuntamente. El análisis de la posible asociación entre género y tener o no hermanos en el mismo centro, no resultó en asociaciones significativas (Chi cuadrado=0,980; $g l=1 ; p=0,322$ ).

En la Tabla 60 podemos observar el tiempo que tardan los participantes en el estudio en desplazarse desde sus casas a la escuela para asistir al colegio. Podemos observar cómo hasta un $60 \%$ de los alumnos tardan hasta media hora en llegar al colegio desde sus casas, habiendo aproximadamente un $20 \%$ de alumnos que tardan entre 30 minutos y una hora en llegar a clase. Finalmente poco más o menos un $18 \%$ de alumnos que tardan más de una hora en dirigirse de su casa a la escuela todos los días.

Tabla 60. Distribución de los participantes según el tiempo que tardan en desplazarse de casa al colegio

\begin{tabular}{llll}
\hline tiempo clase & $\mathrm{N}$ & $\%$ & \% Acum. \\
\hline Hasta 10 minutos & 16 & 22,86 & 23,19 \\
$10-20$ minuts & 17 & 24,29 & 47,83 \\
$20-30$ min & 9 & 12,86 & 60,87 \\
$30-40$ & 4 & 5,71 & 66,67 \\
$40-50$ & 2 & 2,86 & 69,57 \\
$50-60$ & 8 & 11,43 & 81,16 \\
mas de 1 hora & 13 & 18,57 & 98,57 \\
NR & 1 & 1,43 & 100,00 \\
Total & 70 & 100,00 & \\
\hline
\end{tabular}

A continuación pasamos a analizar el porcentaje de participantes que han tenido una escolarización continuada o. Los datos se recogen en la Figura 104. En dicha Figura se observa cómo solo un $52,86 \%$ de los alumnos han mantenido una 
escolarización constante desde que iniciaron sus estudios de primaria frente a un $47,14 \%$ que han abandonado la escuela durante al menos un curso desde que fueron matriculados por primera vez. Esto supone una diferencia de solo 5,72 puntos y es reflejo de uno de los problemas más graves de la educación en Etiopía, el abandono escolar y la matriculación intermitente.

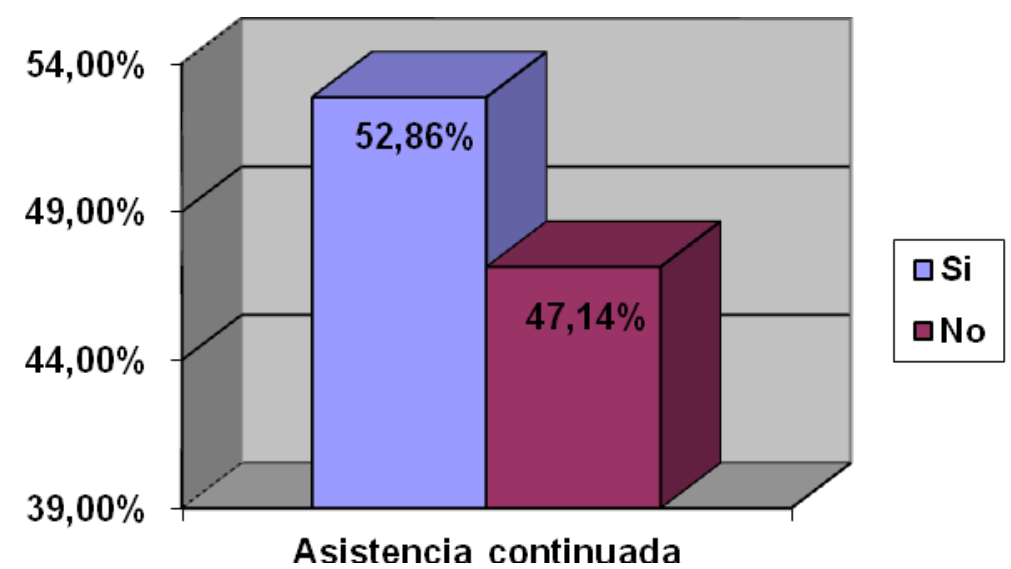

Figura 104. Porcentaje de participantes que han tenido una escolarización continuada o no

El análisis de la asociación entre asistencia continuada o no y el género puso de manifiesto la ausencia de significación (Chi cuadrado =0,694; $g l=1 ; p=0,405$ ). Por tanto, es posible afirmar que la ausencia continuada o no a la escuela no parece estar asociada al género.

En suma, el análisis de las características o perfil de los alumnos que acuden a la escuela de Qillenso, si bien se ha centrado únicamente en los escolarizados a partir del tercer grado, refleja varios de los problemas detectados en las estadísticas nacionales y regionales, a saber: una mayor presencia de estudiantes masculinos, una dificultad en acceder a la escuela debido a las condiciones físicas del terreno, una falta de asistencia continuada en la escuela, un retraso en el grado que se cursa, respecto a la edad.

Tras presentar las características más importantes de los participantes y de su situación, lo que nos permite hacernos una idea de cómo son los alumnos de la escuela de Qillenso, pasamos a dar respuesta a los restantes objetivos e hipótesis. 


\subsubsection{Resultados de satisfacción con la escuela y de calidad de vida}

Lo primero que analizaremos será el bloque de preguntas relacionados con la satisfacción de los alumnos con la escuela. Como podemos ver en la Tabla 61 cada enunciado ha sido puntuado con un mínimo de 1 punto y un máximo de 4 obteniendo en todas las preguntas un resultado medio superior a 2 por lo que podemos concluir que los participantes en el estudio muestran un alto grado de satisfacción con la escuela. Estos resultados avalan nuestra segunda hipótesis.

De esta serie de preguntas además podemos destacar que el resultado más alto se ha obtenido en la pregunta número 16, en la que los alumnos manifiestan mostrar un elevado grado de satisfacción cuando logran realizar un buen trabajo en la escuela. Por el contrario, la puntuación media más baja se obtiene en la pregunta número 11 que hace referencia a posibles problemas de bulling en la escuela. No obstante, la dispersión y rango de las puntuaciones hace pensar que algunos alumnos se enfrentan a estas situaciones.

Tabla 61. Estadísticos descriptivos de las puntuaciones en satisfacción con la escuela

\begin{tabular}{lrrrrr}
\hline & N & Mínimo & Máximo & Media & $\begin{array}{c}\text { Desv. } \\
\text { típ. }\end{array}$ \\
& & & & &, 867 \\
1. Trabajo con compañeros & 69 & 1 & 4 & 2,88 &, 771 \\
2. Trabajamos en grupos & 70 & 1 & 4 & 3,01 &, 770 \\
3. Ayudo a mis compañeros & 68 & 1 & 4 & 2,78 &, 815 \\
4. Mis compañeros me ayudan & 68 & 1 & 4 & 2,69 & 1,042 \\
5. Muestran nuestros trabajos para que los demás lo & 67 & 1 & 4 & 2,72 & \\
vean. & & & & & \\
6. Mi profesor me escucha & 70 & 1 & 4 & 2,74 & 1,188 \\
7. Mi profesor me ayuda & 68 & 1 & 4 & 2,96 &, 984 \\
8. Ayudo a mi profesor & 67 & 1 & 4 & 2,51 & 1,021 \\
9. Las reglas son justas. & 68 & 1 & 4 & 3,34 & 1,016 \\
10. Hay niños que son desagradables con los demás & 69 & 1 & 4 & 2,54 &, 884 \\
11. Se meten conmigo & 68 & 1 & 4 & 2,28 &, 895 \\
12. Si estoy triste los maestros se preocupan por mi & 67 & 1 & 4 & 3,12 &, 826 \\
13. Cuando hay peleas, el profesor lo arregla de forma & 67 & 1 & 4 & 3,09 & 1,041 \\
justa. & & & & & \\
14. Voy mejorando día a día. & 68 & 1 & 4 & 3,16 & 1,101 \\
15. Mi profesor me deja elegir el trabajo que hacer. & 69 & 1 & 4 & 2,46 & 1,008 \\
16. Me siento contento cuando hago un buen trabajo. & 69 & 1 & 4 & 3,38 &, 925 \\
17. Entiendo los deberes que me Mandan para casa & 68 & 1 & 4 & 3,06 &, 808 \\
18. Mi profesor me pregunta lo que hago en casa. & 65 & 1 & 4 & 3,26 &, 871 \\
19. Mi familia piensa que éste es un buen centro. & 70 & 1 & 4 & 3,11 &, 986 \\
20. Si no voy a clase mi profesor me pregunta por qué & 69 & 1 & 4 & 2,84 &, 994 \\
21. Mi familia me pregunta por mis deberes & 70 & 1 & 4 & 2,86 &, 997 \\
22. Cuando llego a mi casa tengo tiempo para realizar & 70 & 1 & 4 & 2,80 &, 894 \\
mis deberes & & & & & \\
\hline
\end{tabular}


Para un análisis más detallado, en la Tabla 62 se presentan los porcentajes de respuesta obtenidos para las diferentes categorías y cada uno de los ítems. Como se recordará, las respuestas fluctuaban desde Casi Nunca (1) hasta Casi Siempre (4). Merece la pena prestar atención al elevado porcentaje de respuestas que indican "casi nunca", en ítems referidos a: "mi profesor me escucha, con un $27.1 \%$ de los estudiantes que manifiestan que eso no sucede casi nunca. Lo mismo es posible afirmar ante ítems como: "Mi profesor me deja elegir el trabajo que hacer" (23,2\% casi nunca), "Ayudo a mi profesor" (22,4\% casi nunca), "Muestran nuestros trabajo para que los demás lo vean" (19,4\% casi nunca) o "Mi familia me pregunta por mis deberes" $(15,7 \%)$. Estos resultados sugieren la existencia de estrategias educativas poco motivadoras, tanto por parte de los profesores como por parte de las familias, al menos en un porcentaje elevado de los estudiantes.

Tabla 62. Distribución, en porcentajes, de las puntuaciones en satisfacción con la escuela

\begin{tabular}{|c|c|c|c|c|}
\hline Items & 1 & 2 & 3 & 4 \\
\hline 1. Trabajo con compañeros & 11,6 & 8,7 & 59,4 & 20,3 \\
\hline 2. Trabajamos en grupos & 5,7 & 11,4 & 58,6 & 24,3 \\
\hline 3. Ayudo a mis compañeros & 7,4 & 20,6 & 58,8 & 13,2 \\
\hline 4. Mis compañeros me ayudan & 11,8 & 17,6 & 60,3 & 10,3 \\
\hline 5. Muestran nuestros trabajos para que los demás lo vean. & 19,4 & 13,4 & 43,3 & 23,9 \\
\hline 6. Mi profesor me escucha & 27,1 & 4,3 & 35,7 & 32,9 \\
\hline 7. Mi profesor me ayuda & 10,3 & 19,1 & 35,3 & 35,3 \\
\hline 8. Ayudo a mi professor & 22,4 & 20,9 & 40,3 & 16,4 \\
\hline 9. Las reglas son justas. & 10,3 & 8,8 & 17,6 & 63,2 \\
\hline 10. Hay niños que son desagradables con los demás & 15,9 & 24,6 & 49,3 & 10,1 \\
\hline 11. Se meten conmigo & 23,5 & 30,9 & 39,7 & 5,9 \\
\hline 12. Si estoy triste los maestros se preocupan por mi & 6,0 & 10,4 & 49,3 & 34,3 \\
\hline 13. Cuando hay peleas, el profesor lo arregla de forma justa. & 13,4 & 9,0 & 32,8 & 44,8 \\
\hline 14. Voy mejorando dia a día. & 14,7 & 8,8 & 22,1 & 54,4 \\
\hline 15. Mi profesor me deja elegir el trabajo que hacer. & 23,2 & 21,7 & 40,6 & 14,5 \\
\hline 16. Me siento contento cuando hago un buen trabajo. & 8,7 & 4,3 & 27,5 & 59,4 \\
\hline 17. Entiendo los deberes que me Mandan para casa & 5,9 & 11,8 & 52,9 & 29,4 \\
\hline 18. Mi profesor me pregunta lo que hago en casa. & 7,7 & 4,6 & 41,5 & 46,2 \\
\hline 19. Mi familia piensa que éste es un buen centro. & 10,0 & 12,9 & 32,9 & 44,3 \\
\hline 20. Si no voy a clase mi profesor me pregunta por qué & 13,0 & 18,8 & 39,1 & 29,0 \\
\hline 21. Mi familia me pregunta por mis deberes & 15,7 & 10,0 & 47,1 & 27,1 \\
\hline 22. Cuando llego a mi casa tengo tiempo para realizar mis deberes & 11,4 & 17,1 & 51,4 & 20,0 \\
\hline
\end{tabular}

A continuación presentamos los estadísticos descriptivos de la escala de Calidad de Vida Infantil. En la Tabla 63 se exponen los resultados obtenidos en las diferentes dimensiones de la escala. Lo primero que llama la atención es que al 
igual que en las respuestas sobre satisfacción con la escuela y en calidad de vida los participantes en el estudio han mostrado un alto grado de satisfacción, obteniéndose una media de 2,95 en el total.

Si analizamos los distintos aspectos de la CVI, es posible apreciar cómo la puntuación promedio más alta se relaciona con el bienestar material mientras que la media más baja se obtiene en el aspecto relacionado con el bienestar físico.

Tabla 63. Estadísticos descriptivos de las puntuaciones en calidad de vida infantil

\begin{tabular}{llrrrr}
\hline & N & \multicolumn{1}{c}{ Mínimo } & Máximo & Media & Desv. típ. \\
\hline Bienestar Emocional & 70 & 2,00 & 3,60 & 2,79 &, 38 \\
Relaciones Interpersonales & 70 & 1,92 & 3,69 & 2,96 &, 36 \\
Desarrollo Personal y Actividades & 70 & 1,75 & 4,00 & 3,04 &, 47 \\
Bienestar Físico & 70 & 1,60 & 4,00 & 2,78 &, 59 \\
Bienestar Material & 70 & 1,00 & 4,00 & 3,21 &, 60 \\
Total CVI & 70 & 2,26 & 3,69 & 2,95 &, 34 \\
\hline
\end{tabular}

En la Tabla 64 se presenta la frecuencia de la distribución de respuestas para cada uno de los ítems. Como se recordará, la escala se puntúa en una escala que va desde Casi Nunca (1) a Casi Siempre (4). Se puede apreciar cómo por lo general los estudiantes ofrecen respuestas que denotan una elevada frecuencia en ítems con valencia positiva (p.e. me llevo bien con mis hermanos), mientras que los ítems con una valencia negativa tienden a obtener una baja frecuencia (p.e. en la escuela las cosas me salen mal). Algunas excepciones lo constituyen las respuestas a ítems como: "estoy preocupado" o "mis padres me pegan". Por otro lado, es interesante observar el elevado porcentaje de respuestas obtenidos en ítems como "estoy contento con mis notas o rendimiento en la escuela", "no entiendo los deberes que me ponen en el colegio", o ."me divierten las cosas que hacemos en la escuela".

Todos estos resultados están informándonos de costumbres como el uso del castigo físico que, sin embargo, parece estar normalizado y a los estudiantes no les genera mayor malestar. La percepción de la escuela como un lugar divertido donde se sienten bien, no se sienten solos y donde se tienen amigos, con un maestro que les felicita cuando hacen las cosas bien y que les trata como a los demás, pero también un sitio donde les ponen deberes que no entienden, nos hace pensar en que la escuela cumple más bien una función de mejora de los aspectos relativos al 
Bienestar Emocional y Relaciones Interpersonales que de los aspectos académicos o de Desarrollo Personal.

Tabla 64. Distribución de frecuencias de respuestas en la escala de Calidad de Vida

\begin{tabular}{|c|c|c|c|c|}
\hline Items & 1 & 2 & 3 & 4 \\
\hline 01. Me siento contento & 4,3 & 7,2 & 47,8 & 40,6 \\
\hline 02. Duermo tranquilo & 7,2 & 5,8 & 29,0 & 58,0 \\
\hline 03. Me llevo bien con mis hermanos & 8,7 & 2,9 & 27,5 & 60,9 \\
\hline 04. Mis padres me felicitan por lo que hago bien & 5,7 & 11,4 & 45,7 & 37,1 \\
\hline 05. Me gustan las cosas que tengo (juguetes, ropa,e tc) & 5,8 & 5,8 & 29,0 & 59,4 \\
\hline 06. Tengo Dolores de cabeza o de otro tipo & 26,1 & 14,5 & 47,8 & 11,6 \\
\hline 08. En la escuela las cosas me salen mal & 42,6 & 20,6 & 27,9 & 8,8 \\
\hline 09. Los fines de semana hago cosas que me gustan & 8,6 & 8,6 & 42,9 & 40,0 \\
\hline 10. Mi maestra/o me felicita por las cosas que hago bien & 4,3 & 7,2 & 47,8 & 40,6 \\
\hline 11. Pienso que de mayor sere muy feliz & 10,3 & 10,3 & 27,9 & 51,5 \\
\hline $\begin{array}{l}\text { 12. Mi maestra/o me trata de forma diferente que a los demás } \\
\text { compañeros }\end{array}$ & 41,4 & 20,0 & 25,7 & 12,9 \\
\hline 14. Me siento orgulloso de mí mismo & 14,5 & 15,9 & 34,8 & 34,8 \\
\hline 15. Me cuesta concentrarme o prestar atención en la escuela & 40,6 & 17,4 & 31,9 & 10,1 \\
\hline 16. Estoy preocupado & 11,6 & 14,5 & 44,9 & 29,0 \\
\hline 17. Mis padres me pegan & 20,0 & 31,4 & 38,6 & 10,0 \\
\hline 19. Mi casa es bonita y cómoda & 7,4 & 7,4 & 25,0 & 60,3 \\
\hline 20. Puedo tener las cosas que quiero & 6,0 & 17,9 & 44,8 & 31,3 \\
\hline $\begin{array}{l}\text { 21. Puedo contar a alguien de mi familia las cosas feas/malas que me } \\
\text { pasan }\end{array}$ & 8,6 & 24,3 & 35,7 & 31,4 \\
\hline 23. Juego con mis amigos & 4,3 & 8,7 & 49,3 & 37,7 \\
\hline 24. En la escuela me siento solo & 38,8 & 19,4 & 23,9 & 17,9 \\
\hline 25. Me siento cansado, sin energía para corer, saltar o estudiar & 24,6 & 24,6 & 39,1 & 11,6 \\
\hline 27. Estoy contento con mis notas(o rendimiendo) en la escuela & 4,5 & 9,0 & 41,8 & 44,8 \\
\hline 30. Mis compañeros me pegan o me gritan más que a otros & 51,4 & 14,3 & 24,3 & 10,0 \\
\hline 32. Mls padres me dejan elegir (por ejemplo la ropa, etc) & 8,7 & 18,8 & 47,8 & 24,6 \\
\hline 33. No entiendo los deberes que me ponen en el colegio & 22,1 & 20,6 & 41,2 & 16,2 \\
\hline 34. Cuando tengo tiempo libre puedo jugar a muchas cosas & 2,9 & 15,9 & 42,0 & 39,1 \\
\hline 35. Me gusta mi casa o mi habitación & 5,8 & 8,7 & 17,4 & 68,1 \\
\hline 36. Me divierte las cosas que hacemos en la escuela & 7,2 & 8,7 & 24,6 & 59,4 \\
\hline 38. Tengo amigos en la escuela & 6,1 & 16,7 & 27,3 & 50,0 \\
\hline 39. A mis compañeros les gusta estar conmigo & 3,1 & 16,9 & 53,8 & 26,2 \\
\hline 40. Estoy triste, con ganas de llorar & 43,5 & 17,4 & 26,1 & 13,0 \\
\hline 42. Tengo Dolores (de barriga, cabeza, etc) & 32,8 & 26,6 & 29,7 & 10,9 \\
\hline 43. MI vida es muy bonita & 12,9 & 14,3 & 25,7 & 47,1 \\
\hline
\end{tabular}




\begin{tabular}{lllll}
\hline Items & $\mathbf{1}$ & $\mathbf{2}$ & $\mathbf{3}$ & $\mathbf{4}$ \\
\hline 44. Me gustaría ser distintos de como soy & 13,4 & 14,9 & 49,3 & 22,4 \\
45. Tengo ganas de vomitar o problemas de estómago & 24,6 & 17,4 & 43,5 & 14,5 \\
& & & & \\
& 13,0 & 24,6 & 43,5 & 18,8 \\
46. Me pongo nervioso & 27,5 & 17,4 & 34,8 & 20,3 \\
47. Los demás piensan que hago todo mal. & 25,7 & 21,4 & 40,0 & 12,9 \\
48. Mis padres me exigen mucho & 27,5 & 23,2 & 37,7 & 11,6 \\
49. Mis compañeros se ríen de mí & 11,6 & 14,5 & 17,4 & 56,5 \\
50. Mi familia tiene suficiente dinero & 4,3 & 24,6 & 52,2 & 18,8 \\
51. Tengo tiempo libre suficiente & 14,9 & 10,4 & 53,7 & 20,9 \\
52. Ml familia me da cosas que me gustan & 2,9 & 12,9 & 20,0 & 64,3 \\
53. Me siento bien en la escuela & & & &
\end{tabular}

Los resultados obtenidos avalan, de nuevo, la existencia de una elevada percepción de calidad de vida en sus diferentes componentes, lo que nos permite confirmar la tercera hipótesis.

\subsubsection{Relación entre satisfacción escolar y calidad de vida}

Lo primero a destacar es que todas las dimensiones de calidad de vida muestran una correlación significativa entre ellas, a excepción de la relación entre Bienestar Físico y Bienestar Material. siendo las más altas las correlaciones con las dimensiones de las relaciones interpersonales y el desarrollo personal y actividades. Es interesante destacar cómo las correlaciones más bajas entre las dimensiones de calidad de vida se relacionan con el factor Bienestar Material, que se relaciona a su vez con las posesiones, pertenencias o riqueza. Podría decirse que para estos alumnos, la satisfacción o calidad de vida no se relaciona tanto con lo que uno posee sino con el desarrollo personal y actividades, o con las relaciones interpersonales.

Por otro lado y respecto al análisis de la asociación entre satisfacción con la escuela y calidad de vida, los análisis ponen de manifiesto la existencia de correlaciones más elevadas entre Bienestar Material y Desarrollo Personal y Actividades con el cuestionario de Satisfacción con la Escuela. Por otro lado, la satisfacción escolar no se asocia significativamente con el Bienestar Físico o con el Bienestar Emocional. Teniendo en cuenta que los ítems de la escala de calidad de vida que aluden a la escuela se centran en los factores de Relaciones 
Interpersonales y de Desarrollo Personal y Actividades, podemos decir que la hipótesis cuarta ha recibido un sustancial apoyo.

Tabla 65. Correlaciones de Pearson entre las dimensiones de calidad de vida y satisfacción escolar

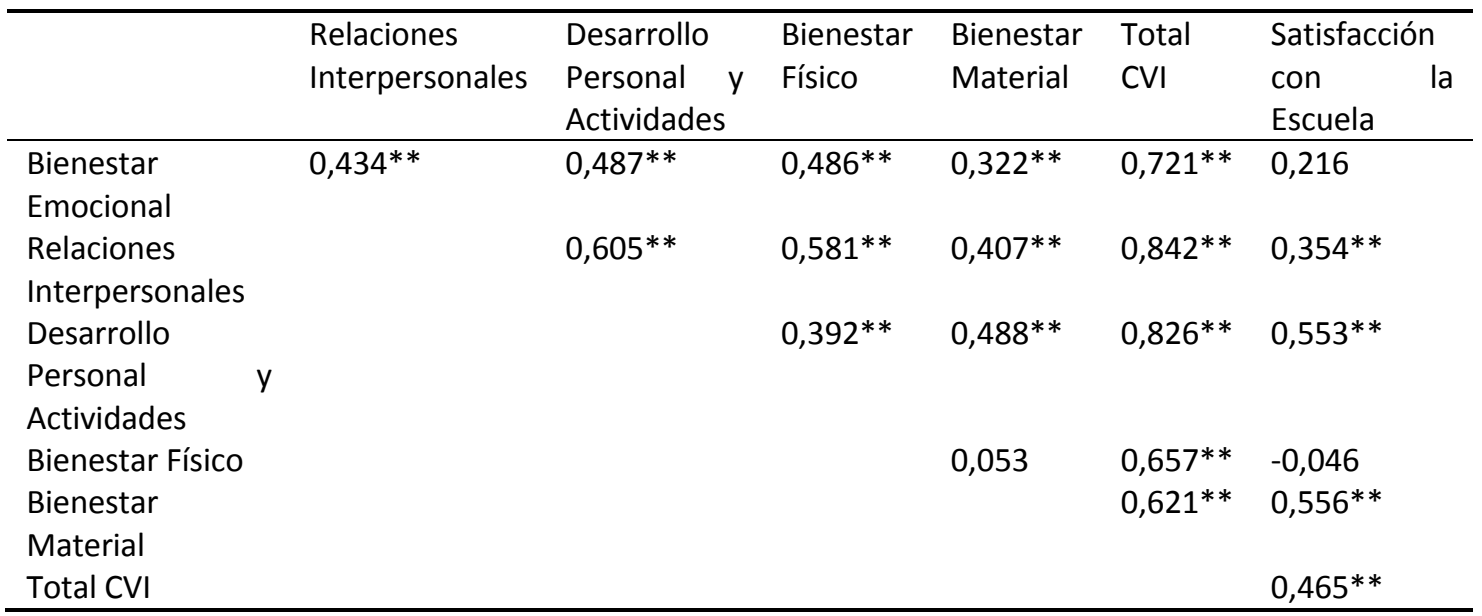

** La correlación es significativa al nivel 0,01 (bilateral).

\subsubsection{Impacto de variables socioculturales en la satisfacción escolar y en la calidad} de vida

Pasamos en primer lugar a determinar el posible impacto del nivel formativo. Los análisis multivariados indicaron la existencia de diferencias significativas, tomando todas las variables simultáneamente [Lambda de Wilks= 0,$\left.186 ; F_{(44,58)}=0,186 ; p=0,024\right]$. En la Tabla 66 se presentan las puntuaciones obtenidas y su significación.

Se puede observar en dicha Tabla cómo mientras que en algunas de las cuestiones no se aprecian diferencias significativas en otras sí que observamos dichas diferencias. Concretamente, se puede apreciar un ascenso de la satisfacción de tercero a cuarto curso para volver a descender en el quinto en las preguntas 5, 6, $9,12,16$ y 20 . Esto puede deberse al cambio de ciclo entre 40 y 50 que, como expusimos anteriormente, es uno de los cuellos de botella del sistema en el que se produce un gran número de repeticiones y abandonos.

Por otra parte en las preguntas 18 y 21 se observa que las diferencias significativas se producen en una escala ascendente que provoca que haya una satisfacción creciente entre tercer y quinto curso. Estas diferencias entre estos dos 
grupos de preguntas pueden deberse a que mientras las primeras hacen referencia a aspectos internos del día a día en la escuela, el segundo grupo hace referencia al trabajo de los alumnos en su casa, por lo cual parece indicar que detrás del descenso de la satisfacción en el primer grupo al llegar a quinto curso puede estar el cambio de ciclo educativo y el impacto que esto tiene en las prácticas y modos de relacionarse en la escuela.

Tabla 66. Estadísticos descriptivos y significación de las diferencias (Anova) en función del curso

\begin{tabular}{|c|c|c|c|c|c|c|c|}
\hline Variables & & $\mathbf{N}$ & Media & D.T. & E.T. & $\mathbf{F}$ & Sig. \\
\hline \multirow[t]{4}{*}{ 1. Trabajo con compañeros } & & & & & & 0,418 & 0,660 \\
\hline & Tercero & 21 & 3,00 & 1,049 & 0,229 & & \\
\hline & Cuarto & 22 & 2,91 & 0,684 & 0,146 & & \\
\hline & Quinto & 26 & 2,77 & 0,863 & 0,169 & & \\
\hline \multirow[t]{4}{*}{ 2. Trabajamos en grupos } & & & & & & 1,674 & 0,195 \\
\hline & Tercero & 21 & 2,76 & 0,889 & 0,194 & & \\
\hline & Cuarto & 22 & 3,09 & 0,811 & 0,173 & & \\
\hline & Quinto & 27 & 3,15 & 0,602 & 0,116 & & \\
\hline \multirow[t]{4}{*}{ 3. Ayudo a mis compañeros } & & & & & & 0,012 & 0,988 \\
\hline & Tercero & 21 & 2,76 & 0,889 & 0,194 & & \\
\hline & Cuarto & 20 & 2,80 & 0,696 & 0,156 & & \\
\hline & Quinto & 27 & 2,78 & 0,751 & 0,145 & & \\
\hline \multirow{4}{*}{ 4. Mis compañeros me ayudan } & & & & & & 1,878 & 0,161 \\
\hline & Tercero & 21 & 2,71 & 0,845 & 0,184 & & \\
\hline & Cuarto & 21 & 2,43 & 0,870 & 0,190 & & \\
\hline & Quinto & 26 & 2,88 & 0,711 & 0,140 & & \\
\hline \multirow{4}{*}{$\begin{array}{l}\text { 5. Muestran nuestros trabajo para que los } \\
\text { demás lo vean. }\end{array}$} & & & & & & 6,349 & 0,003 \\
\hline & Tercero & 20 & 2,10 & 1,071 & 0,240 & & \\
\hline & Cuarto & 21 & 3,14 & 0,793 & 0,173 & & \\
\hline & Quinto & 26 & 2,85 & 1,008 & 0,198 & & \\
\hline \multirow[t]{4}{*}{ 6. Mi professor me escucha } & & & & & & 6,452 & 0,003 \\
\hline & Tercero & 21 & 2,24 & 1,136 & 0,248 & & \\
\hline & Cuarto & 22 & 3,41 & 0,734 & 0,157 & & \\
\hline & Quinto & 27 & 2,59 & 1,309 & 0,252 & & \\
\hline \multirow[t]{4}{*}{ 7. Mi professor me ayuda } & & & & & & 1,539 & 0,222 \\
\hline & Tercero & 20 & 2,65 & 1,040 & 0,233 & & \\
\hline & Cuarto & 22 & 3,00 & 0,976 & 0,208 & & \\
\hline & Quinto & 26 & 3,15 & ,925 & 0,181 & & \\
\hline \multirow[t]{4}{*}{ 8. Ayudo a mi professor } & & & & & & 1,476 & ,236 \\
\hline & Tercero & 19 & 2,53 & 1,172 & 0,269 & & \\
\hline & Cuarto & 22 & 2,77 & 869 & 0,185 & & \\
\hline & Quinto & 26 & 2,27 & 1,002 & 0,197 & & \\
\hline \multirow[t]{4}{*}{ 9. Las reglas son justas. } & & & & & & 4,078 & 021 \\
\hline & Tercero & 21 & 2,86 & 1,276 & 0,278 & & \\
\hline & Cuarto & 22 & 3,68 & ,646 & 0,138 & & \\
\hline & Quinto & 25 & 3,44 & 917 & 0,183 & & \\
\hline \multirow{4}{*}{$\begin{array}{l}\text { 10. Hay niños que son desagradables con los } \\
\text { demás }\end{array}$} & & & & & & 2,056 & 136 \\
\hline & Tercero & 21 & 2,38 & 1,024 & 0,223 & & \\
\hline & Cuarto & 21 & 2,86 & 655 & 0,143 & & \\
\hline & Quinto & 27 & 2,41 & ,888 & 0,171 & & \\
\hline \multirow[t]{3}{*}{ 11. Se meten conmigo } & & & & & & 1,281 & ,285 \\
\hline & Tercero & 20 & 2,25 & 910 & 0,204 & & \\
\hline & Cuarto & 21 & 2,52 & ,814 & 0,178 & & \\
\hline
\end{tabular}




\begin{tabular}{|c|c|c|c|c|c|c|c|}
\hline Variables & & $\mathbf{N}$ & Media & D.T. & E.T. & $\mathbf{F}$ & Sig. \\
\hline & Quinto & 27 & 2,11 & ,934 & 0,180 & & \\
\hline \multirow{4}{*}{$\begin{array}{l}\text { 12. Si estoy triste los maestros se preocupan por } \\
\text { mi }\end{array}$} & & & & & & 4,074 & 022 \\
\hline & Tercero & 19 & 2,68 & 1,108 & 0,254 & & \\
\hline & Cuarto & 21 & 3,33 & ,730 & 0,159 & & \\
\hline & Quinto & 27 & 3,26 & ,526 & 0,101 & & \\
\hline \multirow{4}{*}{$\begin{array}{l}\text { 13. Cuando hay peleas, el profesor lo arregla de } \\
\text { forma justa. }\end{array}$} & & & & & & ,730 & ,486 \\
\hline & Tercero & 20 & 2,90 & 1,165 & 0,261 & & \\
\hline & Cuarto & 21 & 3,05 & ,921 & 0,201 & & \\
\hline & Quinto & 26 & 3,27 & 1,041 & 0,204 & & \\
\hline \multirow[t]{4}{*}{ 14. Voy mejorando dia a día. } & & & & & & 1,722 & 187 \\
\hline & Tercero & 20 & 2,80 & 1,196 & 0,268 & & \\
\hline & Cuarto & 22 & 3,41 & 959 & 0,204 & & \\
\hline & Quinto & 26 & 3,23 & 1,107 & 0,217 & & \\
\hline \multirow{4}{*}{$\begin{array}{l}\text { 15. Mi profesor me deja elegir el trabajo que } \\
\text { hacer. }\end{array}$} & & & & & & ,283 & ,754 \\
\hline & Tercero & 21 & 2,48 & 981 & 0,214 & & \\
\hline & Cuarto & 21 & 2,33 & 1,065 & 0,232 & & \\
\hline & Quinto & 27 & 2,56 & 1,013 & 0,195 & & \\
\hline \multirow{4}{*}{$\begin{array}{l}\text { 16. Me siento contento cuando hago un buen } \\
\text { trabajo. }\end{array}$} & & & & & & 8,497 & ,001 \\
\hline & Tercero & 21 & 2,76 & 1,221 & 0,266 & & \\
\hline & Cuarto & 21 & 3,76 & 0,436 & 0,095 & & \\
\hline & Quinto & 27 & 3,56 & 0,698 & 0,134 & & \\
\hline \multirow{4}{*}{$\begin{array}{l}\text { 17. Entiendo los deberes que me Mandan para } \\
\text { casa }\end{array}$} & & & & & & 2,059 & ,136 \\
\hline & Tercero & 21 & 2,90 & 0,995 & 0,217 & & \\
\hline & Cuarto & 21 & 2,90 & 0,539 & 0,118 & & \\
\hline & Quinto & 26 & 3,31 & 0,788 & 0,155 & & \\
\hline \multirow{4}{*}{$\begin{array}{l}\text { 18. Mi profesor me pregunta lo que hago en } \\
\text { casa. }\end{array}$} & & & & & & 7,194 & ,002 \\
\hline & Tercero & 19 & 2,68 & 1,003 & 0,230 & & \\
\hline & Cuarto & 21 & 3,43 & 0,811 & 0,177 & & \\
\hline & Quinto & 25 & 3,56 & 0,583 & 0,117 & & \\
\hline \multirow{4}{*}{$\begin{array}{l}\text { 19. Mi familia piensa que éste es un buen } \\
\text { centro. }\end{array}$} & & & & & & 1,713 & 188 \\
\hline & Tercero & 21 & 2,86 & 1,153 & 0,252 & & \\
\hline & Cuarto & 22 & 3,05 & 1,090 & 0,232 & & \\
\hline & Quinto & 27 & 3,37 & 0,688 & 0,132 & & \\
\hline \multirow{4}{*}{$\begin{array}{l}\text { 20. Si no voy a clase mi profesor me pregunta } \\
\text { por qué }\end{array}$} & & & & & & 5,417 & 0,007 \\
\hline & Tercero & 21 & 2,38 & 0,865 & 0,189 & & \\
\hline & Cuarto & 22 & 3,32 & 0,945 & 0,202 & & \\
\hline & Quinto & 26 & 2,81 & 0,981 & 0,192 & & \\
\hline \multirow[t]{4}{*}{ 21. Mi familia me pregunta por mis deberes } & & & & & & 7,136 & 0,002 \\
\hline & Tercero & 21 & 2,33 & 1,155 & 0,252 & & \\
\hline & Cuarto & 22 & 2,77 & 1,066 & 0,227 & & \\
\hline & Quinto & 27 & 3,33 & 0,480 & 0,092 & & \\
\hline \multirow{4}{*}{$\begin{array}{l}\text { 22. Cuando llego a mi casa tengo tiempo para } \\
\text { realizar mis deberes i }\end{array}$} & & & & & & 0,497 & 0,611 \\
\hline & Tercero & 21 & 2,76 & 0,995 & 0,217 & & \\
\hline & Cuarto & 22 & 2,95 & 0,950 & 0,203 & & \\
\hline & Quinto & 27 & 2,70 & 0,775 & 0,149 & & \\
\hline
\end{tabular}


Continuando con el análisis de posible peso de variables socioculturales en la satisfacción escolar y por lo que se refiere al tiempo en que los niños tardan en acceder al colegio, los análisis multivariados reflejaron una ausencia de diferencias significativas [Lambda de Wilks $\left.\left.=0,085, F_{(88,105}\right)=1,033 ; p=0,392\right]$.

En la misma línea, tras analizar el posible impacto del género en las valoraciones de los estudiantes, los análisis multivariados evidenciaron la existencia de asociaciones significativas [Lambda de Wilks=0,382; $F_{(22,30)}=2,210 ; p=0,022$ ]. Los análisis de varianza indicaron la existencia de diferencias significativas en los ítems 2,3 y 5. En todas todos ellos las chicas mostraron un grado de satisfacción significativamente superior al de sus compañeros varones. Estas tres preguntas guardan estrecha relación con la variable social de la educación ya que hacen referencia al trabajo en grupo y a la exposición del trabajo propio en la clase como ejemplo.

Estos datos parecerían indicar que las chicas obtienen un mayor grado de reconocimiento social en la escuela que los chicos siendo especialmente grande la distancia en la quinta pregunta, lo que parece indicar que las chicas obtienen de esta manera una gran satisfacción por el reconocimiento público de su trabajo, situación que puede deberse al efecto que supondría este reconocimiento en la autoestima de las chicas en una sociedad en la que se produce una marginación femenina en la vida pública y una menor valoración del trabajo femenino frente al masculino.

Tabla 67. Estadísticos descriptivos y significación de las diferencias (Anova) en función del género

\begin{tabular}{|c|c|c|c|c|c|c|c|}
\hline Variables & & $\mathbf{N}$ & Media & D.T. & E.T. & $\mathbf{F}$ & Sig. \\
\hline \multirow[t]{3}{*}{ 1. Trabajo con compañeros } & & & & & & 0,754 & 0,388 \\
\hline & Chica & 19 & 2,74 & 1,10 & 0,25 & & \\
\hline & Chico & 50 & 2,94 & 0,77 & 0,11 & & \\
\hline \multirow[t]{3}{*}{ 2. Trabajamos en grupos } & & & & & & 5,672 & 0,020 \\
\hline & Chica & 20 & 3,35 & 0,67 & 0,15 & & \\
\hline & Chico & 50 & 2,88 & 0,77 & 0,11 & & \\
\hline \multirow[t]{3}{*}{ 3. Ayudo a mis compañeros } & & & & & & 5,226 & 0,025 \\
\hline & Chica & 20 & 3,10 & 0,72 & 0,16 & & \\
\hline & Chico & 48 & 2,65 & 0,76 & 0,11 & & \\
\hline \multirow[t]{3}{*}{ 4. Mis compañeros me ayudan } & & & & & & 0,903 & 0,346 \\
\hline & Chica & 19 & 2,84 & 0,76 & 0,18 & & \\
\hline & Chico & 49 & 2,63 & 0,83 & 0,12 & & \\
\hline $\begin{array}{l}\text { 5. Muestran nuestros trabajo para que los } \\
\text { demás lo vean. }\end{array}$ & & & & & & 6,461 & 0,013 \\
\hline
\end{tabular}




\begin{tabular}{|c|c|c|c|c|c|c|c|}
\hline Variables & & $\mathbf{N}$ & Media & D.T. & E.T. & $\mathbf{F}$ & Sig. \\
\hline & Chica & 19 & 3,21 & 0,79 & 0,18 & & \\
\hline & Chico & 48 & 2,52 & 1,07 & 0,15 & & \\
\hline \multirow[t]{3}{*}{ 6. Mi profesor me escucha } & & & & & & 1,896 & 0,173 \\
\hline & Chica & 20 & 3,05 & 1,15 & 0,26 & & \\
\hline & Chico & 50 & 2,62 & 1,19 & 0,17 & & \\
\hline \multirow[t]{3}{*}{ 7. Mi profesor me ayuda } & & & & & & 3,600 & 0,062 \\
\hline & Chica & 20 & 3,30 & 0,86 & 0,19 & & \\
\hline & Chico & 48 & 2,81 & 1,00 & 0,14 & & \\
\hline \multirow[t]{3}{*}{ 8. Ayudo a mi profesor } & & & & & & 0,029 & 0,866 \\
\hline & Chica & 19 & 2,47 & 1,07 & 0,25 & & \\
\hline & Chico & 48 & 2,52 & 1,01 & 0,15 & & \\
\hline \multirow[t]{3}{*}{ 9. Las reglas son justas. } & & & & & & 1,234 & 0,271 \\
\hline & Chica & 20 & 3,55 & 0,76 & 0,17 & & \\
\hline & Chico & 48 & 3,25 & 1,10 & 0,16 & & \\
\hline \multirow{3}{*}{$\begin{array}{l}\text { 10. Hay niños que son desagradables con } \\
\text { los demás }\end{array}$} & & & & & & 0,302 & 0,585 \\
\hline & Chica & 19 & 2,63 & 0,90 & 0,21 & & \\
\hline & Chico & 50 & 2,50 & 0,89 & 0,13 & & \\
\hline \multirow[t]{3}{*}{ 11. Se meten conmigo } & & & & & & 0,088 & 0,768 \\
\hline & Chica & 18 & 2,33 & 1,03 & 0,24 & & \\
\hline & Chico & 50 & 2,26 & 0,85 & 0,12 & & \\
\hline \multirow{3}{*}{$\begin{array}{l}\text { 12. Si estoy triste los maestros se } \\
\text { preocupan por mi }\end{array}$} & & & & & & 3,982 & 0,050 \\
\hline & Chica & 18 & 3,44 & 0,62 & 0,15 & & \\
\hline & Chico & 49 & 3,00 & 0,87 & 0,12 & & \\
\hline \multirow{3}{*}{$\begin{array}{l}\text { 13. Cuando hay peleas, el profesor lo } \\
\text { arregla de forma justa. }\end{array}$} & & & & & & 0,026 & 0,873 \\
\hline & Chica & 18 & 3,06 & 1,11 & 0,26 & & \\
\hline & Chico & 49 & 3,10 & 1,03 & 0,15 & & \\
\hline \multirow[t]{3}{*}{ 14. Voy mejorando dia a día. } & & & & & & 3,952 & 0,051 \\
\hline & Chica & 19 & 3,58 & 0,96 & 0,22 & & \\
\hline & Chico & 49 & 3,00 & 1,12 & 0,16 & & \\
\hline \multirow{3}{*}{$\begin{array}{l}\text { 15. Mi profesor me deja elegir el trabajo } \\
\text { que hacer. }\end{array}$} & & & & & & 0,100 & 0,753 \\
\hline & Chica & 19 & 2,53 & 1,07 & 0,25 & & \\
\hline & Chico & 50 & 2,44 & 0,99 & 0,14 & & \\
\hline \multirow{3}{*}{$\begin{array}{l}\text { 16. Me siento contento cuando hago un } \\
\text { buen trabajo. }\end{array}$} & & & & & & 2,018 & 0,160 \\
\hline & Chica & 19 & 3,63 & 0,76 & 0,17 & & \\
\hline & Chico & 50 & 3,28 & 0,97 & 0,14 & & \\
\hline \multirow{3}{*}{$\begin{array}{l}\text { 17. Entiendo los deberes que me Mandan } \\
\text { para casa }\end{array}$} & & 69 & 3,38 & 0,93 & 0,11 & 2,904 & 0,093 \\
\hline & Chica & 18 & 3,33 & 0,77 & 0,18 & & \\
\hline & Chico & 50 & 2,96 & 0,81 & 0,11 & & \\
\hline \multirow{3}{*}{$\begin{array}{l}\text { 18. Mi profesor me pregunta lo que hago } \\
\text { en casa. }\end{array}$} & & 68 & 3,06 & 0,81 & 0,10 & 2,219 & 0,141 \\
\hline & Chica & 17 & 3,53 & 0,72 & 0,17 & & \\
\hline & Chico & 48 & 3,17 & 0,91 & 0,13 & & \\
\hline \multirow{3}{*}{$\begin{array}{l}\text { 19. Mi familia piensa que éste es un buen } \\
\text { centro. }\end{array}$} & & 65 & 3,26 & 0,87 & 0,11 & 0,209 & 0,649 \\
\hline & Chica & 20 & 3,20 & 0,95 & 0,21 & & \\
\hline & Chico & 50 & 3,08 & 1,01 & 0,14 & & \\
\hline \multirow{3}{*}{$\begin{array}{l}\text { 20. Si no voy a clase mi profesor me } \\
\text { pregunta por qué }\end{array}$} & & 70 & 3,11 & 0,99 & 0,12 & 1,254 & 0,267 \\
\hline & Chica & 20 & 3,05 & 0,89 & 0,20 & & \\
\hline & Chico & 49 & 2,76 & 1,03 & 0,15 & & \\
\hline \multirow{2}{*}{$\begin{array}{l}\text { 21. Mi familia me pregunta por mis } \\
\text { deberes }\end{array}$} & & 69 & 2,84 & 0,99 & 0,12 & 3,429 & 0,068 \\
\hline & Chica & 20 & 3,20 & 1,06 & 0,24 & & \\
\hline
\end{tabular}




\begin{tabular}{lccccccc}
\hline Variables & & N & Media & D.T. & E.T. & F & Sig. \\
\hline & Chico & 50 & 2,72 & 0,95 & 0,13 & & \\
22. Cuando llego a mi casa tengo tiempo & & 70 & 2,86 & 1,00 & 0,12 & 0,347 & 0,558 \\
para realizar mis deberes & & & & & & \\
& Chica & 20 & 2,70 & 0,92 & 0,21 & & \\
& Chico & 50 & 2,84 & 0,89 & 0,13 & & \\
& & 70 & 2,80 & 0,89 & 0,11 & \\
\hline
\end{tabular}

Por otra parte el posible impacto de la asistencia o no continuada a clase, no reveló diferencias significativas [Lambda de Wilks=0,553; $F_{(22,30)}=1,103 ; p=0,395$ ]. Del mismo modo, la asistencia o no de hermanos al mismo colegio tampoco afectó significativamente a los resultados [Lambda de Wilks=0,466; $F_{(22,30)}=1,561$; $p=0,127]$. Por tanto, podemos concluir que de las variables socioculturales analizadas, tan solo la pertenencia a diferentes cursos y el género afectan a algunas de las valoraciones sobre la satisfacción con la escuela. Por tanto, nuestra quinta hipótesis ha obtenido un apoyo parcial.

En cuanto al análisis del Impacto de variables socioculturales en la calidad de vida, El análisis multivariado del posible peso del género no reveló diferencias significativas [Lambda de Wilks $=0,972 ; F_{(5,64)}=0,367 ; p=0,869$ ]. Tampoco se encontraron diferencias en función del tiempo que tardan los alumnos en llegar a clase [Lambda de Wilks $\left.=0,768 ; F_{(20,200)}=0,829 ; p=0,677\right]$. Igualmente, la asistencia continuada o no al colegio no incidió significativamente en los resultados [Lambda de Wilks=0,941; $\left.F_{(5,64)}=0,808 ; p=0,548\right]$. En la misma línea, tener o no hermanos en el mismo centro no afectó significativamente a los resultados [Lambda de Wilks= 0,$\left.889 ; F_{(5,64)}=0,1,595 ; p=0,174\right]$. Así pues, al menos en los chicos y chicas que han respondido al cuestionario, no se aprecian diferencias en cuanto a su calidad de vida. Por tanto, nuestra hipótesis sexta no se ha visto confirmada.

\subsection{CONCLUSIONES}

Una vez analizados todos los datos que han arrojado los cuestionarios, es el momento de llevar a cabo un análisis más detallado que nos ayude a interpretar su significado. Empezaremos analizando los datos relativos a nuestro primer objetivo y primera hipótesis. Así, el primer dato a destacar es la superior presencia masculina que femenina, concretamente, 20 chicas frente a 50 chicos. Esto es debido a la 
mayor matriculación masculina frente a la femenina en la escuela de Qillenso, diferencia de género que se va haciendo mayor según se asciende en los cursos. Por otra parte, queda patente que pese a ser menor el número de alumnas que de alumnos, cuando hay diferencias significativas de satisfacción dependiendo del género son las chicas las que obtienen un grado mayor de satisfacción. Esto podría deberse a que las alumnas sean conscientes de lo privilegiado de su situación frente a muchas otras niñas que no logran acceder a la educación.

A continuación pasaremos a analizar la distribución según el curso de los participantes y el porqué de la misma. Es importante recordar que descartamos incluir en el estudio a alumnos de primer y segundo grado ya que consideramos que no tenían la madurez suficiente ni las competencias básicas necesarias para poder entender correctamente las cuestiones que se les planteaban y por lo tanto sus contestaciones podían inducirnos a error. Por lo tanto llevamos a cabo nuestra investigación con participantes de tercero, cuarto y quinto curso solamente, los cuales tenían una distribución bastante uniforme. Los participantes de tercero y cuarto y curso aportaban aproximadamente un $60 \%$ del total mientras que los participantes de quinto curso suponían el aproximado 40\% restante. Esta presencia superior de alumnos de quinto curso puede parecer que choca con lo expuesto hasta el momento sobre el progresivo abandono escolar del sistema educativo pero tiene su explicación en que el año académico en el que realizamos nuestro estudio era el primero que se ofertaba este quinto grado por lo que había una demanda de asistencia al mismo superior a la normal en la zona.

Además entre los participantes también se puede observar una creciente presencia femenina del tercer al quinto curso, pasando de un $14,3 \%$ a un $44,4 \%$. No conocemos todos los factores que han causado este aumento pero creemos que el elevado porcentaje de alumnas en quinto curso puede deberse a la labor de concienciación que los misioneros combonianos han llevado a cabo para fomentar la escolarización femenina y a la situación excepcional del quinto curso en el año en el que realizamos nuestro estudio como indicamos anteriormente. 
Otro aspecto importante sobre los participantes en el estudio que debemos analizar es su edad media y el arco de edades en las que están comprendidos. La media que ha arrojado nuestro estudio es de 11,13 años, lo que supone una media superior a la ideal, la cual sería de 10,08 años según la edad oficial a la que los alumnos tienen que tener en los cursos estudiados. Además entre los participantes hay dos alumnos que no alcanzan la edad mínima oficial para cursar el primer curso y 28 que tienen edades superiores a la máxima ideal para cursar quinto curso.

El análisis de los porcentajes de participantes que han mantenido su escolarización de manera interrumpida frente a los que no la han hecho pone de manifiesto que tan solo hay 5,72 de ventaja para los primeros. Esto sugiere que casi un $50 \%$ de los participantes ha abandonado en algún momento la escuela desde que se matriculó por primera vez. Esto es un dato realmente preocupante ya que a medida que avanza la edad es más probable que los alumnos dejen la escuela para incorporarse al mercado laboral y, en el caso de las niñas, para casarse. Por ello, una escolarización ininterrumpida supone una garantía mayor de que los alumnos logren acabar al menos el primer ciclo de educación primaria.

De estos participantes un $77,14 \%$ tenía hermanos o hermanas asistiendo a clase en el mismo colegio de Qillenso. Este porcentaje tan elevado se debe a varios motivos. El primero de ellos es la elevada fecundidad en el país y en la zona, que propicia que haya un elevado número de niños en edad escolar. El segundo es que, como señalamos en capítulos precedentes, muchos padres esperan a que varios hermanos tengan edad escolar para matricularlos a la vez y que vayan juntos al colegio.

Continuando con las respuestas a nuestros objetivos e hipótesis, pasamos a analizar los resultados sobre satisfacción escolar y calidad de vida, empezando por la satisfacción con la escuela. Así, todas las puntuaciones obtenidas han mostrado un alto grado de satisfacción con la escuela, lo que nos indica que los participantes en la investigación valoran positivamente su día a día en la escuela. Esto es muy importante ya que si los alumnos obtienen una experiencia satisfactoria en la escuela, cuando estos mismos alumnos se conviertan en padres y madres valorarán 
la misma como algo positivo para sus hijos. De esta manera será más fácil conseguir el objetivo de la escolarización primaria universal en la zona, además de que ayudará a mitigar problemas como el abandono del sistema educativo prematuro.

Respecto a la calidad de vida infantil los participantes han mostrado un alto grado de satisfacción, obteniéndose una media total de casi 3 puntos sobre 4 . Además en todos los aspectos de la CVI se han obtenido unos grados de satisfacción altos. Aunque pueda parecer sorprendente la puntuación más alta es la obtenida en el bienestar material. Esto puede parecer chocante en un país tan pobre como Etiopía y más en una zona rural y especialmente atrasada como Gujiland pero por ahora los Guji no tienen una sociedad especialmente consumista y valoran mucho más otros aspectos como por ejemplo las relaciones sociales frente a la acumulación de objetos materiales. Además, debido al relativo aislamiento de la zona, no es fácil que los niños y niñas puedan comparar su situación con la de otras partes del planeta más afortunadas en el aspecto económico, por lo que no son tan conscientes de sus limitadas posesiones materiales.

Por último y como expusimos al analizar los resultados expuestos en la Tabla 64 queda claro que los alumnos perciben la escuela como un lugar en el que desarrollan satisfactoriamente lazos sociales que a su vez les otorgan satisfacción emocional pero también un sitio donde tienen que enfrentarse a actividades que realmente no comprenden, lo que nos hace pensar en que la escuela cumple para ellos más bien una función de desarrollo de los aspectos emocionales y de las relaciones sociales que académica, por lo cual quedaría claro que la escuela está ejerciendo sobre todo una labor de socialización más que de formación.

A continuación pasaremos a analizar las conclusiones que hemos obtenido de la relación entre satisfacción escolar y calidad de vida. Volvemos en este apartado a incidir en el hecho de que las correlaciones más bajas entre las dimensiones de calidad de vida se relacionan con el factor Bienestar Material, que se relaciona a su vez con las posesiones, pertenencias o riqueza. En la línea de comentarios previamente expuestos, parece que para estos alumnos, la satisfacción 
o calidad de vida no se relaciona tanto con las posesiones sino con el desarrollo personal y actividades, o con las relaciones interpersonales.

Por otro lado, el hecho de que las correlaciones más elevadas entre las dimensiones de calidad de vida se produzcan entre la dimensión de Relaciones Interpersonales y la de Desarrollo Personal y Actividades confirma alguna de nuestras observaciones sobre la cultura Guji. Así, durante nuestra estancia en el país pudimos ver la gran intensidad de la vida social y familiar de esta sociedad, entendiendo la vida familiar no solo como la familia nuclear sino también como la más extensa. Además los resultados coinciden con la importancia suprema que todos los Guji otorgan a los lazos familiares y a las relaciones de amistad.

Respecto al análisis de la asociación entre satisfacción con la escuela y calidad de vida, los análisis ponen de manifiesto la existencia de correlaciones especialmente elevadas entre Bienestar Material y Desarrollo Personal y Actividades con el cuestionario de Satisfacción con la Escuela. Como también señalamos, el hecho de que los ítems de la escala de calidad de vida que aluden a la escuela se centren en los factores de Relaciones Interpersonales y de Desarrollo Personal y Actividades, pueden ayudar a explicar estos resultados.

A continuación pasaremos a exponer los resultados obtenidos en cuanto al impacto de las variables socioculturales en la satisfacción con el colegio dependiendo de variables sociodemográficas. Así, por un lado, dependiendo del curso hay dos grupos de variables que han mostrado diferencias significativas; el primer grupo está formado por variables relacionadas con aspectos del funcionamiento diario de la escuela ciñéndose a las actividades dentro del centro educativo. En este primer grupo la satisfacción asciende de tercer a cuatro curso para volver a descender a quinto. Creemos que este descenso se debe al cambio de sistema que se produce entre cuarto y quinto curso al cambiar el ciclo educativo. Estos cambios son de carácter organizativo como por ejemplo la presencia de nuevas asignaturas, la desaparición de la promoción automática, la incorporación de nuevos profesores al desaparecer la figura del profesor-tutor que enseñaba todas las asignaturas del curso como ocurría hasta cuarto... Todos estos cambios 
hacen perder la sensación más familiar y de mayor seguridad que tenían los niños en los primeros cursos al estar con el mismo profesor. En definitiva, ello pudiera estar afectando negativamente a la satisfacción con la escuela.

Por otro lado, y contrariamente a lo expuesto anteriormente, en el segundo grupo de preguntas en el que hemos observado diferencias significativas la satisfacción de los participantes en el colegio ha ido ascendiendo desde tercero a quinto, obteniendo en este último curso la puntuación más alta. Estas preguntas hacían referencias a aspectos de la vida escolar que tienen que ver con el desarrollo del trabajo del alumno fuera del colegio, en su casa. Una posible explicación a estos resultados pudiera relacionarse con el hecho de que los alumnos que alcanzan niveles educativos superiores cuentan en su casa con un mayor apoyo. Así, estos datos pudieran reflejar el hecho de que el entorno familiar apoye a estos niños que continúan los estudios y que ello explique precisamente el hecho de que dichos niños prosigan su formación.

Continuando con el análisis de variables socioculturales, hemos encontrado que el tiempo en que los niños tardan en acceder al colegio no afecta a su satisfacción con el mismo. Posiblemente, el hecho de que para estos niños sea algo normal desplazarse largas distancias para acceder a distintos servicios o realizar tareas encomendadas por sus progenitores, haga que esta variable, que para los países occidentales constituye un factor relevante, en este caso no produzca diferencias significativas.

Los análisis revelan también el impacto del género en la satisfacción escolar. Como indicamos en estas páginas, creemos que esta mayor satisfacción se debe a que las chicas encuentran en la escuela un espacio de una relativa igualdad frente al exterior de la misma en el que los roles de género tradicionales las mantienen un una posición de inferioridad en las relaciones sociales. Estos resultados avalan la importancia de potenciar la participación y el reconocimiento del trabajo de las chicas en la escuela como vía para apoyar el empoderamiento de las mujeres en la sociedad Guji. Así, si desde pequeños se inculcan a chicos y chicas valores de igualdad y respeto, será más fácil que estos valores sean aceptados culturalmente. 
Esto es especialmente importante, teniendo en cuenta que en la escuela fuimos testigos de la reproducción de los roles de género tradicionales de manera continuada.

Un resultado sorprendente por cuanto que es contrario a nuestra hipótesis de partida, es la ausencia de diferencias en la calidad de vida de los niños que asisten a la escuela de Qillenso. Así, en contra de nuestras predicciones, ni el género, el curso, u otras variables afectan a la valoración de los resultados. Pudiera parecer que la asistencia a la escuela ejerce un efecto homogeneizador de la calidad de vida. Si bien no podemos saber cómo es la calidad de vida de los niños que no asisten a la escuela y que por tanto, sus respuestas no han sido objeto de estudio, podría decirse como conclusión final que pese a lo precaria que es la situación de muchos aspectos de la vida de los niños en la zona de Qillenso como son la situación económica de sus familias, la falta de acceso a muchos servicios, la falta de comodidades, su necesidad de trabajar para sus familias o la "baja" calidad de la educación que se imparte en la zona, los niños y niñas sienten que tienen una buena calidad de vida, en otras palabras son unos niños felices. Coincidimos no obstante con otros autores y resultados en relación a la calidad de vida, en el sentido de que, como señalan Jenaro et al., (2005):

Additional studies need to be conducted in order to test if such differences are better explained as cultural differences that need to be respected, or as disadvantaged situations that need to be prevented (p.738).

En este sentido, quisiéramos mencionar varios estudios sobre pobreza infantil realizados en el país y que proceden a su vez de un estudio internacional denominado Young Lives. Dicho estudio pone de manifiesto, entre otros aspectos, que las experiencias de pobreza relativa y de exclusión social son tan comunes en la Etiopía contemporánea como en la Norteamericana o la Europea (Camfield, 2010). Estos datos deben servir para ampliar el foco sobre la pobreza infantil e incluir no sólo aspectos relacionados con la nutrición y educación sino también los costes psicosociales de la carencia de recursos culturalmente adecuados que permitan una plena participación en la sociedad (Camfield, 2010). El estudio pone también de 
manifiesto que las concepciones de los niños sobre la pobreza son muy específicas del contexto y de los aspectos sociales (Camfield, 2010).

Desde nuestro punto de vida creemos que el origen de que los niños perciban esta buena calidad de vida junto a su satisfacción escolar se debe tanto a componentes culturales como a su privilegiada situación frente a otros niños de la zona. Estos componentes culturales que ayudan a los niños a tener una mejor calidad de vida son entre otros para nosotros la riqueza e importancia en el desarrollo personal de las relaciones familiares y sociales en las que los niños están envueltos. Así, nosotros mismos pudimos observar cómo los niños, tanto en su tiempo libre como cuando estaban realizando algún tipo de tarea, siempre iban acompañados de familiares y contaban en general con unas redes de amistad bastante fuertes. Esta importancia que se otorga a las relaciones familiares y sociales crea a su vez una solidaridad en la zona de la que se benefician los niños y su calidad de vida.

Así, su satisfacción en la escuela, pese a lo limitado de los recursos de dicha escuela, es un asunto de perspectiva. Así, es evidente que desde nuestro punto de vista externo, acostumbrados a las escuelas europeas, la escuela de Qillenso nos parece una escuela en la que tanto la infraestructura como la calidad de la enseñanza es muy limitada, también es verdad que si la comparamos con las escuelas de la zona la escuela de Qillenso es una escuela sobresaliente; tanto la calidad de los materiales de construcción como la disponibilidad de recursos pedagógicos o educativos es mucho mejor que la de las escuelas de la zona. Tanto los alumnos como sus familiares son plenamente conscientes de este hecho, lo que justifica su entusiasmo por la escuela. Además, la presencia continuada de los Padres Combonianos en la escuela ha hecho que la calidad y los métodos de enseñanza en la escuela de Qillenso incorporen elementos e ideas que mejoran dicha educación frente a la educación que se imparte en las demás escuelas de la zona. 


\section{DISCUSIÓN Y CONCLUSIONES FINALES}

Al comenzar esta investigación nos planteamos una serie de hipótesis, objetivos y preguntas a los que hemos dado respuesta mediante la aplicación de un proceso metodológico que diseñamos durante la fase de planificación del proyecto de investigación.

Dos de nuestros objetivos a la hora de iniciar esta investigación eran, primero, estudiar en profundidad la realidad educativa de Etiopía y así poder establecer comparaciones entre nuestros datos y observaciones con la realidad a nivel nacional. También queríamos conocer el funcionamiento de la escuela de los Padres Combonianos de Qillenso mediante la elaboración de una etnografía sobre la misma. Pretendíamos así generar un conocimiento experto sobre la escuela que nos permitiera identificar los puntos fuertes y débiles de esta institución educativa y analizar cómo ello afectaba a la educación de los alumnos y a su calidad de vida.

La investigación ha transcurrido de lo más general a lo más específico por lo que, en primer lugar, hemos presentado los marcos, históricos, políticos, económicos e ideológicos en los que se inscriben estas dos realidades. Así pues, desde una concepción materialista hemos accedido de primera mano a la estructura y superestructura donde se encontraba la realidad en la que íbamos a trabajar.

El estudio bibliográfico sobre la historia, economía y situación política del país se ha visto complementado con las observaciones realizadas durante nuestra experiencia de campo en el país. Hemos además prestado especial atención a la historia de los Oromo y hemos realizado una comparación histórica no controlada de las sociedades de Etiopía y sobre las relaciones entre los Oromo y los grupos dominantes. A su vez, hemos realizado una etnohistoria de los Oromo que nos ha permitido recabar datos diacrónicos sobre su sociedad y cultura que a su vez nos 
ayudado a interpretar de una manera más acertada los datos sincrónicos obtenidos de la etnografía de los Guji del área de Qillenso.

Los hallazgos derivados de este análisis nos permiten afirmar que en Etiopía la construcción del discurso nacional ha estado dominado fuertemente por la etnicidad y por los choques entre las etnias del norte, Amhara y Tigriña, con las etnias del sur. Esto ha provocado que, en la creación de la identidad nacional etíope, las etnias del norte se hayan atribuido a sí mismas el protagonismo y hayan relegado a las demás etnias que conforman el país, especialmente a la Oromo y a los musulmanes, los papeles de antagonistas en el proceso de construcción nacional.

Ejemplo de ello es cómo se narraba tradicionalmente la migración Oromo hacia el norte y la posterior expansión Amhara hacia el sur, de modo que estos procesos expansivos eran explicados atribuyéndoles unas características diametralmente opuestas. Así, mientras que el caso amhara se abordaba con adjetivos como cruzada y reunificación, el caso de los Oromo era definido como invasión o desastre. Esta situación se ha visto favorecida a su vez por la tradicional debilidad de la estructura estatal etíope que hasta fechas muy recientes seguía siendo de corte feudal. A ello se añade el agravante provocado por la expansión militar del estado etíope hacia el sur, que provocó que nobles amhara y tigriños gobernaran sobre enormes masas de campesinos de otras etnias y que estos mismos campesinos vieran cómo eran desposeídos de sus tierras que eran entregadas a miembros de las etnias del norte para quienes pasaron a trabajar como campesinos sin tierra o directamente como siervos adscritos a la misma. Posteriormente los procesos de refuerzo e implantación de la estructura estatal etíope en el último siglo no se llevaron a cabo con una intención integradora de modo que todas las etnias obtuvieran su espacio y reconocimiento como iguales; por el contrario, las nuevas estructuras estatales fueron utilizadas para perpetuar esta dominación y para llevar a cabo un proceso de aculturación con la intención de amharizar y homogeneizar a todos los grupos del país y controlar así el territorio de una manera más eficiente. En este sentido, coincidimos hasta cierto punto en el 
análisis que algunos autores como Melbaa (1999) hacen de la expansión amhara sobre nuevos territorios como un movimiento colonialista, ya que el tipo de gobierno impuesto, los desplazamientos de población, la captura de esclavos, la expropiación de tierras, el asentamiento de poblaciones y guarniciones militares en los nuevos territorios o los procesos de aculturación coinciden perfectamente con el típico comportamiento de un gobierno colonial. No obstante, este proceso tiene unas características propias que lo alejan del colonialismo más clásico y lo convierten más bien en una lucha entre dos modelos sociales por el control de un territorio. Estas características van desde la poca diferencia cultural y tecnológica entre conquistados y conquistadores hasta la larga historia de relaciones entre ambas sociedades. No hay que olvidar que la expansión amhara ha supuesto el último capítulo de una serie de movimientos de expansión y retroceso entre ambas sociedades, provocado en gran medida por el acceso privilegiado de los monarcas amhara a las modernas armas de fuego europeas, frente a sus rivales.

Esta situación se ha tratado de corregir de cierta manera durante las últimas décadas, primero con la lenta concesión de derechos y servicios a todos los pueblos del imperio; posteriormente con la, en teoría, igualitaria revolución del Derg y finalmente, con la creación del nuevo sistema estatal federal en el que se otorga cierto grado de autogobierno a cada una de las etnias principales del país y se les reconocen una serie de derechos lingüísticos y políticos que en teoría les han puesto en pie de igualdad con las etnias políticamente dominantes del país. Además el gobierno está inmerso en una constante campaña de fomento del nacionalismo etíope sirviéndose para ello de toda clase de medios. La derrota de la invasión italiana o la lucha contra el Derg han supuesto ocasiones para exaltar dicho nacionalismo, sin las guerras contra Eritrea o los programas de desarrollismo económico caracterizados por la llamada constante a la participación ciudadana en grandes proyectos nacionales como la construcción de la "Presa del milenio". Toda esta campaña de exaltación del nacionalismo y de los logros nacionales pretende a su vez reforzar la adhesión y apoyo de los ciudadanos al partido gubernamental, ya 
que estos éxitos son atribuidos al gobierno y a los partidos que lo respaldan y se tilda de traidores y terroristas a cualquiera que muestre la más mínima oposición.

Coincidimos con Hussein (2008) quien señala que en Etiopía, la agenda nacional para la construcción del país ha descansado ampliamente en la amharización del imperio. Los agentes homogeneizadores impuestos por la superioridad amhara frente a otros idiomas en el país (Hussein, 2008). Los esfuerzos actuales por revitalizar la lengua Oromo chocan con la fuerza del gobierno que continúa limitando la puesta en marcha de políticas lingüísticas y culturales igualitarias. De este modo, el idioma continúa siendo un medio para legitimar fines políticos (Hussein, 2008)

Todos estos esfuerzos y movimientos han llevado a que entre gran parte de la población haya un sentimiento de orgullo de pertenecer a Etiopía, pero es indudable que las tensiones y enfrentamientos étnicos siguen muy presentes y vivos en el día a día. Ejemplo de ello es el miedo que muestran las élites tigriñas y amharas que dominan el gobierno a cualquier manifestación de descontento por parte de miembros de otras etnias como los Oromo. Esto viene a mostrar cómo los partidos políticos se han convertido en el nuevo vehículo para la confrontación étnica. Además, como hemos señalado anteriormente, el recelo entre los miembros de distintas etnias y las tensiones que esto provoca son fáciles de vislumbrar tras la campaña de acoso y encarcelamiento de la oposición, la falta de garantías en las elecciones o por la dureza con la que son reprimidas las manifestaciones de estudiantes en la Oromía.

También coincidimos con Habermann (2011) quien sostiene que Etiopía está realizando indudablemente enormes progresos, especialmente en temas como la infraestructura, educación y nivel de vida. Sin embargo, existe un creciente desacuerdo sobre lo que constituye un desarrollo apropiado para Etiopía. Existe la firme creencia de que el desarrollo de un estado se basa en el crecimiento económico, pero existen también dudas sobre si dicho desarrollo económico ha llevado a una mayor equidad. La sociedad etíope se mueve entre el mantenimiento de los valores tradicionales y la asunción de nuevos valores que se derivan de una 
creciente implicación en un mundo globalizado. En dicha escena, mientras que los actores cada vez más ricos están apareciendo en la escena nacional, los pobres aún no obtienen beneficios suficientes de este desarrollo (Habermann, 2011).

Por otra parte también hay que destacar que desde el gobierno, aunque de una manera más sutil que en periodos históricos anteriores, se siguen promoviendo los valores culturales del norte como ejemplo a seguir en toda Etiopía, asimilando la idea de desarrollo y modernidad a lo amhara y fomentando que los valores tradicionales de las otras sociedades que conviven en Etiopía sean considerados sinónimos de subdesarrollo y pobreza. Esto se aprecia muy claramente en la dicotomía lingüística que se da en las ciudades, donde el idioma amhárico es considerado cosmopolita mientras que los otros idiomas son considerados de gente recién emigrada desde el campo.

Todos estos devenires históricos han provocado que en Etiopía se hayan creado una serie de discursos enfrentados en los que la etnicidad es fundamental a la hora de determinar las identidades y su posicionamiento frente al estado etíope. Además las relaciones históricas y étnicas y los miedos, recelos y odios que provocan han sido y son fundamentales no sólo para entender la relación de las distintas poblaciones con el estado etíope y sus instituciones, sino también para comprender la valoración que de los distintos grupos otorgan a la educación y el porqué de su estructura, contenidos y modo de implantación. Así, el estado actual de los miembros de la etnia Guji en la zona de Qillenso es un reflejo de todos estos acontecimientos junto a los cambios que está viviendo Etiopía en la actualidad.

En el capítulo etnográfico sobre los Guji hemos descrito y analizado el estado en el que encontramos a la sociedad Guji en el área de Qillenso. La comparación de nuestros datos con trabajos etnográficos anteriores nos ha permitido vislumbrar algunos cambios culturales. Creemos sin embargo importante realizar un análisis más profundo de los cambios detectados y de las situaciones que creemos pueden seguir provocando un cambio cultural. Y ello porque futuros cambios en el statu quo socioeconómico y cultural tendrán obligatoriamente un impacto en la 
educación en la zona y en la relación, valoración e interiorización que los Guji hagan del sistema educativo.

Retomando lo anteriormente expuesto, en la zona de Qillenso vive una sociedad inmersa en un momento de profundo cambio, en la que tradiciones culturales con varios siglos de antigüedad conviven con las nuevas costumbres e innovaciones que están llegando a la zona. Hasta cierto punto podría decirse que es una sociedad que está perdiendo su identidad frente a la llegada de nuevos valores sociales que están transformando la cultura Guji de diferentes maneras, como resumimos a continuación.

El primero de estos cambios se relaciona con la pérdida de homogeneidad y de cohesión interna de esta sociedad, que puede amenazar la identidad de grupos enteros de Guji como ya pasó con las subtribus que adoptaron las costumbres sidamo o somalíes. La primera fractura social que observamos en la zona donde realizamos nuestra investigación es la que se está abriendo entre los Guji que permanecen en zonas rurales y los que por diversos motivos se han trasladado a vivir en las incipientes ciudades de la zona; aunque ambos grupos están sometidos al mismo proceso de aculturación, el proceso es mucho más rápido y profundo entre quienes viven en las ciudades ya que todos los cambios que se introducen en la zona llegan primero a las ciudades y de allí poco a poco se extienden a las zonas rurales. Un ejemplo de ello es que mientras en las ciudades de la zona los Guji conocen y hablan el amhárico, en las zonas rurales un gran número desconoce el idioma. Además gran parte de las nuevas poblaciones que se están asentando en la zona por intermediación del gobierno lo hacen en las ciudades trayendo consigo nuevos valores culturales que los Guji, siguiendo la mejor tradición Oromo, interiorizan rápidamente sin analizar si son o no beneficiosos para ellos. Un ejemplo de ello lo tenemos con la introducción del cultivo del árbol de la falsa banana introducido por los Gedeo. En consecuencia, estos Guji que viven en las ciudades son además la puerta de entrada para el proceso de aculturación que está sufriendo toda la población Guji en su conjunto, ya que los Guji de zonas rurales tratan de imitar a los de las zonas urbanas para ser más "modernos y desarrollados". 
Por otra parte está surgiendo una creciente estratificación social que está transformando las relaciones sociales tradicionales e introduciendo nuevas relaciones en un pueblo como los Guji que se había mantenido bastante igualitario y en el que sólo tras la conquista amhara se había originado una elite dominante pero muy limitada en número y poder. Este hecho había cambiado ya en nuestra presencia sobre el terreno, donde pudimos observar cómo estaban empezando a surgir nuevas clases sociales en la zona con la introducción de las nuevas actividades económicas o administrativas.

De esta manera, entre las nuevas clases sociales ha surgido un nuevo grupo social conformado por los trabajadores del gobierno, entre cuyos miembros hay tanto Gujis como etíopes de otras etnias. Este grupo de burócratas no sólo tiene una situación económica mejor al combinar sus trabajos de oficina y sus explotaciones agrícolas, sino que es también un grupo de poder muy importante y con un fuerte corporativismo. La gran mayoría pertenece al partido político del gobierno lo que les otorga cierto poder e inmunidad, por lo que fenómenos como la corrupción y los sobornos están muy extendidos. Además esta corrupción es permitida por el gobierno como modo de asegurarse la fidelidad de los funcionarios, ya que muchas veces el único castigo que recibe un corrupto es su traslado de una localidad a otra como pudimos observar en el caso de un policía de la zona a quien conocimos. Es más, la corrupción está tan normalizada que si se pretende realizar cualquier trámite con la administración lo normal es desembolsar alguna cantidad de dinero para asegurarse de que las gestiones lleguen a buen puerto.

Otro nuevo grupo en claro ascenso social es el formado por los nuevos comerciantes que están surgiendo con la introducción de nuevas actividades económicas y la llegada de nuevas mercancías debido a la mejora de las comunicaciones en la zona. Estas nuevas actividades, como ya detallamos anteriormente, han provocado no sólo la apertura de nuevos nichos laborales, sino también la transformación de algunos de los valores culturales más tradicionales de la sociedad. En este sentido es importante señalar que anteriormente para los Guji 
un hombre que no se dedicara a la ganadería sino a actividades comerciales era hasta cierto punto despreciado ya que no se le tenía en cuenta como un Guji de pleno derecho. Sin embargo, con el nuevo éxito social y económico de esta población, estas profesiones han pasado a ser mucho más respetadas y deseadas, siendo en ocasiones sinónimo de riqueza para los Guji. Pese a estos cambios, la ganadería sigue siendo para éstos la mayor fuente de prestigio social, sobre todo en las zonas más rurales, si bien ya no es la "única". Creemos además que este nuevo prestigio de profesiones que necesitan de una formación académica para poder acceder a ellas podría ser utilizado como un estimulante para el fomento de la educación.

Otros nuevos elementos que se han introducido en la sociedad Guji como factores diferenciadores dentro de la misma y que han tenido un gran impacto cultural son las nuevas confesiones religiosas o la pertenencia a partidos políticos. Dichas confesiones religiosas están introduciendo factores nuevos en las relaciones sociales y de poder dentro de las comunidades Guji. Se han introducido principalmente numerosas iglesias protestantes que además se están configurando como herramientas de promoción social, pues están actuando como grupos de apoyo y presión que promueven el ascenso social de sus miembros y que "exigen" de los mismos la devolución de los favores. Ejemplo de ello lo vimos cuando en una disputa por un terreno ocupado por un aldeano protestante, los miembros protestantes de la administración fallaron inmediatamente a favor del mismo y fue necesario llegar a una instancia judicial superior para que el ocupante fuera obligado a desalojar el terreno. La penetración del Islam es creciente con la llegada de nuevos grupos de población y la conversión de la autóctona, mientras que el catolicismo y la Iglesia Ortodoxa mantienen una baja presencia o incluso retroceden. Además los pastores protestantes, sacerdotes católicos e imanes están desplazando en cierta medida a los ancianos como fuentes de autoridad moral tradicional. Estas nuevas religiones están provocando a su vez una serie de cambios culturales en el área como por ejemplo el pronunciado descenso de las familias poligámicas, el rechazo al consumo de alcohol, o al menos su censura pública, o la 
mejora de la situación de la mujer con la condena del maltrato físico. Por otra parte están también provocando efectos negativos, como el surgimiento de enfrentamientos por motivos religiosos o la expansión de un cristianismo fundamentalista que prevemos tendrá un efecto negativo sobre las campañas de control de la natalidad, el uso del preservativo para evitar el contagio del VIH o que, como pudimos observar, están reforzando la creencia de que las enfermedades mentales están causadas por espíritus y demonios.

Otro elemento social novedoso es el creado por la implantación de grupos políticos afines al gobierno en la zona. Pertenecer a uno de estos partidos se ha convertido en otro medio de promoción social; afiliarse al partido y demostrar lealtad al gobierno se ha convertido en un medio de asegurarse un trato preferente por parte de la administración aunque también el oculto rechazo por una gran cantidad de la población opuesta al gobierno. Por el contrario, significarse públicamente contra el gobierno puede ocasionar desde problemas labores, sociales hasta encarcelamiento o incluso torturas.

En suma, tanto los elementos religiosos como políticos han venido a añadir diferenciaciones internas dentro de los Guji; además estos nuevos grupos de carácter religioso o político han venido a sustituir en cierta medida parte de las funciones sociales que anteriormente ejercían los grupos generacionales de la Gada y han provocado la sustitución de los líderes de la Gada por una nueva clase de líderes sociales de carácter económico, político o religioso. Con ello se ha reemplazado una de las características más definitorias de la sociedad Guji, la Gada, que ya estaba en franca decadencia, por una serie de nuevos elementos adoptados en las últimas décadas. Ello constituye otro ejemplo de la aculturación a la que se enfrenta este pueblo. Este cambio cultural posee tanto una vertiente positiva como una negativa; del lado positivo destaca su posible utilización para fomentar la educación en la zona, ya que dentro de estos nuevos líderes en la sociedad se pueden incluir a los maestros, figuras muy respetadas y quienes se trata con un gran respeto y educación. Esto les convierte en candidatos perfectos para protagonizar acciones de concienciación social sobre diversos temas, siendo 
especialmente importante el papel que podrían desarrollar en la promoción de la educación. Sin embargo, lamentablemente y como ya expusimos en capítulos previos, la gran mayoría de los profesores con quienes trabajamos en Qillenso y en otras partes de la Oromía no eran buenos candidatos a convertirse en líderes comunitarios. En cuanto a las repercusiones negativas, las nuevas actividades económicas que están llegando a la zona no sólo pueden favorecer la valoración de la educación por la necesidad de mano de obra con una mayor formación sino que producirán una aceleración en el proceso de urbanización de la zona con las consecuencias que ello traerá para todos los aspectos de la cultura Guji y del sistema educativo de la zona.

Centrándonos ahora en el papel de la mujer en la sociedad Guji y en los cambios que hemos observado, podemos decir que la situación de las mujeres entre los Guji es todavía de franca desventaja. Es verdad que tradicionalmente las mujeres Guji han dispuesto de cierto grado de autonomía y libertad pero paradójicamente la llegada de nuevos valores culturales en teoría "más avanzados" han provocado en nuestra opinión un retroceso en muchos aspectos de esta autonomía y libertad.

El retroceso del que hablamos se ha producido por la entrada de las ideas más reaccionarias de la cosmología cristiana y musulmana respecto a las mujeres, diseminadas en la zona por la proliferación de Iglesias protestantes y el Islam. Otras ideas que han entrado en la zona tienen su origen en la etnia amhara que culturalmente es mucho más restrictiva con la mujer que los Oromo. Por ejemplo, la valoración de la virginidad de la mujer hasta el matrimonio procede de la influencia amhárica ya que tradicionalmente los Oromo eran muy permisivos con las relaciones sexuales prematrimoniales y las infidelidades. Además, pese a la llegada de ideas que censuran los comportamientos violentos contra la mujer, otros comportamientos culturales tradicionales siguen completamente vigentes como la violencia de género contra la mujer en el espacio familiar. Así pues, creemos que pese a la llegada de nuevas ideas y situaciones que en teoría empoderan a la mujer, la llegada de otros nuevos valores reaccionarios frente a la misma junto a la 
pervivencia de algunos valores tradicionales, han provocado un retroceso de la situación de la mujer en la zona como ya señaló, en un caso similar en Kenia, la investigadora Hilarie Ann Kelly (1992).

También hemos sido testigos de cómo, por la construcción de nuevas infraestructuras o servicios, el patrón de población está empezando a cambiar por toda la zona; las casas antes dispersas se están empezando a agrupar en los márgenes de la carretera o cerca de polos de atracción de población como los hospitales u otros lugares en los que se presta algún tipo de servicios. Estos cambios pueden tener un impacto positivo para la educación en la zona ya que la creación de centros de población obligará al gobierno a dotarlos de servicios. Por ejemplo, como vimos en nuestra experiencia de campo, el gobierno utiliza la dispersión de la población como excusa para no instalar servicios afirmando que no compensa el gasto de su instalación. Por otra parte, como ya indicamos cuando expusimos las campañas llevadas por el Derg, la concentración de población podría traer consecuencias negativas para los Guji, pero por otra parte en este caso el traslado de población se está haciendo de manera voluntaria y más racionalmente.

Resumiendo, a la luz de lo expuesto concluimos que los cambios actuales que se viven en la zona de Qillenso pueden abrir una ventana para la mejora de la educación al hacer posible un nicho de trabajo que requiere mano de obra capacitada y que haría ver a las familias la ventaja económica que obtendrían sus hijos si lograran una buena escolarización. Sin embargo, al mismo tiempo hay una serie de condicionantes culturales y económicos que siguen obstaculizando la escolarización sobre todo en el caso de las chicas y cuya solución requeriría una fuerte inversión económica, tiempo y campañas de concienciación.

Siguiendo el planteamiento que hemos trazado para esta investigación de ir de lo más general a lo más específico, pasamos a continuación a analizar el sistema educativo etíope tanto a nivel nacional como regional de la Oromía. La conclusión a la que hemos llegado es que, tanto en Etiopía como en la Oromía, el sistema educativo adolece de los mismos problemas y limitaciones. Estos problemas, que hemos abordado con mayor profundidad en los capítulos precedentes, se centran 
en temas como la baja calidad de la educación, problemas de organización y estructura del sistema educativo, problemas relacionados con el profesorado, o falta de igualdad de oportunidades entre los estudiantes de zonas rurales frente a los de zonas urbanas. También hemos mencionado problemas relativos a la utilización política de la educación, a la falta de universalidad de la misma, a la necesidad de asimilación del sistema educativo como algo propio por parte de la población o a la situación de desventaja de las chicas frente a los chicos a la hora de poder aprovechar las oportunidades educativas.

Todos estos problemas son compartidos tanto por Etiopía como por la Oromía, pero en ésta es aún más precaria que a nivel nacional debido a condicionantes culturales e históricos que contribuyen a explicar por qué la mayoría de los indicadores analizados en el tercer capítulo de la presente Tesis Doctoral arrojen resultados inferiores en la Oromía frente a la media de Etiopía. Por otro lado, el análisis de los indicadores de ambas realidades a lo largo de los últimos años muestran que tanto Etiopía como la Oromía están experimentando los mismos procesos de mejora en los datos de matriculación bruta y neta, reducción del abandono escolar y repetición. No obstante, también se están produciendo sucesos de carácter negativo como podría ser por ejemplo el hecho de que, tras años de aumento sostenido de la matriculación femenina, la brecha entre los géneros se haya estabilizado o incluso haya aumentado ligeramente en los últimos años. De esta manera queda claro que tanto a nivel nacional como regional, el sistema educativo ha experimentado una serie de cambios y movimientos positivos pero también sigue acuciado por una serie de problemas que se resisten a desaparecer o que incluso están volviendo a tomar fuerza.

Centrándonos en la investigación más empírica realizada en la presente Tesis Doctoral, creemos mencionar a una serie de resultados obtenidos tanto de la etnografía de la escuela de Qillenso como de los cuestionarios rellenados por los propios alumnos. Como ya hemos indicado, planteamos el trabajo empírico como las dos caras de una misma moneda, ya que una nos da una visión etic mientras que la otra nos proporciona una visión emic de la misma realidad. 
Hemos optado por realizar un estudio en profundidad de una sola escuela, más que por llevar a cabo un estudio más extenso de la realidad educativa en la zona, y ello por varias razones. La primera es que la presente investigación no sólo pretende generar conocimiento sobre la realidad actual, sino que tiene la vocación de proponer líneas de actuación para mejorar la calidad del proceso de enseñanzaaprendizaje. Por ello creemos que la escuela de Qillenso, al pertenecer a una misión católica, tiene las características necesarias para ello. En esta escuela sí se podrían implantar algunas de las medidas que creemos necesarias para mejorar la situación educativa y de calidad de vida infantil frente a las escuelas públicas de la zona, donde los intereses políticos, o simplemente una burocracia tan compleja como la etíope, harían mucho más difícil cuando no imposible la aplicación de cualquiera de estas medidas.

Además, dadas las limitaciones encontradas para llevar a cabo nuestro trabajo, comprendimos que la calidad de los conocimientos generados iba a ser mucho mayor si centrábamos nuestros esfuerzos en una sola escuela que si tratábamos de abarcar todas las escuelas de la zona. Preferimos de esta manera generar un conocimiento más profundo y específico que obtener una imagen más somera y general. Consideramos también que los informes del gobierno etíope y de otras organizaciones ofrecían una panorámica general que queríamos contrastar con la realidad vivida.

La etnografía de la escuela de Qillenso nos permitió además comprender una serie de hechos sobre la realidad educativa del centro que nos sirvió para ajustar las entrevistas y cuestionarios empleados para estudiar la calidad de vida infantil y la satisfacción con la escuela y percepción de inclusión. También nos permitió dar respuesta al objetivo general y a los objetivos específicos planteados. Así, hemos esta descubierto la realidad y el funcionamiento de la escuela de Qillenso; además logramos comprender cómo encajaba la escuela en su entorno geográfico y sociológico y señalar las ventajas e inconvenientes que estos contextos suponían para el funcionamiento de la institución. 
En nuestra presencia en el campo pudimos constatar que la educación reglada de corte occidental que se ha implantando en Etiopía y por tanto en Gujiland es un claro factor de cambio cultural y tiene un impacto en la identidad Guji. Dicho de otra manera y como ya señaláramos previamente, la educación es un claro factor que altera o modifica la cultura Gujii. Este pueblo como ya hemos expuesto a lo largo de esta investigación se encuentra en un momento de cambio cultural acelerado y aculturación debido a la entrada en escena de nuevos factores sociales, políticos e ideológicos y al surgimiento de nuevas actividades económicas.

La educación no es ajena a este proceso y menos aún en un contexto de dominación social y étnica como el de Etiopía, en el que con anterioridad ya se ha utilizado el sistema educativo como método de aculturación por parte de las etnias dominantes sobre el resto. Bajo nuestro punto de vista quedó claro como el sistema educativo etíope tiene un claro carácter homogeneizador y de promoción tanto de la cultura amhara como del partido político en el poder que son asimilados a la idea de progreso aunque en la actualidad este proceso de aculturación se lleve a cabo de una manera más sutil que en periodos anteriores.

De tal manera en Gujiland pudimos observar como las relaciones dominación cultural e imposición cultural de las clases dominantes que se dan en la escuela según Bourdieu y Passeron () están presentes de una manera muy sutil, ocultando estas relaciones de dominación étnica bajo la idea de la transmisión de conocimientos. Ejemplo de ello era la incesante exaltación de la figura del anterior primer ministro del país que había fallecido recientemente cuando llevamos a cabo nuestro trabajo de campo o la forma en la que los libros de texto del país relataban la historia del mismo o que el amhárico pese a no tener un carácter oficial sea enseñado como la lengua "oficial" del país.

Ejemplo de cómo la educación esta provocando un cambio en la identidad Guji allí donde el sistema educativo es más potente lo pudimos observar cuando al desplazamos a las ciudades del área constatamos como muchos jóvenes usaban el amhárico como lengua y no el Oromo en la calle frente a la gente de mayor edad que seguía usando el Oromo como primera opción de comunicación. 
Por otra parte debido a la debilidad del propio sistema educativo el impacto de la educación como factor de cambio cultural esta mitigado en Gujiland. Pese a ello si que esta afectando a la cultura Guji, ya que no solo provoca unos limitados cambios culturales directos sino que esta sirviendo para ayudar a que otros factores y situaciones provoquen un cambio cultural más efectivamente al proporcionarles entre otras cosas una justificación y un respaldo ideológico.

El trabajo de campo nos ha permitido también comprobar que el modelo educativo que se sigue en Qillenso igual que en el resto de Etiopía esta muy influenciado por la educación anglosajona, modelo que se ha tomado como referencia a la hora de montar el sistema educativo del país. Esto es debido a la importancia histórica que ha tenido tanto Inglaterra como EEUU en el desarrollo del sistema educativo etíope tras la Segunda Guerra Mundial como afirman autores como Henze (2000) o Zewde (2001).

Este aspecto anglosajón se puede observar en la organización de los ciclos escolares, en la formación de los maestros o en la importancia que se da a la lengua inglesa como idioma vehicular de la educación a partir de la educación secundaria.

Por otra parte no hay que subestimar la importancia que tiene el componente "local" en el sistema educativo del país. Así, pese a que desde el Ministerio de Educación de Etiopía se esta implantando un sistema educativo formal de corte occidental también se están implantando programas de educación informal para atender a las diversas realidades de país que escapan de los contextos sociales para los que estos sistemas formales fueron diseñados en Occidente.

Además, en las propias instituciones más formales de educación como puede ser la propia escuela de Qillenso, el componente cultural local es tan importante que hasta cierto punto diluye el modelo Occidental de educación en el día a día de la escuela. Puede que el diseño y organización sean de corte Occidental y que esto sea origen de una parte importante del desfase entre la realidad etíope y el sistema educativo pero también es verdad que la aplicación de la educación una vez alcanzado el nivel del "terreno" la "etiopeiza" hasta cierto grado ya que la 
metodología educativa, los recursos didácticos, las materiales o las actitudes pedagógicas de los maestros son muy alejadas de las que se esperaría encontrar uno si se aplicara correctamente un modelo de escuela anglosajón.

Centrándonos en un análisis más concreto de la escuela y su contexto, es evidente que el entorno rural donde se encuentra la escuela, en una zona especialmente deprimida, aislada y falta de servicios básicos como la luz eléctrica o el agua potable son dificultades a los que esta escuela ha de enfrentarse y que, junto a la realidad económica y a alguno de los valores culturales Guji, condicionan negativamente la forma en la que se lleva a cabo el proceso de enseñanzaaprendizaje y al modo en que los usuarios de la escuela se acercan y utilizan esta institución educativa.

Durante nuestra investigación también nos quedó claro que el personal escolar está a su vez condicionado por esta realidad ya que parte de su falta de "profesionalidad" se puede atribuir a los condicionantes culturales y económicos en los que está inmersa esta sociedad. Sin embargo, para ser justos, también hay que señalar que esa falta de "profesionalidad" quedó también patente en nuestra anterior estancia en Etiopía en un contexto urbano. Así pues, parece claro que la falta de formación o motivación en el profesorado a nivel nacional es un problema que requiere de un profundo abordaje.

También hemos logrado cumplir el objetivo de conocer y analizar la evolución de los distintos indicadores, estadísticas y datos a lo largo de la historia de Qillenso para posteriormente comprarlos con los que ya disponíamos a nivel regional y nacional. Los análisis nos han permitido verificar que estos indicadores han seguido en Qillenso unos patrones similares a las estadísticas existentes tanto a nivel regional como nacional. Respecto a las semejanzas y diferencias en los problemas detectados, consideramos que existen problemas idénticos o muy similares en los tres niveles analizados. Además, al ser Qillenso una escuela de una zona rural está especialmente en sintonía con los problemas que afectan al sistema educativo en los ambientes rurales. 
Así, la situación educativa de Qillenso es más frágil que la media de la Oromía o de Etiopía. Nuestras propias observaciones confirman que este fenómeno no es propio de Qillenso únicamente sino que al visitar otras escuelas y hablar con gente de la zona hemos percibido que en todo el área se reproducen las mismas situaciones que en la escuela de Qillenso. Y ello sin olvidar que esta escuela de los Padres Combonianos destaca por su calidad e infraestructuras pues, por ejemplo, la escuela pública que visitamos en la zona que era un simple barracón construido con madera y uralita. De hecho, profesores de otras escuelas querían trasladar su puesto de trabajo a Qillenso.

Por último tras nuestra etnografía podemos afirmar que los Padres Combonianos constituyen el activo más importante a tener en cuenta a la hora de mejorar el desempeño de la escuela de Qillenso. Con su presencia otorgan a la escuela una serie de características y ventajas potenciales sobre las escuelas de su entorno que podrían traducirse en programas y actuaciones que, como sugerimos anteriormente, podrían mejorarían enormemente la calidad de la enseñanza impartida en la escuela. Esta mejora redundaría en un aumento de la asistencia a clase, un aumento de las tasas de matriculación, una disminución de las tasas de abandono escolar y un aumento de los años de escolarización. Esto no solo afectaría a los alumnos de la escuela de Qillenso sino que serviría de ejemplo para las escuelas de la zona que podrían adoptar alguna de las medidas que se demostraran más exitosas, siempre dentro de las posibilidades reales que tienen las escuelas públicas.

Conviene insistir, pese a todas las limitaciones que el sistema tiene, que la educación en niños de primaria de áreas en conflicto como era el caso de Etiopía hace unos años, ha puesto de manifiesto que dicha educación constituye además un vehículo para socializar a los niños. Además restaura una rutina, constituye un entorno seguro para ellos y les permite creer que hay un futuro mejor para ellos; ello también explica que los alumnos estén muy motivados a finalizar sus estudios (Winthrop y Kirk, 2008). 
Por otra parte no hay que olvidar que los Padres Combonianos están restringidos en sus capacidades de actuación por la política de la propia Iglesia Católica en Etiopía, por sus limitaciones presupuestarias y por el gran número de requisitos, permisos y dificultades crecientes que el gobierno etíope impone a quien que desea llevar a cabo cualquier tipo de actividad dentro del país. Es más, los propios Padres Combonianos nos comentaron, e incluso pudimos ser testigos de ello, cómo las autoridades educativas etíopes presionaban constantemente en diversas cuestiones relacionadas con el funcionamiento interno de la escuela e intentaban apropiarse de competencias de la misma que, según los acuerdos firmados entre los misioneros y la oficina regional de educación, eran potestad de los Padres Combonianos.

Una vez expuestos los principales resultados de la investigación etnográfica y las posibles implicaciones que de ellos se derivan, pasamos a presentar los datos más relevantes que se desprenden de la aplicación de los autoinformes y de la observación participante. Así, tanto las respuestas de los participantes como nuestras observaciones sugieren que los alumnos de la escuela de Qillenso muestran unas características sociodemográficas similares a las de los escolares de primaria de la Oromía y de Etiopía.

Además como ya expusimos al analizar los resultados en el capítulo quinto de la presente investigación, los alumnos mostraron una elevada satisfacción con su calidad de vida y con la escuela, especialmente en los aspectos relacionados con las relaciones sociales y el desarrollo personal. Por otra parte hemos detectado la existencia de asociaciones positivas y significativas entre satisfacción con la escuela y calidad de vida y hemos verificado que las variables socioculturales afectan significativamente tanto a la valoración de la satisfacción con la escuela como a la satisfacción con la calidad de vida. Coincidimos por tanto con Camfield (2010) quien puso de manifiesto que las concepciones de los niños etíopes sobre la pobreza son muy específicas del contexto y de los aspectos sociales.

Todas estas conclusiones obtenidos tanto de la etnografía como del estudio sobre inclusión y calidad de vida nos han proporcionado información exhaustiva de 
cómo funciona la escuela de Qillenso, con sus virtudes, defectos y de cómo los distintos agentes que forman parte del proceso de enseñanza-aprendizaje se relacionan con esta institución. También hemos obtenido información sobre cómo los alumnos perciben su participación en la escuela y sobre el impacto que su escolarización tiene en su calidad de vida. La información recogida debiera tenerse en cuenta antes de llevar a cabo cualquier intento de actuación para mejorar el proceso de enseñanza-aprendizaje en la escuela y por extensión en la zona o para intentar mejorar la calidad de vida infantil en la zona.

Por otra parte y siguiendo de nuevo a Jenaro et al., (2005) consideramos que siempre queda espacio para realizar una investigación en mayor profundidad que permita distinguir entre los aspectos o valores culturales que se han de "respetar" y aquéllos que deberían intentar cambiarse para reducir situaciones de inequidad y mejorar la situación de la educación en la zona. O como señala Bernal (2008), Si la cultura es un añadido yuxtapuesto a la naturaleza, también lo son la razón, la libertad y lo social. No hay oposición entre naturaleza y cultura, sino que la primera conduce - no determina - a la segunda con la actividad racional y libre, lo que explica la raíz de la diversidad cultural, e incluso nos proporciona un fundamento sólido para respetarla. En este sentido, creemos que la presente investigación constituye un primer paso en el conocimiento de la educación entre los Guji y de la calidad de vida de sus niños, aspectos hasta ahora no abordados.

Para complementar nuestra valoración sobre la educación, la cultura y el impacto de todo ello en los alumnos y futuros responsables del devenir del país, destacamos las reflexiones de Bernal (2008) quien plantea que:

La cultura como una segunda naturaleza expone, mediante la diversidad que la caracteriza, qué es la naturaleza humana. Ninguna cultura supone la realización completa del fin de la naturaleza humana, ningún individuo logra todas las posibilidades en plenitud de una cultura, ni de la humanidad. A esto se suma que ninguna cultura es estática, tampoco lo es el sujeto humano. La naturaleza es esencial, la cultura es accidental. Pero la naturaleza de cada ser humano en su desarrollo cuenta con un accidente imprescindible, que es la cultura, hasta el punto 
de que es difícil la subsistencia sin ella. La cultura es algo adjetivo, pero un adjetivo imprescindible. La cultura son numerosos adjetivos, abundantes accidentes, muchas adquisiciones, múltiples cualidades. No todo desarrollo y adquisición cultural tiene el mismo calado en lo que los seres humanos son y pueden ser. Por ejemplo, aprender una lengua -adquisicion cultural- supone el medio para desarrollar otras dimensiones humanas esenciales, y esto es más relevante que aprender esta lengua concreta, lo cual también es cultural. Los educadores precisan distinguir, para ordenar fines y medios, el valor relativo de los elementos culturales (Bernal, 2008, págs. 136-137)

Para finalizar creemos necesario aludir, tanto a las limitaciones a las que hemos tenido que hacer frente al llevar a cabo este trabajo de investigación, como a las oportunidades que la antropología aplicada puede ofrecer al desarrollo de la zona de Etiopía objeto de estudio. Así, una de las primeras limitaciones es la producida por el miedo que tiene la población para hablar de algunos temas. Como hemos explicado anteriormente, en Etiopía se vive una dictadura encubierta, por lo que existen reticencias a la hora de hablar de temas que puedan tener un componente político o que puedan ser interpretados como una crítica al gobierno. En varias ocasiones, etíopes con los que hablamos afirmaron que había muchos informantes del gobierno y que era mejor no hablar de ciertos asuntos. Otra limitación que hemos sufrido es la provocada por la gran dispersión poblacional en la zona, lo que unido a nuestro limitado presupuesto nos ha impedido realizar un estudio más profundo de las familias de los estudiantes. Estudios posteriores debieran contribuir a completar la información aquí proporcionada sobre el aspecto familiar de la educación.

La limitación anteriormente expuesta a supuesto nos ha impedido a su vez obtener información sobre los niños y niñas que no estaban escolarizados en la zona, de los cuales no se conoce el número exacto ni las razones por las cuales no asisten a la escuela. Ello nos hubiera ayudado a comprender mejor los fenómenos del abandono escolar y de la no escolarización. Futuros esfuerzos investigadores debieran también abordar a estos "niños invisibles", al menos desde un punto de vista educativo. 
Una tercera limitación se relaciona con el hecho de que a la hora de seleccionar los participantes para el estudio basado en cuestionarios, tuvimos que limitar nuestro trabajo a los alumnos de tercer, cuarto y quinto curso. Como indicáramos previamente, los alumnos de cursos anteriores carecían de la madurez necesaria para completar las encuestas por sí mismos y no queríamos que sus respuestas fueran condicionadas por la presencia de un profesor de la escuela que le impidiera contestar sinceramente a algunas cuestiones relacionadas con el claustro de la escuela de Qillenso. Lamentablemente esto nos ha privado de la imagen que los alumnos de los primeros cursos tienen sobre su calidad de vida y sobre la inclusión y satisfacción escolar. No obstante, este efecto negativo queda mitigado por el hecho de que nuestro trabajo diario de campo nos proporcionó información de la escolarización de estos alumnos de primeros cursos.

Otro aspecto que pudiera ser considerado como una limitación, lo constituye el hecho de que al seleccionar las herramientas y metodologías de recogida de información decidimos dejar fuera de nuestro "kit de herramientas" la utilización de la entrevista estructurada en profundidad. Adoptamos esta medida ya que, debido a nuestra convivencia con los Padres Combonianos y al trato diario con profesores y alumnos, creímos más oportuno ir preguntando ocasionalmente las distintas cuestiones sobre las que queríamos obtener una respuesta en un ambiente más informal. En nuestra experiencia, ello nos permitiría obtener unas respuestas más sinceras y relajadas que las derivadas de una entrevista de carácter formal que probablemente hubiera producido un discurso elaborado coincidente con las opiniones y versiones gubernamentales, teniendo en cuenta la situación política descrita con anterioridad. Además la convivencia diaria nos dio la oportunidad de formular las mismas cuestiones de distinta manera y en diversas ocasiones. Esta "triangulación" nos permitió valorar la veracidad de las respuestas y los matices que éstas iban teniendo en cada ocasión. Estamos además muy satisfechos con el desempeño y resultados obtenidos de las herramientas y metodologías aplicadas, ya que se han demostrado oportunas y fiables para dar respuesta a las preguntas formuladas al principio de esta investigación. 
Por último, antes de finalizar este apartado creemos conveniente sugerir o incidir en una serie de líneas de investigación y de actuación que han quedado abiertas tras finalizar este trabajo. En primer lugar, creemos necesario realizar una etnografía monográfica sobre los Guji, ya que los únicos estudios que hemos encontrado realizados hasta la actualidad son parciales, o tienen bastante antigüedad. Ello permitiría analizar el cambio cultural que están experimentando los Guji, antes incluso de que el proceso de aculturación termine diluyendo su cultura. Hasta ahora el estudio más amplio disponible es el llevado a cabo por Lonferninni en los años 70 del Siglo XX centrado más en aspectos descriptivos que analíticos.

En segundo lugar, creemos que sería interesante llevar a cabo un estudio del mismo tipo que el nuestro ampliando la muestra a varios colegios de la zona e incluso incluyendo colegios de educación secundaria para obtener una panorámica más extensa de la situación educativa en el área. Ello serviría a su vez para confirmar o refutar nuestras conclusiones sobre las similitudes y diferencias en los aspectos educativos que se dan en Qillenso, respecto al área Guji en particular, y respecto al nivel regional y nacional más general ya que como sostiene Petra $\mathrm{M}$. Pérez:

Desde nuestra propuesta se entiende que laAntropología de la Educación ha de desarrollarse cientificamente construyendoteorías sobre hipótesis que puedan contrastarse, mejorarse o rechazarse. Para elloes necesario que esas teorías puedan ponerse a prueba, ya que, entendemos, queel tipo de proposiciones que incluyen generalmente las teorías en Antropología dela Educación en las sociedades complejas son susceptibles de contrastación. (Pérez, 1998, pág., 221)

En tercer lugar, creemos relevante realizar un estudio longitudinal o de seguimiento. Particularmente, el seguimiento de sus antiguos alumnos podría ayudar a mejorar nuestra comprensión del impacto real que la educación supone en la vida de sus ex alumnos.

Finalmente estamos convencidos de que mediante esta investigación hemos logrado, en primer lugar, crear una serie de conocimientos expertos sobre la realidad educativa de Etiopía y sobre el marco político, económico y social en la que 
ésta se inscribe. Segundo, un conocimiento en profundidad de cómo funciona un típica escuela en una zona rural del país. Además, hasta donde sabemos, no existen estudios similares al presente, centrados en los miembros de esta etnia. Si bien hay algún estudio general sobre la educación en Etiopía y sobre el cambio social, como los recogidos en la obra de Mikas y Kebede (2010), ninguno se ha centrado en el análisis de la conexión entre la inclusión y satisfacción escolar y la calidad de vida infantil.

Además, con la excepción de los trabajos del Profesor Francisco Giner Abati ${ }^{2}$ tanto en formato audiovisual como en un formato más tradicional (Giner Abati, 2002), hay una práctica inexistencia de investigaciones en antropología sobre Etiopía en las ciencias sociales españolas. Ello ofrece justificación adicional a la pertinencia y originalidad de nuestra investigación, ya que no solo arroja luz sobre una etnia tan desconocida como la Guji sino que puede ayudar a dar a conocer la realidad de un país tan mitificado y del que se tienen tantos prejuicios como Etiopía.

Por último no queremos terminar, sin antes volver a incidir en la importancia de los valores sociales y la forma de vida tradicionales como fuentes de calidad de vida entre los niños y niñas Guji y el respeto que por nuestra parte merecen estos valores. Así, todo intento por promover un cambio cultural que combata situaciones de desventaja debe, en última instancia, ser llevado a cabo con la participación, conocimiento y consentimiento de la propia sociedad Guji.

\footnotetext{
${ }^{2}$ Véase por ejemplo: http://www.rtve.es/alacarta/videos/los-ultimos-indigenas/ultimos-indigenasdassanetch/2009289/
} 


\section{REFERENCIAS BIBLIOGRÁFICAS}

Aalen, L. (2002). Ethnic federalism in a dominant party state: The Ethiopian experience 1991-2000. Bergen: Chr. Michelsen Institute.

Asselin, M., y Doiron, R. (2009). Ethiopia's "Reading Rooms" offer hope for the future. Reading Today, 26(5), 22-22.

Banco Mundial (2014). Etiopía. Información disponible en: http://www.worldbank.org/en/country/ethiopia.

Bates, B. (1979). The Abyssinian difficulty: The Emperor Theodorus and the Maqdala Campaign, 1867-1868, Oxford: Oxford University Press.

Baxter, P.T.W, Hultin, J. y Triulzi, A. (1996). Being and Becoming Oromo: Historial and Anthropological Enquiries. Uppsala: Nordiska Afrikainstitutet.

Bernal, A. (2006). Antropología de la educación para la formación de profesores. Educación y Educadores, 9, 149-167.

Bernal, A. (2008). Temas centrales de la antropología de la educación contemporánea. Educación y Educadores, 11, 129-144.

Bond, T.G. y Fox, C.M. (2001). Applying the Rasch model: Fundamental measurement in the human sciences. Mahwah, NJ: Lawrence Erlbaum Associates.

Booth, T. y Ainscow, M. (2002). Index for Inclusion. Developing learning and participation in schools. Bristol UK: Centre for Studies on Inclusive Education (CSIE).

Bourdieu, P. y Passeron, J. C. (2001). La Reproducción. Elementos para una teoría del sistema de enseñanza, Libro 1. Madrid: Editorial Popular. 
Bulcha, M (1988). Flight and integration: causes of mass exodus from Ethiopia and problems of integration in the Sudan. Uppsala: Nordiska Afrikainstitutet

Calatayud, J.M. (2012). En Etiopía a los periodistas los meten en la cárcel o los matan sin problemas. Consultado el 5 de Noviembre de 2013 en la WWW: http://sociedad.elpais.com/sociedad/2012/02/07/actualidad/1328619408_8 38695.html.

Camfield, L. (2010). "Even If She Learns, She Doesn't Understand Properly". Children's Understandings of Illbeing and Poverty in Five Ethiopian Communities. Social Indicators Research, 96(1), 85-112. doi: $10.1007 / \mathrm{s} 11205-009-9468-z$

Central Statistical Agency [Ethiopia] and ICF International. (2012). Ethiopia Demographic and Health Survey 2011. Addis Ababa, Ethiopia and Calverton, Maryland, USA: Central Statistical Agency and ICF International.

Charbonneau, L. (2013, 17 de julio). Exclusive: Eritrea pays warlord to influence Somalia - U.N. Experts. Consultado el 5 de Noviembre de 2013 en la WWW: http://www.reuters.com/article/2013/07/17/us-somalia-eritrea-unidUSBRE96G06U20130717

de Salviac, M. 2005 [1901]. An Ancient people, great African nation, traducido por Ayalew Kano, (East Lansing, Michigan).

Debsu, D. N. (2009). Gender and Culture in Southern Ethiopia: An Ethnographic Analysis of Guji-Oromo Women's Customary Rights. African Study Monographs, 30(1) 15-36,

Díaz de Rada , A., Velasco , H. M. y García, F. J. (1993). Lecturas de antropología para educadores. El ámbito de la antropología de la educación y de la etnografía escolar Madrid: Trotta.

Embretson, S.E. y Reise, S.P. (2000). Item response theory for psychologists. Mahwah: Lawrence Erlbaum Associates. 
Etefa,T. (2008). Pan-Oromo Confederations in the Sixteenth and Seventeenth Centuries, The Journal of Oromo Studies, 15 (1), 19-40.

Frost, M., y Little, A. W. (2014). Children's learning practices in Ethiopia: observations from primary school classes. Oxford Review of Education, 40(1), 91-111. doi: 10.1080/03054985.2013.873526

Geertz, C. (2013). La interpretación de las culturas. Barcelona: Gedisa

Gemeda, F. T., Fiorucci, M., y Catarci, M. (2014). Teachers' professional development in schools: rhetoric versus reality. Professional Development in Education, 40(1), 71-88. doi: 10.1080/19415257.2012.759988

Getachew, I. (2001). Beyond the throne: the enduring legacy of Emperor Haile Selassie I. Addis Ababa: Shama Books

Getnet, A. y Getachew, Y. (2007). Proceedings of the Fourth International Conference on Ethiopian Economy. Vols 1 y2. Addis Ababa: Ethiopian Economic Association

Giner Abati, F. (2002). Proyecto audiovisual de documentación cultural comparada. Anales de la Fundación Joaquín Costa, 19, 147-153.

Gomes, A. M. R. (2006). O processo de escolarização entre os Xakriabá: explorando alternativas de análise na antropologia da educação. Revista Brasileira de Educação, 11(32).

González, N. J. (1989). Etiopía: 38 días en el corazón del hambre. Madrid: Mundo Negro.

Government of Ethiopia (2005). Education For Rural People in Ethiopia. Addis Ababa, Ethiopia: Government of Ethiopia. Disponible en: http://www.fao.org/docs/eims/upload/254098/erpreport.pdf

Habermann, B. (2011). Transforming a Country? A Debate on Reimaginations of Development, Change and Crisis in Ethiopia. IDS Bulletin, 42(5), 36-40. doi: 10.1111/j.1759-5436.2011.00248.x 
Hagmann, T. y Mulugeta, A. (2008). Pastoral conflicts and state-building in the Ethiopian lowlands. Afrika Spectrum, 43 (1), 19-37

Harris, C. W. (1843). The highlands of Ethiopia. London: Longmans.

Hassen, M. (2002). Conquest, tyranny, and ethnocide against the Oromo. Northeast African Studies. 9 (3), 15-49.

Henze, P.B. (2000). Layers of time: a history of Ethiopia. London: Hurst \& Company.

Hussein, J. W. (2008). The Politics of Language, Power and Pedagogy in Ethiopia: Addressing the Past and Present Conditions of the Oromo Language. Australian Journal of Linguistics, 28(1), 31-57. doi: $10.1080 / 07268600701522772$

Ibáñez, N., Díaz, T., Druker, S. y Rodríguez, M. S. (2012). La comprensión de la diversidad en interculturalidad y educación. Revista: Convergencia. Revista de Ciencias Sociales, 19(59), 215-240.

ICEX (2012) Etiopía. Guia País. El Cairo: ICEX

Jalata, A. (2010). Oromummaa: Oromo Culture, identity and nationalism. Atlanta: Oromia Publishing Company.

Jalata, A. (2012). Gadaa (Oromo Democracy): An example of classical African civilization. The Journal of Pan African Studies, 5 (1), 126-152

Jaleta, T. (2004). A Contextual Study of A Contextual Study of Guji-Oromo Proverbs: Oromo Proverbs: functions in Focus. (Tesis doctoral) Addis Abeba: Addis Abeba University.

James, W., Donhan, D., kurimoto, E. y Triulzi, A. Editores (2002). Remapping Ethiopia: Socialism and After. Oxford: James Currey.

Jenaro, C., Verdugo, M. A., Caballo, C., Balboni, G., Lachapelle, Y. y Otrebski, W. (2005). Cross-cultural study of person-centred quality of life domains and indicators: a replication. Journal of Intellectual Disability Research, 49, 734739. doi: 10.1111/j.1365-2788.2005.00742.x. 
Jociles, M. I. (2007a). La antropología de la educación en España: La impronta de la inmigración y de los intereses académicos. Alteridades, 17, 93-104.

Jociles, M. I. (2007b). Panorámica de la antropología de la educación en España: estado de la cuestión y recursos bibliográficos. Revista de Antropología Social, 16, 67-116.

Juliano, Dolores (1993). Educación intercultural. Escuela y Minorías étnicas. Madrid: Eudema.

Kanana, F. E. (2013). Examining African Languages as Tools for National Development: The Case of Kiswahili. Journal of Pan African Studies, 6(6), 4168.

Kelly, H.A (1992) From Gada to Islam: The moral authority of gender relations among the pastoral orma of Kenya. Los Angeles: University of California.

Killion, T. (1988). In War-Torn Eritrea, Rebels Gain on an Ethiopian Regime Sustained by U.S. Aid. Consultado el 27 de Septiembre de 2013 en la WWW:http://articles.latimes.com/1988-05-

01/opinion/op3277_1_ethiopian-government

Ko, I. S., You, M. A., Kim, E. S., Lee, T. W., Kim, S., Kim, Y. M. (2010). Family planning practice and related factors of married women in Ethiopia. International Nursing Review, 57(3), 377-382. doi: 10.1111/j.1466-7657.2010.00805.x

Kurimoto, E. y Simonse, S. (1998) (edits). Conflict, age and power in North East Africa: Age systems in transition. Oxford: James Currey.

Lakew, Y., Reda, A. A., Tamene, H., Benedict, S., y Deribe, K. (2013). Geographical variation and factors influencing modern contraceptive use among married women in Ethiopia: evidence from a national population based survey. Reproductive Health, 10(1), 52-61. doi: 10.1186/1742-4755-10-52

Lata, L. (1999). The Ethiopian state at the crossroads: Decolonization and democratization or disintegration? Asmara, Eritrea: The Red Sea Press. 
Latapí, P. (2005). Homo educandus: antropología filosófica de la educación: OCTAVI FULLAT Puebla, Universidad Iberoamericana/Universidad Pedagógica Nacional (Lupus Magíster), 2004, 148 pp. Perfiles educativos, 27, 114-116.

Lee, H., Lee, T., Shin, H., Ahn, H., Kim, M., y Lee, M. (2013). Patterns and predictors of non-use of family planning methods in Ethiopian women: a panel survey. International Nursing Review, 60(3), 335-343. doi: 10.1111/inr.12028

Legesse, A. (1973). Gada: Three approaches to the study of African society. New York: The Free Press.

Legesse, A. (2006). Oromo democracy: An indigenous African political system. Asmara: The Read Sea Press, Inc.

Levine, D. N. (2000). Greater Ethiopia: The evolution of a multiethnic society. Chicago: University of Chicago Press

Linacre, J.M. (2002). What do infit and outfit mean-square and standardized mean? Rasch Measurement Transactions, 16(2), 878.

Linacre, J.M. y Wright, B.D. (1994). Reasonable mean-square fit values. Rasch Measurement Transactions, 8(3), 370.

Lindskog, A. (2013). The effect of siblings' education on school-entry in the Ethiopian highlands. Economics of Education Review, 34, 45-68. doi: 10.1016/j.econedurev.2013.01.012

Lynch, B. M., y L. H. Robbins. (1978). Namoratunga: The First archeoastronomical evidence in Sub-Saharan Africa. Science, 200, 766-768.

Malinowski, B. (1973). Los argonautas del Pacífico Occidental: un estudio sobre comercio y aventura entre los indígenas de los archipiélagos de la Nueva Guinea melanésica. Barcelona: Península.

Marcus, H.G. (2002). A history of Ethiopia. Updated Edition. Berkeley/Los Angeles/ London: University of California Press.

Markakis, J. (2011). Ethiopia: The last two Frontiers. New York: James Currey 
Martínez, P, A. (2008). La antropología visual. Madrid: Síntesis.

Melbaa, G. (1999). Oromia: An introduction to the history of the Oromo people. Mineapolis: Kirk House Publishers.

Milkias, P. y Kebede, M. (edit). (2010). Education, politics and social change in Ethiopia. Los Angeles: Tsehai.

Ministry of Education and UNICEF (2012) Study on Situation of Out of School Children (OOSC) in Ethiopia. Addis Ababa: MOE

Ministry of Education, MoE (2002). The Education and Trainning Policy and Its Implimentation. Addis Ababa: MOE

Ministry of Education, MoE (2013). Education StatisticsAnnual Abstract (2012/2013). Addis Ababa: MOE

Ministry of Finance and Economic Development (2010). Growth and Transformation Plan (GTP) 2010/11-2014/15. Addis Ababa: MOFED.

Ministry of Finance and Economic Development (2013) Annual Progress Report for F.Y. 2011/12 Growth and Transformation Plan. Addis Ababa: MOFED.

Minney, T. (2010). A rising giant. New African(492), 67-70.

Mohammed, A., Woldeyohannes, D., Feleke, A., y Megabiaw, B. (2014). Determinants of modern contraceptive utilization among married women of reproductive age group in North Shoa Zone, Amhara Region, Ethiopia. Reproductive Health, 11(1), 1-15. doi: 10.1186/1742-4755-11-13

Montes del Castillo, A. y Martínez, M. M. J. (2012). Antropología aplicada: Lecturas de Antropología y Trabajo Social. Murcia: Diego Martín.

Montes, A., Pulido, R. A. y García, F. J. (1997). La educación multicultural y el concepto de cultura Revista Iberoamericana de Educación, 13, 223-255.

Munro-Hay, S. (1991). Aksum an African civilisation of late antiquity. Edinburgh: Edinburgh University Press 
Nuresu, T. (2011). In praise of Saayyaa: Oromo songs in praise of the cattle. Harare: PCV.

Oromia Education Bureau (2005). Oromia Regional State Perspective Plan For Universal Primary Education 2005/6-2017/18. Addis Ababa: OEB

Ortiz, C. (2003). La antropología pedagógica en España durante el primer tercio del siglo xx. Revista de dialectología y tradiciones populares, 58(2), 71-92.

Ossola, M. M. (2013). Jóvenes indígenas en la frontera: relaciones entre etnicidad, escolaridad y territorialidad. Revista Latinoamericana de Ciencias Sociales, Niñez y Juventud, 11(2), 2027-7679.

Oyekale, A. S. (2014). Factors Explaining Child Survival in Ethiopia: Application of Two-Stage Probit Model. African Development Review, 26(2), 237-249. doi: $10.1111 / 1467-8268.12078$

Pallma, S. y Sinisi, L. (2004). Tras las huellas de la etnografía educativa: Aportes para una reflexión teórico metodológica. Cuadernos de Antropología Social, 19, 121-138.

Pérez, P. M. (1998). Anrecedentes de la construcción teórica en Antropología de la educación. Teorías de la Educación, 10, 205-231.

Pillay, T. (2010). Critical Perspectives on NGOs and Educational Policy Development in Ethiopia. Journal of Alternative Perspectives in the Social Sciences, 2, 90119.

Programa de las Naciones Unidad para el Desarrollo (PNUD) (2013). Informe sobre Desarrollo Humano 2013. Disponible en: http://www.undp.org/content/dam/undp/library/corporate/HDR/2013Glob alHDR/Spanish/HDR2013\%20Report\%20Spanish.pdf

Rasch, G. (1960). Probabilistic models for some intelligence and attainment tests. Copenhagen: Paedagogiske Institute. 
Regassa, A. (2007). Ethnicity and Inter-ethnic Relations: the 'Ethiopian Experiment' and the case of the Guji and Gedeo (Tesis doctoral) Troms $\varnothing$ : University of Troms $\varnothing$

Regassa, A. (2012). Emerging Ethnic Identities and Inter-ethnic conflict: A Study on Guji-Burji Conflict in South Ethiopia. Journal of Studies in Ethnicity and Nationalism, Vol. 12, No.3.pp.517-533.

Rolleston, C. (2014). Learning profiles and the 'skills gap' in four developing countries: a comparative analysis of schooling and skills development. Oxford Review of Education, 40(1), 132-150. doi: $10.1080 / 03054985.2013 .873528$

Sabeh, E., Verdugo, M.A., Prieto, G. y Contini de González, E.N. (2009). Cuestionarios de Evaluación de la Calidad de Vida en la Infancia. Manual de aplicación. Madrid: CEPE .

Salmon, R., y Eckersley, W. (2010). Where there's no green man: child road-safety education in Ethiopia. Development in Practice, 20(6), 726-733. doi: $10.1080 / 09614524.2010 .491531$

Sathiyasusuman, A. (2011). Mental health services in Ethiopia: Emerging public health issue. Public Health (Elsevier), 125(10), 714-716. doi: 10.1016/j.puhe.2011.06.014

Téllez, I, A. (2007). La investigación antropológica. San Vicente (Alicante): Club Universitario.

Than, K. (2011, 13 de julio) Ethiopia Moves Forward with Massive Nile Dam Project. Consultado el 14 de Noviembre de 2013 en la WWW: http://news.nationalgeographic.com/news/2011/07/110713-/ethiopiasouth-sudan-nile-dam-river-water/

Tijiurimo, A. (2013, 12 de agosto) Ethiopia's Foreign Policy one year after Meles Zenawi: An opportunity for transformation. Consultado el 10 de Diciembre de 2013 en la WWW: http://www.saiia.org.za/opinion-analysis/ethiopias- 
foreign-policy-one-year-after-meles-zenawi-an-opportunity-fortransformation

Tran, M. (2013, 15 de Abril) Ethiopia enlists help of forest communities to reverse deforestation. Consultado el 5 de diciembre de 2013 en la WWW: http://www.theguardian.com/global-development/2013/apr/15/ethiopiaforest-communities-reverse-deforestation

Traub, R.E. (1994). Reliability for the social sciences. Thousand Oaks: Sage.

Ullendorff, E. (1965). The Ethiopians: an introduction to country and people. London: Oxford University Press.

UNESCO (2012) Compendio Mundial de la Educación 2012. Oportunidades perdidas: El impacto de la repetición y de la salida prematura de la escuela. Montreál: Instituto de Estadistica de la Unesco

UNICEF (2012) Investing In Boys and Girls in Ethiopia: Past, Present and Future. Disponible en: http://www.unicef.org/ethiopia/ET_sitan_2012.pdf

UNPAN (2004) Federal Democratic Republic of Ethiopia. Public Administration. $\begin{array}{llll}\text { Country } & \text { Profile. } & \text { Disponible }\end{array}$ http://unpan1.un.org/intradoc/groups/public/documents/un/unpan023264. pdf

Van de Loo, J. (1991) Guji Oromo culture in southern Ethiopia: Religious capabilities in rituals and songs. Berlin: Dietrich Reimer

Velasco, H y Díaz de Rada, A. (2009). La lógica de la investigación etnográfica: un modelo de trabajo para etnógrafos de la escuela. Madrid: Trotta.

Velasco, H. M., y Díaz de Rada, Á. (2009). La lógica de la investigación etnográfica. Un modelo de trabajo para etnógrafos de la escuela. Madrid Trotta.

Waktola, D. K. (2009). Challenges and opportunities in mainstreaming environmental education into the curricula of teachers' colleges in Ethiopia. Environmental Education Research, 15(5), 589-605. doi: $10.1080 / 13504620903151024$ 
Wilson, M. (2005). Constructing measures: An item response modeling approach. Mahwah: Lawrence Erlbaum Associates.

Winthrop, R., y Kirk, J. (2008). Learning for a Bright Future: Schooling, Armed Conflict, and Children's Well-Being. Comparative Education Review, 52(4), 639-661.

Wong, R., Wu, R., Guo, C., Lam, J. K. y Snowden, L. R. (2012). Culturally sensitive depression assessment for Chinese American Immigrants: Development of a comprehensive measure and a screening scale using an item response approach. Asian American Journal of Psychology, 3(4), 230-253.

Wong, R., Wu, R., Guo, C., Lam, J. K. y Snowden, L. R. (2012). Culturally sensitive depression assessment for Chinese American Immigrants: Development of a comprehensive measure and a screening scale using an item response approach. Asian American Journal of Psychology, 3(4), 230-253

World Bank (2012) Ethiopia Economic Update. Overcoming inflation, raising competitiveness. Whashington D.C.: World Bank

Zakes, M. (2013, 5 de noviembre) Africans must speak up for journalist jailed in Ethiopia. Consultado el 19 de Noviembre de 2013 en la WWW: http://www.theguardian.com/world/2013/nov/05/ethiopia-free-eskinder$\underline{\text { nega }}$

Zerihun, A.W., Kibret, H. y Wakiaga, J. (2014) Ethiopia. The African Economic Outlook. Disponible en: http://www.africaneconomicoutlook.org/fileadmin/uploads/aeo/2014/PDF/ CN Long EN/Ethiopie EN.pdf

Zewde, B. (2001). A history of modern Ethiopia, 1855-1991. Oxford: James Curry. 


\section{ANEXOS}

\subsection{CUESTIONARIO SOCIODEMOGRÁFICO}

1. Código (caso)

2. Género:

$\square$ niño $_{1} \quad \square$ niña 2

3. Región:

4. Procedencia: $\square$ rural $_{1} \square$ urbana $_{2}$

5. Edad:

6. Etnia:

7. Clan:

8. Religión:

9. A qué edad comenzó el niño a ir al colegio?

10. Ha ido todos los años de forma continuada?

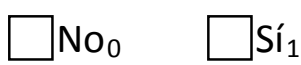

10a.En caso negativo, especificar razones:

11. Hasta qué edad tiene pensado ir al colegio?

11.a. Especificar razones:

12. Tiene más hermanos que asisten a la escuela?

$\mathrm{No}_{0} \square \mathrm{Sí}_{1}$

12a.En caso afirmativo, especificar número. ¿Cuántos?

12b.Han ido todos los años de forma continuada?

$\mathrm{No}_{0} \square \mathrm{Sí}_{1}$

12c.En caso negativo, especificar razones. Razones:

12d. Hay diferencias en cuanto al tiempo estimado en que van a ir los diferentes hermanos a la escuela?

12e. En caso afirmativo, especificar razones (por ejemplo, que a las niñas se las saque antes..)

13. Cuanto tarda en el trayecto entre el colegio y casa (andando)?.

14. Tienen los padres: $\square$ mas $_{2}, \square$ menos $_{0} \circ \square$ iguales $_{1}$ posesiones (vacas, tierras) que los vecinos?

15. Realizan los padres una "parental contribution" por asistir el hijo (o los hijos) a la escuela? $\square \mathrm{No}_{0} \square \mathrm{Sí}_{1}$

16. Ha tenido que ir el niño al médico en los últimos seis meses : $\square \mathrm{No}_{0}$ Sí 1

16a.Especificar las razones:

17. Toma alguna medicación actualmente (si o no)

$\square \mathrm{No}_{0} \square \mathrm{Sí}_{1}$ 
18. Tendría que tomar alguna medicación actualmente (si o no)

19. Ambos padres están vivos (si o no)

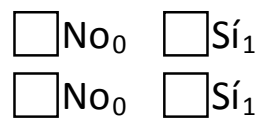

19a. En caso negativo, afecta esta situación a la economía, status, etc., de la familia?

20. Vive con ambos padres (si o no) $\square \mathrm{No}_{0} \square \mathrm{sí}_{1}$

21. Vive con otras personas en el hogar? $\square \mathrm{No}_{0} \square \mathrm{Sí}_{1}$

22. En caso afirmativo, especificar con qué otras personas (especificar vínculo, p.e. tio, abuela, hermanos...):

23. Tiene contactos frecuentes con la familia extensa (tíos, abuelos..) $\square \mathrm{No}_{0} \square$ $\mathrm{Sí}_{1}$

24. Ausencias del niño a la escuela:

- $\square$ una o mas a la semana 1

- $\square$ una cada 15 días $_{2}$,

- $\square$ una cada $30_{3}$,

- $\square$ una cada 3 meses $_{4}$,

- $\square$ una cada 6 meses o mas $_{5}$

25. Razones de la ausencia regular del niño al cole:

- $\square$ Tiene que trabajar para contribuir a la economía de la familia (No o sí 1)

- $\square$ Tiene que ayudar a su madre con las tareas domésticas y el cuidado de sus hermanos (No 0 sí1)

- $\square$ Problemas de transporte o desplazamientos (No o sí1)

- $\square$ Problemas de salud (No osí1)

- $\square$ Otros (especificar) Algunas preguntas son medio "conducidas". (No 0 sí 1)

26. Su rendimiento escolar suele ser, a juicio de sus profesores:

$\square$ muy bajo $_{1} \quad \square$ bajo $_{2} \quad \square$ normal $_{3} \quad \square$ alto $_{4} \quad \square$ muy alto $_{5}$

27. El progreso del niño en el cole es a juicio de sus profesores:

$\square$ muy lento $_{1} \quad \square$ lento $_{2} \quad \square$ normal $_{3} \quad \square$ rápido $_{5} \quad \square$ muy rápido $_{5}$

28. Durante los fines de semana tiene tiempo libre para jugar, etc.:

$\square$ Nunca $_{1} \quad \square$ casi nunca $_{2} \square$ a veces $_{3} \quad \square$ casi siempre $_{4}$

$\square$ siempre $_{5}$

29. Bienes materiales de la familia comparados con los de su entorno, a juicio del catequista o de otro informante,

- $\square$ Mucho Menos que la mayoría

- $\square$ Menos que la mayoría 2

- $\square$ Igual que la mayoría

- $\square$ Mas que la mayoría

- $\square$ Mucho más que la mayoría 
30. La vivienda del niño, en comparación con la de su entorno (a juicio del catequista o de otro informante) es:

- $\square$ Mucho peor que la de la mayoría

- $\square$ Peor que la de la mayoría 2

- $\square$ Igual que la de la mayoría

- $\square$ Mejor que la de la mayoría 4

- $\square$ Mucho mejor que la de la mayoría

31. Las comodidades que tiene en su hogar (agua, servicios higiénicos), en comparación con la de su entorno es, a juicio del catequista o de otro informante,.

- $\square$ Mucho peor que la de la mayoría

- $\square$ Peor que la de la mayoría

- $\square$ Igual que la de la mayoría 3

- $\square$ Mejor que la de la mayoría 4

- $\square$ Mucho mejor que la de la mayoría 


\subsection{Cuestionario de Satisfacción con la Escuela (CAstellano -Oromo)}

(2002)

Cuestionario adaptado del Cuestionario de Inclusión de Booth y Ainscow

\begin{tabular}{|c|c|c|c|c|}
\hline $\begin{array}{l}\text { En clase } \\
\text { Kuta keessa }\end{array}$ & $\begin{array}{l}\text { Casi nunca (1) } \\
\text { Wawwoo, } \\
\text { ljjumaa }\end{array}$ & $\begin{array}{l}\text { A veces (2) } \\
\text { Guddo moti }\end{array}$ & $\begin{array}{l}\text { Bastante (3) } \\
\text { Yenna tokko } \\
\text { tokkoo }\end{array}$ & \begin{tabular}{|lr|}
\multicolumn{2}{|l}{ Casi siempre (4) } \\
Ee, yenna \\
gumma
\end{tabular} \\
\hline $\begin{array}{l}\text { 1. Trabajo con compañeros. } \\
\text { Ani dare kiyya woliin hujadha }\end{array}$ & & & & \\
\hline $\begin{array}{l}\text { 2. Trabajamos en grupos } \\
\text { Nuuti gareen hojjanna }\end{array}$ & & & & \\
\hline $\begin{array}{l}\text { 3. Ayudo a mis compañeros } \\
\text { Ani lansoota kiyya qarqaara }\end{array}$ & & & & \\
\hline $\begin{array}{l}\text { 4. Mis compañeros me ayudan } \\
\text { Lansoonni kiyya ana qarqaarani }\end{array}$ & & & & \\
\hline $\begin{array}{l}\text { 5. Muestran nuestros trabajos para que los } \\
\text { demás lo vean. Barsisoleen huji } M / B \text { nuuti } \\
\text { hunyuu dare tennatti mudhiisani }\end{array}$ & & & & \\
\hline $\begin{array}{l}\text { 6. Mi profesor me escucha } \\
\text { yennaa ani rakkadhu barsisaan kiyya na caqaasa }\end{array}$ & & & & \\
\hline $\begin{array}{l}\text { 7. Mi profesor me ayuda } \\
\text { Yoo barumsi na galiisa dhabe, barsisaan kiyya } \\
\text { ana qarqaara. }\end{array}$ & & & & \\
\hline $\begin{array}{l}\text { 8. Ayudo a mi profesor } \\
\text { An barsisaa kiyya qarqaara }\end{array}$ & & & & \\
\hline $\begin{array}{l}\text { 9. Las reglas son justas. } \\
\text { Seerri manni barumsaa baase (ka } M / B \text { base } \\
\text { diriruuma qaba) }\end{array}$ & & & & \\
\hline $\begin{array}{l}\text { 10. Hay niños que son desagradables con los } \\
\text { demás } \\
\text { Baratooleen baratoota dhibi rakkisanu hin jirani }\end{array}$ & & & & \\
\hline $\begin{array}{l}\text { 11. Se meten conmigo } \\
\text { Baratooleen dhibin ana rakkisani }\end{array}$ & & & & \\
\hline $\begin{array}{l}\text { 12. Si estoy triste los maestros se preocupan por } \\
\text { mi } \\
\text { Yenna ani rakkadhu, barsisooleen ana gaffatani }\end{array}$ & & & & \\
\hline $\begin{array}{l}\text { 13. Cuando hay peleas, el profesor lo arregla de } \\
\text { forma justa. } \\
\text { Yenna baratoleen wolta ka'anu, barsisooleen } \\
\text { dirirumaan dubbi sirresani }\end{array}$ & & & & \\
\hline $\begin{array}{l}\text { 14. Voy mejorando dia a día. } \\
\text { Barumsi guyya guyyaan ani fudhadhu hin } \\
\text { edeama }\end{array}$ & & & & \\
\hline $\begin{array}{l}\text { 15. Mi profesor me deja elegir el trabajo que } \\
\text { hacer. } \\
\text { M/B kessaatti yenna huji adda addaa jiru, } \\
\text { Barsisooleen huji ani barbaadu akka filadhu, } \\
\text { eyyama naf kennani }\end{array}$ & & & & \\
\hline $\begin{array}{l}\text { 16. Me siento contento cuando hago un buen } \\
\text { trabajo. } \\
\text { Yoo hujji hose hojjadhe gammadi nati dage'ama }\end{array}$ & & & & \\
\hline
\end{tabular}




\begin{tabular}{|l|l|l|l|l|}
\hline $\begin{array}{l}\text { En clase } \\
\text { Kuta keessa }\end{array}$ & $\begin{array}{l}\text { Casi nunca (1) } \\
\text { Wawwoo, } \\
\text { ljumaa }\end{array}$ & $\begin{array}{l}\text { A veces (2) } \\
\text { Guddo moti }\end{array}$ & $\begin{array}{l}\text { Bastante (3) } \\
\text { Yenna tokko } \\
\text { tokkoo }\end{array}$ & $\begin{array}{l}\text { Casi siempre (4) } \\
\text { Ee, yenna } \\
\text { gumma }\end{array}$ \\
\hline $\begin{array}{l}\text { 17. Entiendo los deberes que me mandan para } \\
\text { casa. } \\
\text { Huji-mana M/B kessaatti anaf kennanu anaf } \\
\text { gala }\end{array}$ & & & & \\
\hline $\begin{array}{l}\text { 18. Mi profesor me pregunta lo que hago en } \\
\text { casa. } \\
\text { Hujii-mana ani hojjadu barsisaan kiyya na gafata }\end{array}$ & & & & \\
\hline $\begin{array}{l}\text { 19. Mi familia piensa que éste es un buen centro. } \\
\text { Worri kiyya M/B ani baradhu hose akka ite'e } \\
\text { dhugeeffaatani. }\end{array}$ & & & & \\
\hline $\begin{array}{l}\text { 20. Si no voy a clase mi profesor me pregunta } \\
\text { por qué } \\
\text { Yoo Ani gara M/B dhufuu dhabe, barsisooleen } \\
\text { kiyya sababa ana gaffatani }\end{array}$ & & & & \\
\hline $\begin{array}{l}\text { 21. Mi familia me pregunta por mis deberes } \\
\text { Hujii-mana ani hojjadu worri kiyya gafata }\end{array}$ & & & & \\
\hline $\begin{array}{l}\text { 22. Cuando llego a mi casa tengo tiempo para } \\
\text { realizar mis deberes } \\
\text { Yenna mana kiyya galu, hujii- mana hujiisaf } \\
\text { yeroo hose hin qaba }\end{array}$ & & & & \\
\hline
\end{tabular}




\subsection{ESCALA DE CALIDAD DE VIDA INFANTIL CASTELLANO OROMO}

\begin{tabular}{|c|c|c|c|c|}
\hline & $\begin{array}{l}\text { Casi nunca } \\
\text { (1) } \\
\text { Wawwoo, } \\
\text { ljjumaa }\end{array}$ & $\begin{array}{l}\text { A veces (2) } \\
\text { Guddo } \\
\text { moti }\end{array}$ & $\begin{array}{l}\text { Bastante } \\
\text { (3) } \\
\text { Yenna } \\
\text { tokko } \\
\text { tokkoo }\end{array}$ & $\begin{array}{l}\text { Casi siempre } \\
\text { (4) } \\
\text { Ee, yenna } \\
\text { gumma }\end{array}$ \\
\hline $\begin{array}{l}\text { 1. Me siento contento } \\
\text { Gammaddi anatti ghage'ama }\end{array}$ & & & & \\
\hline $\begin{array}{l}\text { 2. Duermo tranquilo } \\
\text { Nageyaan rafa }\end{array}$ & & & & \\
\hline $\begin{array}{l}\text { 3. Me llevo bien con mis hermanos } \\
\text { Ani obboleyaani fi obboletoota tiyya duuchi } \\
\text { woliin nageyaa qaba }\end{array}$ & & & & \\
\hline $\begin{array}{l}\text { 4.Mis padres me felicitan por lo que hago bien } \\
\text { Huji hose yo huju Abbaa fi haati tiyya hamlee } \\
\text { ana kennani. }\end{array}$ & & & & \\
\hline $\begin{array}{l}\text { 5.Me gustan las cosas que tengo (juguetes, } \\
\text { ropa,etc) } \\
\text { Ani waan qabu jaladha }\end{array}$ & & & & \\
\hline $\begin{array}{l}\text { 6.Tengo dolores de cabeza o de otro tipo } \\
\text { Mataan kiyya ana dhiba bowofata yokiin adde } \\
\text { dhiibille ana dhiba }\end{array}$ & & & & \\
\hline $\begin{array}{l}\text { 7.En la escuela las cosas me salen mal } \\
\text { M/B kessaatti ana rakkoo argadha... }\end{array}$ & & & & \\
\hline $\begin{array}{l}\text { 8.Los fines de semana hago cosas que me gustan } \\
\text { Guyya Qedame fi Sambata waanni ana } \\
\text { gamachisu hojadha... }\end{array}$ & & & & \\
\hline $\begin{array}{l}\text { 9.Mi maestra/o me felicita por las cosas que } \\
\text { hago bien } \\
\text { Huji hose yo huju barsiisaan kiyya hamlee ana } \\
\text { kenna }\end{array}$ & & & & \\
\hline $\begin{array}{l}\text { 10.Pienso que de mayor sere muy feliz } \\
\text { Ani yenna guddadhe jirenna kiyya kessa } \\
\text { gammada gudda akka argadhu dhugeeffaadha }\end{array}$ & & & & \\
\hline $\begin{array}{l}\text { 11.Mi maestra/o me trata de forma diferente } \\
\text { que a los demás compañeros } \\
\text { Barsiisaan kiyya baratoota duuchi ila tokkoni hin } \\
\text { ilaalu, inni gara garumma godha }\end{array}$ & & & & \\
\hline $\begin{array}{l}\text { 12.Me siento orgulloso de mí mismo } \\
\text { Ani waan jirenna kiyya yokiin huji tiyyatif hin } \\
\text { boona }\end{array}$ & & & & \\
\hline $\begin{array}{l}\text { 13. Me cuesta concentrarme o prestar atención } \\
\text { en la escuela } \\
\text { M/B yenna duuchi hordofisa ana rakkiso }\end{array}$ & & & & \\
\hline $\begin{array}{l}\text { 14.Estoy preocupado } \\
\text { Ani waan rakko jirenna kiyya hin yaada }\end{array}$ & & & & \\
\hline $\begin{array}{l}\text { 15.Mis padres me pegan } \\
\text { Worri kiyya ana dikani (Iolani) }\end{array}$ & & & & \\
\hline $\begin{array}{l}\text { 16. Mi casa es bonita y cómoda } \\
\text { Manni kiyya hose fi mijaawa }\end{array}$ & & & & \\
\hline 17.Puedo tener las cosas que quiero & & & & \\
\hline
\end{tabular}




\begin{tabular}{|c|c|c|c|c|}
\hline & $\begin{array}{l}\text { Casi nunca } \\
\text { (1) } \\
\text { Wawwoo, } \\
\text { ljjumaa }\end{array}$ & $\begin{array}{l}\text { A veces (2) } \\
\text { Guddo } \\
\text { moti }\end{array}$ & $\begin{array}{l}\text { Bastante } \\
\text { (3) } \\
\text { Yenna } \\
\text { tokko } \\
\text { tokkoo }\end{array}$ & $\begin{array}{lr}\text { Casi } & \text { siempre } \\
\text { (4) } & \\
\text { Ee, } & \text { yenna } \\
\text { gumma } & \end{array}$ \\
\hline Ani wontoota barbaadu argaatiisa dande'a & & & & \\
\hline $\begin{array}{l}\text { 18.Puedo contar a alguien de mi familia las cosas } \\
\text { feas/malas que me pasan } \\
\text { Ani waan rakko tiyyatiif worra kiyya woliin } \\
\text { dhubbatiisa dande'a }\end{array}$ & & & & \\
\hline $\begin{array}{l}\text { 19.Juego con mis amigos } \\
\text { Ani lansoole kiyya woliin tapadha }\end{array}$ & & & & \\
\hline $\begin{array}{l}\text { 20.En la escuela me siento solo } \\
\text { Mana Barumsati kessati kophuma anati } \\
\text { dhage'ama }\end{array}$ & & & & \\
\hline $\begin{array}{l}\text { 21.Me siento cansado, sin energía para corer, } \\
\text { saltar o estudiar } \\
\text { Ani dadhabera (hunna yoo hin qanee utalisa, } \\
\text { yokin rukisisa, yokin dhubisisa hin dandeu) } \\
\text { Dadhabbi nati dhage'ama, hunnayoo rukkisiisaf, } \\
\text { utaliiisaf yookin baratiisaf hin qanne }\end{array}$ & & & & \\
\hline $\begin{array}{l}\text { 22. Estoy contento con mis notas(o rendimiento) } \\
\text { en la escuela } \\
\text { Qabxooti M/B keessati ani argadhu ana } \\
\text { gammachisan }\end{array}$ & & & & \\
\hline $\begin{array}{l}\text { 23.Mis compañeros me pegan o me gritan más } \\
\text { que a otros } \\
\text { Lanzooni kiyya baratota dhibi chaala, ana } \\
\text { rakkisani yokin ana lolani }\end{array}$ & & & & \\
\hline $\begin{array}{l}\text { 24.Mls padres me dejan elegir (por ejemplo la } \\
\text { ropa, etc) } \\
\text { Worri mana ketti waan ati filatiisa jaalattu } \\
\text { eyyama si'if kennani }\end{array}$ & & & & \\
\hline $\begin{array}{l}\text { 25.No entiendo los deberes que me ponen en el } \\
\text { colegio } \\
\text { Huji-mana manni barumsaa anafi kenne nafi hin } \\
\text { gale }\end{array}$ & & & & \\
\hline $\begin{array}{l}\text { 26.Cuando tengo tiempo libre puedo jugar a } \\
\text { muchas cosas } \\
\text { Yenna forfadhu, taapha fedhu taphadha }\end{array}$ & & & & \\
\hline $\begin{array}{l}\text { 27.Me gusta mi casa o mi habitación } \\
\text { Ani mana kiyya guddo jalaadha }\end{array}$ & & & & \\
\hline $\begin{array}{l}\text { 28.Me divierte las cosas que hacemos en la } \\
\text { escuela } \\
\text { Ani gara M/B ideemisa jalaadha... }\end{array}$ & & & & \\
\hline $\begin{array}{l}\text { 29.Tengo amigos en la escuela } \\
\text { Ani M/B keessati lansoole qaba }\end{array}$ & & & & \\
\hline $\begin{array}{l}\text { 30.A mis compañeros les gusta estar conmigo } \\
\text { Lansii kiyya ana woliin teeisa jalatha }\end{array}$ & & & & \\
\hline $\begin{array}{l}\text { 31.Estoy triste, con ganas de llorar } \\
\text { Ani hin gadaa, bo'iisa barbaada }\end{array}$ & & & & \\
\hline $\begin{array}{l}\text { 32.Tengo dolores (de barriga, cabeza, etc) } \\
\text { Ani dhibamera yokin dhibe qaba }\end{array}$ & & & & \\
\hline $\begin{array}{l}\text { 33.MI vida es muy bonita } \\
\text { Jirenni kiyya hose }\end{array}$ & & & & \\
\hline
\end{tabular}




\begin{tabular}{|l|l|l|l|l|}
\hline & $\begin{array}{l}\text { Casi nunca } \\
\text { (1) } \\
\text { Wawwoo, } \\
\text { ljumaa }\end{array}$ & $\begin{array}{l}\text { A veces (2) } \\
\text { Guddo } \\
\text { moti }\end{array}$ & $\begin{array}{l}\text { Bastante } \\
\text { (3) } \\
\text { Yenna } \\
\text { tokko } \\
\text { tokkoo }\end{array}$ & $\begin{array}{l}\text { Casi siempre } \\
\text { (4) } \\
\text { Ee, yenna } \\
\text { gumma }\end{array}$ \\
\hline $\begin{array}{l}\text { 34.Me gustaría ser distinto de como soy } \\
\text { Ani amala keeti jalada }\end{array}$ & & & & \\
\hline $\begin{array}{l}\text { 35Tengo ganas de vomitar o problemas de } \\
\text { estómago } \\
\text { Gadhaan kiyya ana dhiba yookin ana diddissa }\end{array}$ & & & & \\
\hline $\begin{array}{l}\text { 36.Me pongo nervioso } \\
\text { Rakkon gara kiyya yenna dhuttu, ana sodachissa }\end{array}$ & & & & \\
\hline $\begin{array}{l}\text { 37.Los demás piensan que hago todo mal. } \\
\text { Yenna ani huji balesu namooti dhibin huji kiyya } \\
\text { hin jalatanu }\end{array}$ & & & & \\
\hline $\begin{array}{l}\text { 38.Mis padres me exigen mucho } \\
\text { Worri kiyya qarqaarsa guddo ana gaaffatani }\end{array}$ & & & & \\
\hline $\begin{array}{l}\text { 39.Mis compañeros se ríen de mí } \\
\text { Lansooni kiyya ana busheshani }\end{array}$ & & & & \\
\hline $\begin{array}{l}\text { 40.Mi familia tiene suficiente dinero } \\
\text { Worri kiyya karra qabani }\end{array}$ & & & & \\
\hline $\begin{array}{l}\text { 41.Tengo tiempo libre suficiente } \\
\text { Ani yenna foora guddo qaba }\end{array}$ & & & & \\
\hline $\begin{array}{l}\text { 42.MI familia me da cosas que me gustan } \\
\text { Worri kiyya waan ani jalaadhu anaf kennani }\end{array}$ & & & & \\
\hline $\begin{array}{l}\text { 43.Me siento bien en la escuela } \\
\text { Gara M/B ideemiisaf ana gammachiisa }\end{array}$ & & & & \\
\hline
\end{tabular}


